Fall 2011

\title{
2011 Miracle Yearbook
}

Cedarville University

Follow this and additional works at: https://digitalcommons.cedarville.edu/yearbooks

Part of the Higher Education Commons, Organizational Communication Commons, and the Public Relations and Advertising Commons

\section{Recommended Citation}

Cedarville University, "2011 Miracle Yearbook" (2011). Yearbooks. 11.

https://digitalcommons.cedarville.edu/yearbooks/11

This Book is brought to you for free and open access by DigitalCommons@Cedarville, a service of the Centennial Library. It has been accepted for inclusion in Yearbooks by an authorized administrator of DigitalCommons@Cedarville. For more information, please contact digitalcommons@cedarville.edu. 


\section{Table of Contents}

\begin{tabular}{|c|c|}
\hline & Opening \\
\hline & Dedication \\
\hline$\varphi$ & Fall \\
\hline$\theta$ & Faculty \& Staff \\
\hline$\Omega$ & Organizations \\
\hline 14 & Freshmen \\
\hline 面 & Activities \\
\hline 113 & Sophomores \\
\hline 9 & Ministries \\
\hline 12 & Juniors \\
\hline 8 & Athletics \\
\hline 11 & Seniors \\
\hline$\bullet$ & Spring \\
\hline & Miracle Staff \\
\hline & Index \\
\hline
\end{tabular}



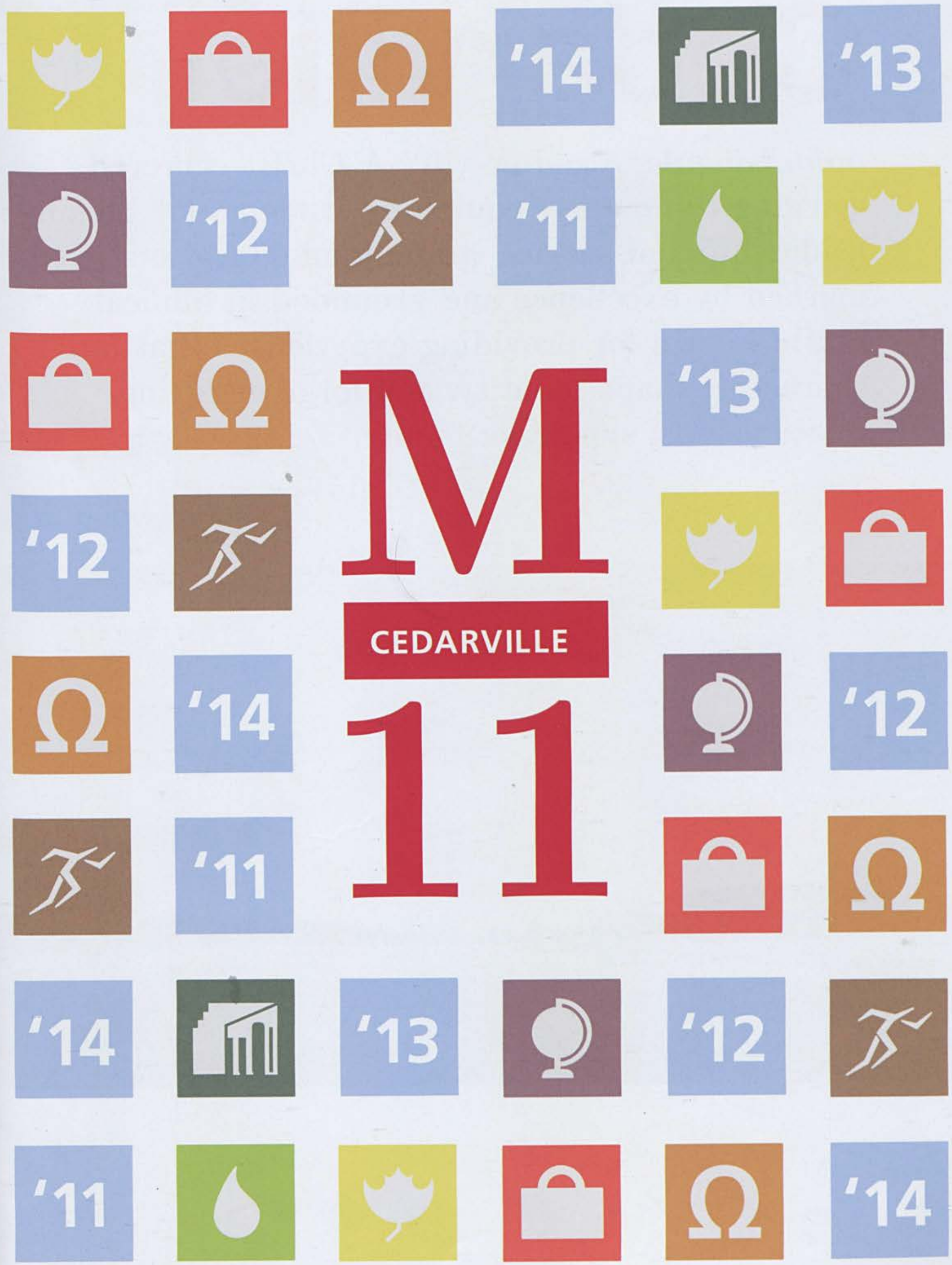

Miracle | Cedarville University | 251 N. Main Street, Cedarville, OH 45314 |Volume 58 | www.cedarville.edu 


\section{Cedarville}

noun, singular \'ced-er-vill \A Christ-centered learning community equipping students for lifelong leadership and service through an education marked by excellence and grounded in biblical truth; known for providing experiences that build character, shape identity, and forge enduring relationships; synonym: family

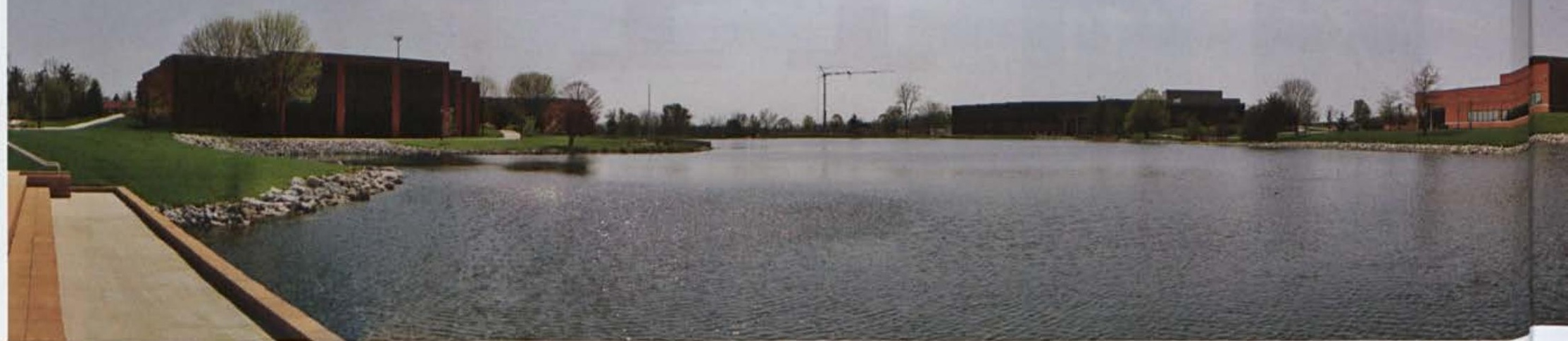




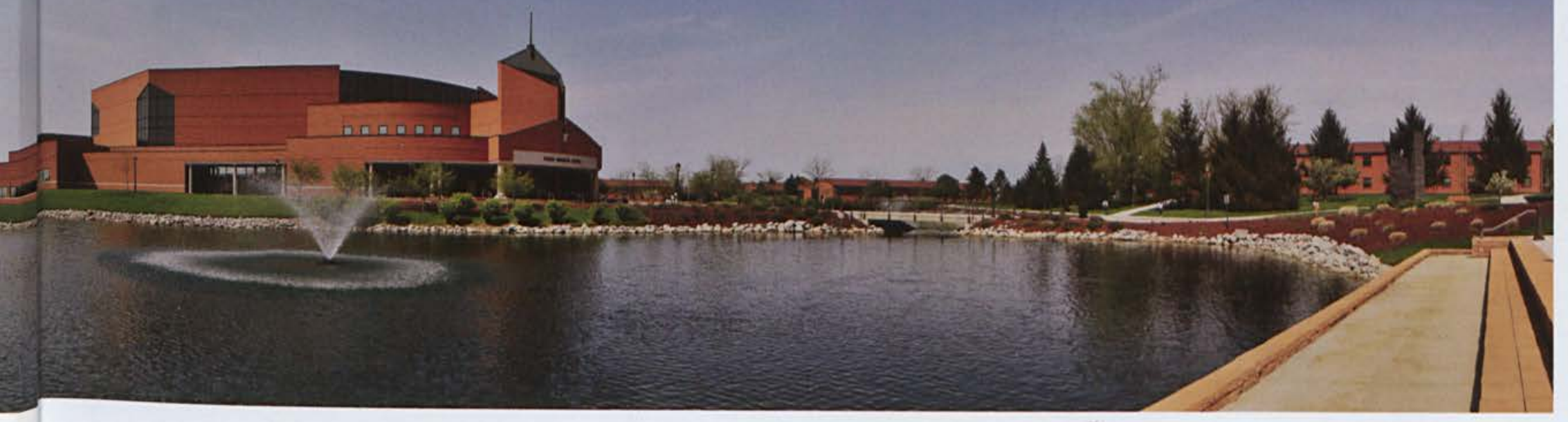
$y$
ص $\Omega$
'14
而
'13Q
'12
'11 


\section{DEDICATION}

More than once a semester, Chris Miller will preface his slides with, "If you have a weak stomach, you might not want to see this," before plastering a photo from his latest hunting expedition on the screen. Then, the class will follow Dr. Miller in a memorized song of the entire Old Testament . . while he runs from one side of the room to the other with the motions to the words. Dr. Miller's passion for the Bible is contagious.

After teaching at World of Life Bible Institute for ten years, Chris Miller and his wife, Pam, moved to Cedarville University for the small-town atmosphere, the Midwest attitude, and the proximity to Indianapolis, where both their parents lived at the time. The required Bible minor at Cedarville helped Dr. Miller make the decision.

Behind this unforgettable Bible professor is a loving and supportive family. Chris and Pam married on June 2, 1980, and as their daughter stated, "Without his fabulous wife, who holds the perfect balance of love, patience, and organization, the mindless professor would have lost his keys, glasses, cars, and kids a long time ago!" They have three children: Mindy, Tim, and Christi, and two grandsons: Jack, born in 2007, and Hunter, born in 2010.

Dr. Dan Estes, Dean of the School of Biblical Studies, said that "Chris listens very carefully and makes wise decisions. He is very good at taking care of all the out-of-sight and behind-the-scenes details that need to be done to make everything run smoothly and look effortless. He's like a musician who does all the hard work in playing to make the whole thing look and sound effortless."

Though his career is a big part of his life, Chris finds time for other activities. These include hunting, hiking, skiing, walking to Mom and Dad's, and attending church at Grace in downtown Cedarville.

Chris' father, Earl Miller, who is ninety-two-years-old, was a World War II B17 pilot and flew 25 missions over Europe. He is and always will be Chris's hero. Dr. Miller takes amazing care of his father and goes to his dad's house almost every evening, further evidence that Dr. Chris Miller has devoted his life to serving others - his students, his children, his wife, and his father-just as God has called us all to do.

\author{
"Well it's hard to list \\ just one thing I love \\ about my husband, \\ but I guess I'd say his \\ sense of humor. In \\ everything, he has \\ always been able to \\ make me laugh!" \\ (Pam Miller)
}

Chris Miller and his wife Pam outside of the Palace of Versailles in France. 2 Chris Miller can't help but smile when he's with his family, especially his grandson Jack. 3 Dr. Miller and his eldest daughter Mindy at a friend's wedding. 4 Chris Miller enjoys hiking with his daughter Christi, a clinical research assistant. $5 \mathrm{Dr}$. Miller combines two of his favorite pastimes: spending time with his son Tim (a preschool teacher) and hunting. Wonder if he caught anything with that bow. 

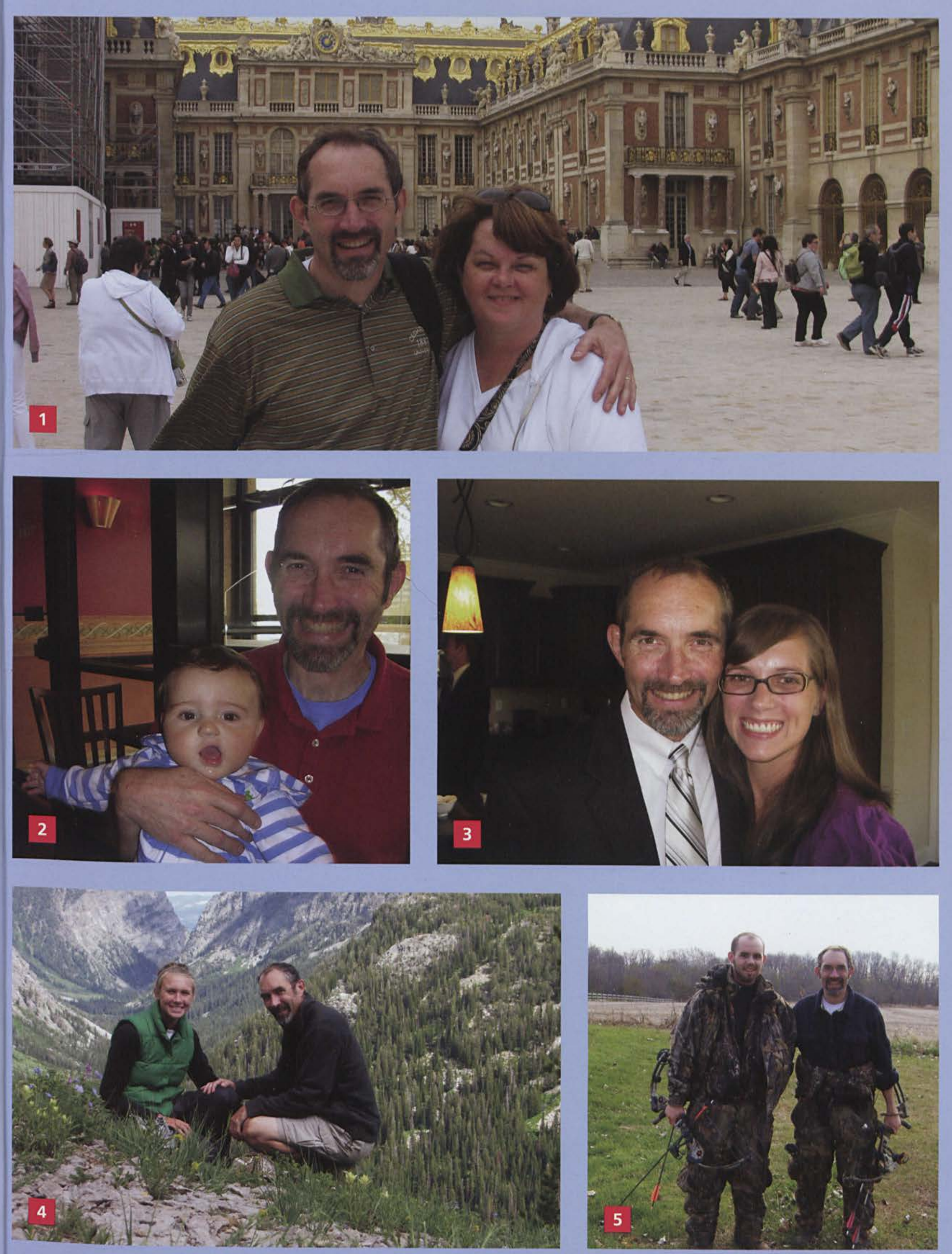

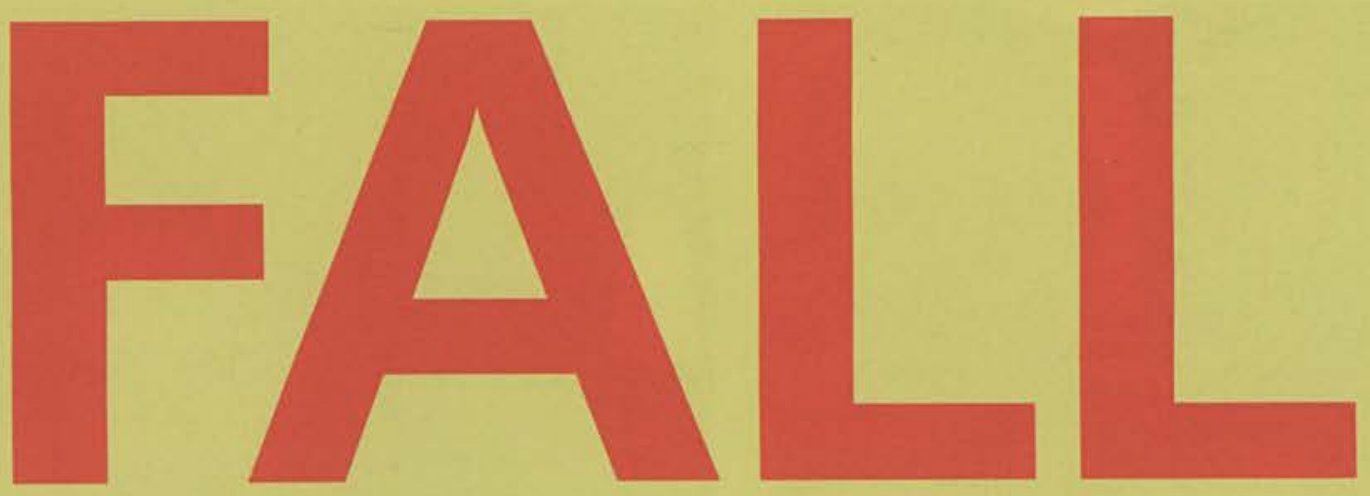

noun \'fol\ Often characterized by sideways rain, bipolar weather, and the start of a new school year. 


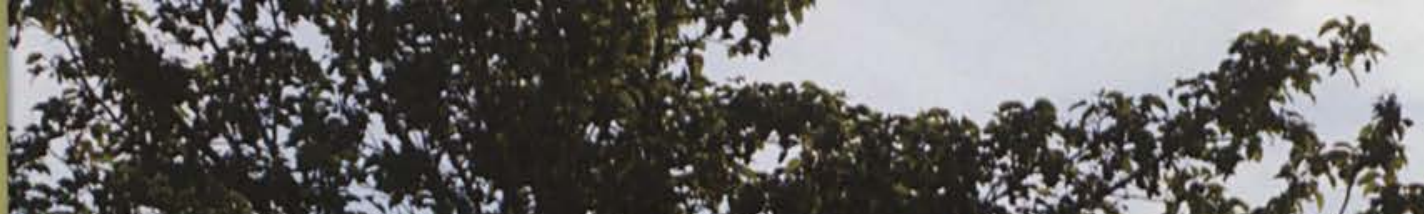

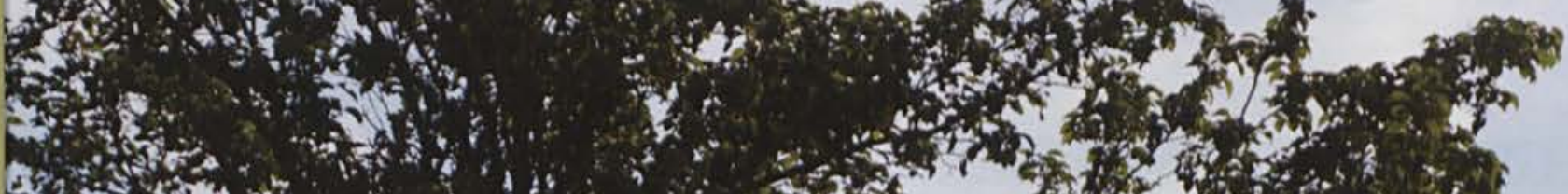

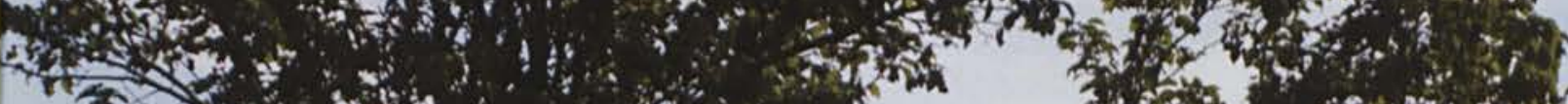
के 5. (f.

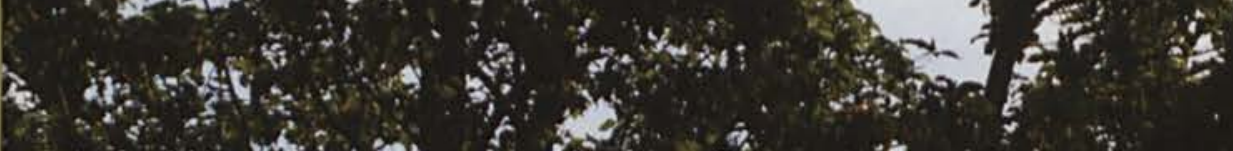

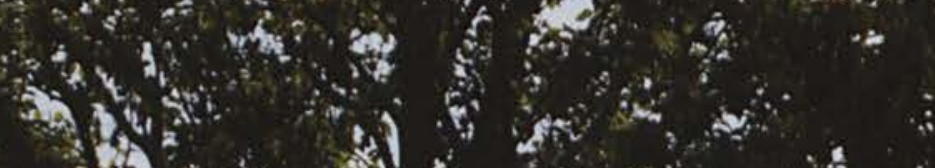

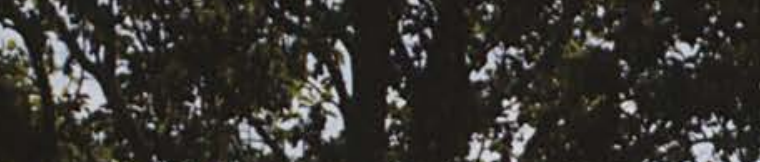

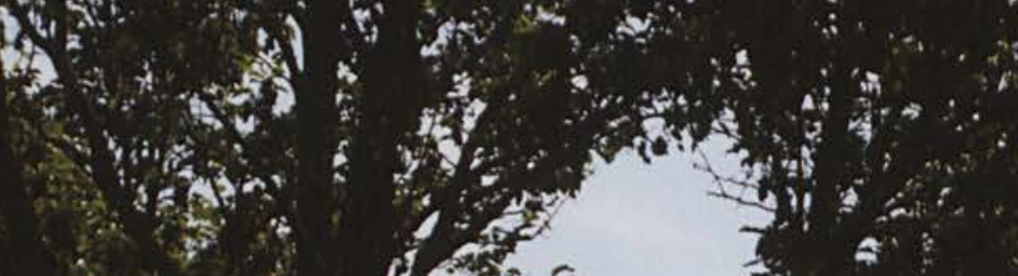
की

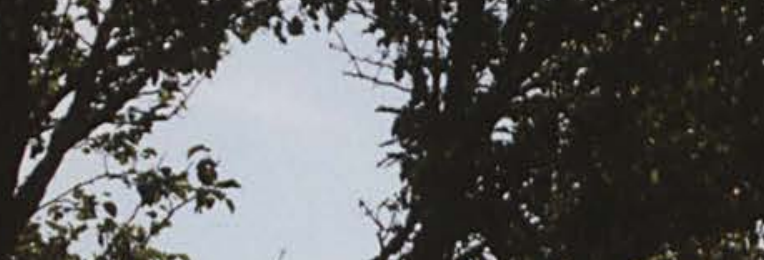 ix 3.

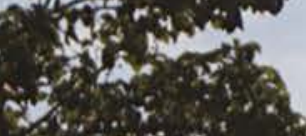

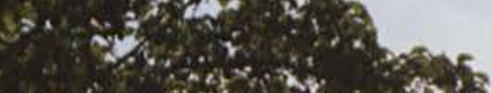

5.

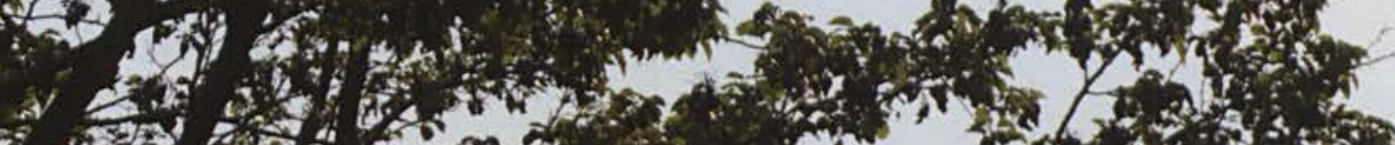

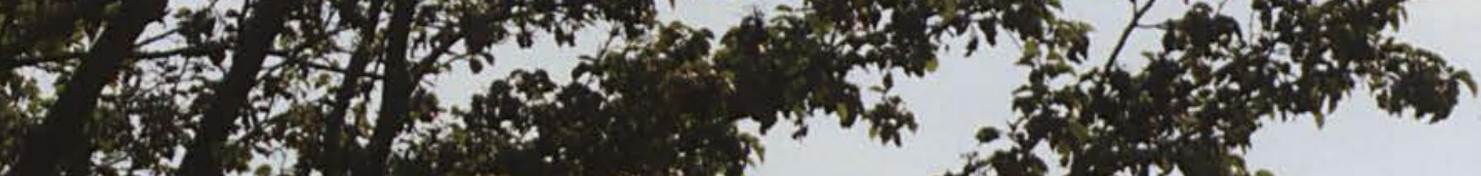
(3) 50 to and का

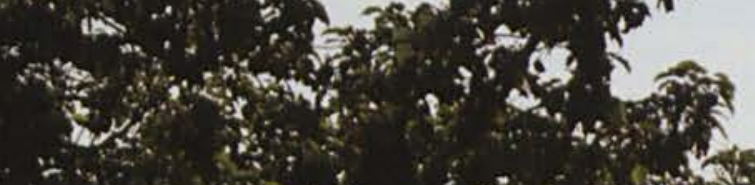
$\therefore$ (t)

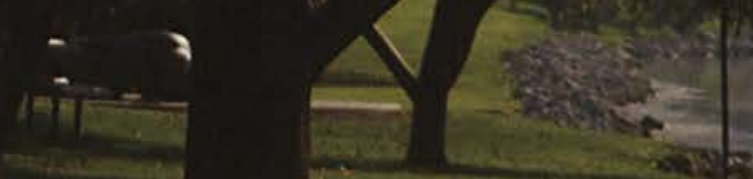

$$
\frac{0.25}{2 x+2}
$$$$
\text { (4) }
$$ 


\section{GETTING STARTED}

It was a humid Friday in August when cars began pulling in at Cedarville University. Early arrival freshman students, their cars loaded with everything necessary to live for a year, were directed to get their key. A line reached from the DMC to the SSC, the freshmen students' faces bright with excitement. The new Printy RD, Charmaine Porter, held a sign attempting to reassure parents. It read: "Don't worry, Mom, we'll take care of your baby." With a welcoming party of RAs, new and returning students, with the help of the Getting Started staff, the Resident Life staff, and even some professors, unloaded cars and tried to fit too much stuff into tiny rooms. Collin Mitchell, an RA in Lawlor, broke the record for the most number of mini-fridges unloaded: nearly sixty over the two days of Getting Started. Immediately, students found their roommates and began bonding over shared intersts.

On Friday night, a welcoming party for early arrival students was held between the SSC and DMC. A mechanical bull was the highlight of the night, lines moving fast as one student after another flew off the bucking bronco. A few accidents occurred in the intense blow-up obstacle course and on that bull, but the victims quickly forgot about their injuries when frozen fruit bars were offered as consolation prizes.

As mom and dad drove off, the students were propelled into meetings, sessions, and small groups, trying to figure out what to do with the freedom of college life. Freshman students devoured the information that would help them through the rest of their college career at Cedarville.

With classes and work on the horizon, students enjoyed their last bit of free summer time by catching up with old friends and meeting new ones.

1 The Lawlor RAs clutch a box of Krispy Kreme donuts stolen from the Printy RAs as Dr. Brown smiles in their midst. 2 Families of freshman students wait in the line stretching from the Dixon Ministry Center to the Stevens Student Center. They need their keys! 3 Printy RA Leanne Dykstra holds up a sign reminding parents to get a key before their student can get into the dorm room. 


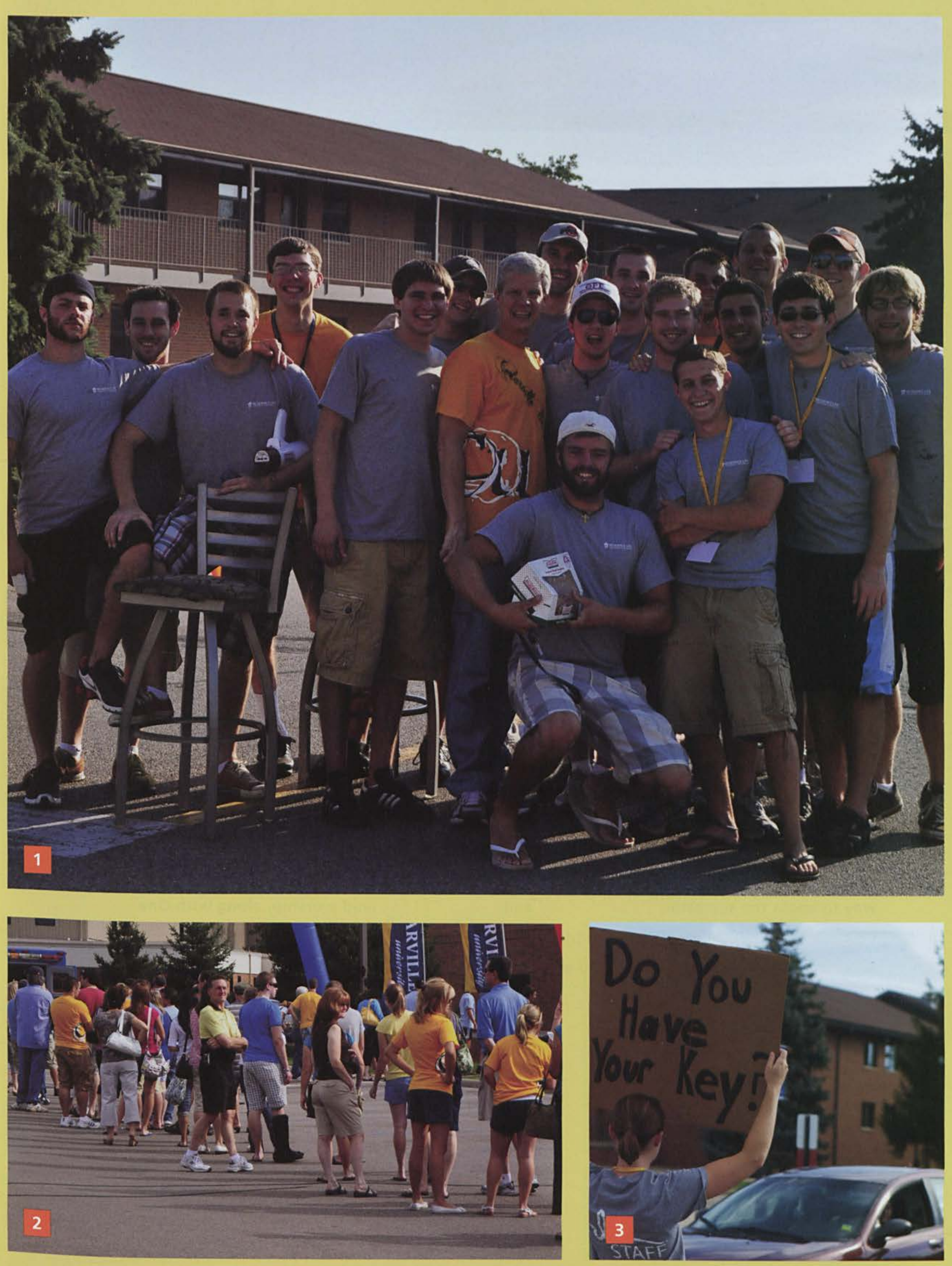




\section{FALL CONFERENCE}

Freshmen scrambling to claim free pews, upperclassmen reuniting from long absences, hymnals marking saved seats, and the traditional fire hazards of book vending surrounding the seal and Dixon statue are all ritual of the always highly anticipated Fall Bible Conference. It's a time when faculty, staff, and students can come together and celebrate the new academic year by worshiping and enjoying a keynote speaker. Since Chapel is very much of a part of students' daily routines, the Fall Bible Conference has become a sort of homecoming for the Cedarville University community as it beckons in the new school year with a strong spiritual focus. It is a fervent Cedarville tradition to start the school year with the university solely focused on God.

Fall Bible Conference speakers have been known to come from all over the world to deliver their messages to Cedarville students, and this year was no different. Students were thrilled to hear that a past chapel favorite, and no stranger to Cedarville's campus, was returning to be the keynote speaker. Chris Williamson, founder and pastor of Strong Tower Church in Franklin, Tennessee, joined Cedarville's community for the second time to enlighten, encourage, and move students to live life without excuses. Throughout the conference Pastor Williamson challenged students to grow in their faith and, for the second time, left a lasting impression on Cedarville University. In usual Chris Williamson fashion, he kept chapel interesting throughout the conference by including personal anecdotes and even performing an original rap. It was clear through his enthusiasm and his interactions with students that Pastor Williamson's love for Christ and for people manifested itself throughout the Fall Bible Conference.

\section{"It's such a good idea to start the year off focusing solely on God and His glory! And Chris Williamson is a dynamic preacher who is down to earth and so profound, yet simple, in his teaching of the Word of God." (Charmaine Porter)}

1 One Voice hosts worship as students lift their hands in praise-an encouraging and renewing way to begin the semester. 2 Darris Sneed and Felicia DeCook lead worship, along with One Voice Gospel Choir, during the Fall Bible Conference. 3 Guest speaker, Chris Willaimson, shares what's on his heart with a chapel full of Cedarville students. 
Every eye will see the coming of the King Jesus is the lord, Jesus is the Lord

at

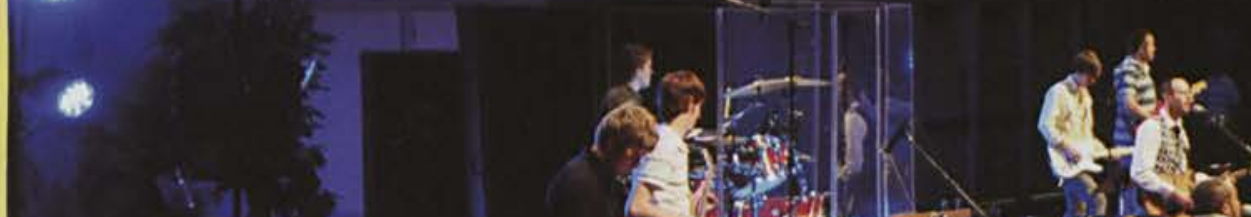




\section{HOMECOMING}

"Road Trip: Find Your Way Back" was the theme for this year's homecoming weekend. The first weekend in October was preceded by a week of alumni chapels showing the current students of Cedarville how to uphold the theme for the year, Real-World Impact. Even De Maurice Smith, the head of the NFL Player's Association, made an appearance during the week this year.

Reunions were spaced throughout the weekend, making time for volleyball and soccer games, and even an alumni baseball game. Homecoming traditions brought back old times for alumni and created new memories for new students, especially those just entering Cedarville.

Living up to the theme of the weekend, floats in the annual Homecoming Parade ranged from "Back-to-the-Future" to OPE's comical version of the Exodus, claiming it as "The First Road Trip." Even the library workers joined in the parade with carts made to look like cars. Staff and students passed out yellow and blue balloons to onlookers, throwing out candy along the way.

Saturday started bright and sunny, the weather perfect for the annual parade, but soon turned rainy and cloudy; Cedarville homecoming attendants were not deterred. Instead of allowing the weather to dampen their spirits, the student body-elected "royalty" kept their spirits up and the smiles on their faces.

Like every year, the weekend blurred together in reunions with old friends and remembering and reliving the Cedarville experience, if only for two days. Cedarville knows how to have a homecoming and knows how to keep its students coming back, even after they graduate.

1 Dr. Brown, looking especially hip in his aviators, passes out balloons to Homecoming parade onlookers. 2 Homecoming Queen and King, Katherine Watson and Nathan Flack, ride the streets of Cedarville in style in a bright red sports car. Being Homecoming King might be worth a ride in the car. 3 The ever-present Cedarville Yellow Jacket mascot fist-bumps basketball game fans at Moonlight Madness to start the season off right. 


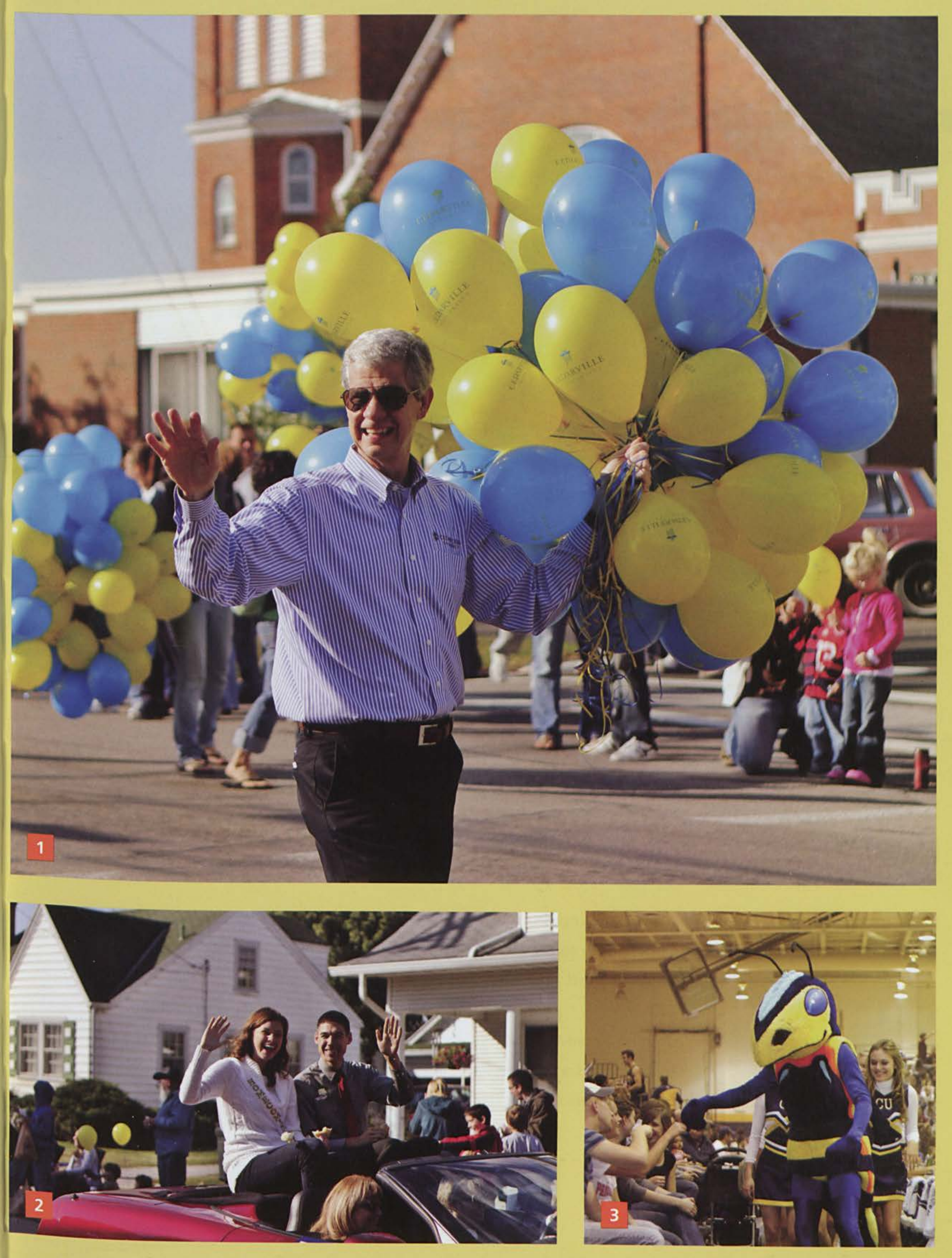




\section{HOMECOMING}

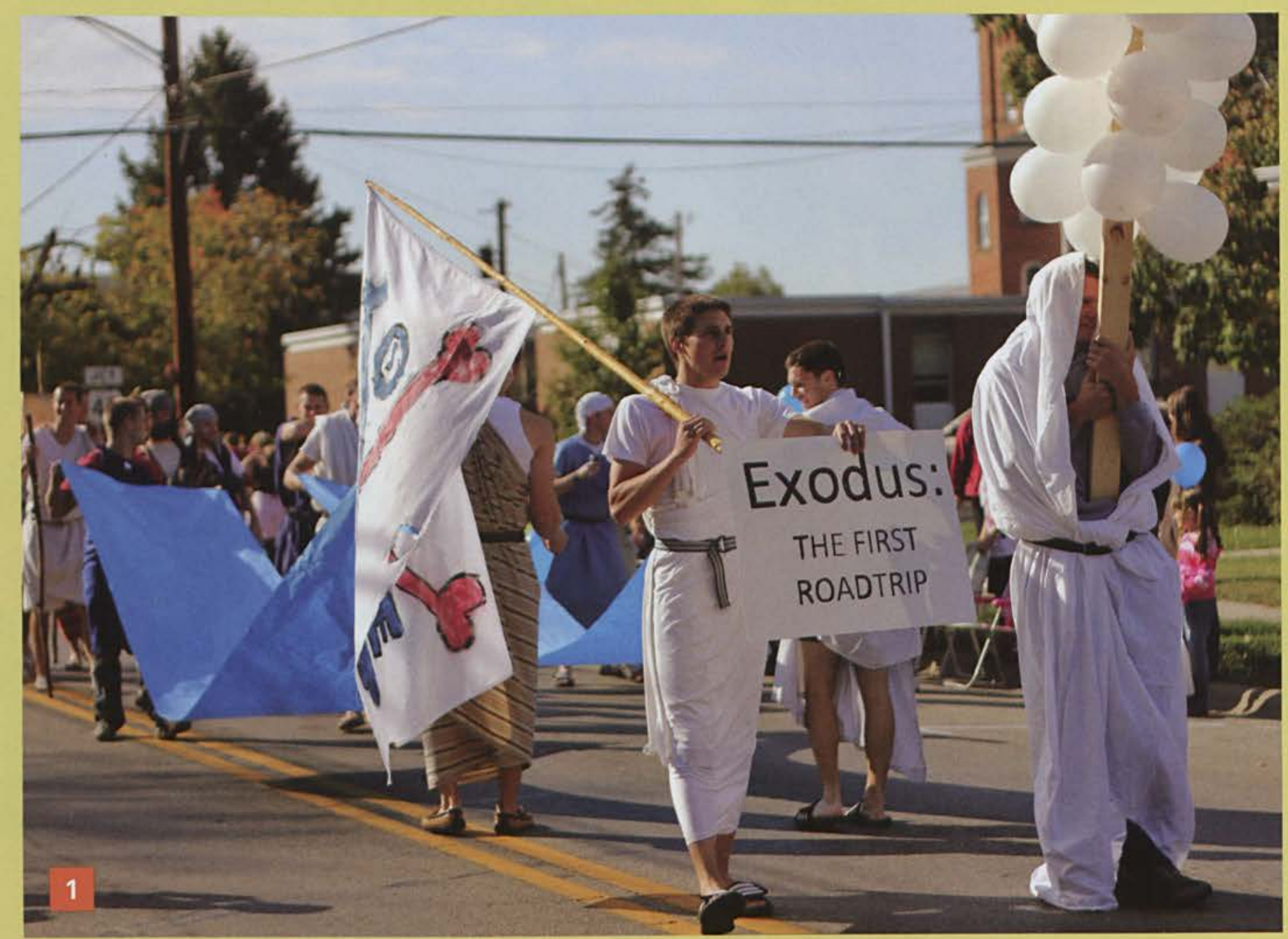

1 Seth Flamm leads OPE's homecoming float. The men's service org calls the Exodus, "The First Road Trip," and even has blue paper to represent water. 2 Cedarville nursing students walk in the homecoming parade and show off their colorful scrubs...and a bedpan. 3 Bre Brown, Alyson Wicker, Maggie Casillo, and Hannah Rauch represent license plates to show this year's "Road Trip" theme in the homecoming parade. 4 Aaron Southworth waves and hands out candy to parade watchers. That duck floatie is a big hit with the crowd! 5 The son of an alumnus plays cornhole outside the SSC. It's obvious this kid has a good arm. 

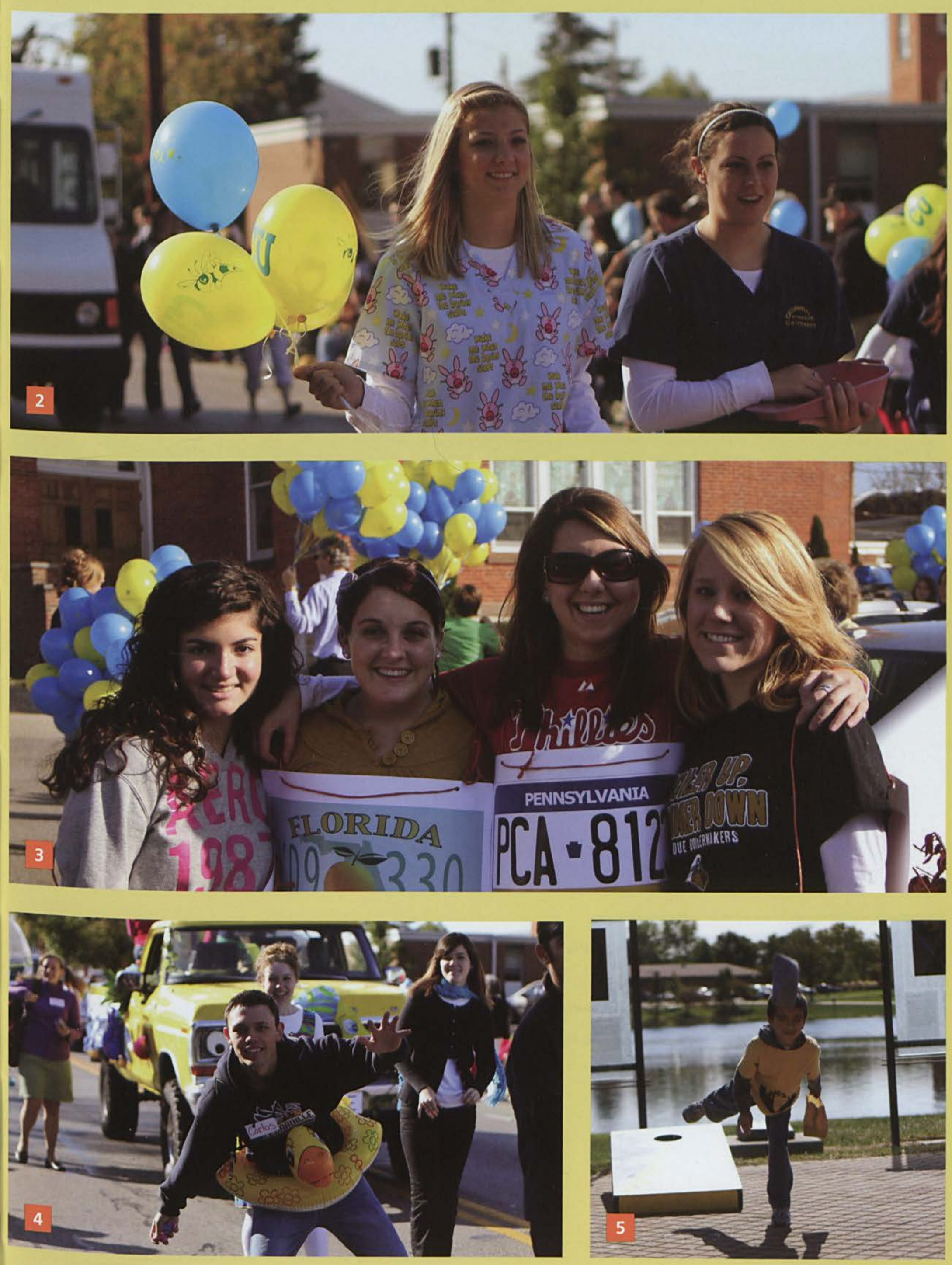


\section{CANOE RACE}

What is there to do with 73 square feet of cardboard and 100 meters of packing tape? Building a canoe and paddling it across Cedar Lake may not be at the top of most lists, but that is the task given to Cedarville's engineering students. It was a clear, crisp afternoon when the student body gathered around the lake to watch the annual Cardboard Canoe Race. This year's race featured 31 engineering teams as well as 5 department canoes. Two at a time, the canoes entered the lake, each carrying two engineering students as well as a non-engineer passenger. Though the races were timed, many of these amateur shipwrights counted their voyage a success if their canoe managed simply to make it across the lake. Spectators watched as the engineering students carefully paddled their less-than-seaworthy vessels.

It was often the passenger's duty to hold the sides of the canoe upright to keep the boat from filling with water. Their efforts were met with varying degrees of success. Some students actually accomplished their goal and made it all the way across the lake in a respectable amount of time. Others discovered the flaws in their design when their boat sank in the middle of Cedar Lake. Rescue teams paddling sturdy wooden canoes assisted in bringing the stranded students back to shore.

After the race, the top sixteen teams participated in a demolition derby. All canoes were reduced to soggy strips of cardboard. Well, all except one. The library dominated not only the demolition derby, but the department races as well. The education department used their experience with the laminating machine to laminate their canoe, making it indestructible by the water.

This traditional event once again proved an exciting and challenging experience for the students who participated and some afternoon entertainment to those who watched.

\footnotetext{
1 Brittney Morris might not have realized she was going for a swim when she volunteered to join Josh Gunderson's canoe. 2 The Education Department's canoe successfully avoids sinking, though the laminated cardboard may have helped. 3 Engineering students paddle their sinking canoe to the water's edge, desperate to make it across Cedar Lake before the paper and cardboard fail.
} 


\section{FALL PLAY}

The Fall Play at Cedarville serves as a chance for many from the community to step onto the campus and see the dedication of both the students and the faculty at Cedarville University. With opening night on Thursday before Homecoming weekend, alumni jump at the chance to see the productions, with evening and matinee shows selling out quickly. The Fall Play was The Importance of Being Earnest, a comedy by Oscar Wilde about pretending to be someone else to escape obligations... and the repercussions that come with it.

"I have always been of opinion that a man who desires to get married should know either everything or nothing," writes Wilde in Earnest. Amy Eiler played the beautiful Gwendolen, and Stephanie Anderson laid claim to the formidable Lady Bracknell. Jordan Hickling and Josiah Smith played the major male leads.

Dave Dion stated, "Working behind scenes lets me see all the technical parts of the show--the costumes, the makeup, the scene setups, the blocking, and all the work--but I still get to enjoy the magic of the play itself."

The plot twists and ironic curves in Earnest forced both the audience (and the actors) to pay attention to the play; what should happen might not happen. Jack and Gwendolen spark a romance - though Jack isn't completely honest about his name - and the lies told in Act I come back to haunt characters throughout the rest of the play. The characters of Earnest unintentionally overcome obstacles through irony and puns, resulting in - of course - happy ending.
"I always get a ticket in advance because the shows are sure to be packed. Students, faculty, parents, and even outside visitors know the value in attending a Cedarville University play." (Mandy Allen)

\section{Ernest (Jordan Hickling) gives Lady Bracknell (Stephanie Anderson) a look of disgust...or is}

it confusion? 2 Judging by their faces, Grace Pilet and Amy Eiler aren't very happy with Josiah Smith. 3 Emily Bush as Miss Prism smiles adoringly at Derek Stockwell, who plays

\section{Rev. Canon Chasuble.}



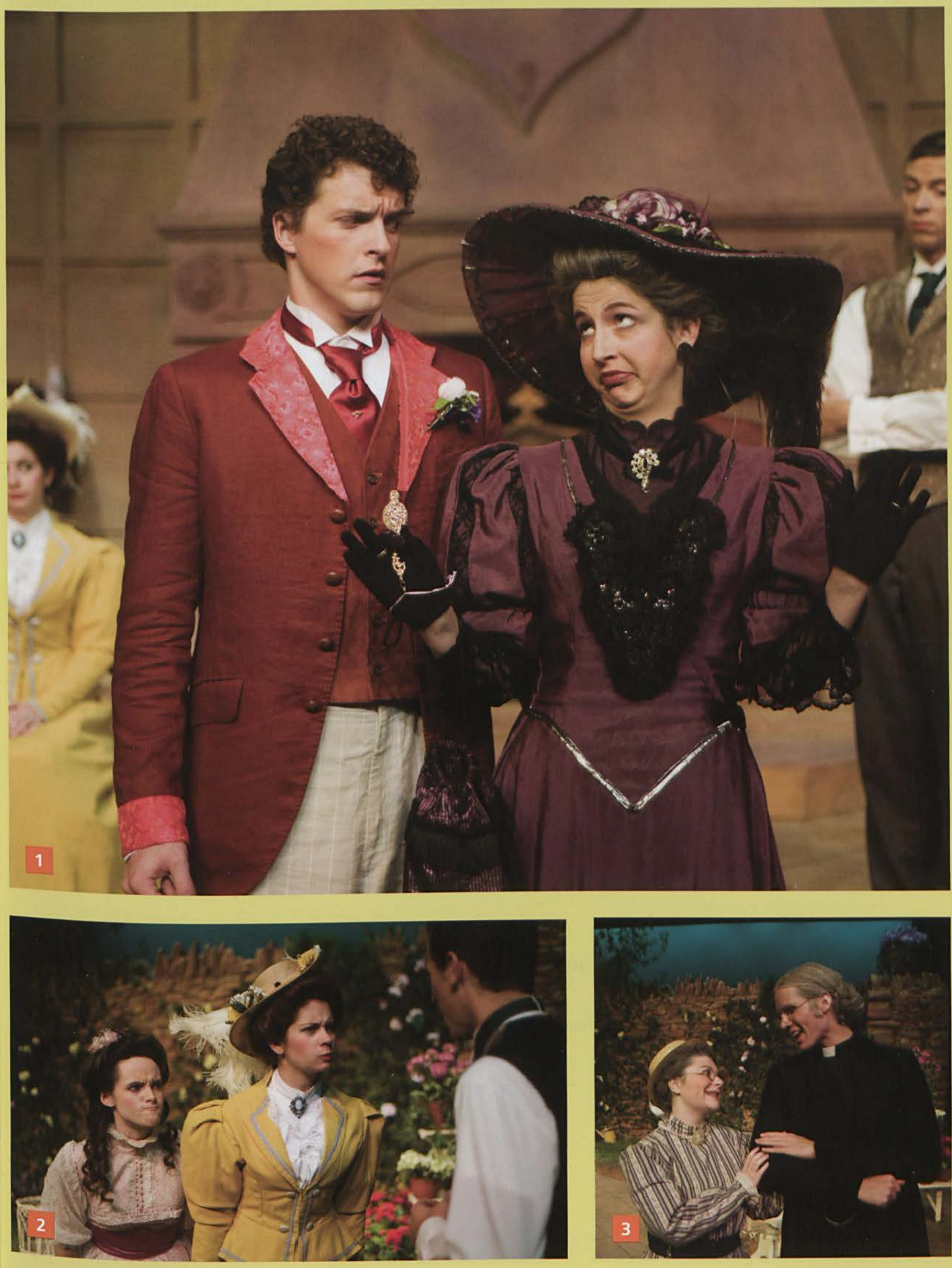


\section{FALL HAPPENINGS}

Labor Day weekend. Since the "father" of Labor Day was born in Cedarville, the parade and fireworks are always worth a weekend trip downtown to CedarFest. This year, the firework display was better than ever, and as the leaves began to fall, the Cedarville campus was filled with events for students to enjoy. The Involvement Fair encouraged both new students and returning students to branch out to the community and, like its namesake, become involved in an activity during their short time at Cedarville.

The Freshman Class started a new event: The Amazing Race. Teams gathered together with a small entrance fee to compete for $\$ 100$ in prize money. Tasks to finish included building a structure of marshmallows and toothpicks, giant-pin bowling, and clue-solving to find the next location. The winners of the event played hard and received $\$ 100$ to show for it.

During Fall Back, on Halloween weekend, the streets between Printy and Lawlor were overflowing for the Block Party. As the night grew late, students began to fill the event rooms to watch the twisted film, Inception. Then, on Saturday night, many students gathered to help solve the mystery at Boddy Mansion in a game of Clue.

Moonlight Madness, hosted partially by Jernelle Ward, packed the gym with students jangling their keys. Sitting down was not an option during this basketball season kick-off. The reveal of a new seating section-the Jacket's Nest-encouraged fans to show their true colors: yellow and blue.

Junior Jam packed the campus with elementary students for a Saturday and challenged Cedarville students to serve as group leaders or committee members. This event was fun for both the children that attended and the Cedarville students that had the chance to interact with the kids. The theme this year was "Extraordinary Examples" and challenged both children and students to be good examples every day.
"I thought the fall street fair held in the Meet Market was great fun! From throwing pumpkins to making cotton candy, and then to painting pumpkins, it was just a fun event. The absolutely frigid weather that day also added to the fun - it certainly didn't get anyone's spirits down!" (Grace Zielger)

\section{Junior Jam volunteers clear their busy schedules to lead groups of elementary school students}

one Saturday in October. 2 JoyAnna McBride helps lead the worship band during the finale of Junior Jam. 3 Taylor Swayze loses himself in his guitar playing at the New Student Talent Show during Dad's Weekend. 


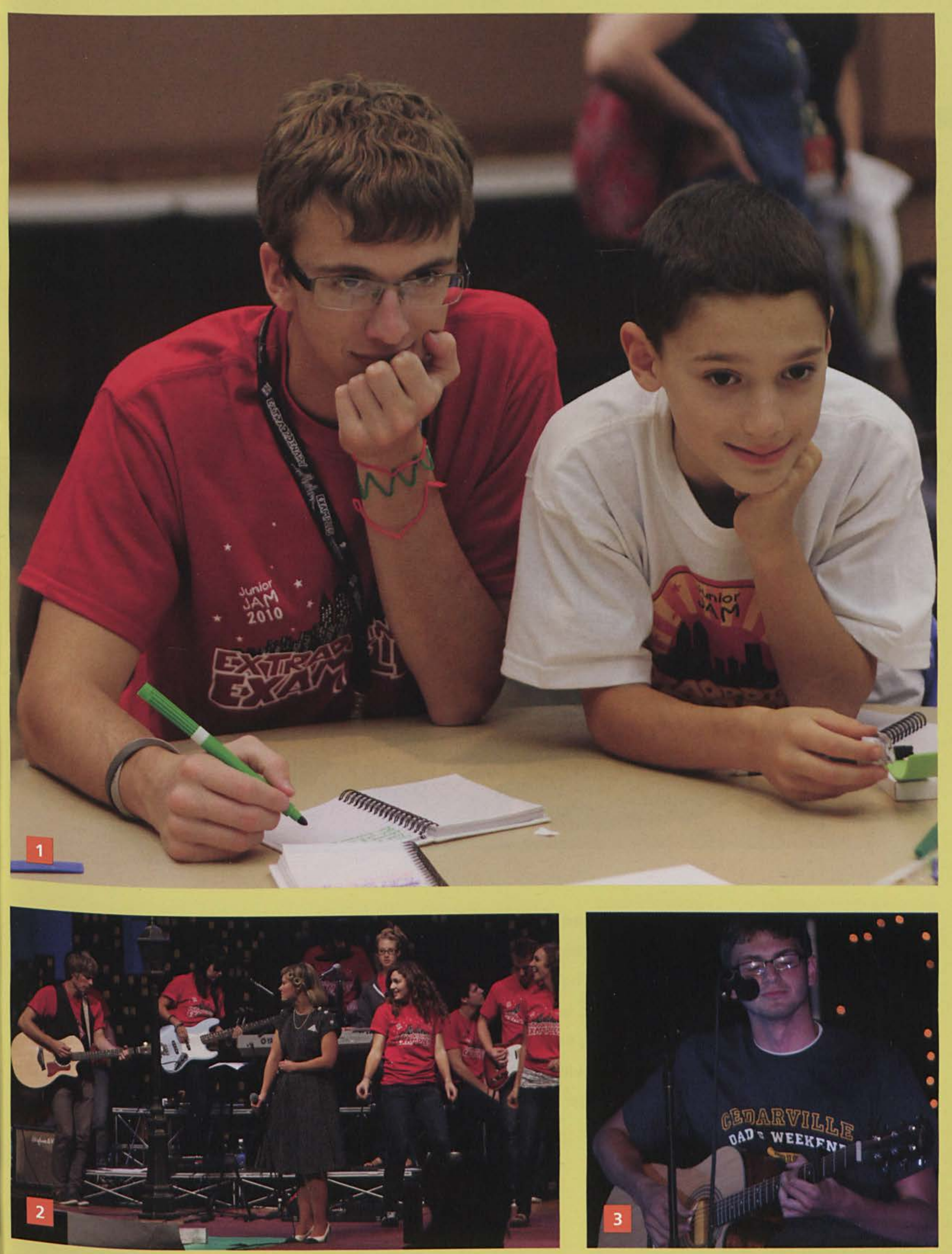




\section{FALL HAPPENINGS}

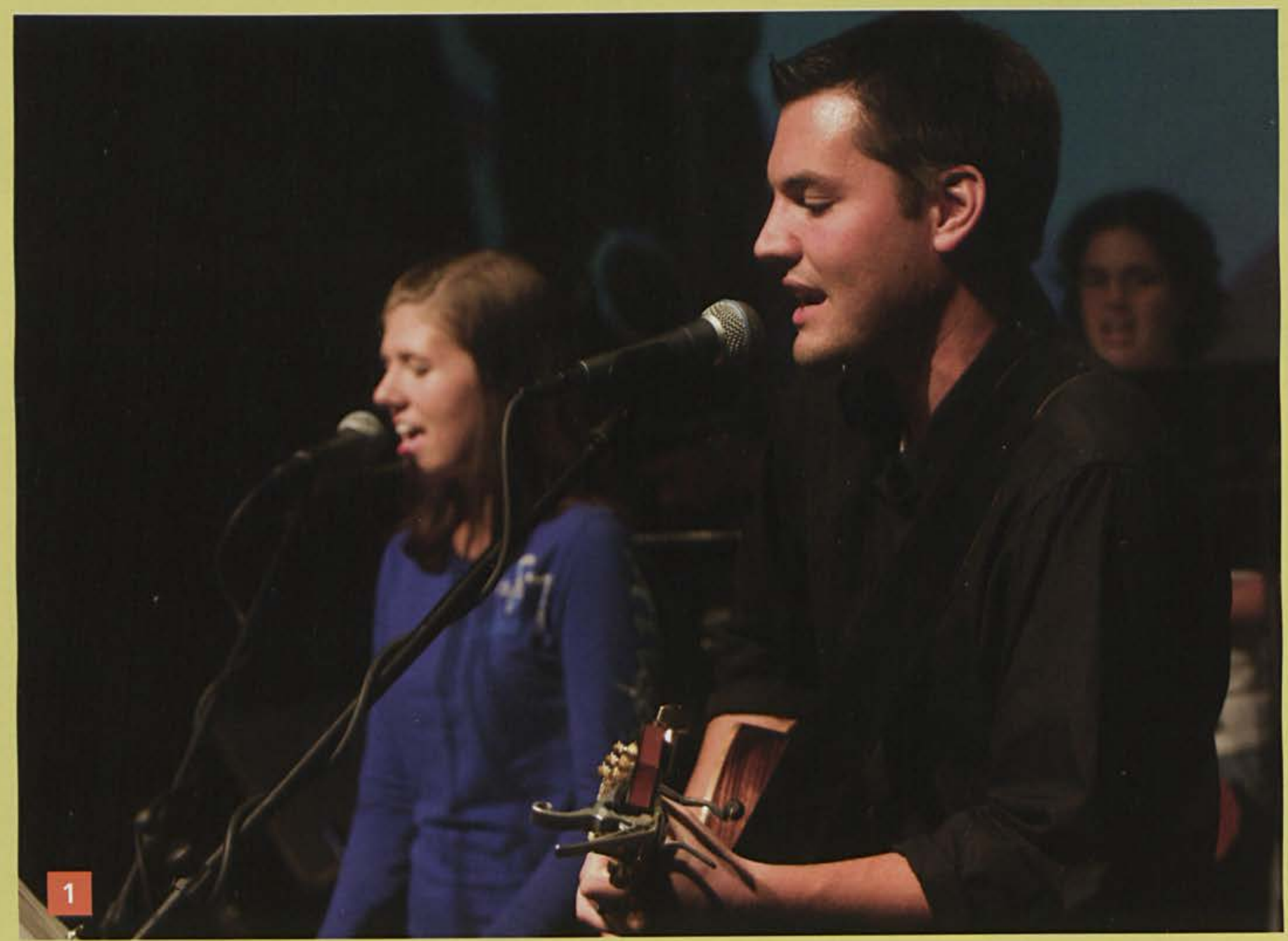

1 Shauna Acheson and Chris Reed lead an "Encounter" worship session in the BTS Youth Ministry room. Worship majors lead "Encounter" multiple times throughout the semester. 2 Stacy Philipps, Jernelle Ward, and Dan Smith don't hold back while hosting Gospel Fest with OneVoice in the DMC Chapel. 3 Sophomore students, including Stuart Li and Emily Sweet, attend the breakfast with Dr. Brown in President's Dining Room. 4 Christopher Hook speaks at the Health Care Ethics Conference, which challenges Cedarville students to question why they believe what they believe. 5 Leland Ryken makes a guest appearance at Cedarville to speak on the importance of being both a Christian and an artist. 


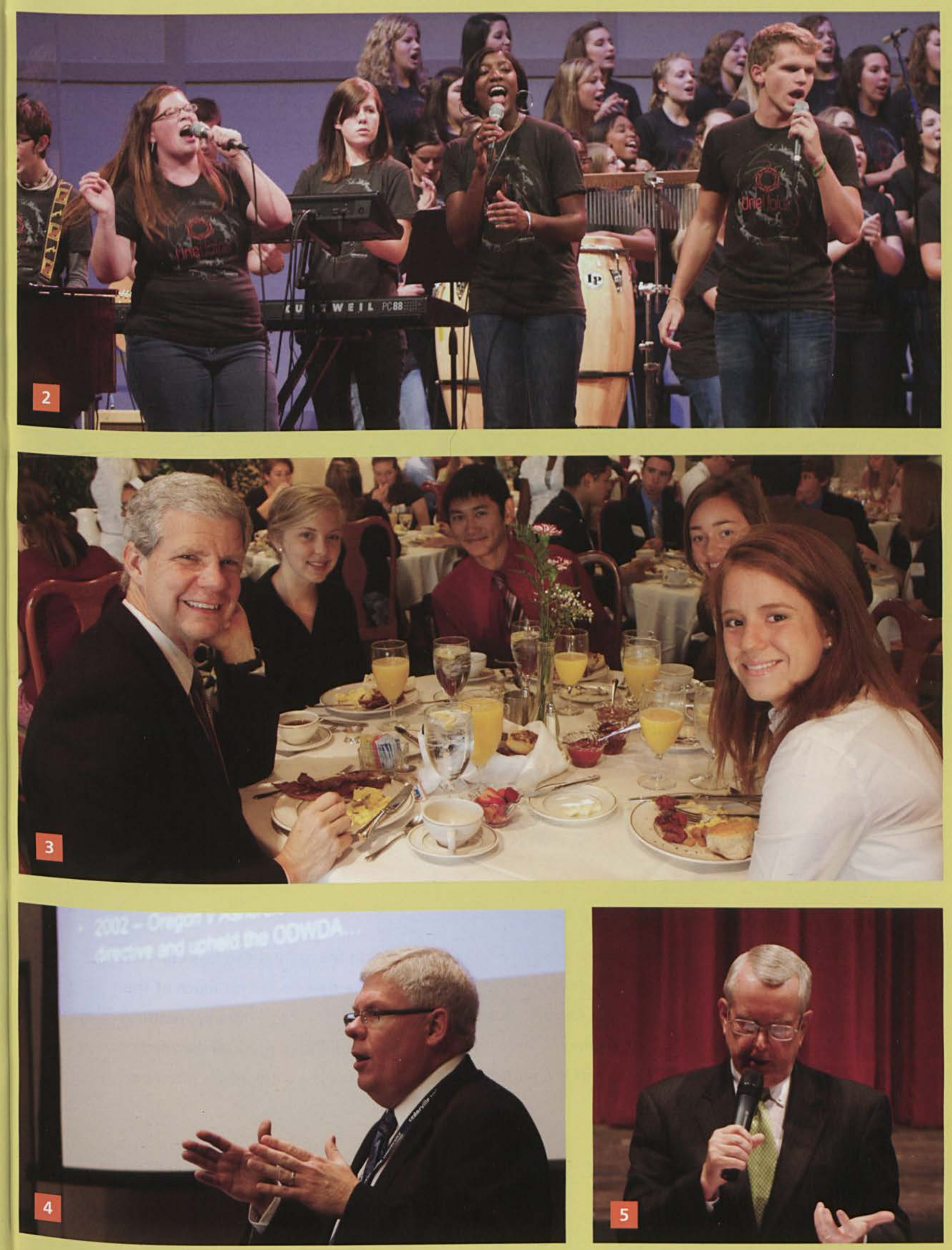




\section{HOLIDAYS}

Winter's chill blew through Cedarville on the first of December, bringing Christmas trees with presents underneath, wreathes, and icicle lights across the campus. Annual activities were planned; Dr. Brown chose his Christmas picture books; Chuck made his midnight biscuits and gravy; Carl Ruby stayed up all night making cinammon buns; Campus Christmas had arrived.

The night started with Denver and the Mile High orchestra playing jazzy traditional Christmas songs and a few original pieces. Their performance brought in students, staff, and families from the area. Then, Dr. Bill Brown took the stage. He read Christmas stories that included The Night Before Christmas (a classic), My Dad Ran Over a Frog (a tradition), and the original Christmas story of Jesus. Next, the film, A Christmas Carol, starring Jim Carrey, began, and the students filled DeVry Theater and the event rooms quickly. This animated version of the classic story was a wonderfuland haunting - way to get the students into the Christmas spirit.

Chucks opened at nine for the annual midnight breakfast. Karaoke performances entertained the audience all throughout the night, including some interpretive dance. Laser tag and cookie decorating kept the Christmas spirit going all through the evening.

A week of classes ensued, and the next weekend arrived quickly with decorations and other preparations for Christmas open dorms. Unit and hall themes varied from Madagascar to Disney princesses, the circus to Oregon Trail, Mario, the Sound of Music, and the Wizard of Oz...even a castle in Rodgers and New York City in Printy. Students worked hard in perfecting their rooms as well as their roles in the event. Other students went though the mazes and scenery that the dorms had set up and enjoyed the efforts the dorms put into making Campus Christmas everything it could be. The festivities were a great way to get away from studying before finals week started.

\section{"When we're all a little burned out towards the end of the semester, Campus Christmas brings us that Christmas spirit and takes our minds off finals - if only briefly - with some holiday fun." (Ben Chasnov)}

1 Denver and the Mile High Orchestra entertains Cedarville during the annual Campus Christmas. Their unique sound, a blend of R\&B, Jazz, Big Band, even Latin, is a new sound for much of the Cedarville student body. 2 Step into Chucks...in a dorm! Christmas Open Dorms always features well-planned and well-executed themes. $3 \mathrm{Dr}$. Brown maintains the holiday tradition by reading My Dad Ran Over A Frog. All he needs is a pair of fuzzy slippers... maybe a Christmas gift from Pastor Rohm? 


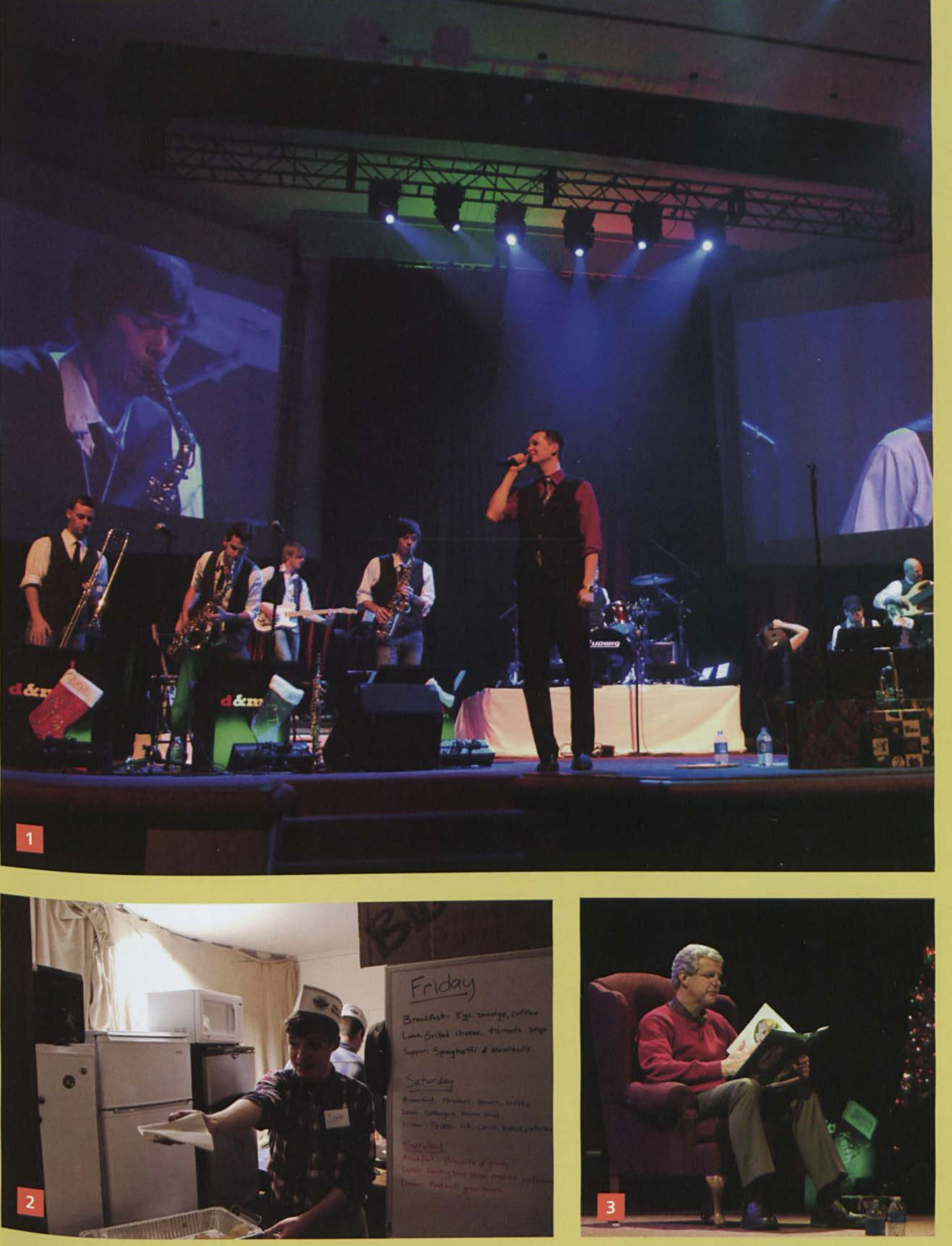




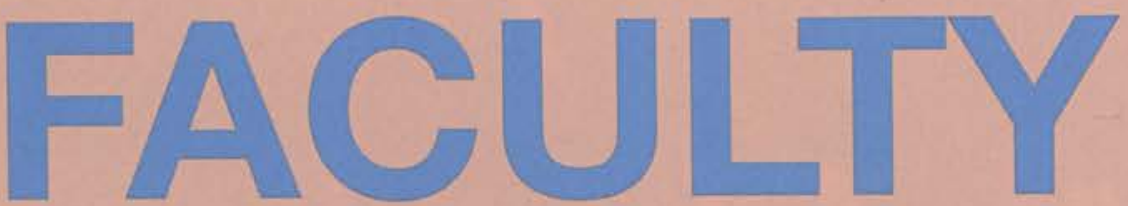

noun \'fæk əl tee \Individuals with a passionate commitment to students in academia; often seen carrying large amounts of caffeinated beverages and tall stacks of papers. 


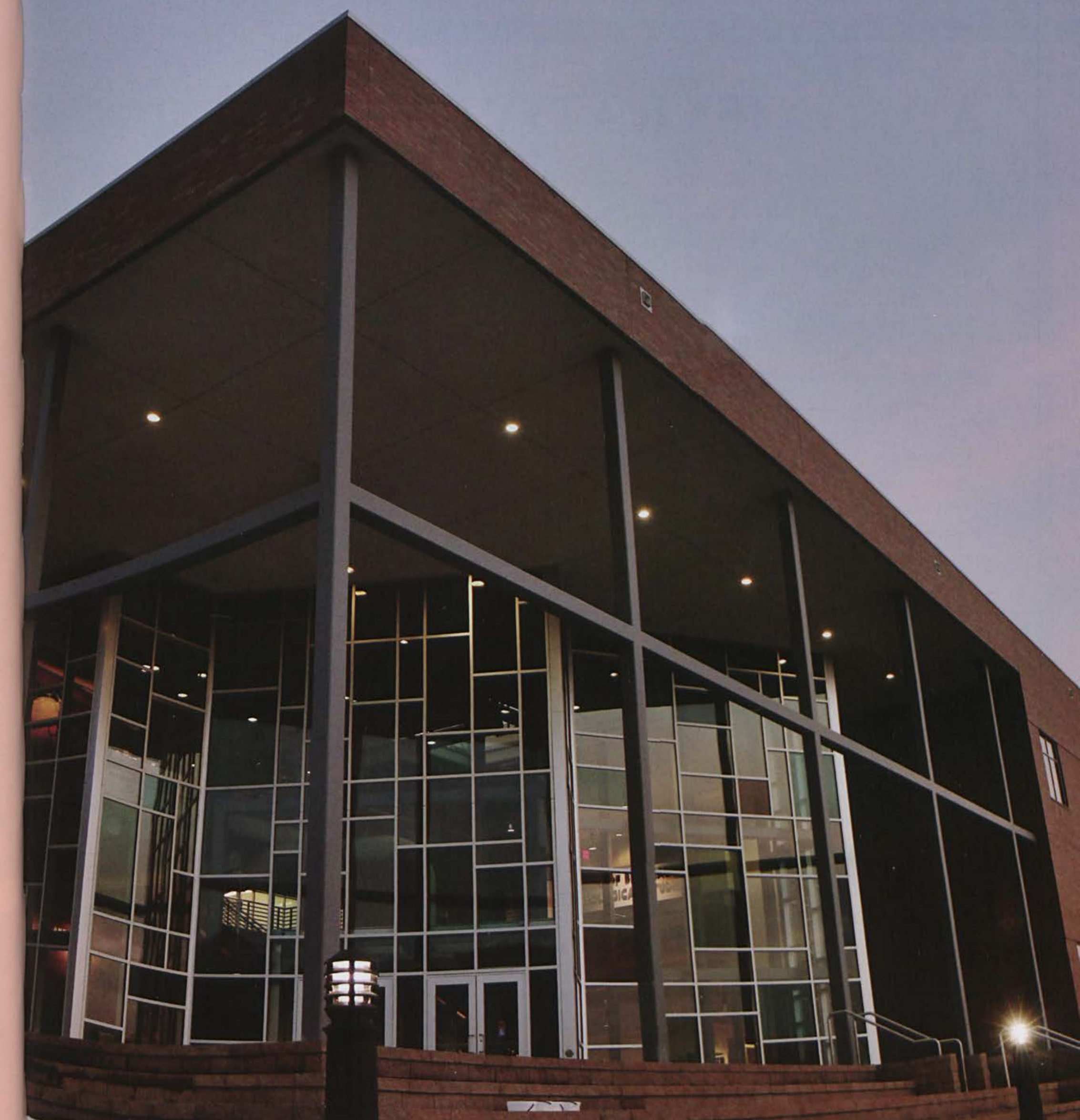




\section{ADMINISTRATIVE COUNCIL}

This edition of The Miracle is a fantastic collection of memories from 2010-2011. It was a year where we celebrated Cedarville University's largest enrollmentand then wondered if winter would ever end!

This time next year, the campus will look a lot different than it does now. From the major renovation of The Hill to the construction of the new Health Science Center, Cedarville continues its ongoing development and facelift.

But right now, we can enjoy the memories of great athlete seasons, outstanding dramatic and musical programs, non-stop student events, and memorable chapels. It is not often that you hear a former Mafia don give parenting advice!

Our theme this year, "Real-World Impact; Unafraid and Unashamed," has given us a glimpse of how God wants to use us. Hidden behind the theme is the truth that the "real world' is not the one where things rot, rust, decay and die. This may be the world we live in now, but the real world is yet to come. It is the world we were made for.

Lynne and I wish you all the best as you continue walking with Christ. You will always be a part of the Cedarville University family. Thanks for sharing part of your journey with us.
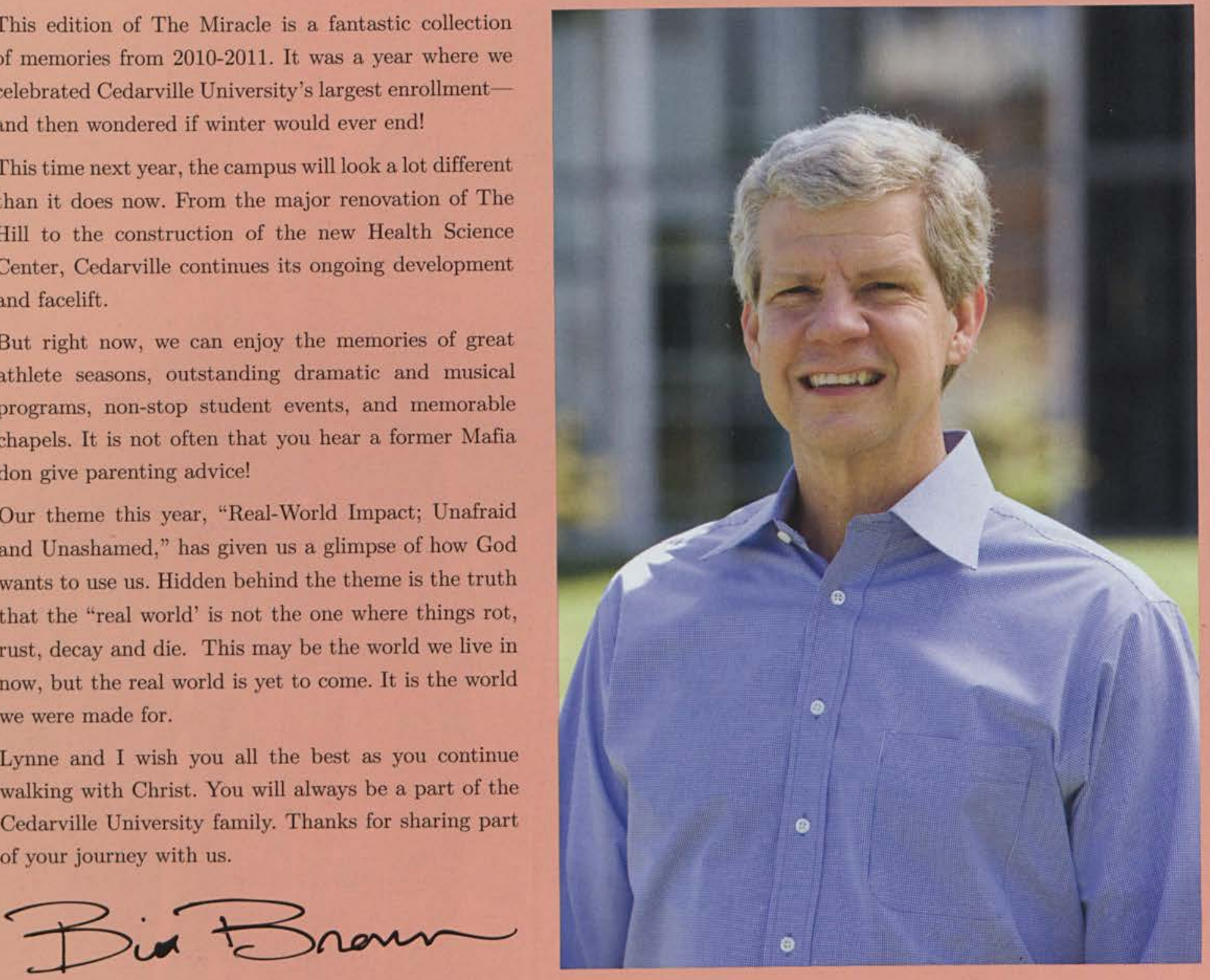

\section{William Bigham Vice President for Advancement 2 Robert Rohm Vice President for Christian}

Ministries 3 Carl Ruby Vice President for Student Life and Assistant Professor of Higher Education

4 Janice Supplee Vice President for Enrollment Management and Marketing 5 John Gredy Provost

6 Philip Grafton Vice President for Finance 7 Rod Johnson Vice President for Operations

8 Thomas Cornman Academic Vice President and Chief Academic Officer 


\section{TRUSTEES}

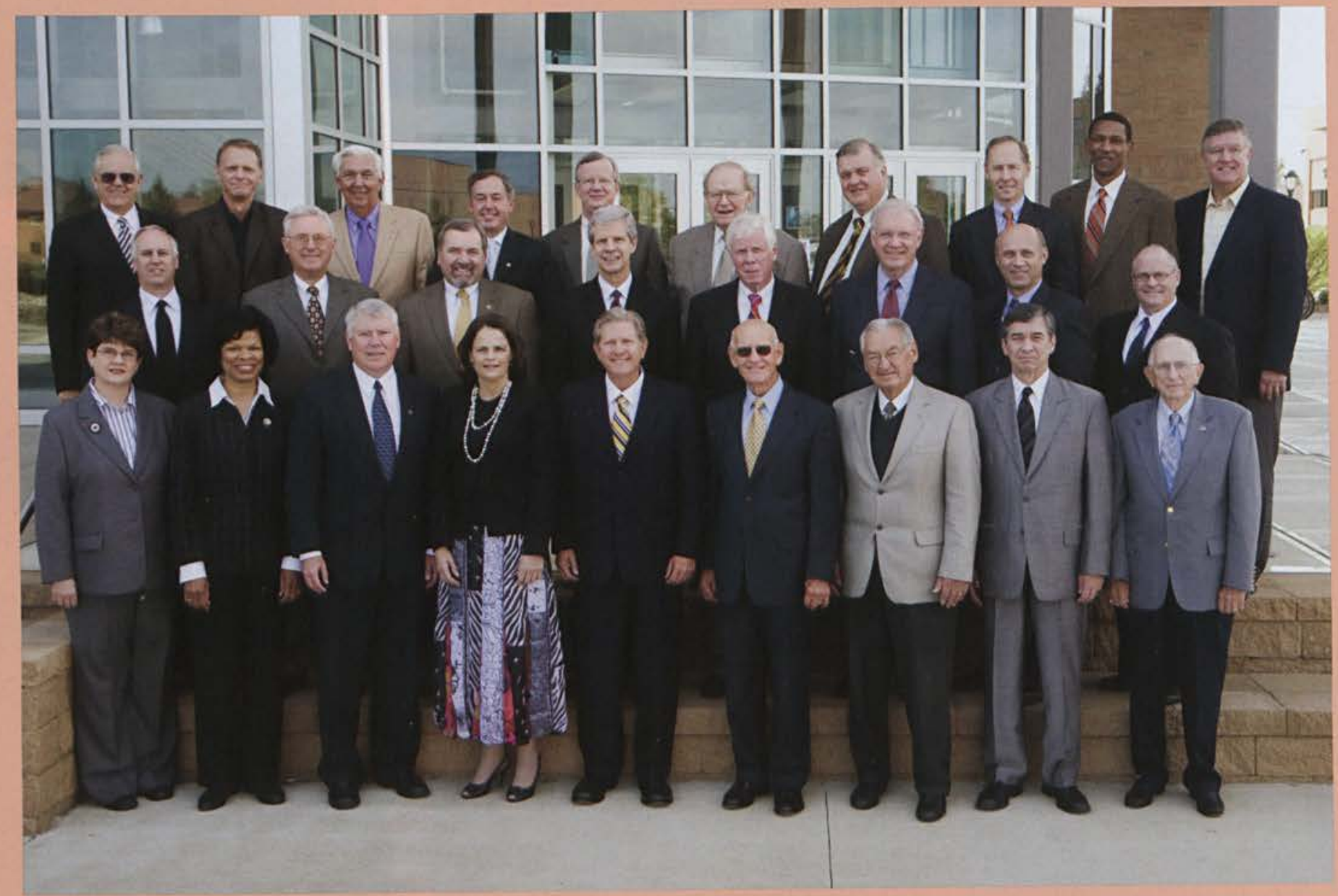

Front Row (left to right): Beth Prentice, Deforia Lane, Ron Becker, Debby Stephens, Hayes Wicker, Joe Godwin, Roy Guenin, Bill Rudd, Fran Bresson

Middle Row (left to right): Jeff Willetts, Bill Bolthouse, Michael Loftis, Bill Brown, Jim DeVries, David Graham, John Blodgett, Bill Williams Back Row (left to right): Al Stevens, John Hays, Gil Brueckner, Randy Miller, David Gower, Gene Apple, Lorne Scharnberg, Randy Wilcox, Dominic McKinley, Chip Bernhard 

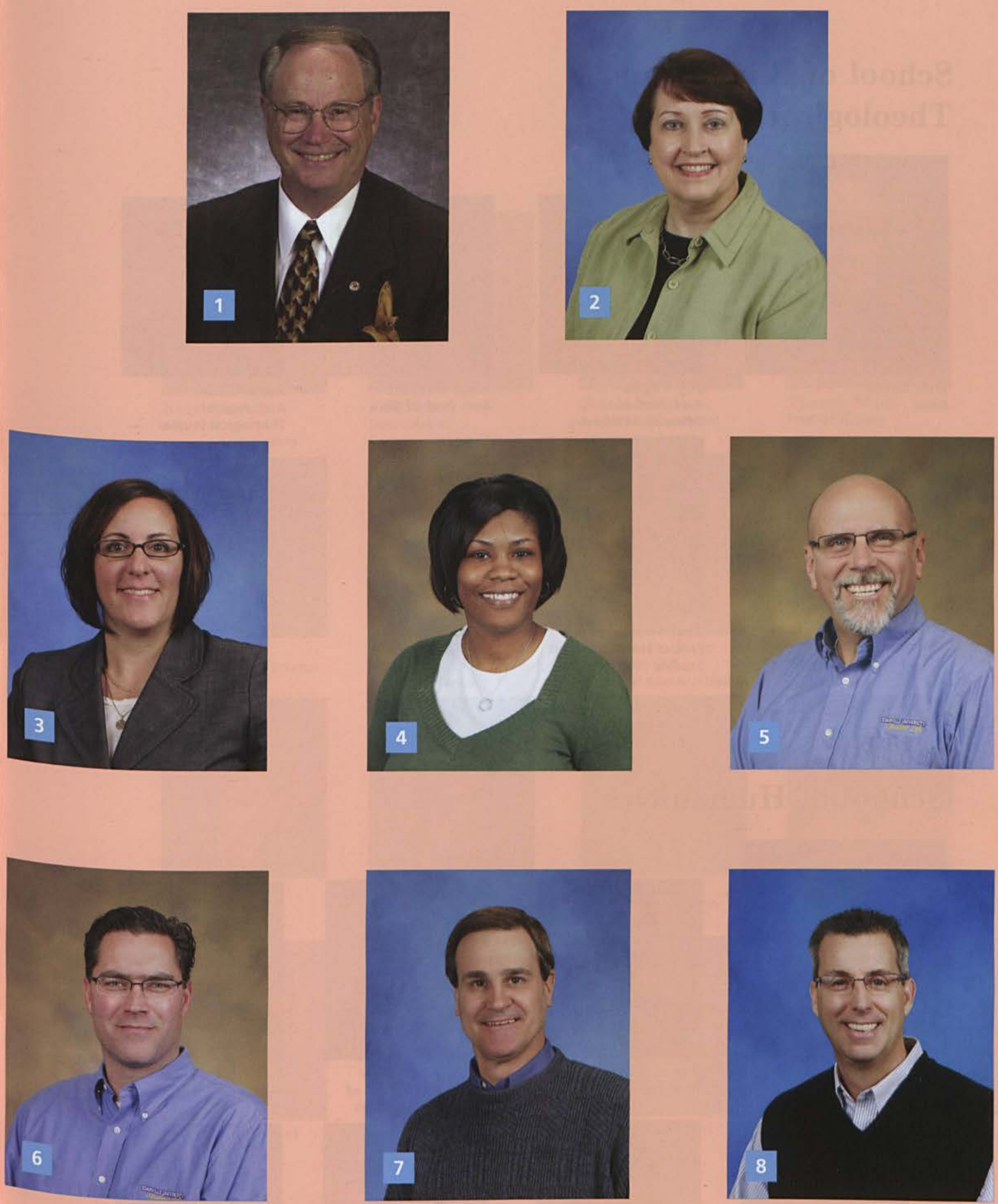

1 Paul Dixon Chancellor 2 Lynn Rohm Administrative Assistant to the Chancellor 3 Kirsten Gibbs Associate Vice President for Student Life/Dean of Students 4 Carmille Akande Dean for Multi-cultural and Special Programs 5 Jon Purple Dean for Student Life Programs 6 Brad Smith Associate Dean of Students 7 John Potter Director of Counseling Services 8 Mark Weinstein Director of Admissions 


\section{School of Biblical and Theological Studies}

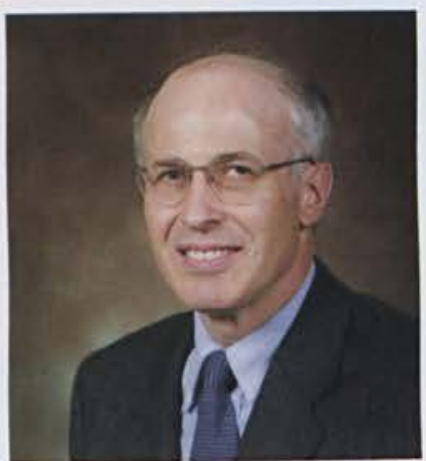

Dan Estes Dean

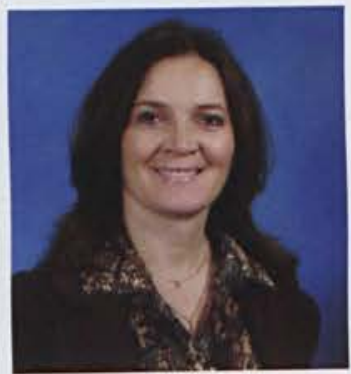

Joy Fagan

Assc. Prof. of

Educational Ministry

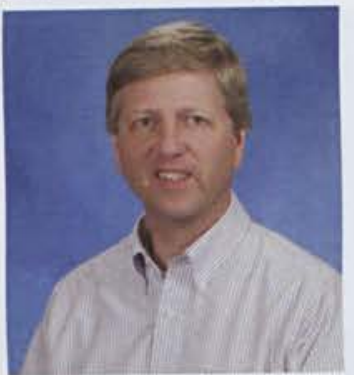

Joel Williams

Prof. of New Testament Studies

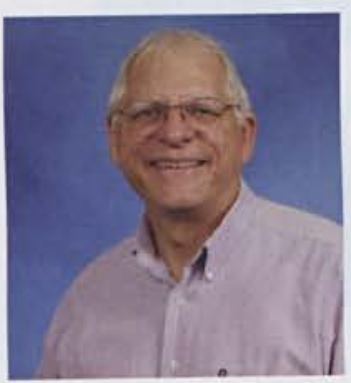

Mike Parrott Asst. Prof. of Bible

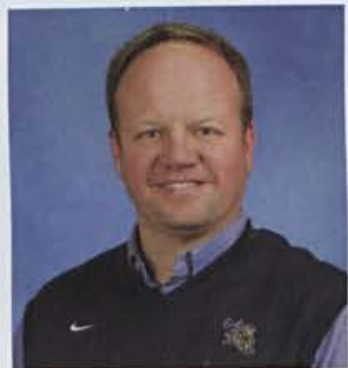

John White

Asst. Prof. of Theological Studies

\section{School of Humanities}

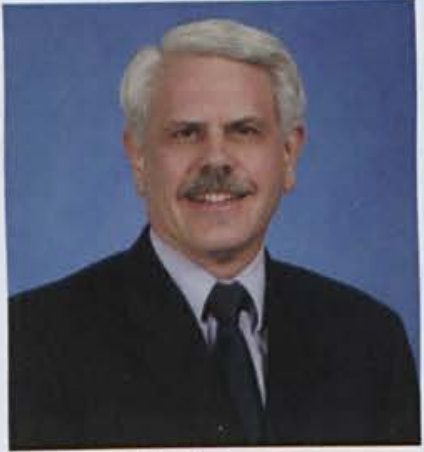

Steven Winteregg Dean

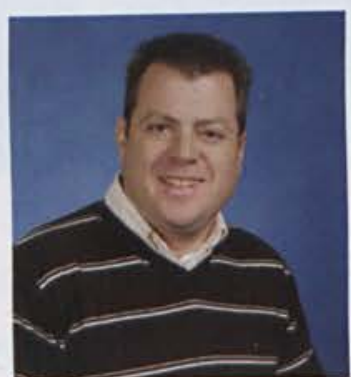

Jeff Gilbert

Assc. Prof. of

Communication Arts

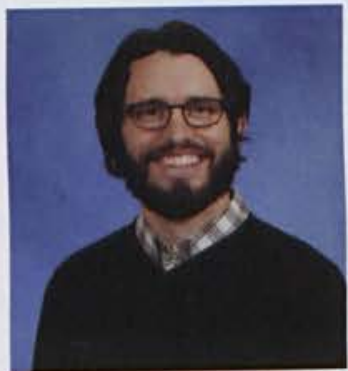

Aaron Gosser Asst. Prof. of Studio Art

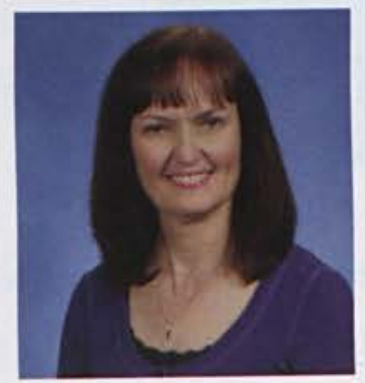

Mischelle McIntosh Asst. Prof. of Communication Arts

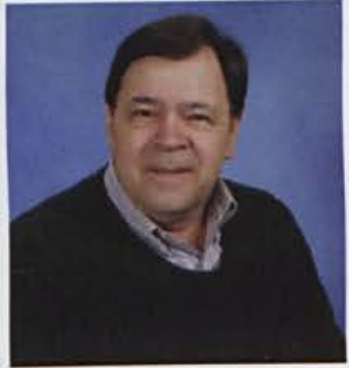

J. Wesley Baker Distinguished Prof. of Communication Arts

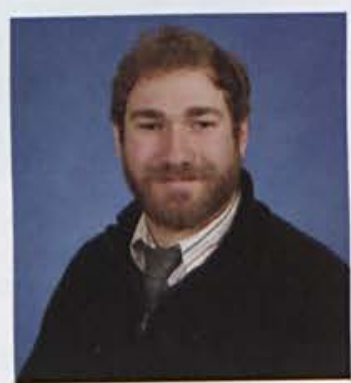

Eric Mishue

Adj. Prof. of

Communication Arts

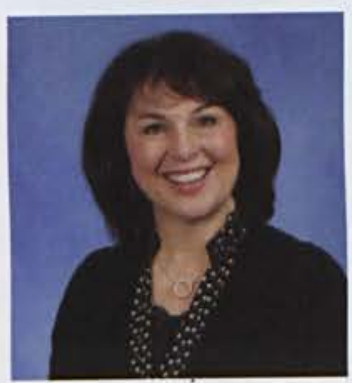

Rebecca Baker Assc. Prof. of Theatre Arts

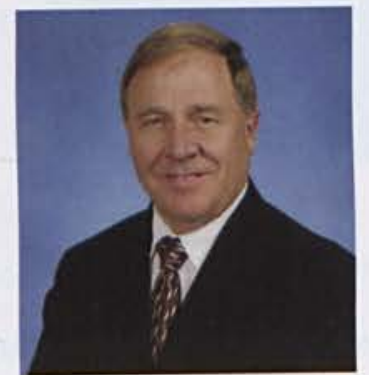

James R. Phipps Sr. Prof. of

Communication Arts 


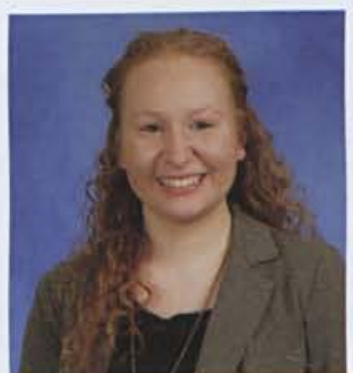

Katy Russell

Adj. Prof. of

Communication Arts

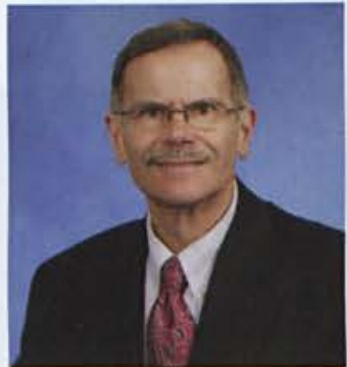

Kevin Sims

Prof. of Political Science

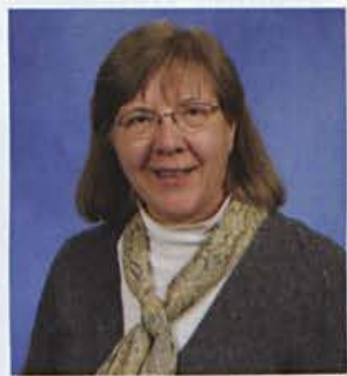

Barbara Loach Prof. of Spanish

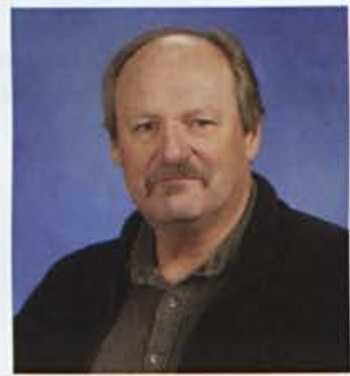

Michael DiCuirci Prof. of Music

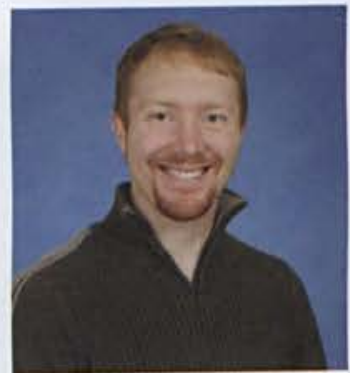

Jeff Simon

Instructor of

Communication Arts

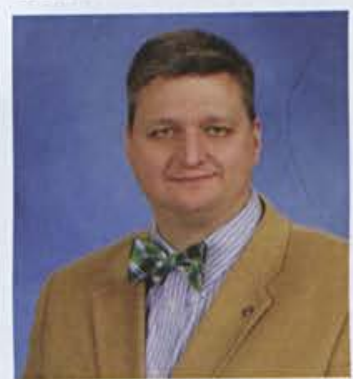

Mark Smith

Assc. Prof. of

Political Science

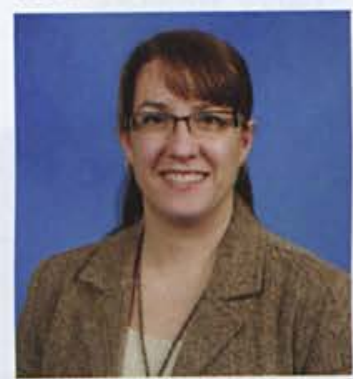

Cyndi Messer

Asst. Prof. of English

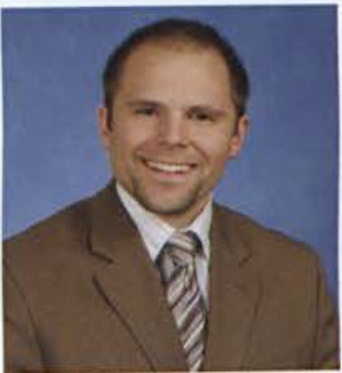

Austin Jaquith

Asst. Prof. of Theory and Composition

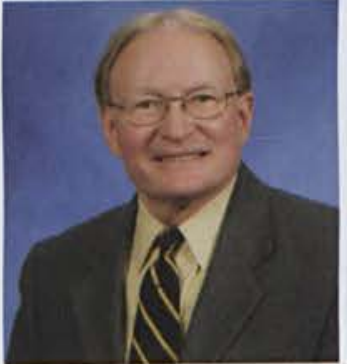

Frank Jenista

Prof. of International Studies

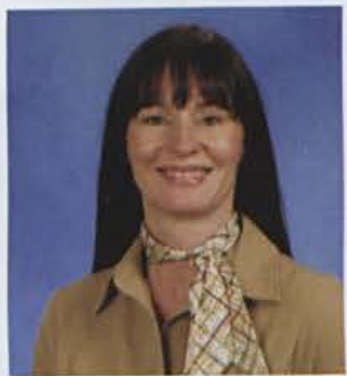

Melissa Faulkner Asst. Prof. of

Technical Communication

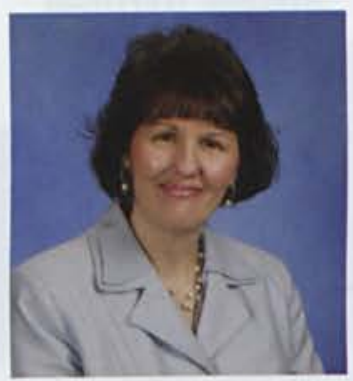

Julie Moore

Assc. Prof. of English

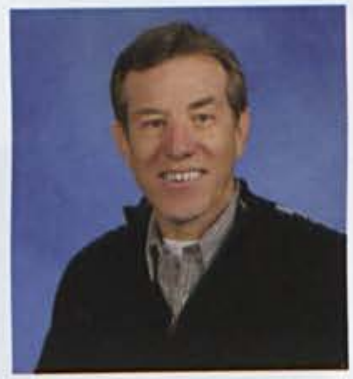

Charles Pagnard Prof. of Music

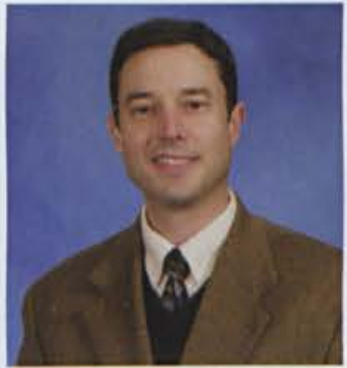

Thomas Mach Prof. of History

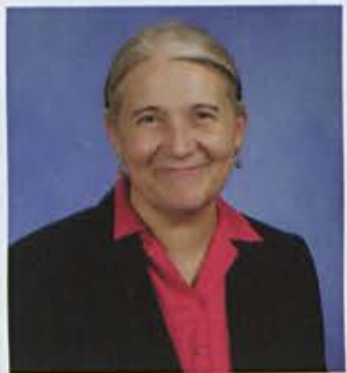

Louise Grandouiller Asst. Prof. of French

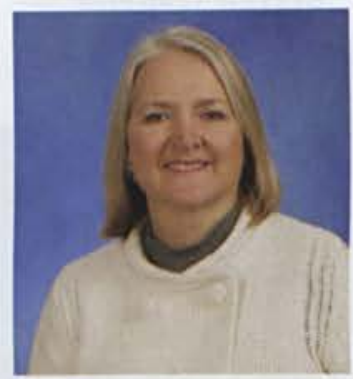

Annis Shaver Asst. Prof. of German

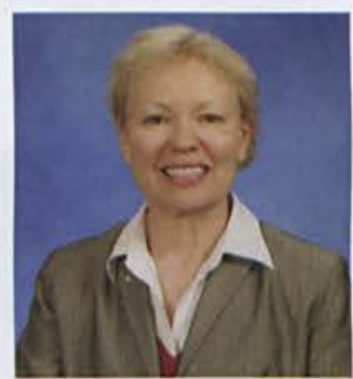

Sandra Yang Asst. Prof. of Music History 


\section{School of Humanities}

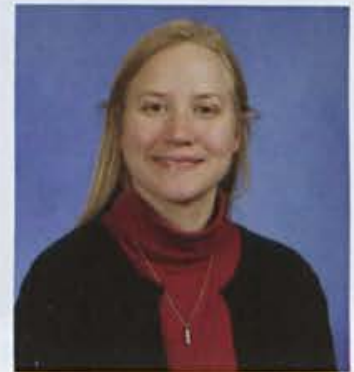

Melody Arab

Lecturer of Mathematics

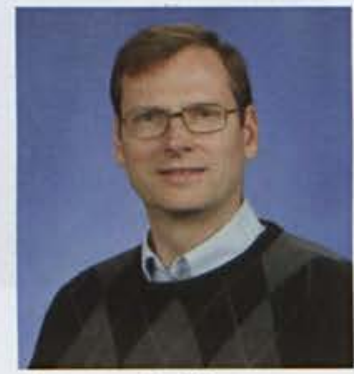

Steven Gollmer Prof. of Physics

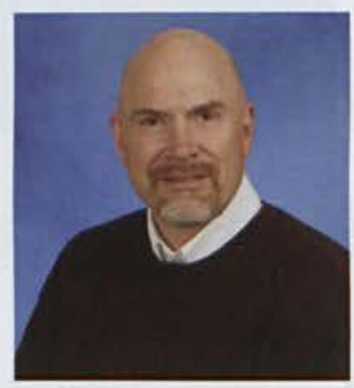

William Jones Assc. Prof. of Biology

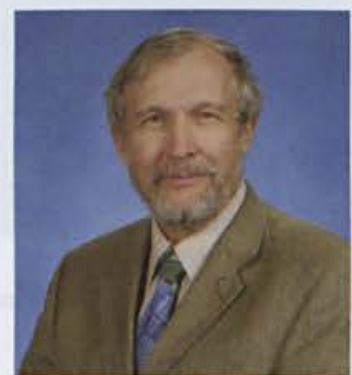

Robert Schumacher Asst. Prof. of Science and Mathematics

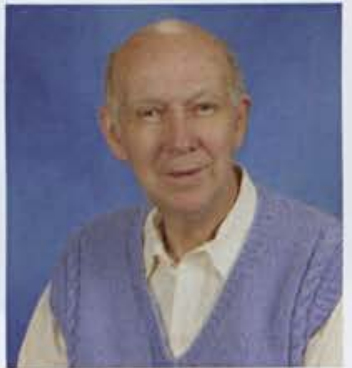

Donald Bauman Prof. of Biology and Chemistry

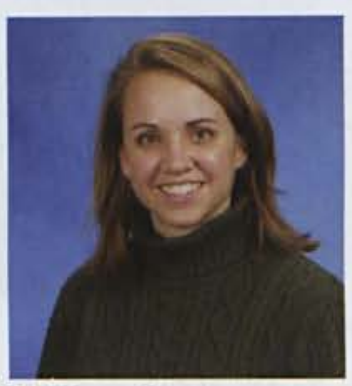

Melissa Hartman Asst. Prof. of Biology

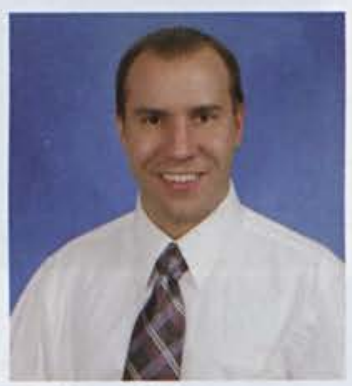

Philip Kirby

Adj. Prof. of Science and Mathematics

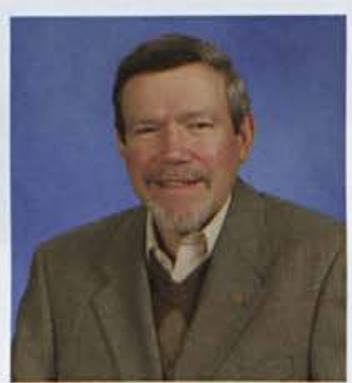

John Silvius

Sr. Prof. of Biology

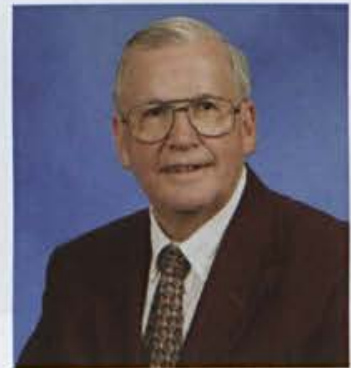

Edwin Braithwaite Prof. of Mathematics

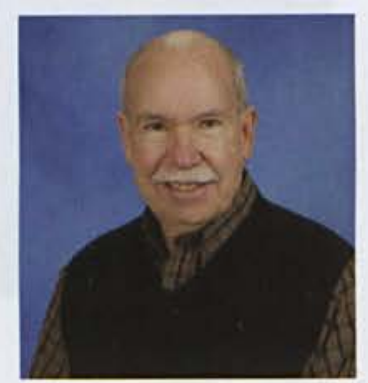

Larry Helmick Sr. Prof. of Chemistry

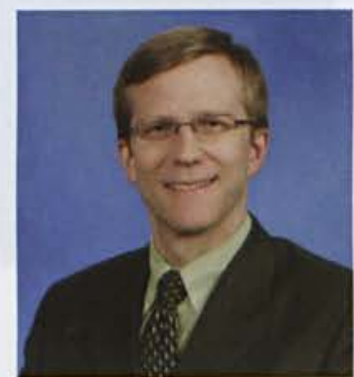

Mark McClain Prof. of Chemistry

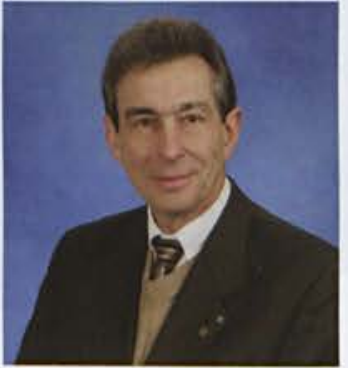

Dennis Flentge Sr. Prof. of Chemistry

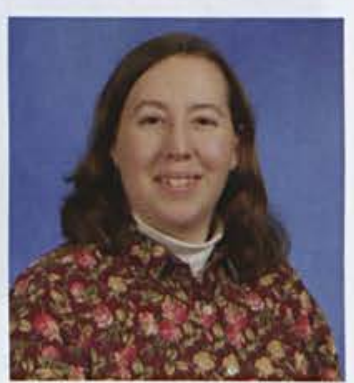

Jennifer Hutchison Asst. Prof. of Mathematics

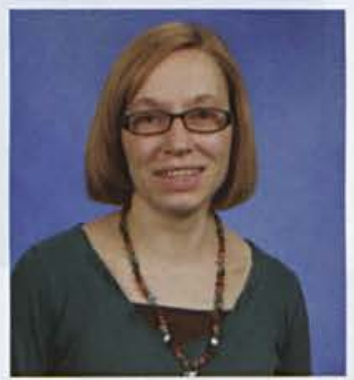

Christina Penrose Administrative Assistant Science and Mathematics 


\section{School of Natural}

\section{and Applied Sciences}

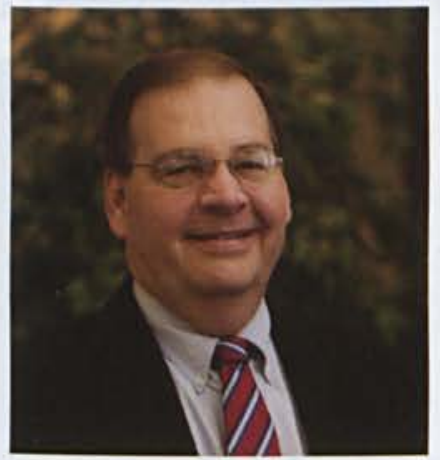

Tom Cornman

Interim Dean

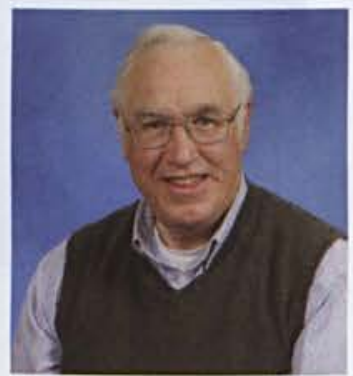

Galen Smith

Prof. of Economics

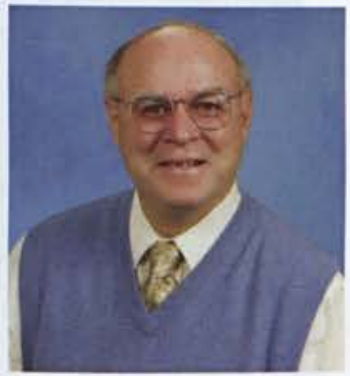

Harwood Hegna

Prof. of Mechanical Engineering

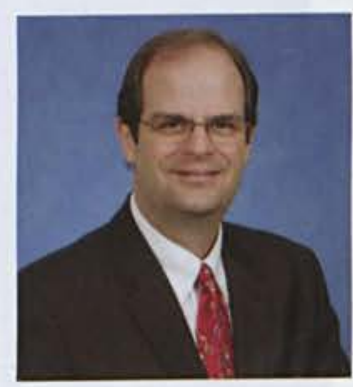

Jeffrey Fawcett Prof. of Marketing

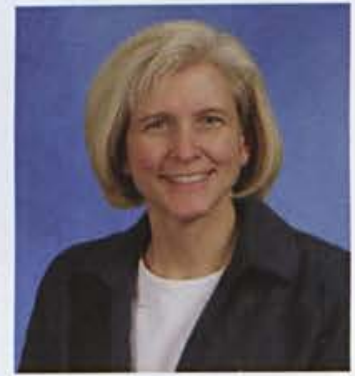

Susan Terkelsen

Asst. Prof. of

Office Technology

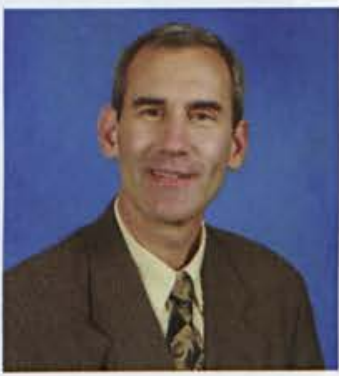

Samuel SanGregory Prof. of Electrical Engineering

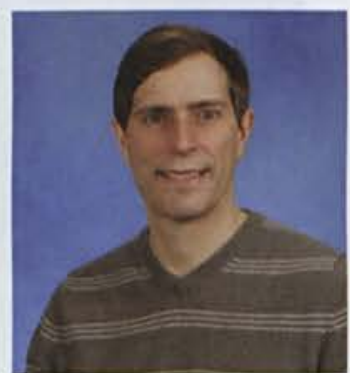

Jeff Haymond Assc. Prof. of Economics

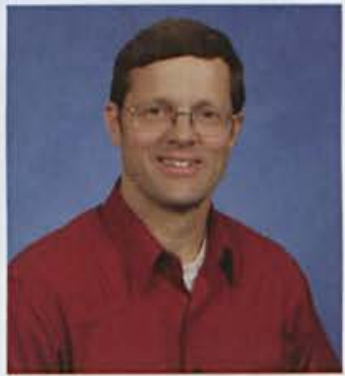

Gerald Brown

Assc. Prof. of

Electrical Engineering

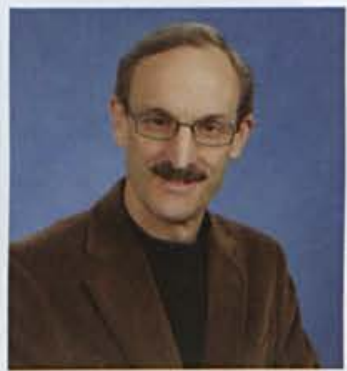

Thomas Thompson Assc. Prof. of Mechanical Engineering

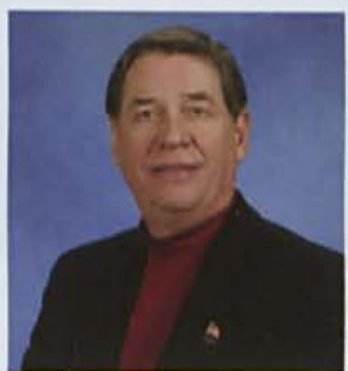

John LeBlanc Assc. Prof. of Management

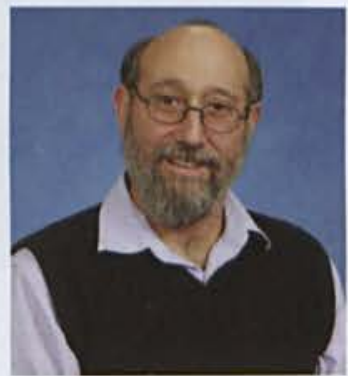

Robert Chasnov Prof. of Engineering

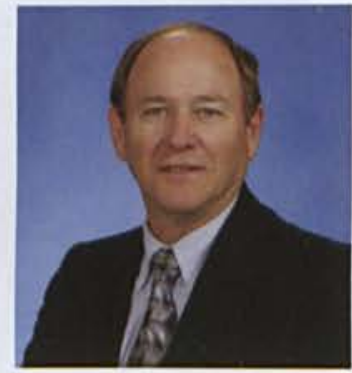

Lawrence Zavodney Sr. Prof. of

Mechanical Engineering

\section{School of Pharmacy}

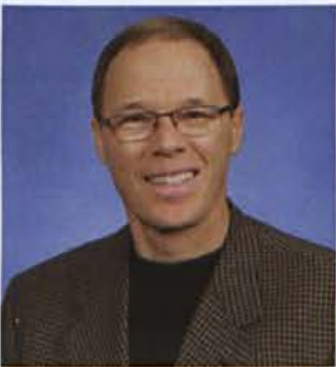

David Ormsbee Asst. Dean, Admission and Advancement

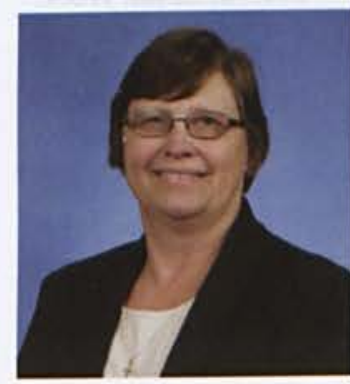

Rebecca Gryka Assc. Prof. of Pharmaceutical Science

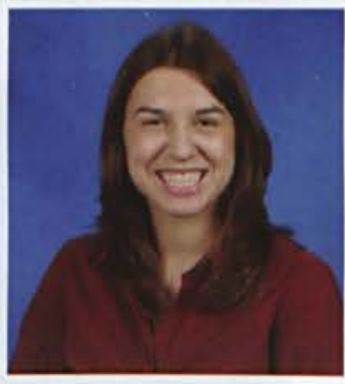

Melody Hartzler Asst. Prof. of Pharmacy Practice

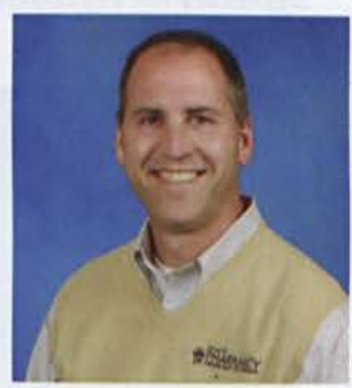

Jeffrey Lewis Assc. Prof. of Pharmacy Practice 


\section{School of Social Sciences}

\section{and Human Performance}

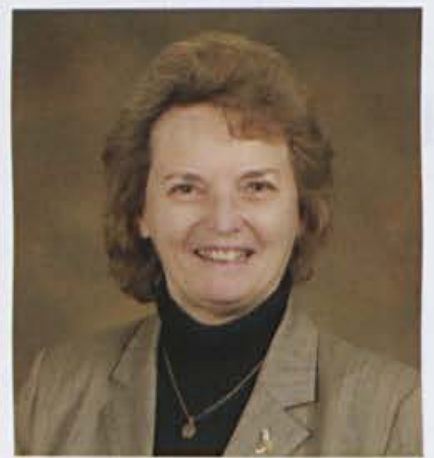

Pam Johnson

Dean

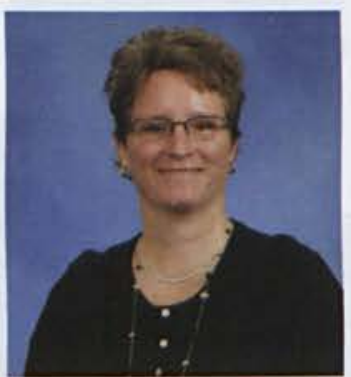

Lori Huckaby

Asst. Prof. of Excercise

and Sport science

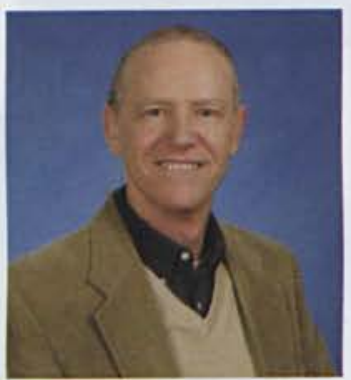

Milton Becknell

Assc. Prof. of Psychology, Dept. Chair

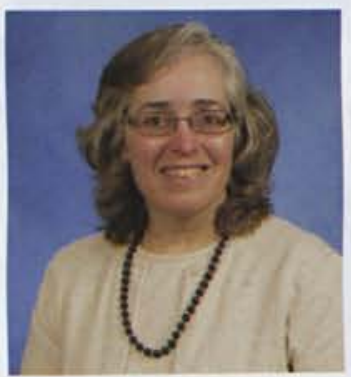

Kay McFarlane Secretary for Psychology

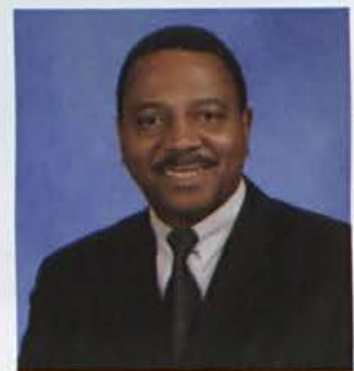

Patrick Oliver

Asst. Prof. of

Criminal Justice

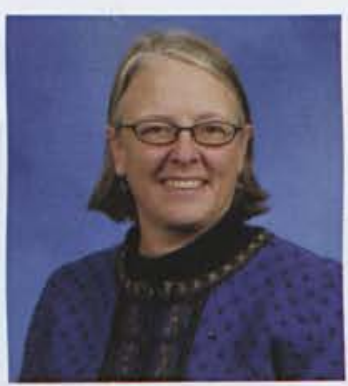

Margaret Grigorenko Asst. Prof. of Education

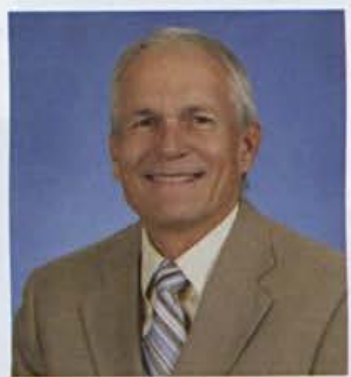

John McGillivray Assc. Prof. of Excercise and Sport science

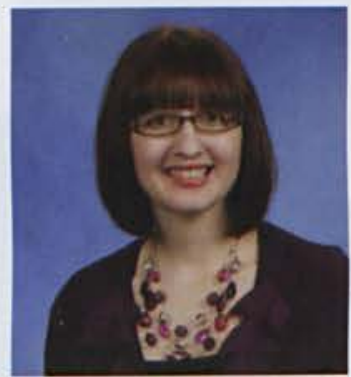

Amanda Burger Asst. Prof. of Psychology

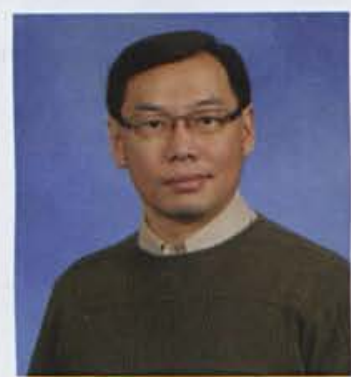

Luke Tse

Assc. Prof. of Psychology

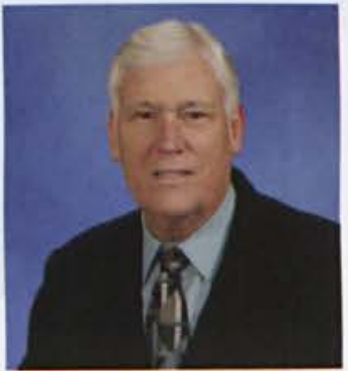

Robert Parr

Prof. of Sociology

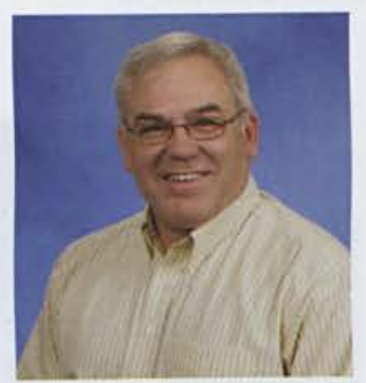

Benson Belleman Asst. Prof. of Excercise and Sport science

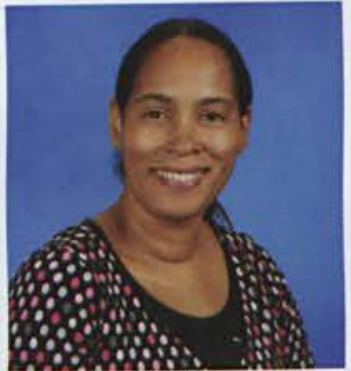

Carolyn Barnett

Asst. Prof. of Nursing

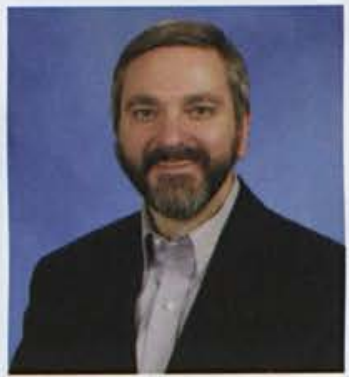

Michael Firmin Prof. of Psychology

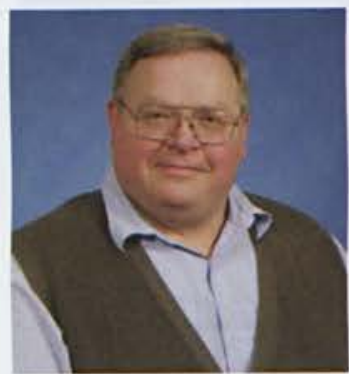

Nelson Henning Prof. of Social Work, Dept. Chair

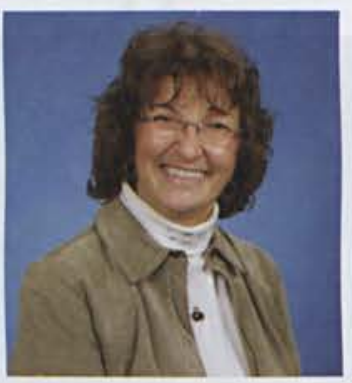

Kathy Freese Assc. Prof. of Excercise and Sport science

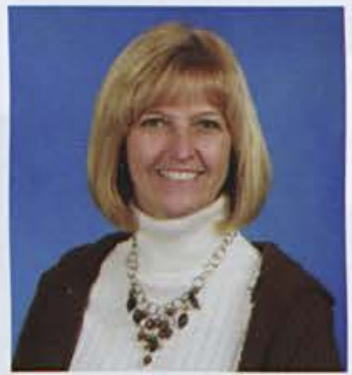

Angelia Mickle

Asst. Prof. of Nursing

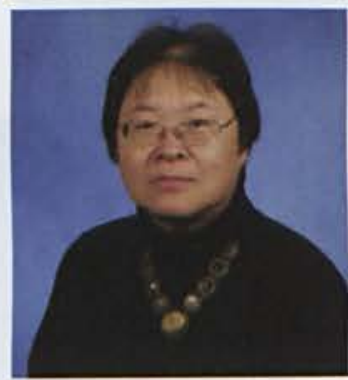

Chi-en Hwang Prof. of Psychology

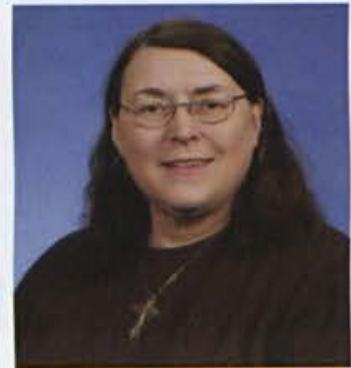

Esther Lanham Admin. Asst. for Social Work, Crimminal Justice, and Sociology 


\section{Library Services}

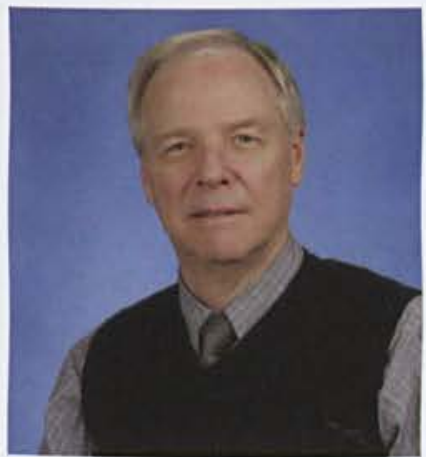

Lynn Brock

Dean

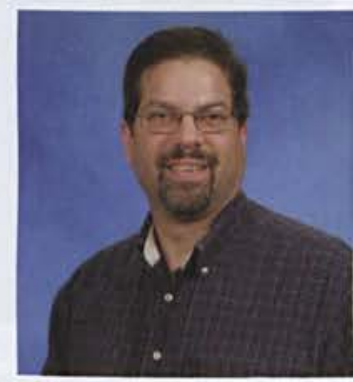

Scott Deetz

AV Services Manager

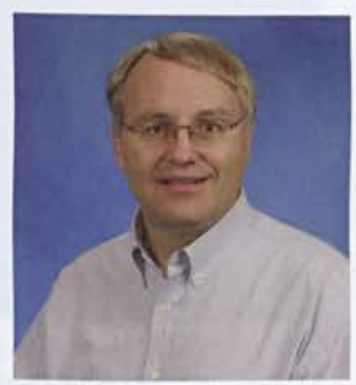

Jeff Gates

Information Services

Librarian

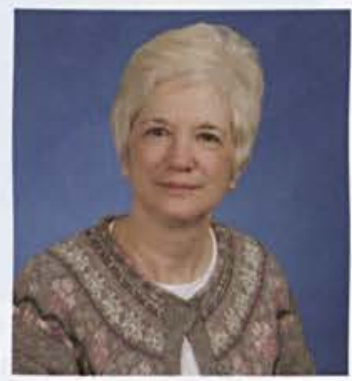

Luann Nicholas

Interlibrary Services

Coordinator

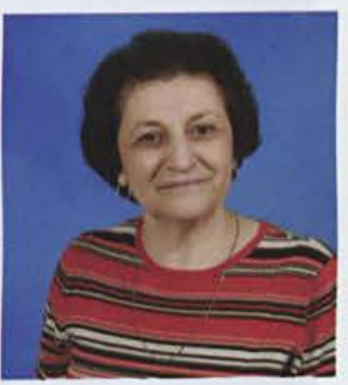

Fran Andrews Office Manager

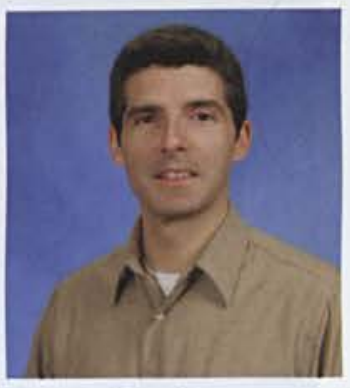

Brent Etzel Instructional Services Librarian

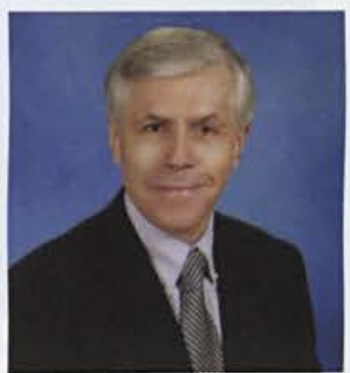

Greg Martin

Cirriculum Materials Center Librarian

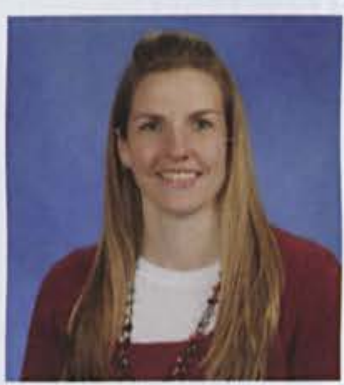

Tricia Clark Public Services Technical Coordinator

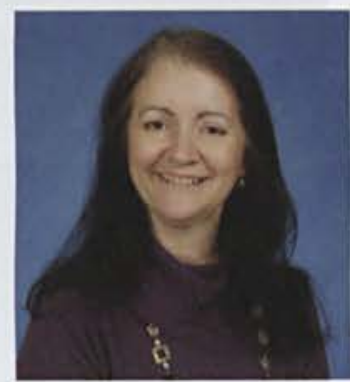

Tonya Fawcett Director of Library Public Services

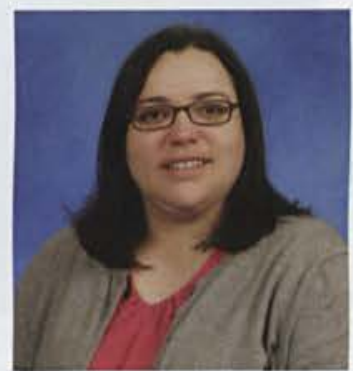

Amy McCoy

Circulation Services Manager

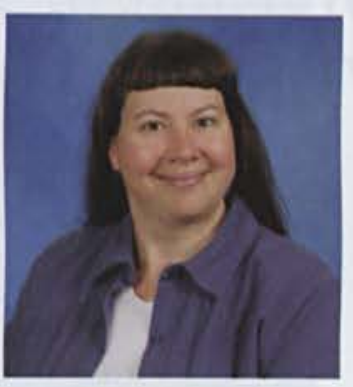

Julie Deardorff Director of Collection Services

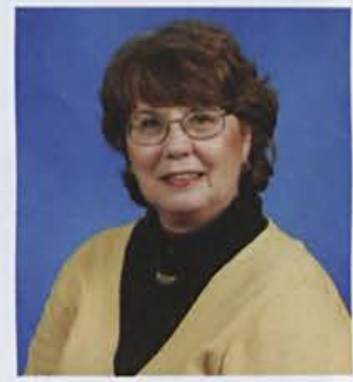

Lynne Funtik Sr. Reference Librarian

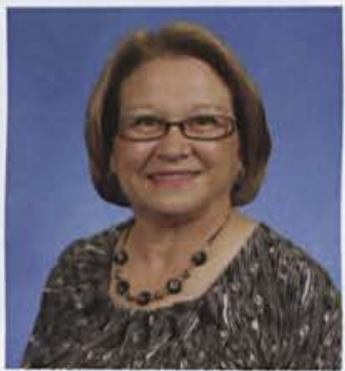

Andi Mounts Asst. Circulation Manager 


\section{Division of Academic Vice President}

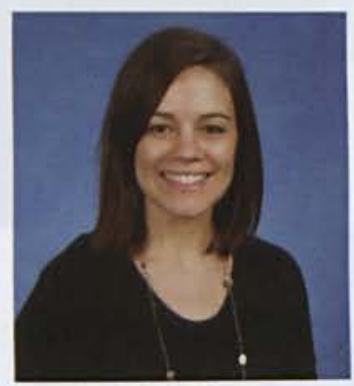

Lauren Black

Office of the Registrar

Records and Registration Assistant

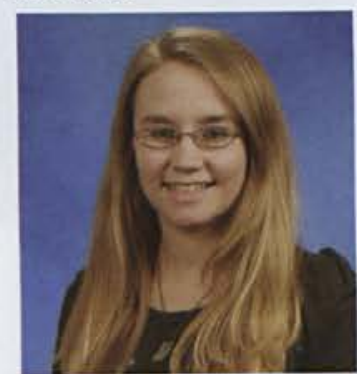

Caiti Tasker

Office of the Registrar

Transcripts and

Verification Assistant

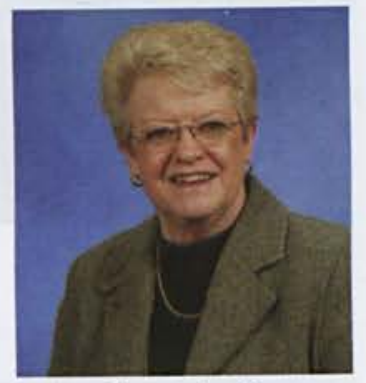

Fran Campbell Office of the Registrar Registrar

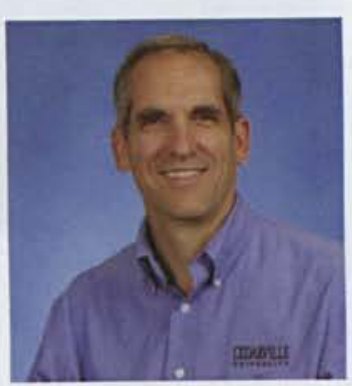

Mark Mathews Campus Recreation Director

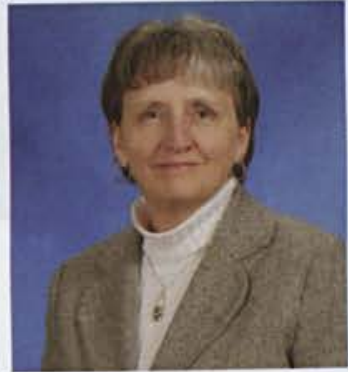

Cynthia Davis Office of the Registrar Assistant to the Registrar

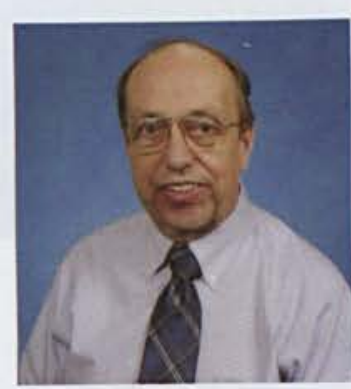

David Rotman Computer Services Chief Information Officer

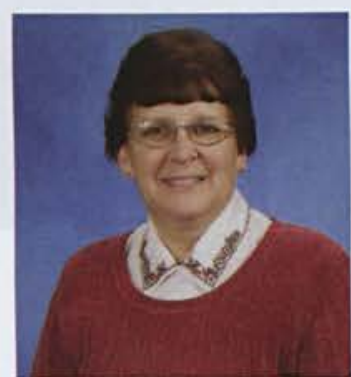

Joyce Smallwood Office of the Registrar Records and Testing Assistant

\section{Division of Development}

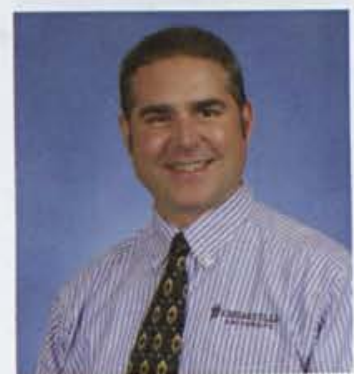

Jeff Beste

Alumni Relations Director 


\section{Business Division}

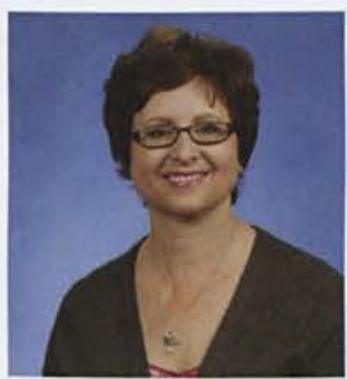

Ann DeLange Bookstore

Buyer

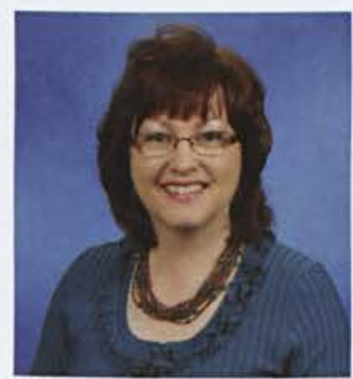

Sarah Young

Bookstore

Trade Book Buyer

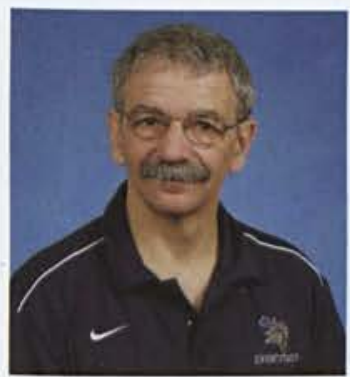

Robert Bielek

Physical Plant

CAD Technician

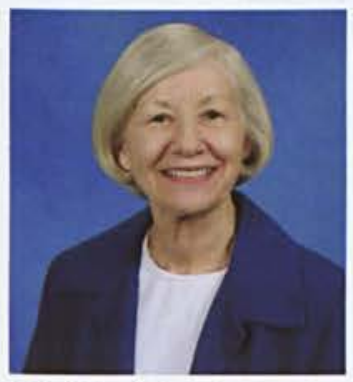

Phyllis Morris

Postal and Print Services Postal Clerk

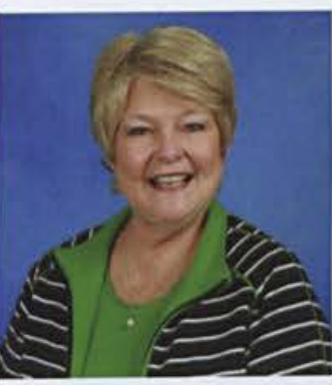

Jeanie LeBlanc

Bookstore

Gift Buyer

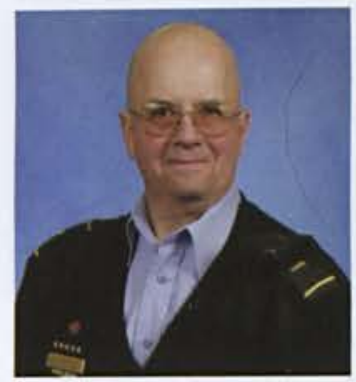

Jim Bowersox

Campus Safety

Security Operrations

Manager

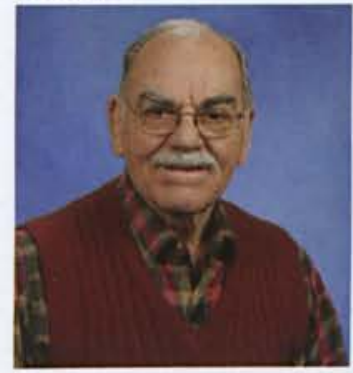

Lee Belleman

Postal and Print Services Postal Clerk

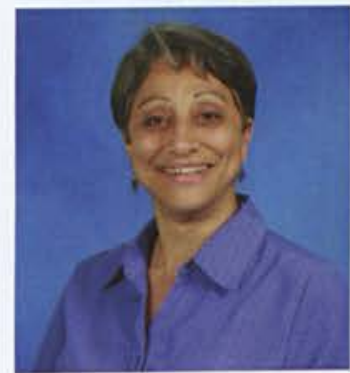

Diane Reid

Postal and Print Services Postal Clerk

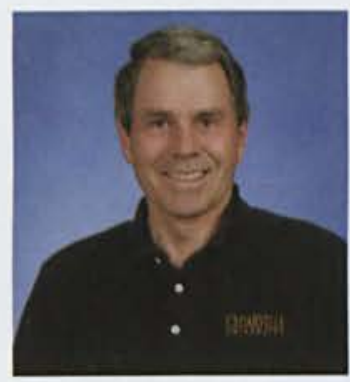

Lee Mattson

Bookstore

Supervisor of Bookstore Operations

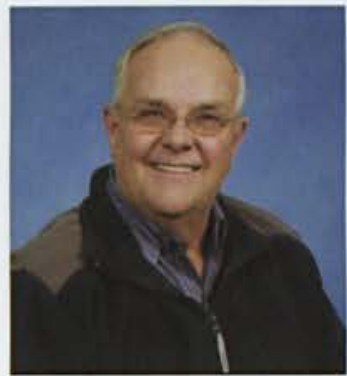

Cooley Turner

Custodial Services

Custodian

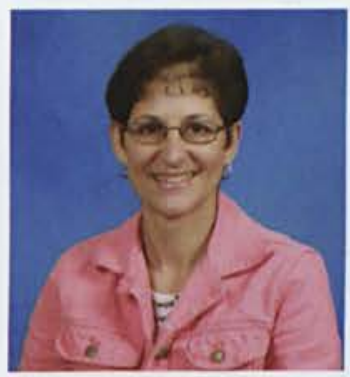

Cindy McDaniel

Postal and Print Services

Print Services Technician

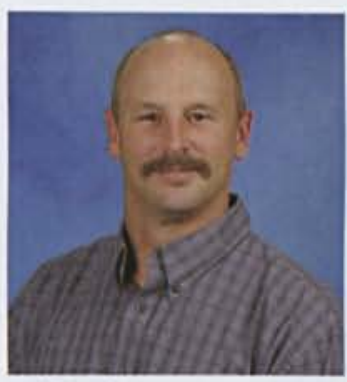

Rill Thompson

Bookstore

Textbook and Back Office Supervisor

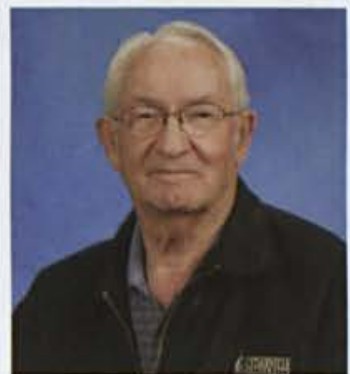

Lavern Musselman

Maintenance

Custodial Equipment Repair

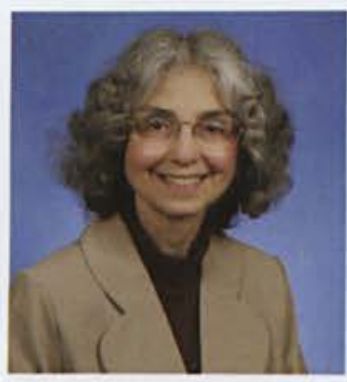

Bonnie McGillivray

Postal and Print Services Post Office Supervisor 


\section{Division of}

\section{Christian Ministries}

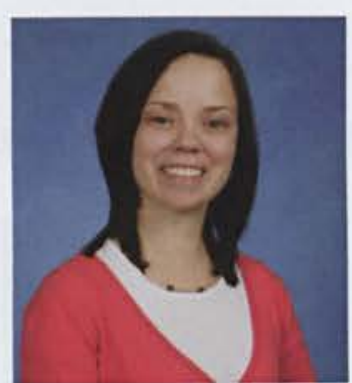

Brooke Colon

Secretary to the VP for Christian Ministries

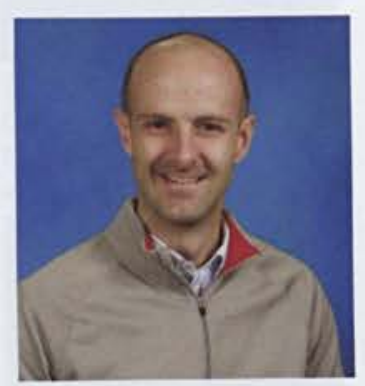

John Wambold Community Ministries Director

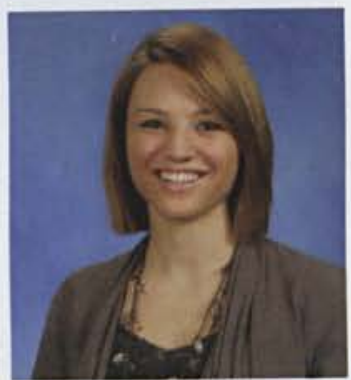

Alise Merrin

Heartsong Ministries Admin. Asst.

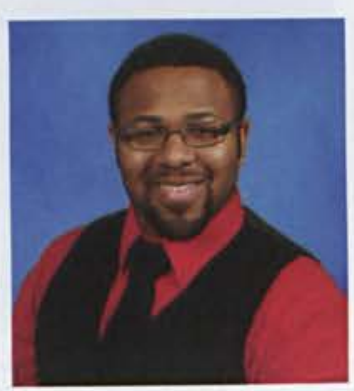

Justin Spann Worship Ministries Director

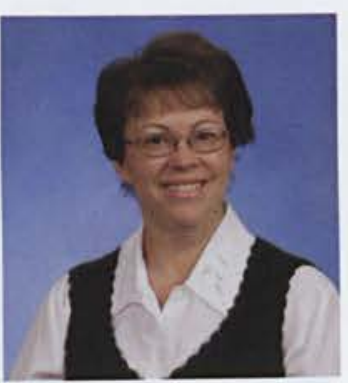

Cheryl Shupe

Exc. Admin. Asst. to the VP for Christian Ministries

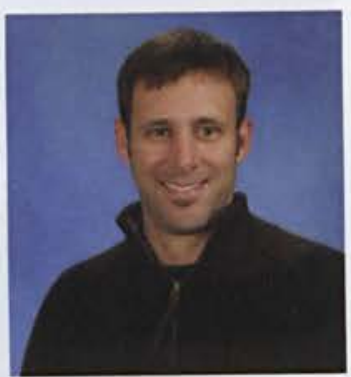

Mark Irving

Discipleship Ministries

Director

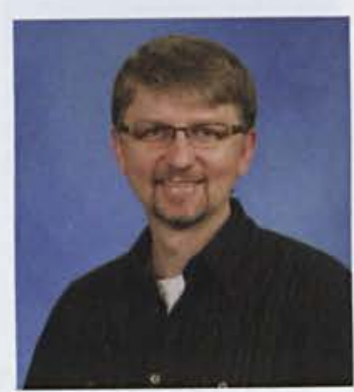

Brandon Waltz

Heartsong Ministries Director

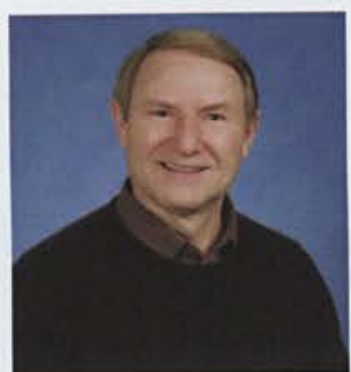

Bruce Traeger Church Relations Director

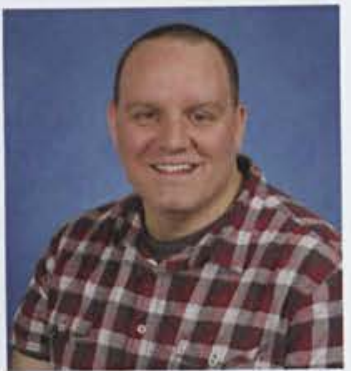

Matt Anderkin Heartsong Ministries Project and Event Manager

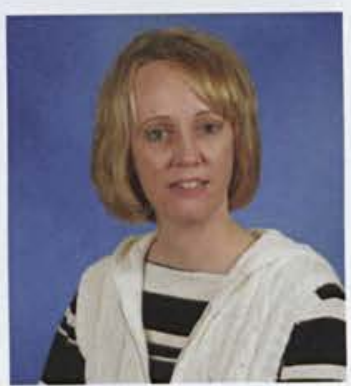

Carol Bliss

Mission Involvement

Services

Secretarial Asst.

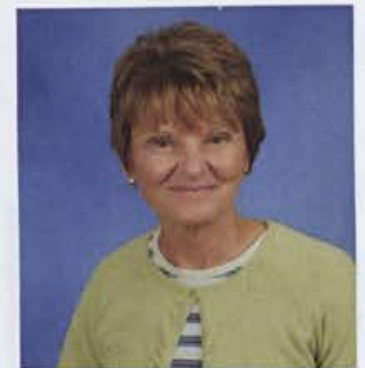

Vicky Hines Community Ministries Admin. Asst.

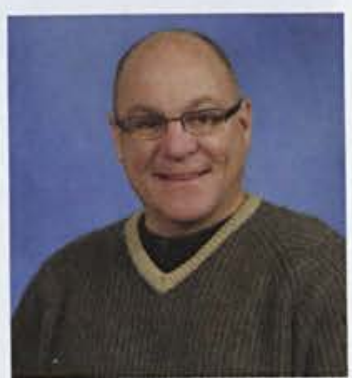

Jim Cato

Heartsong Ministries

Executive Director

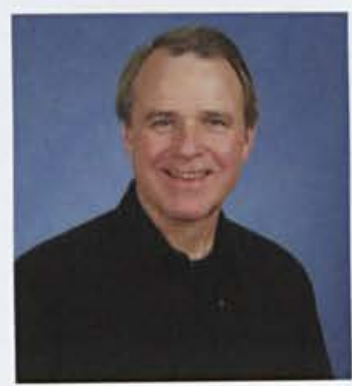

Brian Nester Mission Involvement Services

Director 


\section{Enrollment Division}

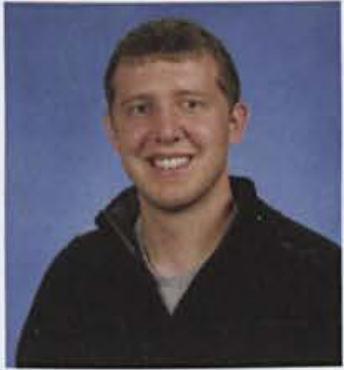

Matt Dearden

Admissions

Admissions Counselor

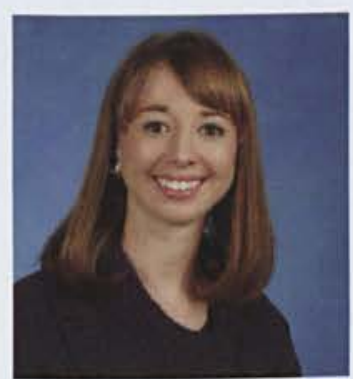

Melissa Troxel Admissions

Guest Coordinator

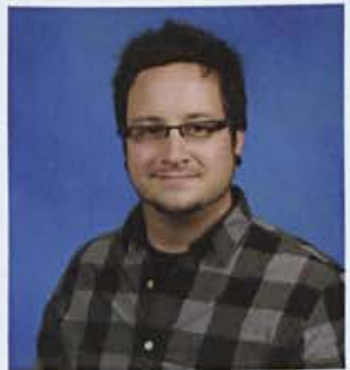

Joshua Wurzelbacher Creative Services Jr. Graphic Designer

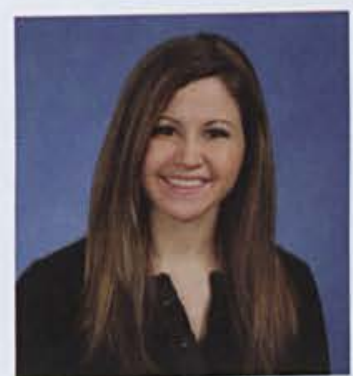

Sandi Larsen

Admissions

Admissions Counselor

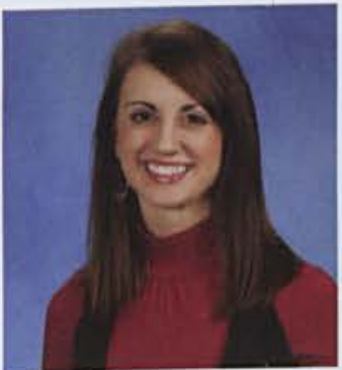

Aubrey Womack

Admissions

Admissions Counselor

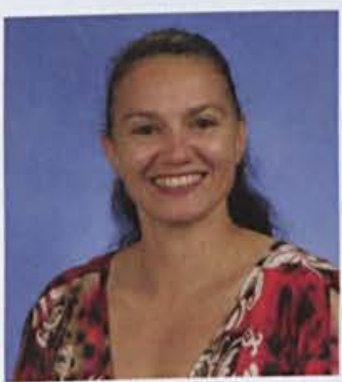

Tonya Bailey Financial Aid Office Compliance Manager

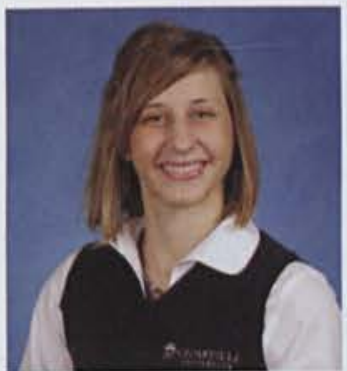

Alicia Poelzer Admissions

Sr. Admissions Counselor

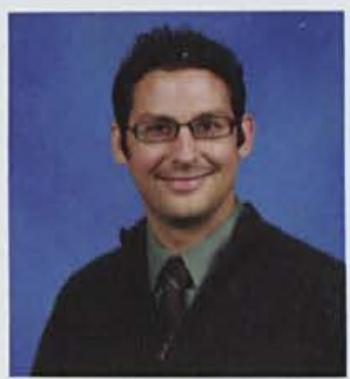

Chad Jackson

Creative Services

Creative Director

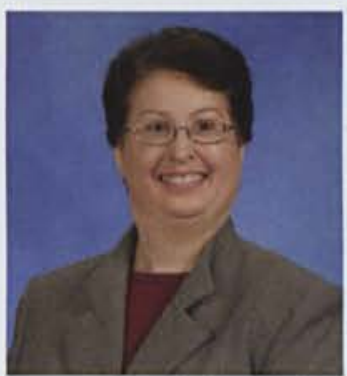

Pamela Flippin

Financial Aid Office

Financial Aid Coordinator

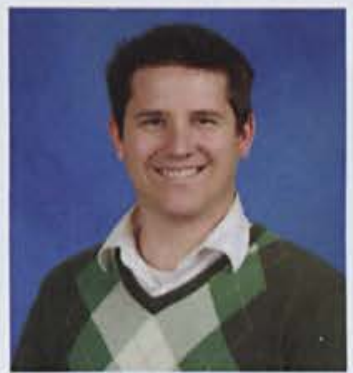

David Stephens Admissions

Admissions Counselor

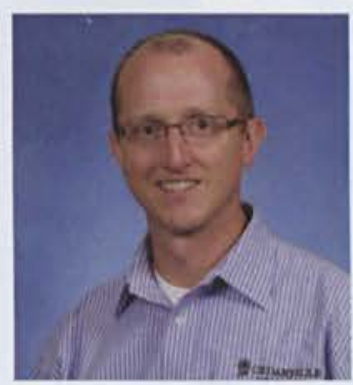

Craig Salisbury

Creative Services

Graphic Designer

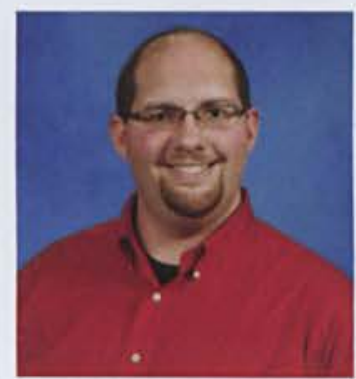

Joel Tomkinson Marketing Director 


\section{Division of \\ Student Services}

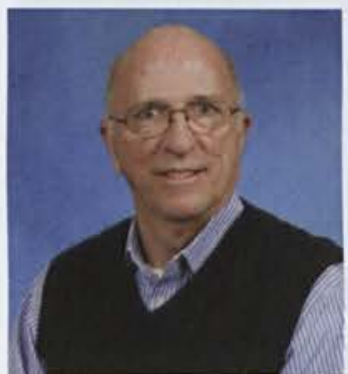

Lew Gibbs

Career Services

Director

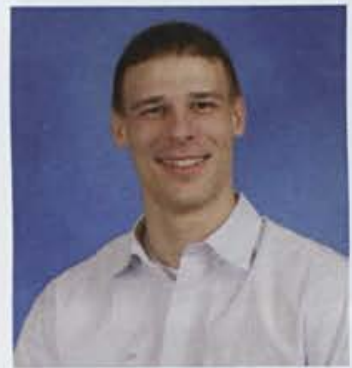

Anthony Mandela Residence Life RD of Lawlor

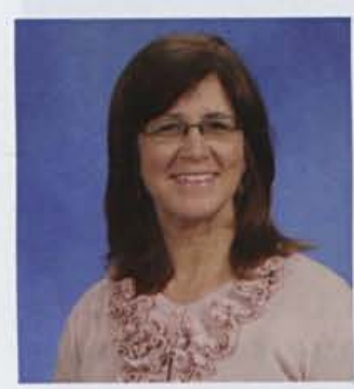

Elaine Keller Student Life Programs Admin. Asst. to the VP for Student Life

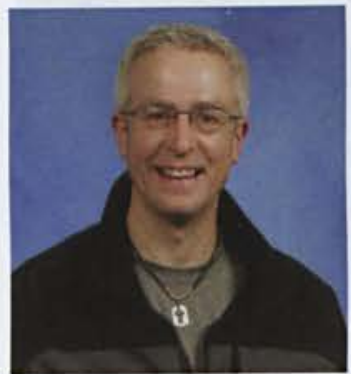

Jeffrey Fulmer Counseling Services Counselor

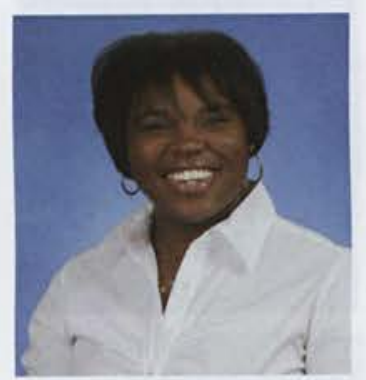

Charmaine Porter Residence Life RD of Printy

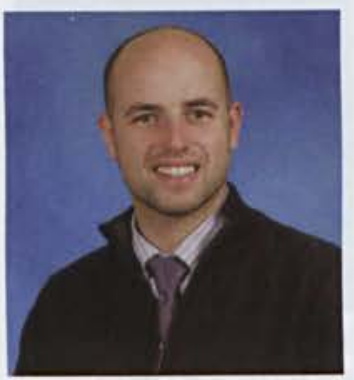

Bob Lutz

Student Life Programs

Assc. Dean for Student Leadership Development

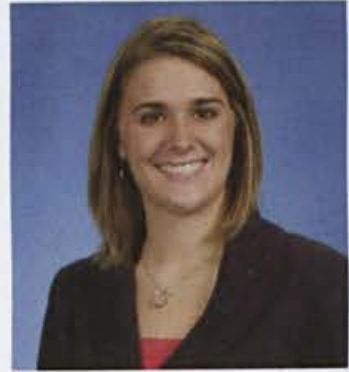

Sarah Banks Residence Life RD of Maddox

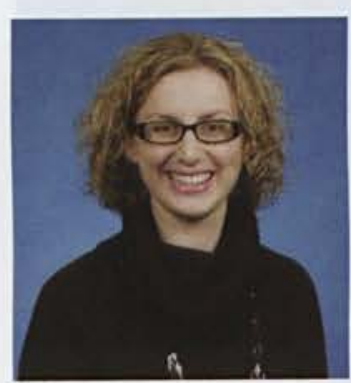

Becky Stowers Residence Life RD of Faith

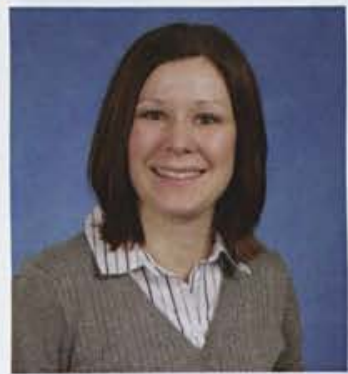

Lynsey Fabian Residence Life RD of McKinney \& Johnson

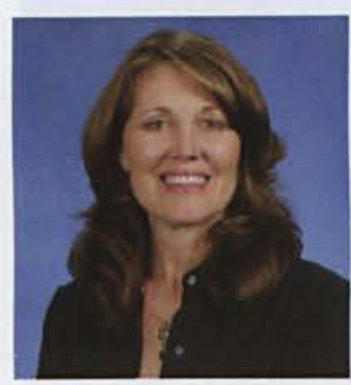

LeAnn Hill

Student Life Programs Admin. Asst. 


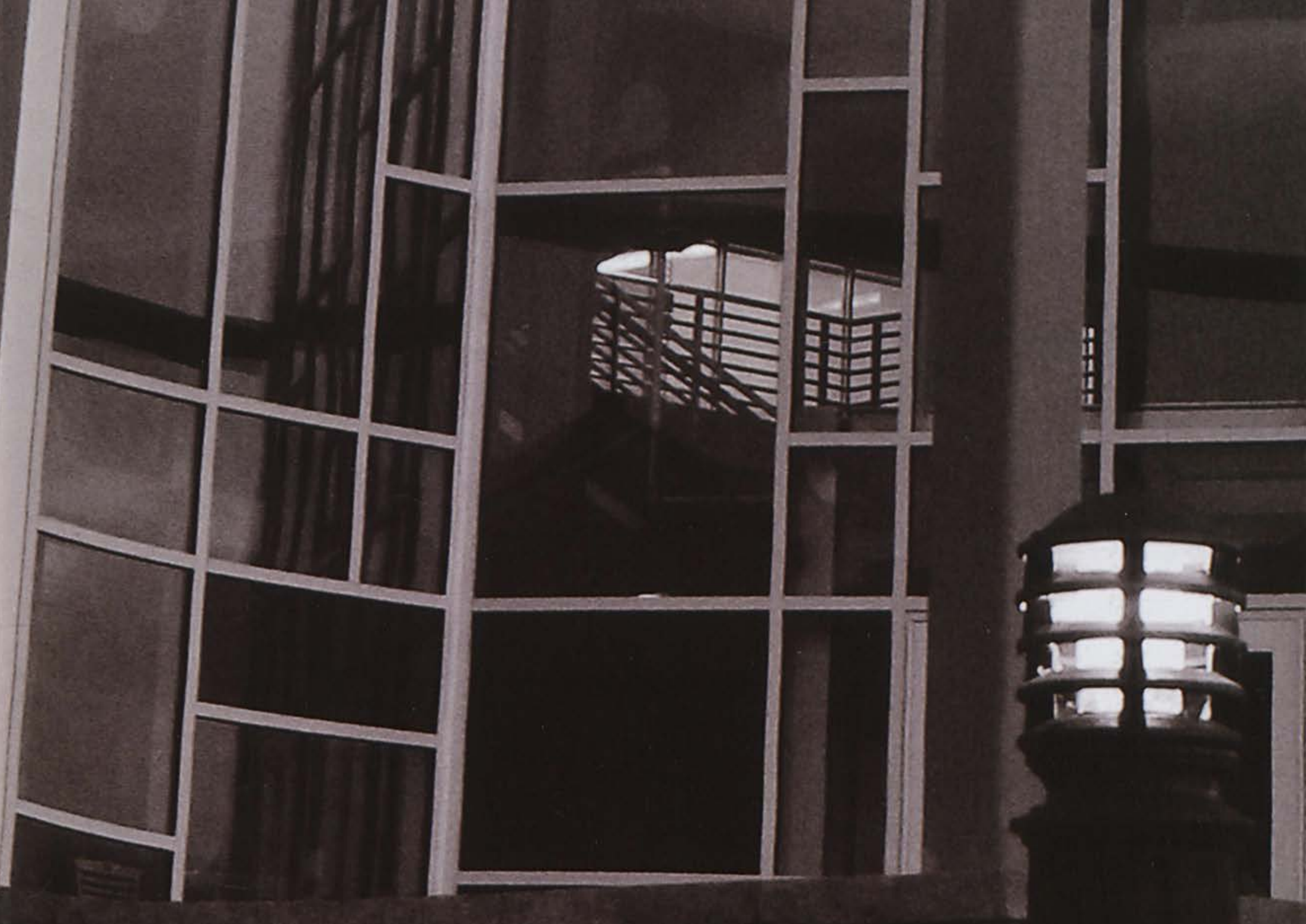




\section{ORGANIZATIONS}

noun, plural \ör-gə-nə-zā-shəns \

Networks of students with shared

social and academic interests; prone to

holding embarrassing initiation rites and amusing fundraisers. 


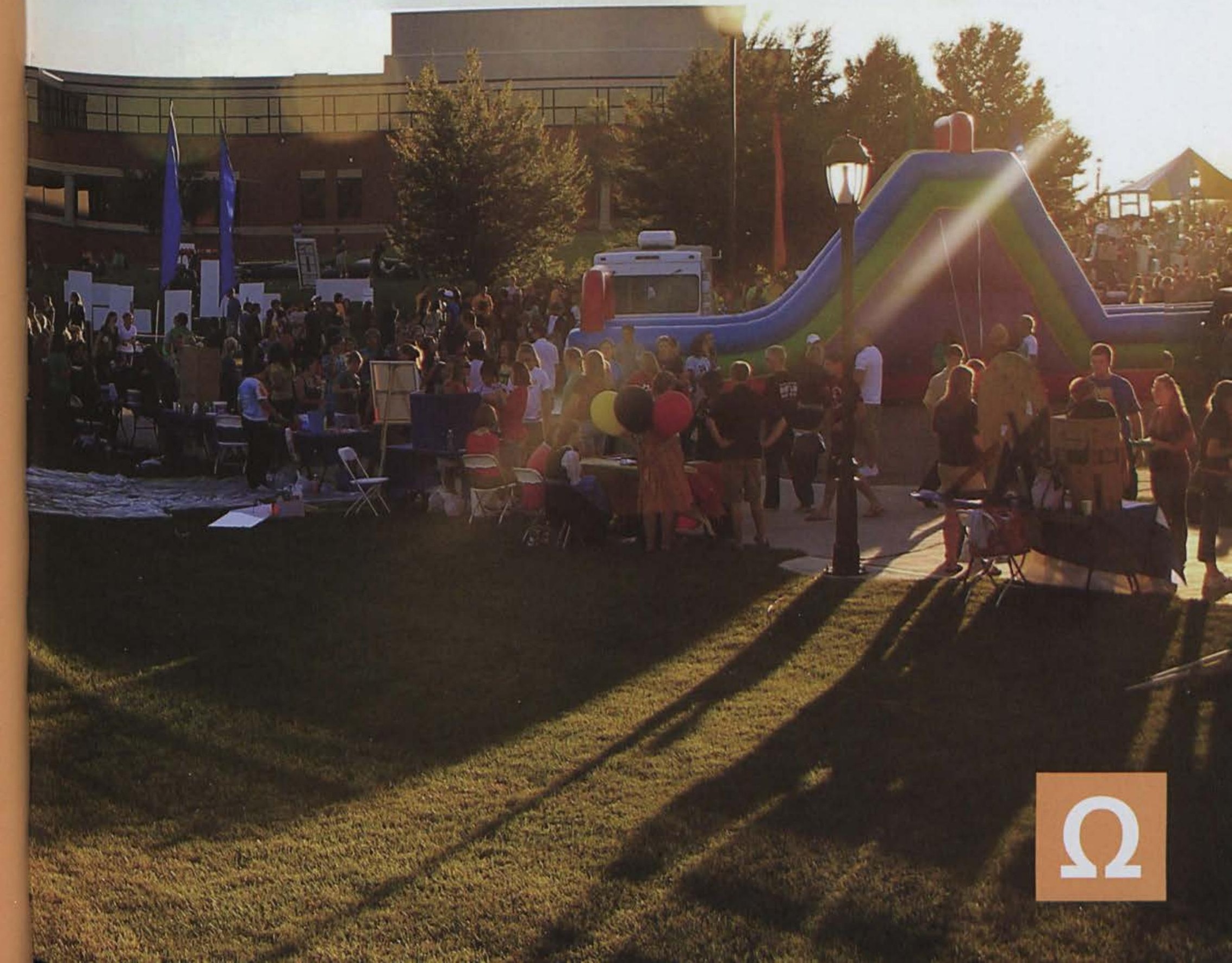




\section{ORGANIZATIONS ACADEMIC}

1 Association of Informational Technology Professionals

President: Lance Yoder

2. Alpha Delta Nu (Students in Criminal Justice)

President: Bradley Thomas

3 Lambda Eta Pi (National Communication Honor Society)

President: Timothy Ronco

4 Psi Kappa Theta (Students in Psychology and Behavioral Sciences)

President: Dylan Black

5 Tau Beta Pi (Engineering Honor Society)

President: Daniel La Croix

6 Society for Technical Communication

President: Abby Keyser

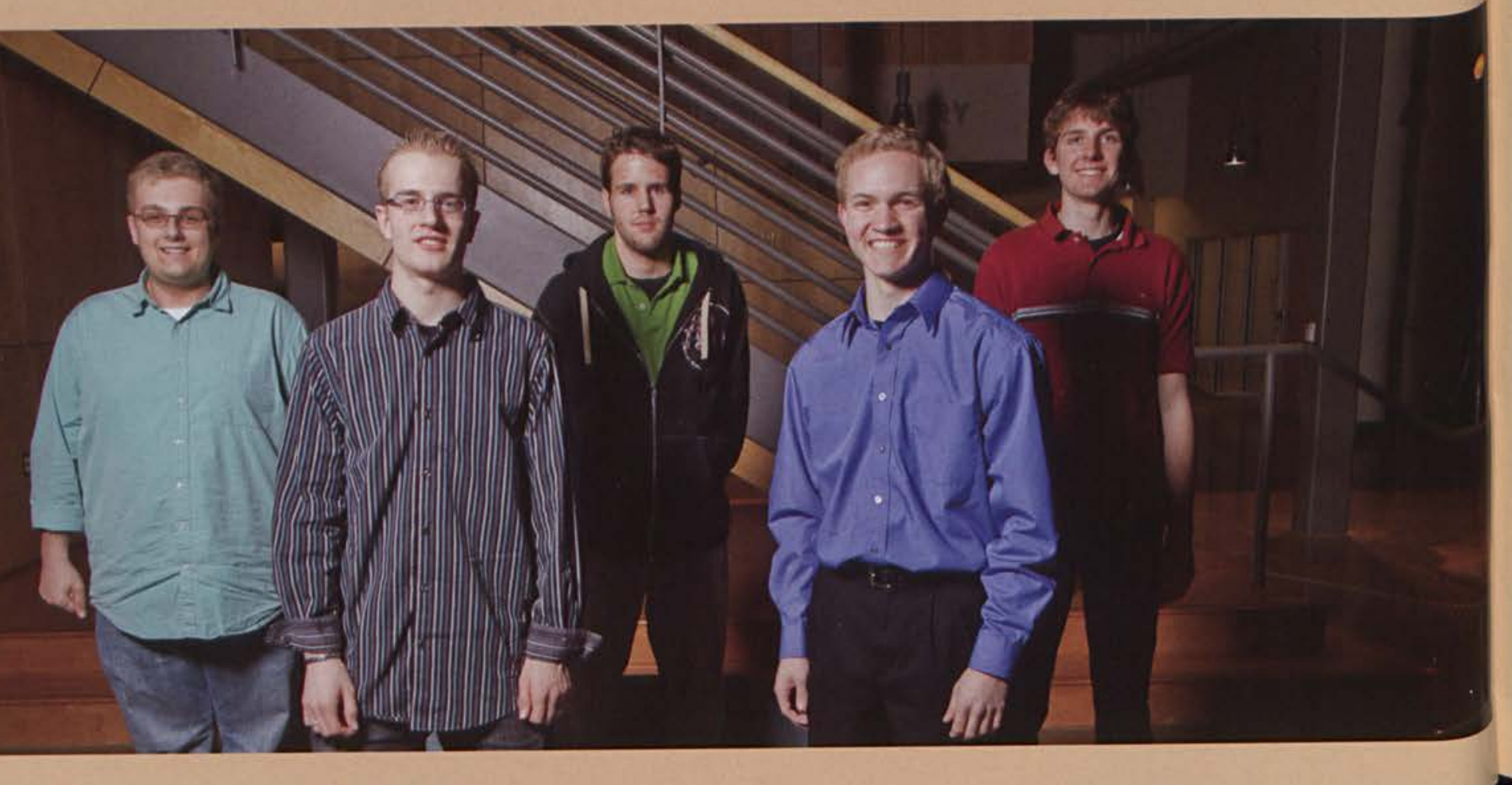




\title{
ORGANIZATIONS ACADEMIC
}

\author{
1 Tau Delta Kappa (Students in the Honors Program) \\ President: Timothy Ronco \\ 2 Junior Class Council \\ President: Robbie Carter \\ 3 Society of Automotive Engineers \\ President: Adam Oakley \\ 4 Society of Women Engineers \\ President: Michelle Doyle \\ 5 Chi Theta Pi (Students in Health-Science Professions) \\ President: Samantha Barclay
}

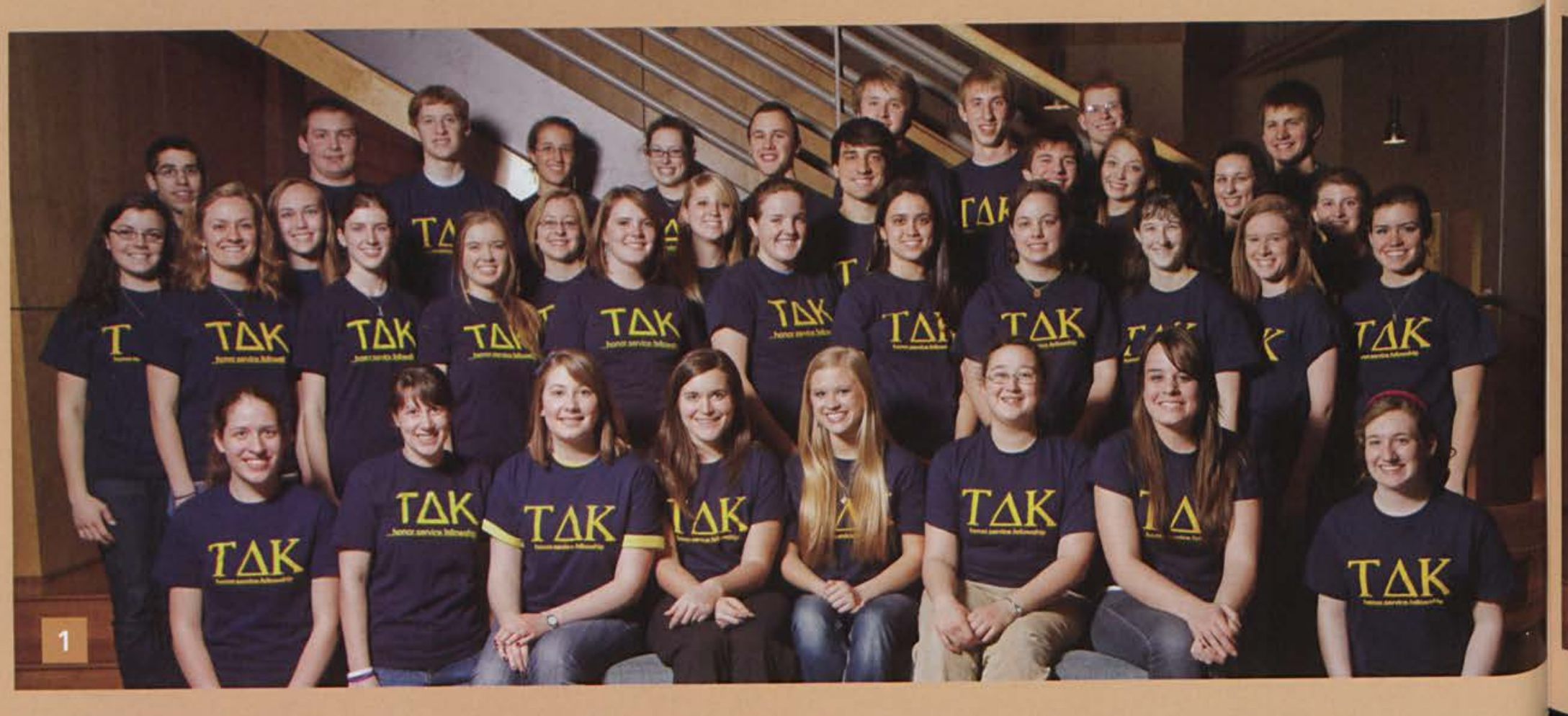




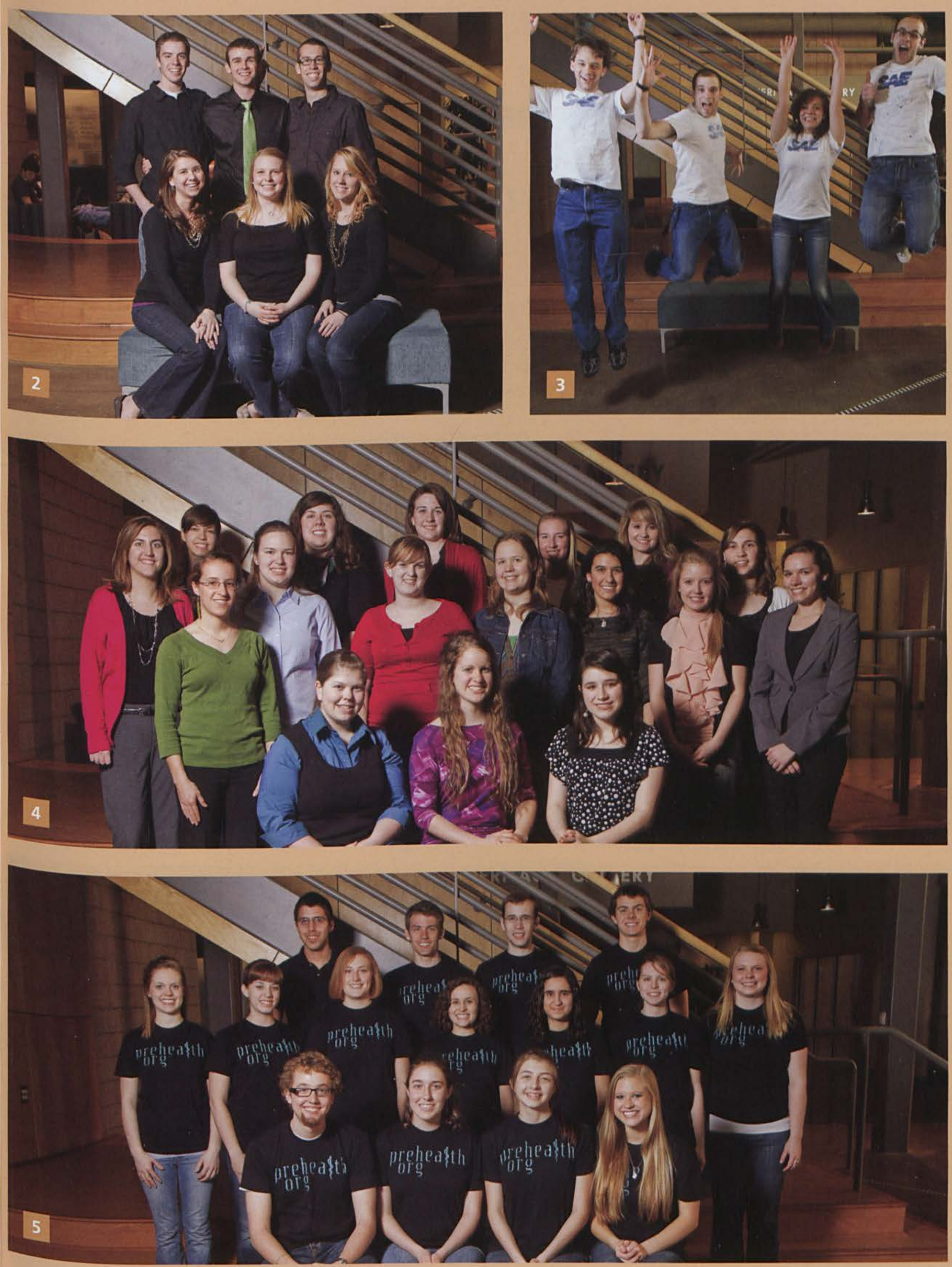




\section{ORGANIZATIONS SERVICE}

\section{CU Emergency Medical Services}

Chief: Richard Marriott

2 Mu Kappa (Serves missionary kids and international students)

President: Jared Junge

3 Delta Alpha Epsilon (Serves alumni and advancemnt division)

Advisor: Jeff Beste

4 Delta Omega Epsilon (Men serving on campus)

President: Nevin Brooks

5 Delta Pi Sigma (Women serving both professionally and personally)

President: Allie Schulert

6 Gamma Chi (Women serving the local church)

President: Kim Hutson

7 International Justice Mission

President: Kara Enterline

8 Alpha Delta Omega (Women seeking to encourage and serve others)

President: Sarah Berwager
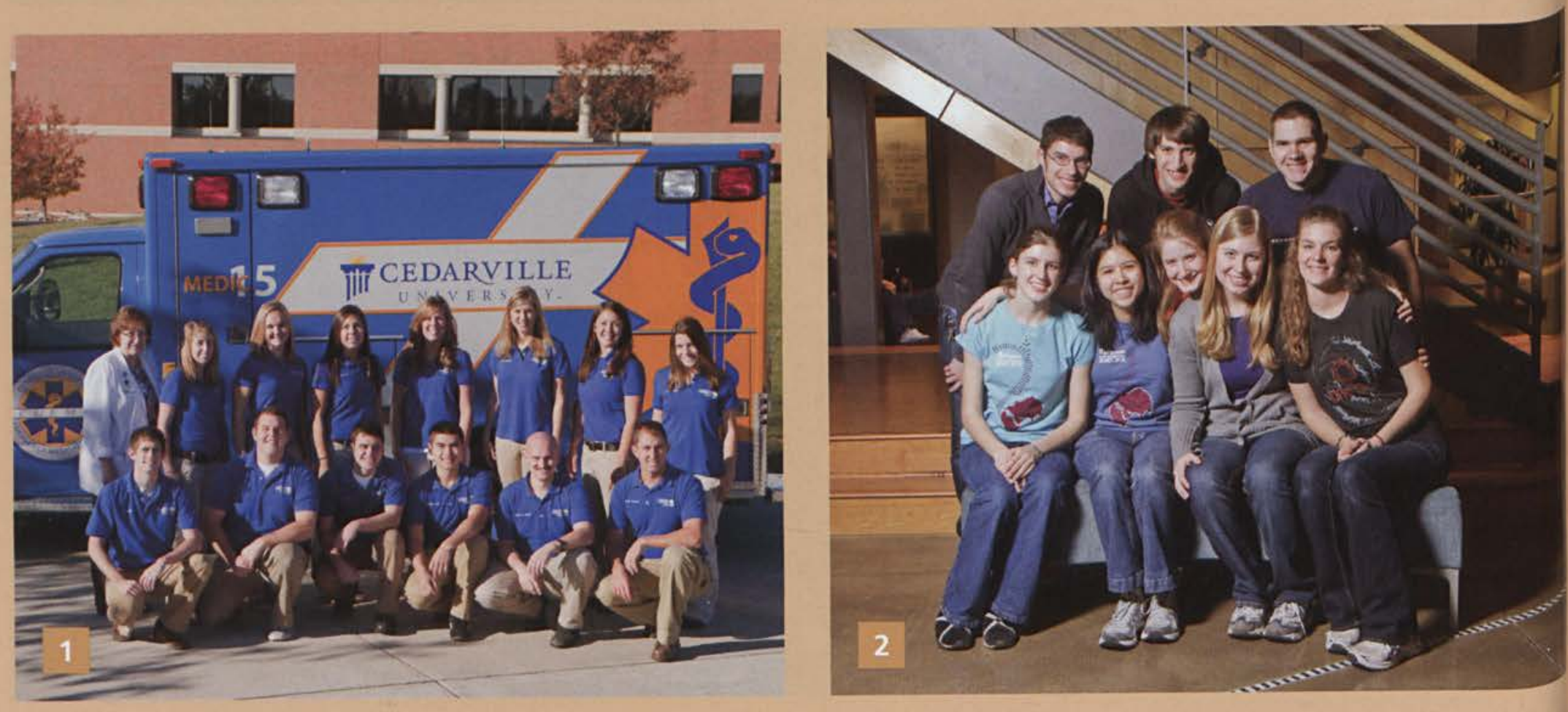


\section{ORGANIZATIONS SERVICE}

1 Phi Epsilon Beta (Women promoting spiritual and social growth)

President: Hannah Filbey

2 Phi Gamma Psi (Promotes social interaction and enhances spiritual growth among women)

President: Kristi Dorbitz

3 Society of Engineers Aiding Missions

President: Leah Pernicano

4 Accounting Society

President: David McQuarry

5 Students in Free Enterprise

President: Katie Scott

6 Spanish Club

President: Melody Lightner
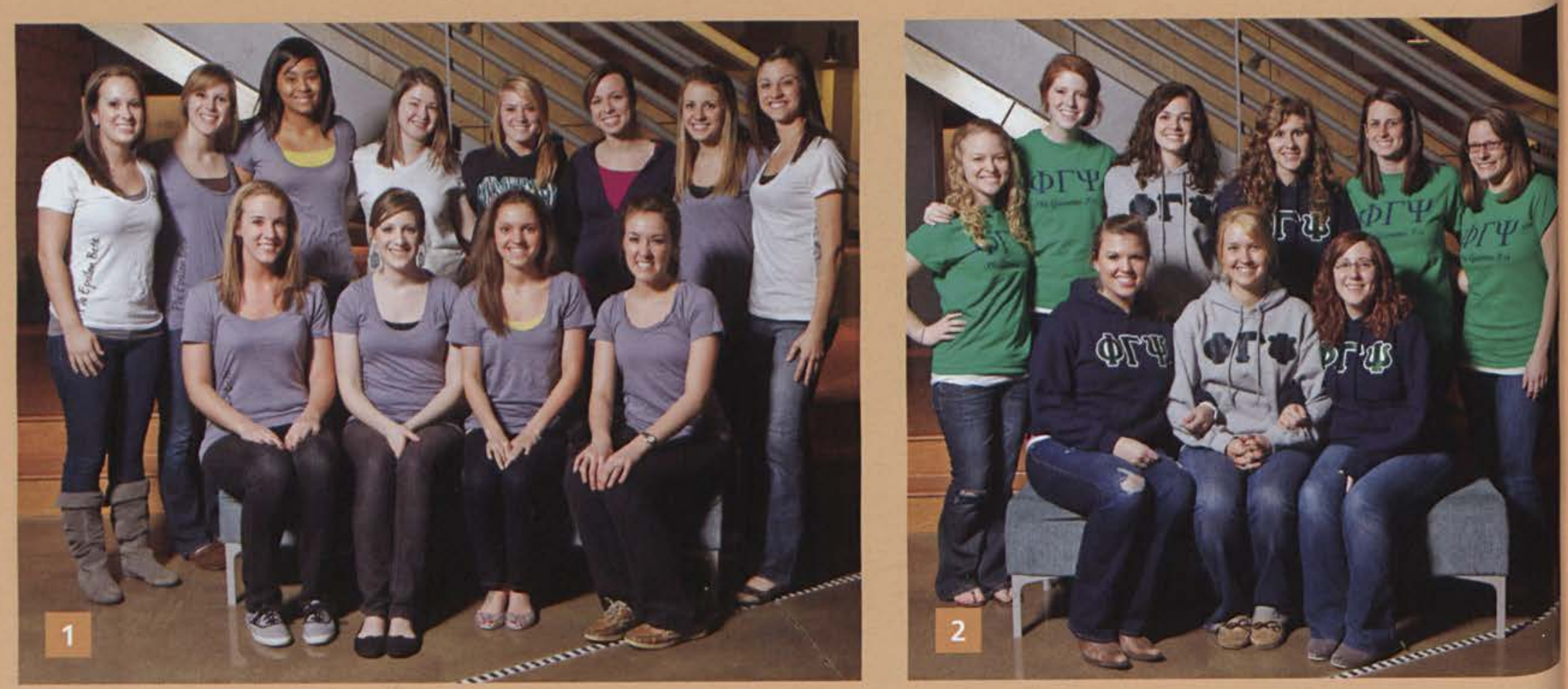


\title{
ORGANIZATIONS SPECIAL INTEREST
}

\author{
1 Alpha Sigma Lambda (American Sign Language) \\ President: Jonathon McCoy \\ 2 CU College Republicans \\ President: Micaela Buesgens \\ 3 Health and Fitness Association \\ President: Jessica Smith \\ 4 Theta Rho Epsilon (OPE: Men seeking to develop character and friendships) \\ President: Colin Mitchell \\ 5 Women of Vision (Interested in global women's issues) \\ President: Katie Foster \\ 6 Pro Terra Forma (Interested in environmental issues) \\ President: Doug Sponsler \\ 7 Women in Business
}

President: Elyse Nemec
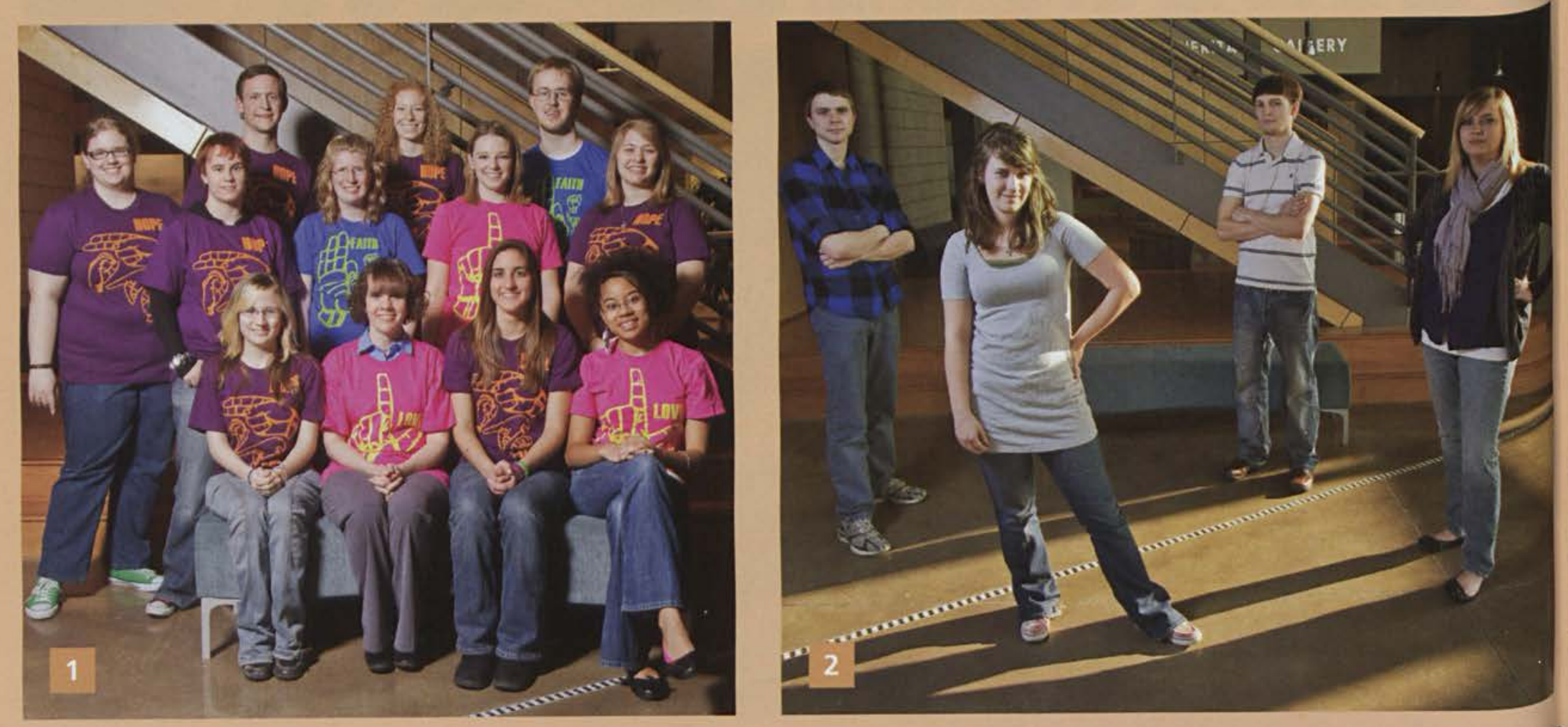


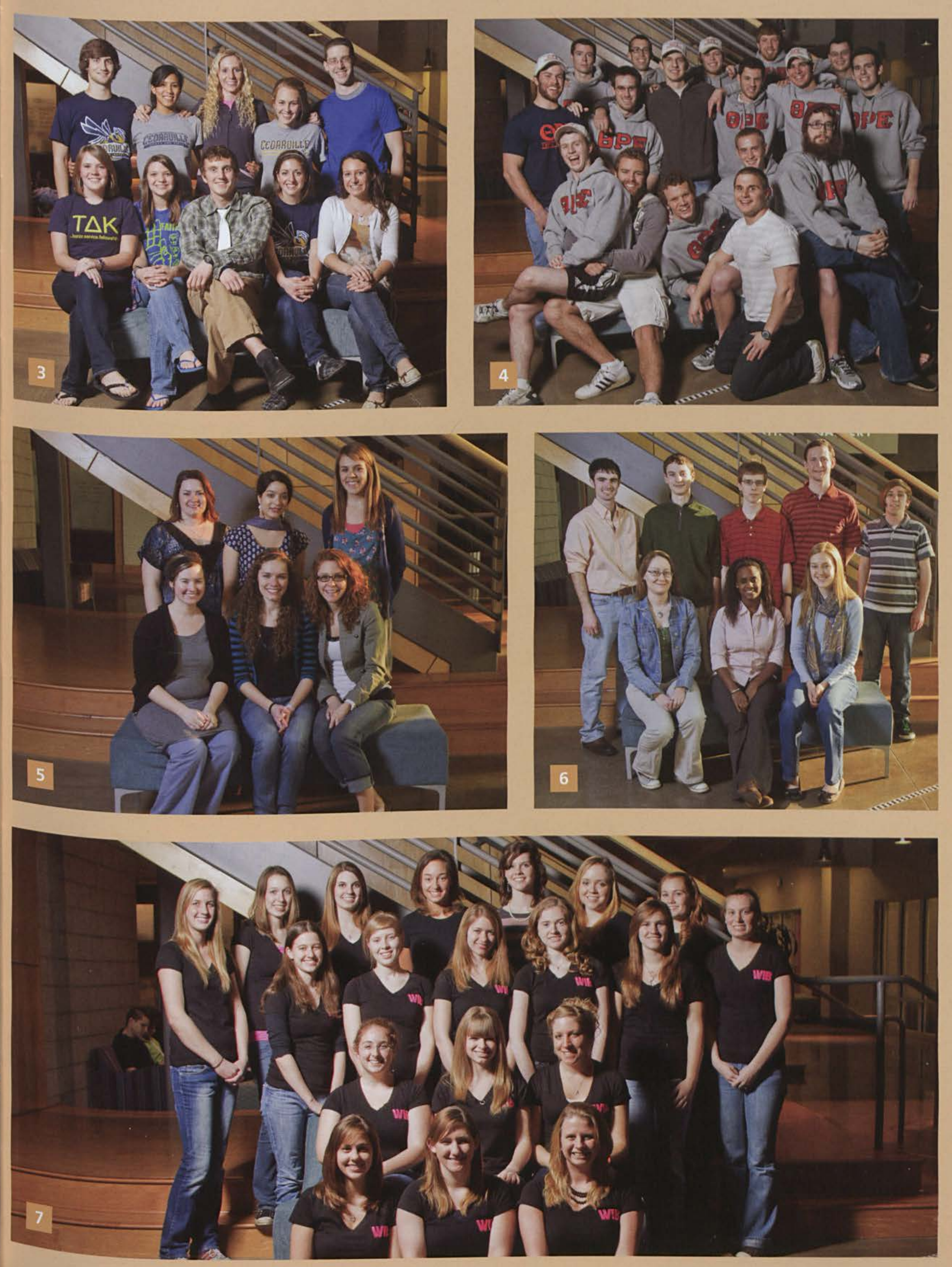




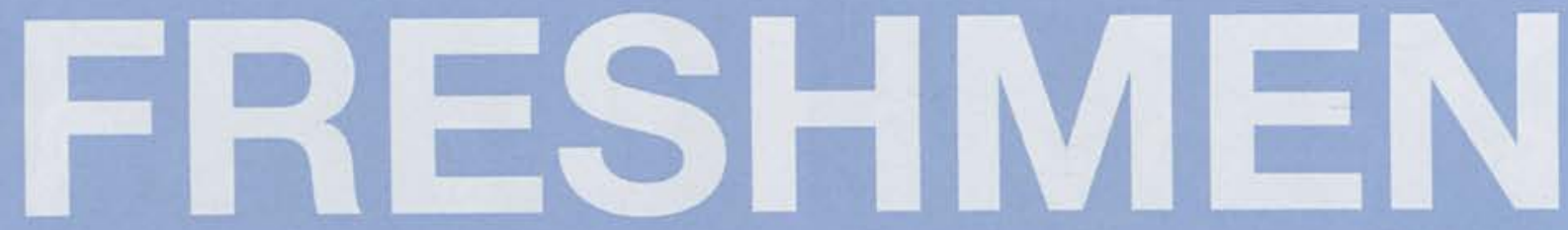

noun, plural \'fresh-men \Fresh-faced, excited students ready to start the next chapter of their education. 


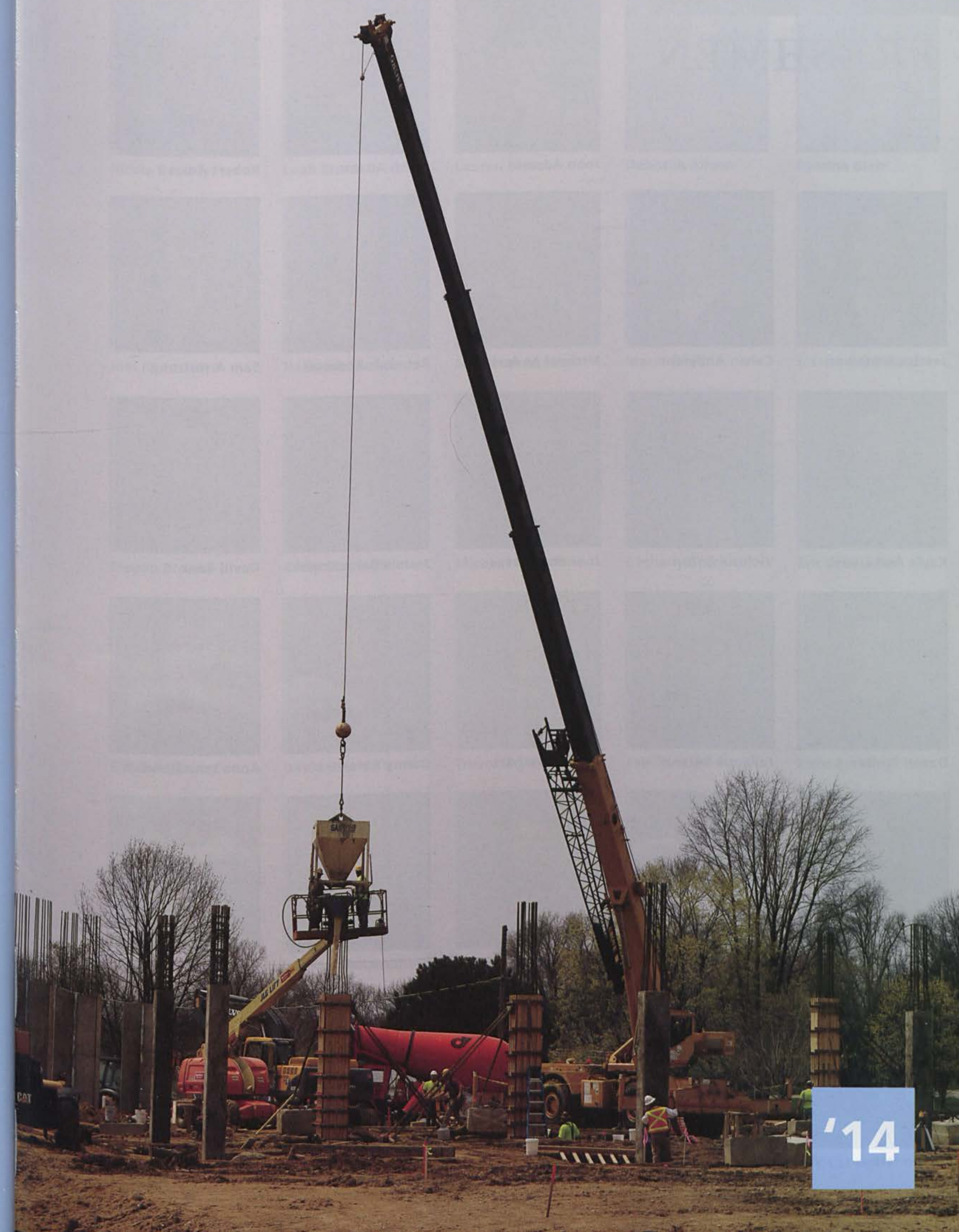




\section{FRESHMEN}

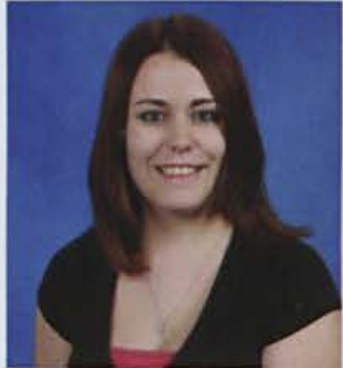

Jessica Amtower

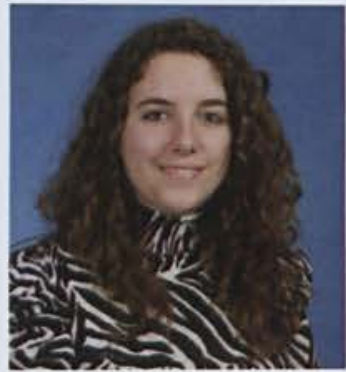

Kayla Ault

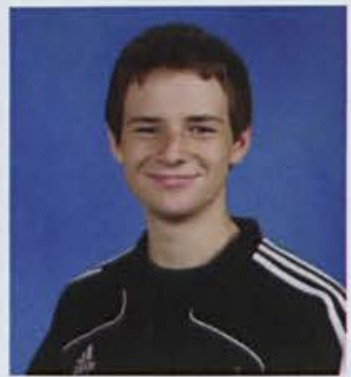

Daniel Barber

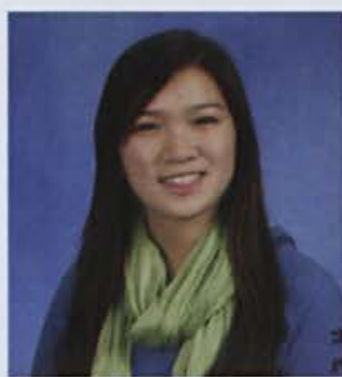

Andrea Bashore

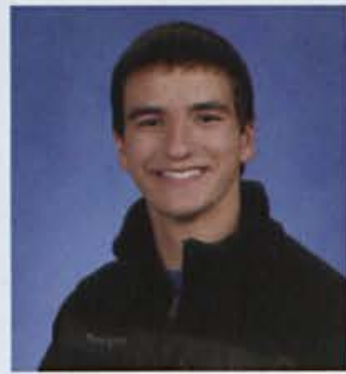

JT Bennett

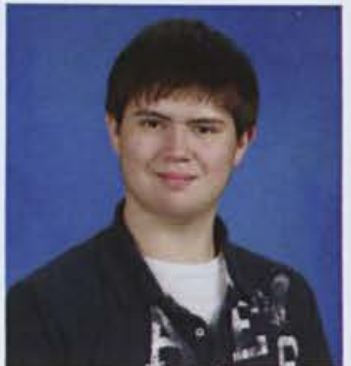

Calvin Anderson

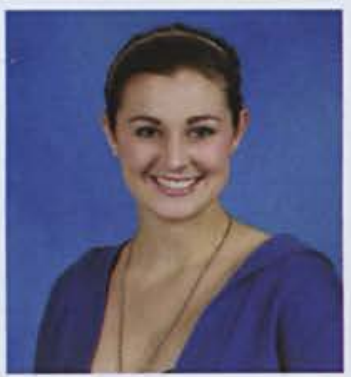

Victoria Bacon

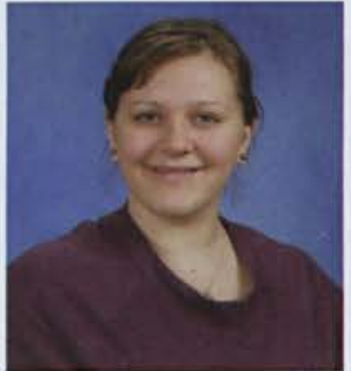

Julianna Barkas

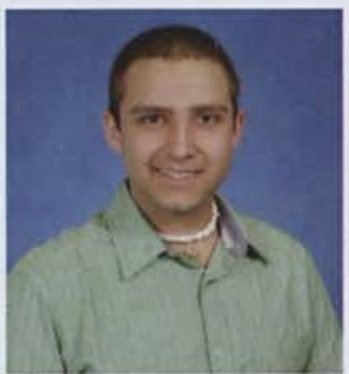

Michael Beach

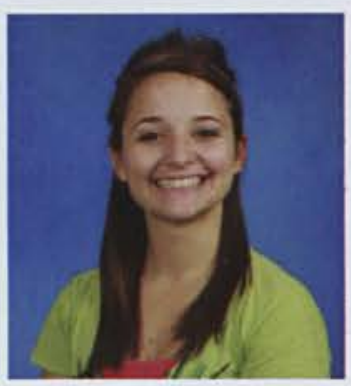

Rebecca Bennett

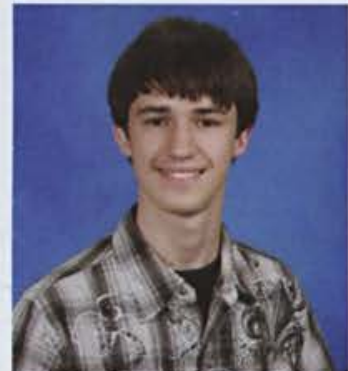

John Adams

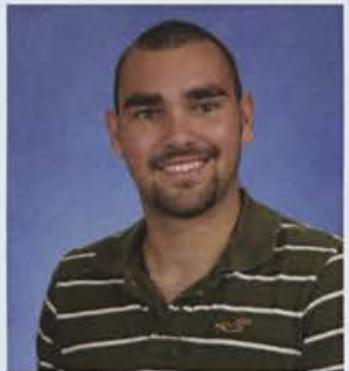

Mitch Adams

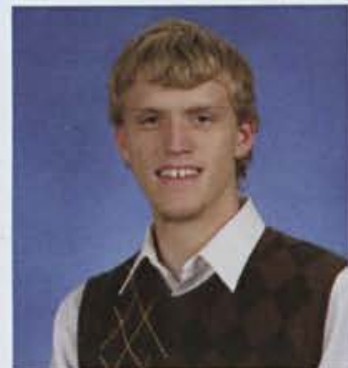

Michael Anderson

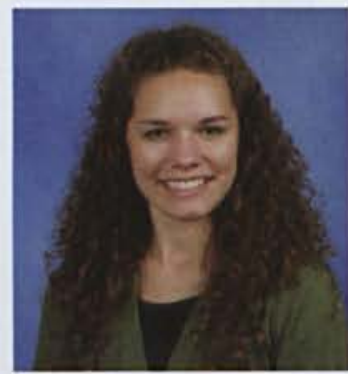

Jonnah Baker

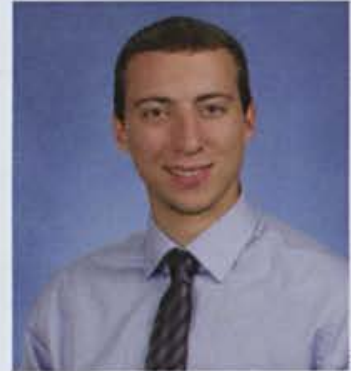

Derek Barnhart

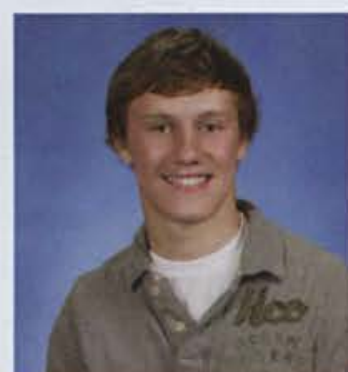

Ryan Beach

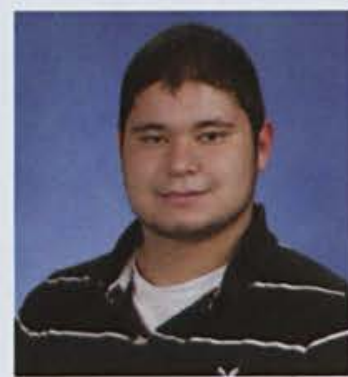

Andrew Bercaw

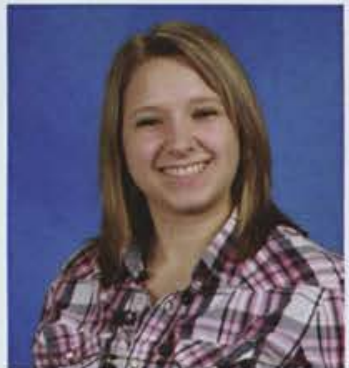

Rebekah Andrews

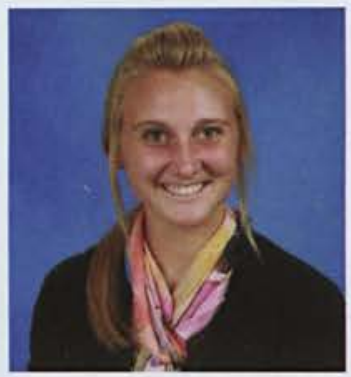

Jasmin Banachowski

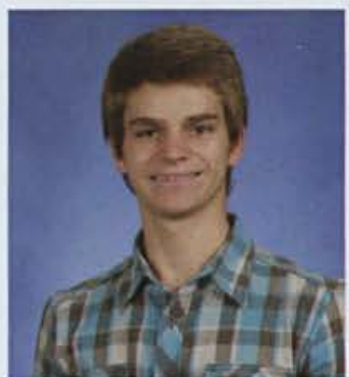

Danny Baron

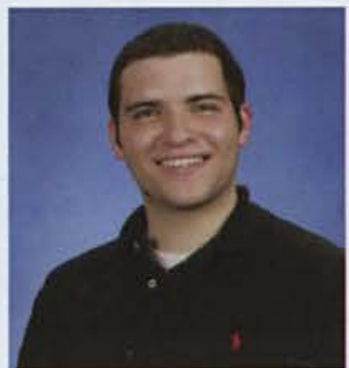

Brandon Bellanti

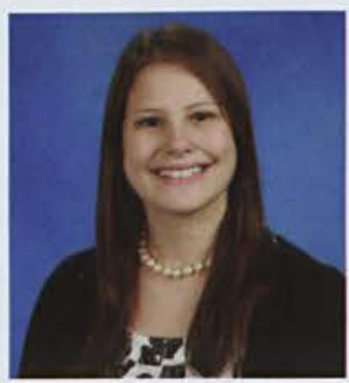

Megan Bernstein

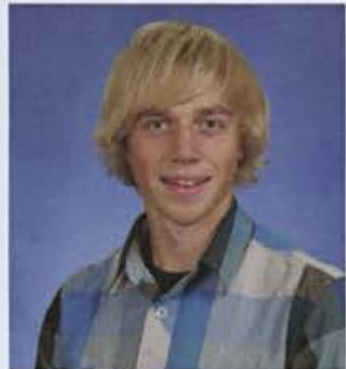

Robert Ames

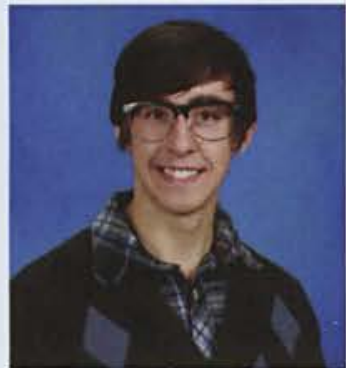

Sam Armstrong

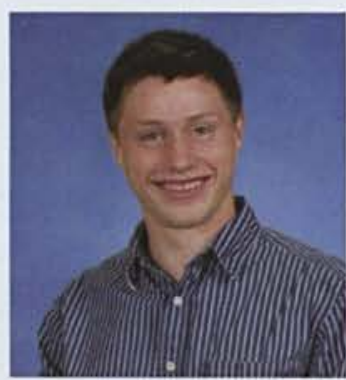

David Banz

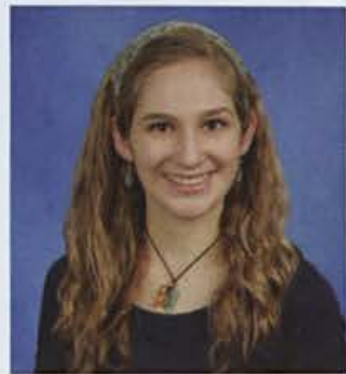

Anna Lynn Barulich

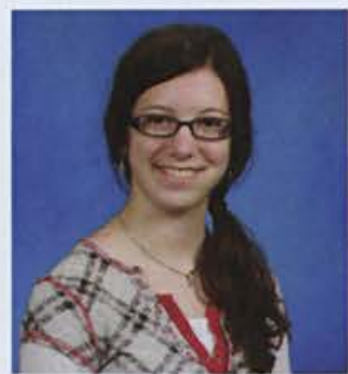

Rachel Belth

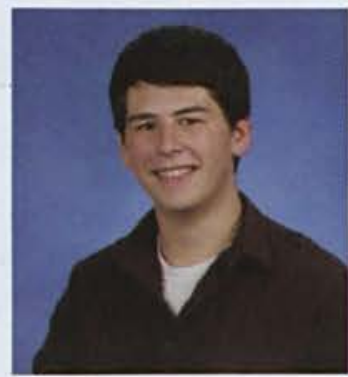

Steve Betz 


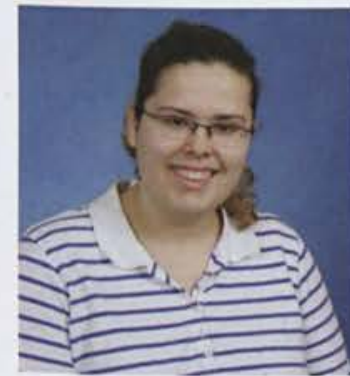

Nicole Beverly

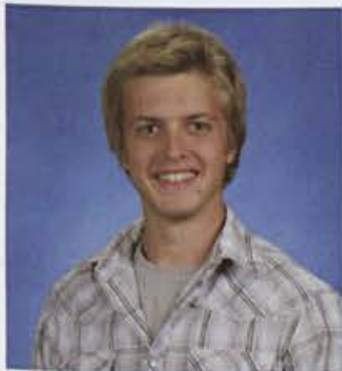

Joel Blunt

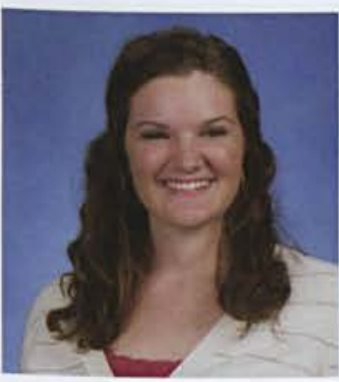

Megan Brewer

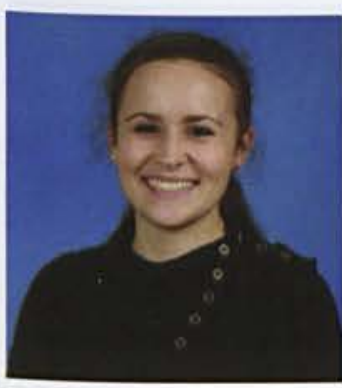

Elizabeth Bruer

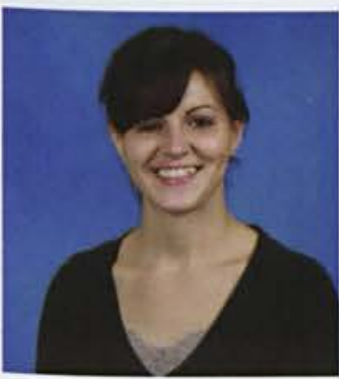

Mary Burkholder

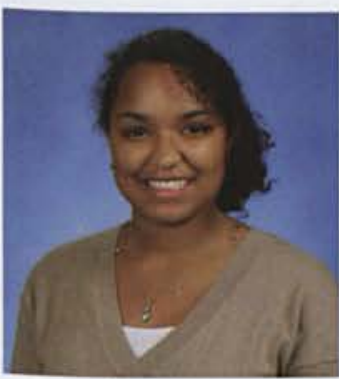

Christina Marie Cappelli

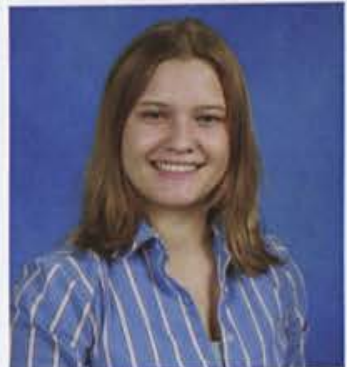

Leah Bierer

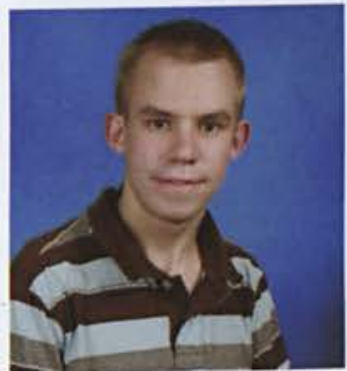

Nathaniel Bond

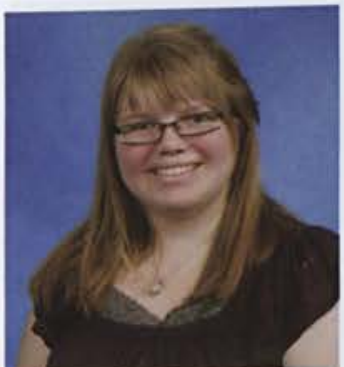

Emily Breyfogle

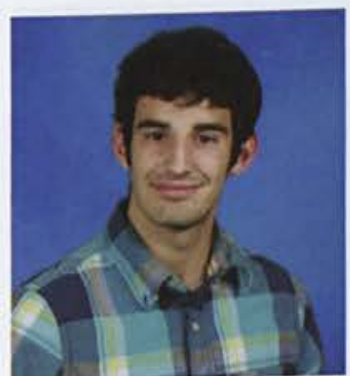

David Brush

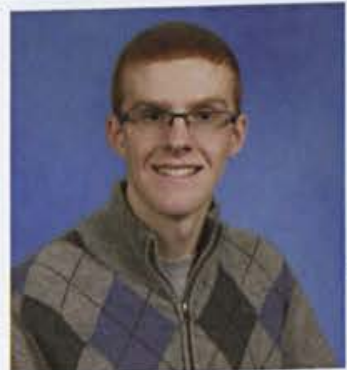

Nathaniel Burrell

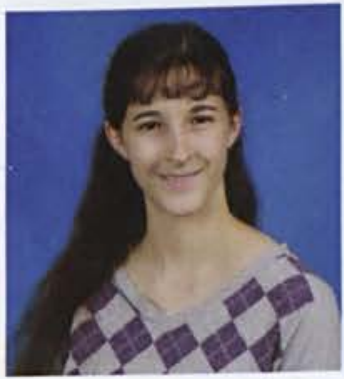

Amy Carmichael

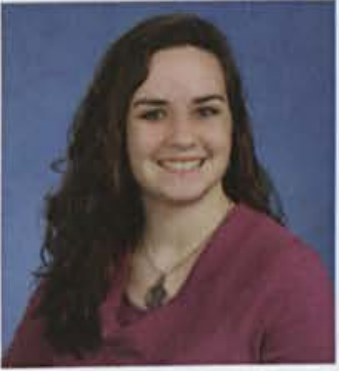

Lauren Bisbee

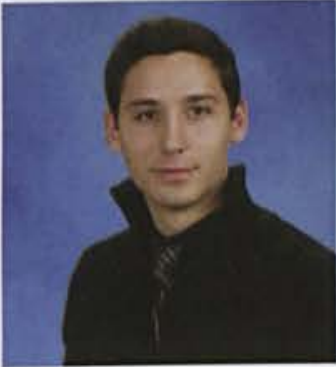

Jonathan Bonifas

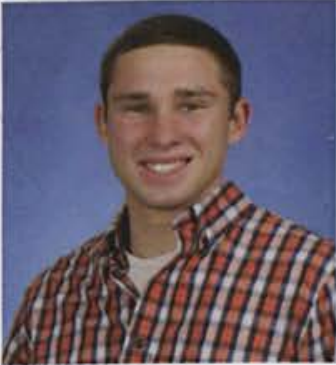

Michael Brittan

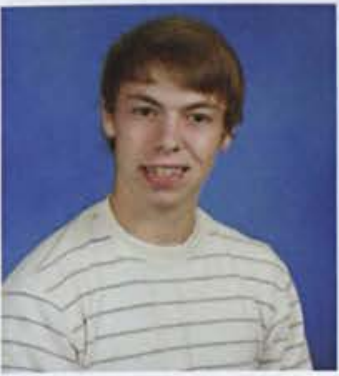

Trevor Bryant

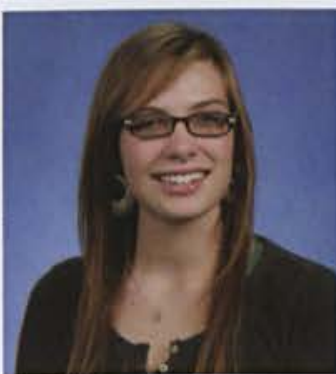

Sarah Busemeyer

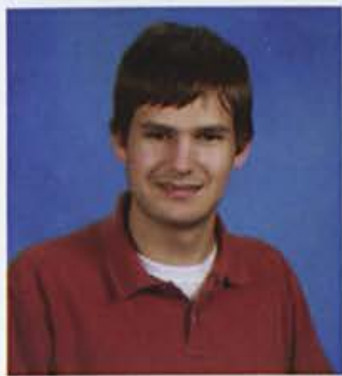

Gregory Carril
Deborah Bitzer

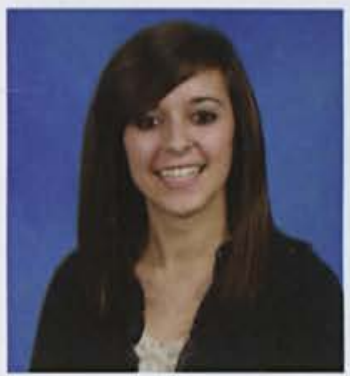

Marie Boyd

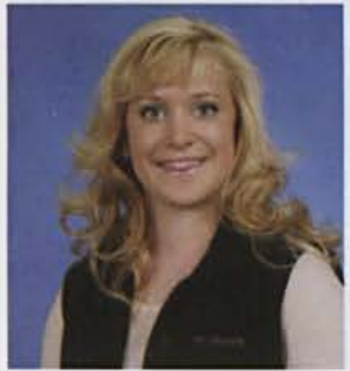

Bethany Brock

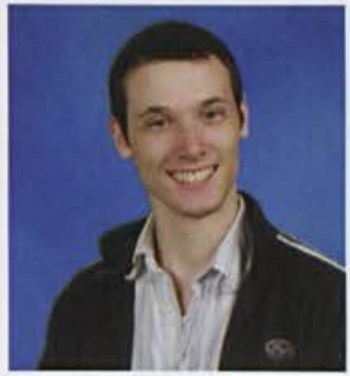

Joel Bundy

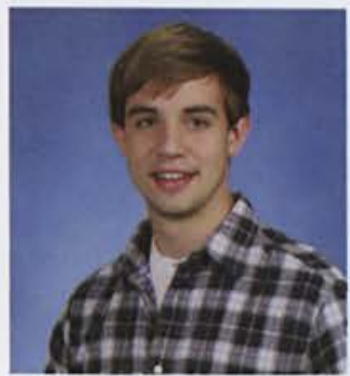

Austin Bush

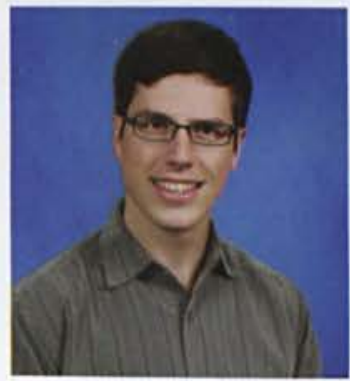

Lewis Carter

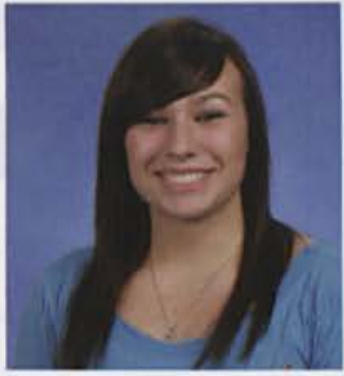

Ryanna Blair

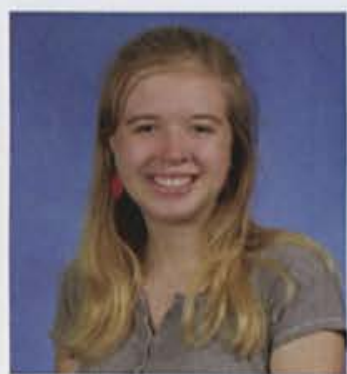

Jessica Bradshaw

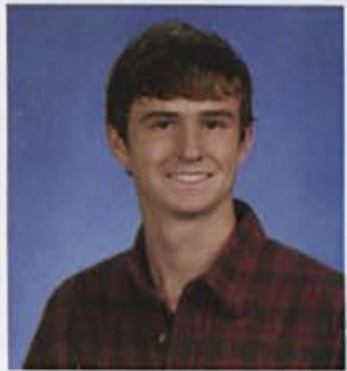

Eric Brueckner

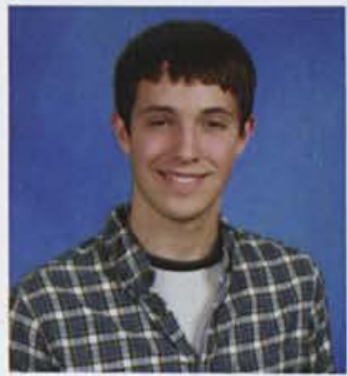

Luke Bunting

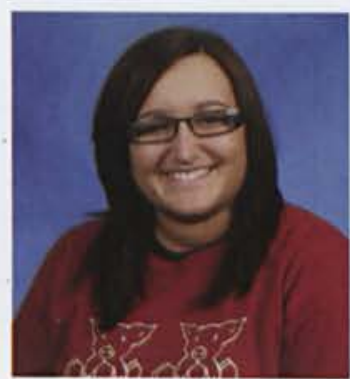

Alivia Byerly

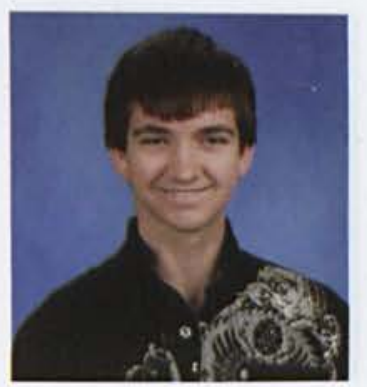

Eric Carver 


\section{FRESHMEN}

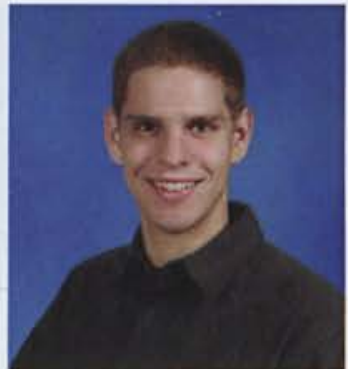

David Caucutt

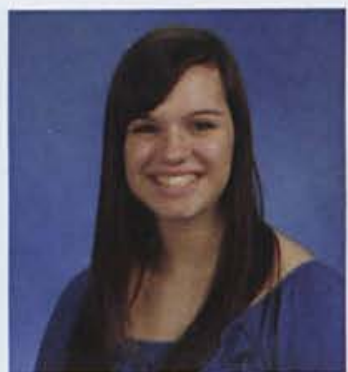

Kelsey Christiansen

\section{Ben Christian}

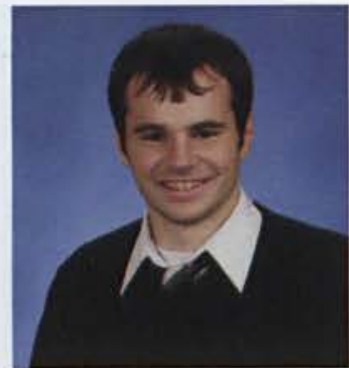

Travis Clark

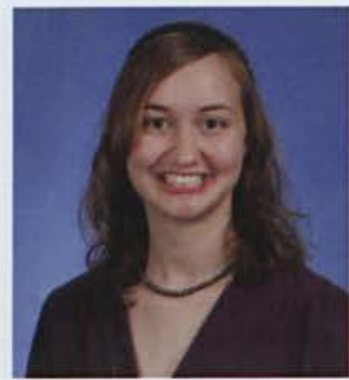

Amy Cuddington

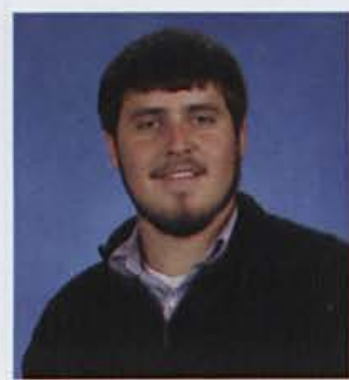

Nicholas Daniels

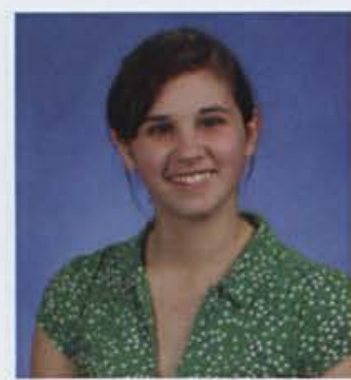

Sarah Denen

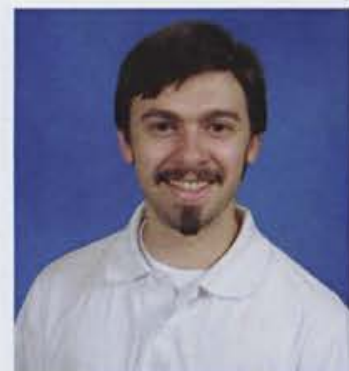

\section{Derrick Chapman}

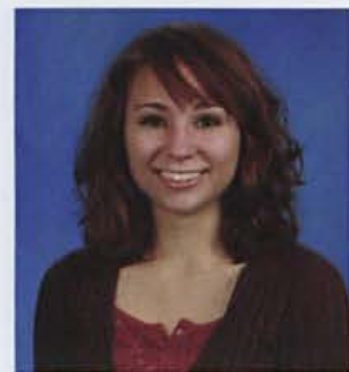

Carolyn Christini

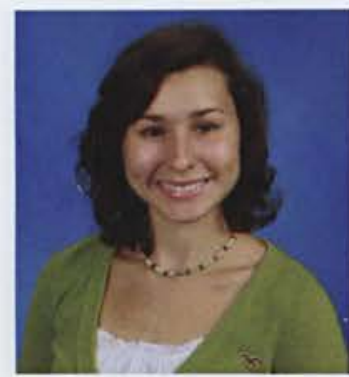

Tiara Coules

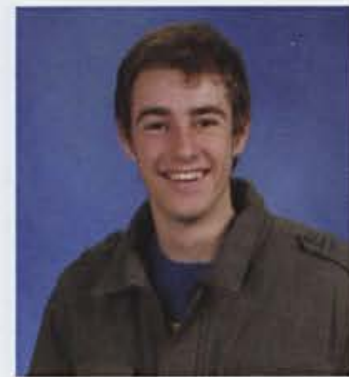

Carter Cummings

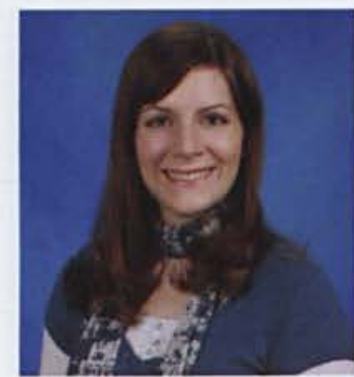

Casey Darst

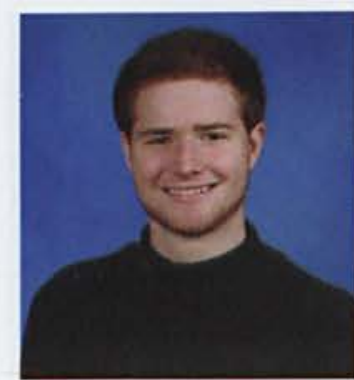

Ian Devins

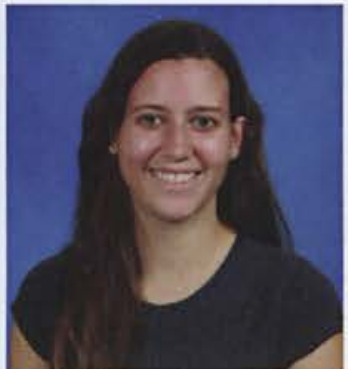

Elisa Cherry

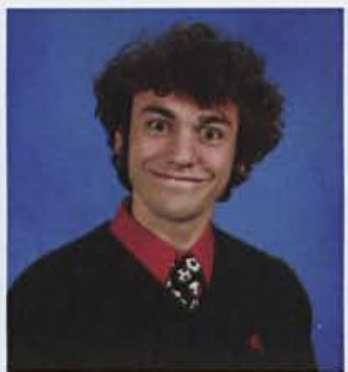

Dylan Cimo

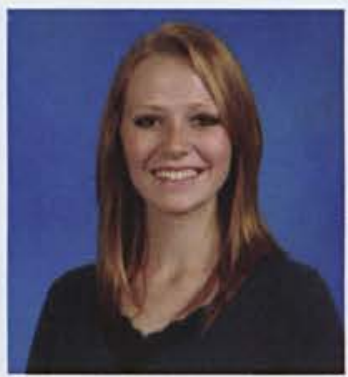

Jerilyn Cox

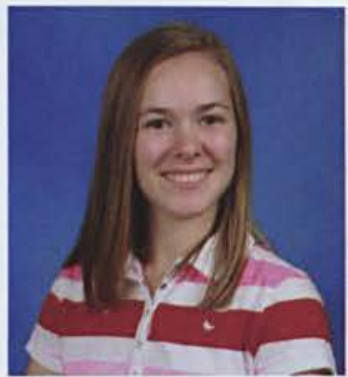

Laura Cummings

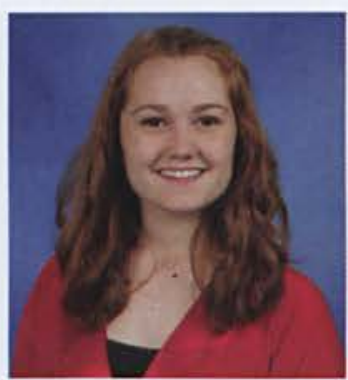

Kristen Day

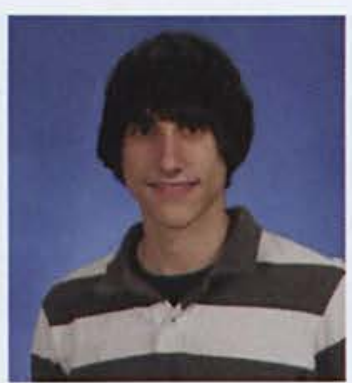

Gregory Devos 


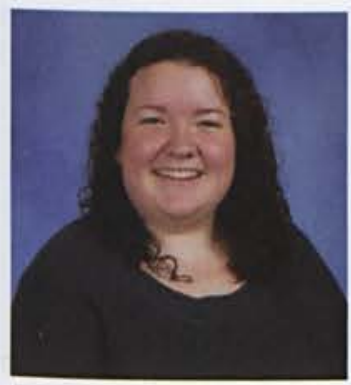

Brittany Dewitt

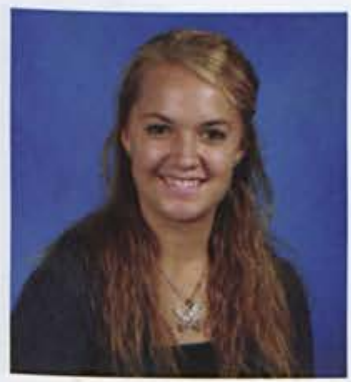

Lydia Douglas

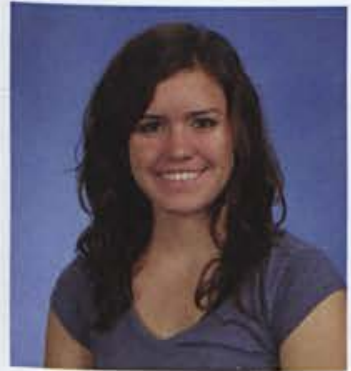

Nicole Dykstra

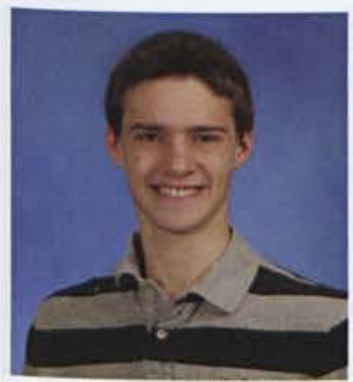

Alex Esbenshade

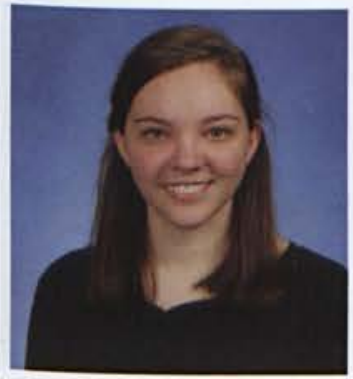

Sarah Firmin

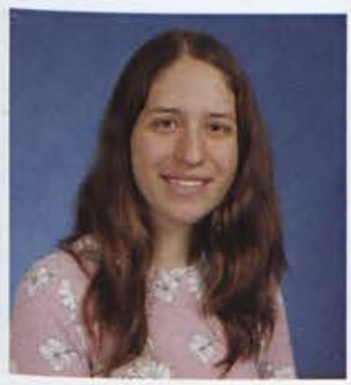

Michelle Frazer

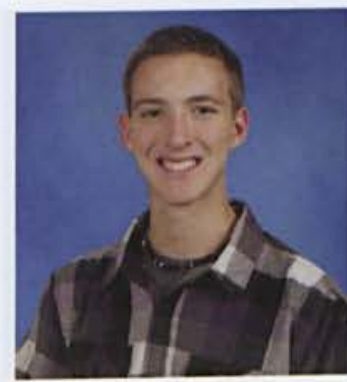

Matthew Dix

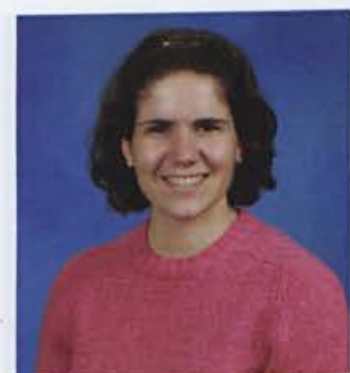

Katherine Drake

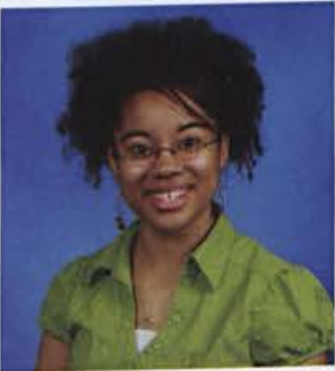

Jessica Dyson

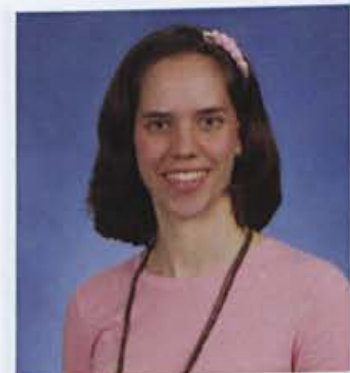

Jennifer Evans

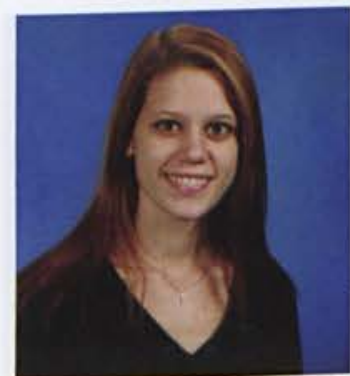

Kelsey Fladda

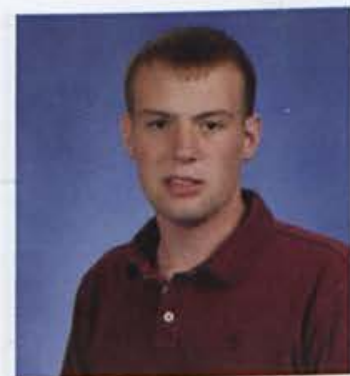

Aaron Free

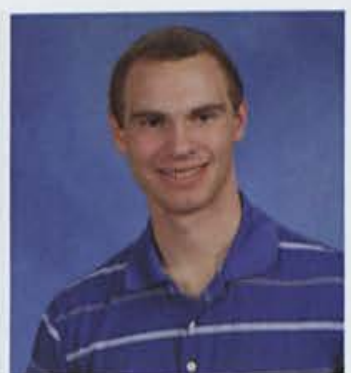

Benjamin Dixson

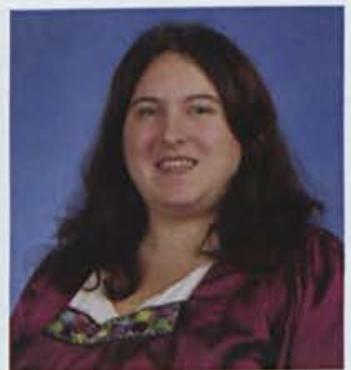

Anna Dubeau

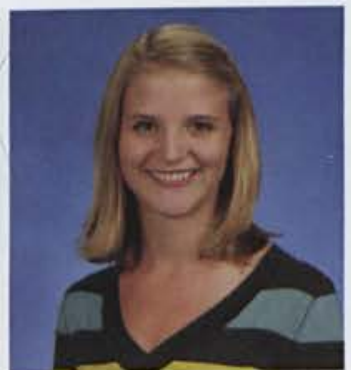

Anna Elliot

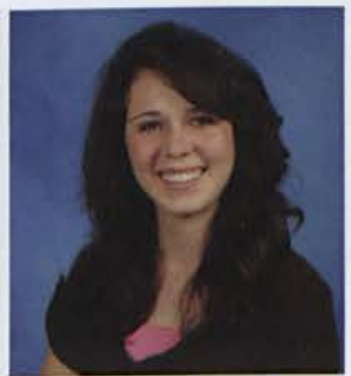

Kaitlin Fain

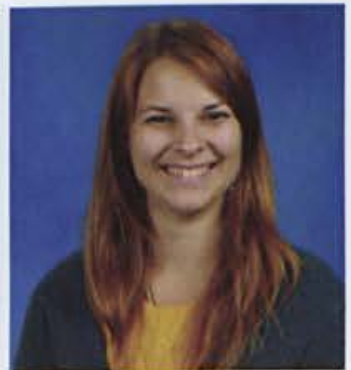

Kaitlyn Fletcher

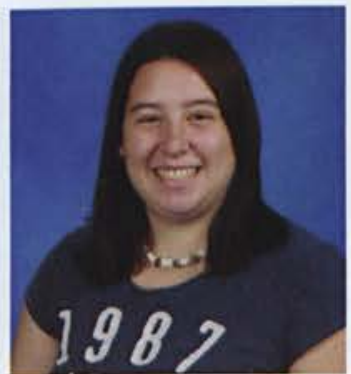

Lauren Gamberdella

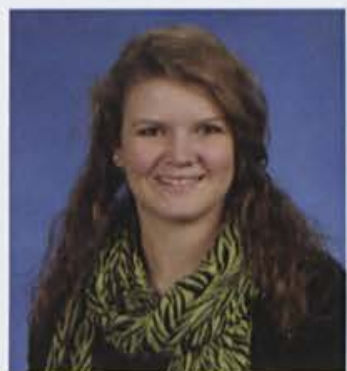

Andrina Doellstedt

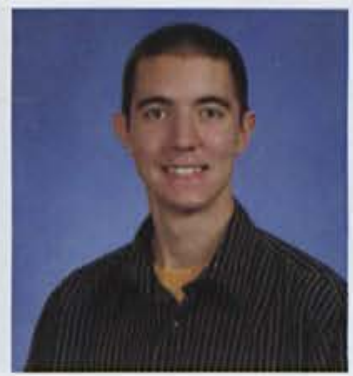

Jacob Dubie

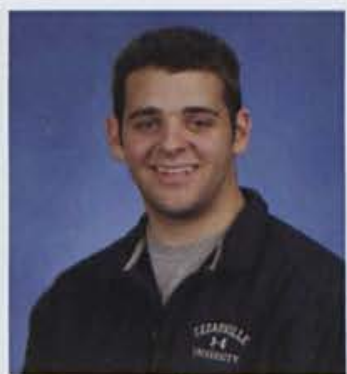

Joshua Elmore

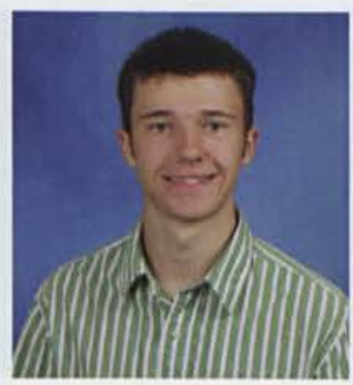

Ryan Farrell

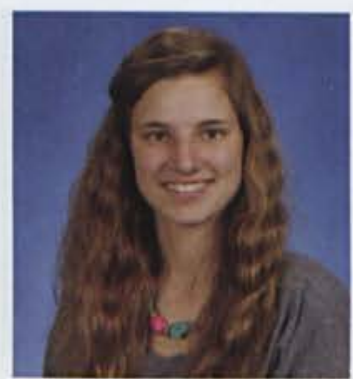

Elena Fouch

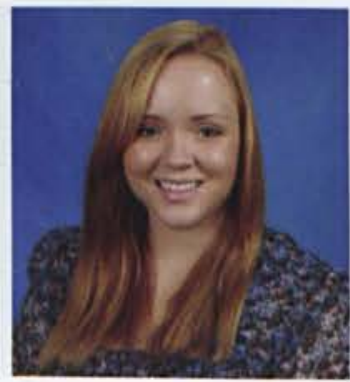

Amber Gardner

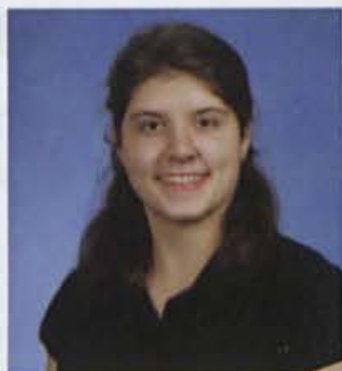

Elizabeth Dossett

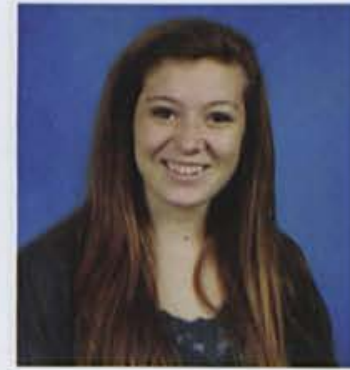

Kelsey Durant

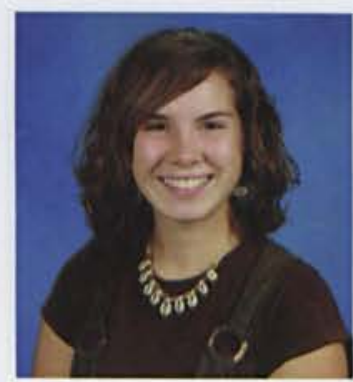

Hannah Elwell

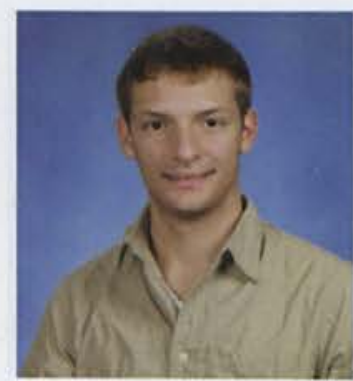

Andrew Fawcett

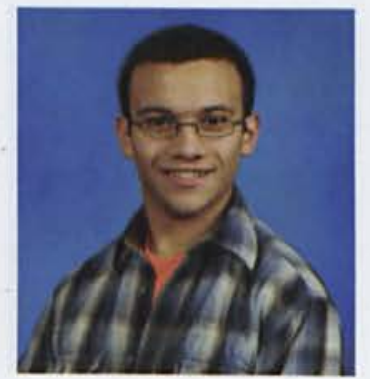

John Frangos

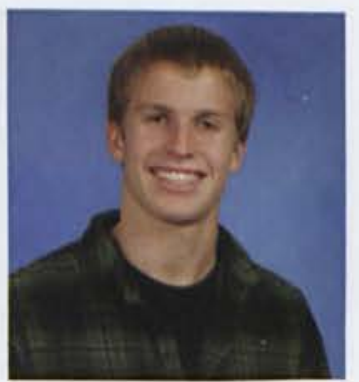

Michael Gardner 


\section{FRESHMEN}

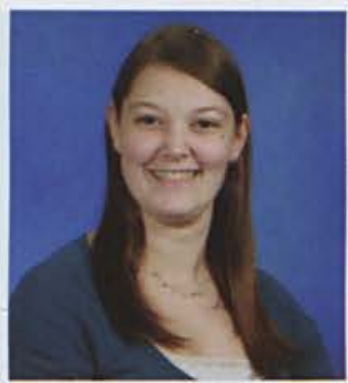

Kimberly Garlick

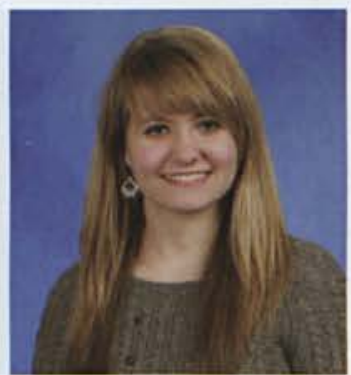

Leah Gillispie

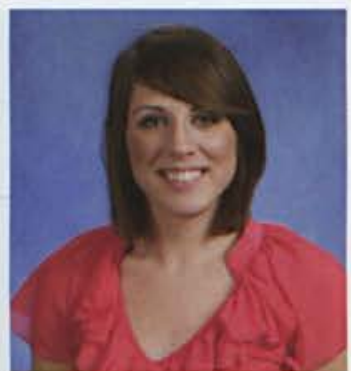

\section{Courtney Graves}

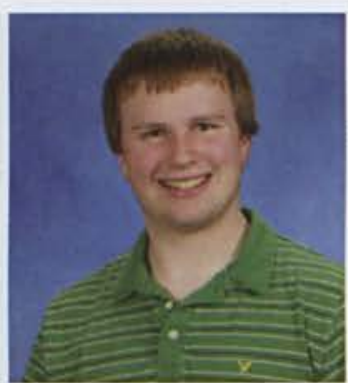

Bryan Grove

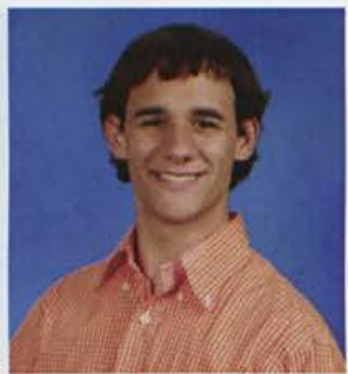

Nathan Hanbury

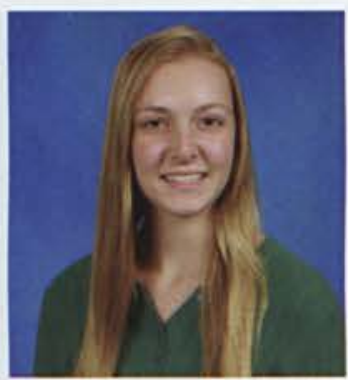

Hannah Harris

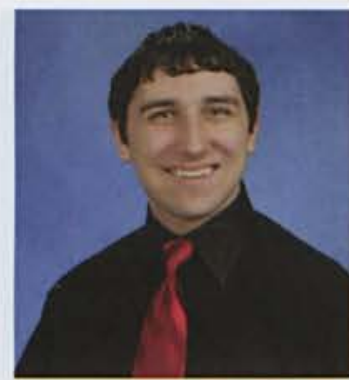

Roger Gelwicks

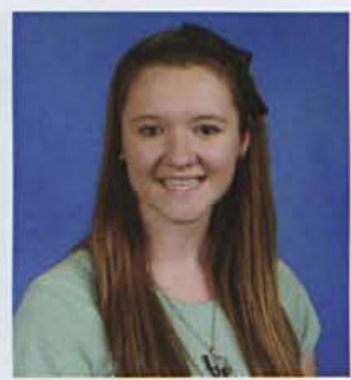

Kortney Good

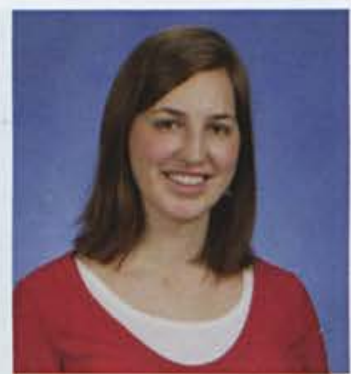

Katie Grayton

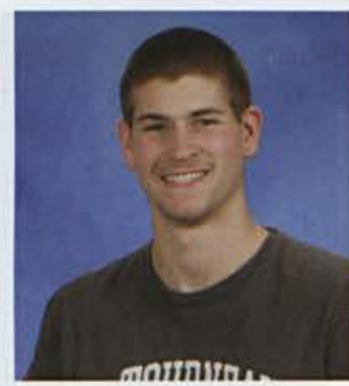

Joshua Gunderson

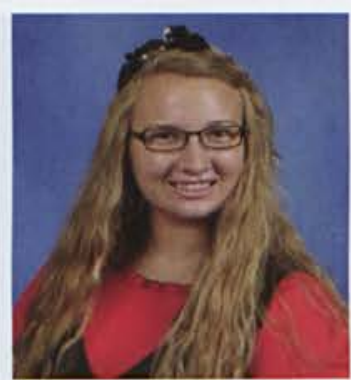

Kelsey Haney

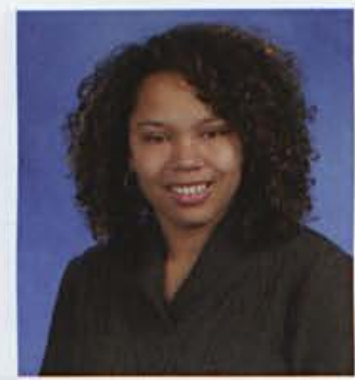

Danikqwa Harrison

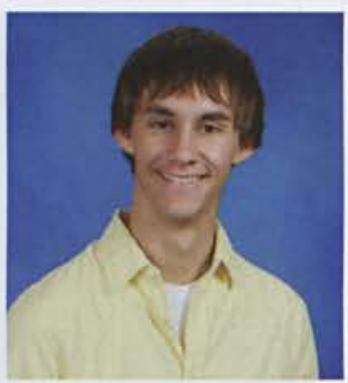

Jared Gerber

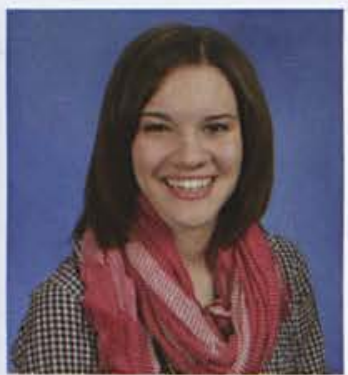

Diane Goodliffe

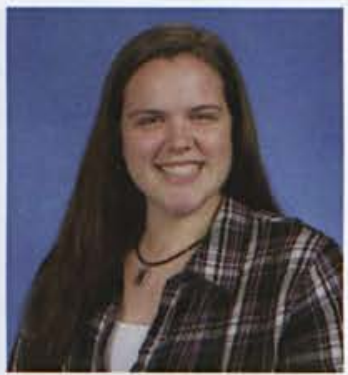

Bethany Green

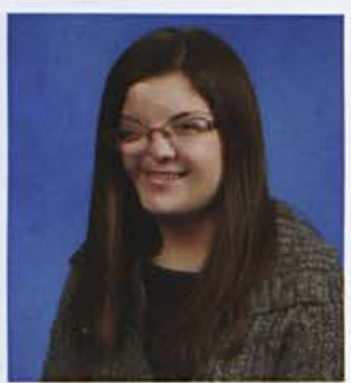

Shelby Haas

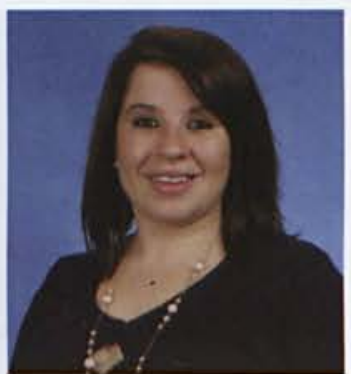

Naomi Haney

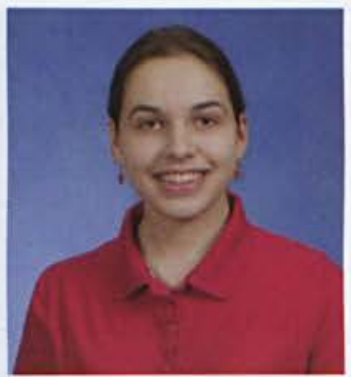

Emily Hartman 


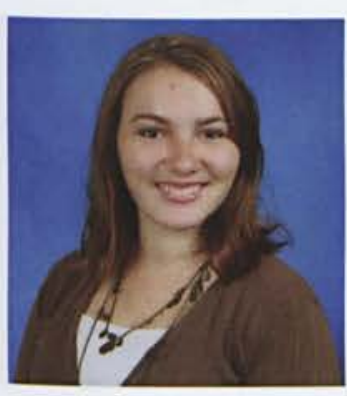

Olivia Harvey

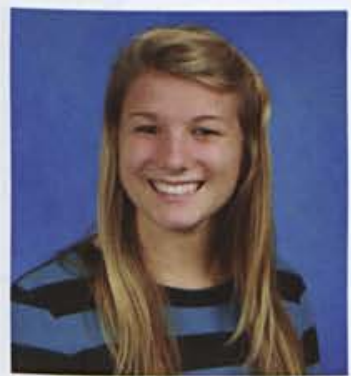

Karly Heitzmann

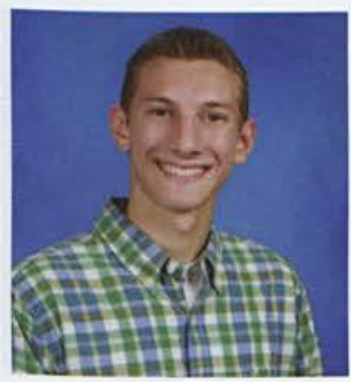

Brandon High

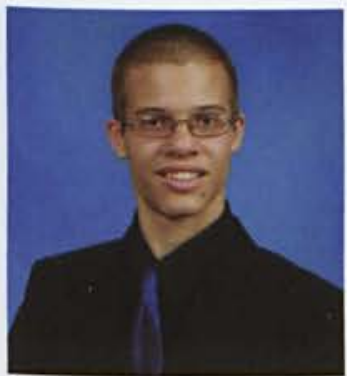

Micah Holck

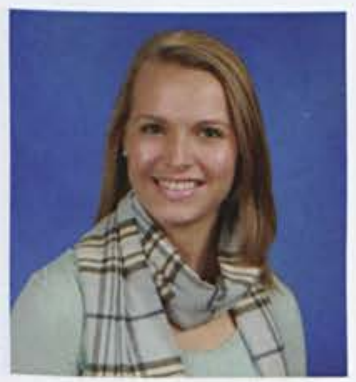

Bethany Hotchkiss

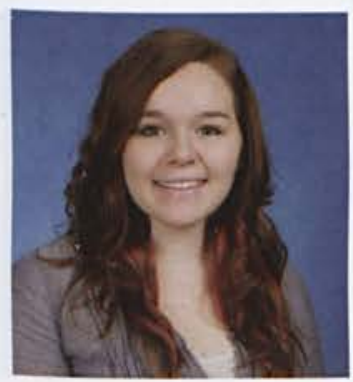

Chelsea Hubbard

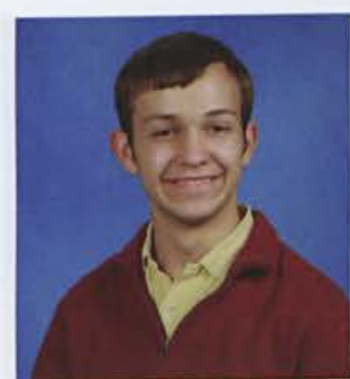

Christian Hayes

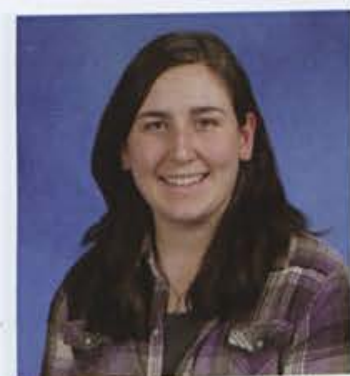

Candace Heller

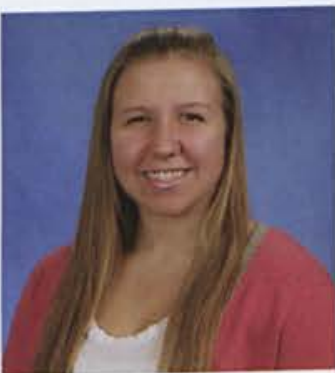

Amanda Hill

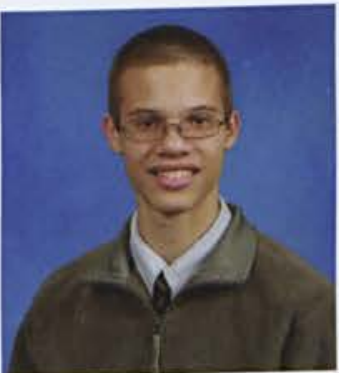

Timothy Holck

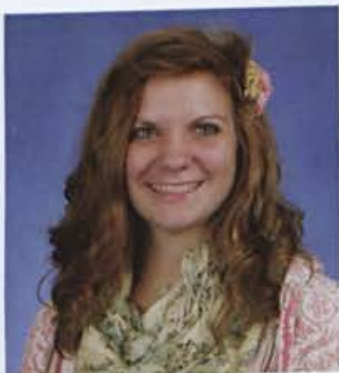

Autum Houser

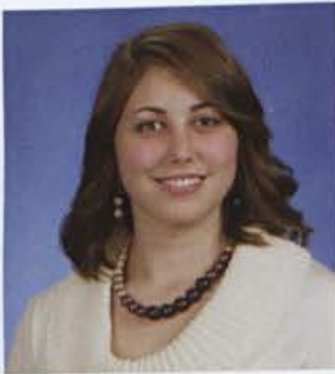

Kelsey Huddle

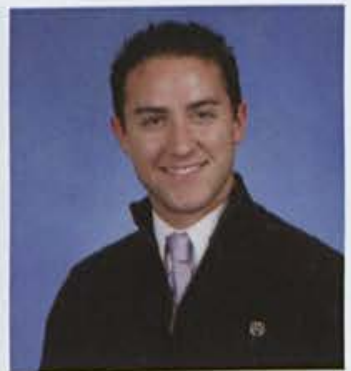

Zachary Heady

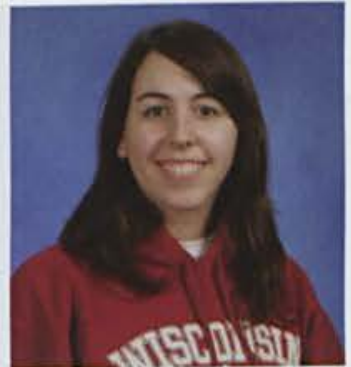

Susan Henley

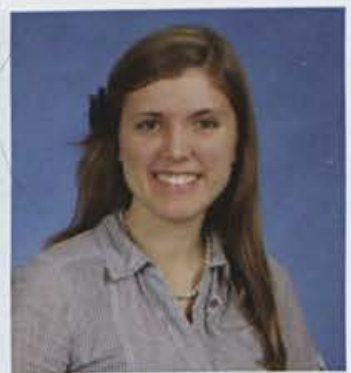

Hanna Hill

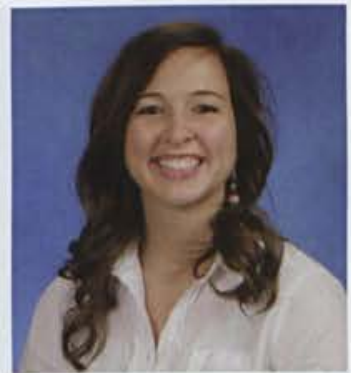

Shanna Holland

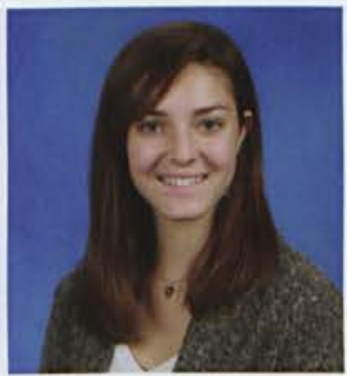

Rebekah Houston

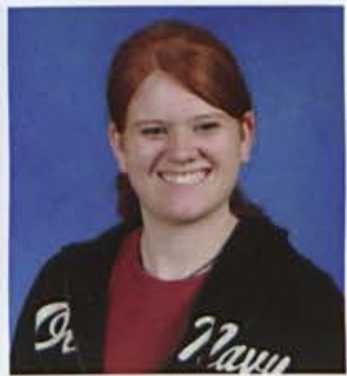

Bethanie Hull

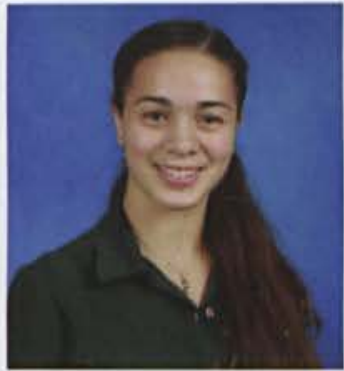

Josephine Hein

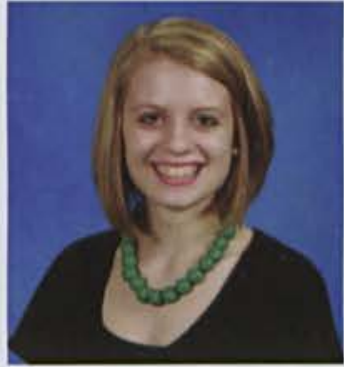

Cassie Herbert

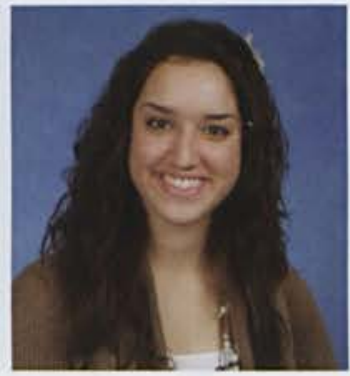

Jessica Hoff

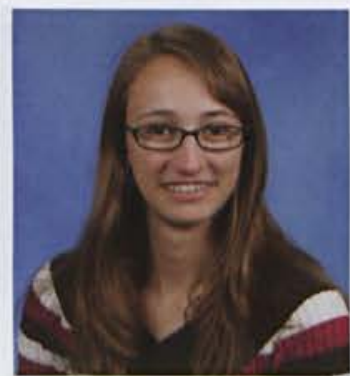

Danielle Holloway

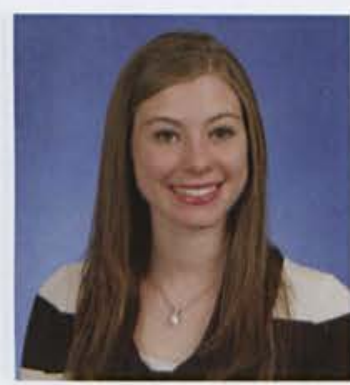

Britney Howland

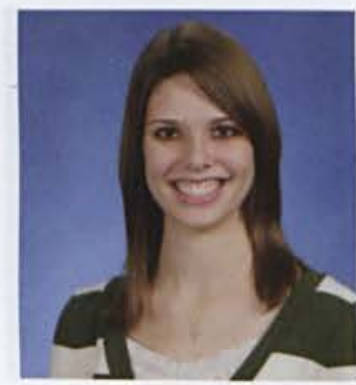

Lauren Hulsey

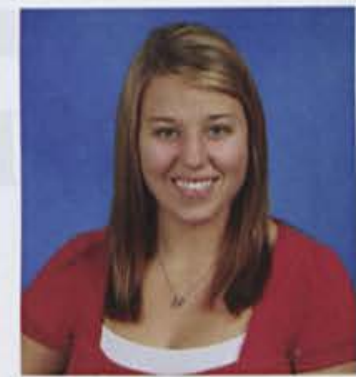

Kara Heineman

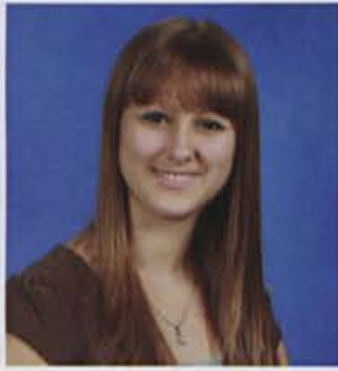

Elizabeth Hicks

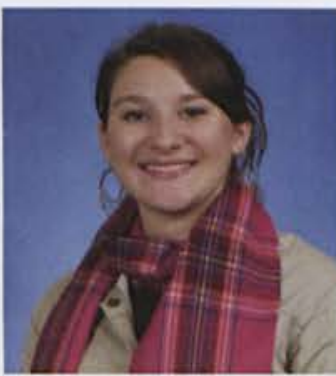

Melissa Hogan

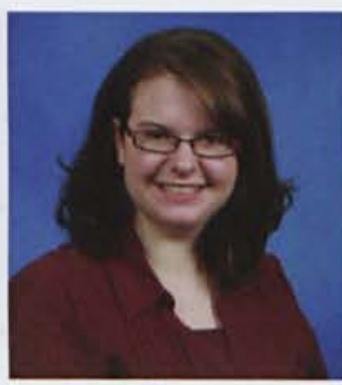

Hillary Hook

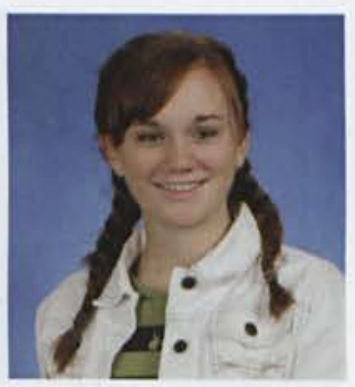

Lauren Howsden

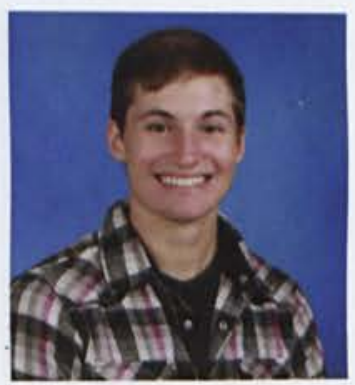

Patrick Hundley 


\section{FRESHMEN}

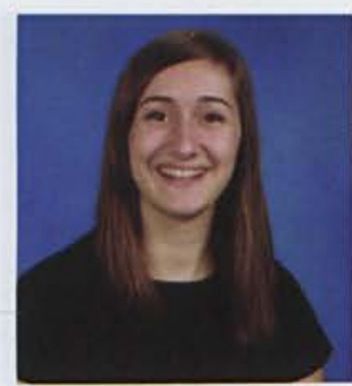

Joanna Huschilt

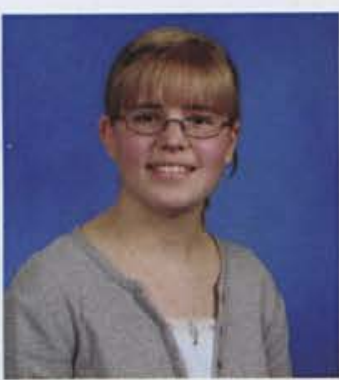

Elizabeth Jeanneret

\section{Brittnie Jarrett}

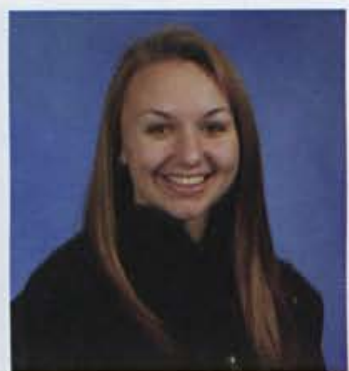

Sarah Johnson

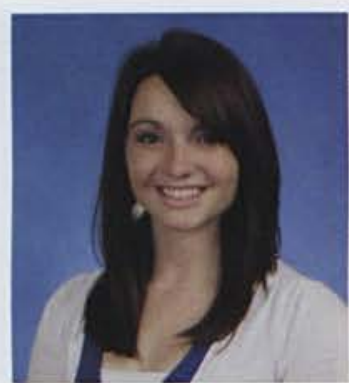

Ashlynn Kelly

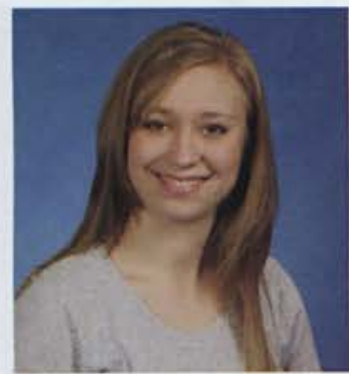

Katelyn Kostreva

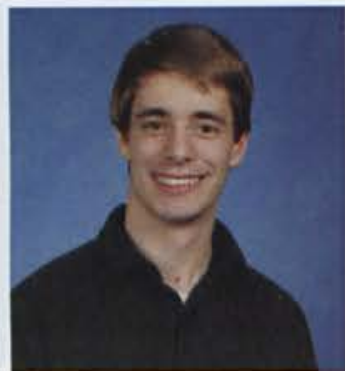

John Lambert

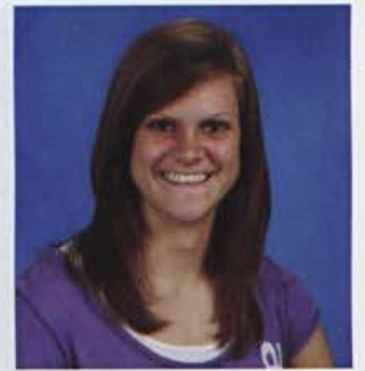

Elizabeth Jones

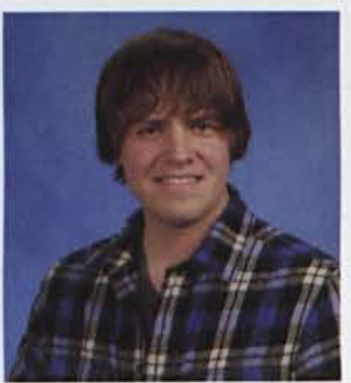

Jonathan Keur

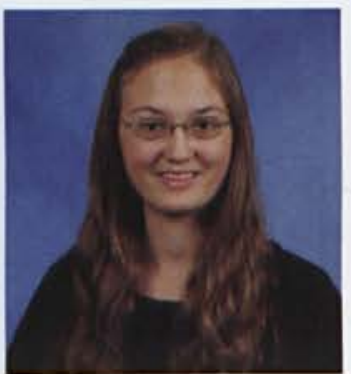

Megan Kuhn

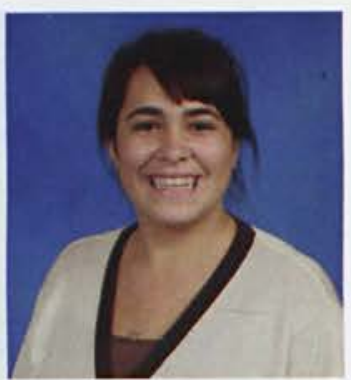

Layna Lange

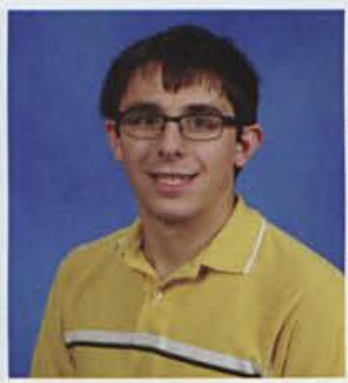

Eric Huseman

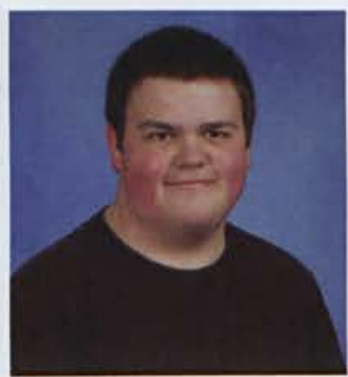

Clay Johnson

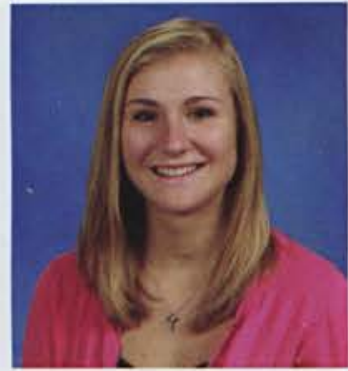

Sarah Jungbauer

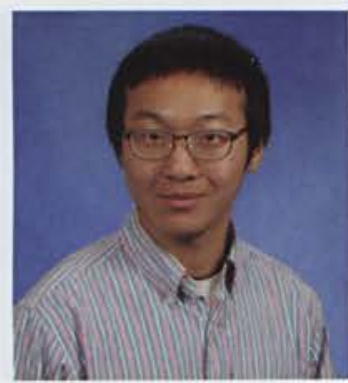

Myeongseop Kim

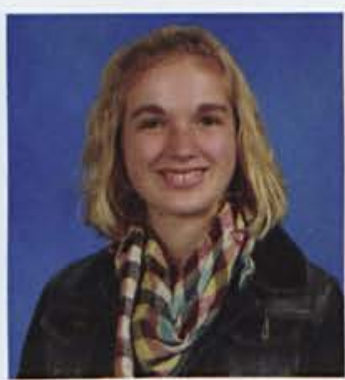

Rachel Kuiken

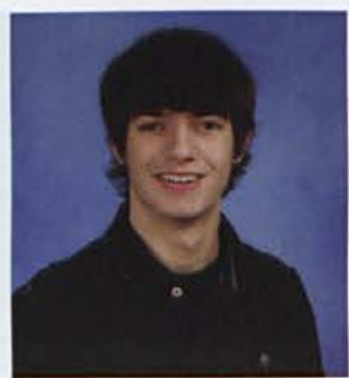

Jonah Langenderfer

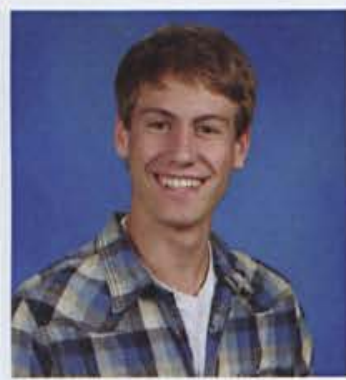

Joel Ingram

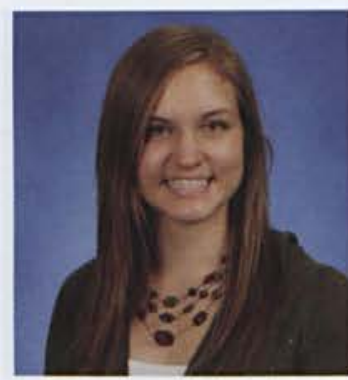

Kaela Johnson

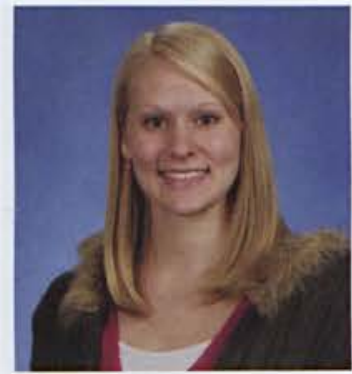

Erica Kacho

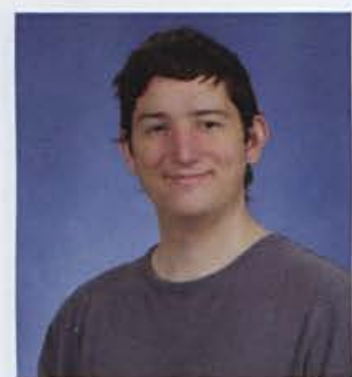

Alex Kitzmiller

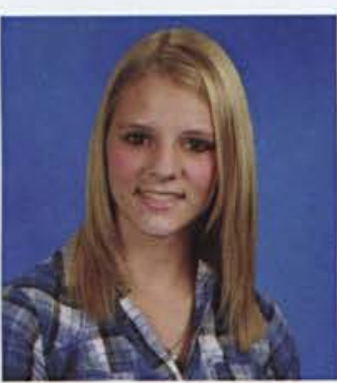

Stephanie La Croix

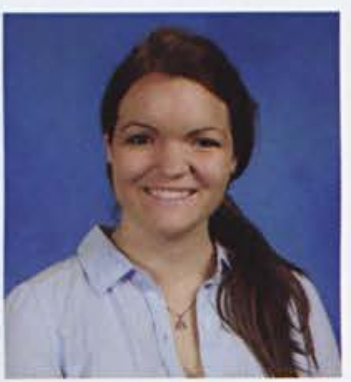

Brittany Larrabee 


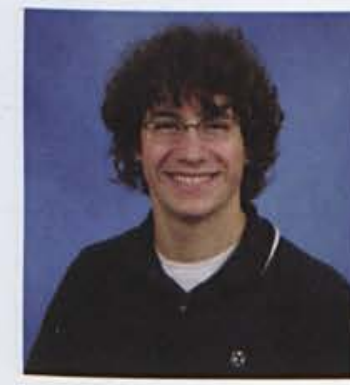

Caleb Larson

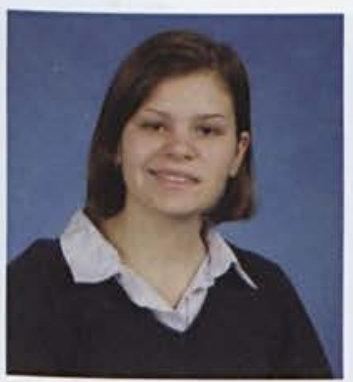

Amanda Lenarski

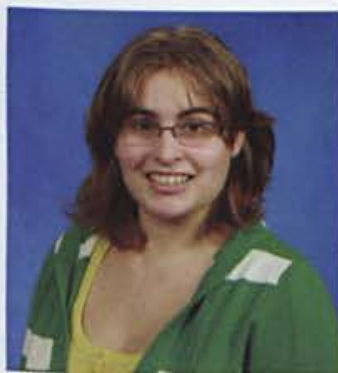

Katherine Logsdon

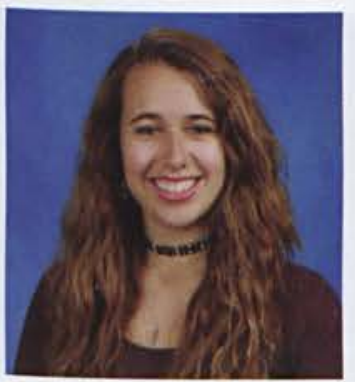

Jaclyn Lucas

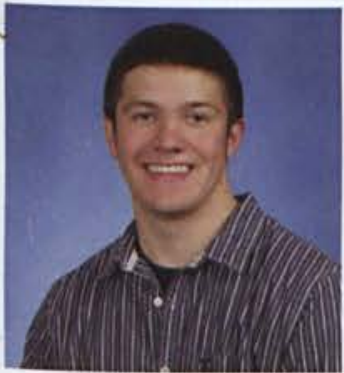

Quentin Lynch

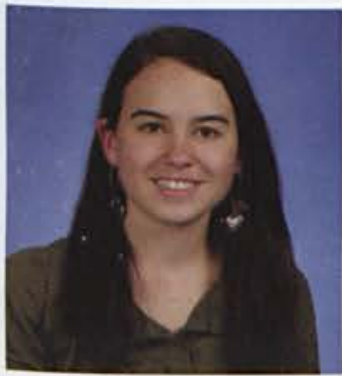

Holly McClellan

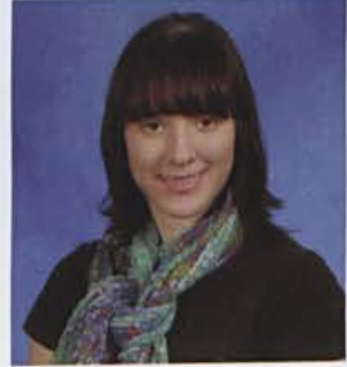

Amanda Lawler

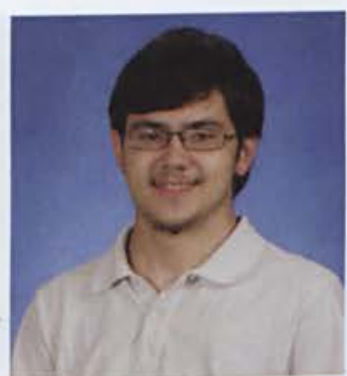

Ian Leong

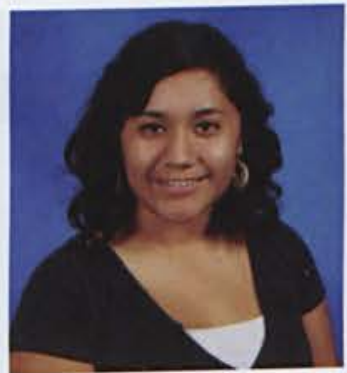

Berenice Lopez

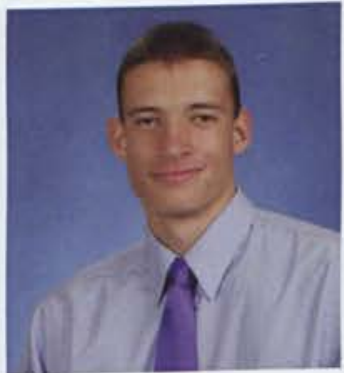

Benjamin Luce

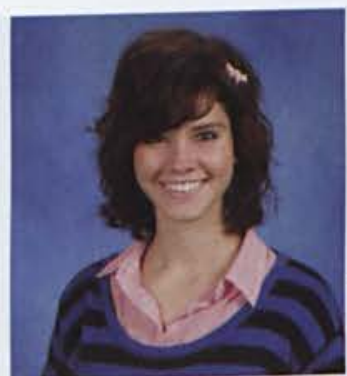

Sarah Makoski

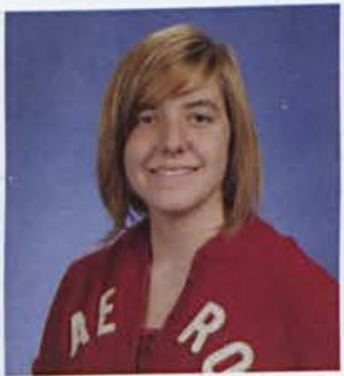

Jennifer McConkey

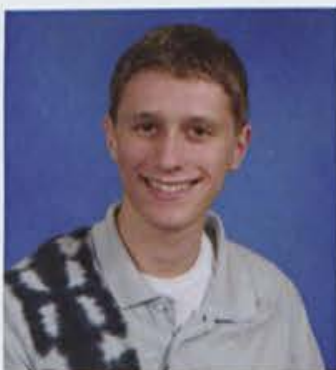

Aaron Le Poire

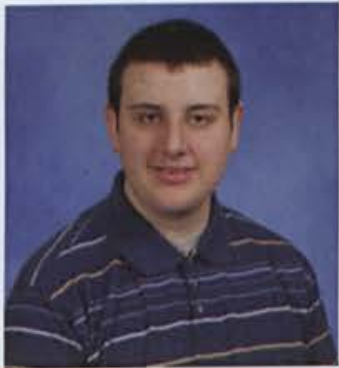

Stephen Linden

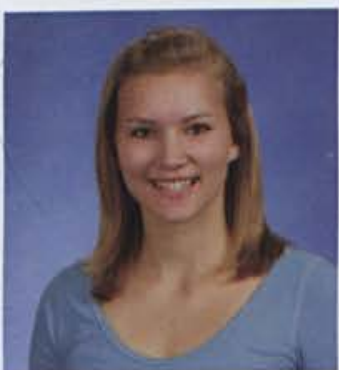

Hannah Losch

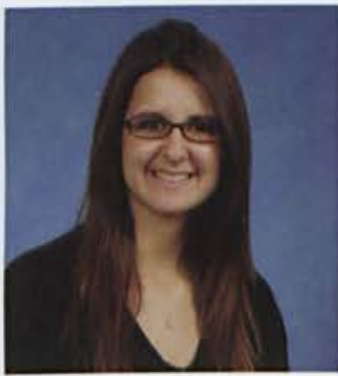

Kelly Lutz

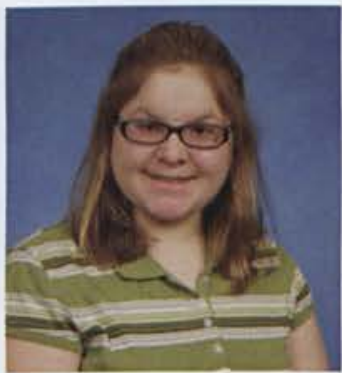

Rebekah Manning

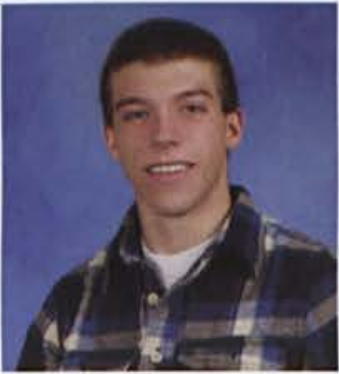

Stephen McCown

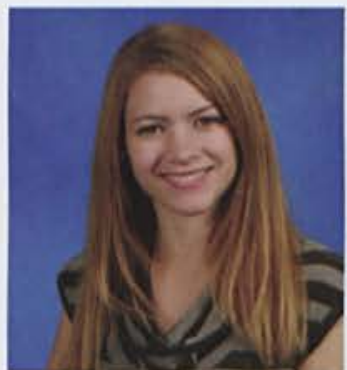

Lani Lear

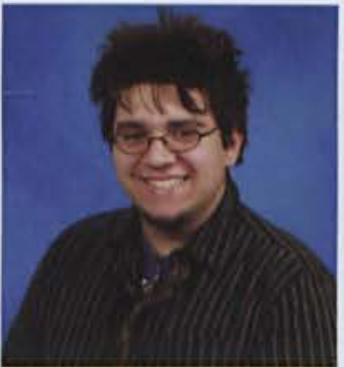

Kevin Little

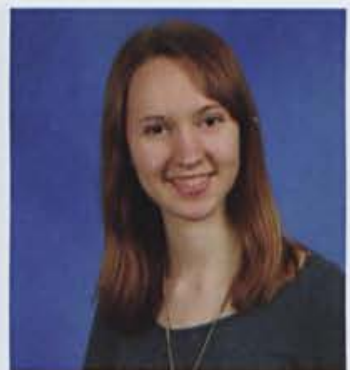

Rachel Lowrance

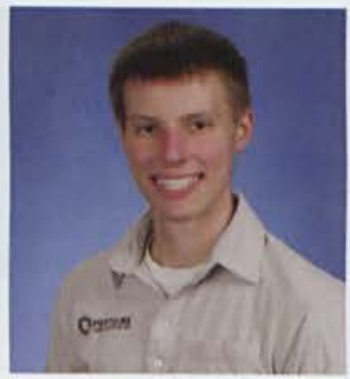

Caleb Lyman

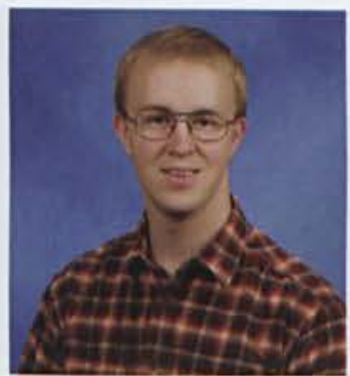

Caleb Marot

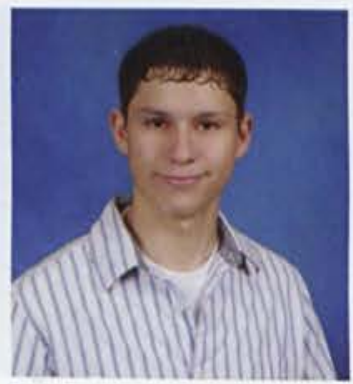

Zach McDaniel

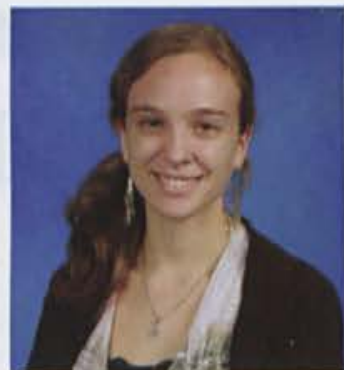

Michayla Lehman

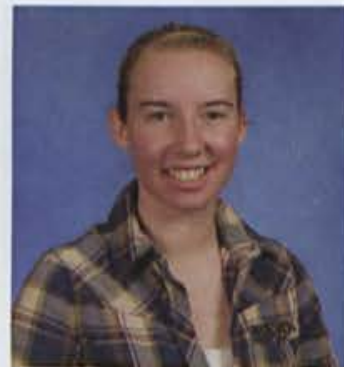

Sarah Loeffler

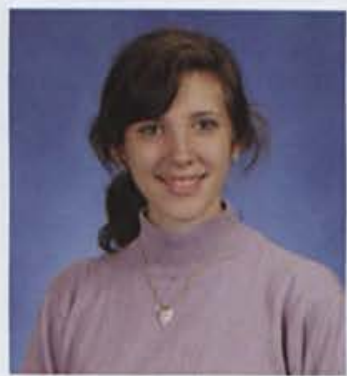

Caitlyn Lucas

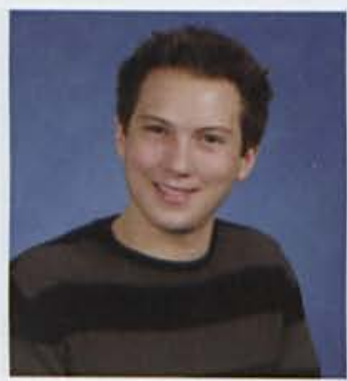

Eric Lynch

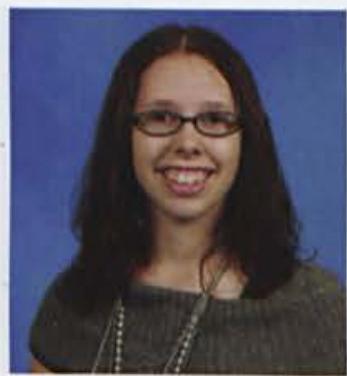

Ashley Marple

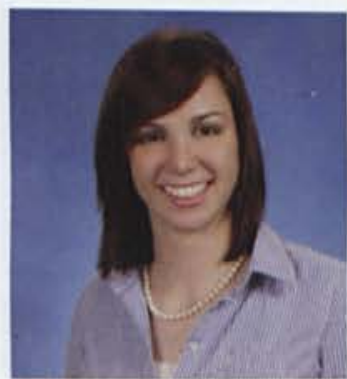

Kelly McDonald 


\section{FRESHMEN}

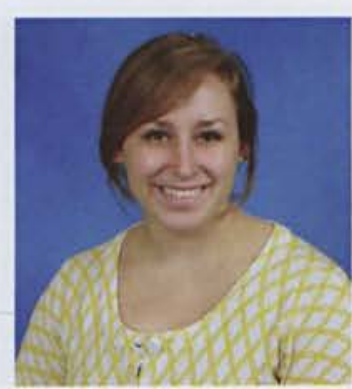

Lindsay McGee

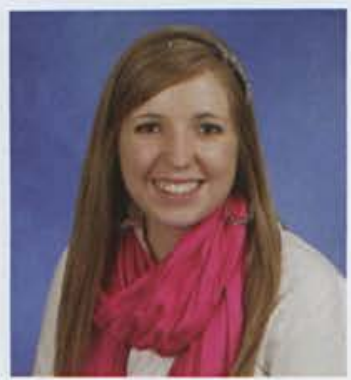

Megan McNicol

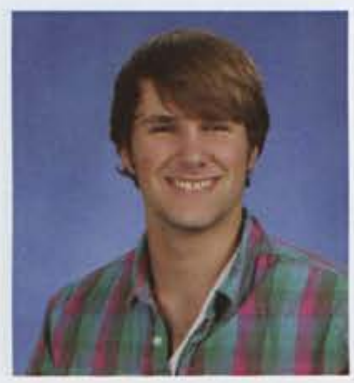

Nathan Miller

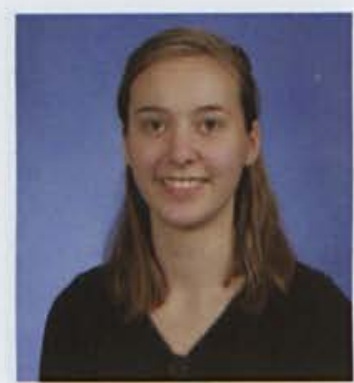

Rachel Molstre

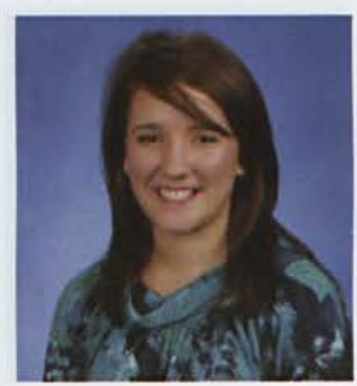

Anne Morris

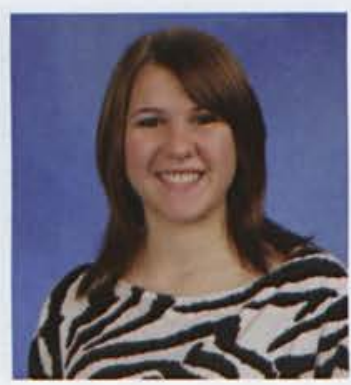

Chelsea Musser

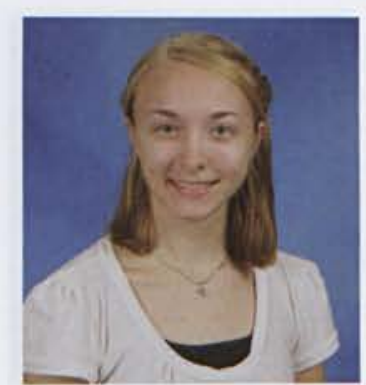

Joy McTaggart

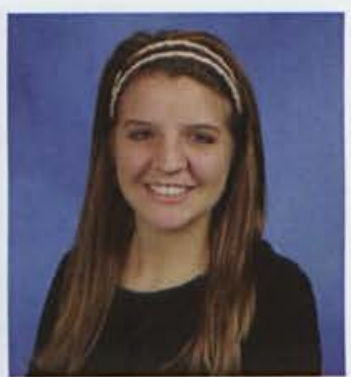

Rebecca Miller

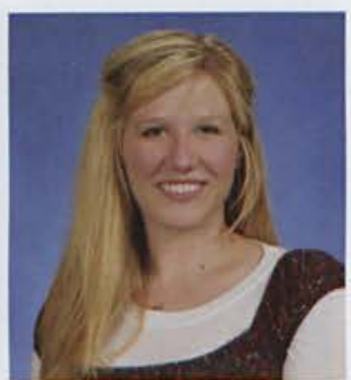

Alyssa Moore

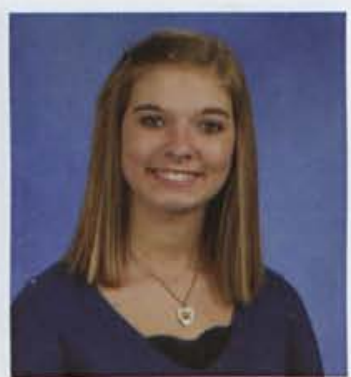

Brittney Morris

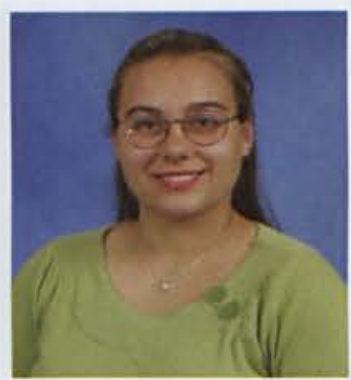

Nyomi Myers

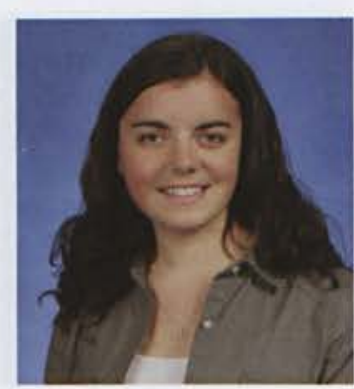

Sara Melucci

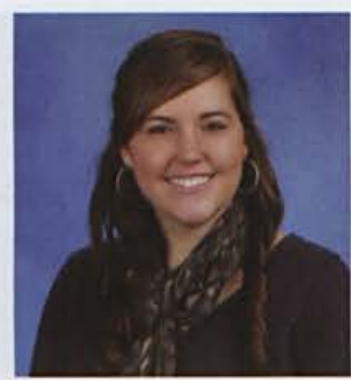

Sarah Miller

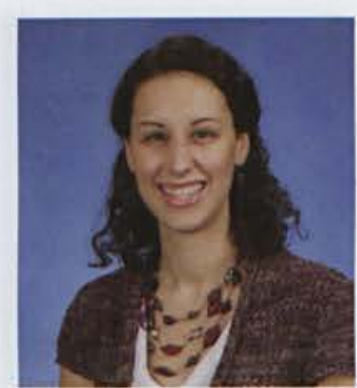

Ashley Moore
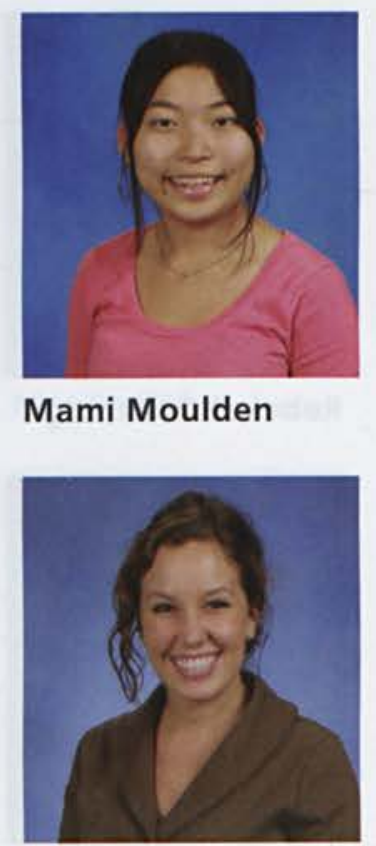

Emily Neal
Mami Moulden

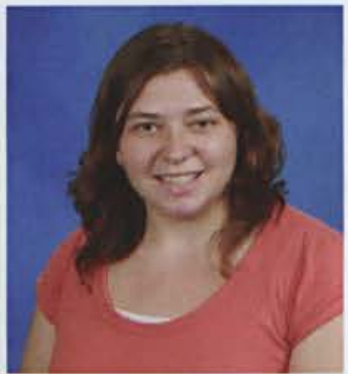

Alicia McLeod

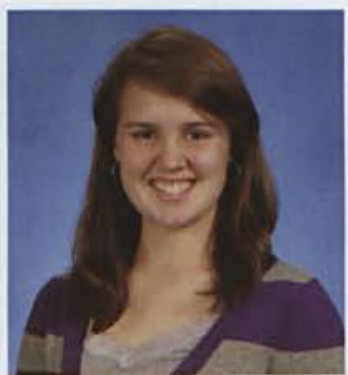

Larissa Miller

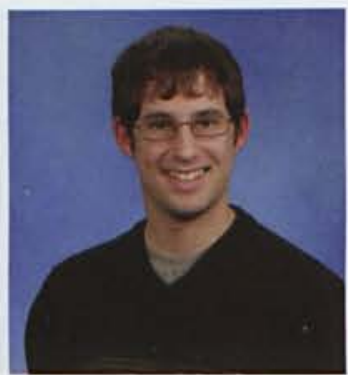

David Moeller

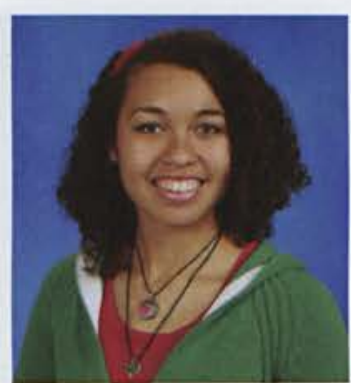

Ellen Moore

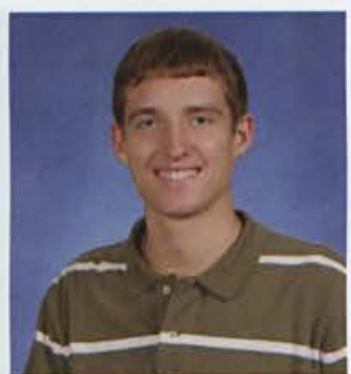

Brandon Muck

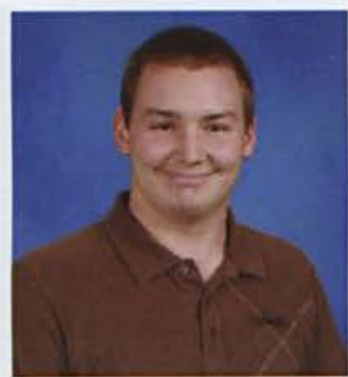

Garrett Nelson

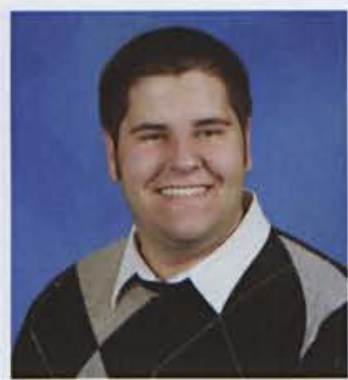

Zachary McMeen

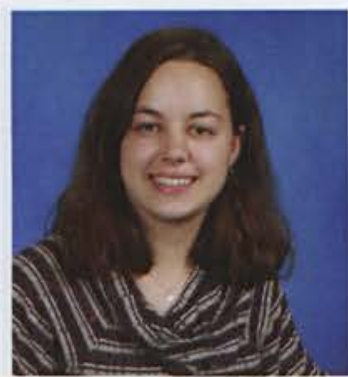

Mary Miller

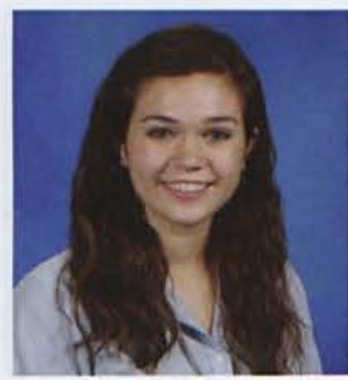

Megan Moffitt

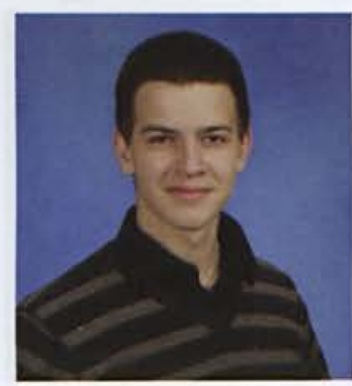

Simeon Morell

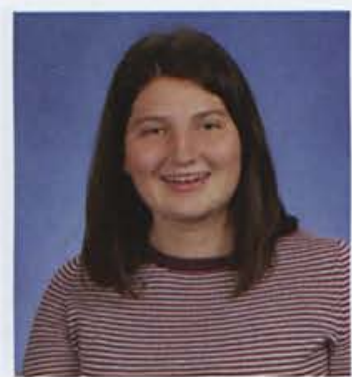

Victoria Mueller

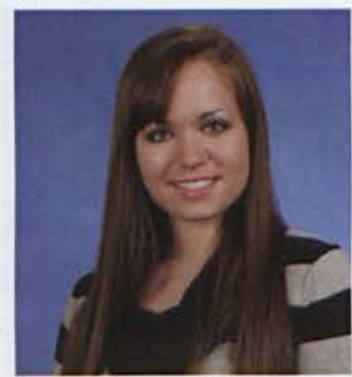

Emily Neville 


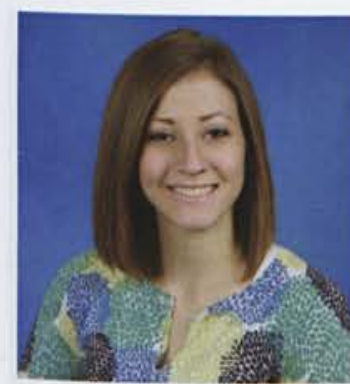

Elise Newcomer

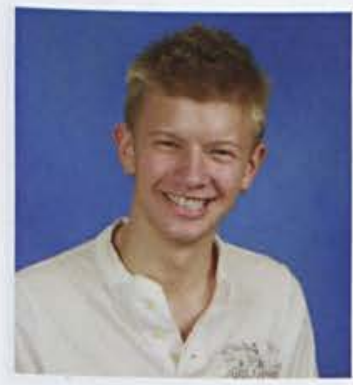

Caleb Nissley

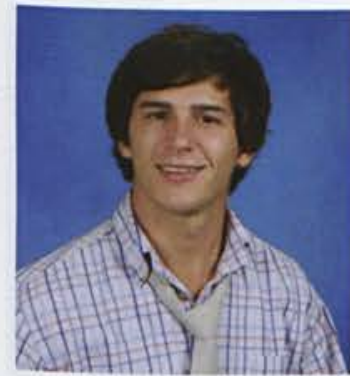

Troy Pancake

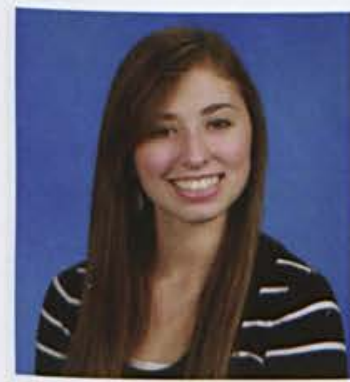

Sarah Pelletier

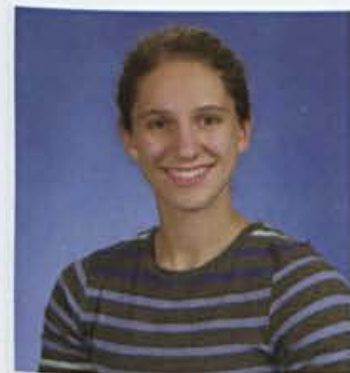

Breanne Peters

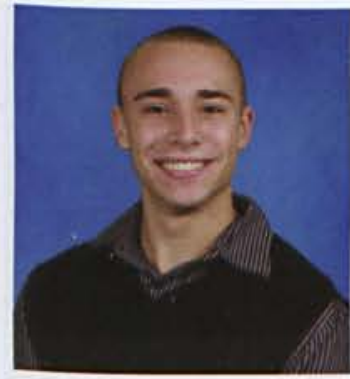

Benjamin Pickett

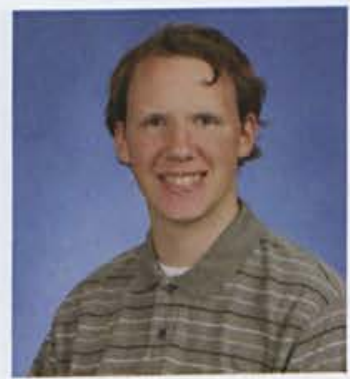

Joseph Newman

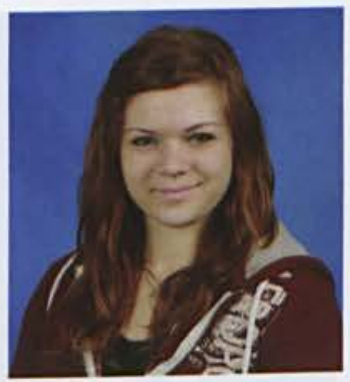

Krista Norris

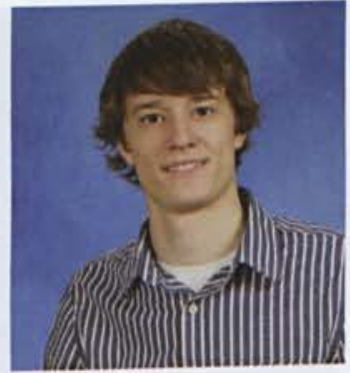

Joseph Parker

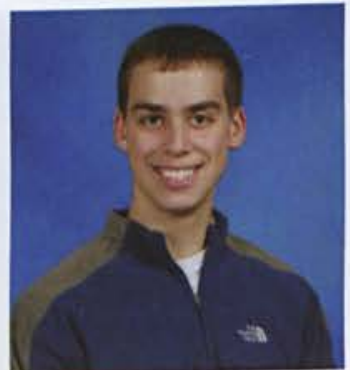

Michael Pelyhes

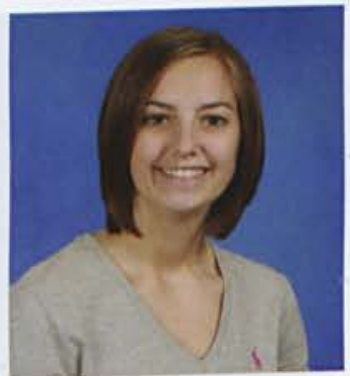

Ashley Peterson

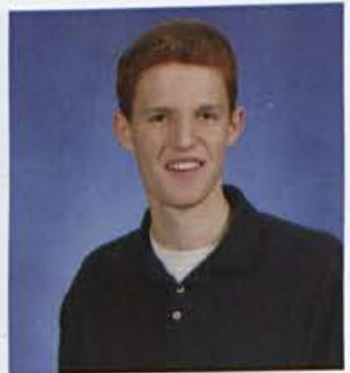

Nathan Pilling

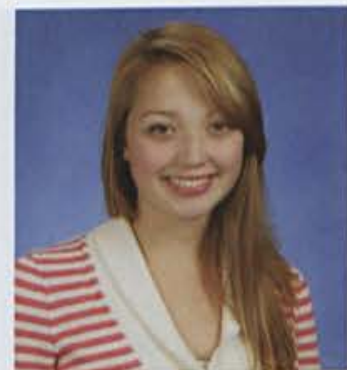

Kelsey Newman

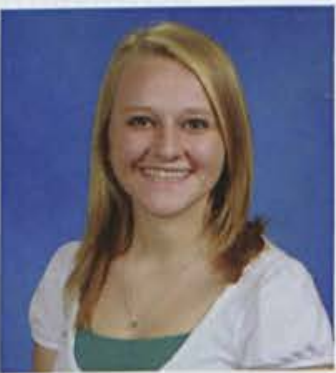

Allison Nygren

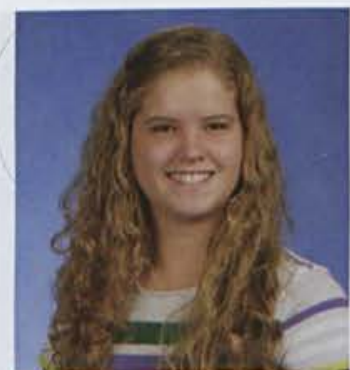

Kendra Parker

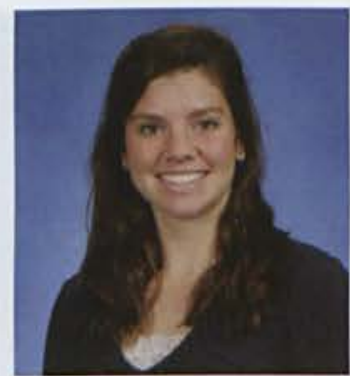

Victoria Pent

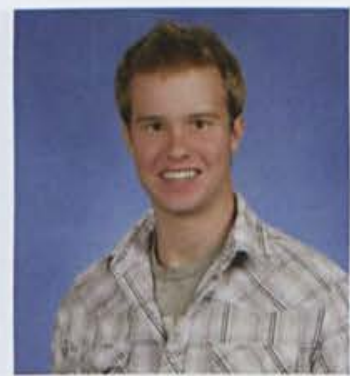

Dan Peterson

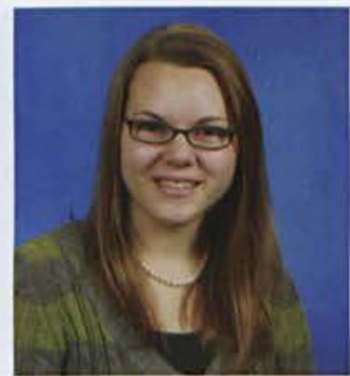

Marcia Pinkerton

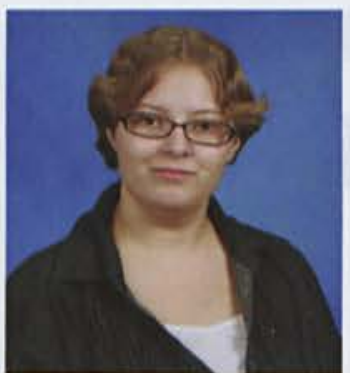

Rachel Niemi

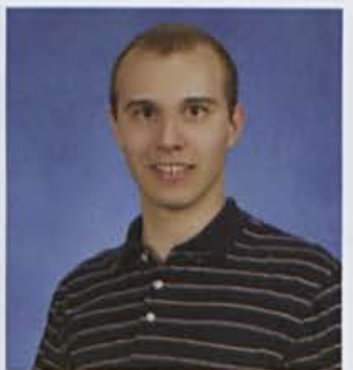

Nathan Paddock

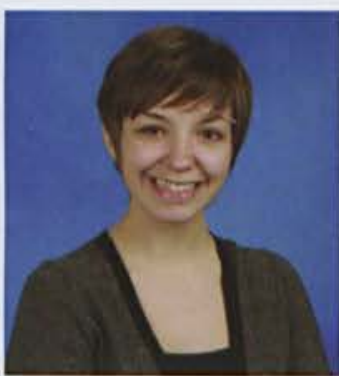

Brianna Parrish

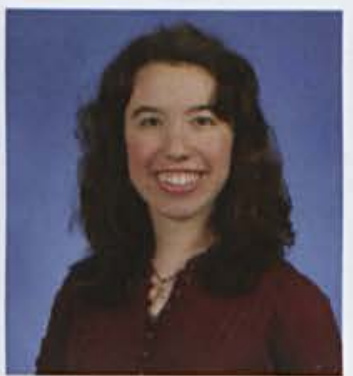

Kara Pernicano

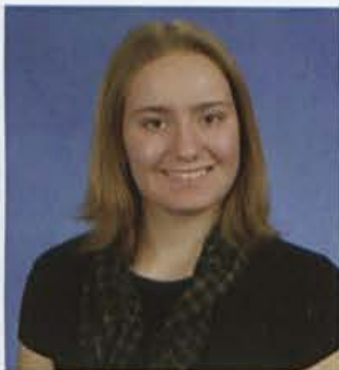

Gwen Phillips

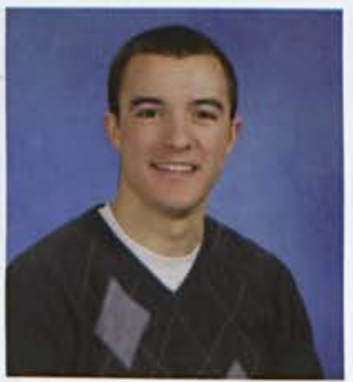

Andrew Porter

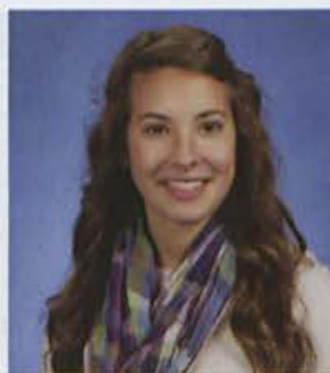

Kayla Nikkel

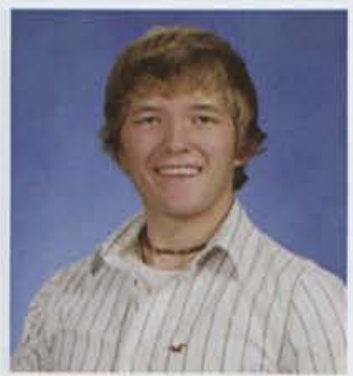

John David Paff

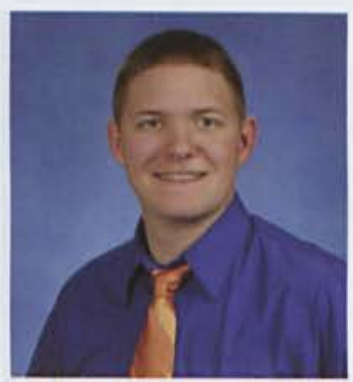

Daniel Paulsen

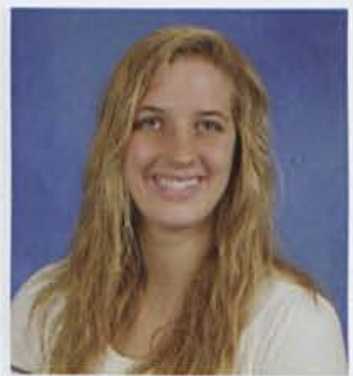

Danielle Petek

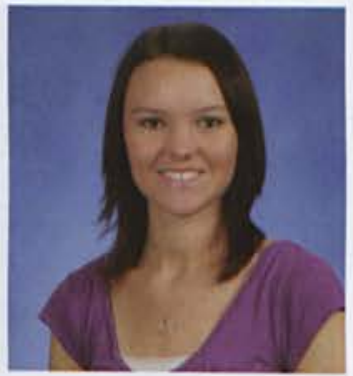

Rebekah Piasecki

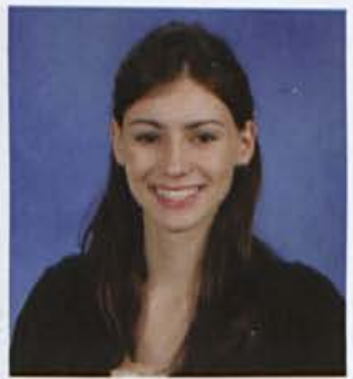

Chelsea Powell 


\section{FRESHMEN}

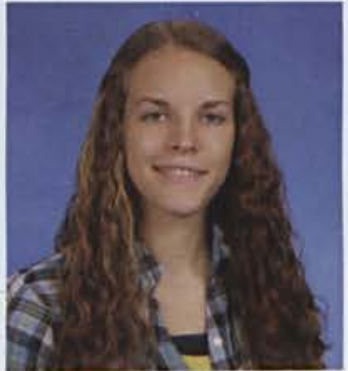

Rebecca Powlus

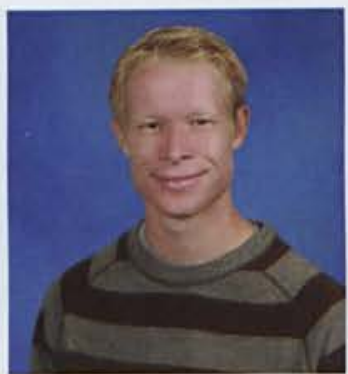

Eli Pyles

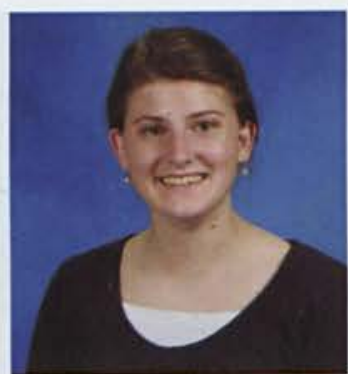

Molly Reich

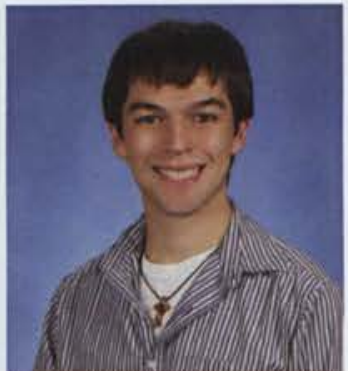

Adam Ripley

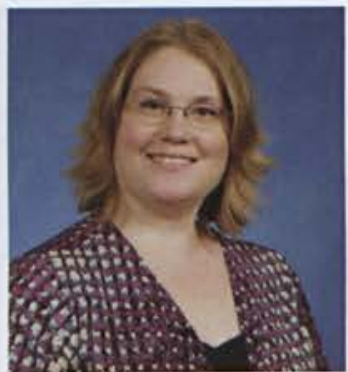

Amy Roy

Hannah Rostan

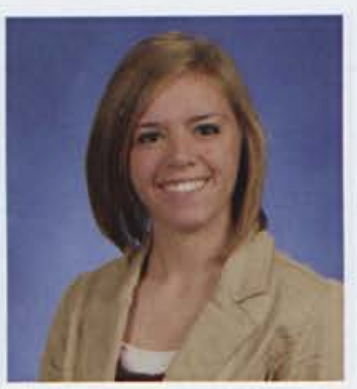

Sara Savard

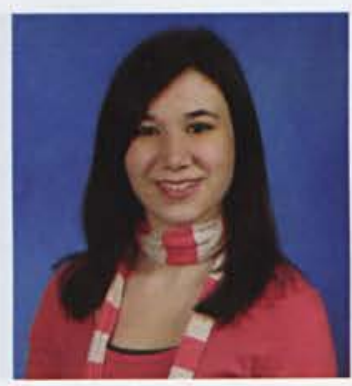

Rebecca Scarpone

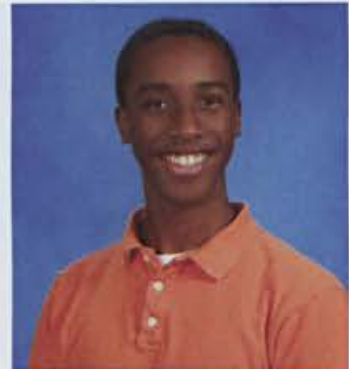

Walter Nathan Price

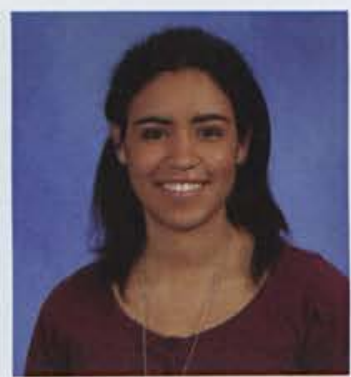

Andria Quirindongo

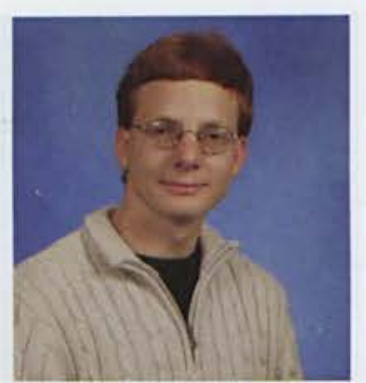

Samuel Reihmer

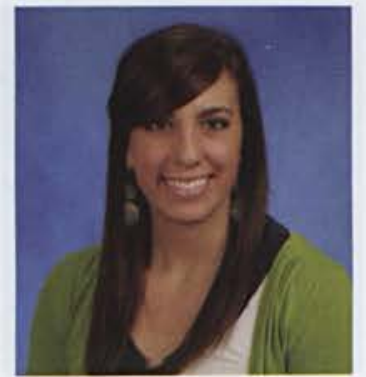

Stephanie Rogers

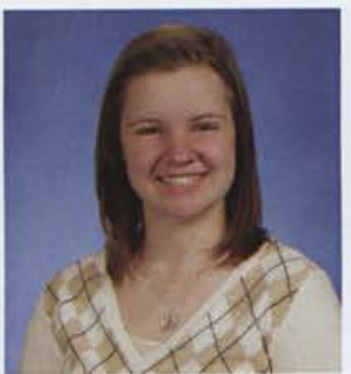

Amanda Rozelle

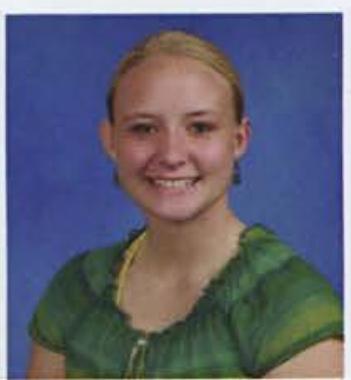

Allison Schaefer

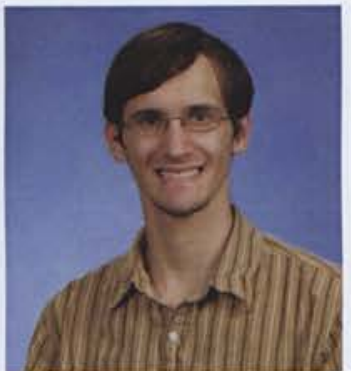

Jonathan Proctor

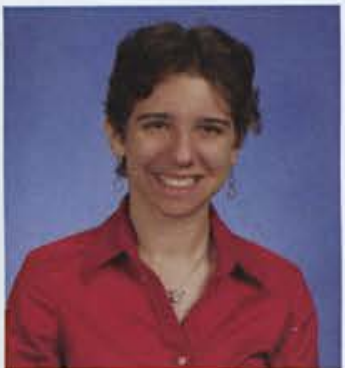

Lindsay Ramsland

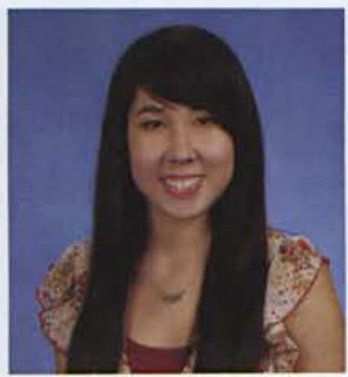

Crystabel Reiter

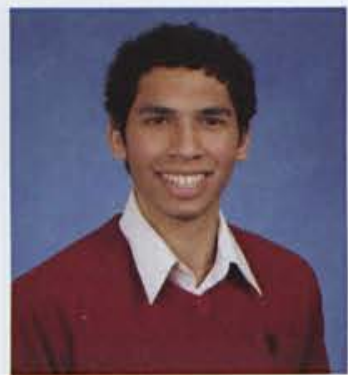

David Ross

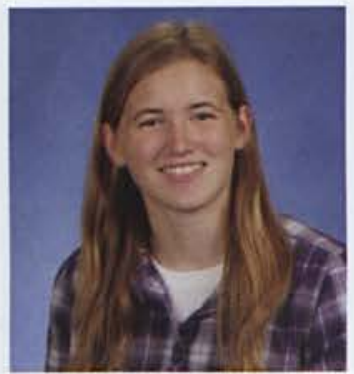

Brittany Santee

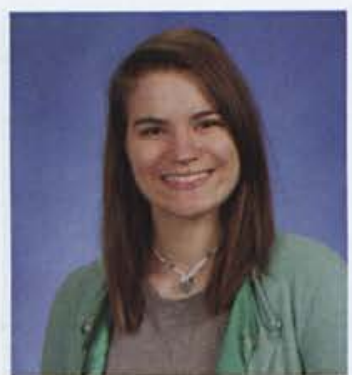

Lauren Schmidt 


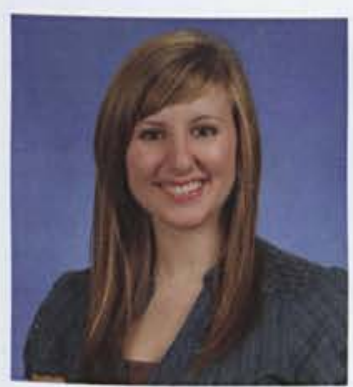

Brittni Schneider

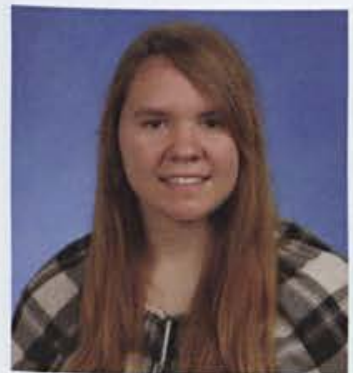

Kristi Schweitzer

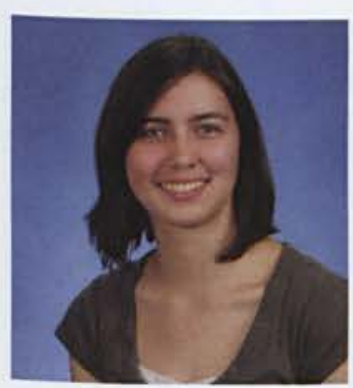

Melissa Seeman

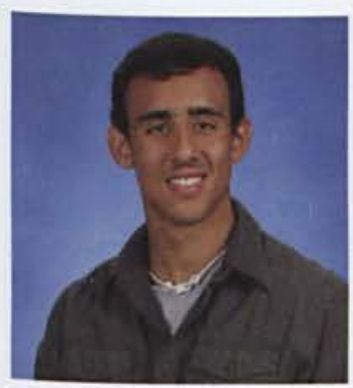

Eric Shomo

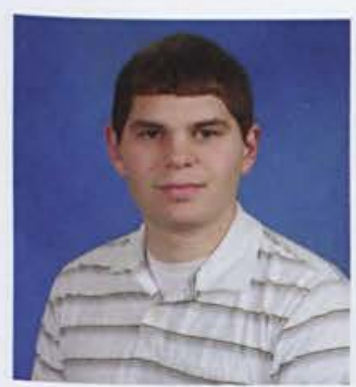

Jesse Silk

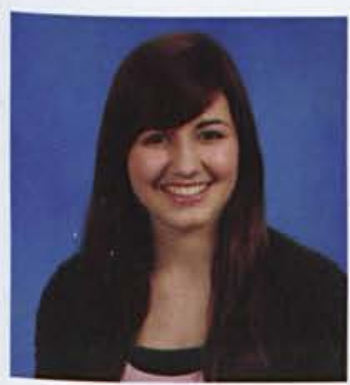

Kimberly Small

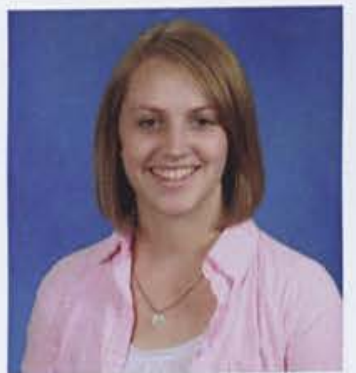

\section{Becca Schnepp}

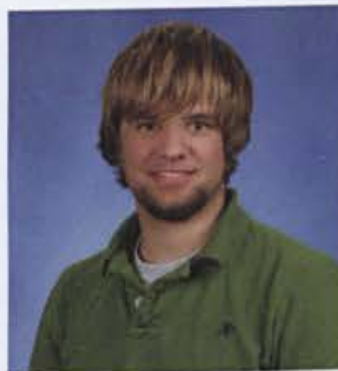

Austin Scott

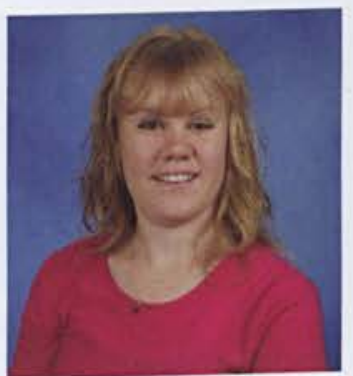

Jessica Settle

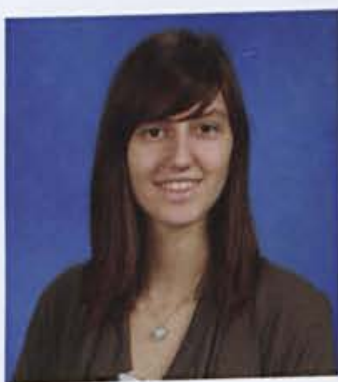

Kaleigh Shonk

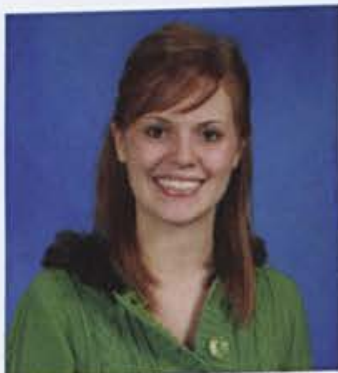

Rachel Silvey

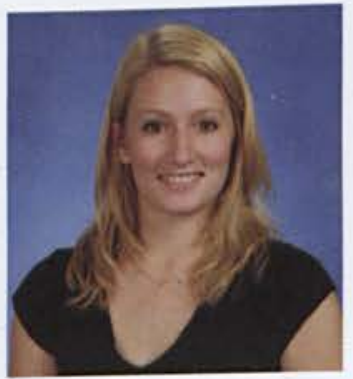

Brittany Smith

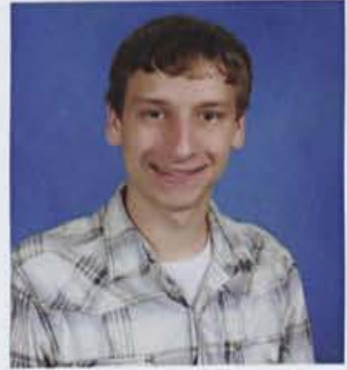

Matthew

Schoenwald

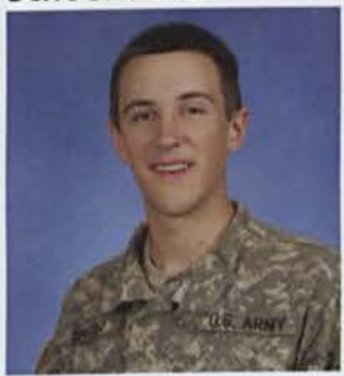

Paul Seabold

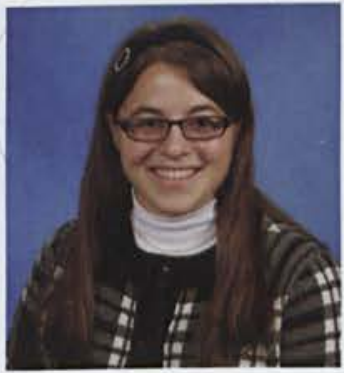

Rahel Seybold

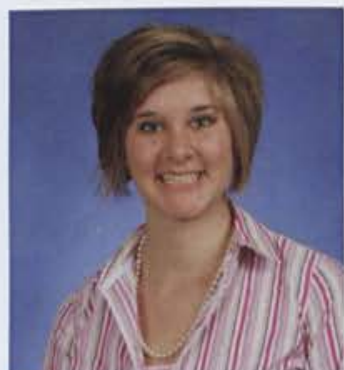

Amanda Short

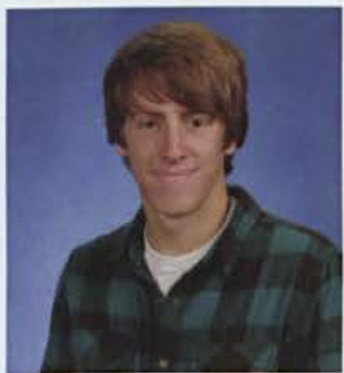

Jesse Sincock

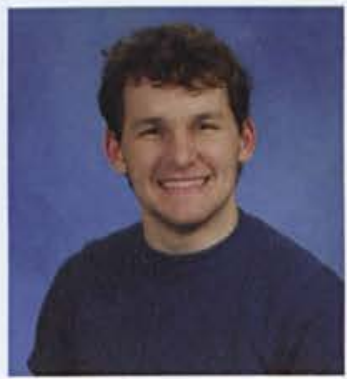

Caleb Smith

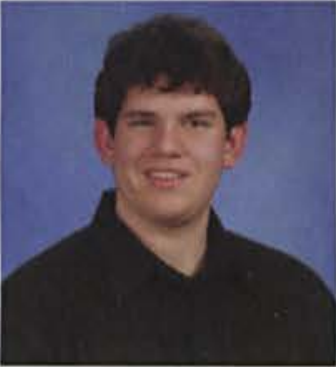

Niklaus Schroeder

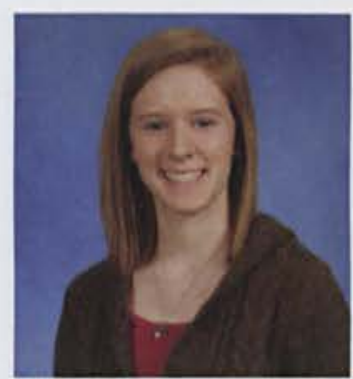

Emily Sears

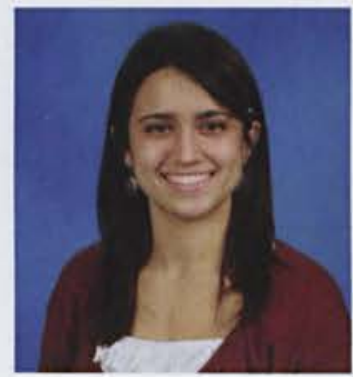

McKenzie Shenk

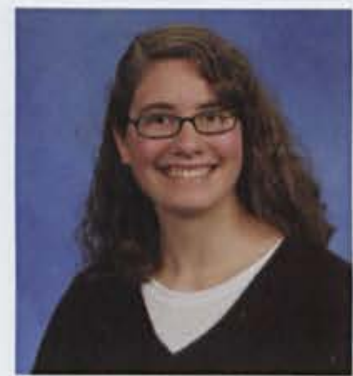

Ashley Short

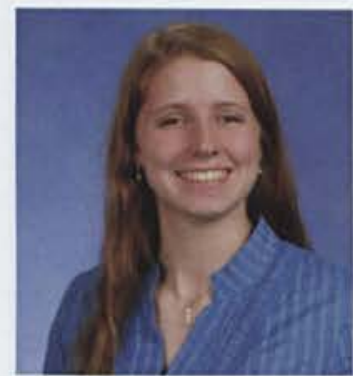

Adrian Sjoquist

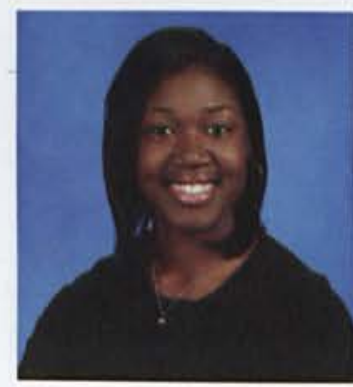

Courtney Smith

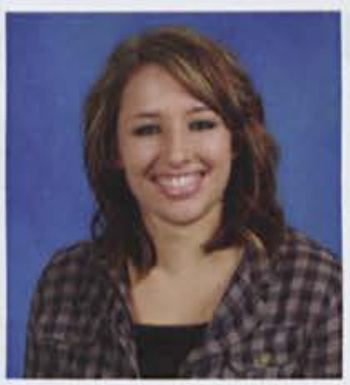

Carly Schumacher

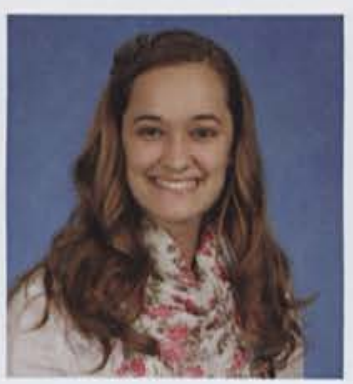

Caitlyn Seegers

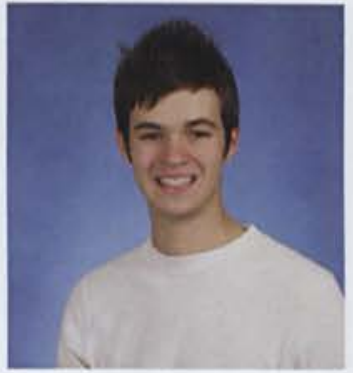

Michael Shoemaker

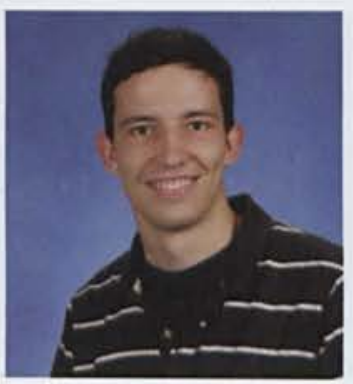

Caleb Shoulders

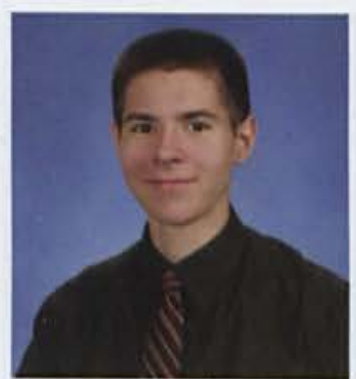

Joel Slabach

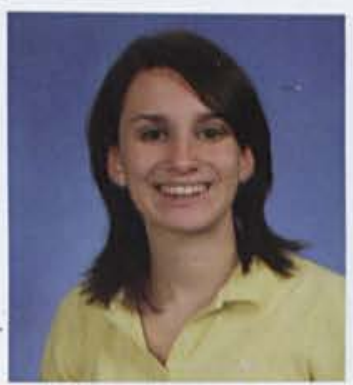

Lindsay Smith 


\section{FRESHMEN}

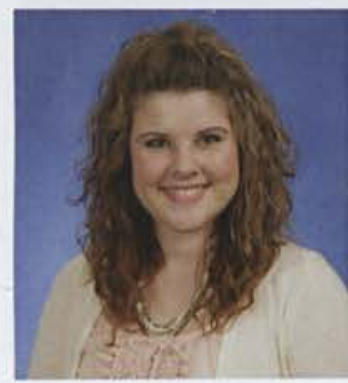

Audrey Snyder

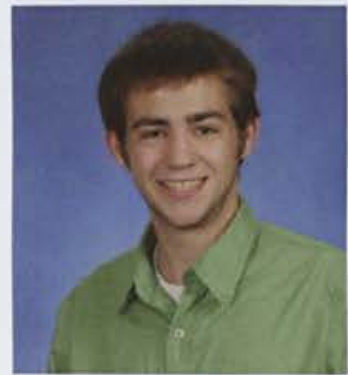

Luke St. Pierre

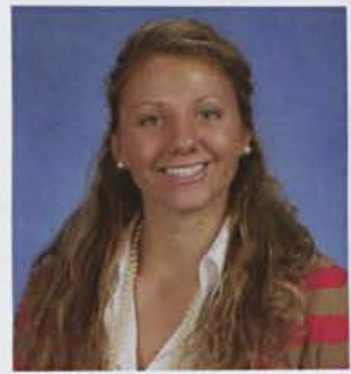

Alicyn Stein

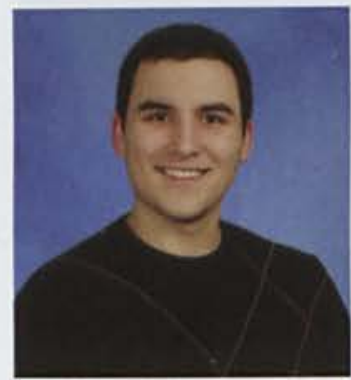

Oliver Straitiff

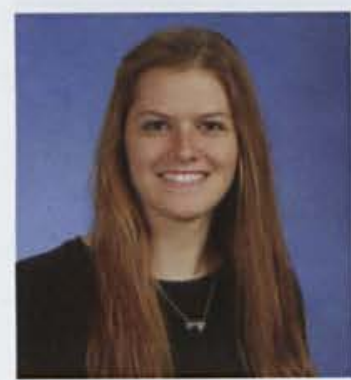

Kerith Sunden

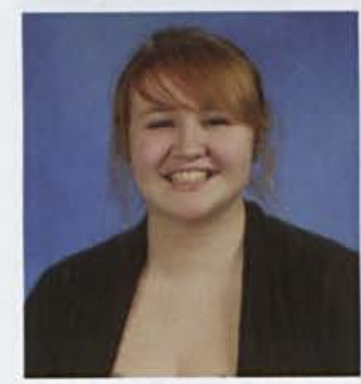

Ashley Thompson

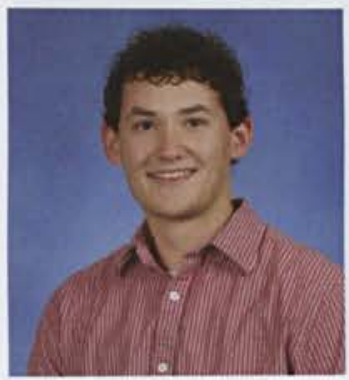

Pete Stack

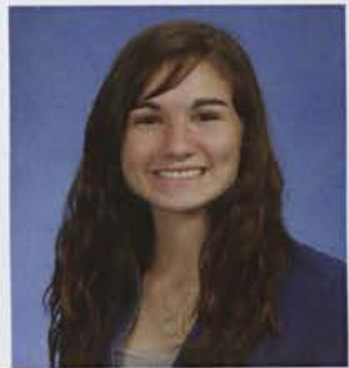

Suzanna Stern

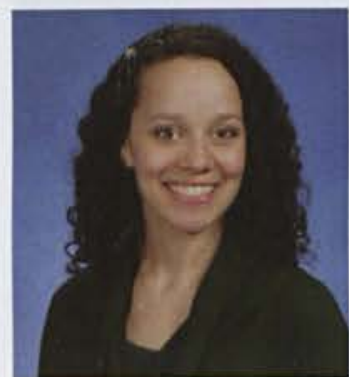

Hope Strayer

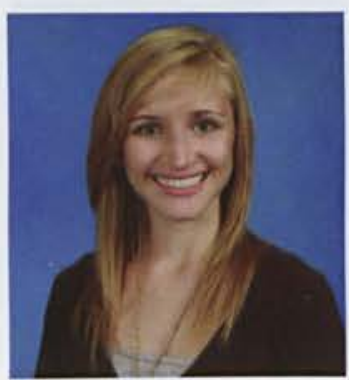

Emily Swanson

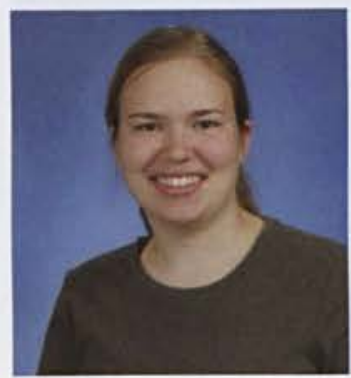

Julia Thompson
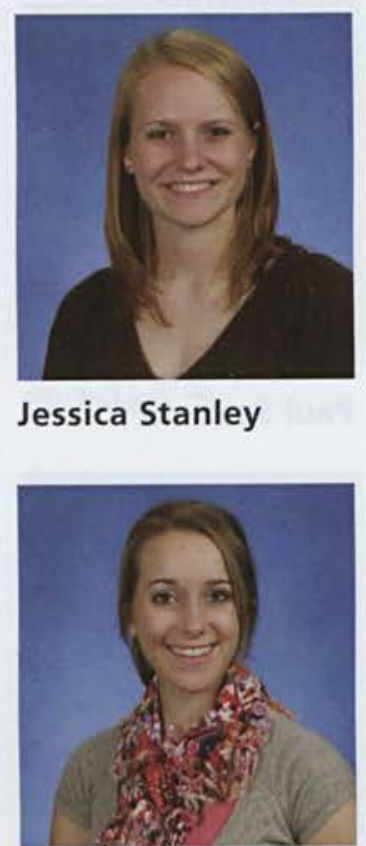

Jessica Stevanus

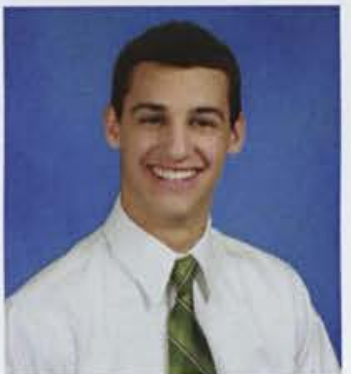

Caleb Strejc

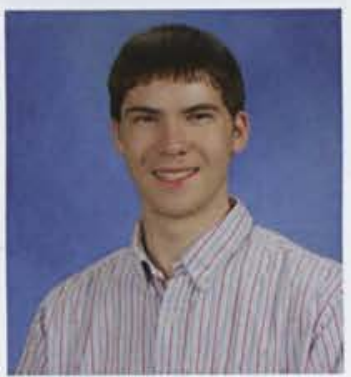

Cameron Swett

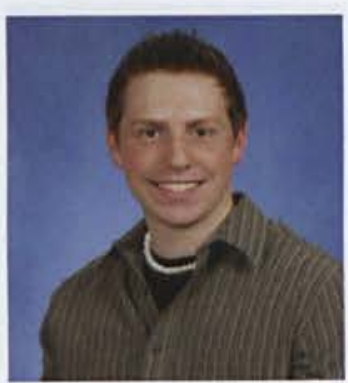

Kyle Thompson
Jessica Stanley

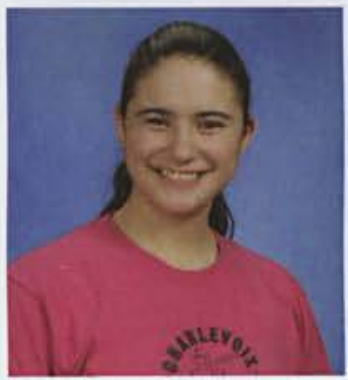

Jennifer Spann

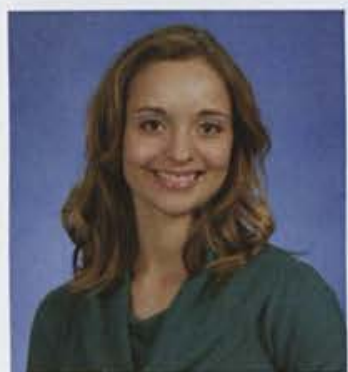

Audrey Stearns

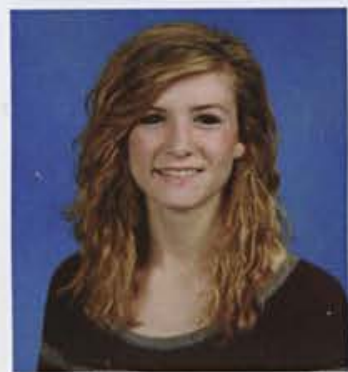

Lyndsay Stine

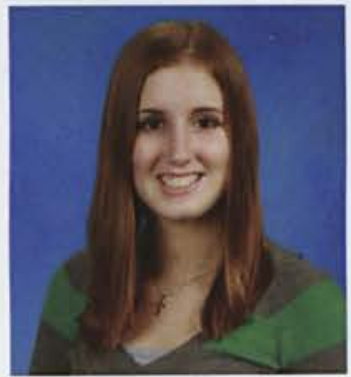

Cameron Sturgeon

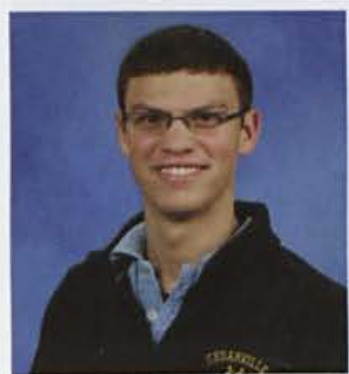

Joshua Taylor

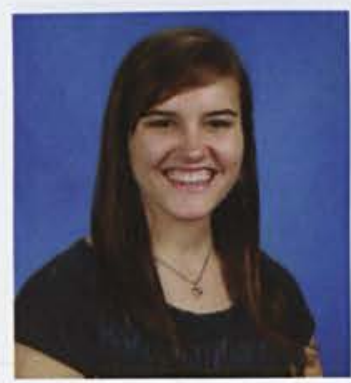

Abigail Toburen

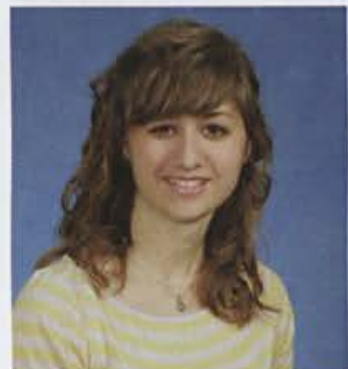

Olivia Speros

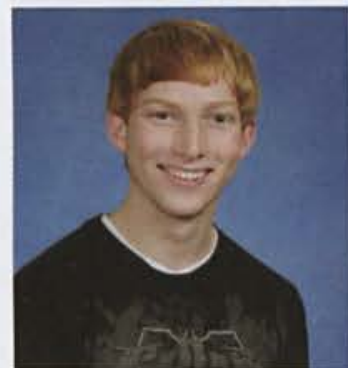

Andrew Stecker

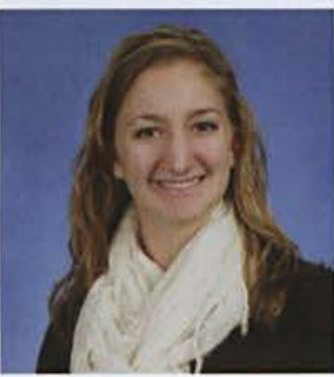

Katelyn Stover

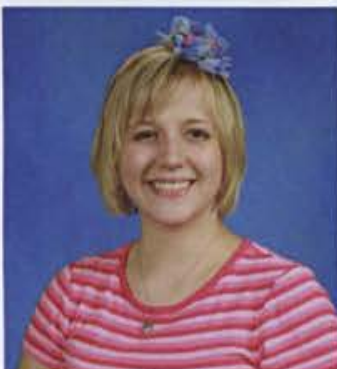

Kaitlyn Sturm

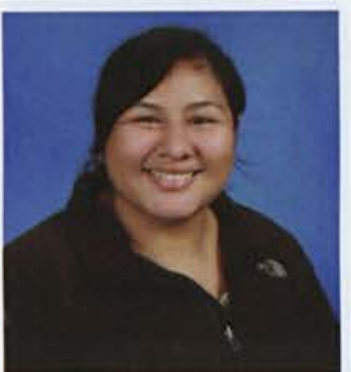

Melissa Terrazas

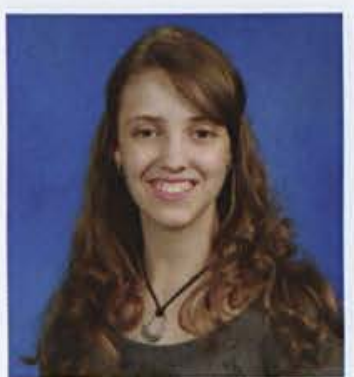

Abigail Tomlinson 


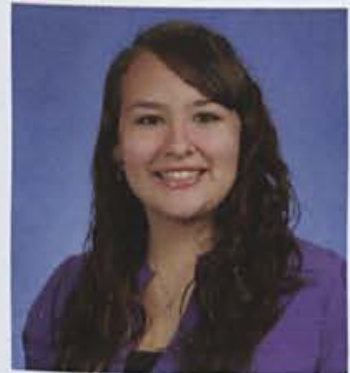

Alyson Torres

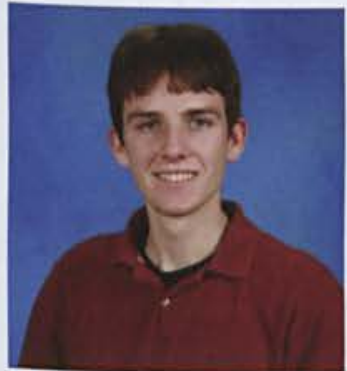

Vincent Van Dintel

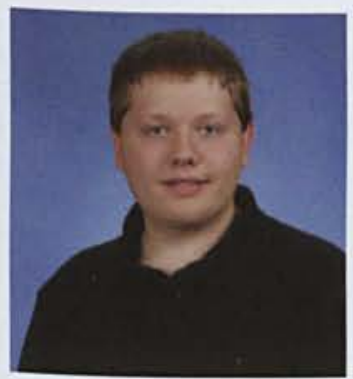

Zachary Wallace

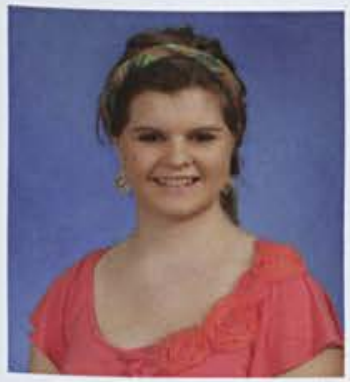

Jossee Weigand

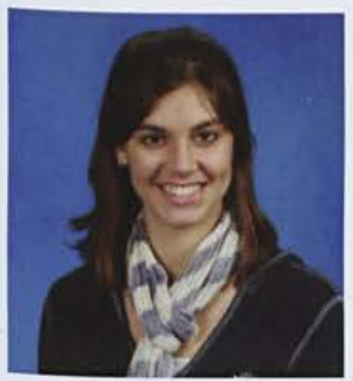

Marybeth Whitfield

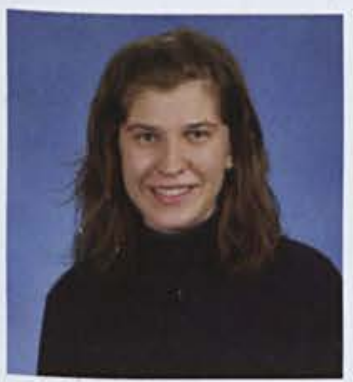

Jessica Willey

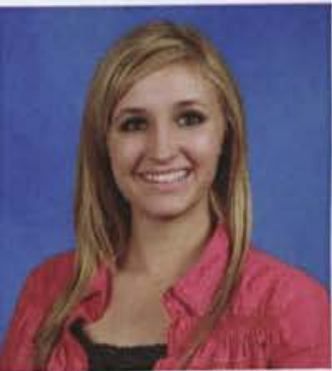

Madison Troyer

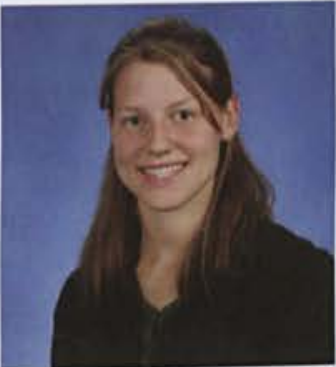

Claire Vanderhart

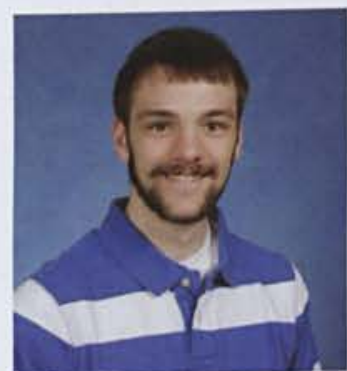

Samuel Walter

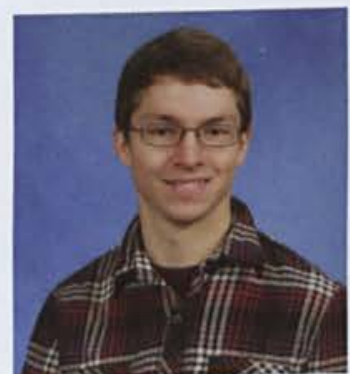

Matthew Welkie

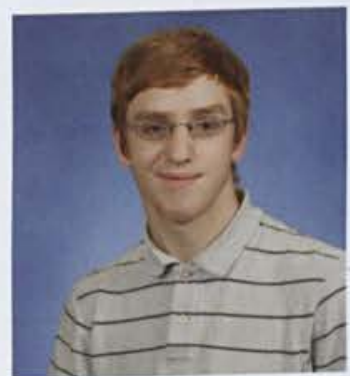

Donald Whittemose

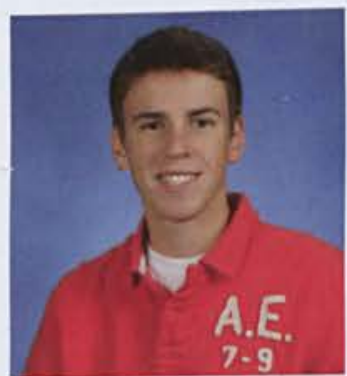

Brandon Williams

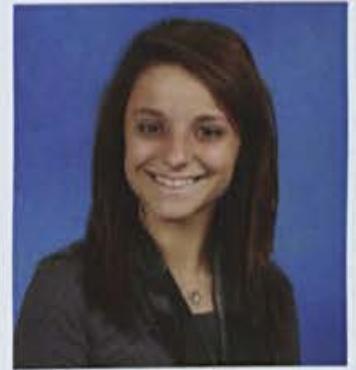

Lauren Trumble

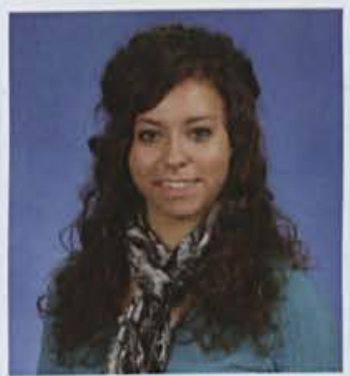

Tara Venturini

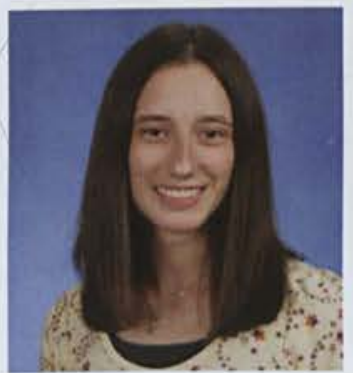

Chelsae Ward

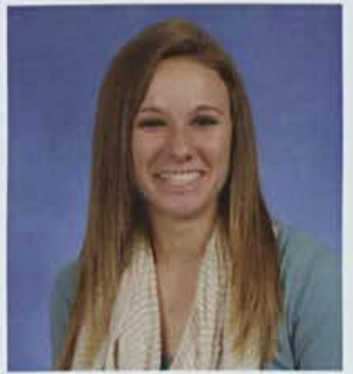

Kara West

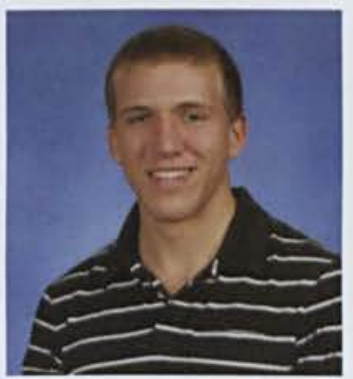

Joel Widman

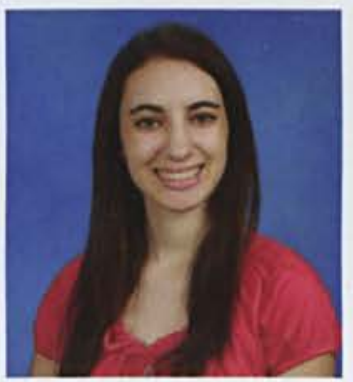

Kaitlyn Williams

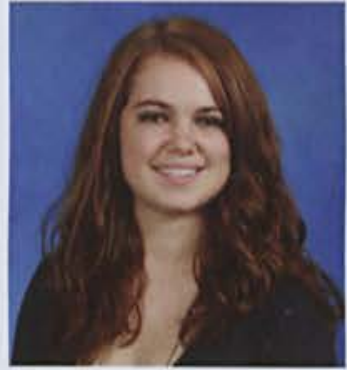

Colleen Trump

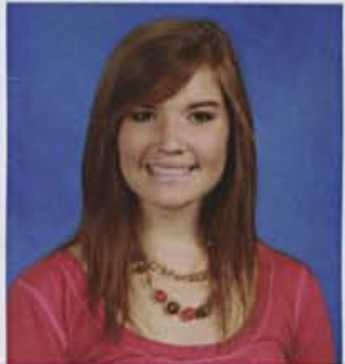

Korinna Waggoner

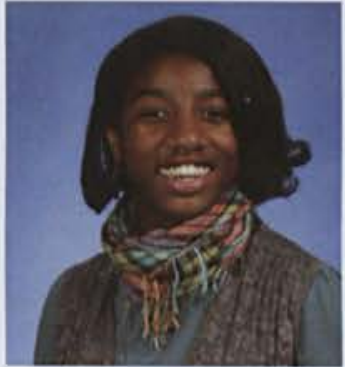

Jerielle Ward

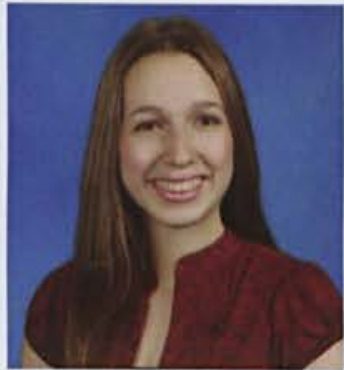

Krissa Weyandt

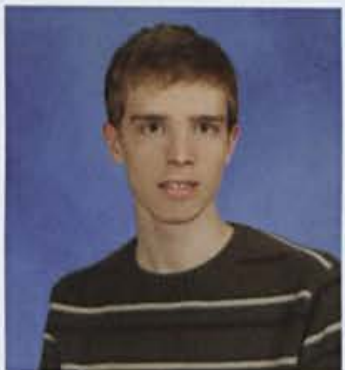

Patrick Wilkie

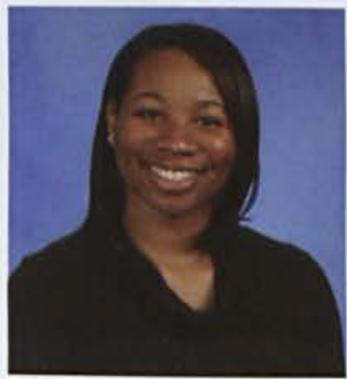

Lauren P. Williams

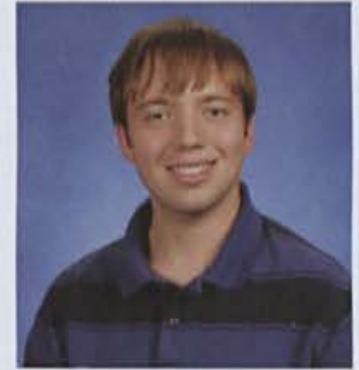

Brennan Ujcich

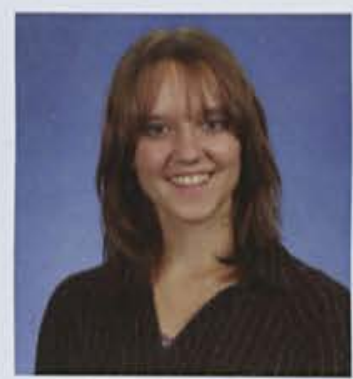

Chelsea Walker

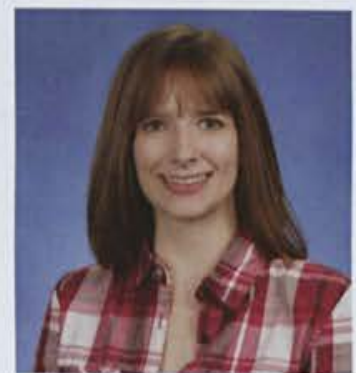

Ashley Warner

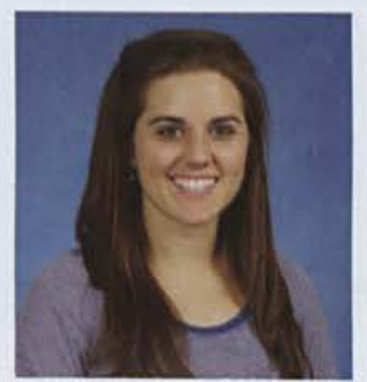

Joanna Wheatley

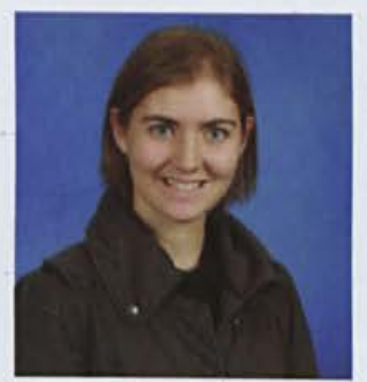

Megan Willeford

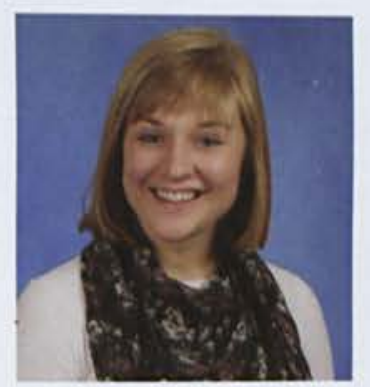

Bethany Wilson 


\section{FRESHMEN}

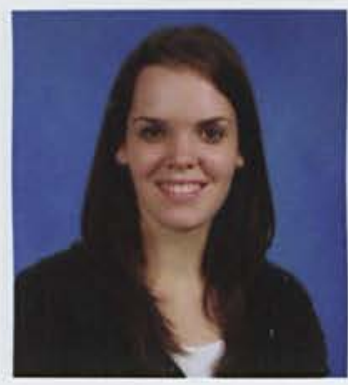

Amy Witt

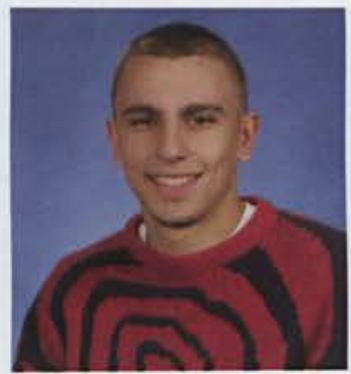

Zachary Wurst Cronrath

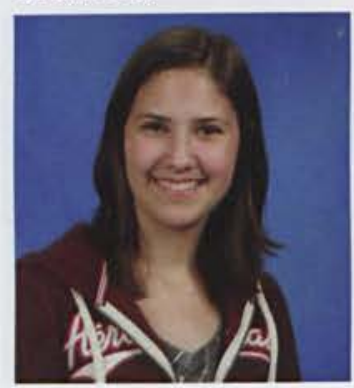

Grace Ziegler

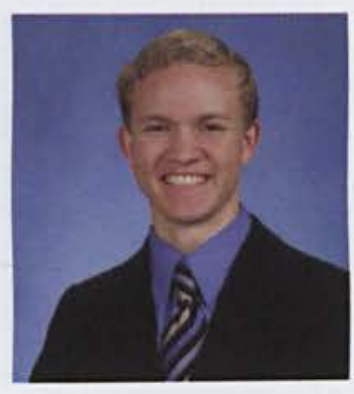

Benjamin Winston

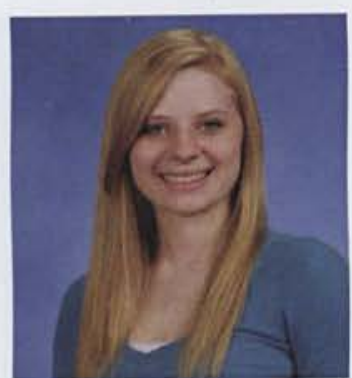

Susanna Woolston

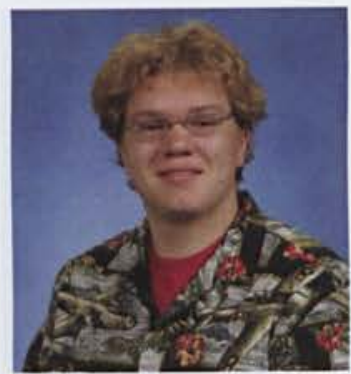

David Yoder

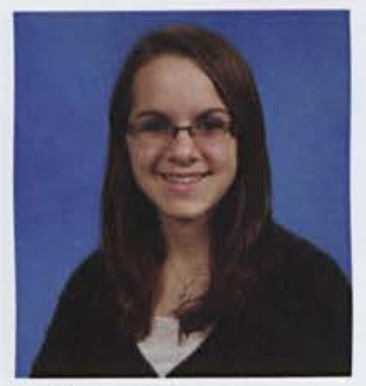

Kelsey Winters

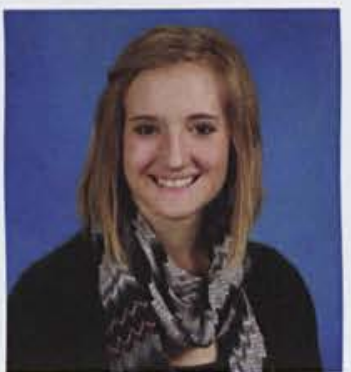

Lauren Wright

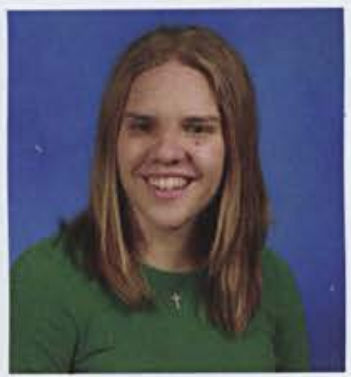

Marissa Yorgey

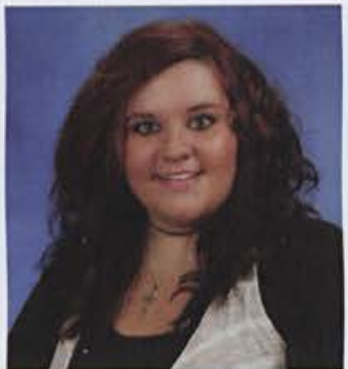

Kadie Wisniewski

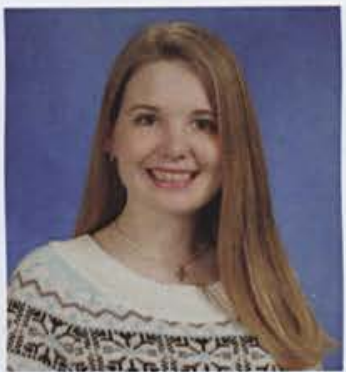

Rebecca Wunderlich

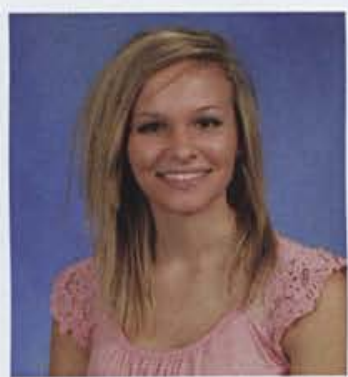

Tiffany Zehel 


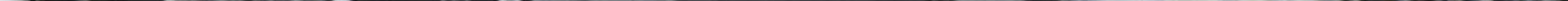




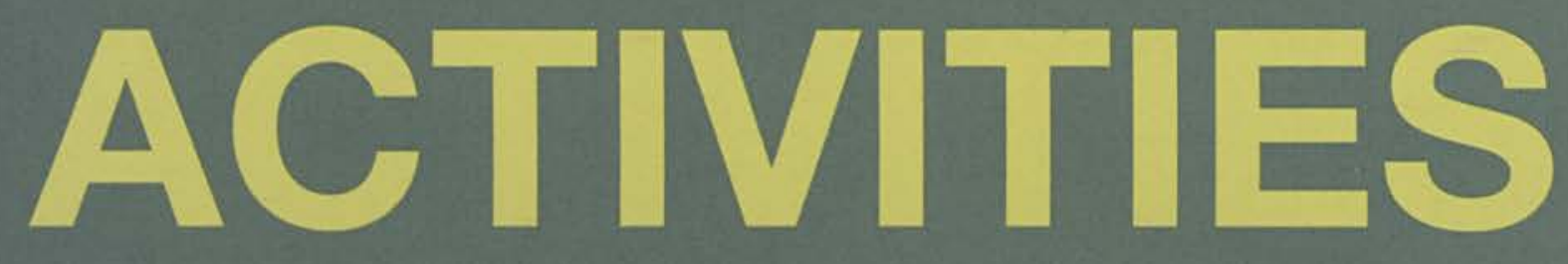

noun, plural |ak-'ti-və-tēs \Opportunities for involved students; symptoms include a closet full of Cedarville t-shirts and a dailyflooded email inbox. 


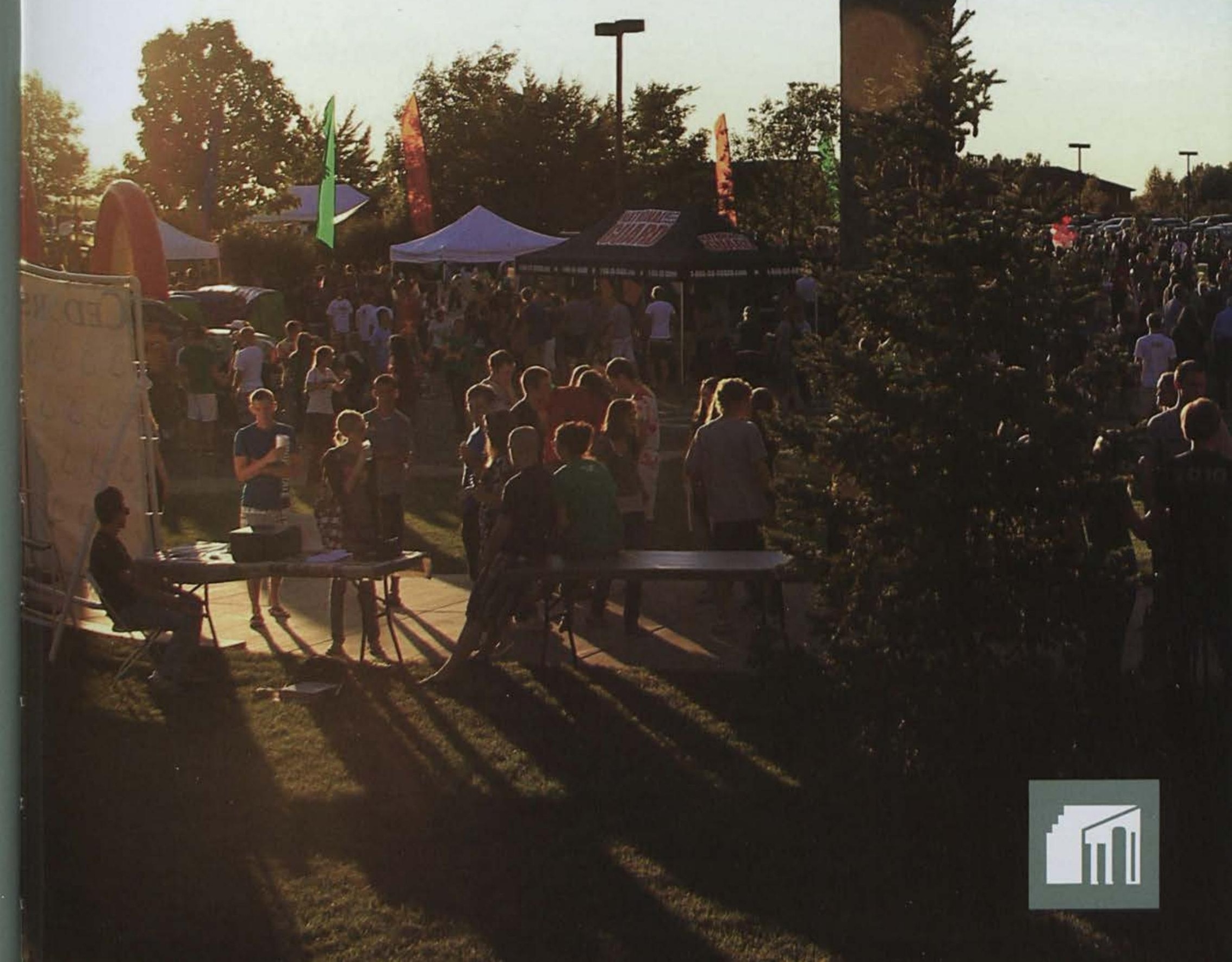




\section{CHAPELS}

Cedarville's Chapels this year featured several memorable speakers. Local pastors, like Rob Turner, pastor at Apex Community Church, and David Smith, pastor of Fairhaven Church in Centerville, spoke to the student body. Dr. Brown used almost every Monday to encourage students on "Real-World Impact." He gave the students insight on how to answer some of the tough questions that could be brought up by non-believers or questioning believers, as well as addressing other great topics.

This year, a favorite chapel speaker was Gianna Jessen. Gianna Jessen, a failedabortion survivor, showed her fiery passion for life in the short time she spoke in chapel. Jessen stated she is grateful for every day that God had given her, and she has dedicated her life to making every day His. Lisa Dykes said, "I really enjoyed hearing her speak because she spoke about not wasting your time on men you have to make excuses for."

Mary Armstrong described her appreciation for Will Schenck. Armstrong appreciated Schenck so much because "he was from an industry we don't often hear about in chapel: Rolling Stone magazine and then fashion. He really embodies the 'real-world impact' Cedarville strives to teach its students."

Other chapel speakers challenged students on an intellectual level, forcing them to integrate biblical learning with secular issues. Ken Ham offered some advice to students: find answers to all questions in Genesis. Mark Yarhouse presented Christian research on a well-publicized subject: homosexuality and who it impacts, as well as what the how the church should respond to an individual struggling with same-sex attraction.

With Justin Spann heading up worship, Cedarville made an effort to add more One Voice chapels, and the students overall really enjoyed this addition. Whether through its music or messages, chapel made an impact on Cedarville students so that they could, in turn, impact their "real worlds."

1 Rob Turner embraces Cedarville culture in a plaid shirt while speaking words of wisdom to the students during chapel. 2 ROTC honors the United States flag during the Pledge of Allegiance and the singing of the "Star Spangled Banner" for Veteran's Day chapel. 3 Dr. Bill Brown shows off his school spirit for the upcoming basketball Gold Rush game to encourage students to go. T-shirts aren't allowed in chapel! 4 OneVoice choir leads the student body in worship during the yearly Once Voice chapel, directed by Justin Spann. 


\section{STUDENT-LED CHAPELS}

While student-led chapels had several things in common, each brought something unique to the stage of Jeremiah Chapel.

The freshman class officers' goal was to stick out and be different. "We wanted to be different from normal chapels," Joel Israel, freshman class chaplain, said. For their spring chapel, the class gave away Rinnova gift cards to anyone who could find one of several pairs of flip flops hidden under the pews. But Israel said the biggest change was probably having worship songs after the message.

Matt McDonald, junior class chaplain, said their officers' goal for chapel was to focus on our relation to God. A highlight for McDonald was hearing when his message made a difference in a person's life. "It is so amazing to have testimonies in which the Word of God influences the life of a person in such a way that they change their actions or beliefs in order to glorify God and magnify His name," McDonald said.

Sophomore Class Chaplain Christian Figueredo said he wanted to make sure his messages were focused on God and the Gospel. How did he pick his topics? "Pastor Rohm probably actually gave me the best advice on that," Figueredo said. Since class chaplains only get to speak twice a year, he said Rohm told him to choose something he was passionate about and something he was learning in his own Bible study.

The senior class wanted to keep each chapel centered on a theme, Craig Hefner, senior class chaplain, said. For example, they ended with music so that they could fit it into the theme of the message.

SGA chapel had everything from Star Wars references to the ever-loved chapel movies. But it had more than that. Bob Rohm, Vice President for Christian Ministries, said SGA Chaplain David Moser was able to go deep but still relate what he was speaking on to students' lives. "David is, I think, a brilliant young man who has a passion for God's Word," Rohm said.

"They are alwyas

uplifting and

encouraging. They're

fun to watch and give

me another reason

to look forward to

Fridays."

(Sean Powers)

1 "We tried, as best as we could, to make the chapel flow in a way that made sense and followed our theme for the chapel," says Craig Hefner, senior class chaplain, on delivering his message to the student body during a senior class chapel. 2 Sam Charlier leads guitar in the sophomore class worship band, playing "We Fall Down" by Chris Tomlin, as students sing along. 3 The senior class worship band leads the Cedarville community in praising God at a senior class chapel with music tailored to the chapel message. 4 Sophomore Class Chaplain, Christian Figueredo, makes his point to attentive listeners at a sophomore class chapel. "You can't bootleg The Passion," he claims to illustrate his point. 


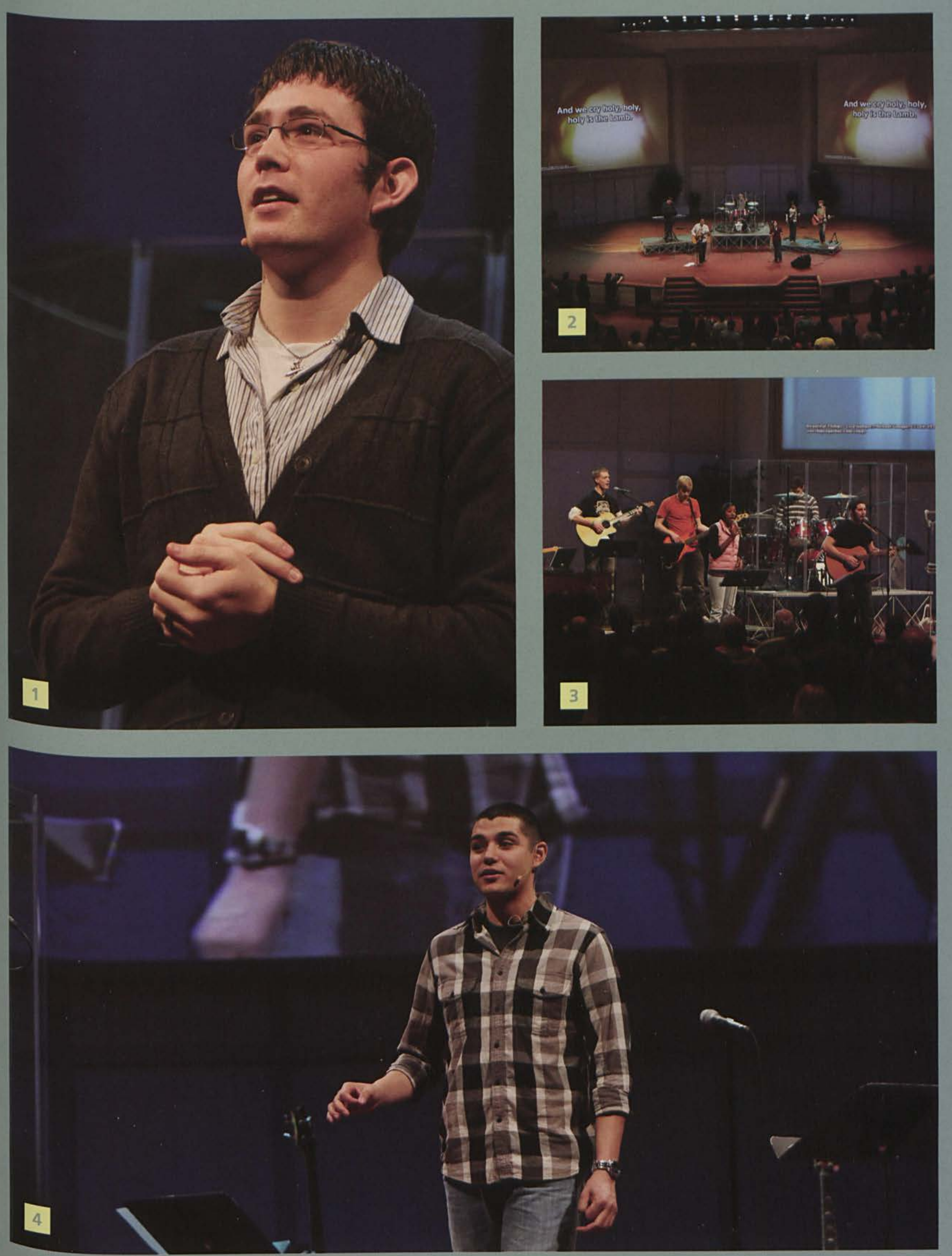




\section{CLASSES}

The thrill of college life begins in mid-August when the flurry of campus events fills up a planner before we can even realize it. Intramural sports, Interruptions, chapel, orgs, friends, ministries - the possibilities to get plugged in and active at Cedarville are endless. And then, it happens: classes start, and all that free time we students once had to fill with extracurricular activities no longer exists. Classes are the core of Cedarville and receiving an education. One class that challenged students to think in a manner much different from what they were used to was "Intro to Urban Ministry." This class, though not required by most majors, gathered an assortment of students, some filling electives and others simply interested in Urban Ministry. Nathaniel Bond encouraged even prospective students to take the class, which may be getting a little ahead of the game.

Professor TC Ham started his career at Cedarville this year by taking over some of the Old Testament courses usually taught by Dr. Miller, TC, as he was often referred to by his students, carried on the passion for OT literature found in Dr. Miller's classes and poured that passion into his students' study of the Old Testament.

Bible courses weren't the only ones with such an positive influence on students, however. Dr. Melissa Faulkner's Design of Manuals class wrote a manual in spring semester entitled "Air National Guard Family Guide." This manual providesd critical information for the families of Air National Guard members. John Michael Mumme said, "Writing this manual, my classmates and I had the unique chance to work for something beyond a grade. Knowing that what we were writing would be useful and encouraging to all the members of the Air National Guard, seeing the appreciation Mr. and Mrs. Muncy expressed, made the long and stressful hours of writing this manual more than worth it."

\author{
"I'm even planning on \\ taking his Development \\ class next year because I \\ enjoy his teaching style \\ so much. You can really \\ tell he likes what he's \\ teaching," \\ (Malia Amling \\ on Bible Professor \\ TC Ham)
}

1 Cindy Wingert explains directions to her biology lab using hand motions; perhaps that helps with clarity. 2 Michelle Blackstone studies her subject during Painting class with Professor Aaron Gosser. The class utilizes the spring weather and has class outside of Fine Arts. 3 Students in Professor Hwang's Psychology class take careful notes for studying later, since they may be the best device to help get the much-sought-after "A." 4 Dr. John Silvius take his biology class into the field, literally. Students journey through the grass during their field trip to complete a Prairie Field lab. 


\section{WOMEN'S RESIDENCE LIFE}

Residence life has been an integral part of Cedarville University. Women's residence halls were often the center for socialization. Community lounges filled with groups looking for an area to watch a movie or hardcore game-watchers staring intently at the TVs. During those special times each semester-open dorms - the women in the residence halls were well aware of the massive amount of cleaning before the men could enter the world of women.

Beyond the normal everyday activities, the women appreciated the events that were arranged for the whole dorm to enjoy together. For example, the annual Printy Wars involved much planning, and they would often break campus quiet hours. All of the girls gathered in the parking lot every year, and units battled each other through exciting games headed by the RAs. Only the strongest and most creative girls could win. Lawlor boys as well as other girls' dorms gather ed to watch as Printy girls dressed up in costumes and performed tasks such as passing an orange by the neck or passing a sponge full of water without squeezing. Printy also started the PMS panel this year: Pressure, Men, and Self-Image. This panel called in speakers like Dean Gibbs to speak to the Printy girls on current issues about these three topics.

Willetts enjoyed their first Printy-like experience as the girls also competed in battles against each other, from "best toilet paper mummy" to high-heeled egg-passing races. Willett's Wazoo was able to push the girls to the limit and create a new atmosphere of competition.

From costumes and competitions to prayer and laughter, the women's residence halls never experienced a dull moment. The women of God molded at Cedarville University will hold on to their experiences and relationships formed for years, even if it started with a competitve spirit over a Printy-Maddox football game.
"Between decorating
for Campus Christmas
and random late
night fire alarms, you
develop relationships
with people you
otherwise never
would!"
(Micaela Buesgens)
1 Wait, what are those boys doing in here? Oh, it must just be open dorms, the one time males are allowed inside the hallowed halls of the girls' dorms. 2 Sandi Patton and her friend Whitney Caudill share some time together while Whitney visits Cedarville. Visitors often enjoy the welcoming atmosphere of CU. 3 TV lounges give groups of students a chance to take a break from studying to watch Glee or American Idol. 4 Heather Cox enjoys a night of board games with friends: a healthy alternative to all-night study sessions.




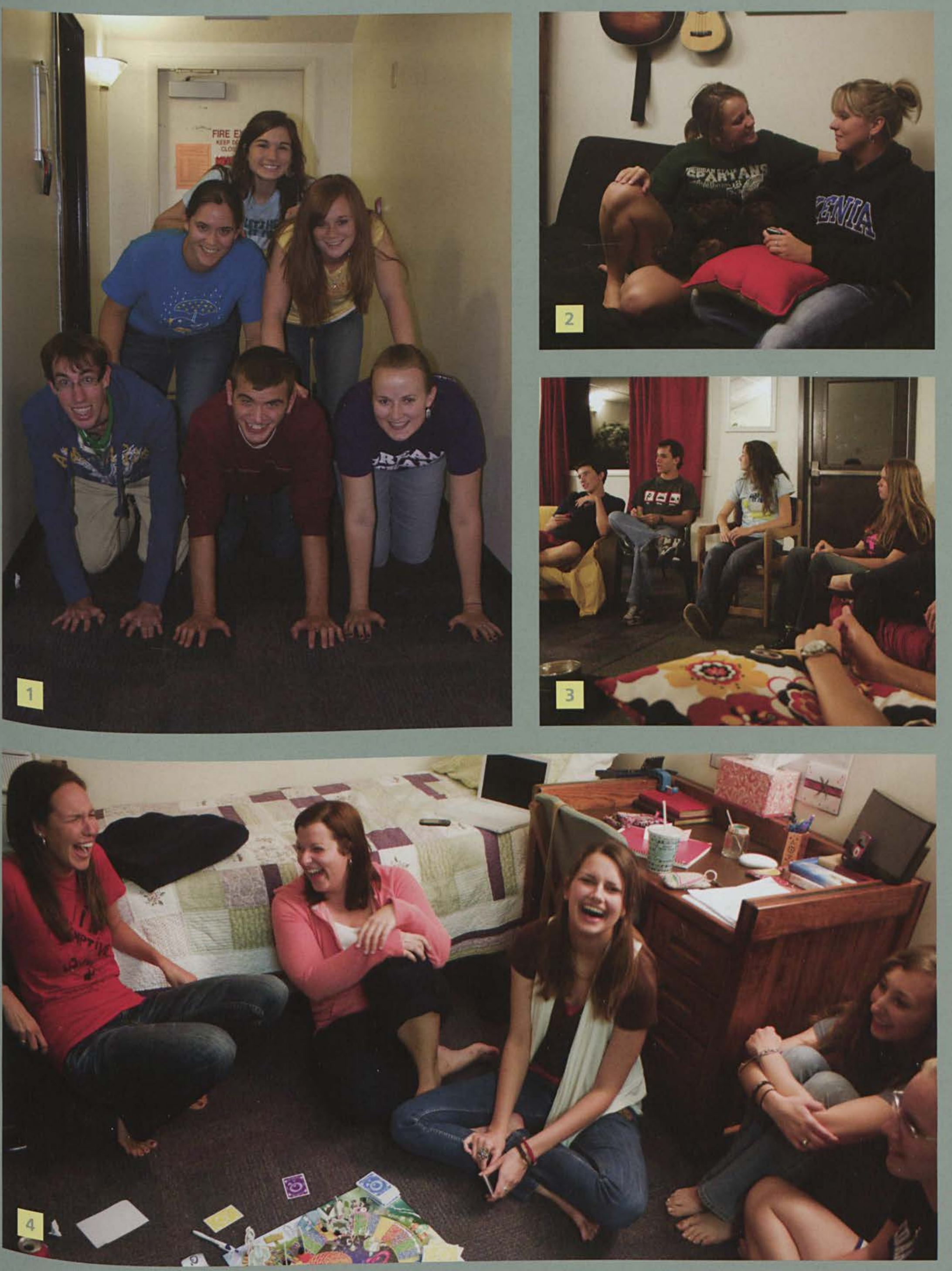




\section{MEN'S RESIDENCE LIFE}

When more than one thousand guys are trying to make it for nine months in a small, Ohio town on an even smaller college campus, there is bound to be both some great times and some challenging ones. Cedarville's men's residence life had both.

As for fun, several men's dorms stuck with tradition. Residents of Lawlor Hall participated in events such as Lawlorpalooza and Lawlor $(K)$ night. At Lawlor (K)night, Rob Turner, pastor at Apex Community Church in Dayton, spoke about biblical manhood.

"We didn't try to break much new ground this year," said Anthony Mandela, Resident Director of Lawlor. "We continued with the dorm events that have worked well for us in the past and have been encouraging and enjoyable for the guys." He described life in Lawlor as "Brotherhood. Growth. Fun."

Other men on campus had some spontaneous fun as well. When an ice storm hit Cedarville and school was canceled, the guys on the Hill decided they were hungry. "We kind of did a dorm-wide Rip Run," the Hill Resident Director, Adam McCune, said. He claimed they cleaned out the store. Likewise, for fun, Rickard residents participated in Man Week, where they lived like men for a week, as if that were much different than every other day.

In addition to fun, Cedarville men also had to deal with some challenges this year. Those at the Hill had to prepare to live in a renovated version of their dorm. "There's been some community challenges just in preparing for this big building change," McCune said.

The way guys at Brock dealt with challenges was the favorite part of the year for Justin Dodson, resident director. He said there is nothing greater than a man who has the humility to admit he needs help and another man coming alongside willing to invest in his life. "That is not just Student Life, but real life beyond Cedarville, and there is nothing I love more than seeing people dig into each other's lives in significant ways so that they continue in that when they leave here," Dodson said.
"At 1 a.m., Marshall 3 comes alive. These bonds and memories are forever forged in the book of my life." (Dan Bidlack)
1 Looks like this squad of superheroes is ready to protect Lawlor from any foe. 2 These well- armed boys look ready to take on any invaders that managed to get past the superheroes outside. 3 Guitar players, like John Teat, abound in the dorm, often filling the halls of the men's dorms with (sometimes) beautiful music. 4 Who knows where they're going, but these Lawlor residents are certainly excited about it.



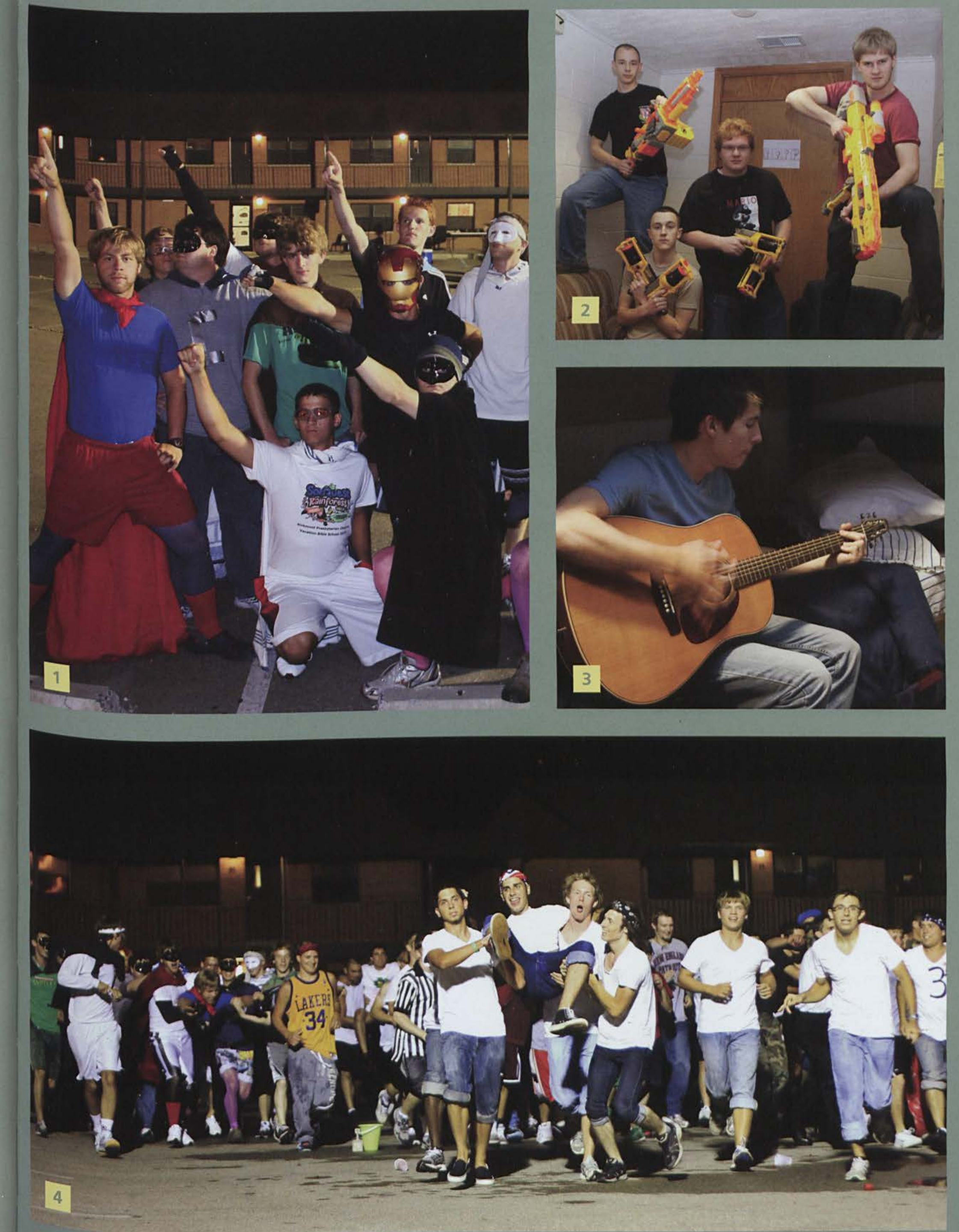


\section{CHUCKS, HIVE, \& RINNOVA}

Chucks has been feeding the hungry masses of students for years, and usually Cedarville students leave its cafeteria well fed and full. But like all things in life, day after day of the same food can become routine, and Cedarville students soon crave a little excitement and creativity in their dining options. The selfcook line and sandwich smashers offered alternatives to the Home Cooking and Grill line, and these make-your-own choices often had long lines of students waiting to try their hand at cooking, Chuck's style. This year, the addition of rotisserie chicken to the Chuck's menu became another meal option, and daily chicken specials made Chuck's already limitless number of choices even more varied.

Perhaps a picnic outside sounds more appealing - though not in the middle of December. Many students used the first warm days of spring and last warm days of fall to grab a transfer meal at the Hive - Stinger pizza being one of the best - and sit out by the lake for pleasant atmosphere, company, and food. During the winter months, a transfer meal may not have been necessary because some lucky students could win a free pizza at Thursday Night Trivia or spend some time with a smoothie enjoying an Interruption on the Hive stage.

Finally, a staple in the college student's life: caffeine. Rinnova offered quick, easy, and well-priced coffee on campus... plus it tasted great, too. For those not into plain coffee, Rinnova offered a White Nova or a Chai. New to the Rinnova area this year was the Rinnova internet café, a study area with computers for those students that like to have coffee at the tips of their hardworking fingertips. More computers were added at the beginning of spring semester to keep up with the high demand for the area, and apparently, the busyness of the lower SSC didn't keep students from getting homework done.

1 Lunchtime at Chucks is a busy place. Students rush in to get food, but, in the process, find a little time to stop and chat with friends in the lines. 2 Kayla Girtz uses her meal time to multitask: eat and study. Here at Cedarville, every spare minute must be utilized! 3 The sandwich line is always a popular food option in Chucks. The combinations are endless, and the sandwich smashers make meals that much better. 4 Marcia Pinkerton takes a gulp of her Rinnova drink outside the Hive; nothing like a little caffeine to help power a college student through the day, and Rinnova is just where to find that! 


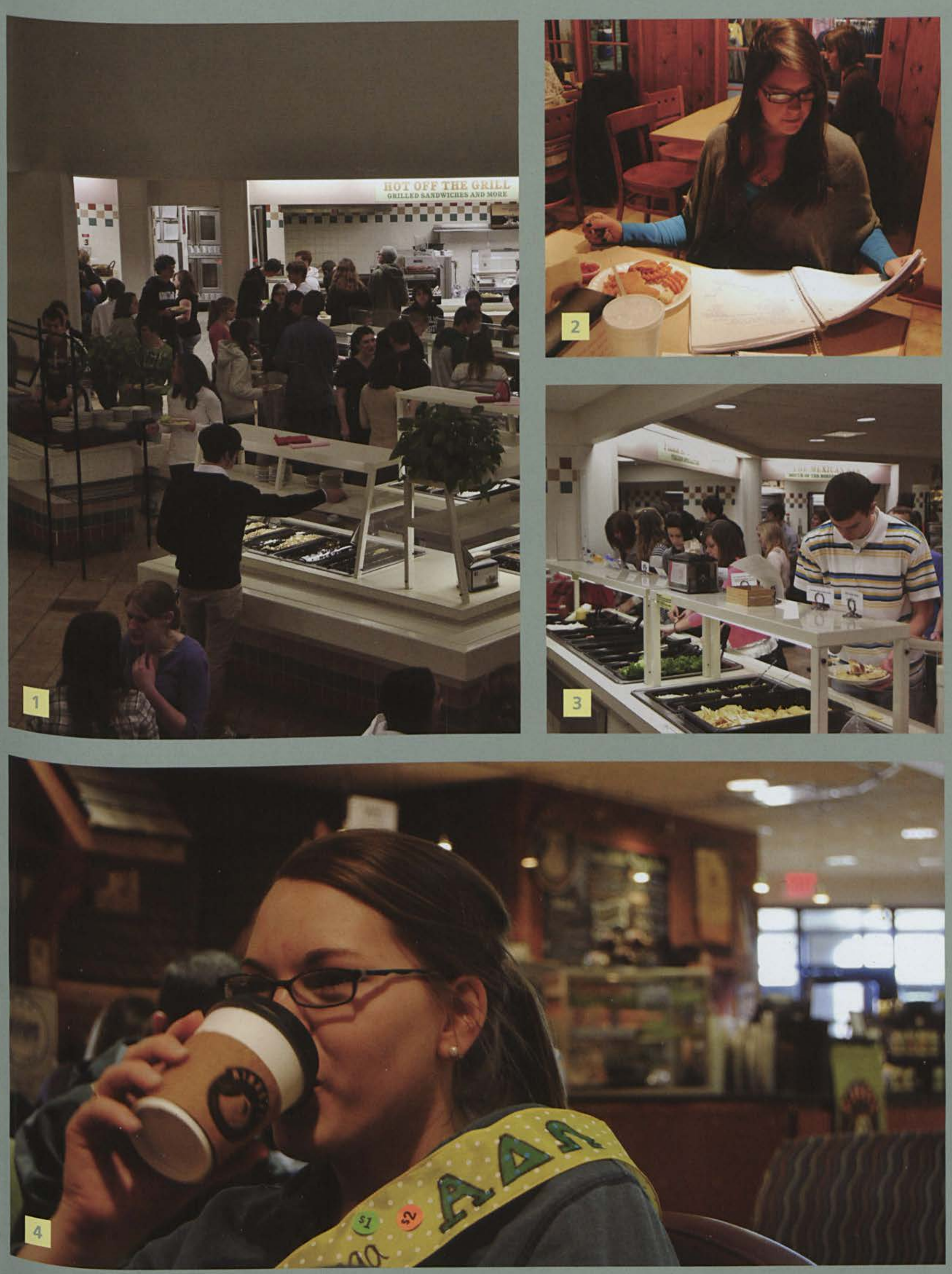




\section{INTERRUPTIONS}

For students looking to hang out and experience new styles of music, Cedarville had just the thing. On Tuesday and Thursday nights, Interruptions showcased the musical talents of Cedarville students and gave aspiring musicians a chance to perform in front of a live audience. "I love playing Interruptions," said senior Taylor Valarik, who played his eighth and final feature Interruption in February. "They're super chill, your friends come out and support you, and it's awesome to be able to be creative and play the kind of music you want, in any style you want." Valarik performed with his fiancé, Rachel Lee. Levi Crowley, a senior, played three Interruptions. He said, "Many people approach Interruptions as a concert, but I prefer to think of it as an opportunity to make music and hang out with friends."

Styles ranged from acoustic to bluegrass to rap. Some students performed by themselves or in a duo, while others played in a large band. Musicians performed original songs as well as covers of favorite or well-known artists. Alison McQuarry began writing songs over the summer, and after performing at some coffee shops, she decided to share her music by playing an Interruption. "It was a lot of fun getting to play for my friends!" she said. Brandon Oliger enjoyed performing with a group, playing original songs as well as a lot of classic rock. He even took requests from the audience.

Each Interruption was a unique experience, always something new, and, above all, a great way for Cedarville students to enjoy each other's musical talents. With a coffee or smoothie from Rinnova, some homework, and a group of friends, the Hive was the best place to spend a relaxing weeknight.
"Hearing and enjoying other students play is fun and highly encour- aging. Participating in Interruptions is going to be one of my best memories from my time here." (Matthew Dix)

1 Students gather outside the lower SSC to watch Interruptions in the early fall; tables make the area great for getting homework done, or at least looking like homework is getting done. 2 Grayson Cato and Hayden Browning pair up for their Interruption between the lake and the hill outside the SSC. Before the weather can turn cold, this provides the perfect location for a break from studying. 3 Students watch Rachel Lee and Taylor Valarik sing and play in the Hive. These two aren't just an Interruption duo...they're also engaged! 4 Taylor Swayze and Brandon Cruise entertain students looking for a break at their ALT night Interruption following TRON. 


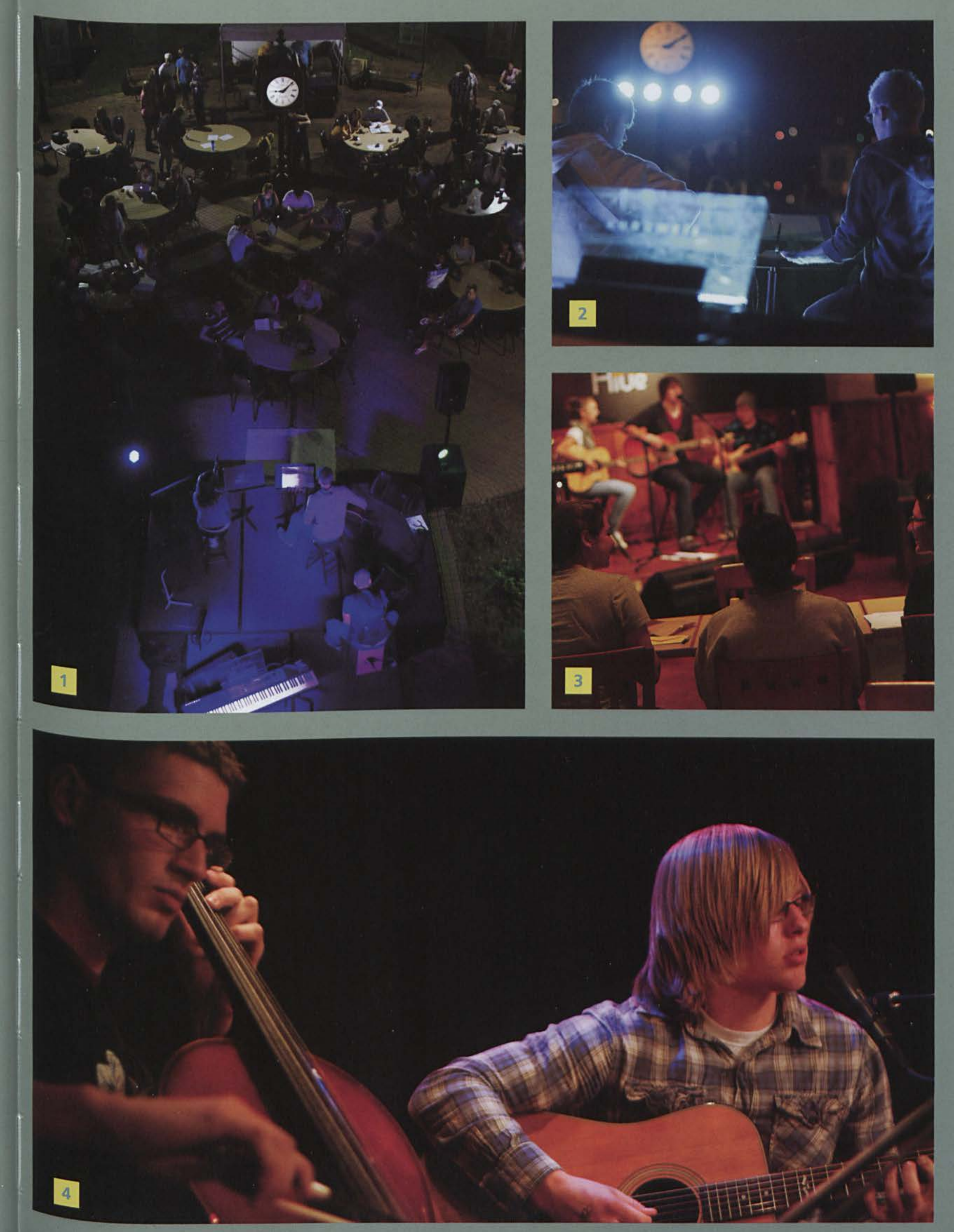




\section{IN TOWN}

Many students find Cedarville's quaint, small-town feel appealing, though their hometown background is varied. Whether living on or off campus, students appreciated the quiet, homey atmosphere. Some found Cedarville a great place for biking or just going for a walk. Others enjoyed town festivities like parades and fireworks, and especially the annual Labor Day celebration.

Cedarville's two coffee houses, Stoney Creek Roasters and Beans-n-Cream, were a big hit with students. When getting off campus was a necessity, these were the places to do it. "I like hanging out at Beans-n-Cream for a lot of reasons," said Elizabeth Patterson. "They have a lot of really good food and drink choices, the cozy, eclectic atmosphere is good for doing my homework or reading or just hanging out with friends, and I LOVE all of the artwork and handcrafted things they have on the walls and for sale."

Right across Main Street from the University campus was Winner's Village Market. A convenient stop for groceries and other miscellaneous necessities, Winner's was frequented by students, at all hours of the day and night, even five minutes before curfew.

Other attractions in town included Subway, which, by being within easy walking distance from the campus, often became a suppertime alternative to Chuck's. Colonial Pizza was popular around dinnertime, too, and recent renovations made the most of space. Students either dined at the restaurant, enjoying its unique atmosphere, or took advantage of the delivery service that would bring a pizza right up to any dorm on campus.

And, as if all this weren't enough, the word was that Cedarville would be getting a Chinese restaurant sometime soon. Returning students looked forward to enjoying a new addition to the little town of Cedarville.

1 Wolves at the Gate, a band with members of Cedarville alumni, hold a concert at Alford Auditorium. This is their second concert at Cedarville. Their previous concert, last year, was well attended by students, and this year called for a repeat. 2 Sam Armstrong and Garrett DeRossett perform an Interruption at Beans $n^{\prime}$ Cream on February 25 with their band Norwegian Forrest Cats. 3 Joy Fagan is interviewed by a film project at Stoney Creek Roasters. The relaxing and homey atmosphere of Roasters provides the ideal backdrop for studying, a coffee break, or a DTR. 4 A group of Cedarville students including Suzanne DeValve, Cheryl Still, Debra Thompson, and Laura Kramer celebrate Labor Day weekend by enjoying a pancake breakfast at the Cedarville firestation. 


\section{INTRAMURALS}

The sweat dripped off her nose. She knew time was running out, but she knew what was at stake. The t-shirt.

Every year Cedarville offers students a chance to live the dream. It never fails that every year the coveted intramural champions t-shirt is one of the most sought after prizes across Cedarville's campus (almost more than the 4.0 mugs). Teams entered sports like soccer, basketball, dodgeball, even wallyball for just a chance at wearing those shirts on a casual Friday. Students worked long and hard, building the ultimate team, just so they could have the chance of earning one of those championship t-shirts.

Of course some goals are nobler than the players that strive for the $t$-shirt prize. Their motivation lay in an attempt to salvage their sanity amidst exams, papers, and projects. Intramurls gave students a much-needed break to work out their pent-up energy on the field or court.

Whatever the end goal, intramurals provided Cedarville's students with a

"Dodgeball this year was incredible. Coming in and knowing the competition, I didn't know how far we could get, but we made it far and won the championship. Dodge these!" (Jennings Gardner) chance to stretch their legs and participate in healthy competition. In sports, it's never really about winning anyway... right?

1 Sand volleyball is definitely a student favorite as it can feel like being at the beach. And in the middle of Ohio, students need a taste of the beach whenever they can get it! 2 Indoor soccer gives students the chance to work on their footwork even during the tempermental Ohio winters. 3 Dodgeball can be quite the heated competition as nothing gets the adrenaline flowing like chucking foam balls at high velocity towards fellow students. 4 Cedarville provides students with excellent facilities to play intramurals. 


\section{Q}

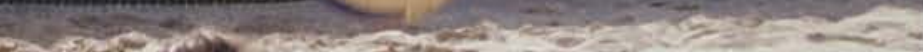

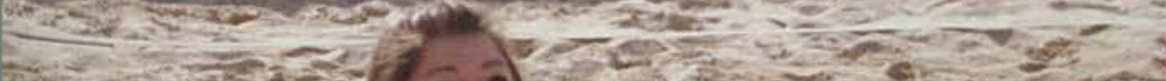

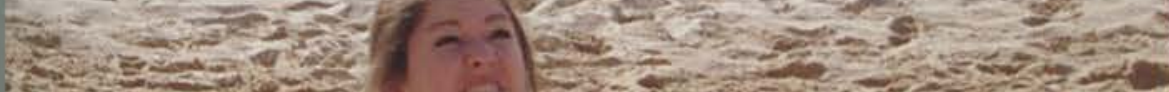

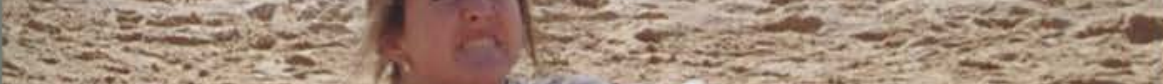

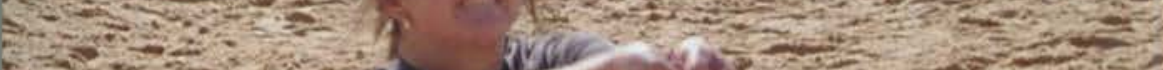

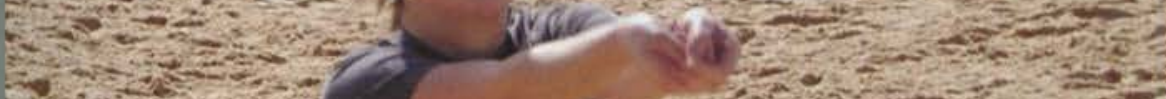

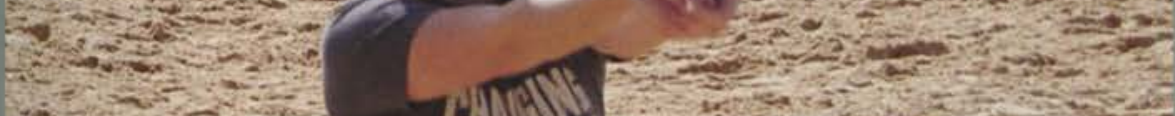

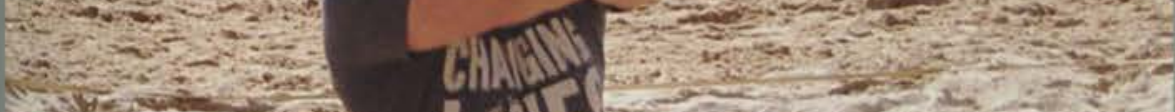

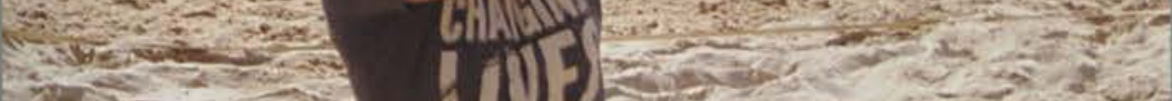

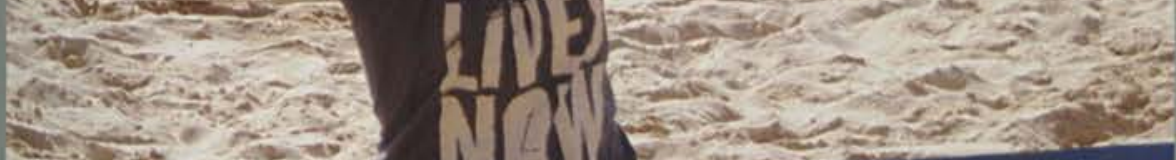
tos.

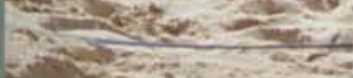

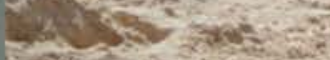

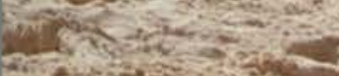

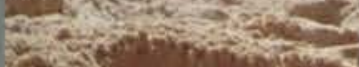

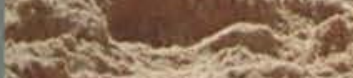

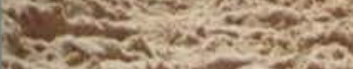

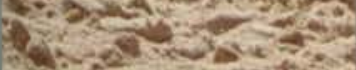

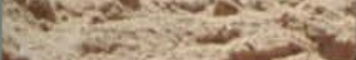
$-2$ $\therefore \rightarrow 55,2$

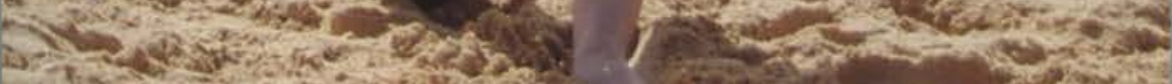

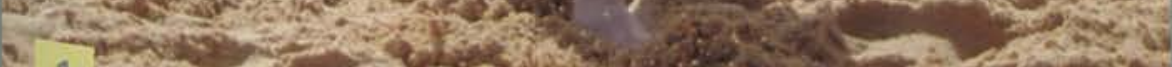

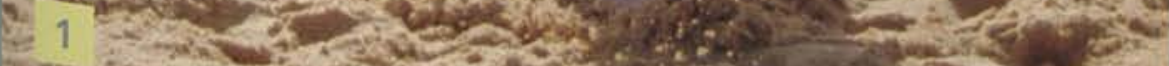

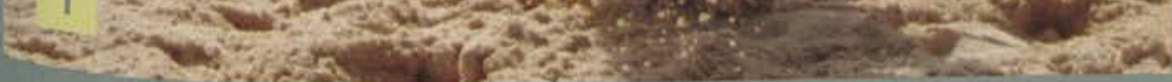

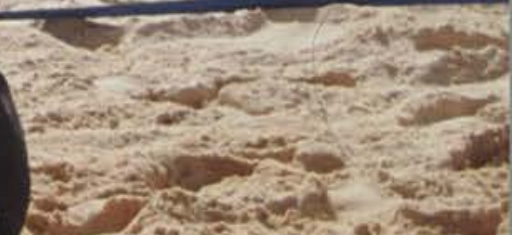
2.

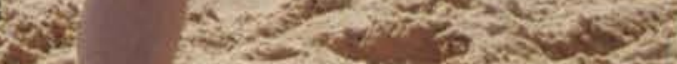

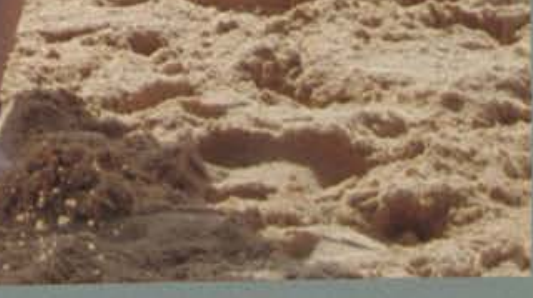
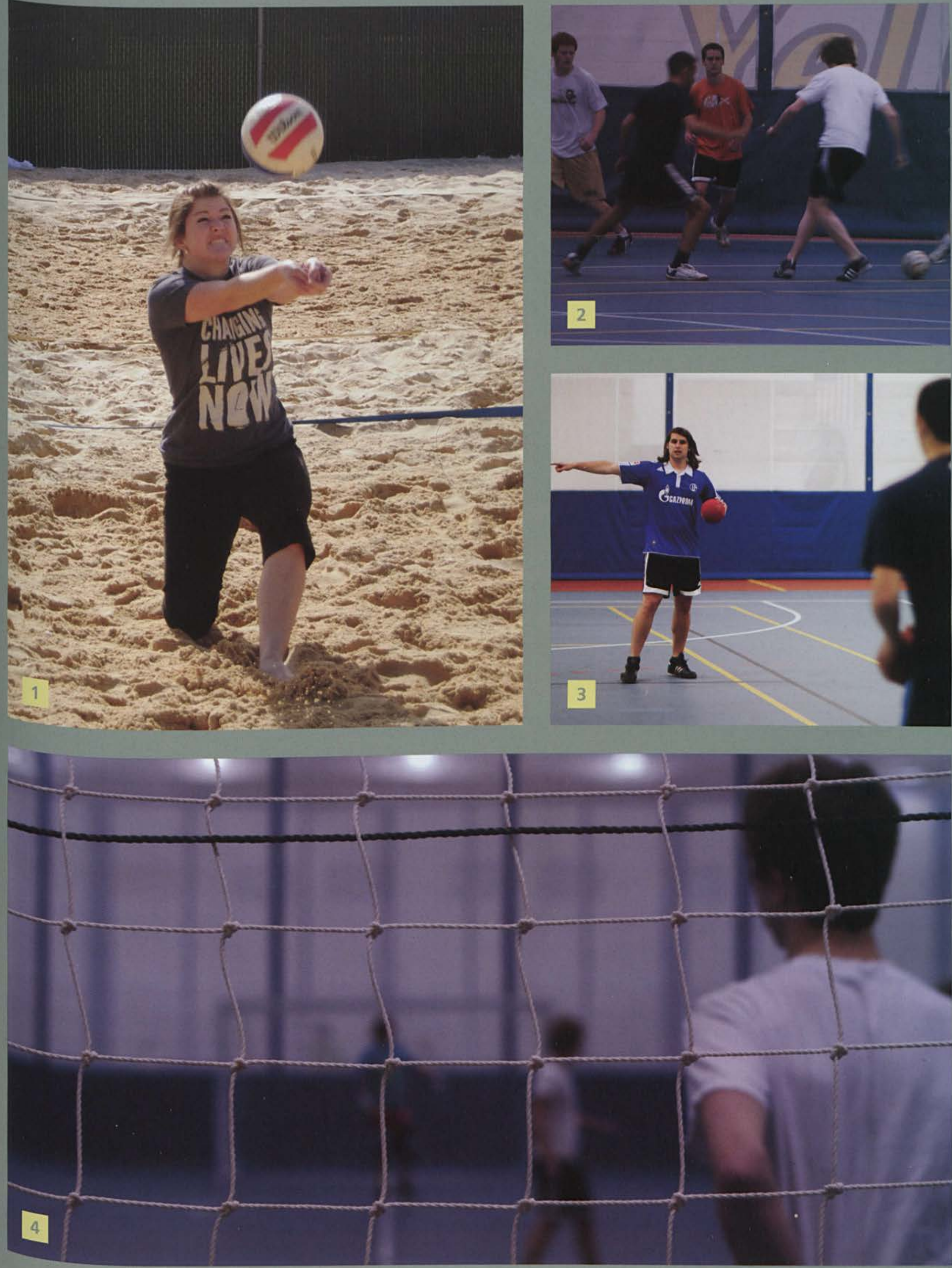


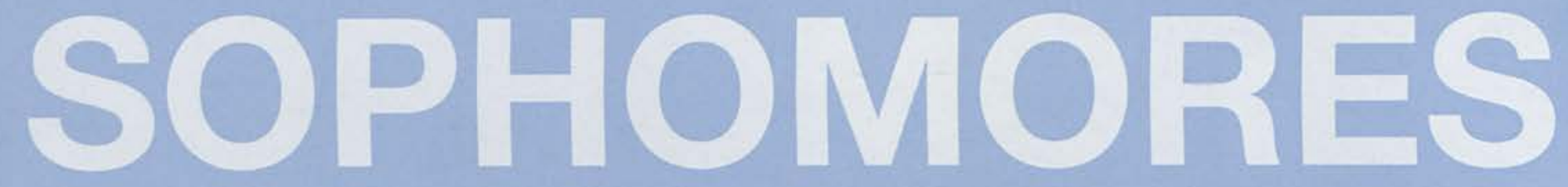

noun, plural \'säf-mörs \Students fully aware of the work necessary to excel at Cedarville University; sighted in the PDR eating breakfast with Dr. Brown. 


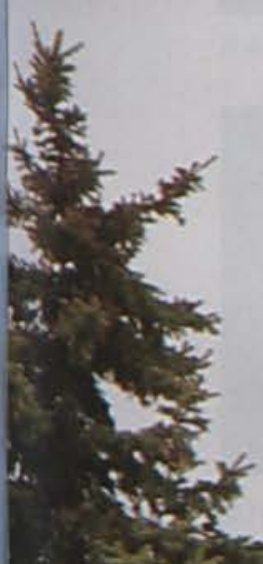

$\therefore$ a.

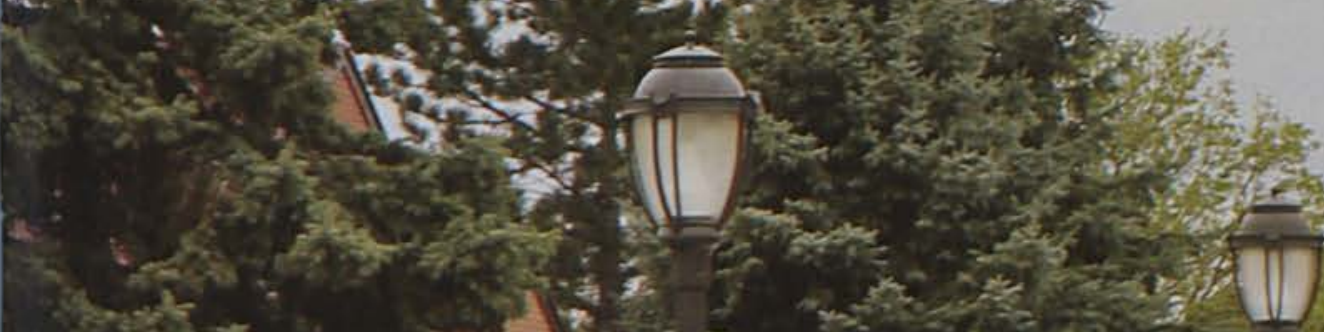

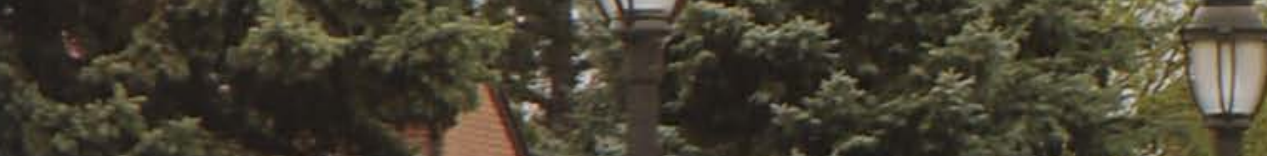

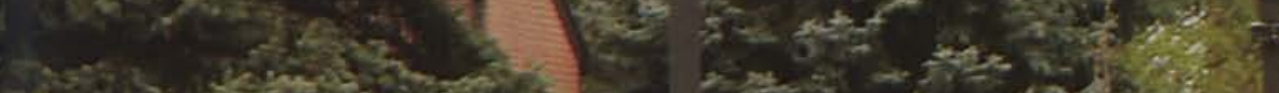

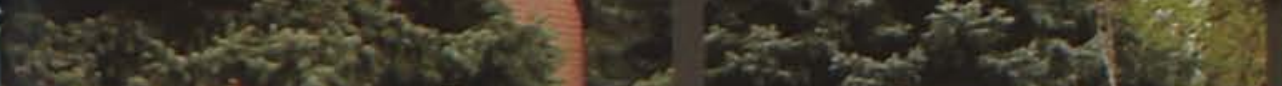

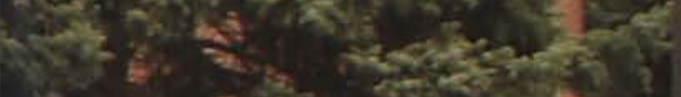

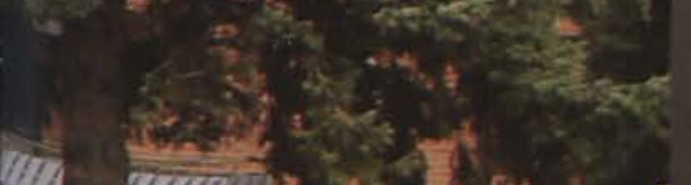

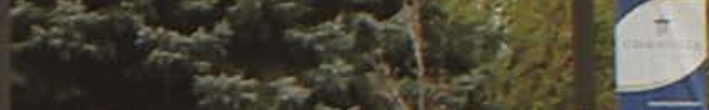

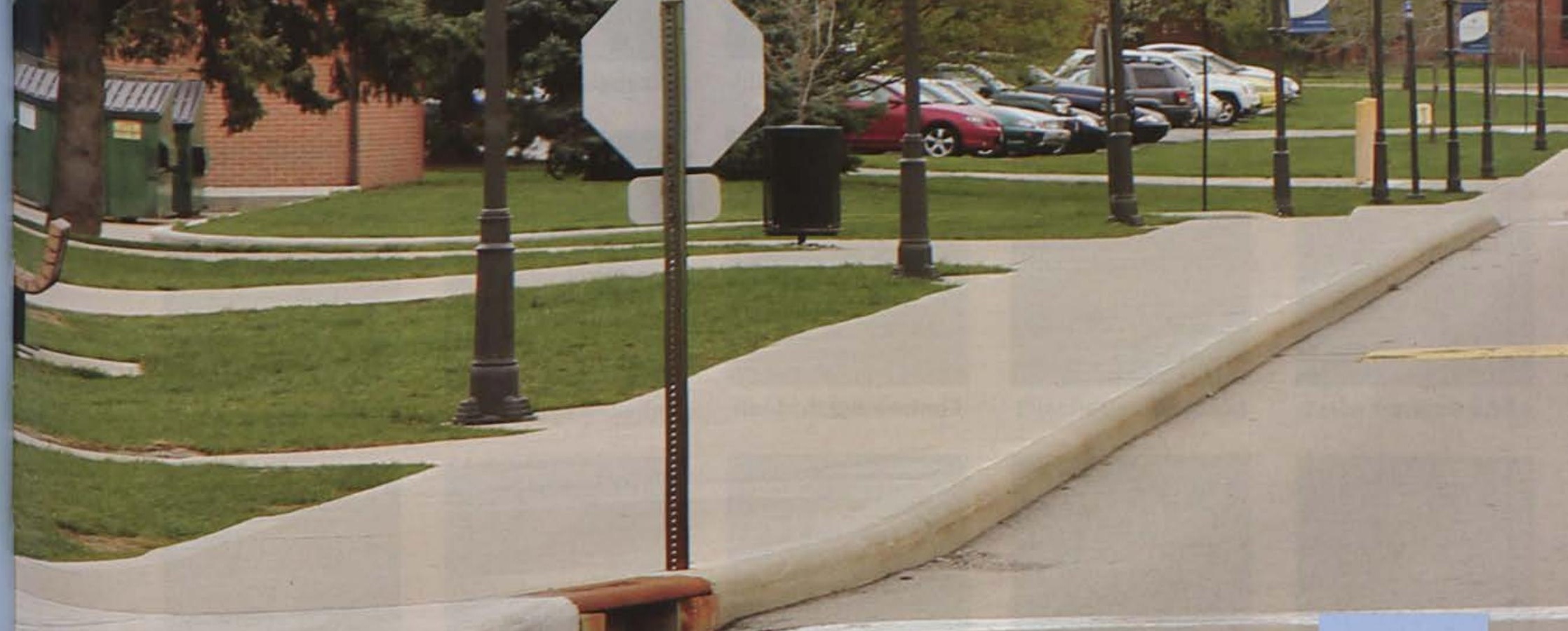




\section{SOPHOMORES}

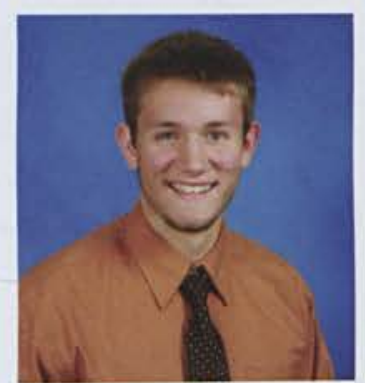

Bryan Adrian

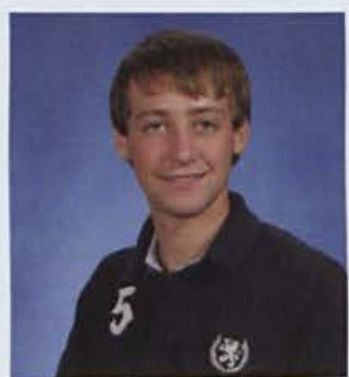

Caleb Alley

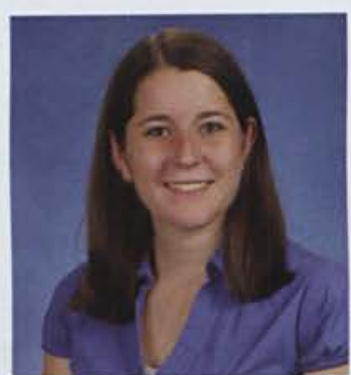

Alexandra Balkus

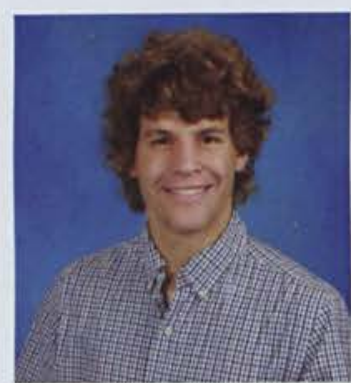

Joshua Beckler

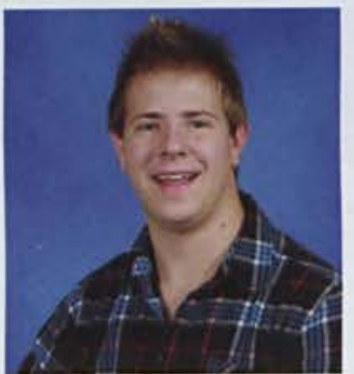

Jay Bowser

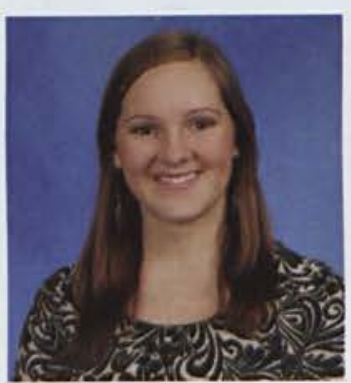

Amy Brown

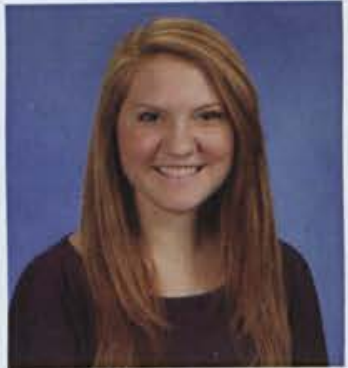

Lauren Amick

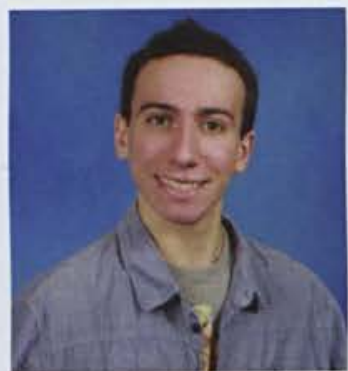

Timothy Bardakjy

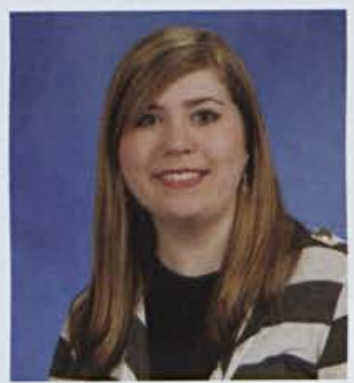

Rebecca Belton

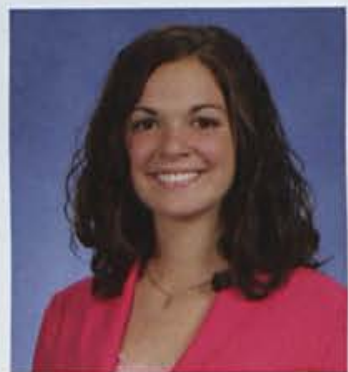

Chelsea Brett

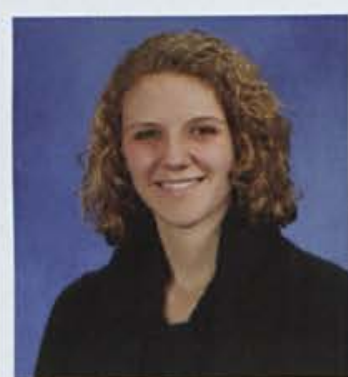

Alison Buchanan

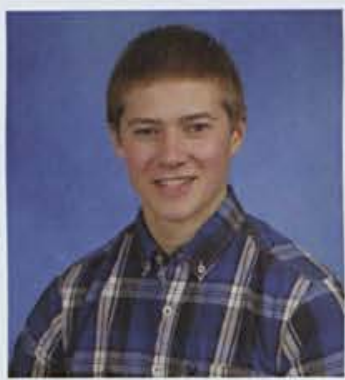

Daniel Adriansen

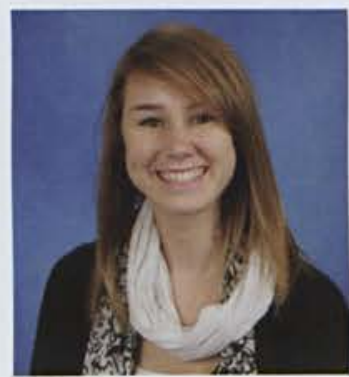

Sarah Arni

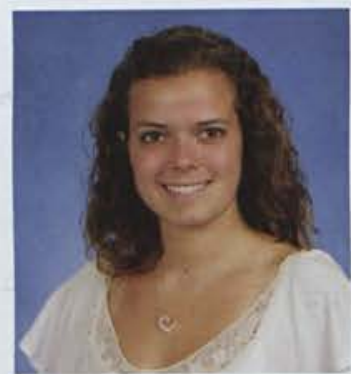

Kaitie Barfell

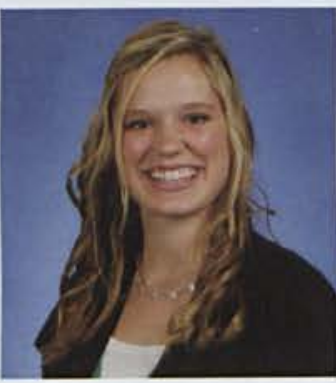

Elizabeth Bennett

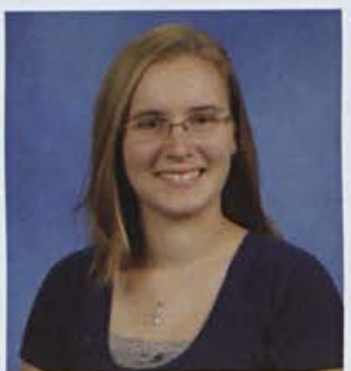

Rebekah Brewer

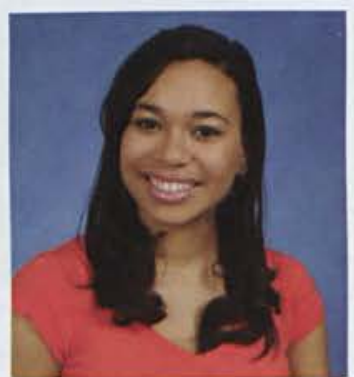

Amanda Bunton

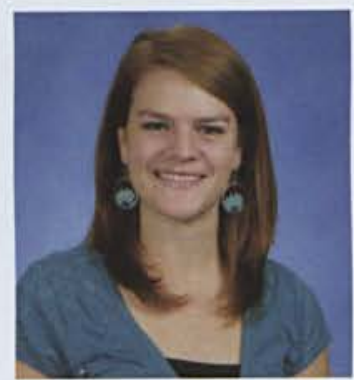

Brianna Ahlgrim

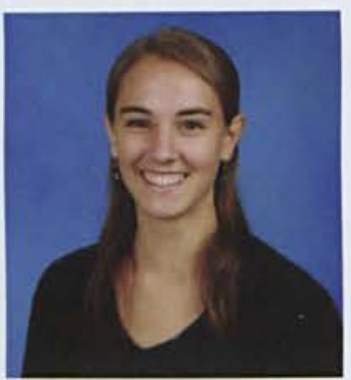

Jamie Atkins

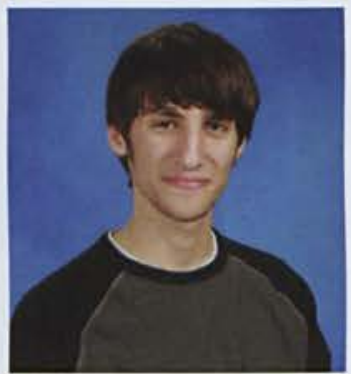

Matthew Bassett

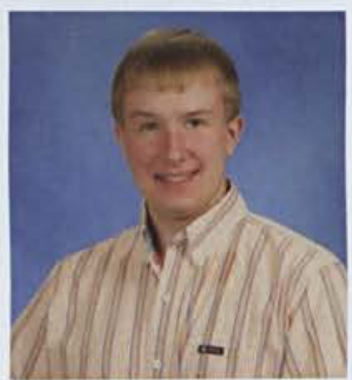

Todd Bouws

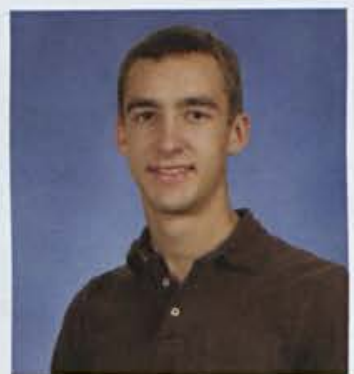

Nathan Briggs

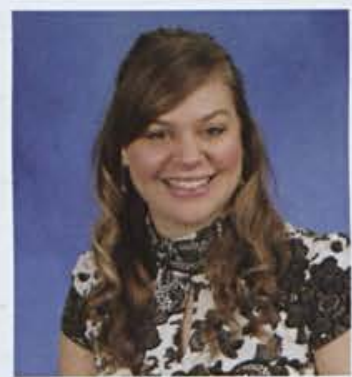

Christina Burns 


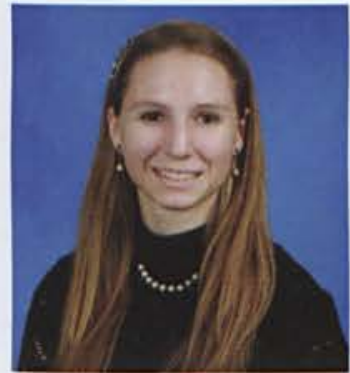

Rachel Burton

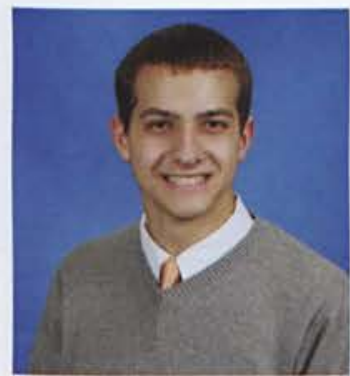

Brian Cates

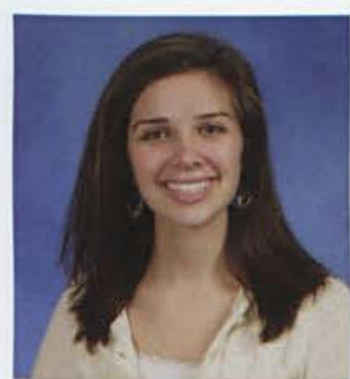

Kelly Classen

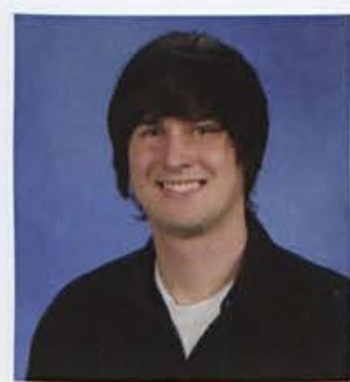

Patrick Cook

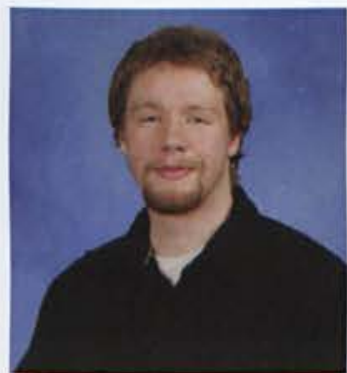

Adrianus Cummings

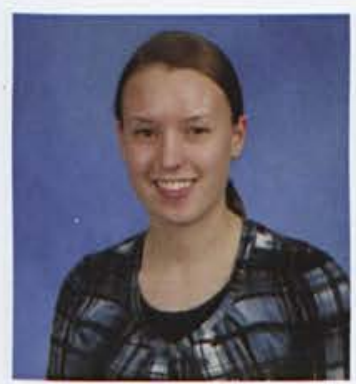

Amy Dahl

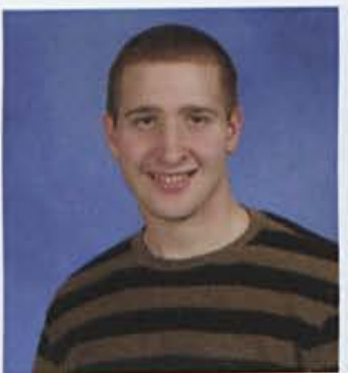

Benjamin Campbell

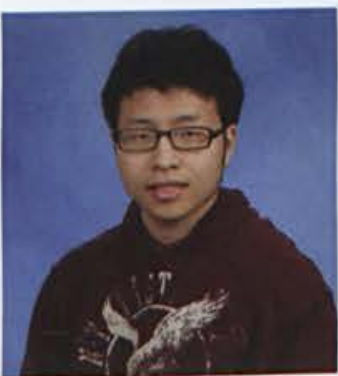

Eunho Cha

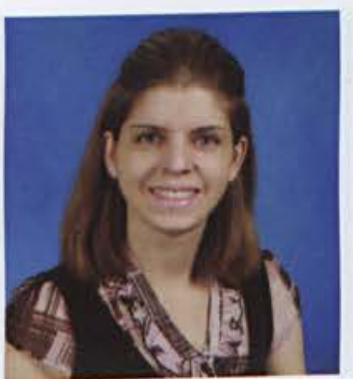

Hannah Cochran

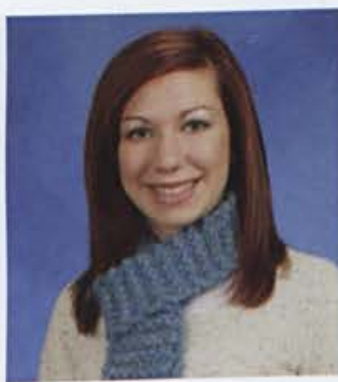

Alicia Corcoran

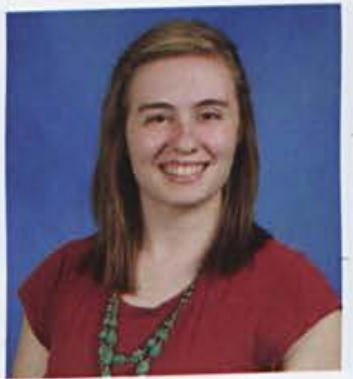

Cassie Curby

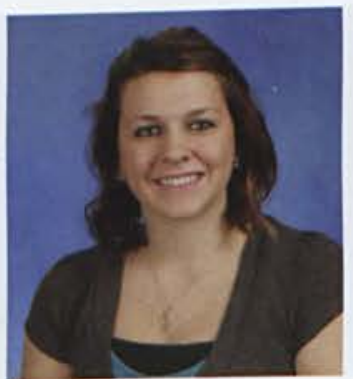

Erica Danner

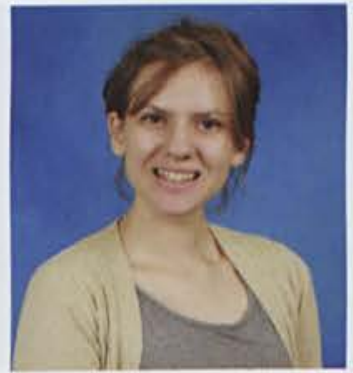

Victoria Cannon

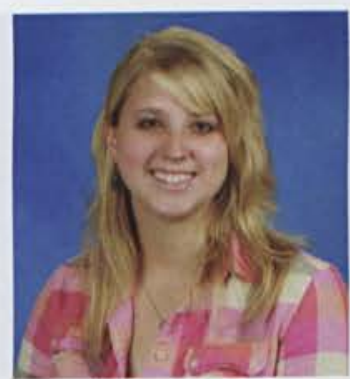

Amy Chase

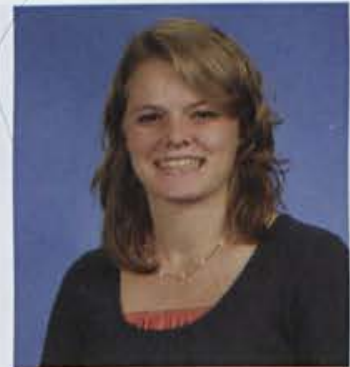

Megan Coffman

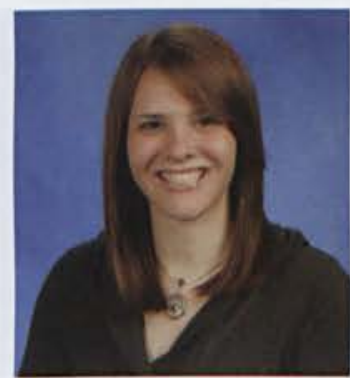

Jillian Crabtree

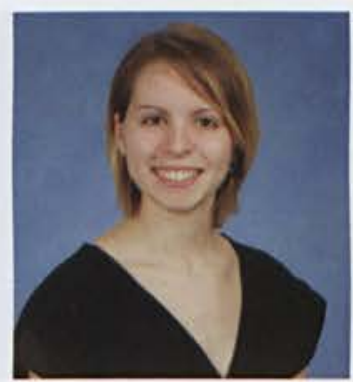

Rebecca Curran

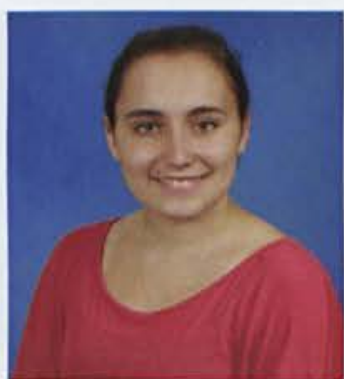

Jackie Decker

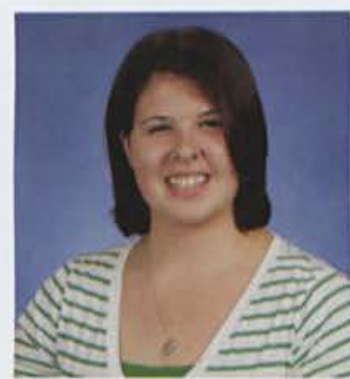

Amy Carroll

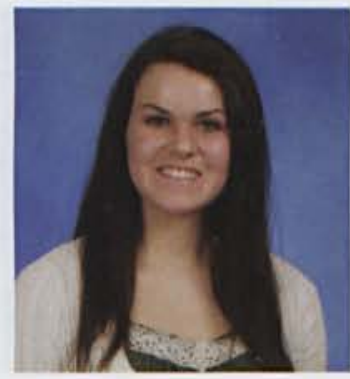

Julie Christiansen

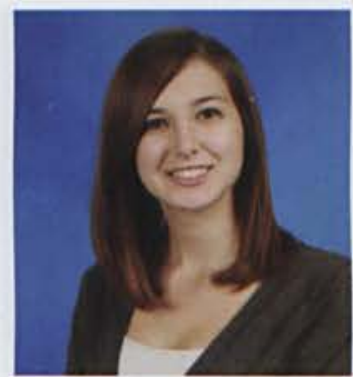

Juliana Coleman

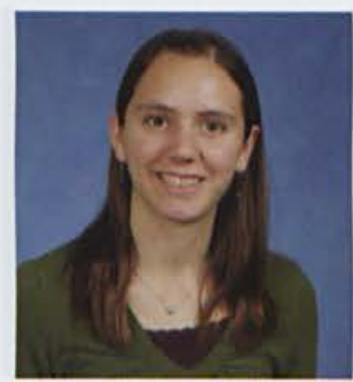

Emily Crizer

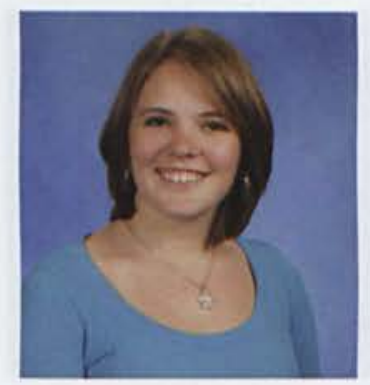

Elizabeth Curwick

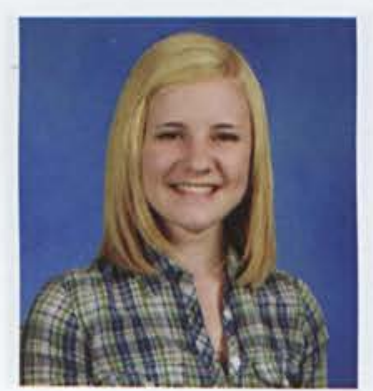

Sarah Deitner

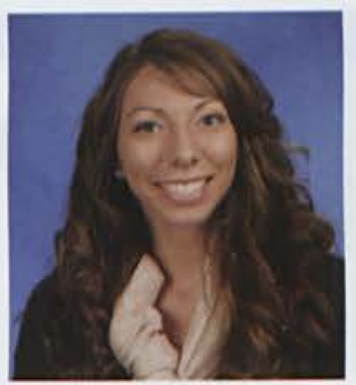

Chelsea Castillo

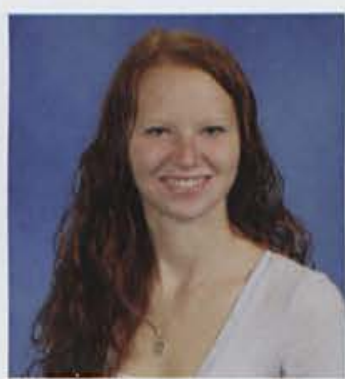

Lauren Clark

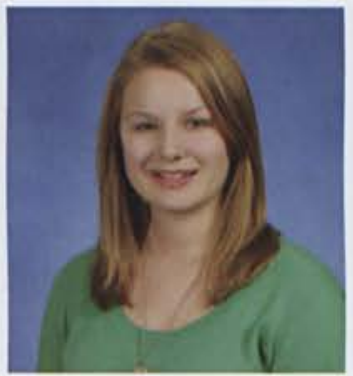

Faith Cook

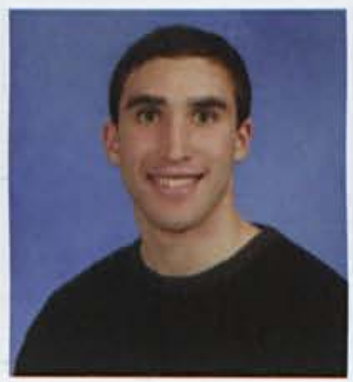

Joseph Crupi

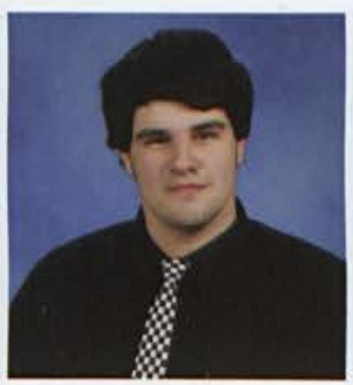

Gavin Custer

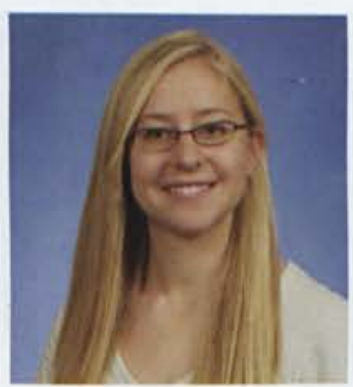

Becky Dennis 


\section{SOPHOMORES}

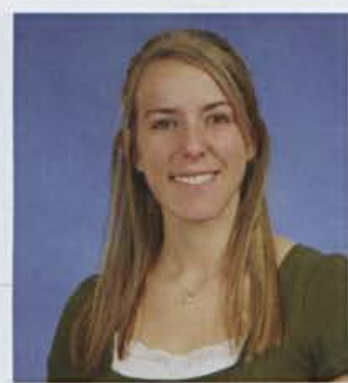

Brooke Devereaux

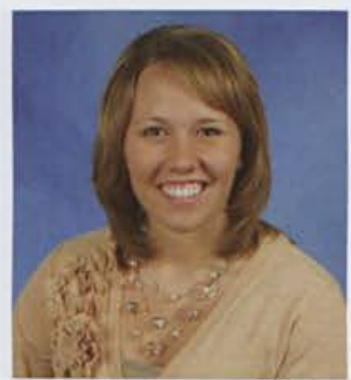

Stephanie Docter

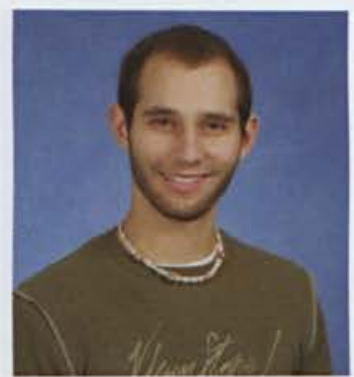

Bryan Earwood

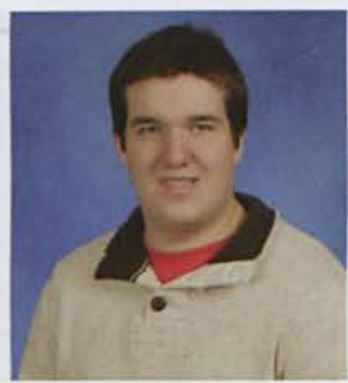

Zach Evans

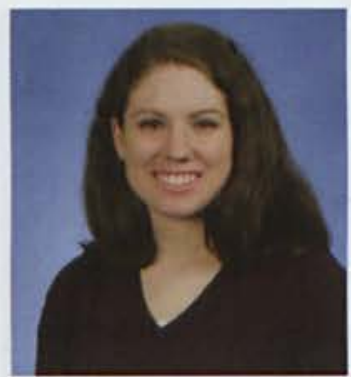

Stacia Firebaugh

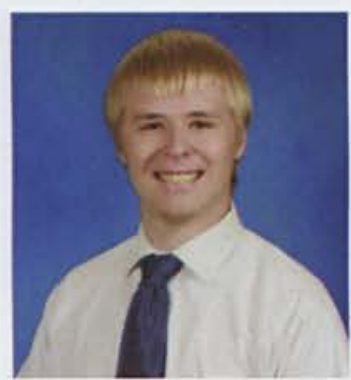

Walter Flow

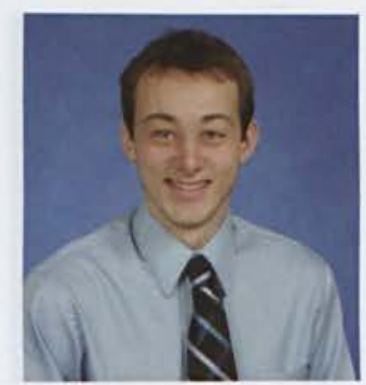

Aaron Duarte

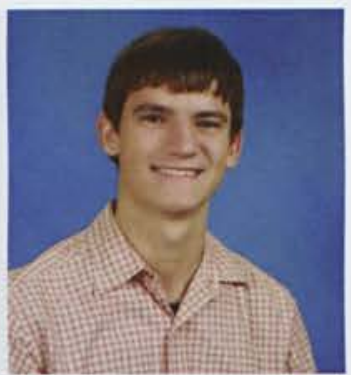

Caleb Enderle

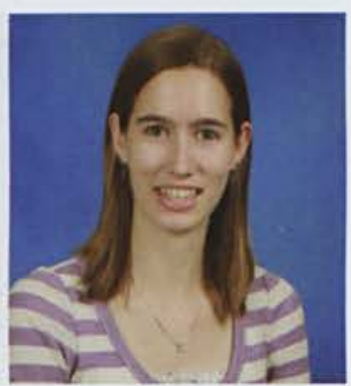

Stephanie Everard

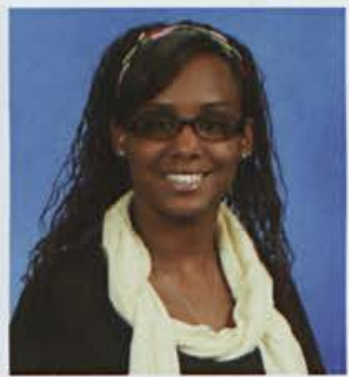

Melodie Fisher

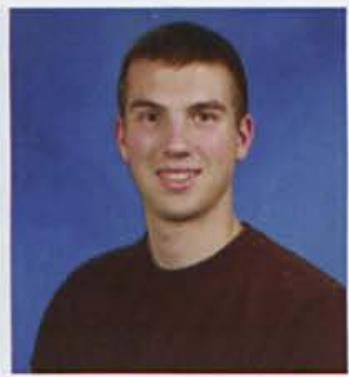

Eric Foley

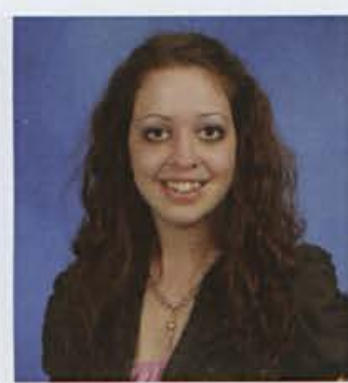

Lisa Dykes

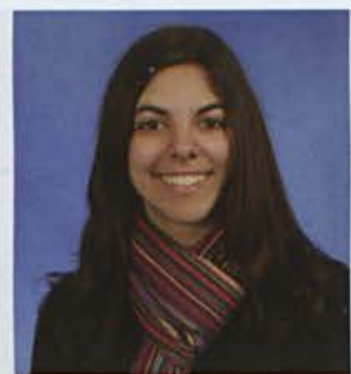

Kathryn Enter

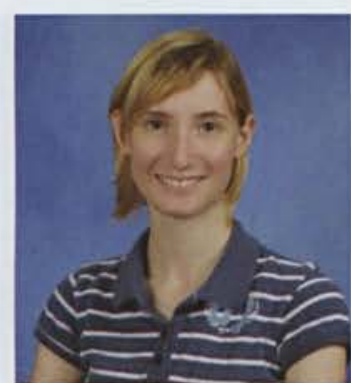

Jillian Fawcett

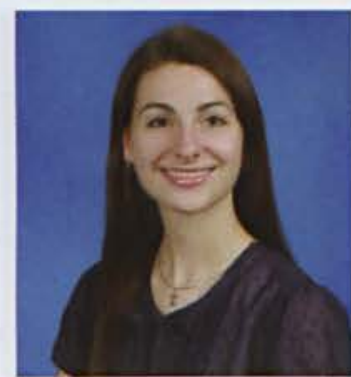

Anna Fitzpatrick

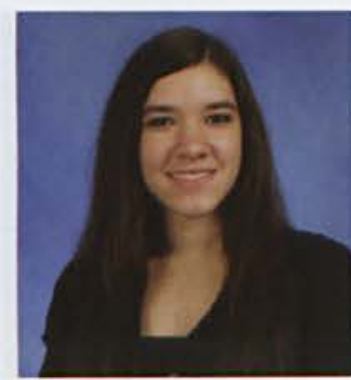

Rachel Fonseca

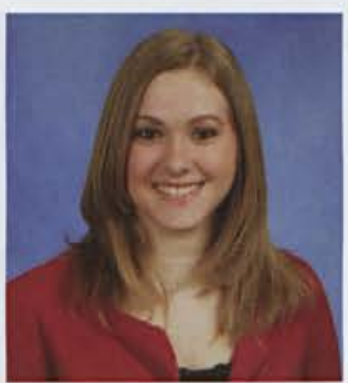

Brooke Dietz

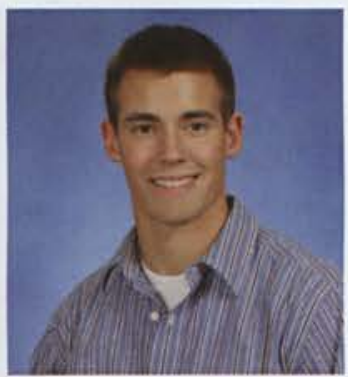

David Dyksterhouse

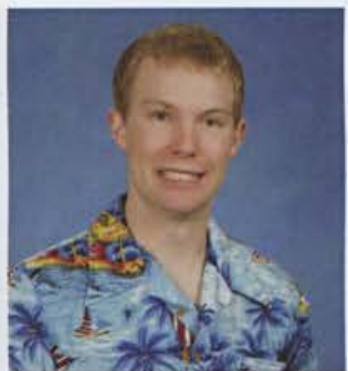

Garrett Erickson

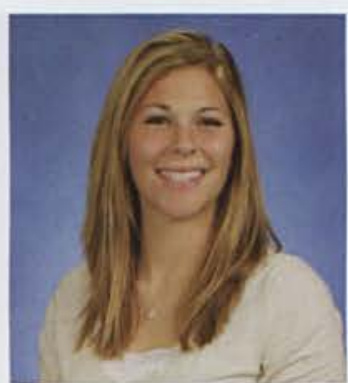

Melissa Featherman

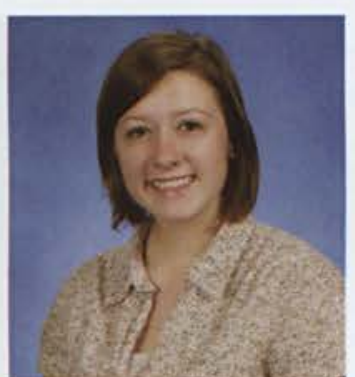

Hannah Fleming

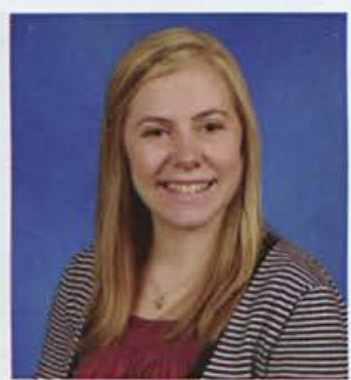

Nikalee Foster

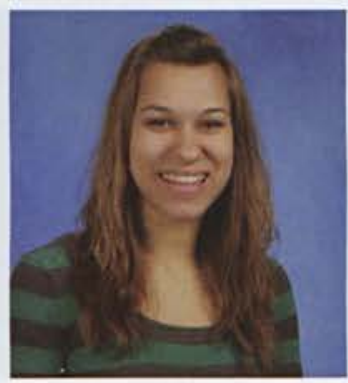

Molly Dinse

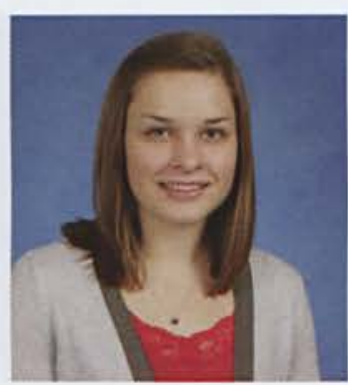

Leanne Dykstra

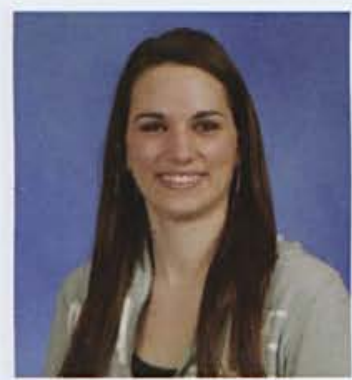

Allison Esbenshade

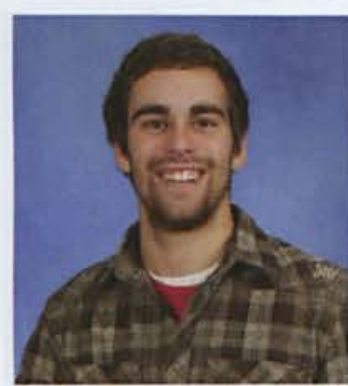

Matthew Finkbeiner

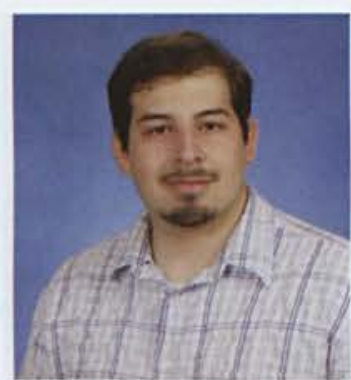

Aaron Flores

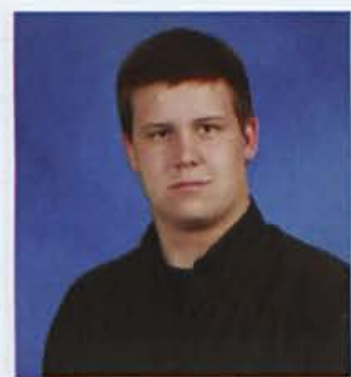

Zachary Franklin 


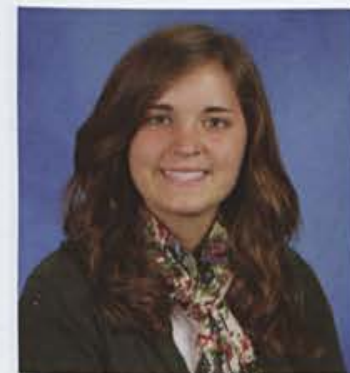

Grace Frederick

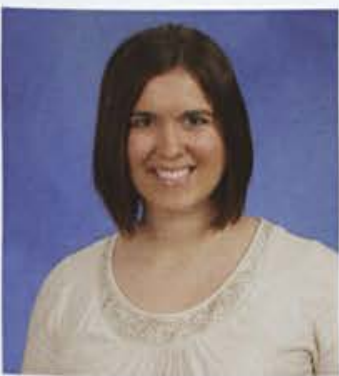

Keely Geringer

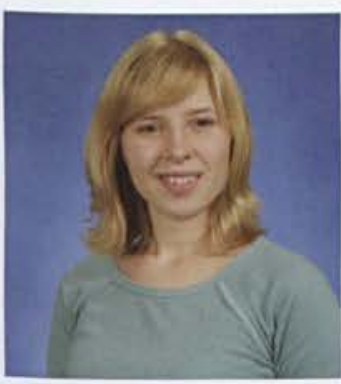

Cassie Gray

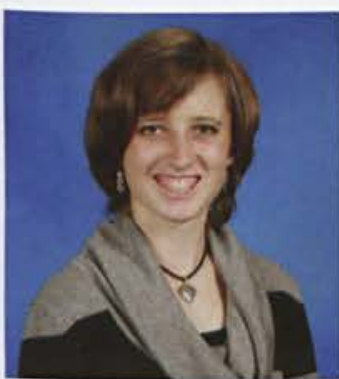

Elizabeth Griffith

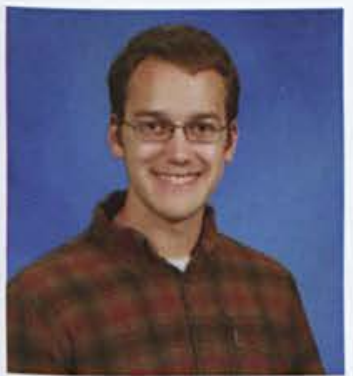

Matt Hawkins

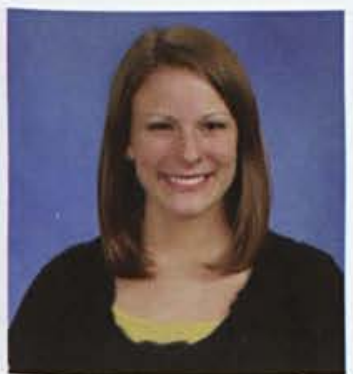

Allison Henry

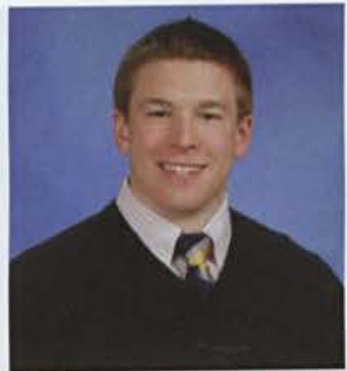

Bradon Gahman

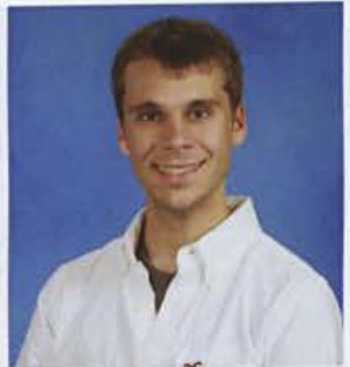

Kyle Girtz

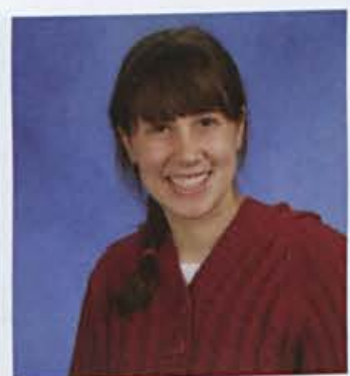

Cora Gray

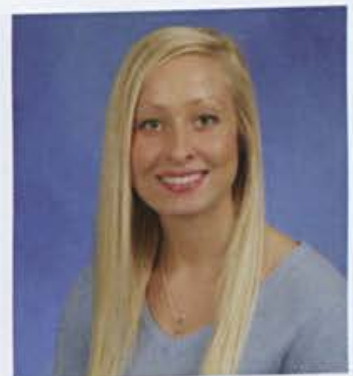

Morgan Gullion

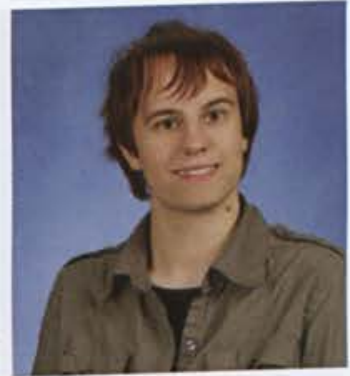

Amanda Hayes

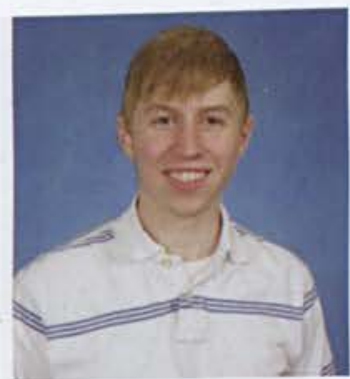

Andrew Herting

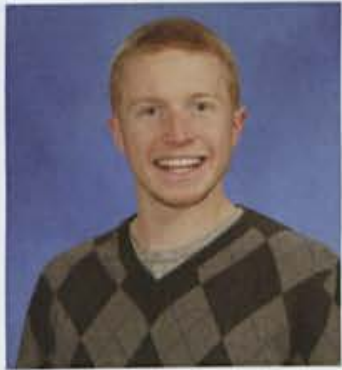

Scott Gardner

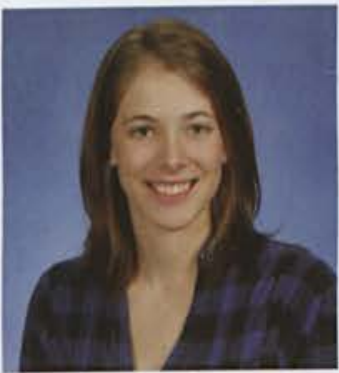

Rebecca Gorrell

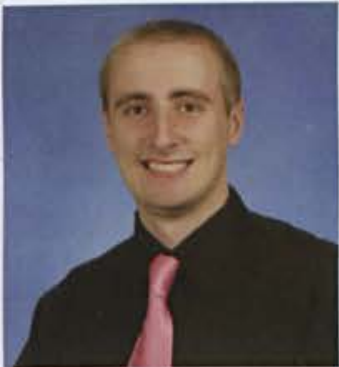

Jr. Gregg

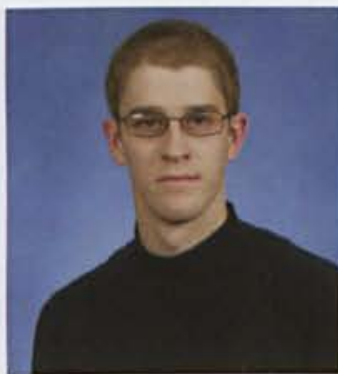

Cody Hall

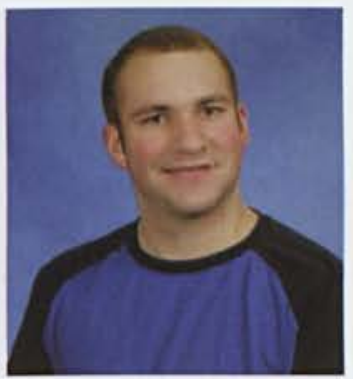

Dave Haywood

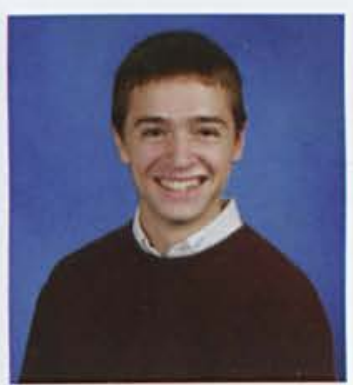

Robert Hinks

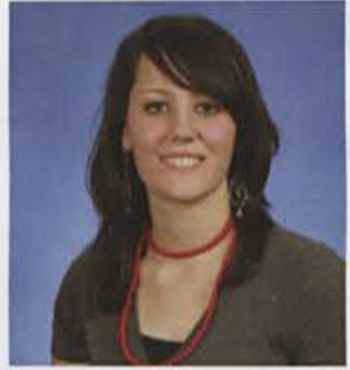

Anna Gates

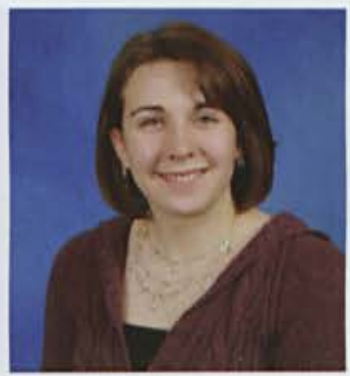

Sharon Grafton

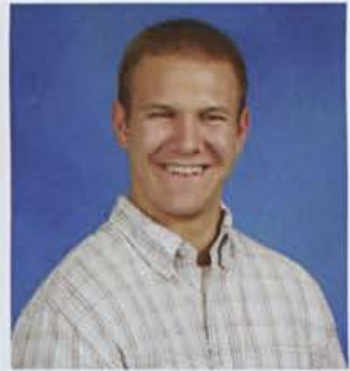

James Gregory

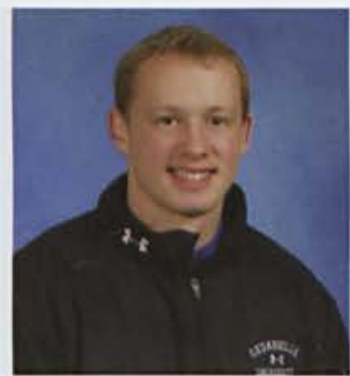

Greg Hannay

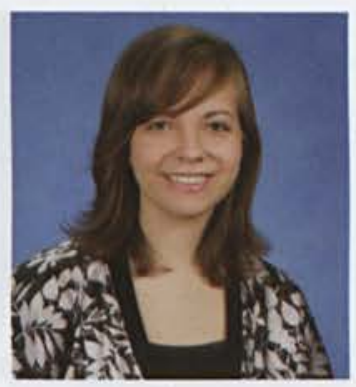

Tessa Hedges

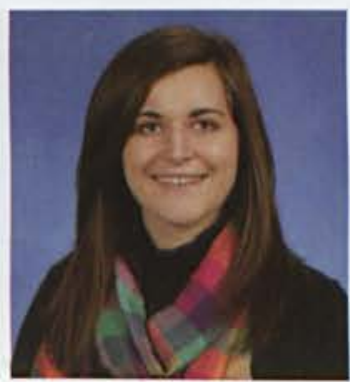

Tayler Hobba

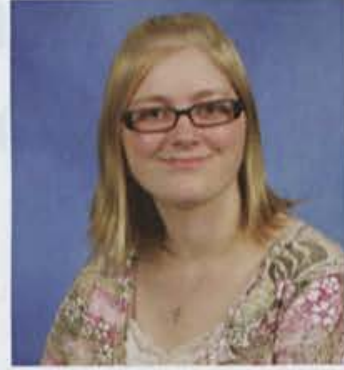

Elizabeth George

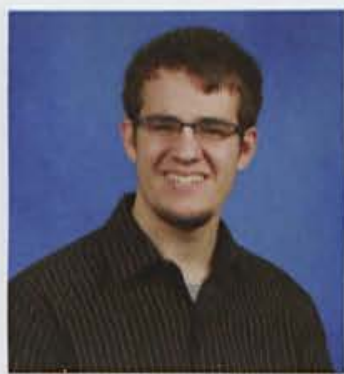

Daniel Grahn

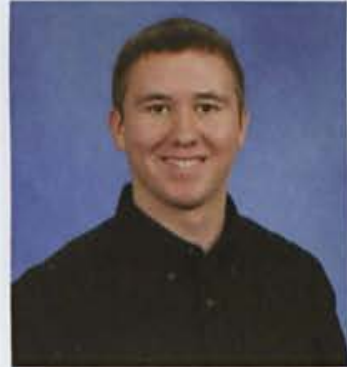

Christopher Griffin

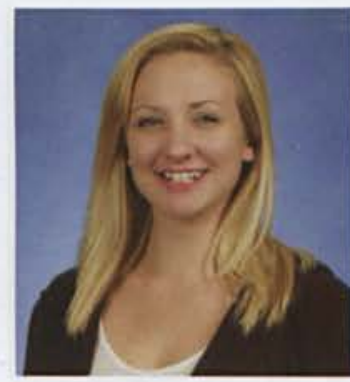

Carly Hartman

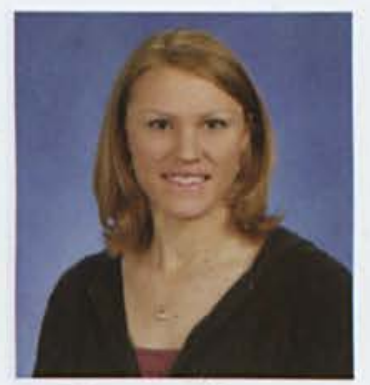

Caitlynn Hellwig

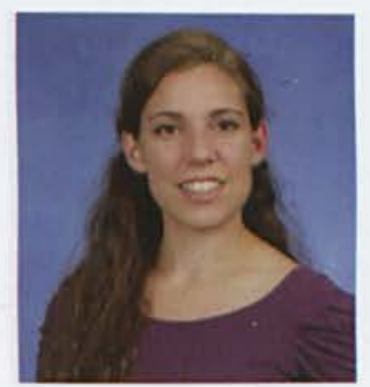

Julia Hodecker 


\section{SOPHOMORES}

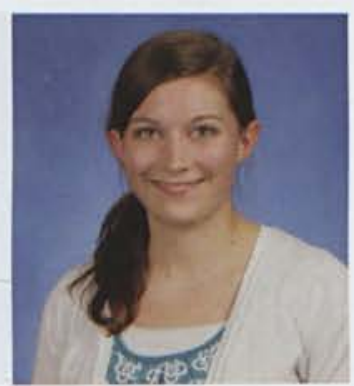

Marina Hof

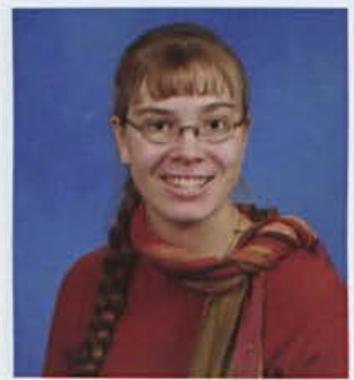

Robin Hrdina

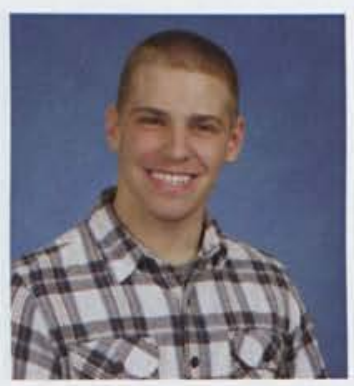

Nate Huston

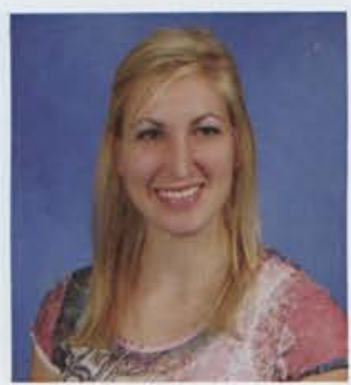

Brooke Johnson

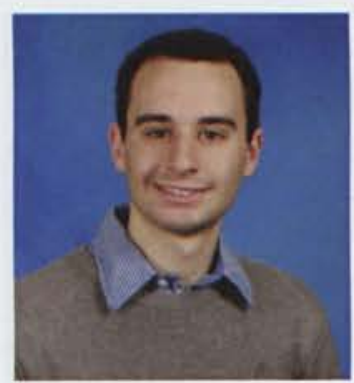

Stephen Johnson

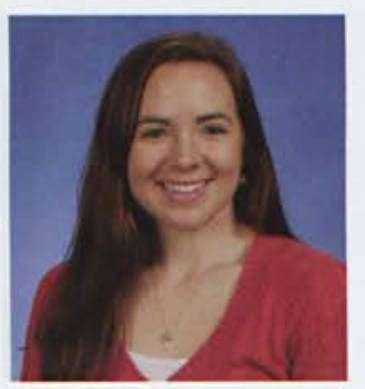

Heather Kirkpatrick

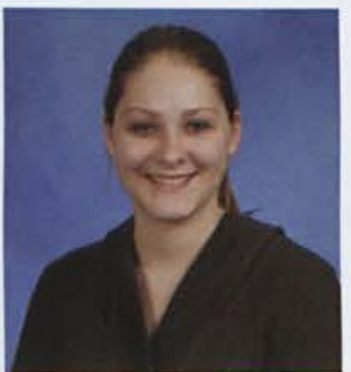

Roxanne Hulbert

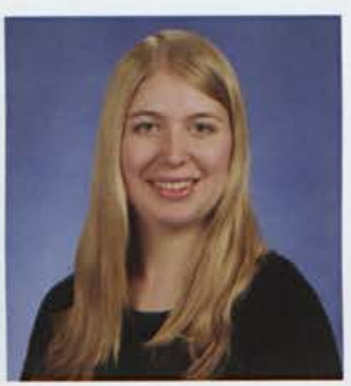

Mary Hutton

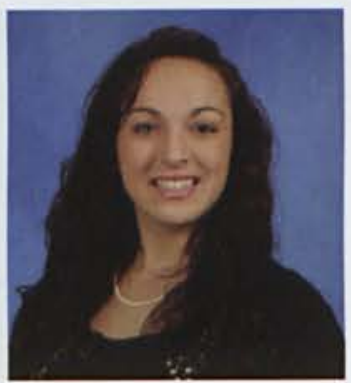

Chloe Johnson

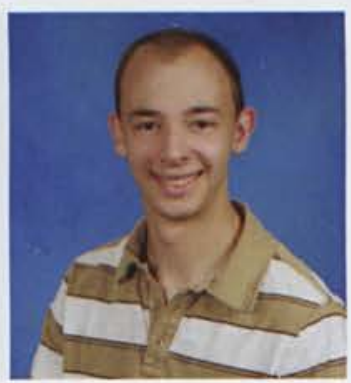

Matthew Kanning

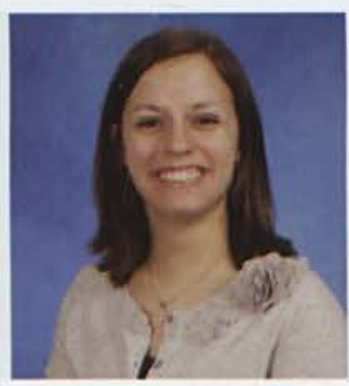

Kristen Kleinberg

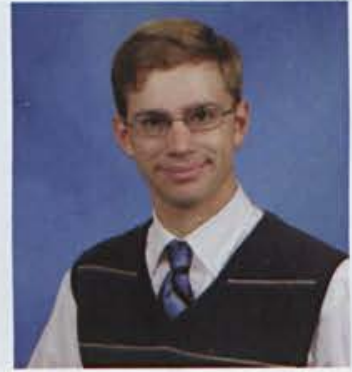

Andrew Hull

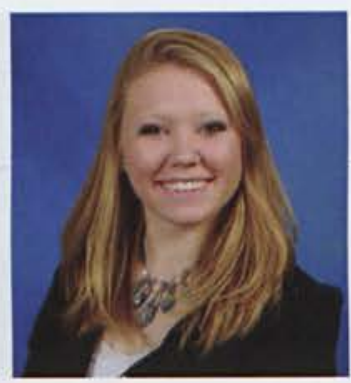

Sarah Irwin

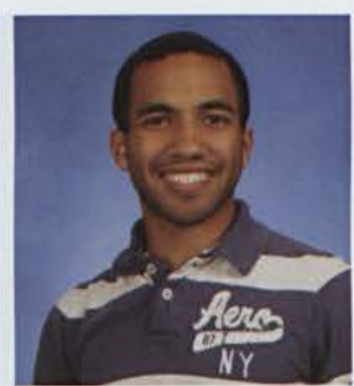

Fred Johnson

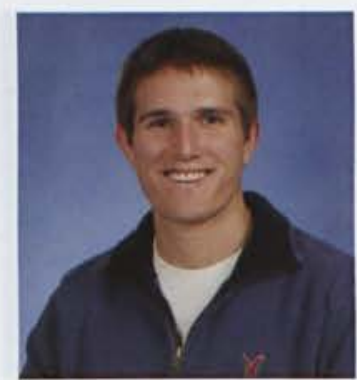

Joshua Karhan

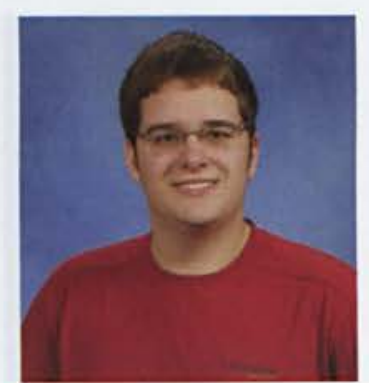

Austin Klob

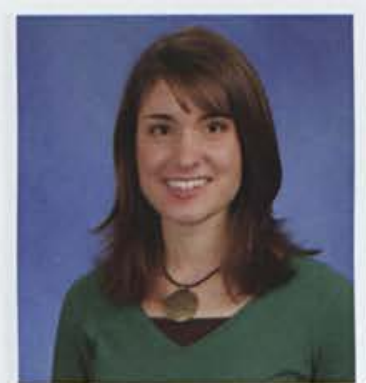

Brandi Hoffer

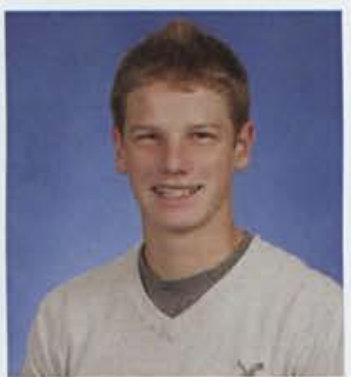

Kyle Hultz

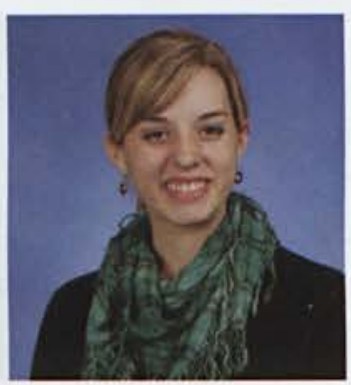

Rebekak Isaac

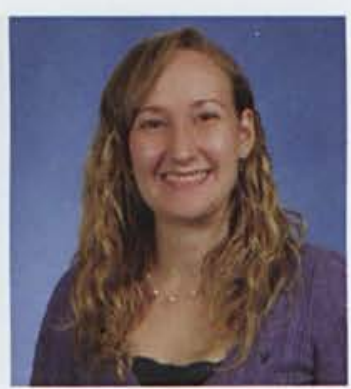

Kirsten Johnson

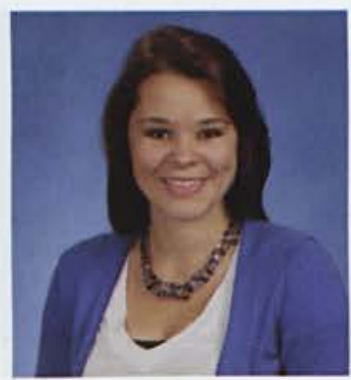

Ruth Kazulak

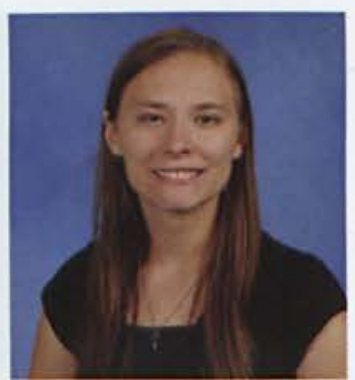

Brittany Koch

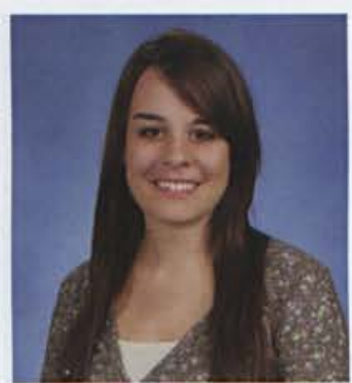

Hannah Holmes

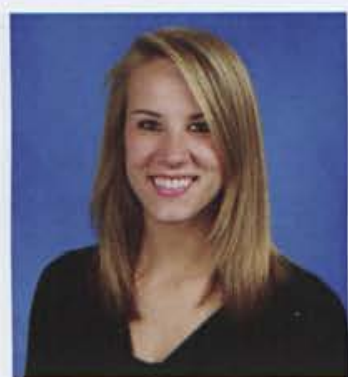

Allie Hundley

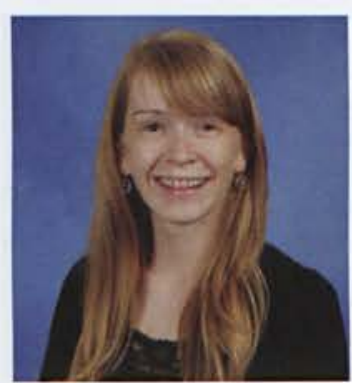

Megan Jahnke

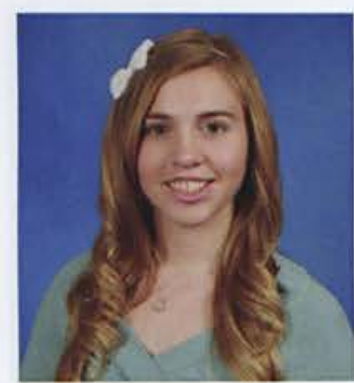

Rachel Johnson

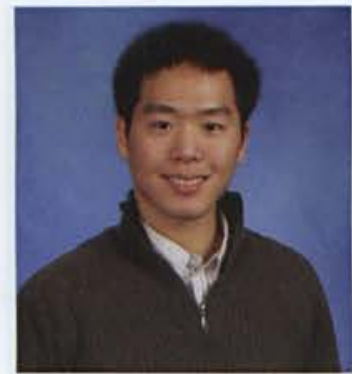

Sang Kim

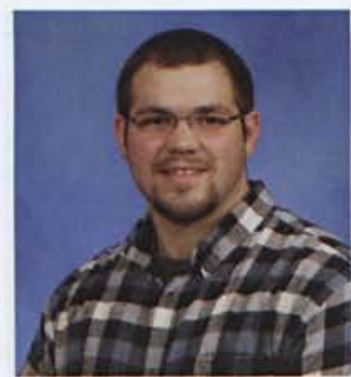

Phil Kochsmeier 


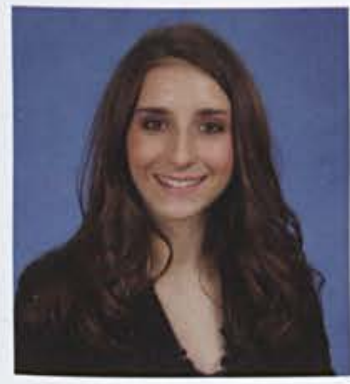

Christine Krapohl

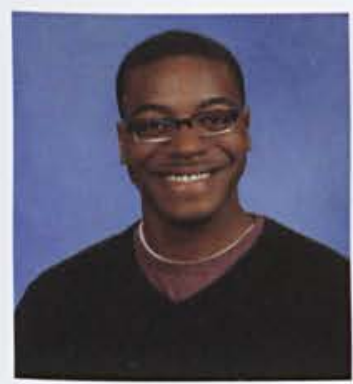

Aaron Lane

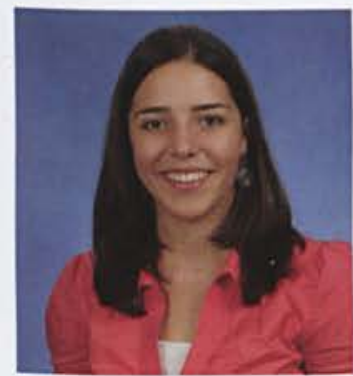

Meredith Lawrence

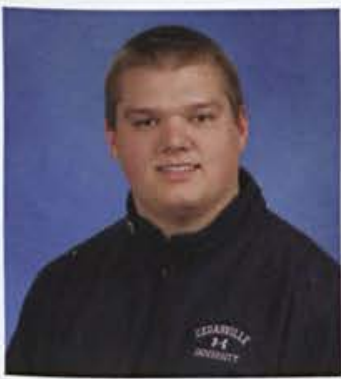

Sam Lemaster

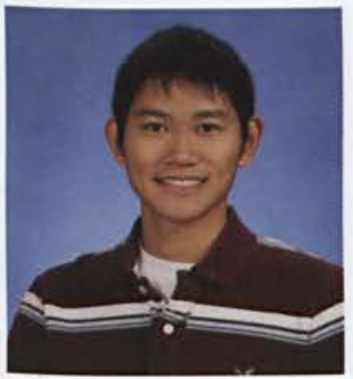

Stuart Li

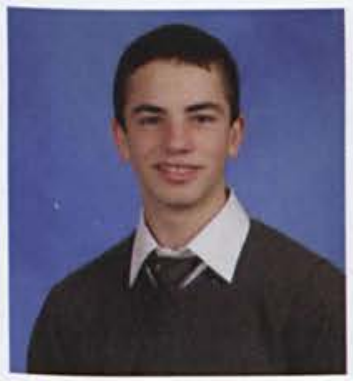

Jordan Long

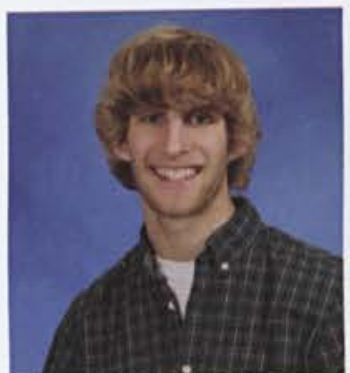

Christopher La Croix

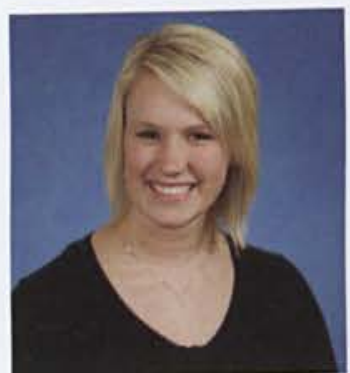

Katherine Langton

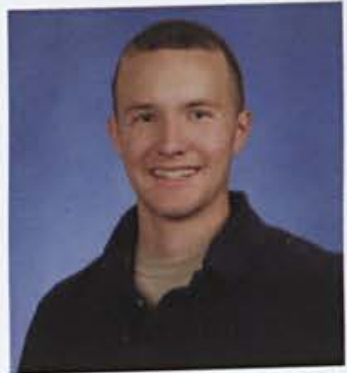

Jacob Layer

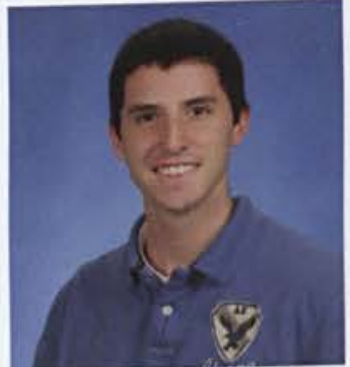

Michael Leonzo

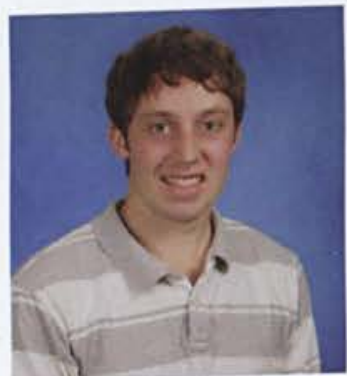

Brian Littlejohn

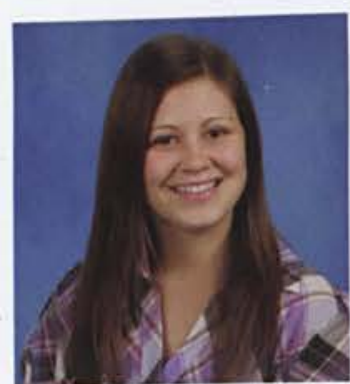

Megan Lowe

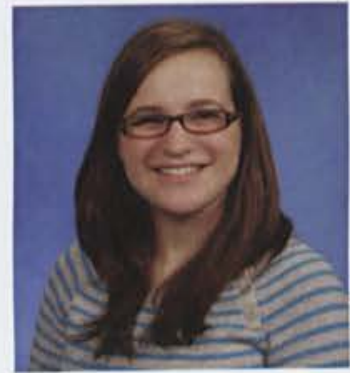

Jessica Lagucki

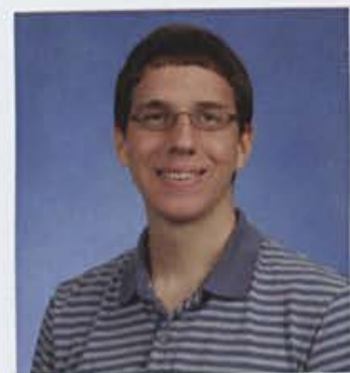

Tieg Laskowske

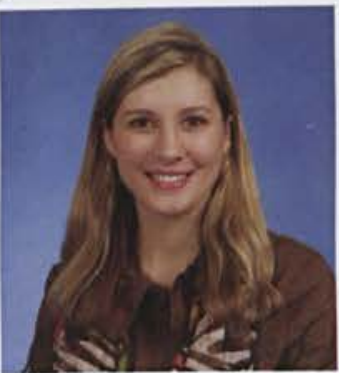

Elizabeth Learst

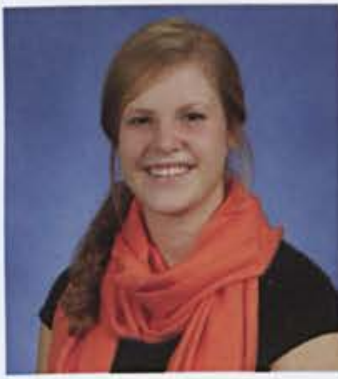

Meredith Lepage

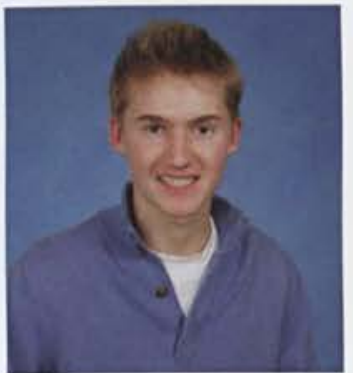

Kenneth Littrell

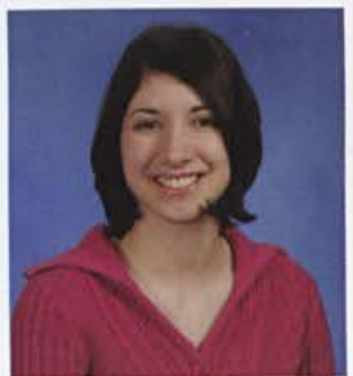

Karen Lucashu

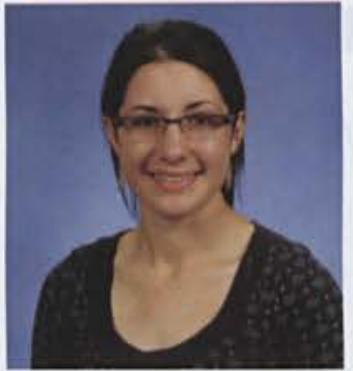

Hannah Lamos

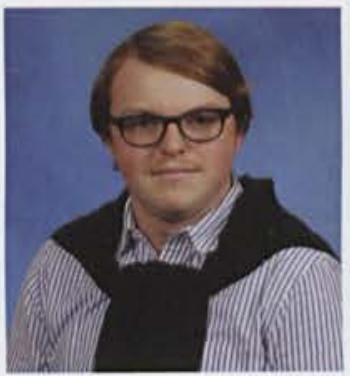

Jason Laub

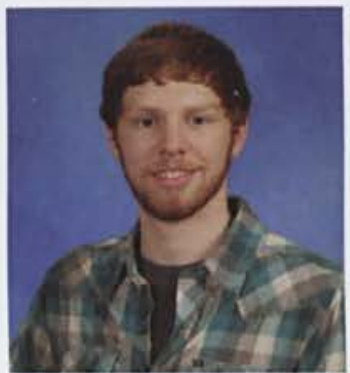

Scott Leavens

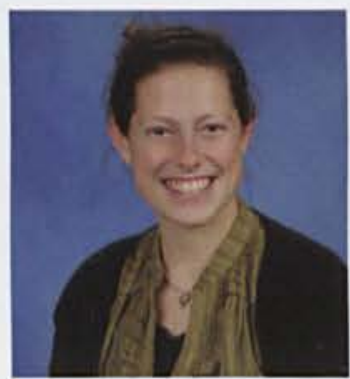

Kristen Lewis

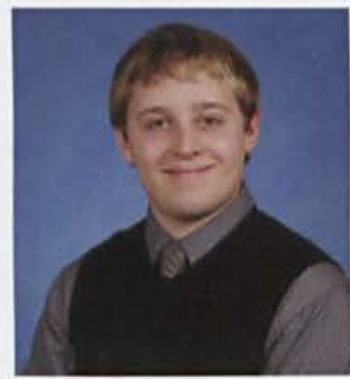

Adam Lockwood

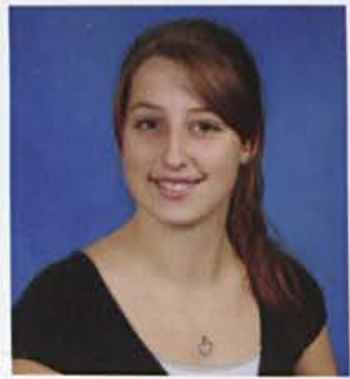

Amelia Lyons

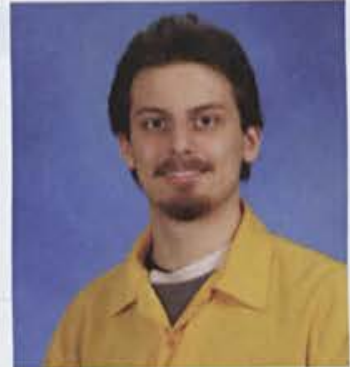

Joseph Lamy

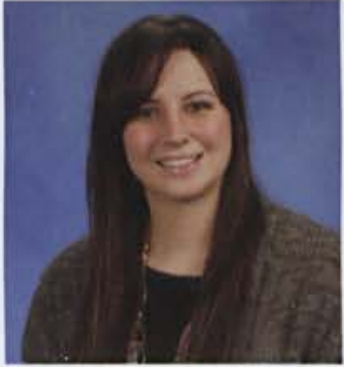

Brittany Lawhorn

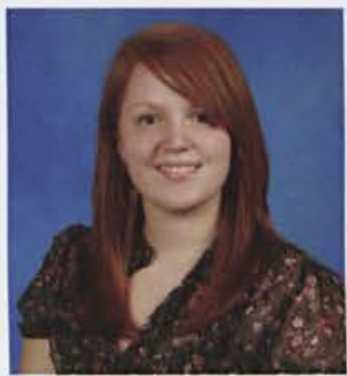

Hilary Leese

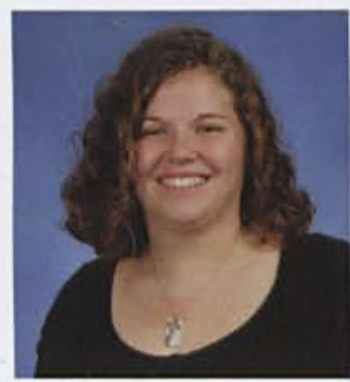

Rachel Lewis

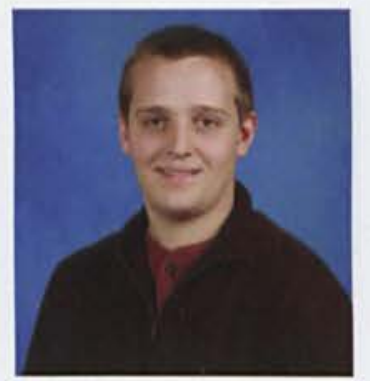

Alan Lockwood

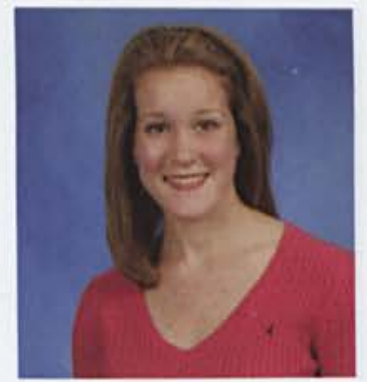

Rebecca Macgilvary 


\section{SOPHOMORES}

Laura McAnallen

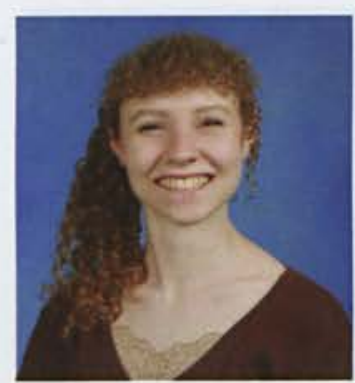

Amanda Miller

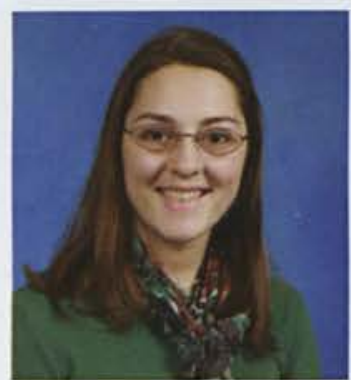

Sarah Morse

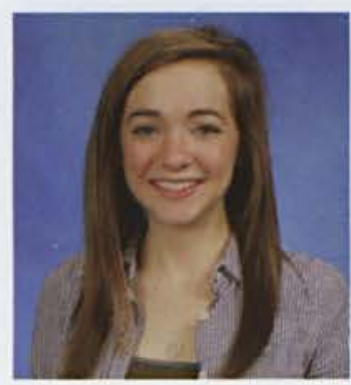

Rachael Myers

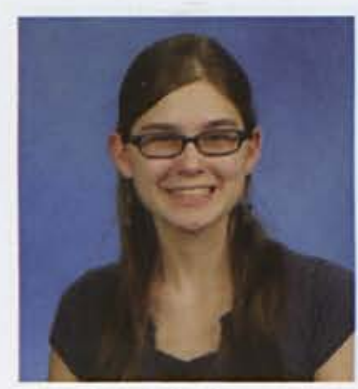

Sarah Nichelson

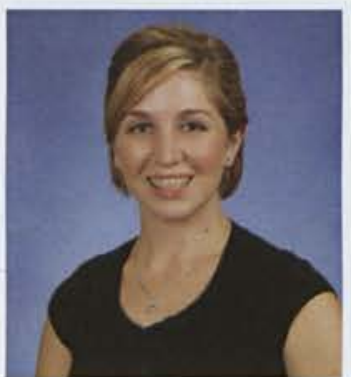

Christa Marquardt

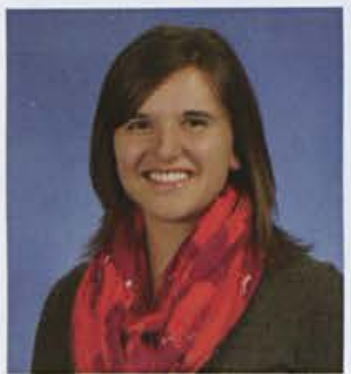

Ivy McClenahan

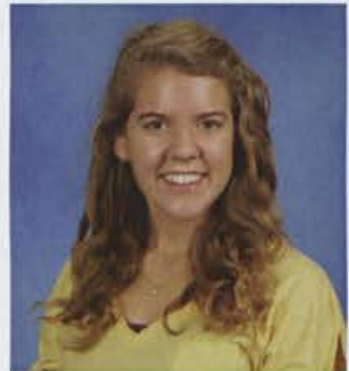

Laura Martin

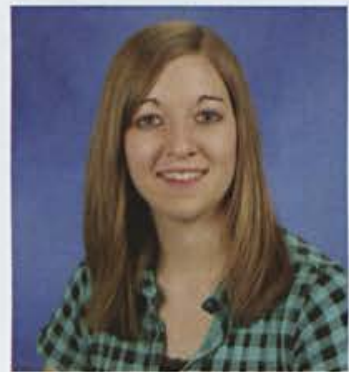

Alison McQuarry

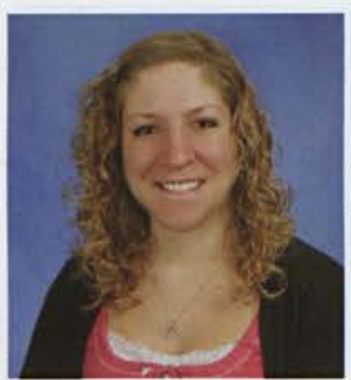

Meredith Moline

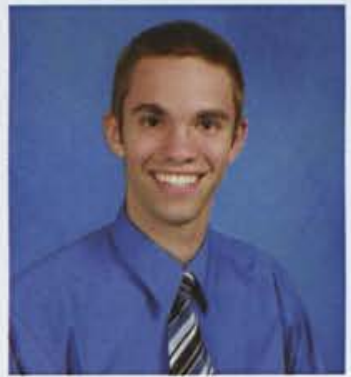

Micah Moughon

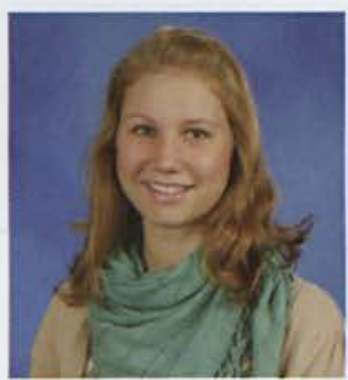

Ruth Myers

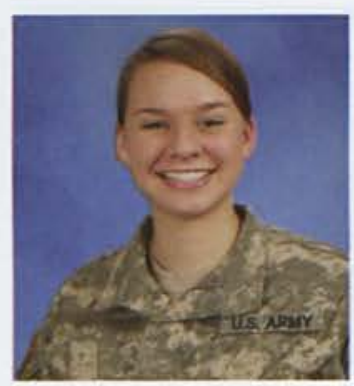

Emma Norris

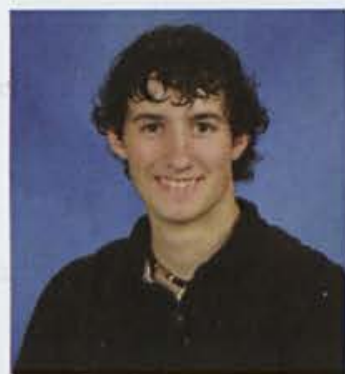

Mike Monroe

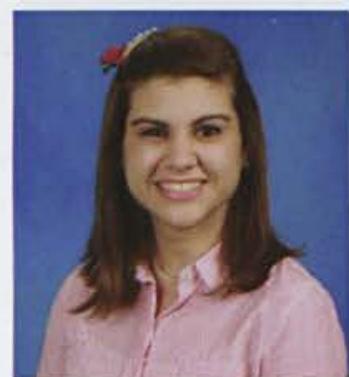

Abigail Mounts

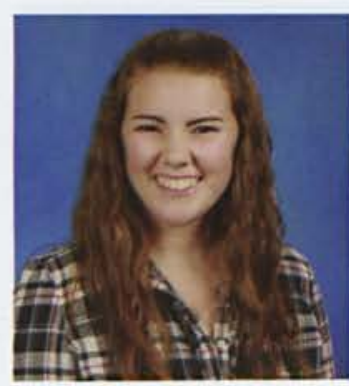

Laura Nagelkirk

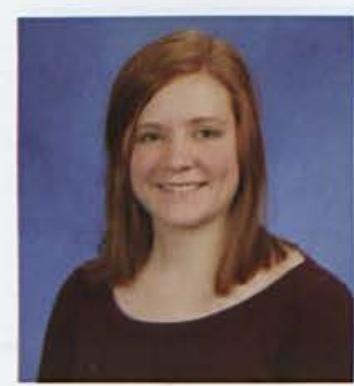

Natalie O'Neel

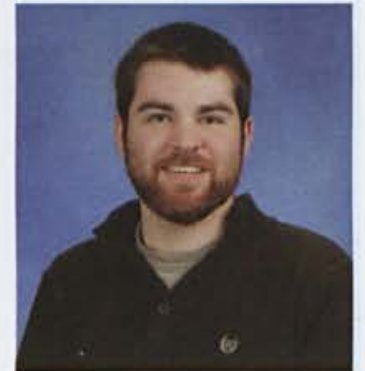

Chris Mattison

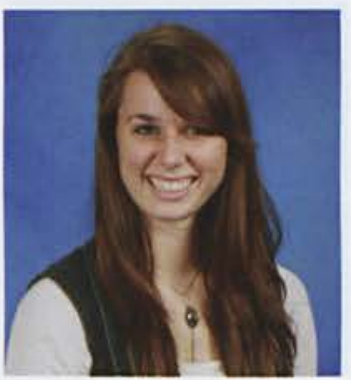

Michelle Mead

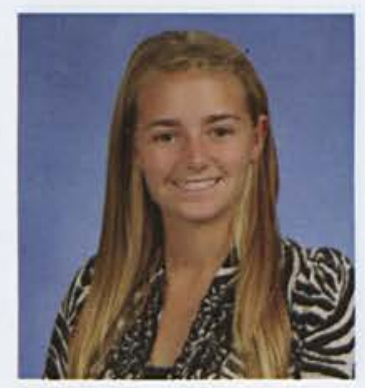

Tabitha Moore

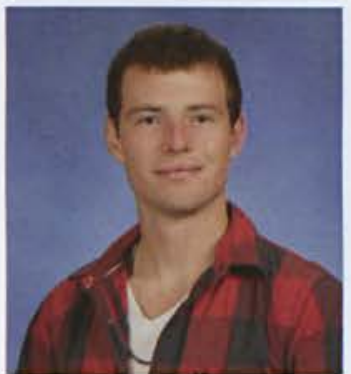

Zachary Murphy

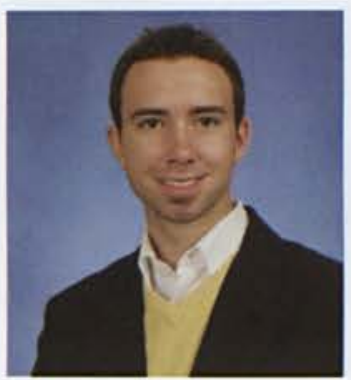

David Nelson

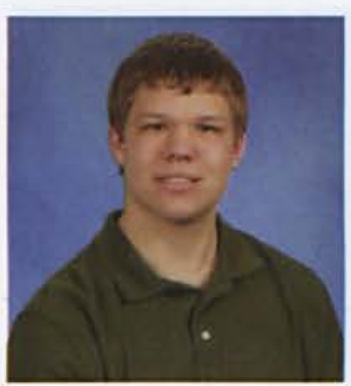

Phillip Olsen 


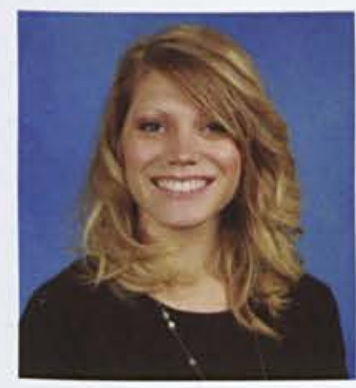

Ashley Palumbo

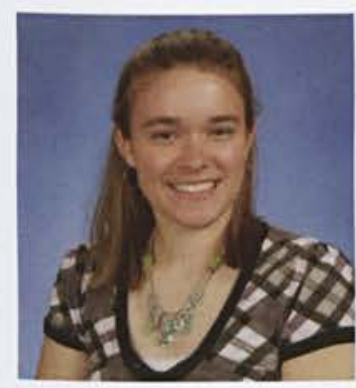

Lauren Petry

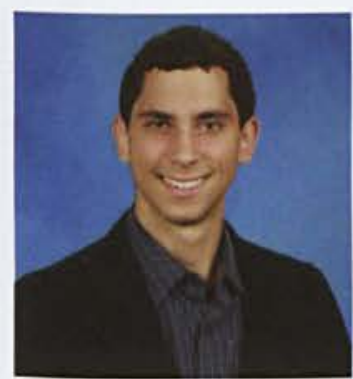

Stephen Port

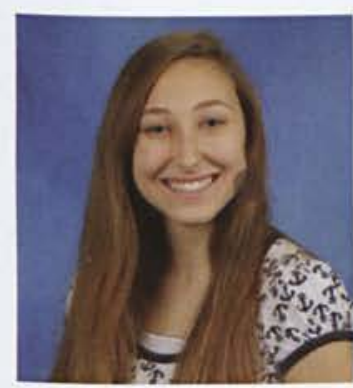

Ruthie Ray

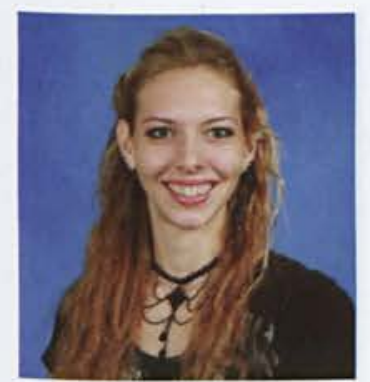

Nicole Roberts

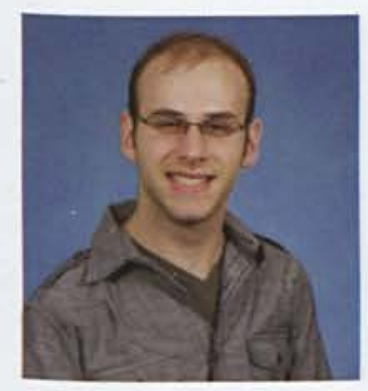

Daniel Santiso

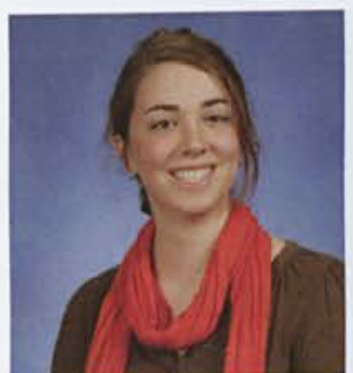

\section{Elizabeth Patterson}

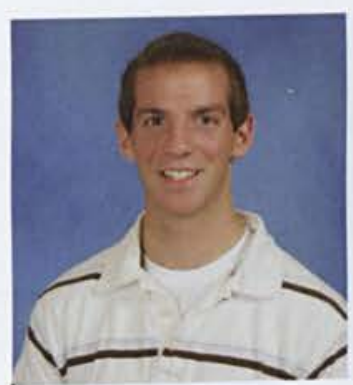

Joel Pfahler

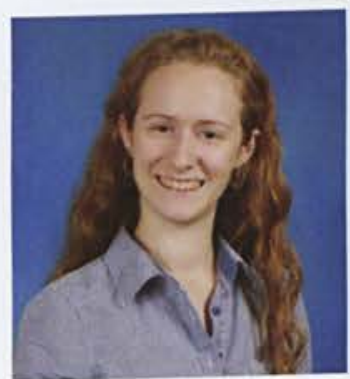

Stephanie Price

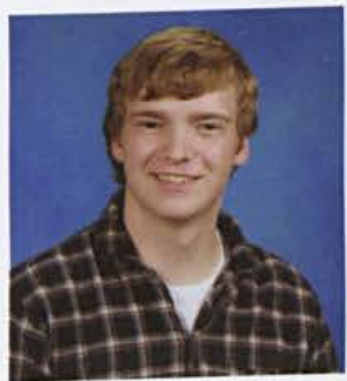

Logan Raymond

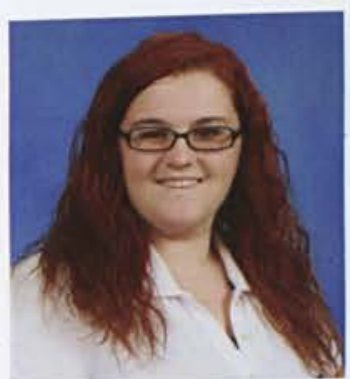

Heather Rose

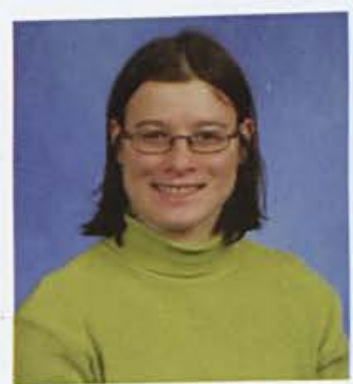

Justina Sargent

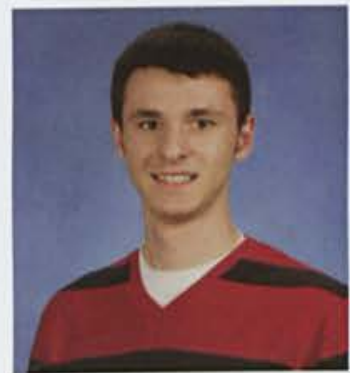

Ryan Patznick

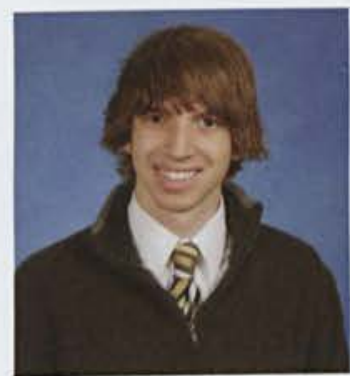

Joseph Piazza

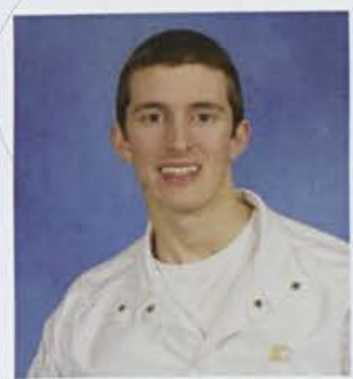

Josh Proemmel

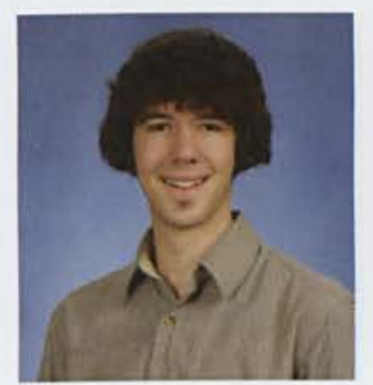

Matthew Reed

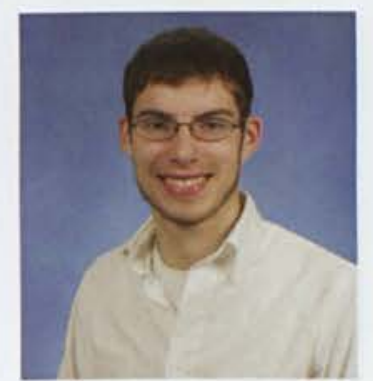

Mark Rotroff

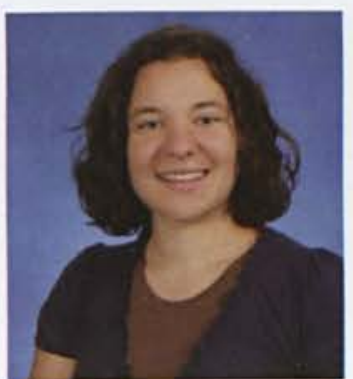

Danielle Sauer

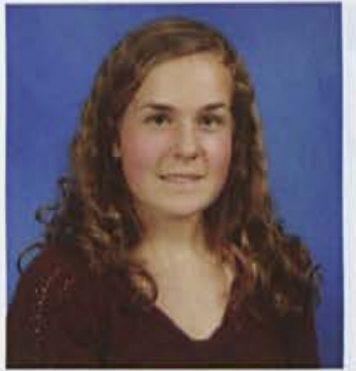

Rachel Pauling

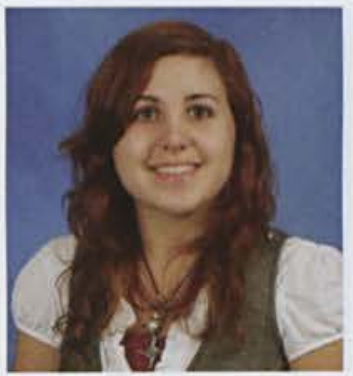

Kim Pilkenton

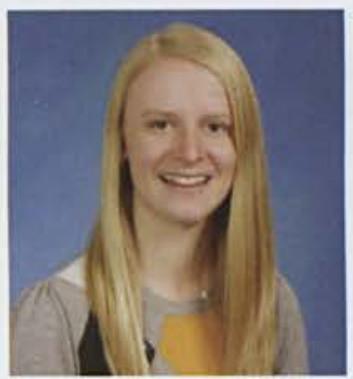

Rebecca Ragle

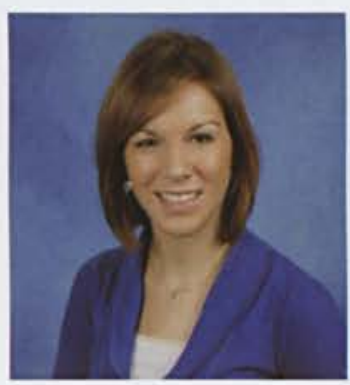

Rebecca Rich

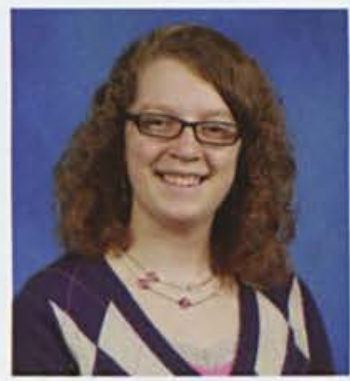

Deanna Ruman

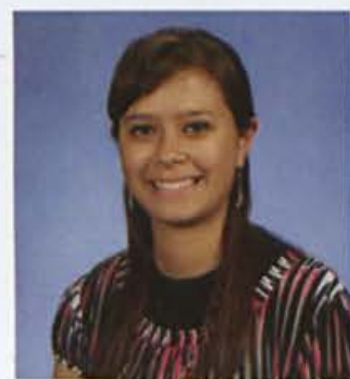

Rebekah Scarpnzzi

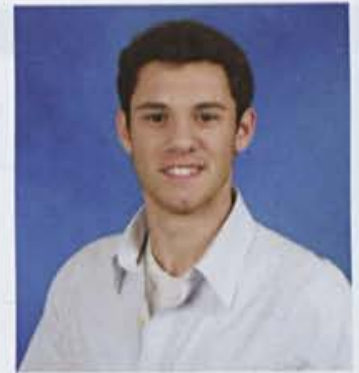

Matthew Petroff

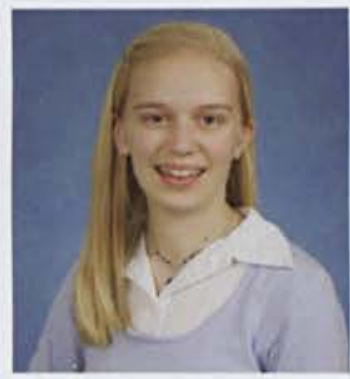

Janette Plumley

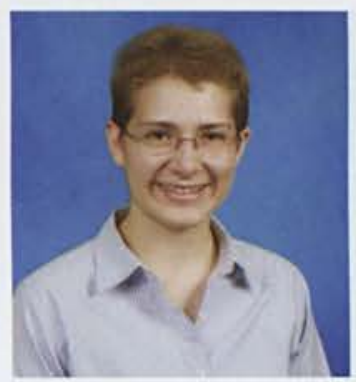

Joy Rapier

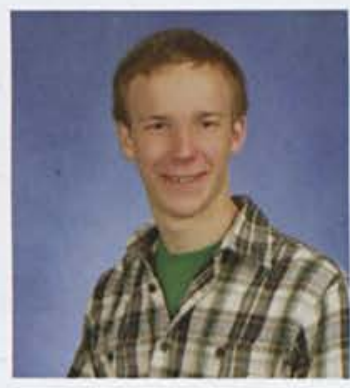

Kyle Ripperger

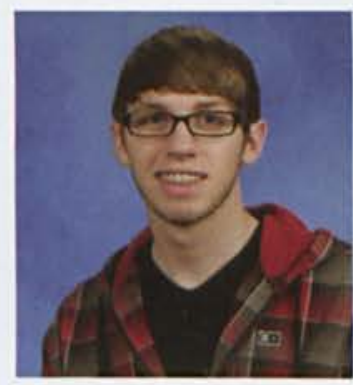

Benjamin Salzmann

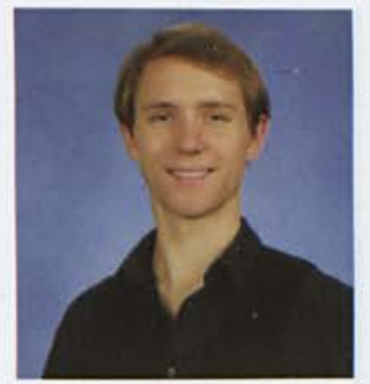

Kyle Schick 


\section{SOPHOMORES}

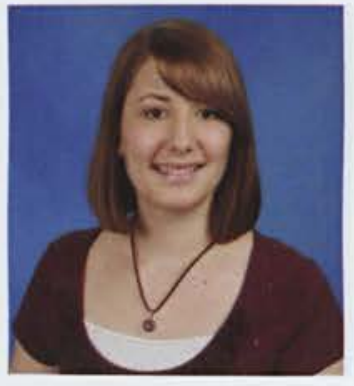

Kirsten Setzkorn

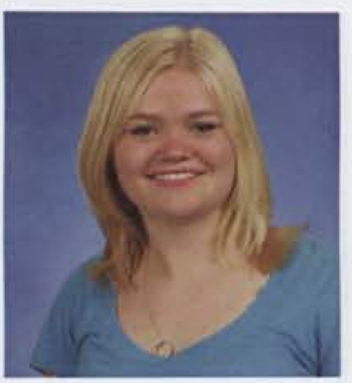

Shayla Shuck

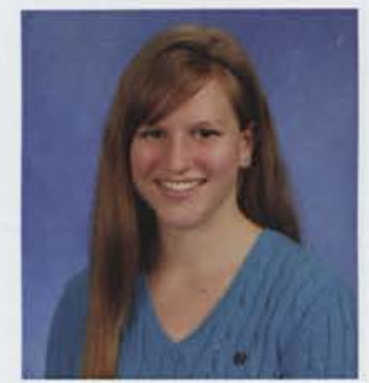

Laura Smith

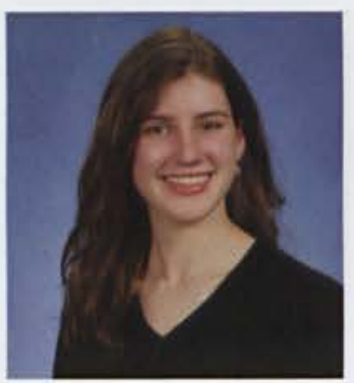

Lillian Stevens

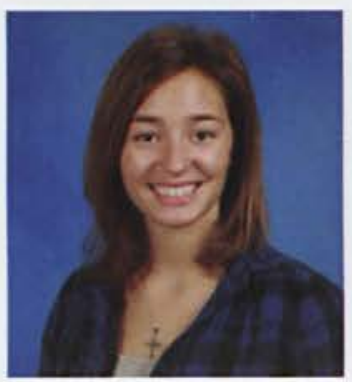

Emily Sweet

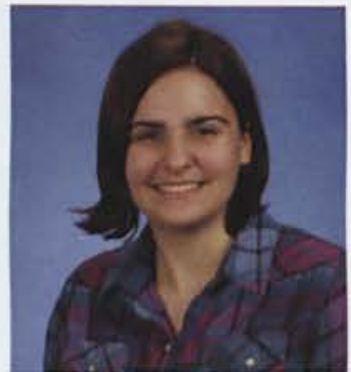

Lauren Shaw

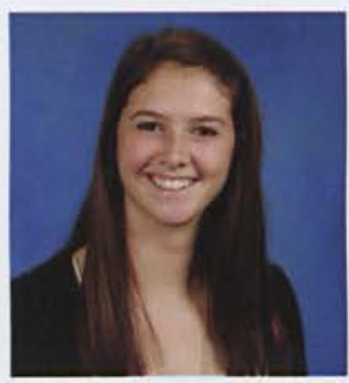

Nicole Siefert

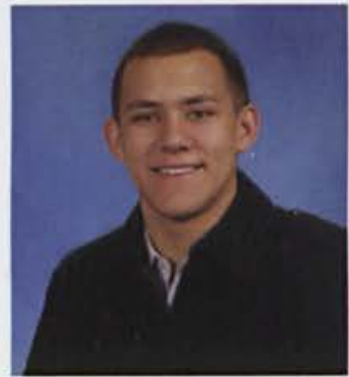

Ridley Snowden

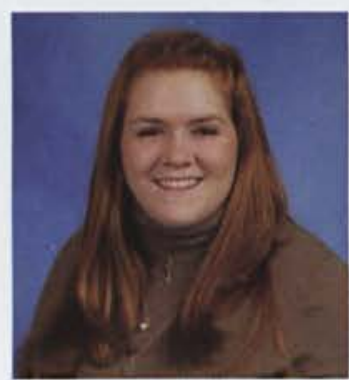

Abigail Stitzinger

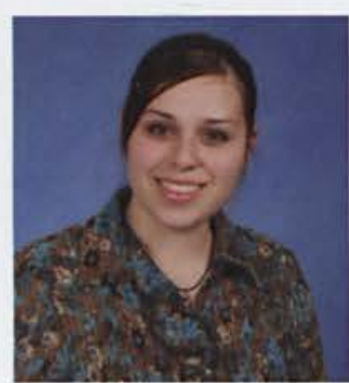

Jaclyn Sweetapple

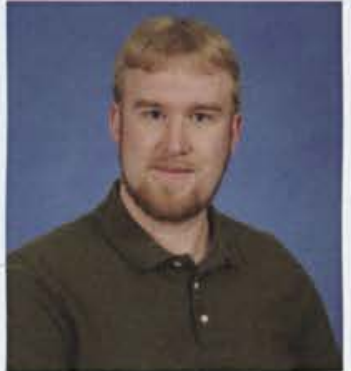

Timothy Schlabach

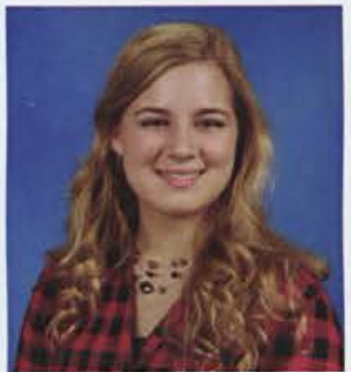

Rachel Shepherd

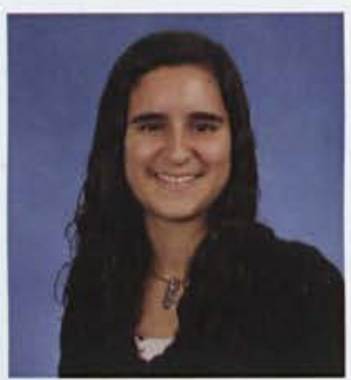

Rose Silbak

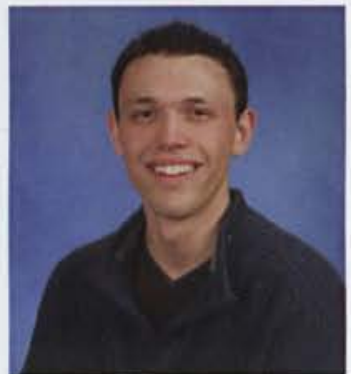

Aaron Southworth

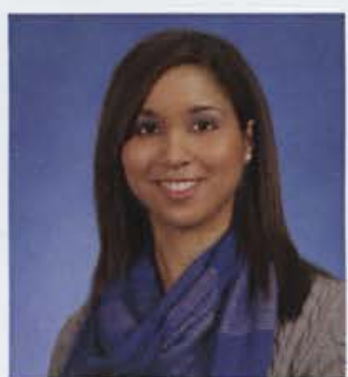

Amber Strickland

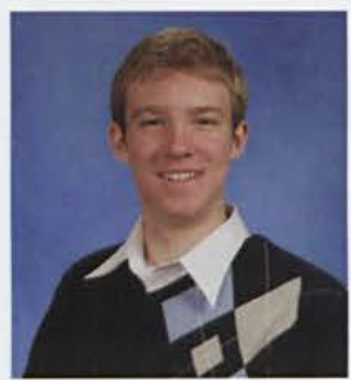

Rockwell Taylor

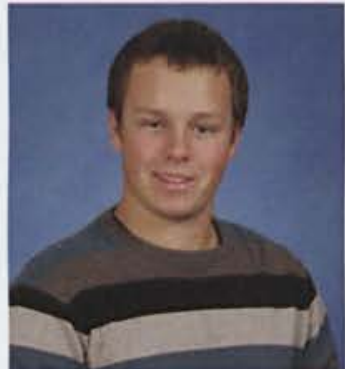

Kurtis Schultz

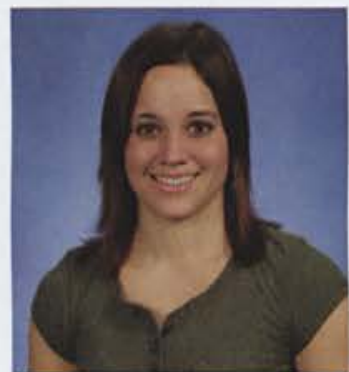

Alexandra Shiff

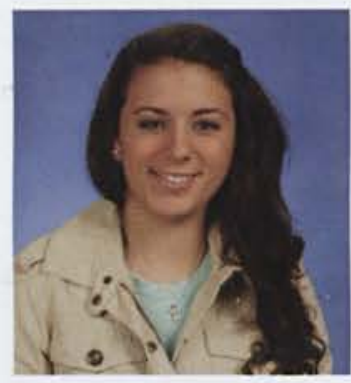

Marissa Simpson

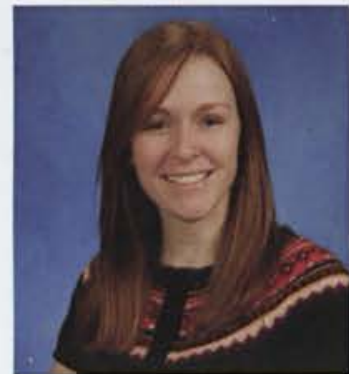

Erika Spudie

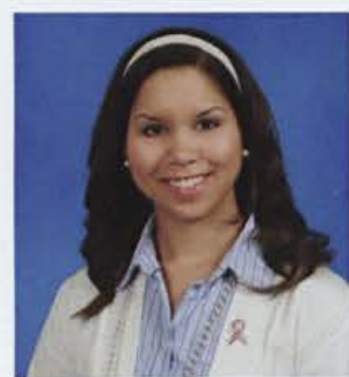

Michelle Strickland

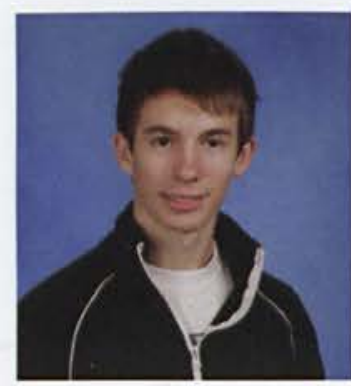

John Teat

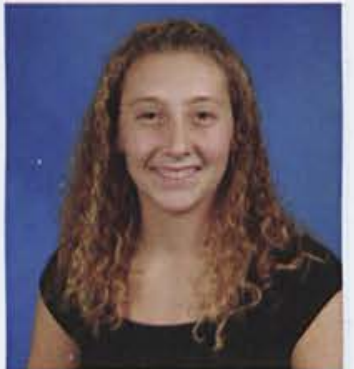

Kait Seelig

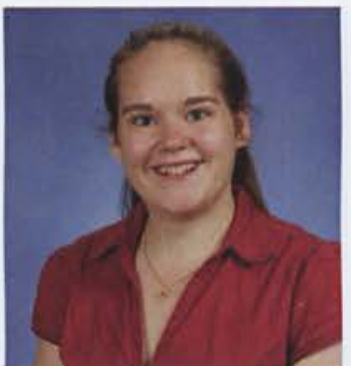

Caroline Shimeall

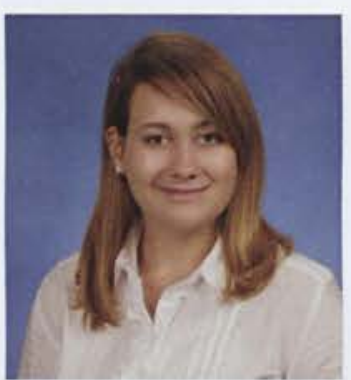

Laura Smith

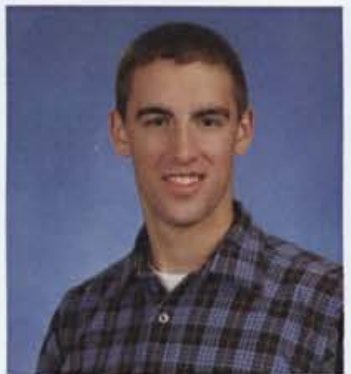

Gerrit Start

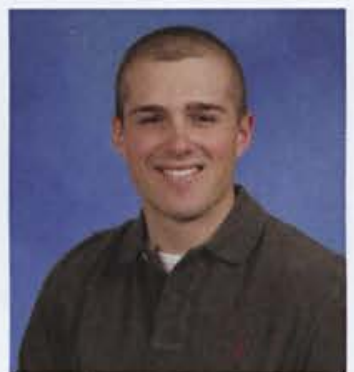

Chase Summerlin

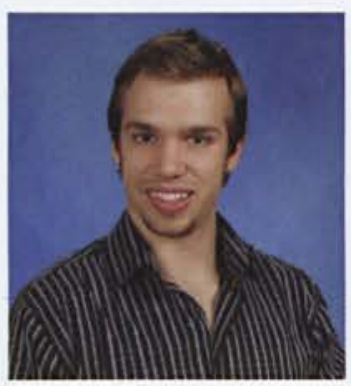

Bernard Terreblanche 


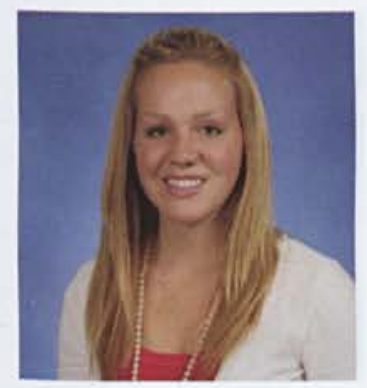

Annie Thacher

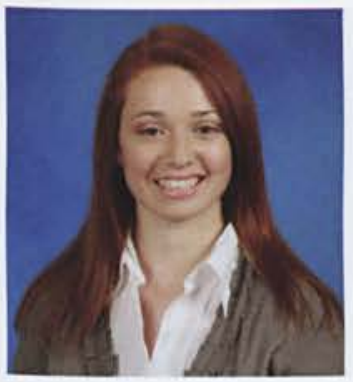

Amanda Turbett

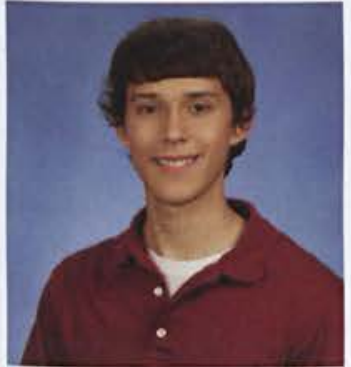

Joshua Van Zandt

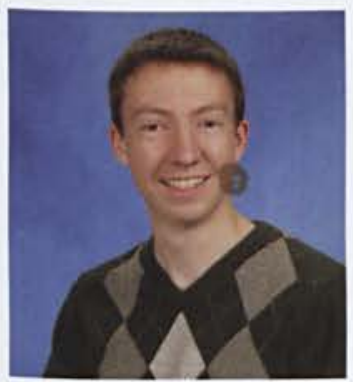

Caleb Wagner

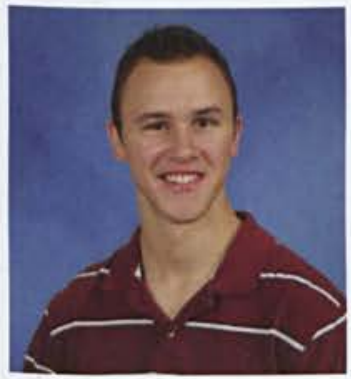

Zak Weston

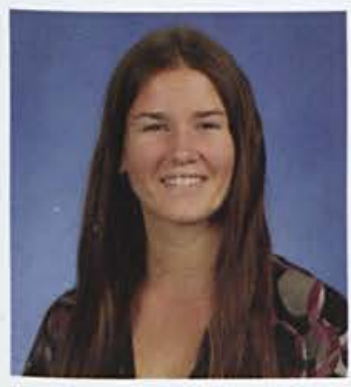

Ellen Wiseman

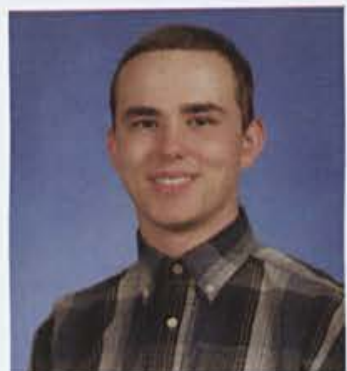

John Throgmorton

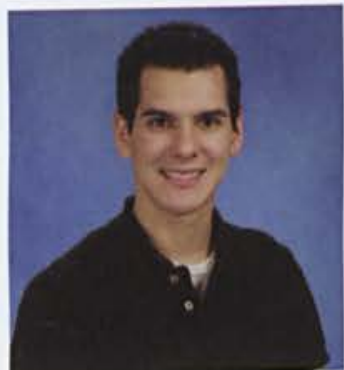

Matthew Turing

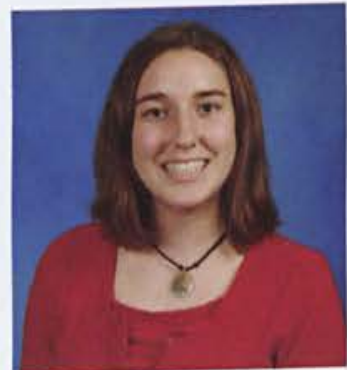

Melinda Vasser

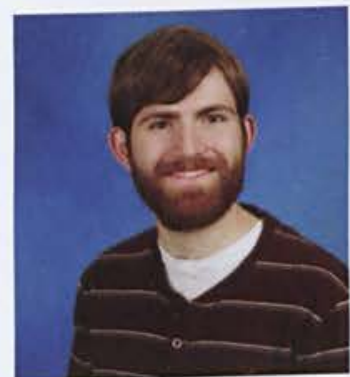

Ethan Walker

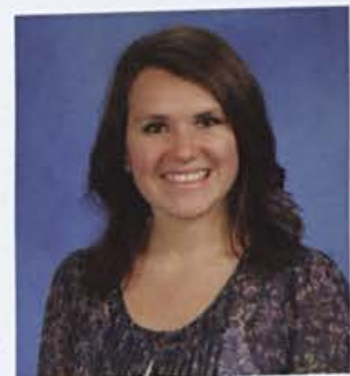

Lauren Williams

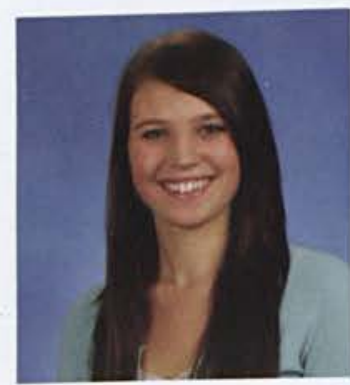

Tiffany Wojnarowski

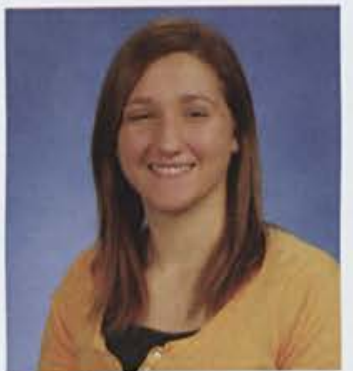

Kelly Troyer

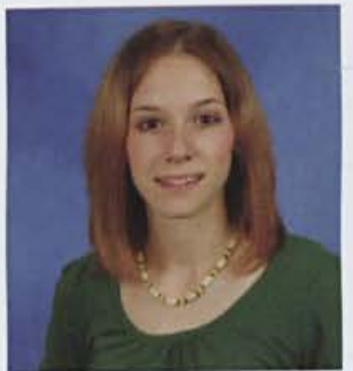

Elise Vachino

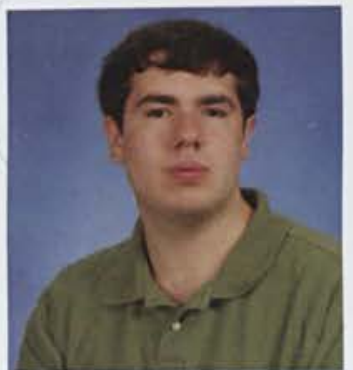

Jonathan Veith

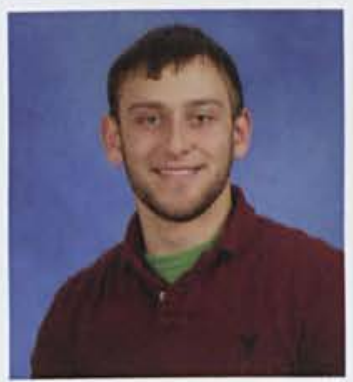

Christopher Ward

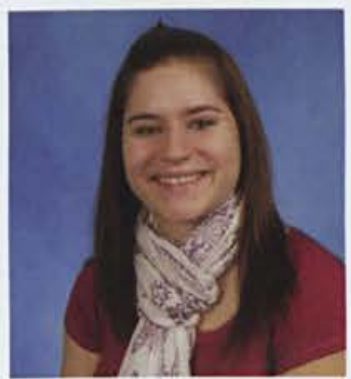

Michelle Wilson

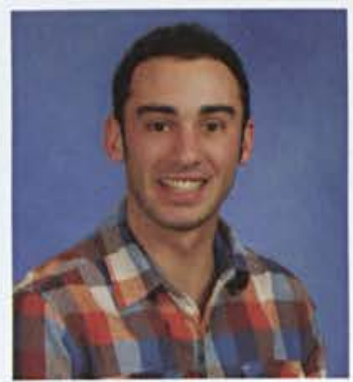

Jarrod Woodbury

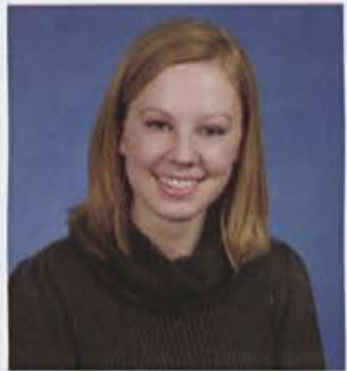

Coleen Tucker

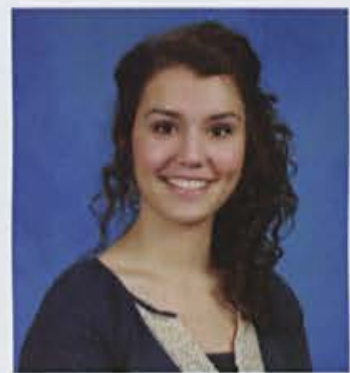

Victoria Vallas

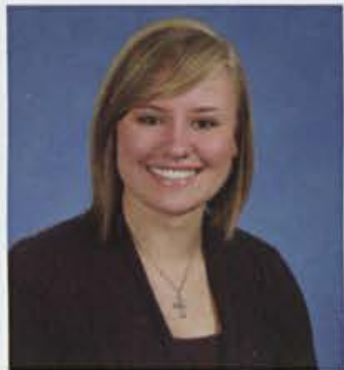

Anna Vendl

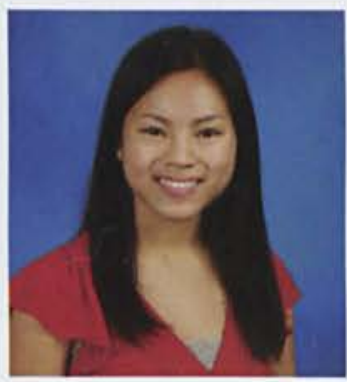

Elisabeth Ware

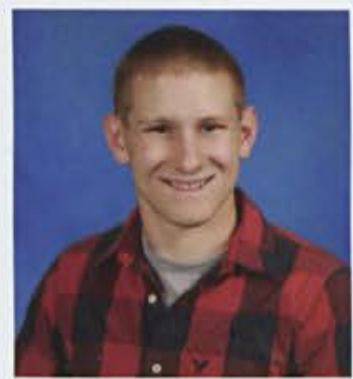

Paul Winfield

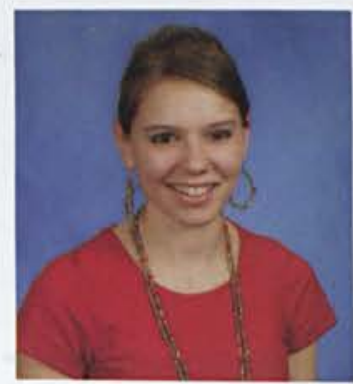

Kera Woolley

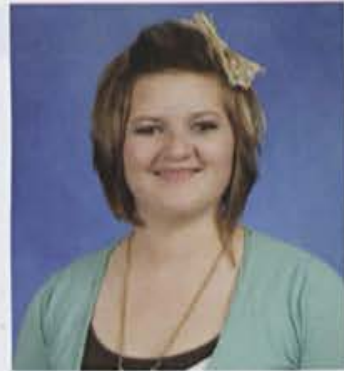

Hannah Tucker

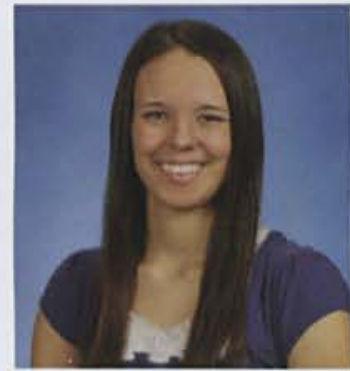

Andrea VanMeter

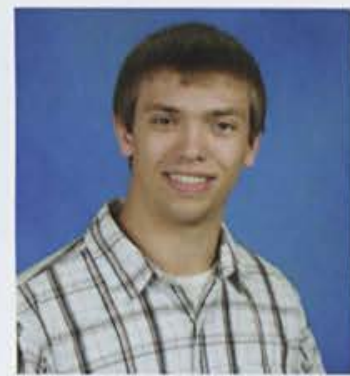

Peter Voland

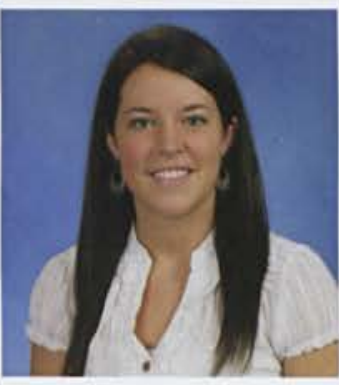

Hannah Wegman

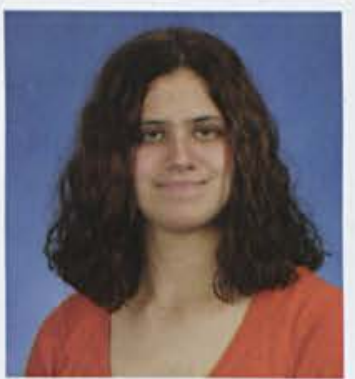

Natalie Winslow

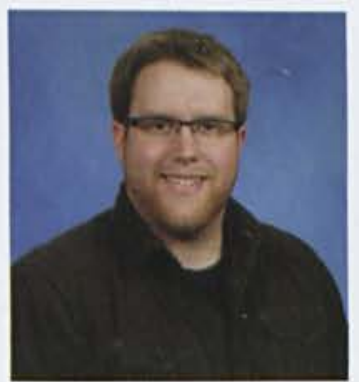

Warner Workman 


\section{SOPHOMORES}

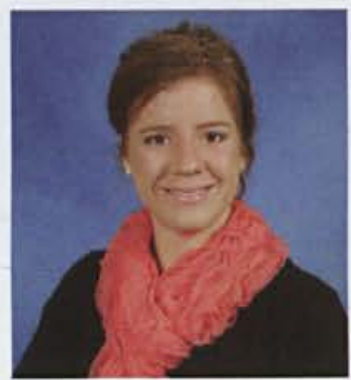

Kristin Wright

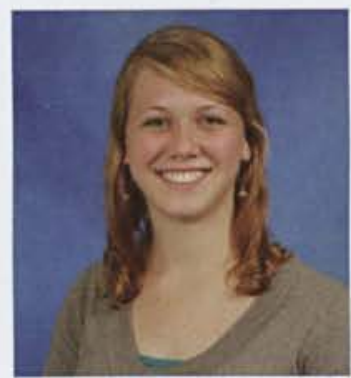

Anna Zavodney

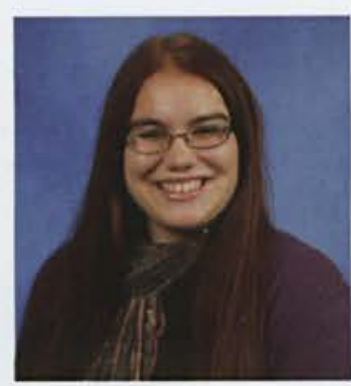

Heidi Zwiebel

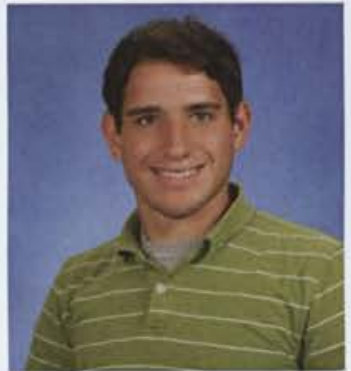

Nathan Wright

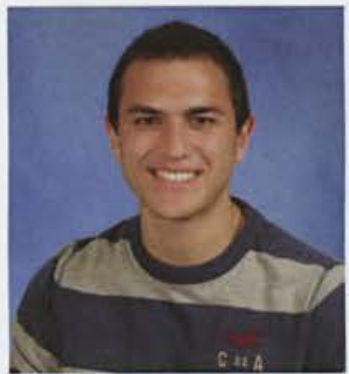

Joseph Zerka

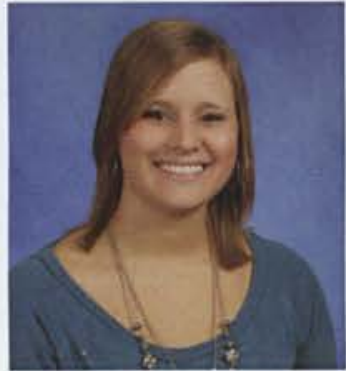

Amy Wuobio

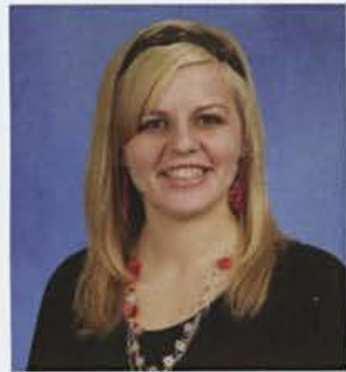

Mary Zimmerman

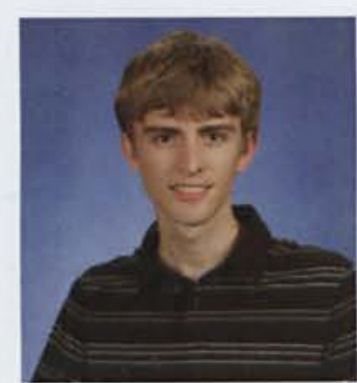

Ethan Zonca

\section{Natalie Youngquist}

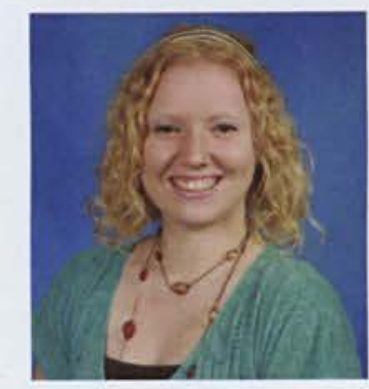

Jacie Yoder

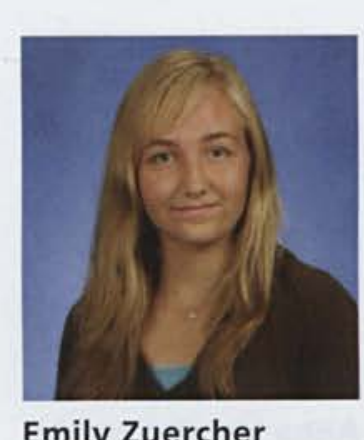

Emily Zuercher

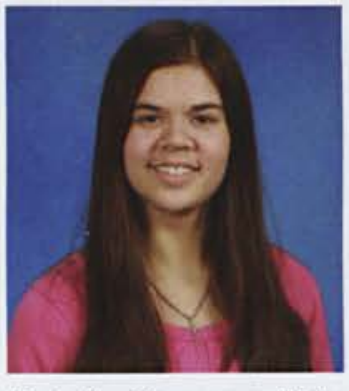





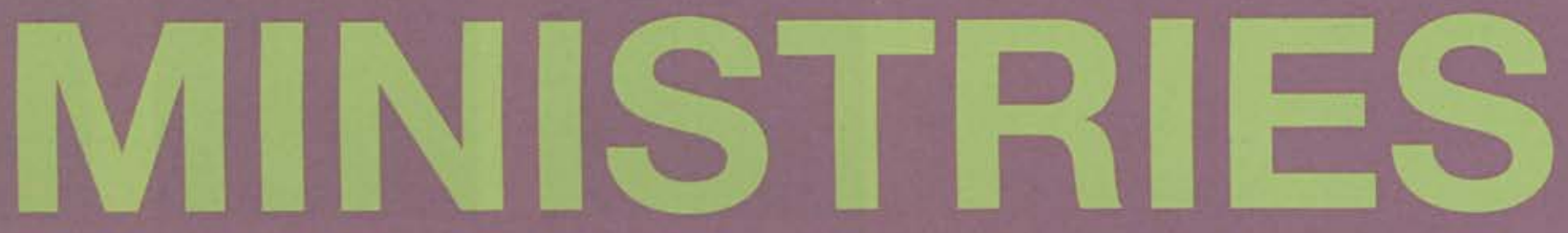

noun, plural \'mi-nə-strēs \A chance for Cedarville students to reach out to the community through service; sometimes takes the place of homework and studying, though this is not advised. 

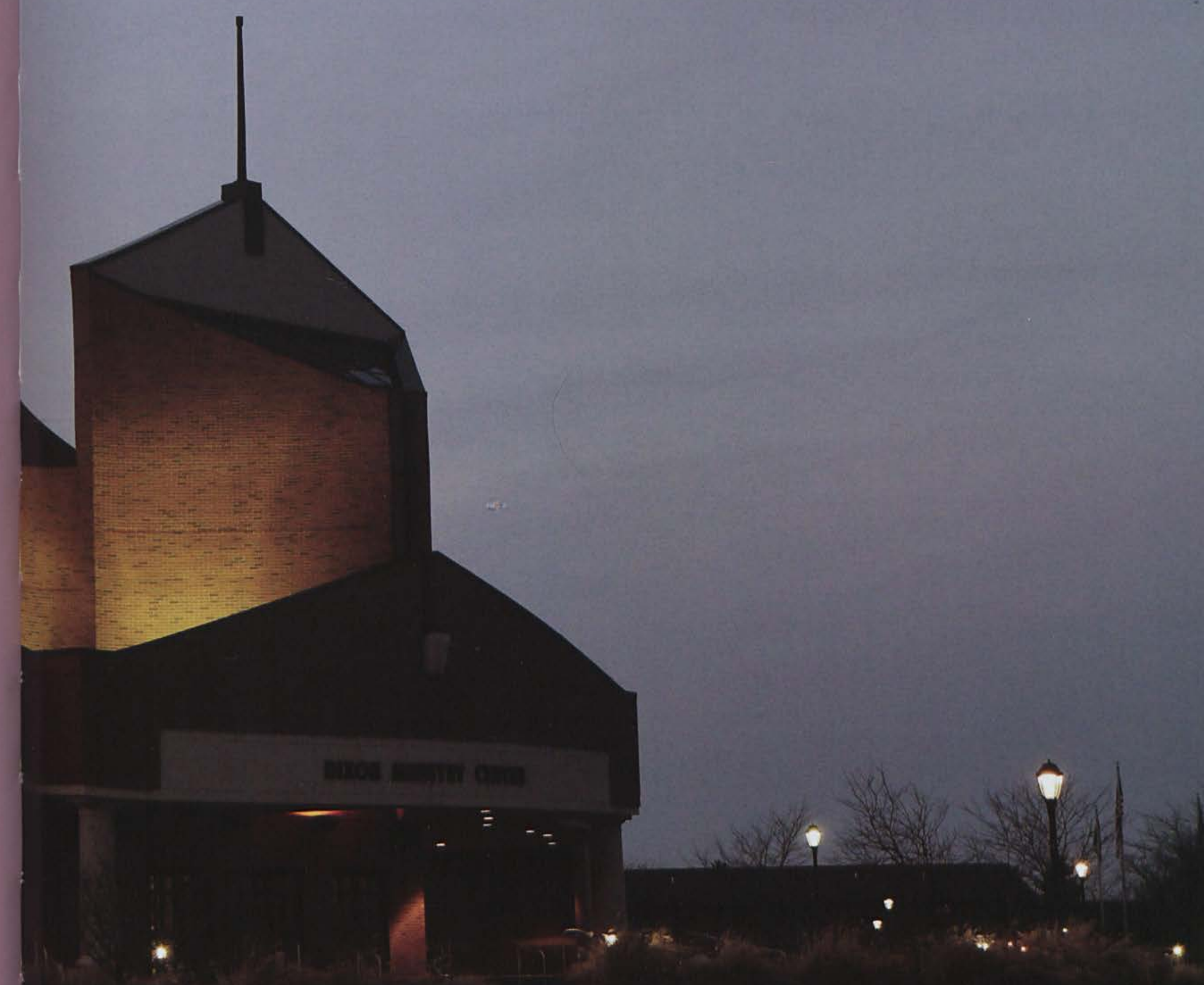

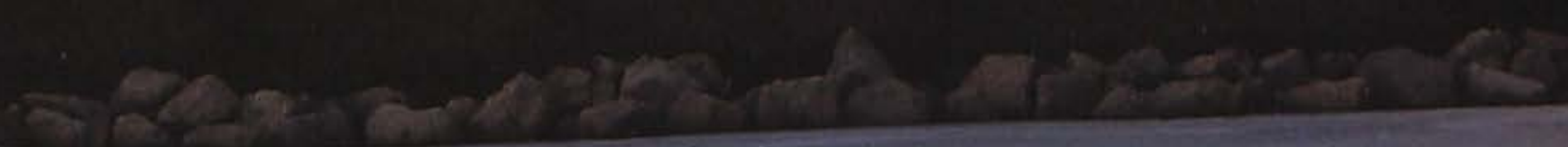

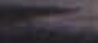

ts? 


\section{COMMUNITY MINISTRIES}

Community ministries at Cedarville equipped students for lifelong leadership and service through partnerships with local churches and community organizations. These volunteer ministry opportunities provided a context where students could apply what they learned in chapel and the classroom in order to make a powerful impact for Christ by meeting real needs in our surrounding communities. These communities surrounding Cedarville contained hospitals, detention centers, faith-based ministries, and many other types of organizations, which Cedarville students involved themselves in throughout the year.

With all of these choices, the community outreach teams allowed students the opportunity to choose minsitries related to their areas of study, personal interests, talents, and experiences. This opportunity encouraged the student body not only to maintain their personal involvement in the local church through weekly attendance but also to utilize their God-given abilities to serve Him right here in Cedarville.
"The King will reply, 'I tell you the truth, whatever you did for one of the least of these brothers of mine, you did for me."” (Matthew 25:40)

1 The Sophomore Class Ministry doing spring cleaning in the park involved a fresh coat of paint. 2 Cedarville students, Stuart Li, Austin Bush, Bayer Watson, and Michelle, go to work on the Ronald McDonald house. 3 Cedarville students volunteer at the park in Cedarville town and help by cleaning up trash and painting the gazebo 4 Josh Schindehette, Sean Powers, Dave Kauffman, Melody Lightner, Meredith Sumner, Michael Leonzo, Natalie Tribbett, Josh Prommel, Lindsay Smith, Elizabeth Hansel, Alex Boucher, Crystal Groves "unload" at the Greene County Jail for their ministry. 

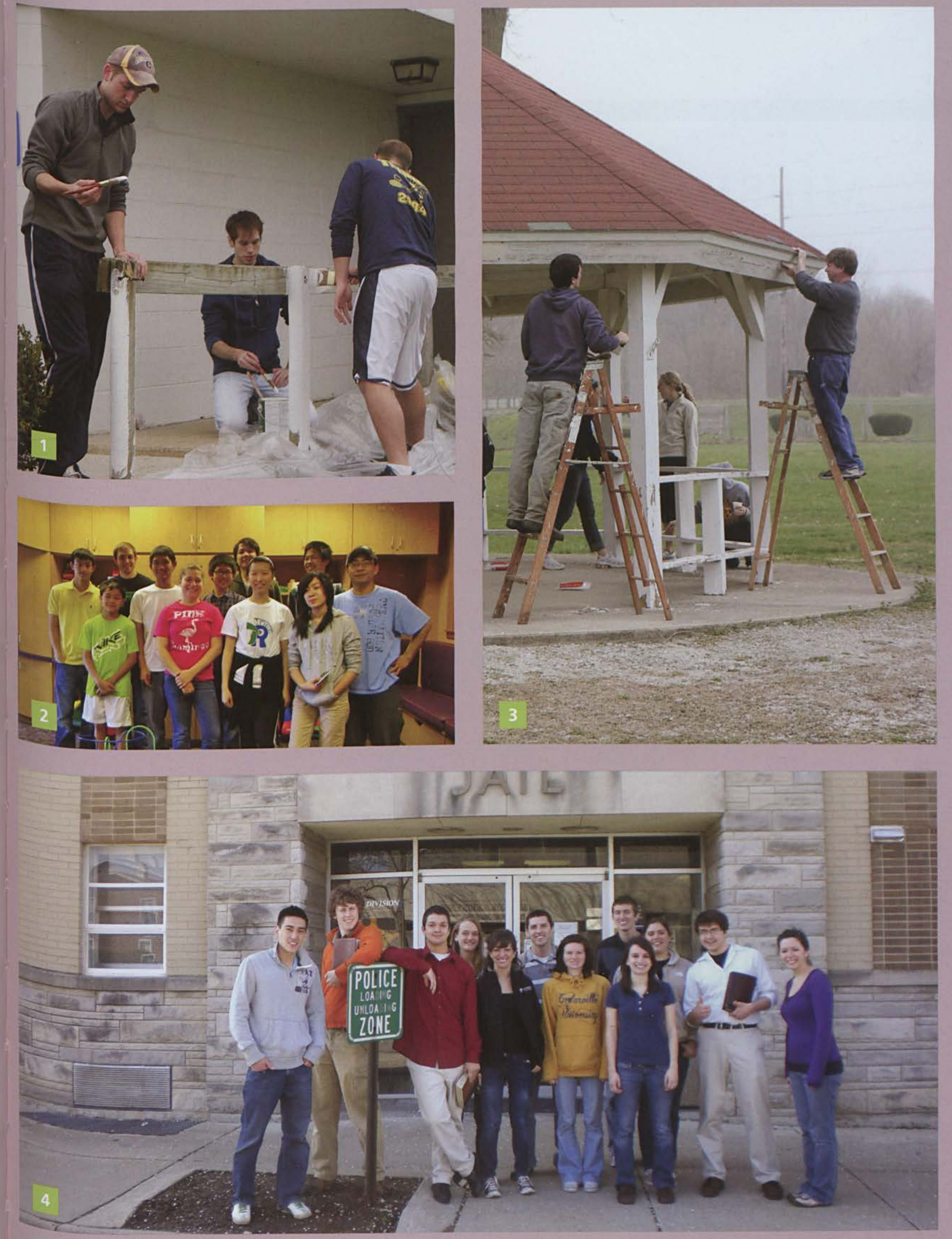


\section{MISSIONS TRIPS}

Mission Involvement Services sent four teams to four different countries over Spring Break, and they each had opportunities to serve in unique ways.

Assistant Professor of Finance Jeff Guernsey led business students from SIFE to Bolivia. Brian Nester, Director of MIS, said this was the first team to go to Bolivia since he has been working with MIS. On their trip, students did a business analysis for a business that World Venture missionaries had started.

Another team went to Mexico to do camps for missionary kids. Nester said this trip has been repeated for the last eight years. The team did a camp for eight to twelve-year-olds and a camp for those thirteen and up. Nester said some missionary kids who were in the United States flew back to Mexico just so they could attend the camp.

"I like to hear their stories right off the plane."

(Brian Nester)

Sophomore Ruthie Ray said the team that went to Peru to help at childcare centers "really bonded" and "created friendships that hopefully will last a lifetime." "The most memorable moment was when our leader, Ken, was trying to tell the kids to sit down, or sentarse, but instead, he kept saying siete, or seven. The poor kids were so confused because they couldn't understand why he was yelling the number seven at them!"

Eleuthera in the Bahamas was the destination of the fourth team. They ministered to kids and through construction. Two of the people who hosted the team were Cedarville graduates.

Though Nester didn't go on a Spring Break trip and usually doesn't, he said a highlight for him is sending off and picking up the teams. He likes to meet them at the airport when they return. "I get to hear their stories right off the plane," Nester said.

\footnotetext{
1 Involved students from the Engineering Department show off their tools on their mission trip to HCJB Global. 2 Keely Geringer, with other members of her ministry team, takes her spring break to serve the residents of Shepherds Home. 3 Lindsay Leppke bonds with the children in the village Maai Mahiu while student teaching in Kenya. 4 Jeff Guernsey leads a team of students, including Sean Gowdy, Matt Coover, and Robert Harrison, on a trip to Bolivia.
} 


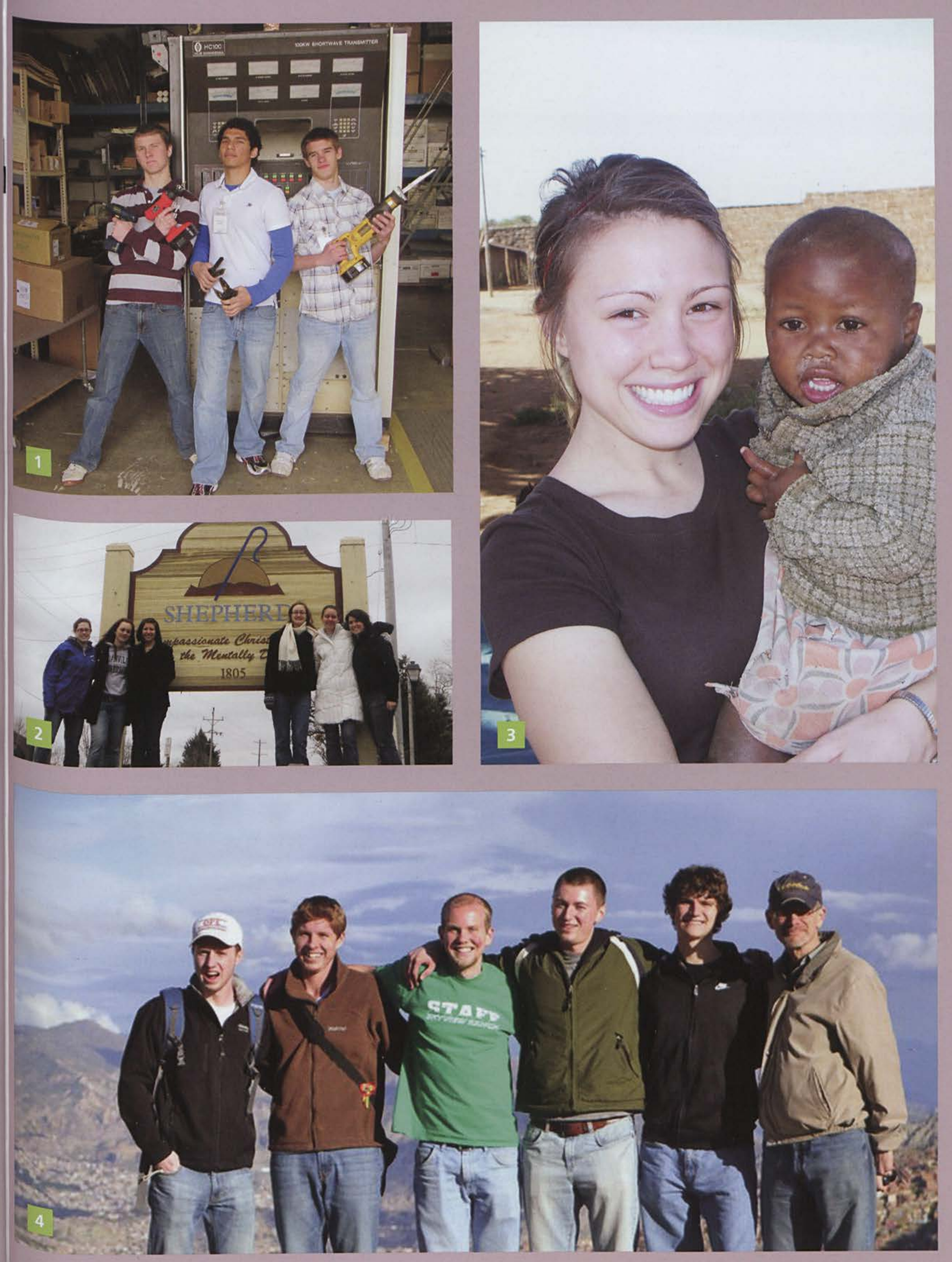




\section{MISSIONS TRIPS}

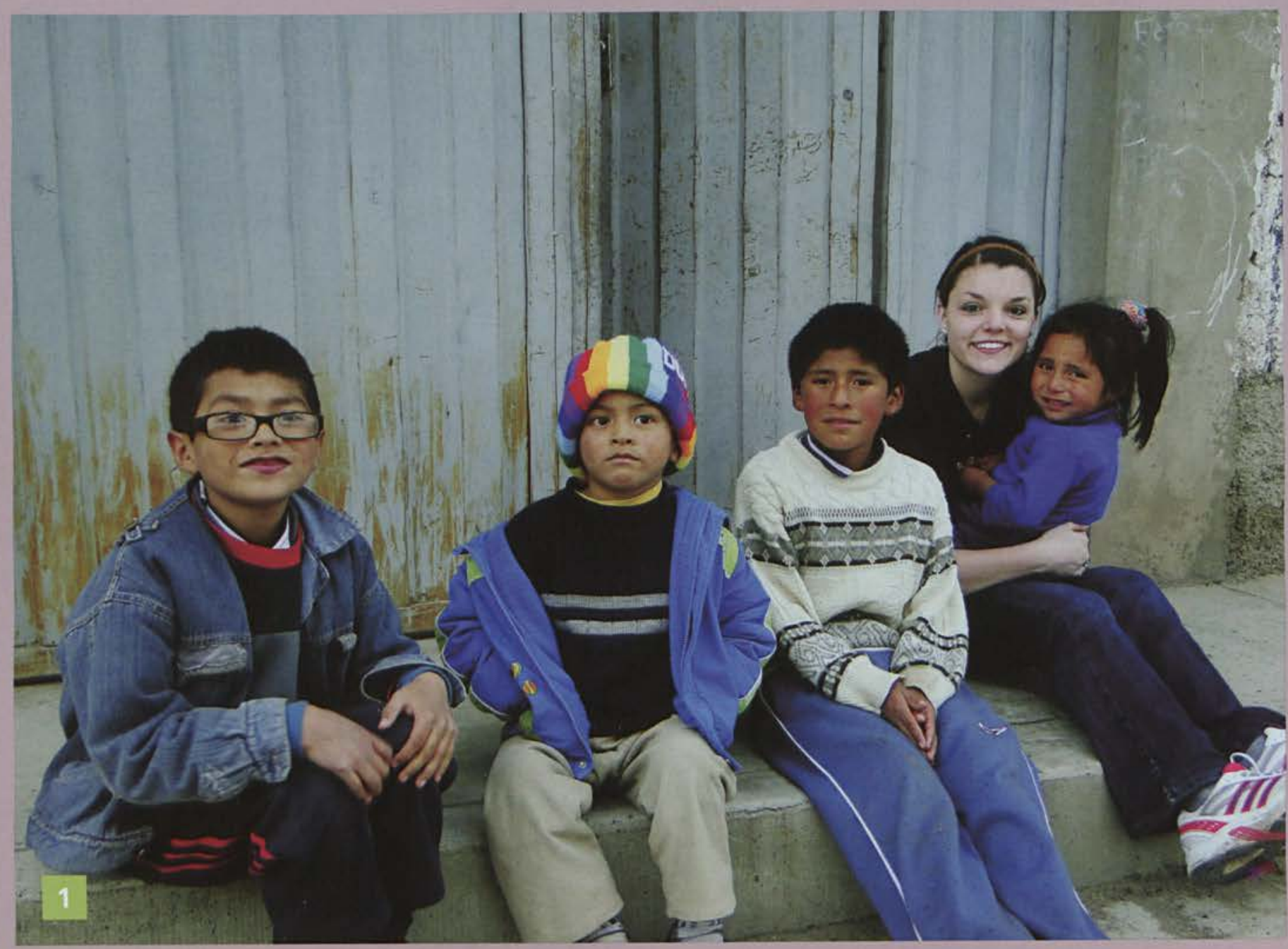

1 Rachel Harris cuddles up with some of the Peruvian children during her spring break missions trip to Peru. 2 The Inner City Impact group takes some time to do a little sight-seeing, visiting the famous Chicago Bean. 3 Missions trips can be fun for students and for the kids they work with! Kelsey Newan plays connects with one of the kids in Chicago. 4 One Cedarville team traveled to Chicago to work with the Community Ministries Chicago Urban Program. 5 Cedarville students to Peru stop for a group shot in the middle of the gorgeous Peruvian landscape. 6 Keely Geringer plays card with some of the residents of the Shepherds Ministries home in Wisconsin. 
(1) (mupe In)

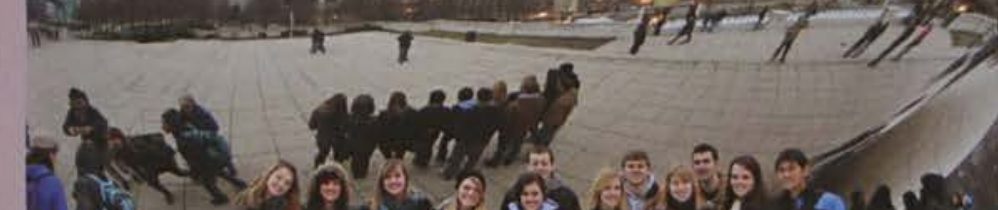

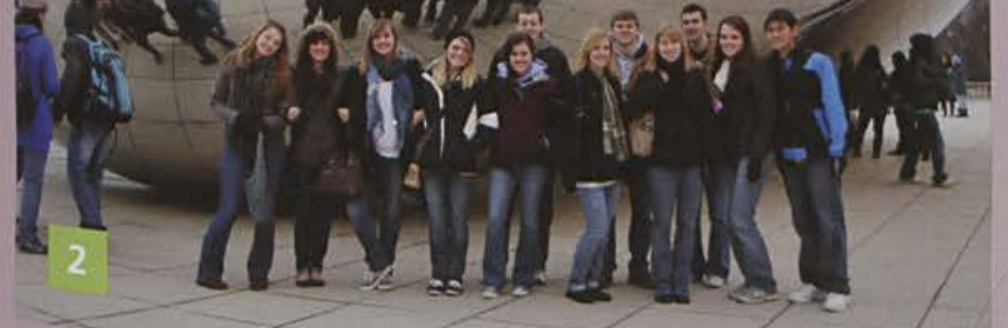
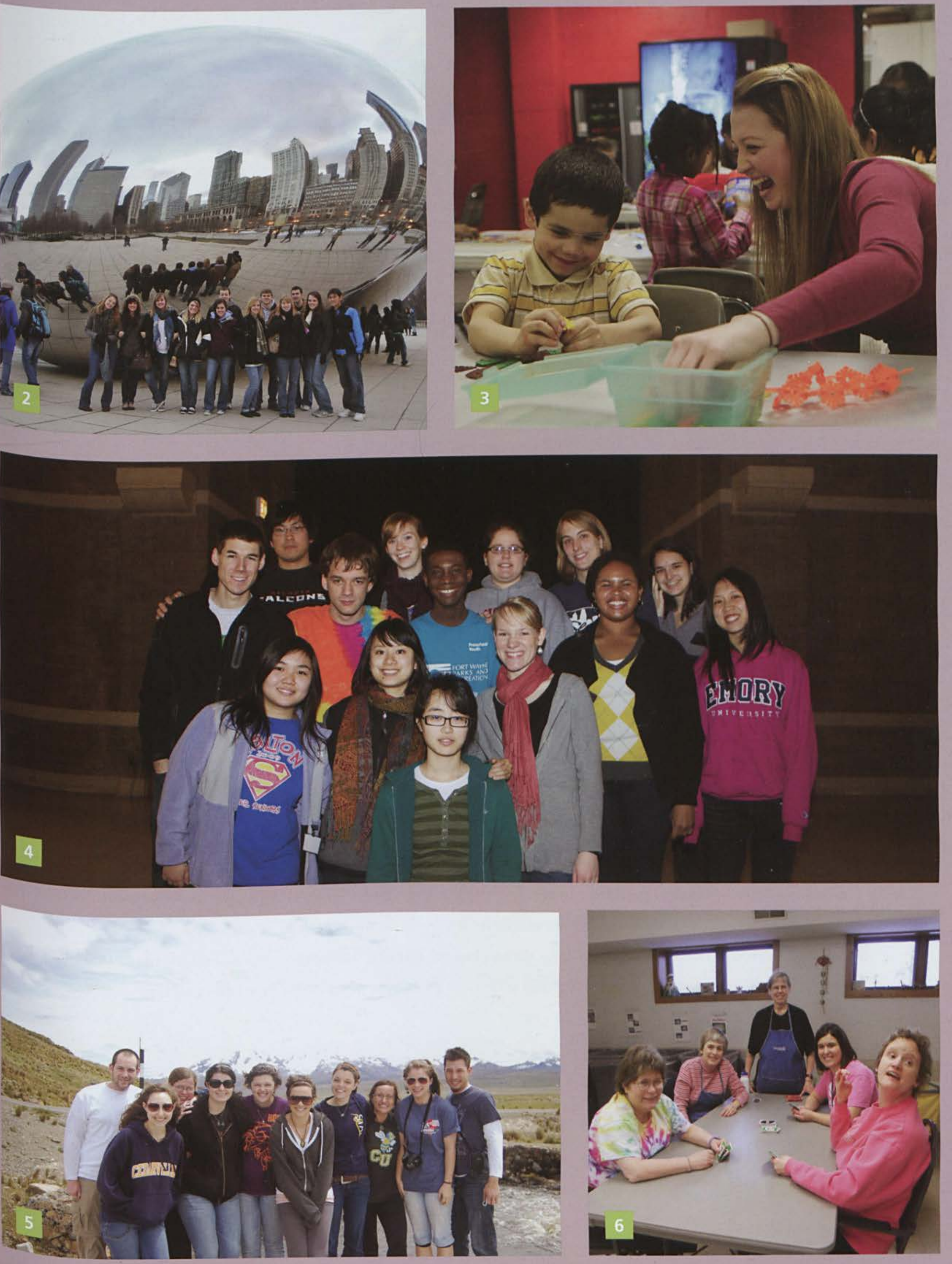


\title{
DISCIPLESHIP
}

Cedarville students heard a lot about the various ministries and outreach opportunities sponsored by SGA or other student organizations on campus. These activities were advertised in chapel, through email, and on posters and T-shirts seen throughout campus. But Cedarville University sponsered one ministry, operating all year long, that impacted the lives of many students, even if it wasn't spoken of often. That ministry was Cedarville's Discipleship ministry.

Discipleship Groups were formed at the beginning of fall semester and continued to meet throughout the rest of the school year. Freshman Becca Powlus participated in one of these groups. "I joined a discipleship group this year because I wanted to be challenged spiritually and to have a chance to develop some close friendships with other girls that I could be accountable to," she said. Discipleship Groups provided a great opportunity for fellowship, accountability, and spiritual growth. For one hour each week, students had a chance to forget about homework and other responsibilities and just engage in fellowship with other believers in an environment that was both challenging and encouraging. Some groups focused their study on a book dealing with a specific topic, while others worked through a book of the Bible. Powlus said of her experience, "It was eye-opening, convicting, frustrating, challenging, yet encouraging all at the same time."

Ves Rieches, a senior, was blessed by the opportunity to be a Discipleship Leader since his sophomore year. He spoke of his experience as both a challenge and an incredible blessing. As his senior year drew to a close, he reflected, "Cedarville would not have been the same without Discipleship ministries."
"Perhaps the biggest lesson I learned or realized was that $\mathrm{I}$ cannot lead a Bible study effectively if I am not in the Word myself." (Ves Rieches)

\author{
1 Discipleship groups help students to focus on the Bible 2 Even while fitting six girls into a \\ dorm room, Bible studies manage to let students open up to each other. 3 Prayer is a big part of \\ discipleship groups. Members often take turns sharing specific requests before they all share in a \\ time of prayer. 4 Sometimes the best thing students can offer each other is a listening ear.
}




\section{HEARTSONG}

Several changes occurred in the Christian Ministries Division touring ministry this year, ranging from organization adjustments to an additional ministry focus.

Jim Cato, Executive Director of HeartSong Ministries, said the touring teams under went the biggest change in the 25 years he has been involved in the ministry. The Touring Teams department of The Master's Puppets, Lifeline Players, and East to West no longer existed because HeartSong Ministries replaced it.

The department consisted of five HeartSong teams. With the reorganization, there was a new focus on ministering to middle school age children, so two of these teams, Heartsong: Generation teams, focused on that age group.

A third new change had to do with summer ministry locations. One HeartSong team was at Lake Ann Camp in the Upper Peninsula of Michigan all summer. They had never had a team there all summer, Cato said.

Chloe Heckman, a vocalist on HeartSong, said going to Lake Ann Camp during the school year was a highlight for her. She talked about driving in the "crazy snow" for ten hours to get there. The camp was like Narnia, Heckman said. "We were out in the middle of God's creation." While there, she said she had the most engaging worship experience she had been a part of.

Heckman's goal for the year was to make herself invisible, making it all about God. "I think it's really easy, especially for me, to be too caught up in that," she said of being up front leading. Her goal came from John 3:30: "He must increase, but I must decrease."

Cato had a goal for the year, too. He said they established that they needed to better teach the reality that the Gospel is to be lived out. "The Gospel is not something that we just accept at one time," Cato said.

\section{Hayden Browning leads the Heartsong Blue Team as they minister to high school students during the Freeze Out at Lake Ann Camp. 2 Candy Hill accompanies the Heartsong team during their all-together chapel. 3 Grayson Cato sings with his team and a group of high-schoolers during one of their travelling ministries. 4 Heartsong helps the Freeze Out students to lift their voices in worship.}



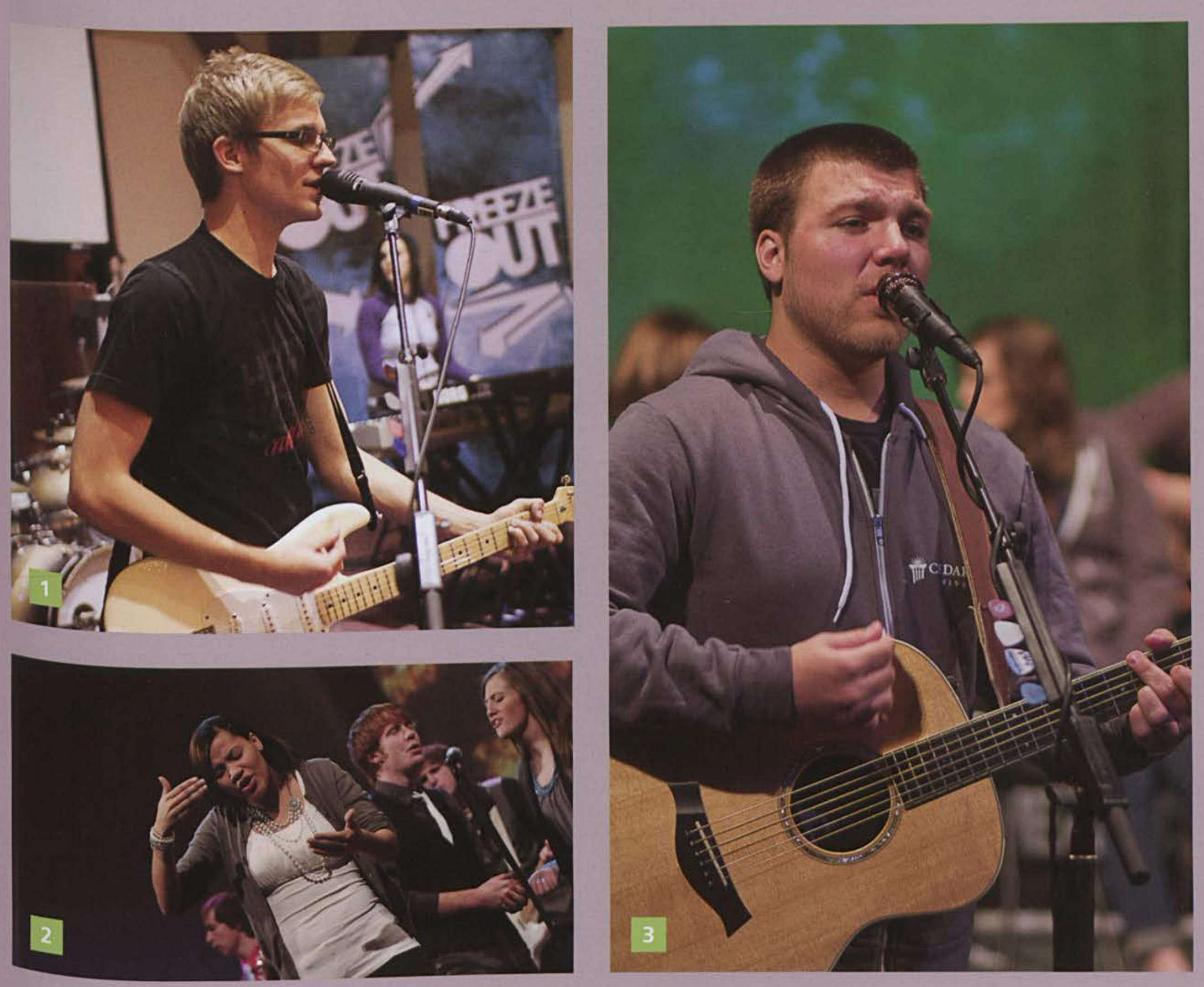

\section{.}




\section{MUSIC GROUPS}

Every year, musical groups on campus worship together through the teams provided by the music department. These groups include Women's Choir, Men's Glee Club, Concert Chorale, and One Voice.

In addition to performing in separate concerts and chapel services, each group has the opportunity to bless other places with their praises. Musical group teams toured and served different churches in worship, even over Spring Break; One Voice will have the opportunity to worship in Australia this summer. No matter what the opportunity, the students involved in Cedarville's music groups were truly blessed by the experience.

Teams used different genres to minister to listeners. Jubilate singers focused their talents on pieces that were more contemporary, while Concert Chorale dedicated more time on classic worship pieces. One Voice was purely unique in the way that they performed, employing a gospel perspective of worship. Women's Choir and Men's Glee Club were teams composed of one gender, forming a group with a unison choir; their music tended to be a mix of musical styles.

Though each group tended to sing separately, all groups (except One Voice) came together for one large performance with the classical band. This year, the collaborated group performed pieces by Leonard Bernstein and learned the piece from a guest conductor. The groups blended in perfect harmony, creating an outstanding version of the pieces. One Voice blessed the chapel experience several times and really kept the student body aware of God's mercy and grace. One student, Allie Hundley, said that her experience was not just a musical blessing. "Not only has One Voice taught me so much about what it means to worship with true freedom, but it's also my second family." This was true of all of the choirs; they quickly became dependant on each other and became like a family.

\section{Men's Glee Club \\ 2 Women's Choir \\ 3 Jazz Band \\ 4 Symphonic Band}

"Not only has One Voice taught me so much about what it means to worship with true freedom, but it's also my second family." (Allie Hundley) 


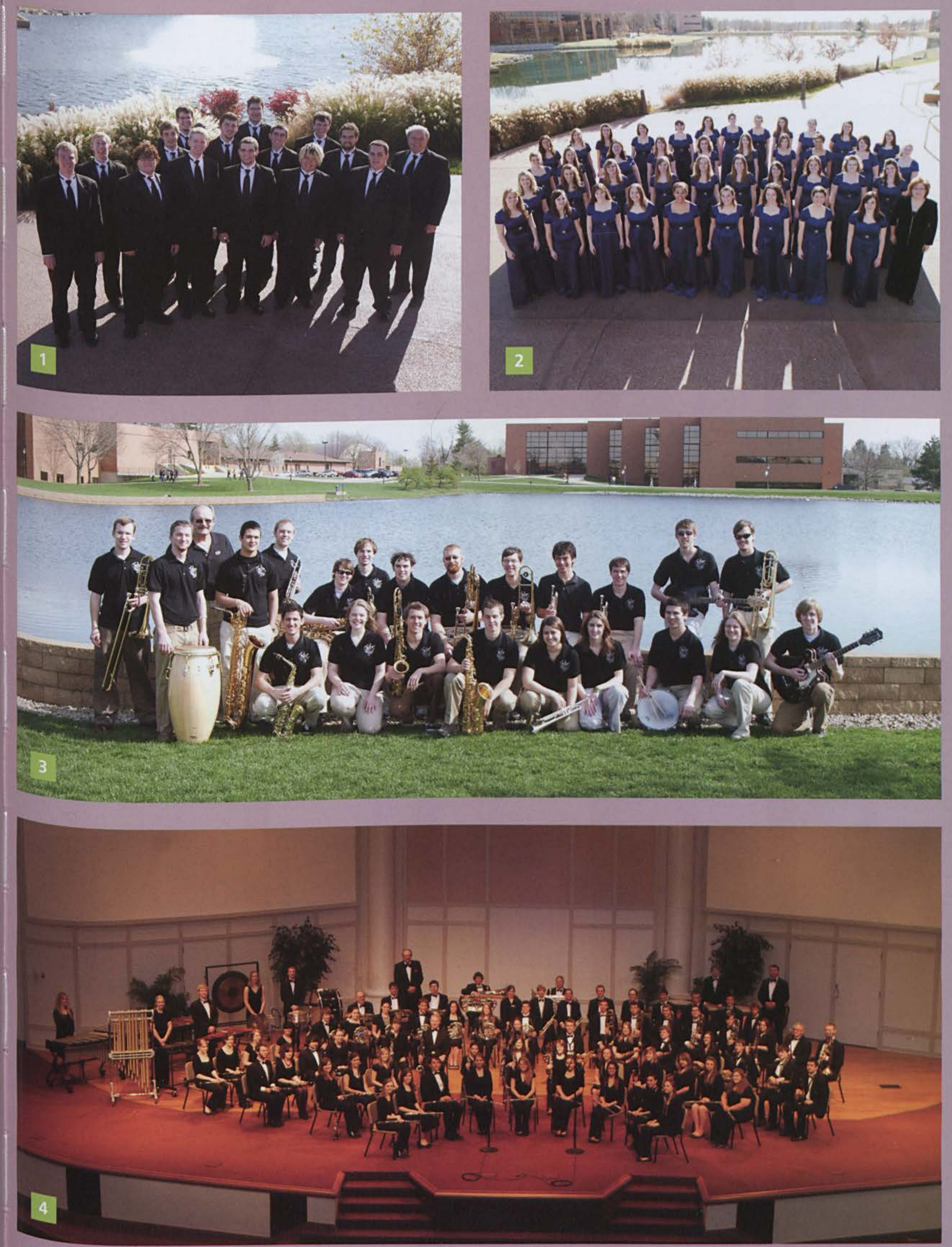




\section{MUSIC GROUPS}

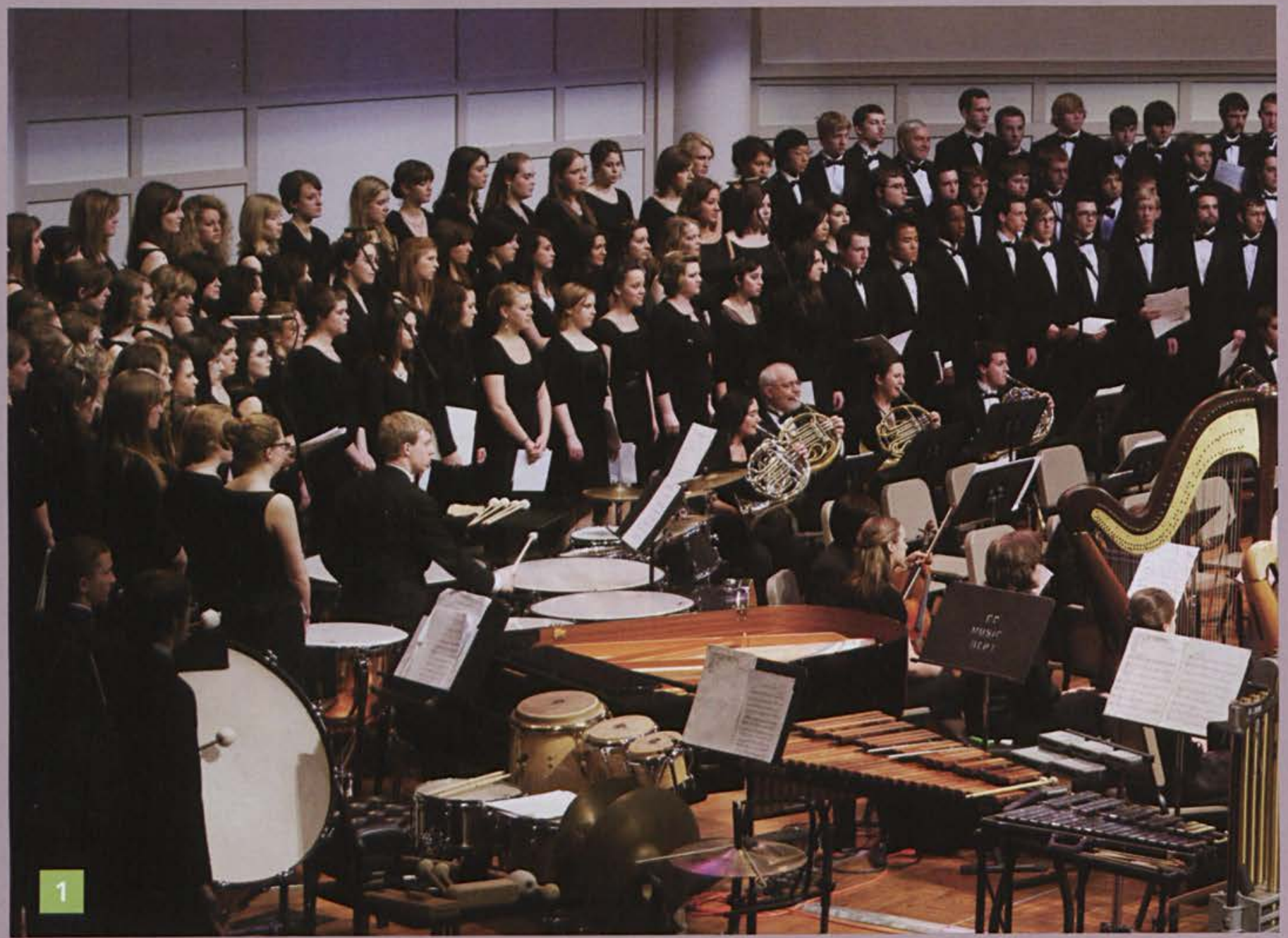

1 Both the Orchestra and Choir perform during the spectacular Masterworks concert, showcasing some of the amazing musical talent at Cedarville. 2 Alex Williams and Ben Chasnov wow the crowd with their fantastic saxophone playing in a Jazz Band concert. They are some talented guys. 3 Tim Cuffman backs up the Jazz Band with his bass, one of the hardest instruments to play jazz music on. 4 The musicians in the Orchestra play to their best during the Masterworks concert. 5 OneVoice leads chapel in some of the most spirited worship that students will experience during the year. 

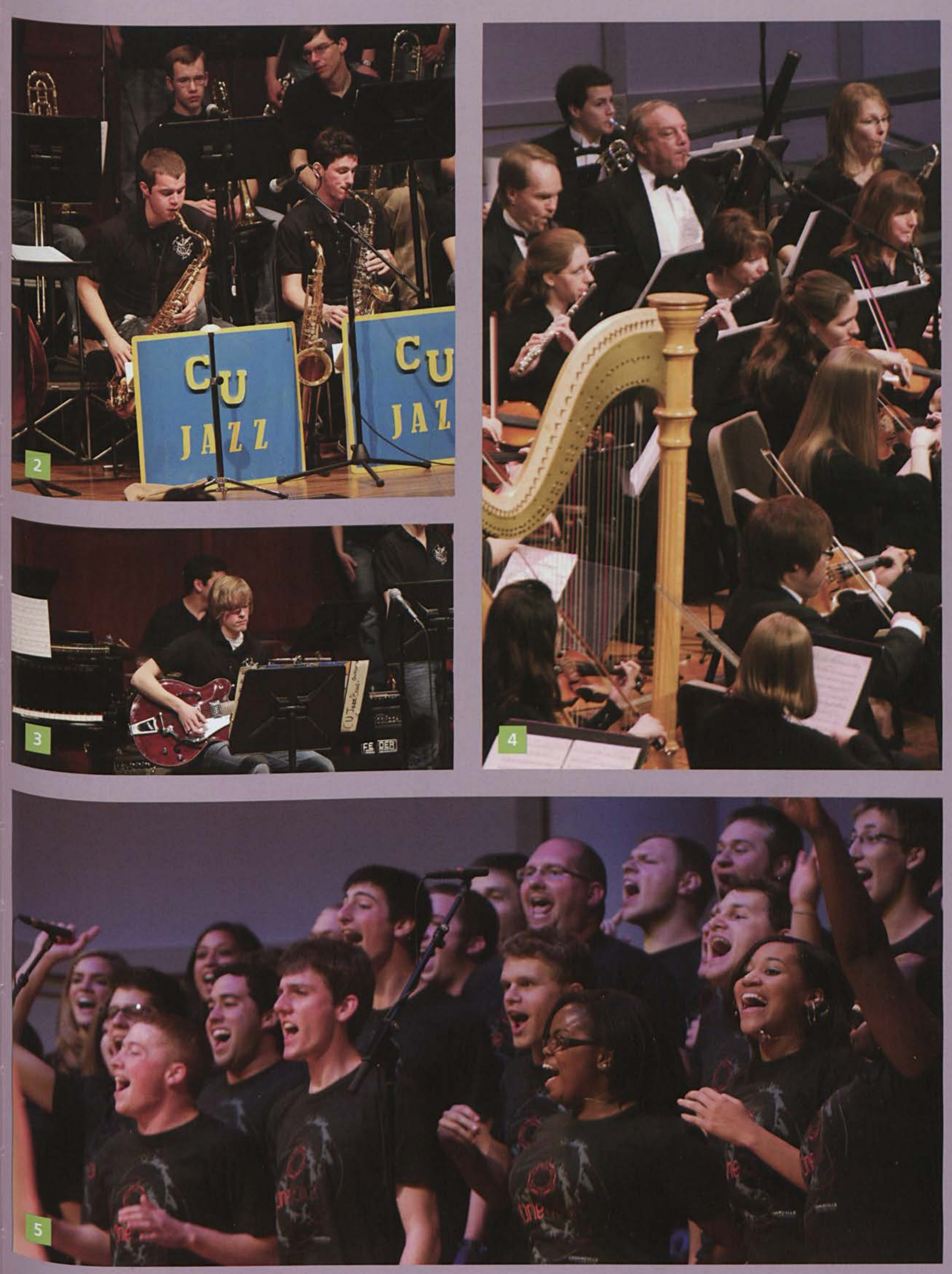


\section{JUNORS}

noun, plural \joon-yers \Students with high anticipation for senior year; often maintain the false expectation that the third year is easy because college is half over. 


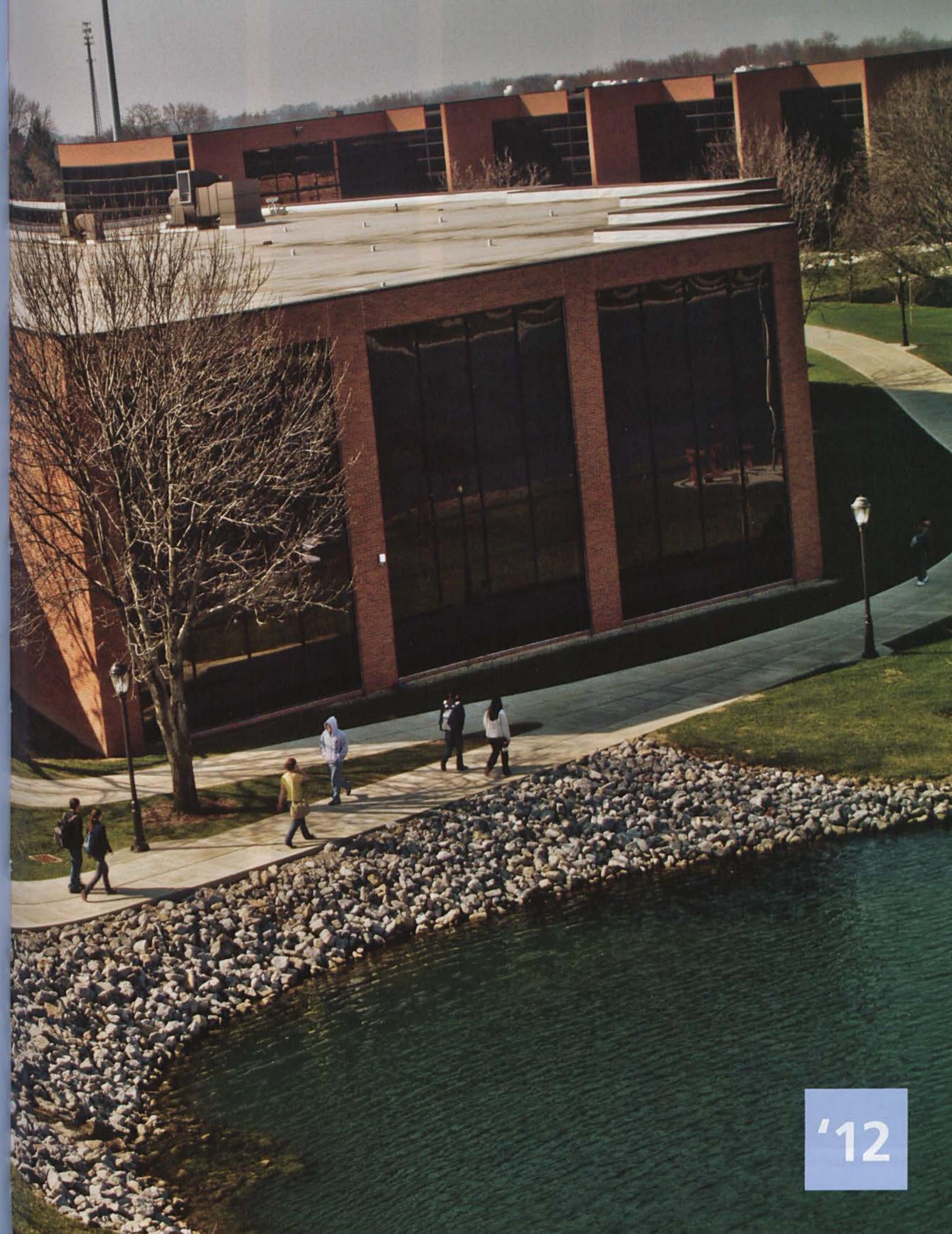




\section{JUNIORS}

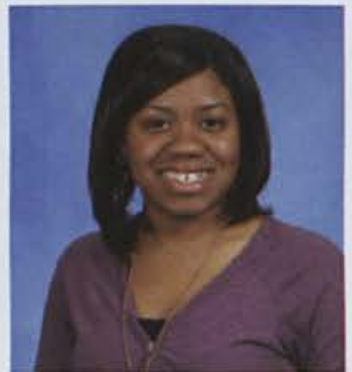

Rachel Arthur

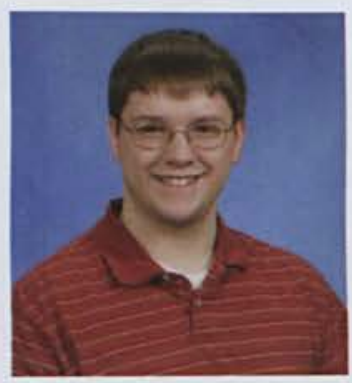

Jacob Barker

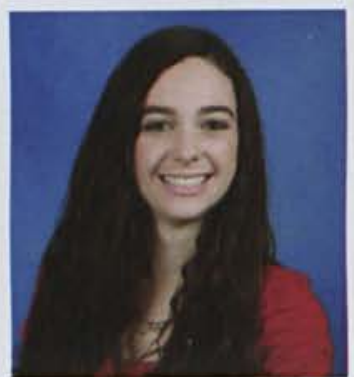

Christine Battis

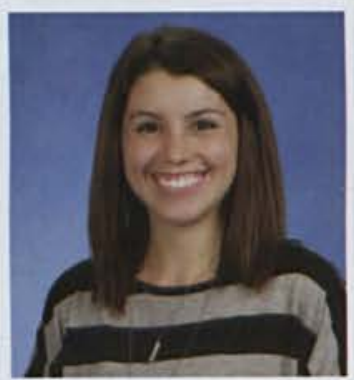

Molly Bewley

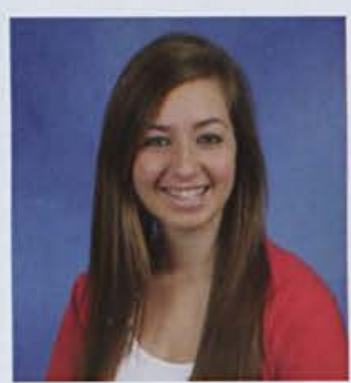

Rachel Bowman

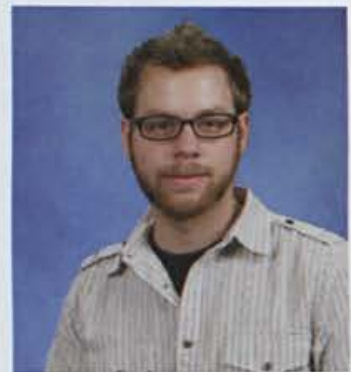

Jonathan Ashley

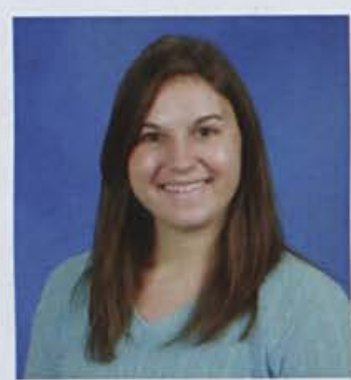

Becky Baron

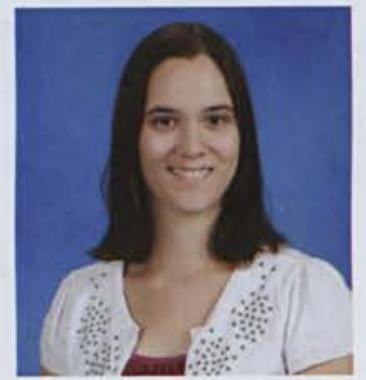

Rachel Beachy

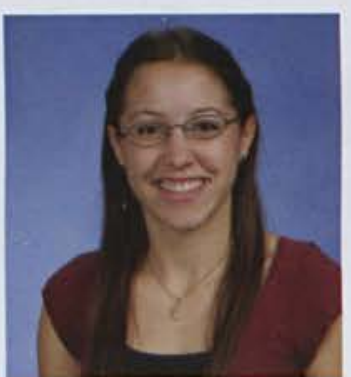

Valentina Blackburn

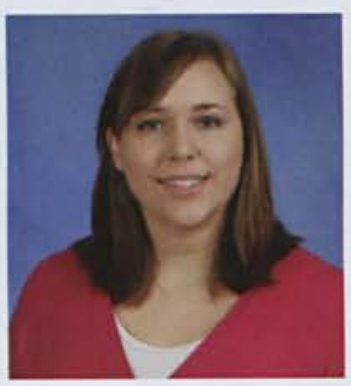

Heather Boyd

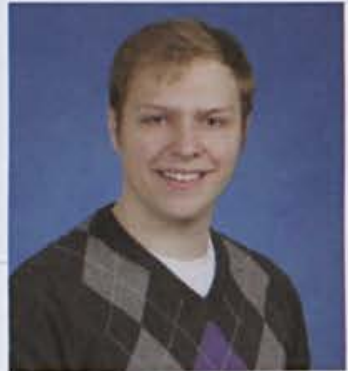

Jonathan Adler

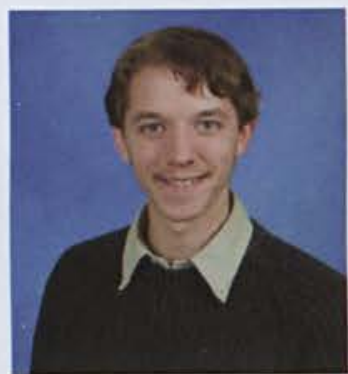

Daniel Bacon

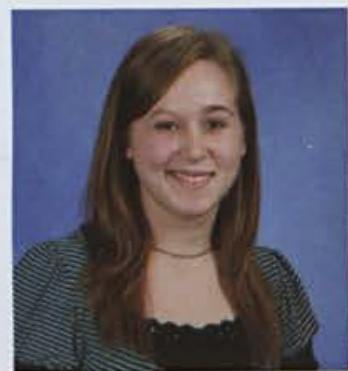

Hannah Barron

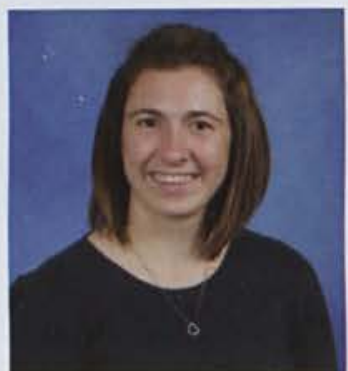

Mary Bernecker

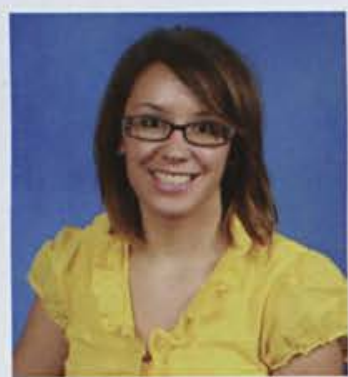

Vawny Blackburn

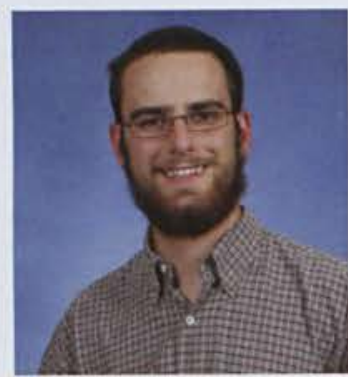

Nathanael Braun

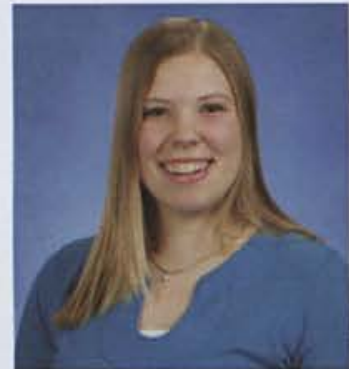

Angela Allen

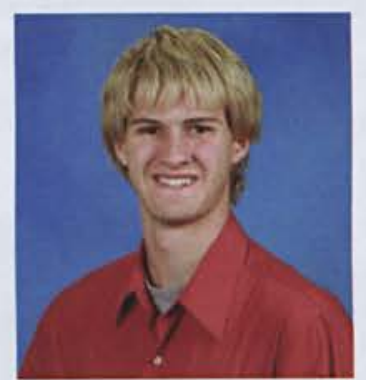

Dane Baldwin

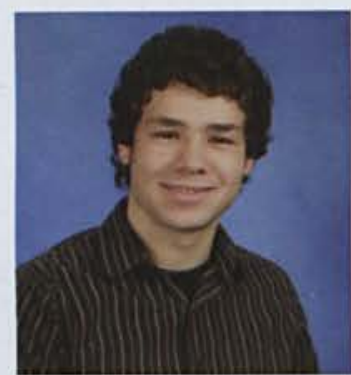

Andrew Bash

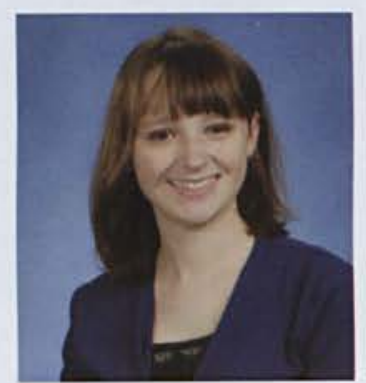

Jennifer Berrigan

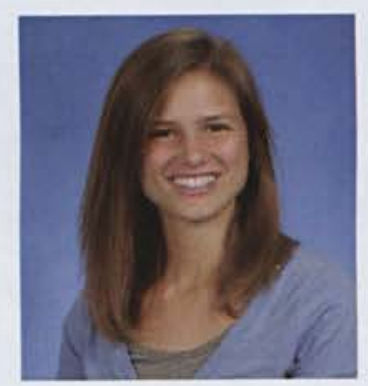

Michelle Blackstone

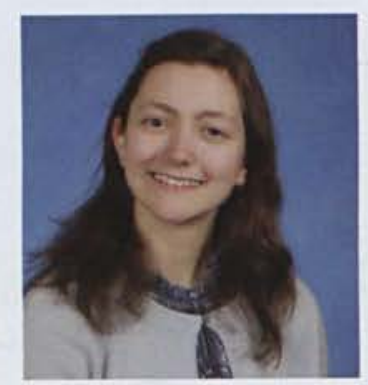

Amanda Brindley

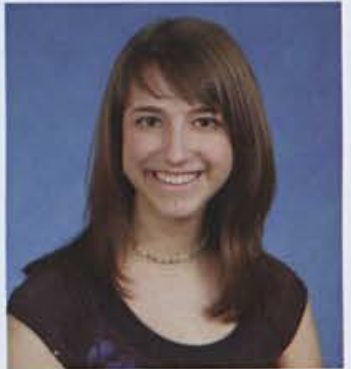

Stephanie Anderson

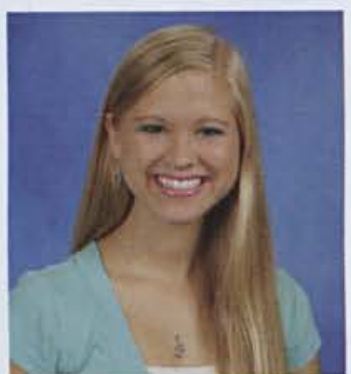

Samantha Barclay

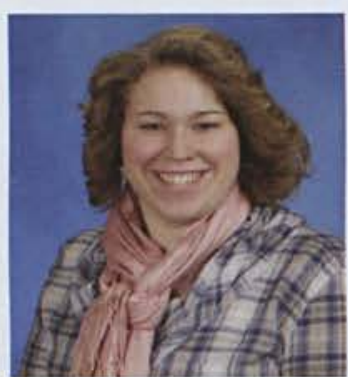

Sarah Bates

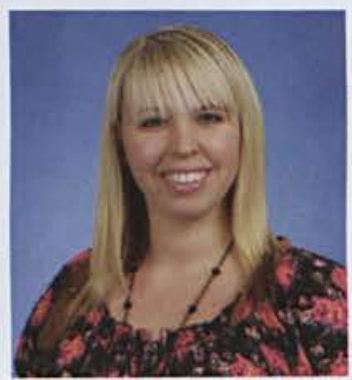

Stefanie Betori

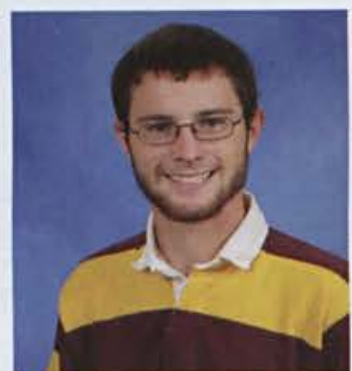

Ethan Blagg

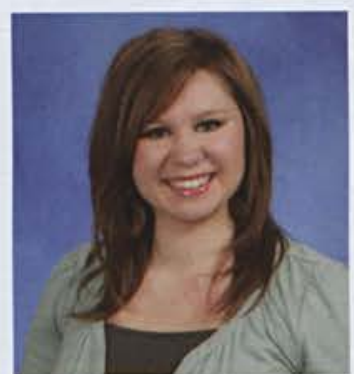

Sarah Brittan 


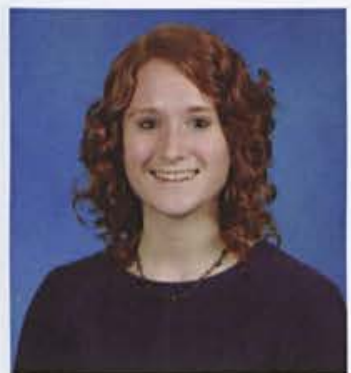

Andrea Brown

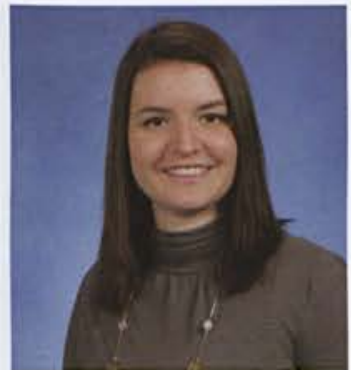

Tiffany Buehler

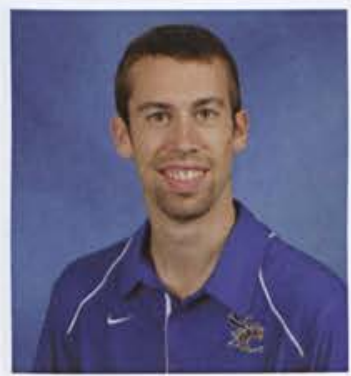

Robbie Carter

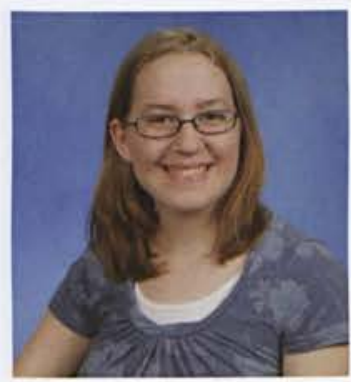

Brenna Christiansen

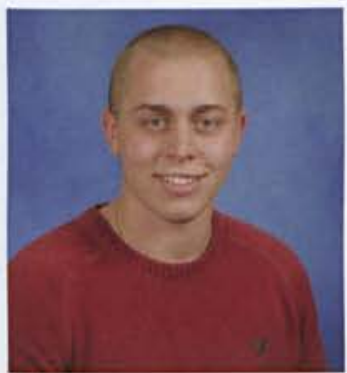

Lucas Clelland

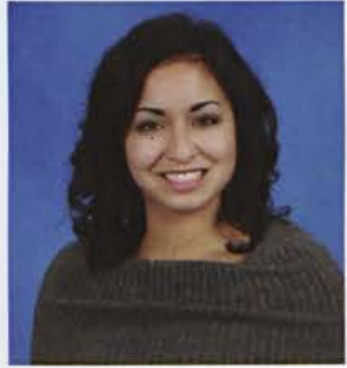

Janemarie Covel

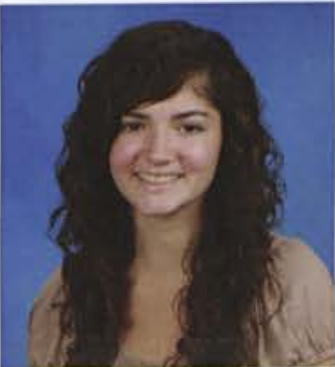

\section{Breanna Brown}

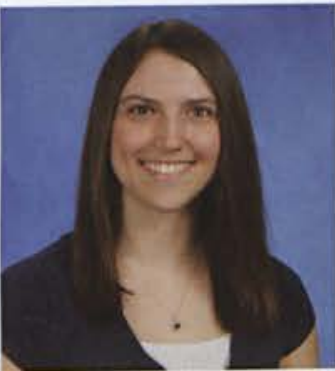

Brittany Burkholder

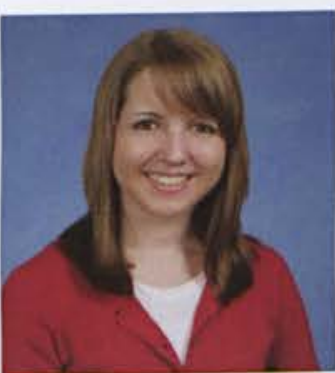

Samantha Cazzell

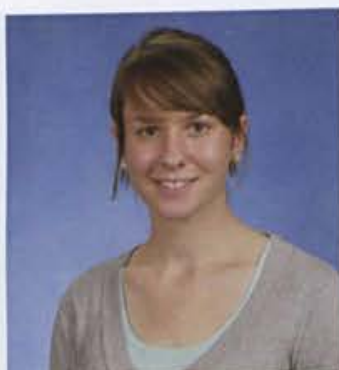

Ruth Christiansen

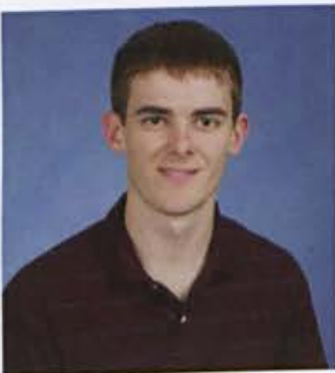

Luke Clore

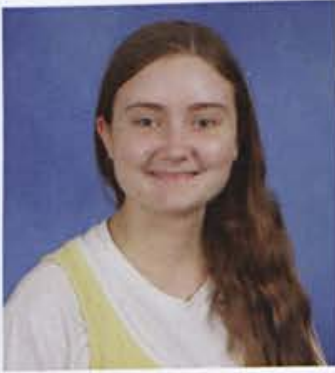

Miriam Crane

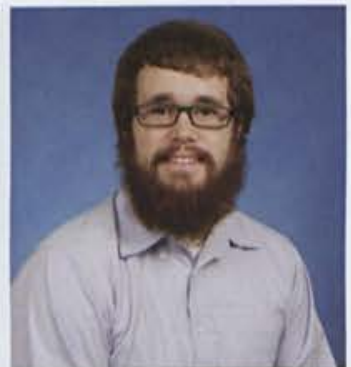

Douglas Brown

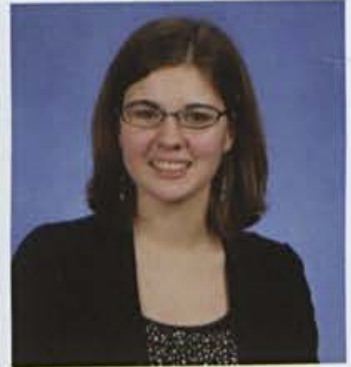

Hannah Campbell

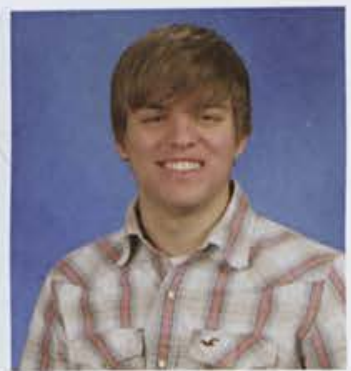

Anthony Chester

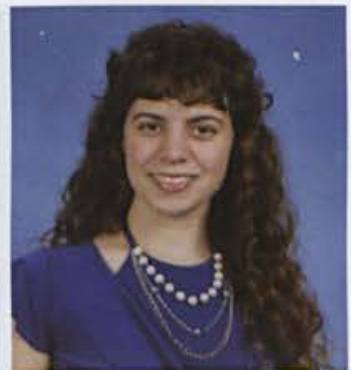

Stephanie Chrystal

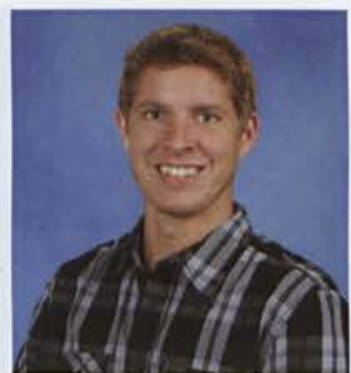

Matthew Coover

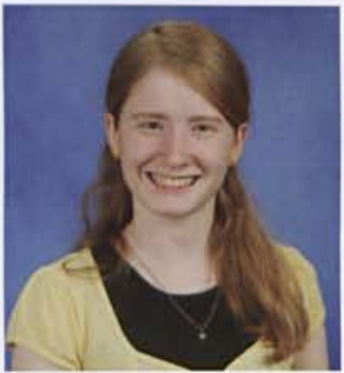

Rebekah Crawford

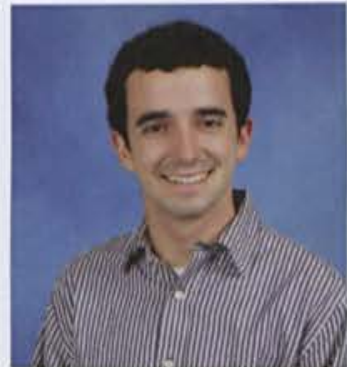

Jacob Brown

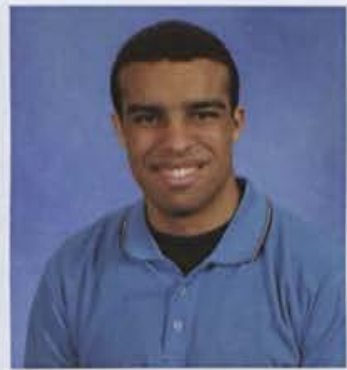

Stephen Campbell

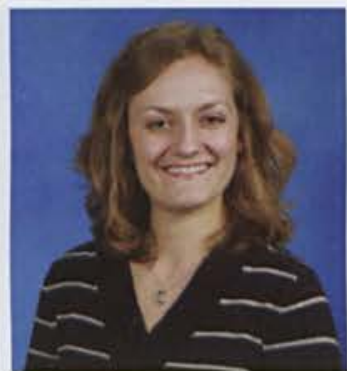

Melissa Cheston

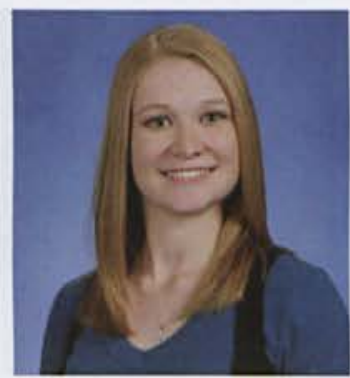

Heather Clark

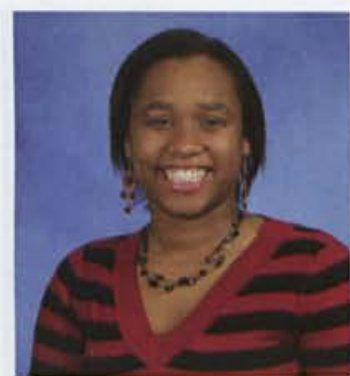

Hope Cornelius

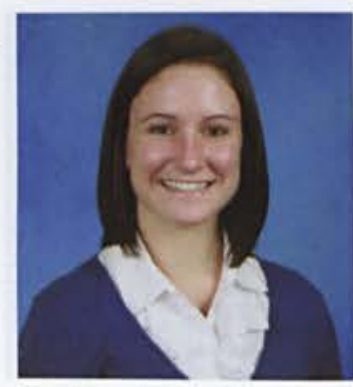

Rachael Currie

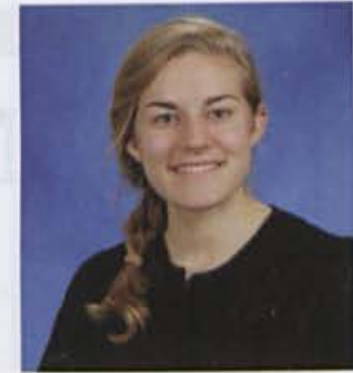

Hannah Bryan

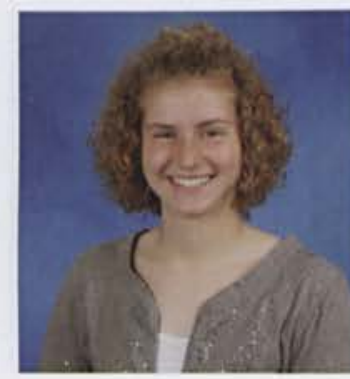

Meagan Carns

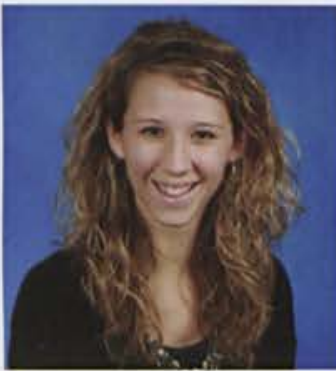

Paige Christiaanse

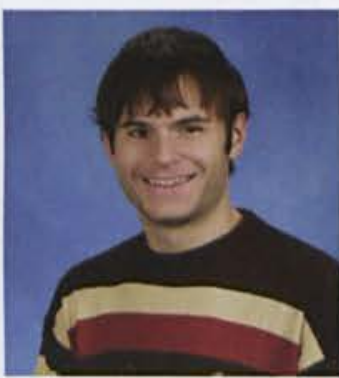

Jordan Clark

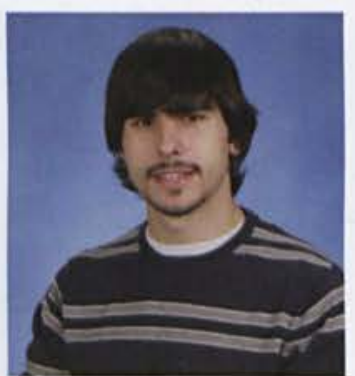

John Coules

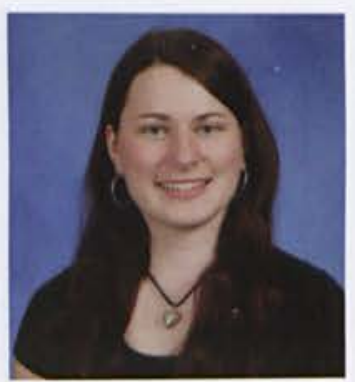

Marissa Cushing 


\section{JUNIORS}

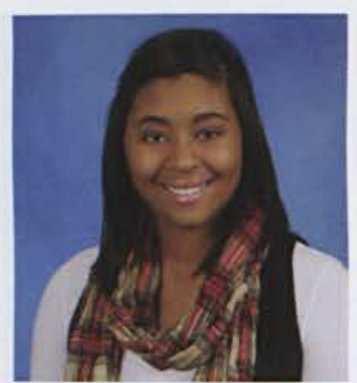

Andrea Davis

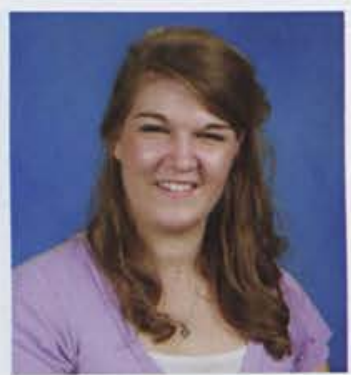

Rebekah Dodson

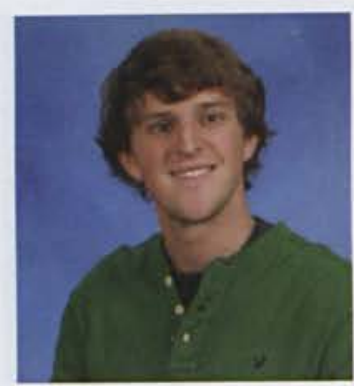

Kyler Dresbach

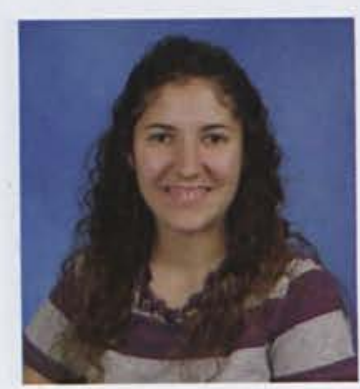

Heidi Edwards

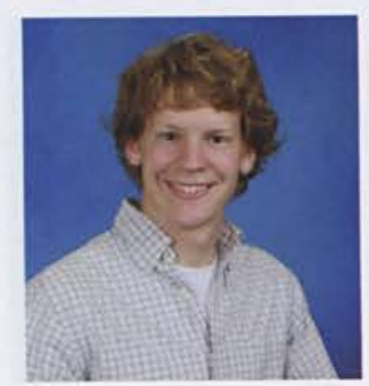

Aron Flaming

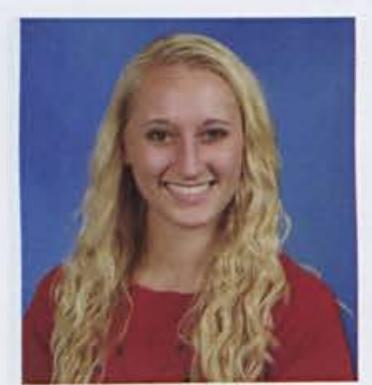

Felicia DeCook

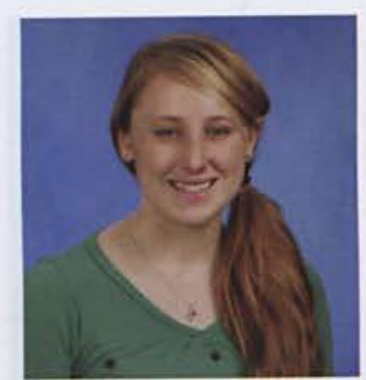

Eimile Dougherty

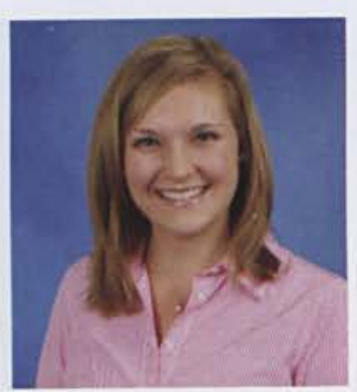

Jean Drimalla

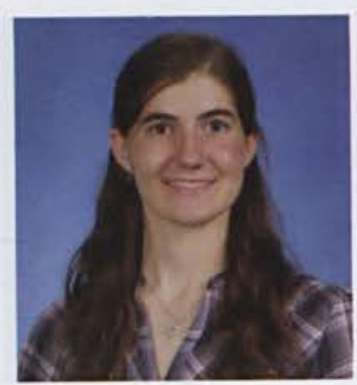

Sabrina Elgersma

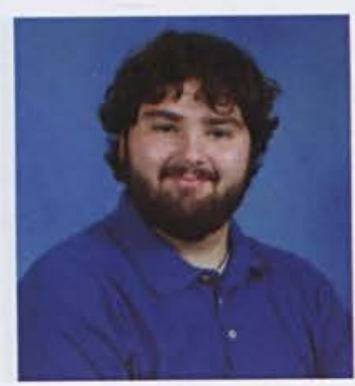

Christopher Flynn

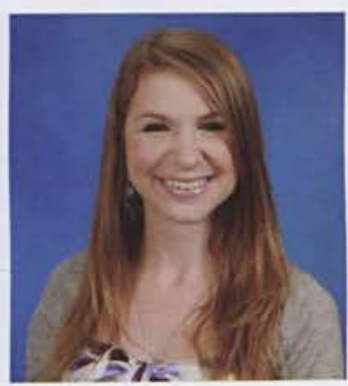

Rebekah Cvetich

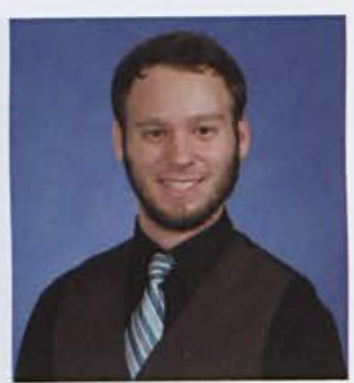

David Dion

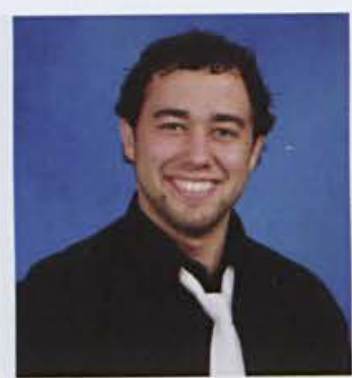

Jordan Doyle

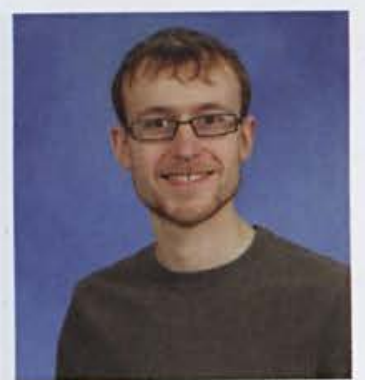

Joel Dulin

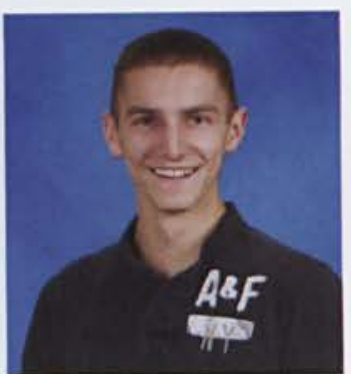

Andrew Englund

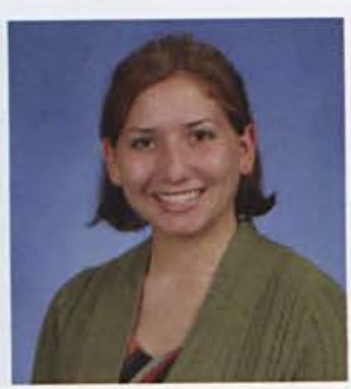

Kaitlyn Fote

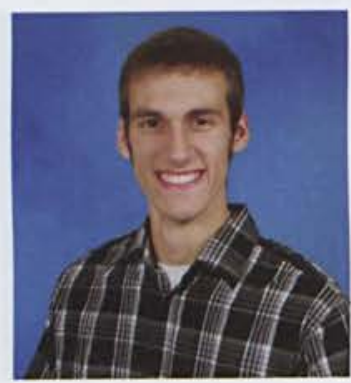

Mark D'Anna

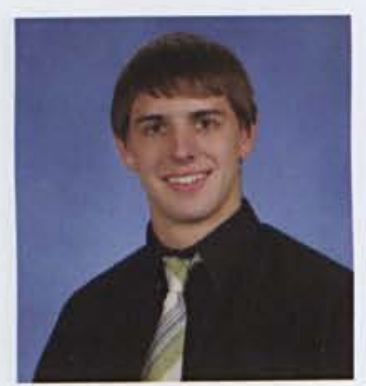

Andrew Dirks

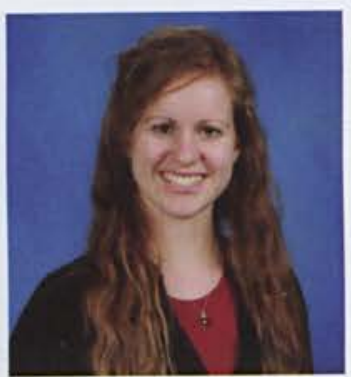

Michelle Doyle

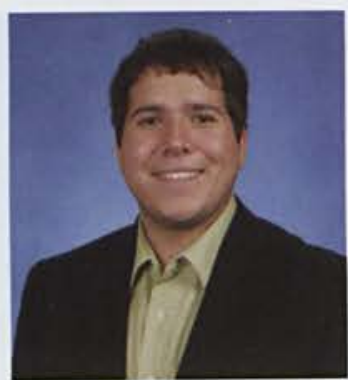

Christopher Durbin

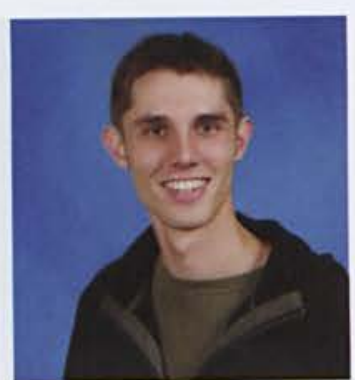

Jeffrey Evans

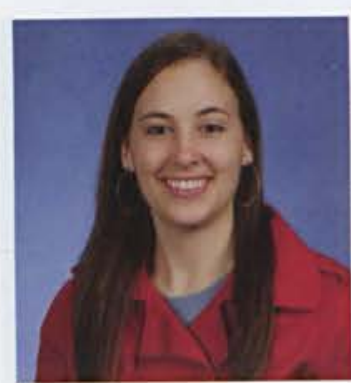

Casey Foulk

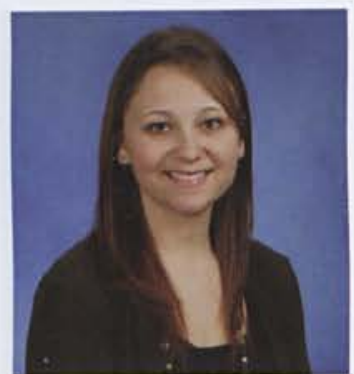

Alisa Daum

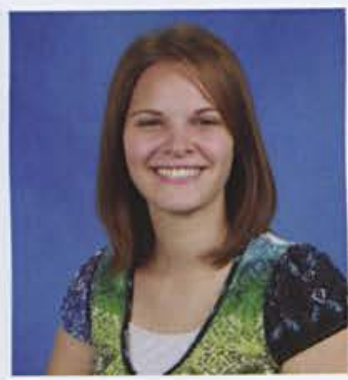

Jennie Dixson

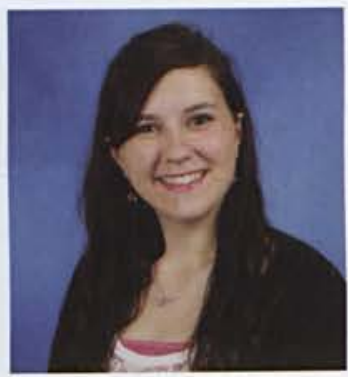

Hannah Dreisbach

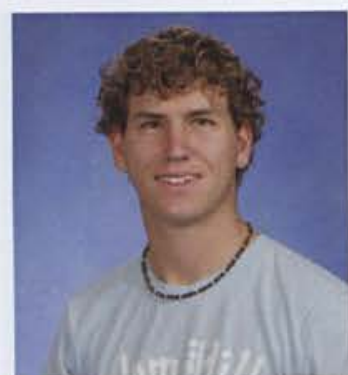

Christopher Eaton

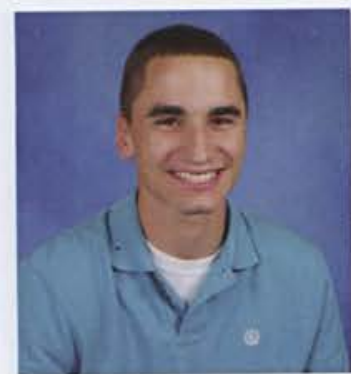

Stephen Feiler

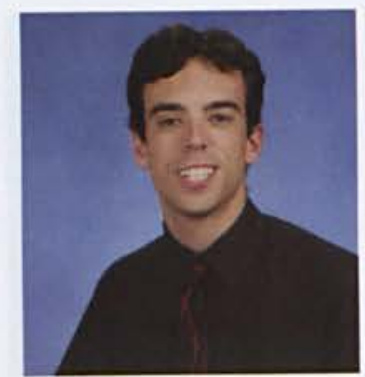

Kyle Fox 


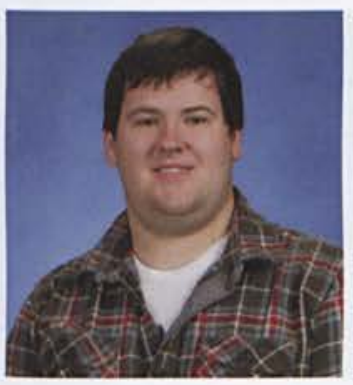

Bryan Frame

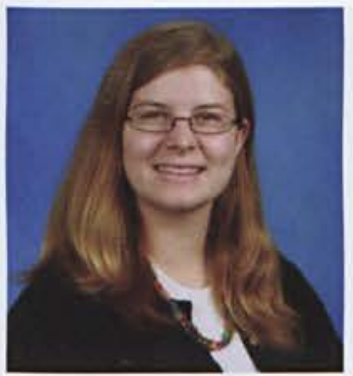

Stephanie Frey

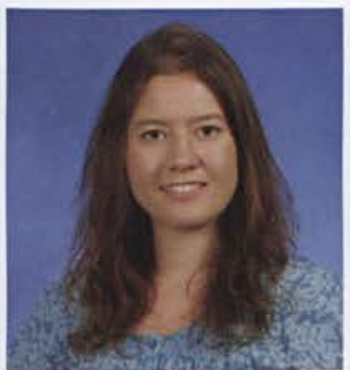

Jennifer Giambalvo

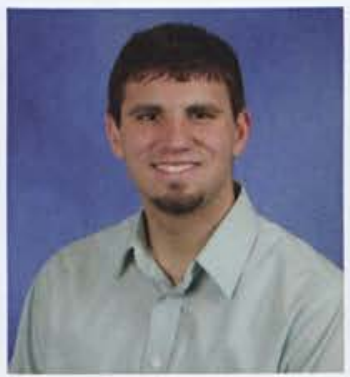

Dane Gordon

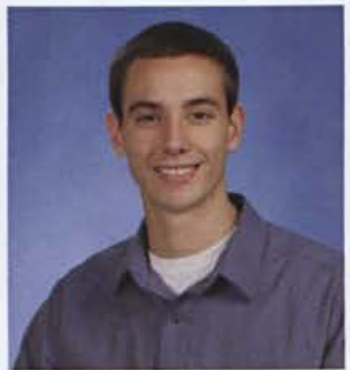

John Greenwell

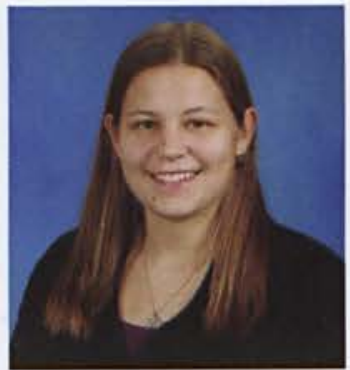

Heather Grosso

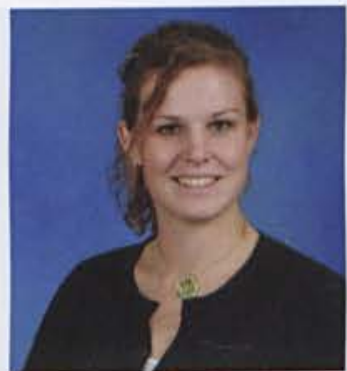

Brianna Franklin

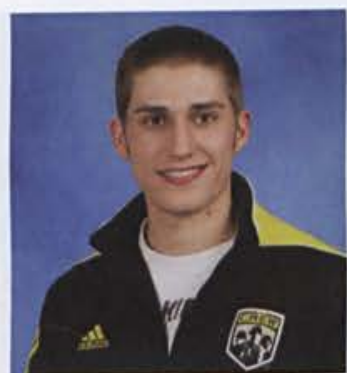

Kolby Gabbert

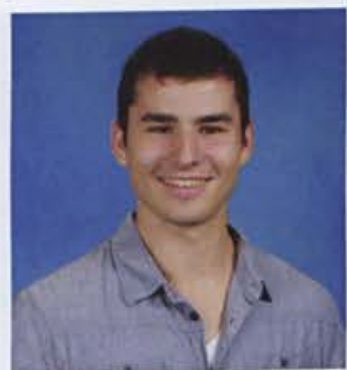

Nicholas Giovacchini

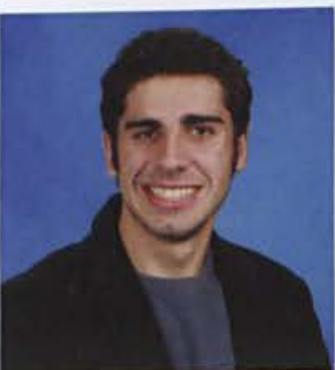

Joshua Gordon

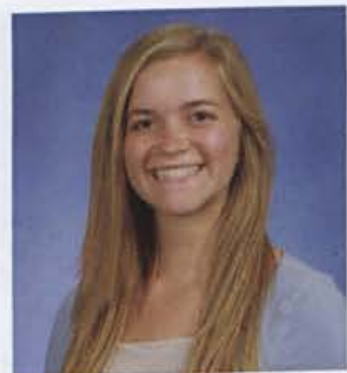

Rachel Greenwood

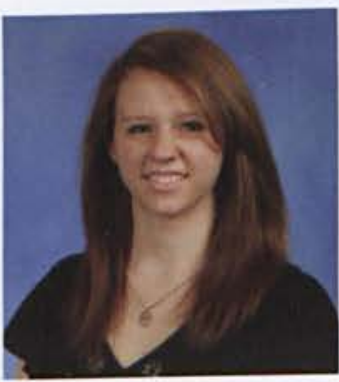

Angela Gunter

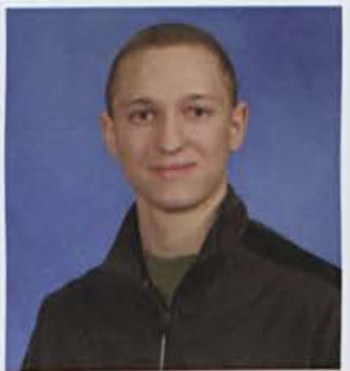

Josiah Franklin

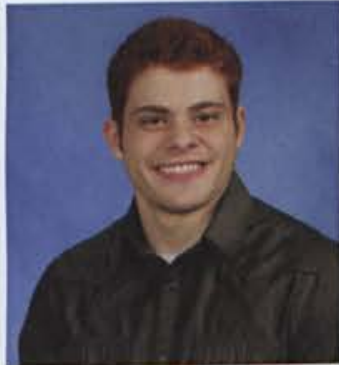

Joe Gallagher

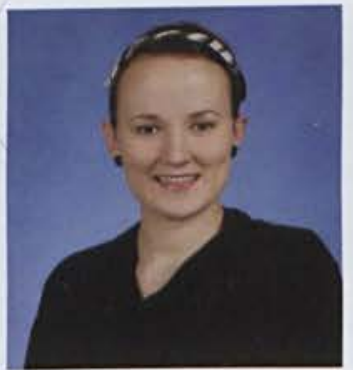

Amelia Glenchur

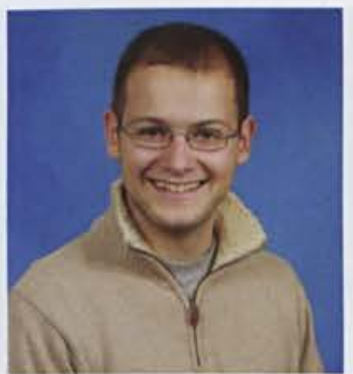

Paul Gordon

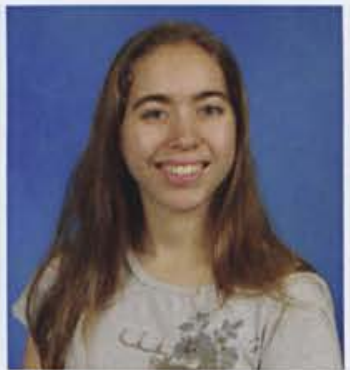

Emily Gregowske

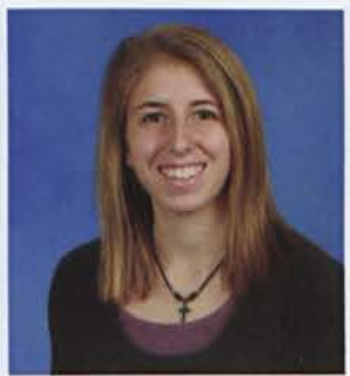

Amanda Harris

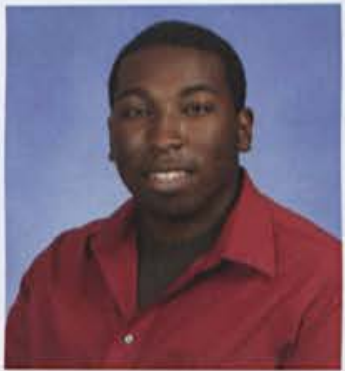

Shaun Frazier

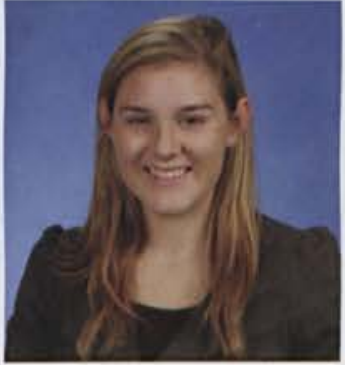

Ellen Geib

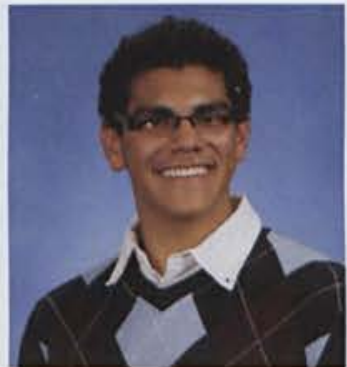

Alexander Gonzalez

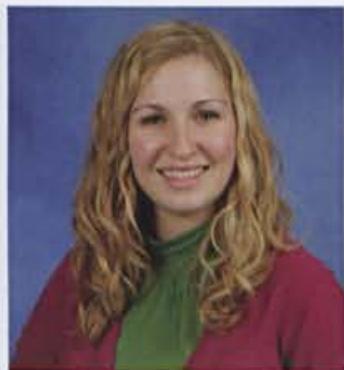

Amy Granger

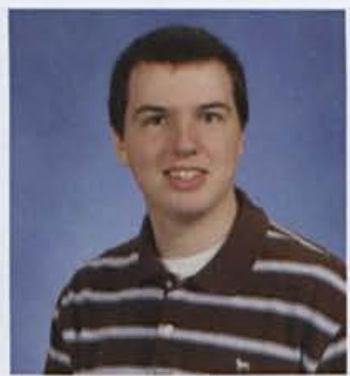

Jason Grier

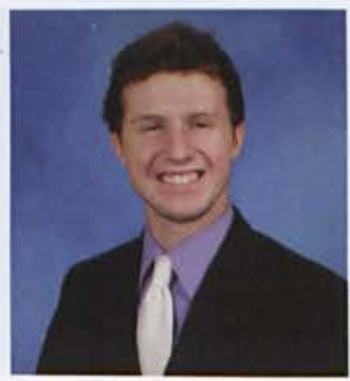

Rob Harrison

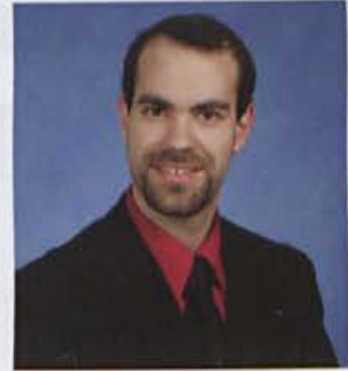

Luke Fredette

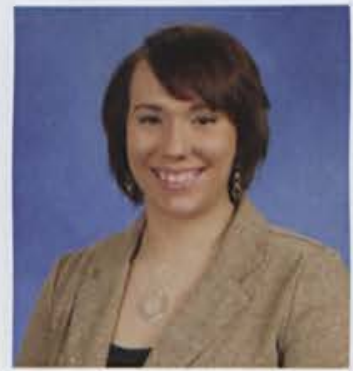

Emilie Gesualdo

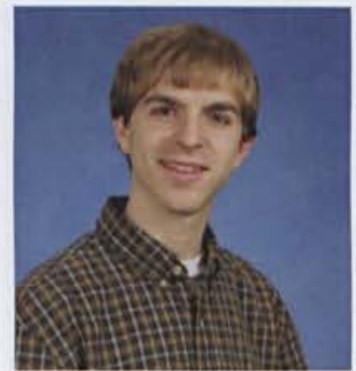

Steven Goodman

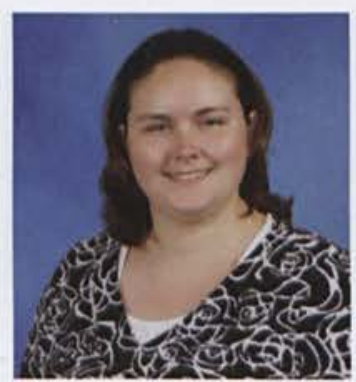

Mary Alyce Greener

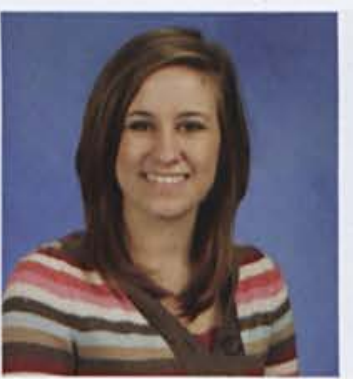

Stephanie Griffith

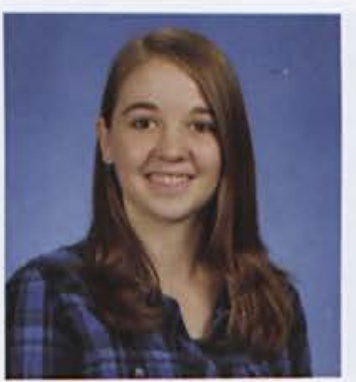

Janalyn Hegle 


\section{JUNIORS}

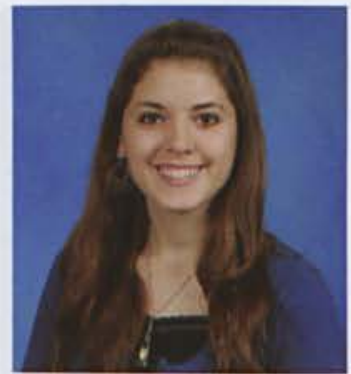

Jenna Hilditch

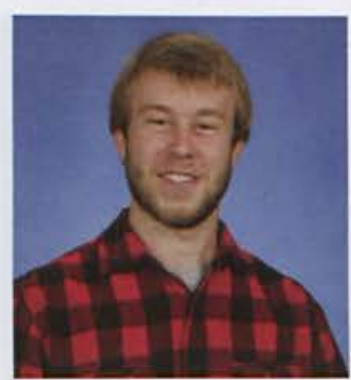

Craig Hunter

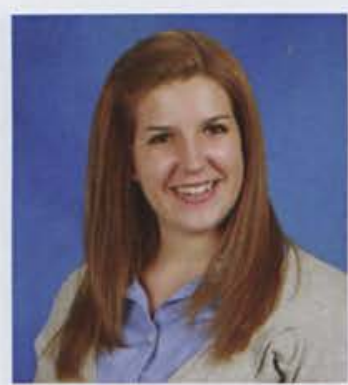

Ashley Janczewski

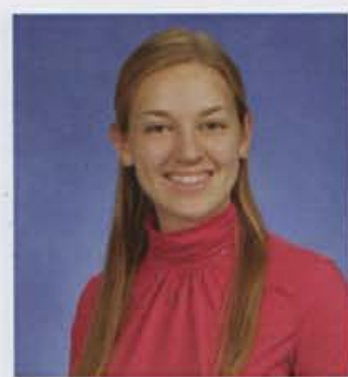

\section{Lindsay Jones}

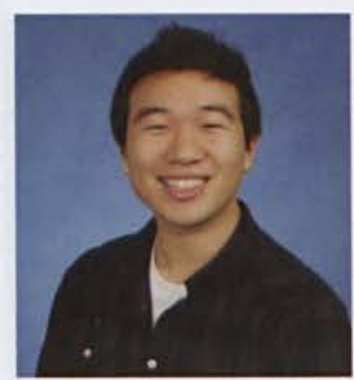

Seung Hwan Kim

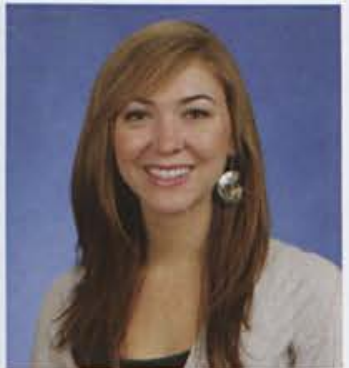

Stephanie Hill

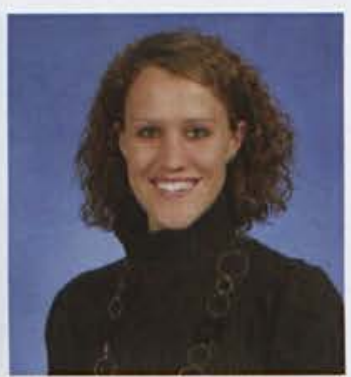

Jessica Huwer

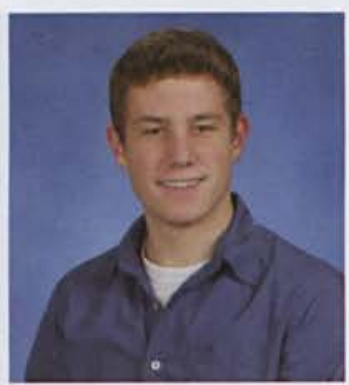

Drew Jantzen

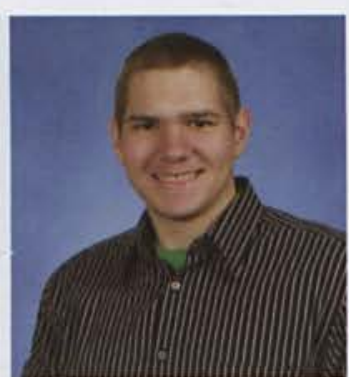

Jared Junge

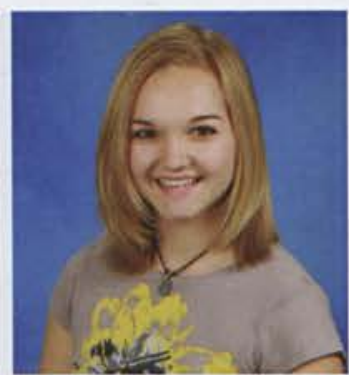

Christina Kinch

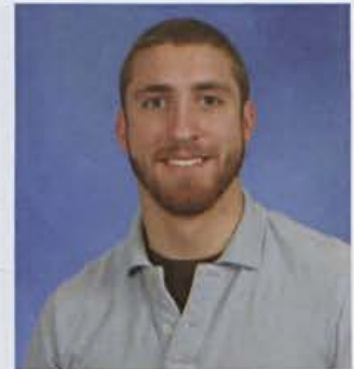

Brandon Hellwig

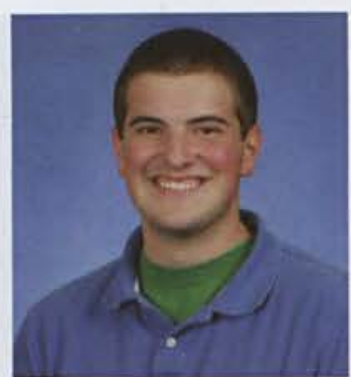

Patrick Hoeflinger

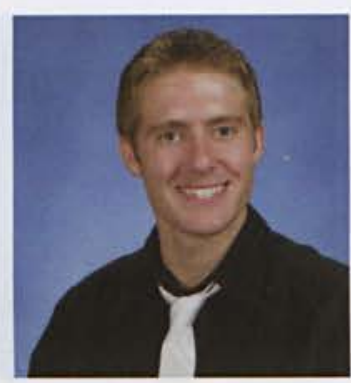

Caleb Ingram

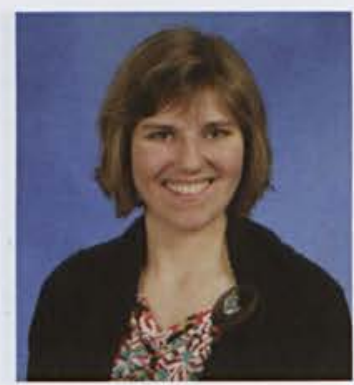

Hayley Johnson

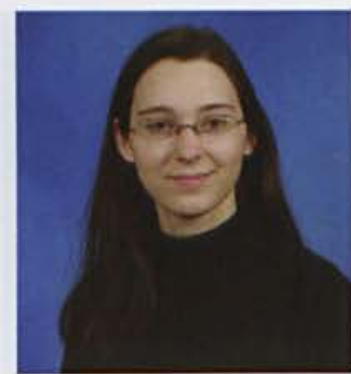

Linda Jupe

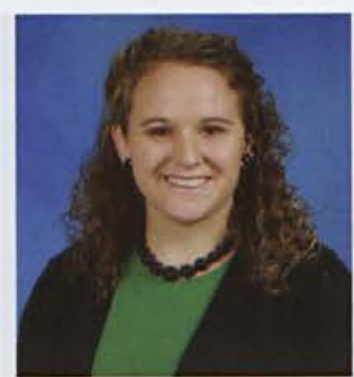

Laura Kirby

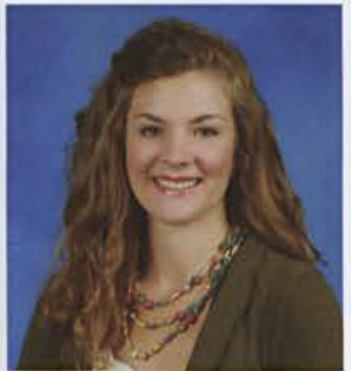

Tiffany Hendricks

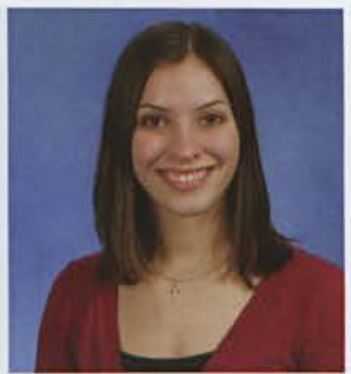

Kristen Hulsey

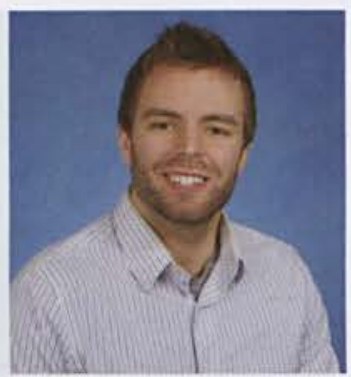

Leif Jacobsen

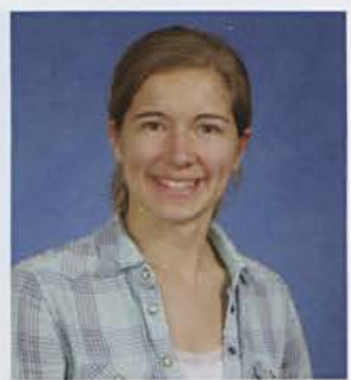

Kendra Johnson

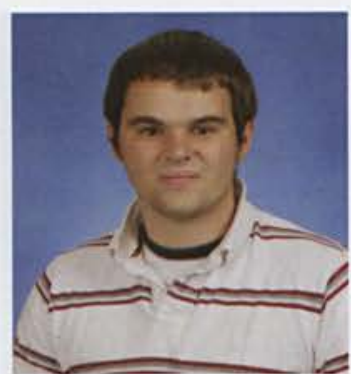

Erik Kane

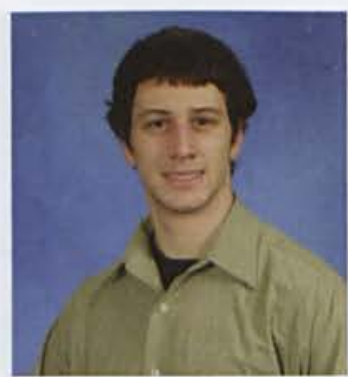

Zachary Klink

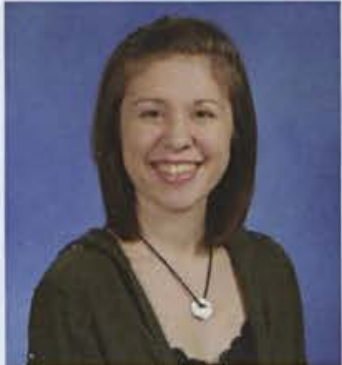

Ashley Herbert

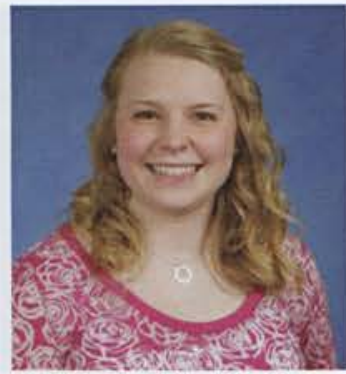

Katie Hunt

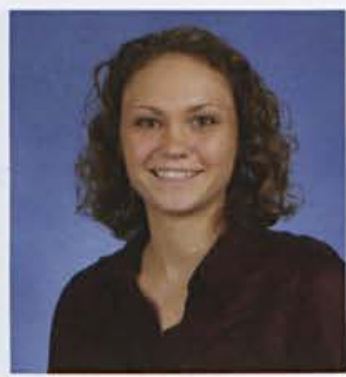

Kathy Jakucki

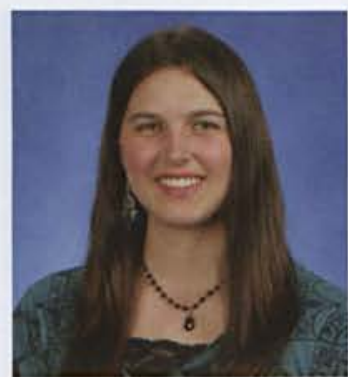

Tonya Johnson

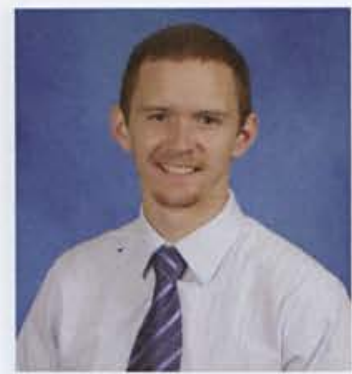

David Kemmenoe

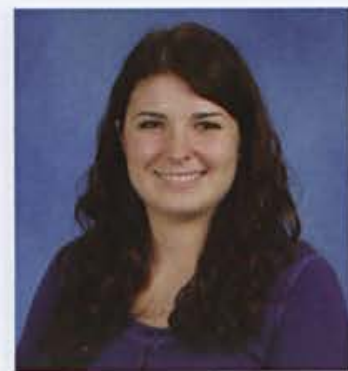

Rebeccah Knott 


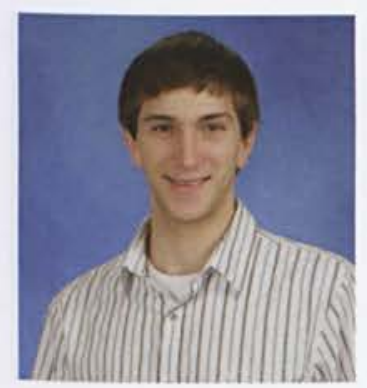

Andrew Koch

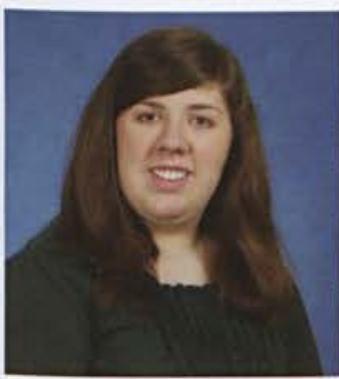

Krista Kroninger

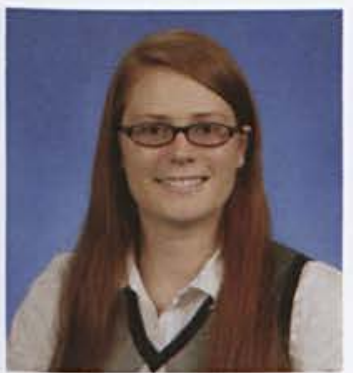

Gabrielle Lassetter

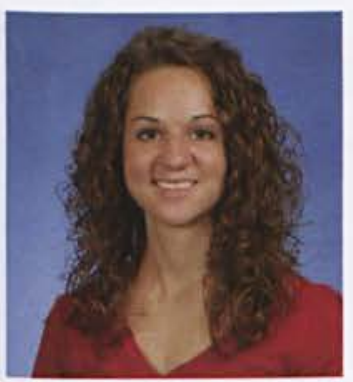

Joanna Leszczynski

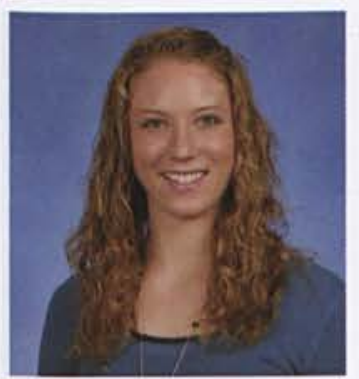

Emilie Lynch

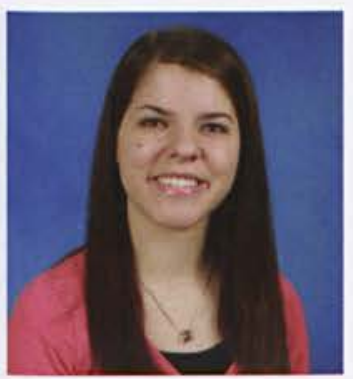

Alyssa McClure

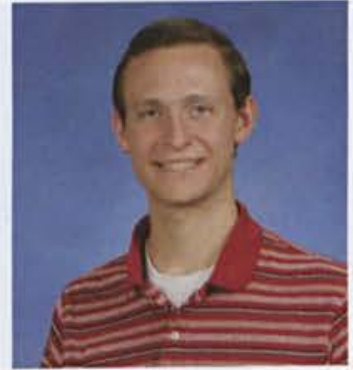

Matthew Koranek

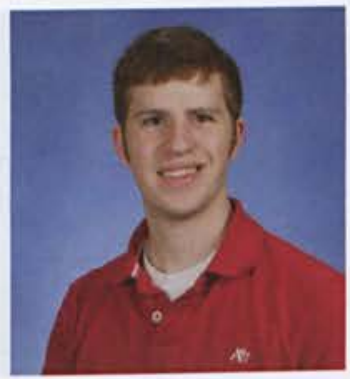

Eric Lamb

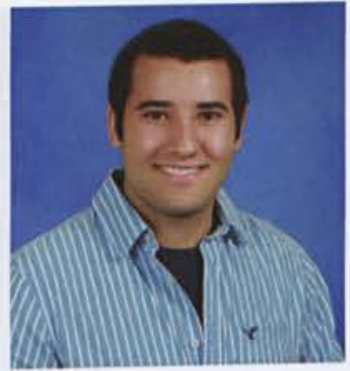

Evan Lavoie

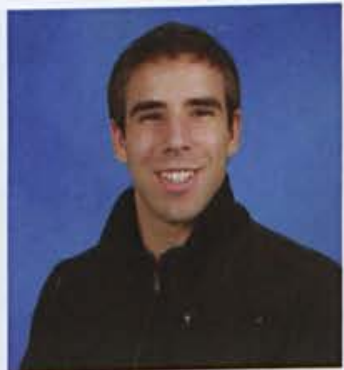

Daniel Lewis

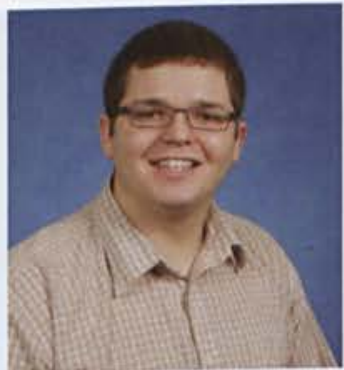

Jeffrey Lynch

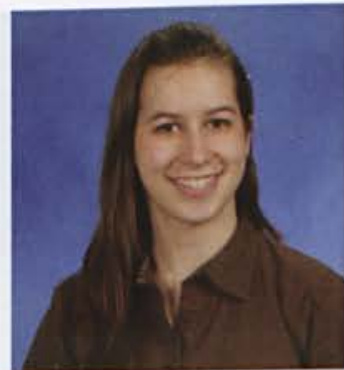

Sarah McEllhenney

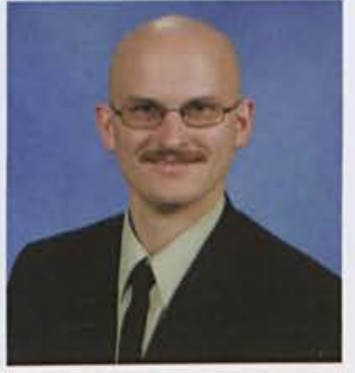

Steven Kostusyk

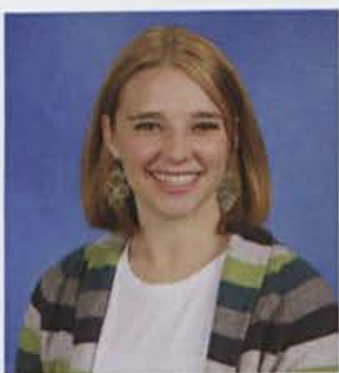

Lauren Lane

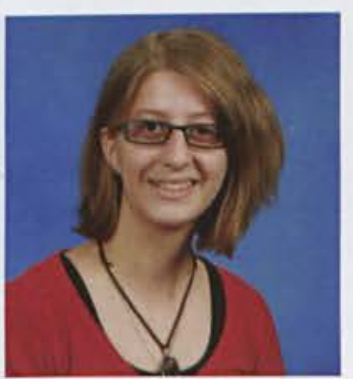

Sarah Lawton

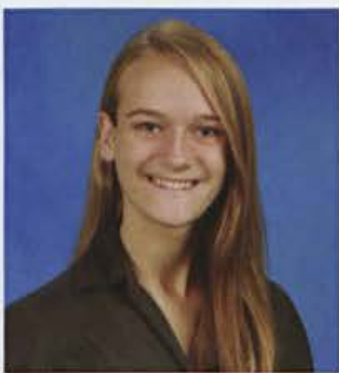

Melody Lightner

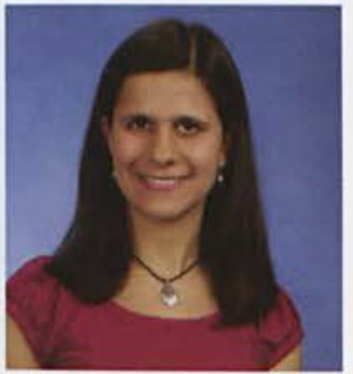

Sarah Maithel

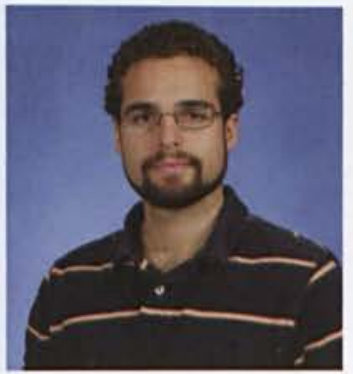

Mark McFarlane

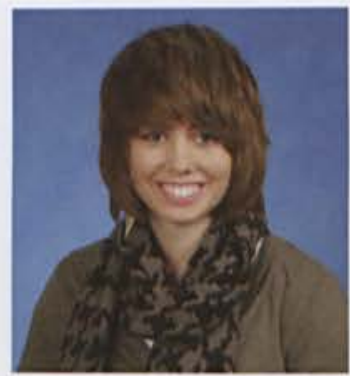

Kathryn Kramer

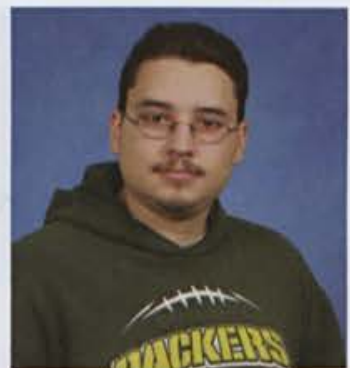

Bobby Langun

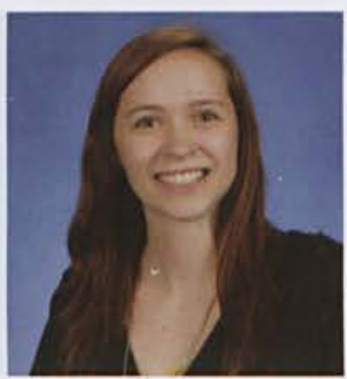

Kara Layton

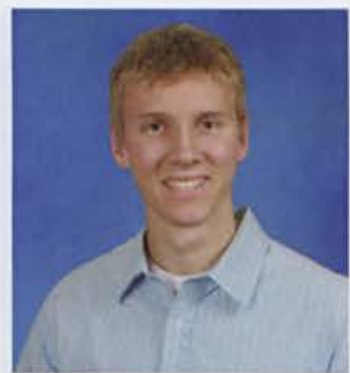

Nathan Losch

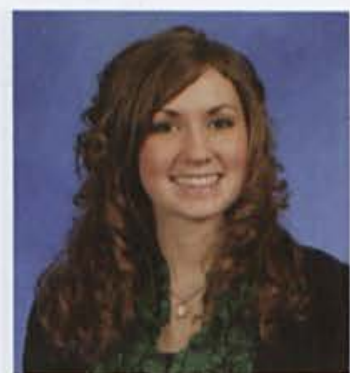

Katherine Marvin

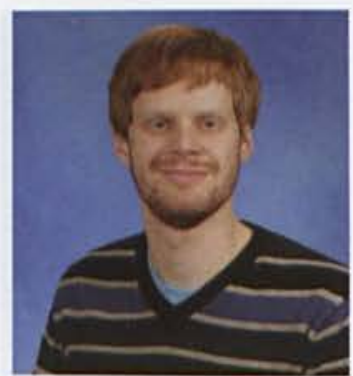

Matthew McLain

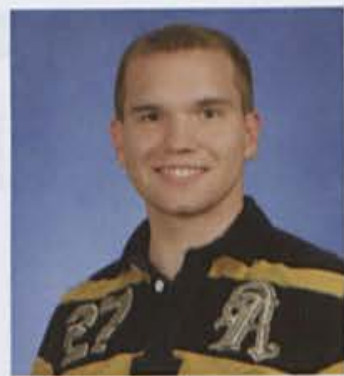

Matt Kroening

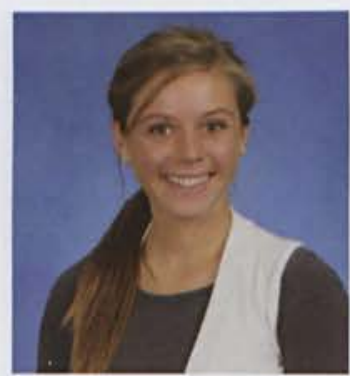

Katie Lanphier

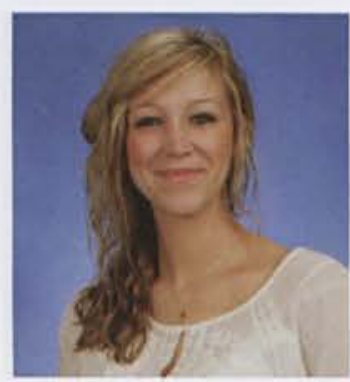

Rachel Lee

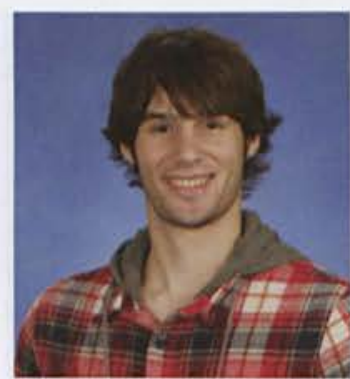

Joshua Lusk

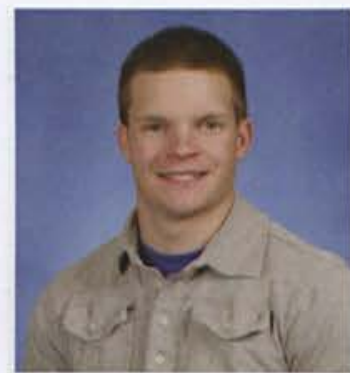

Jeffrey Mattheis

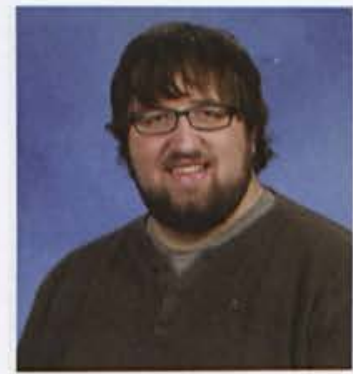

Craig McLeod 


\section{JUNIORS}

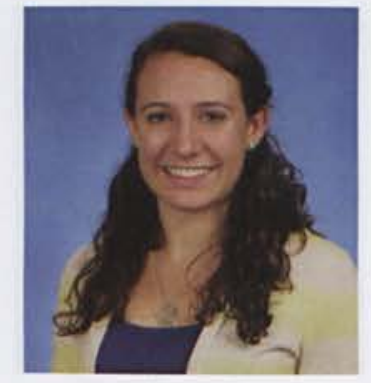

Rachel Miceli

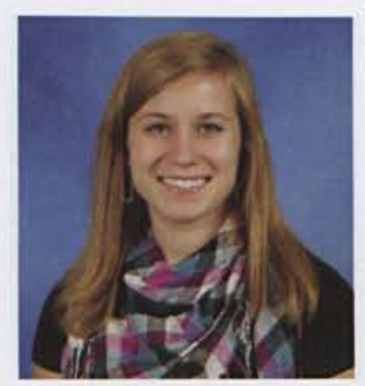

Jennifer Moran

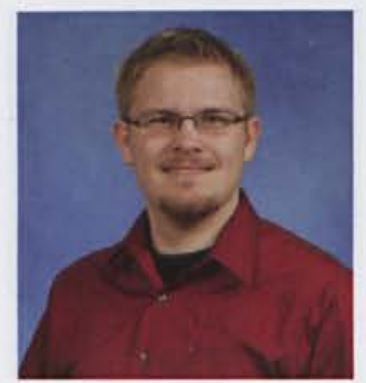

Mitchell Muhlenkamp

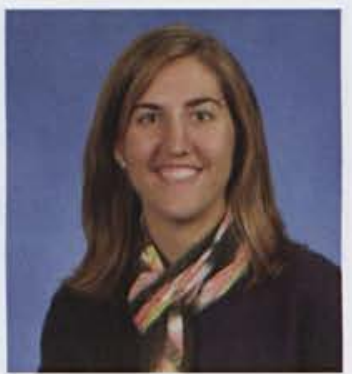

Kirsten Nicolaisen

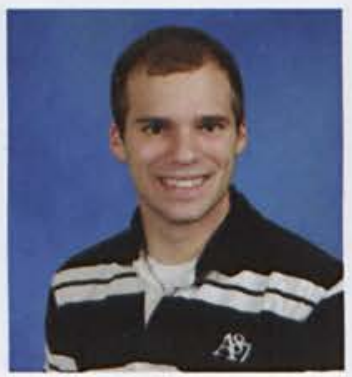

Adam Oakley

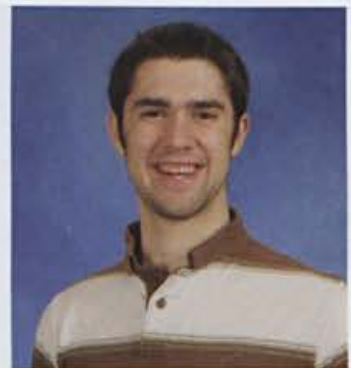

\section{Darren Miller}

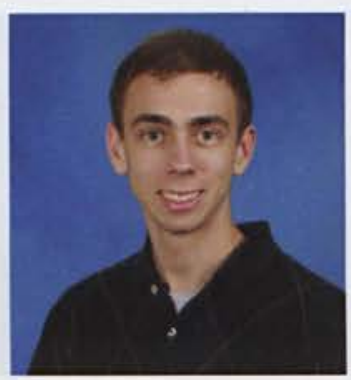

Bradley Morin

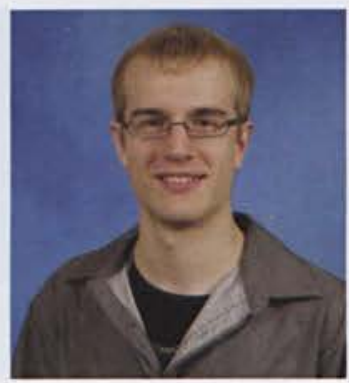

Joshua Muller

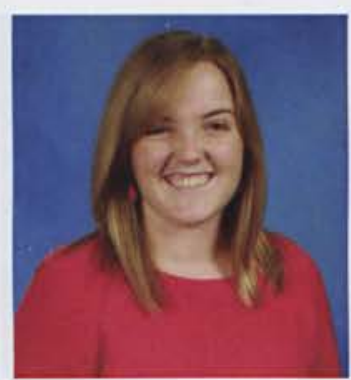

Jerilynn Nine

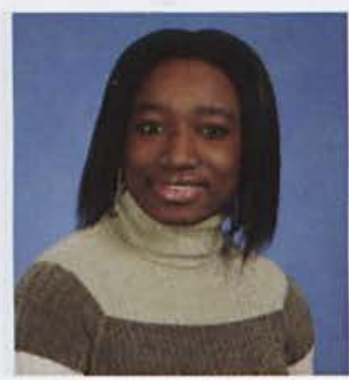

Mary Obielodan

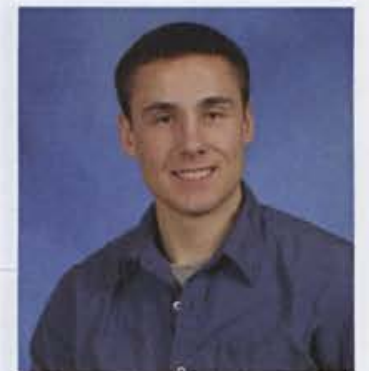

Samuel McLeod

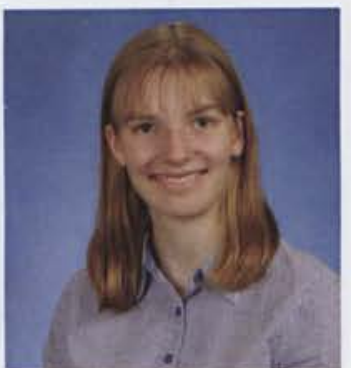

Michelle Mitchener

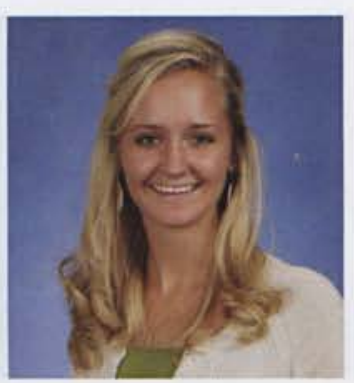

Abigail Morris

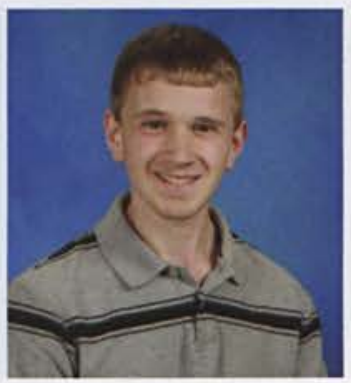

James Myers

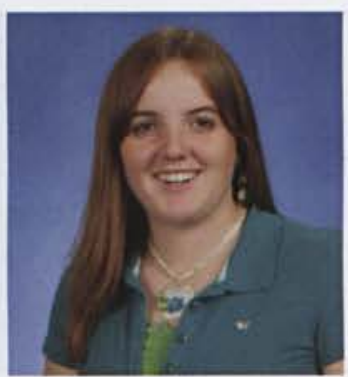

Juliana Nine

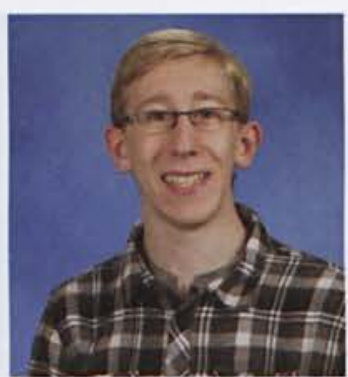

Karl Olson

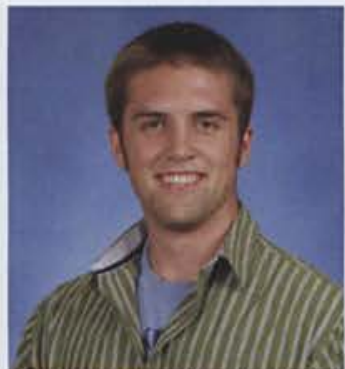

David Medearis

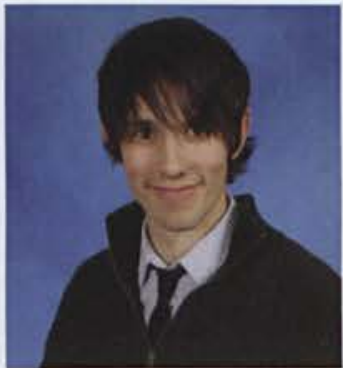

Jared Mittelo

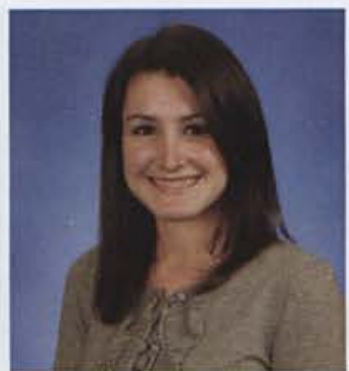

Kaitlyn Morris

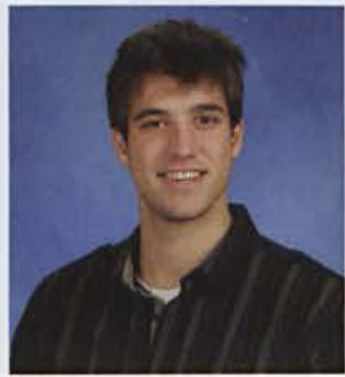

Eric Newman

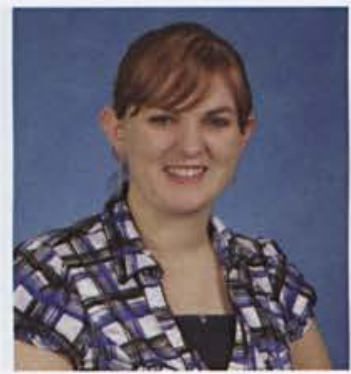

Sarah Norris

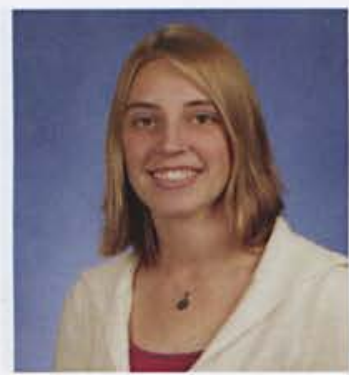

Jennifer Oosterhouse

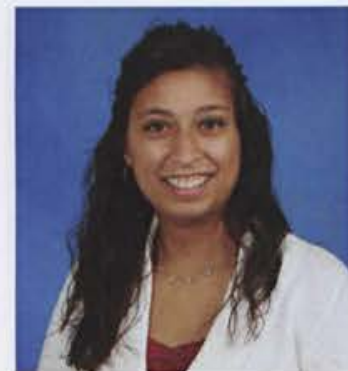

Kalee Medina

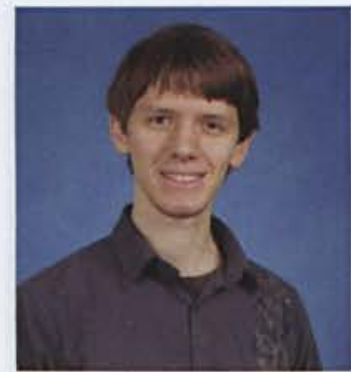

Joel Moore

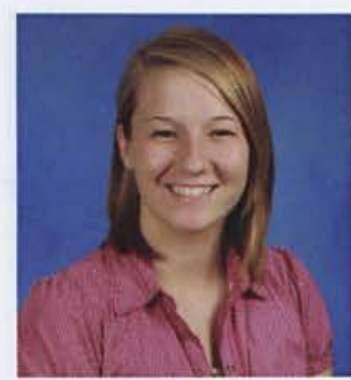

Karen Muckley

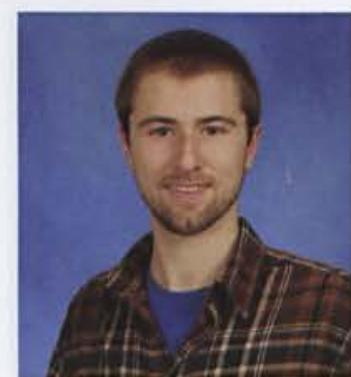

Craig Nichelson

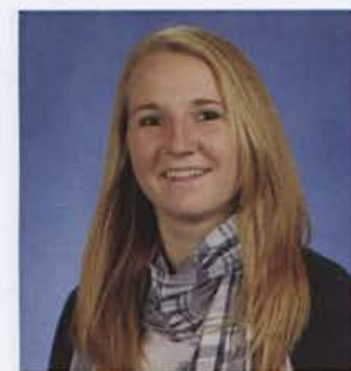

Ashley Nygren

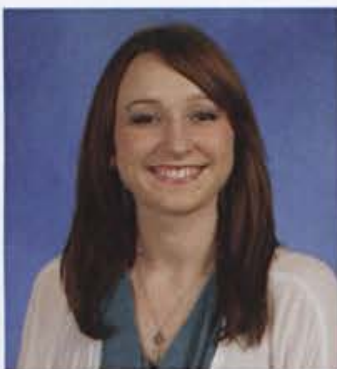

Alyssa Pasma 


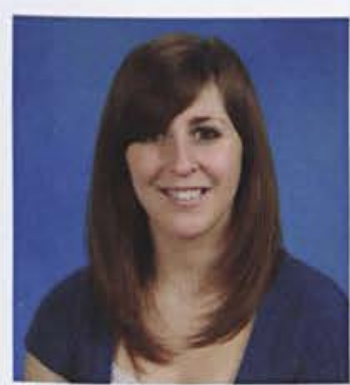

Diana Patrick

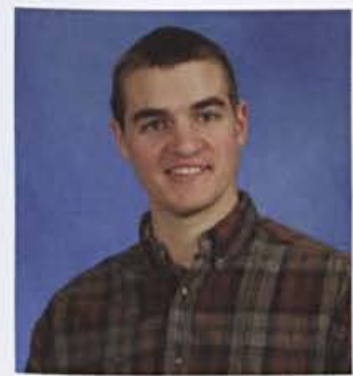

Jordan Petersen

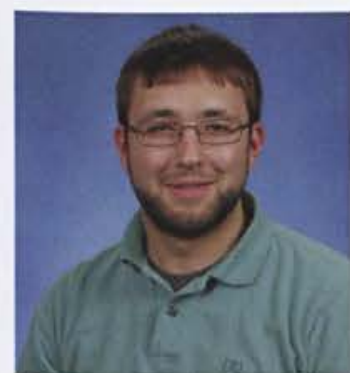

Thomas Poore

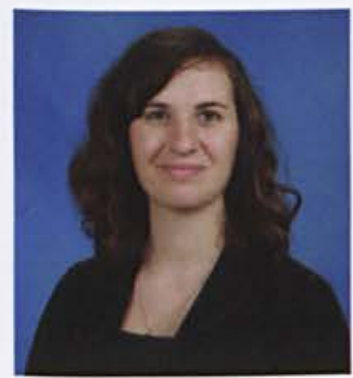

Nina Prozzo

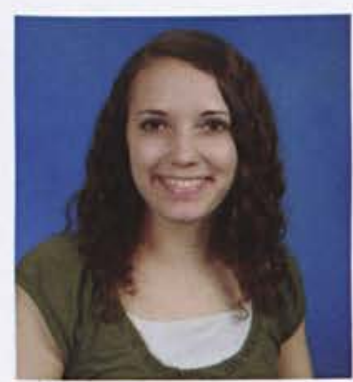

Sarah Rader

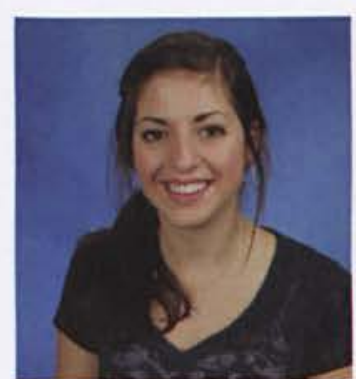

Rebecca Roberts

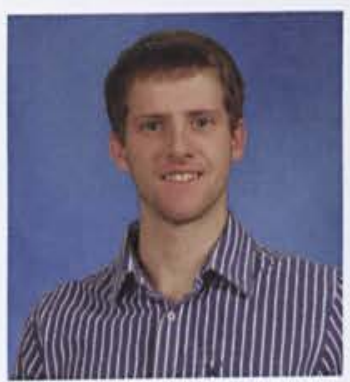

William Patton

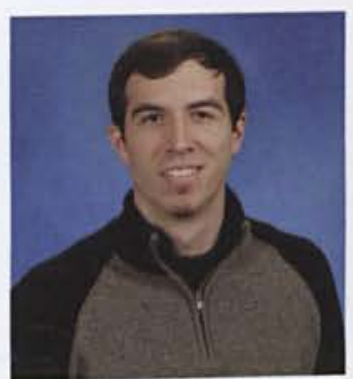

Ethan Peterson

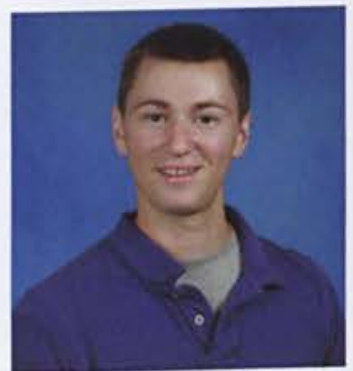

Matthew Porter

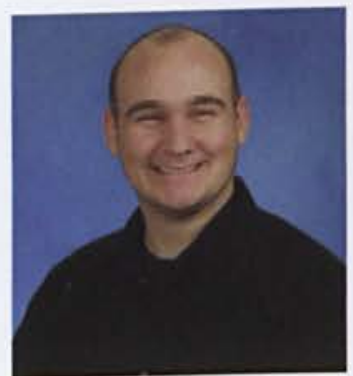

John Pryor

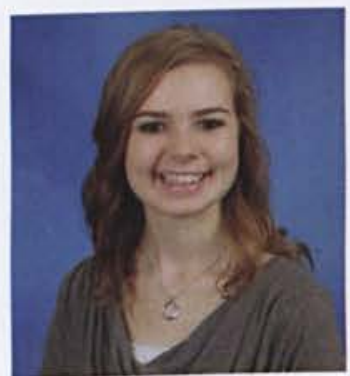

Anna Reisenweaver

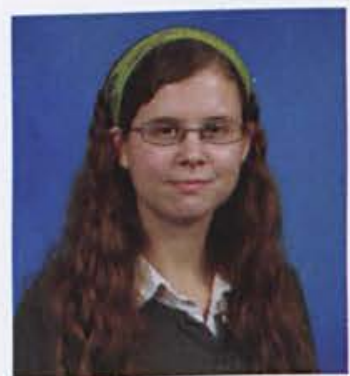

Leah Robertson

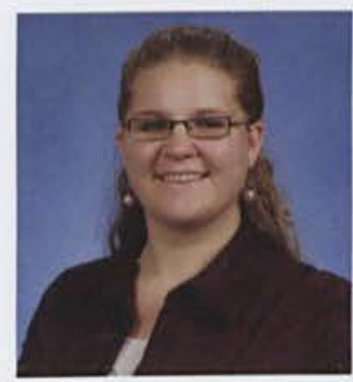

Jillian Payne

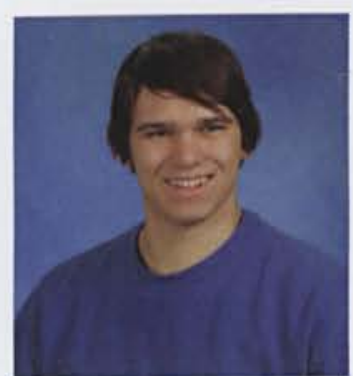

\section{Daniel Petke}

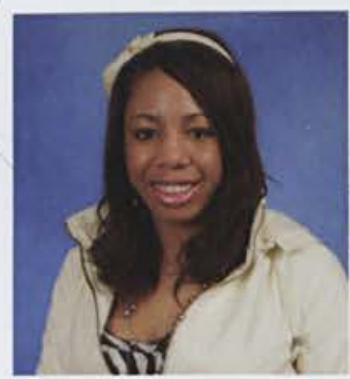

Jessica Presley

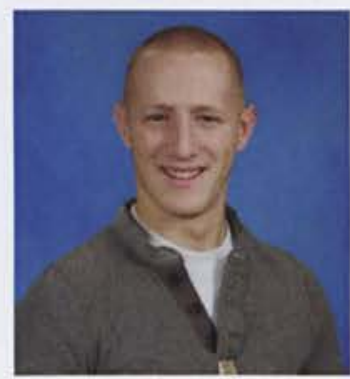

Steven Purtell

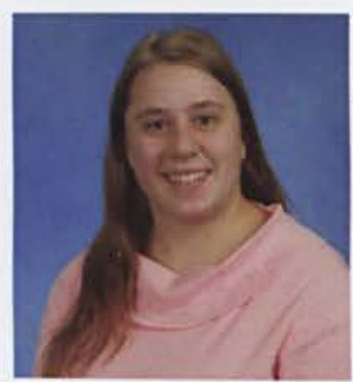

Eadie Rethmeier

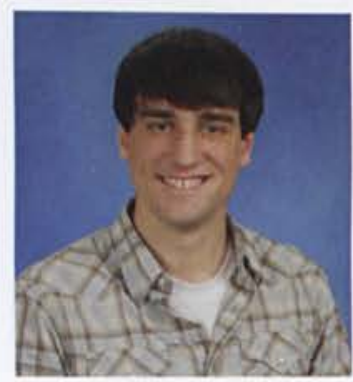

Tim Ronco

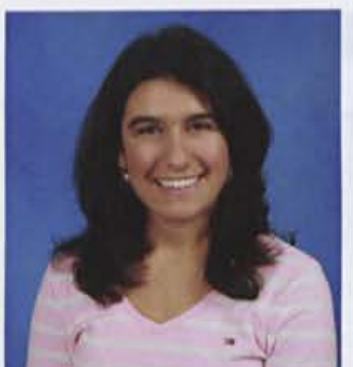

Leah Pernicano

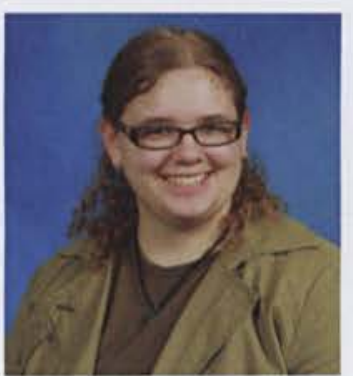

Alyssa Phillips

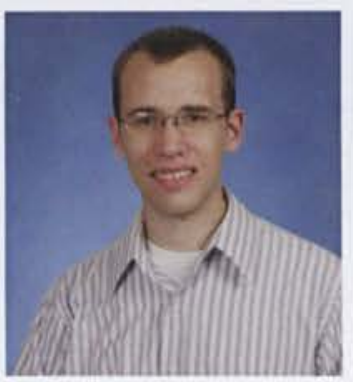

Andrew Price

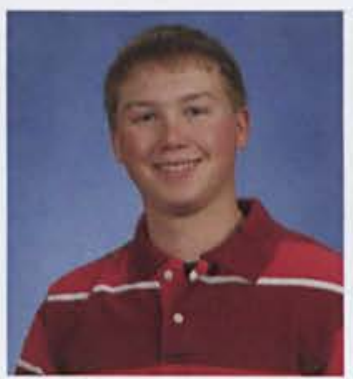

Robert Rabenstein

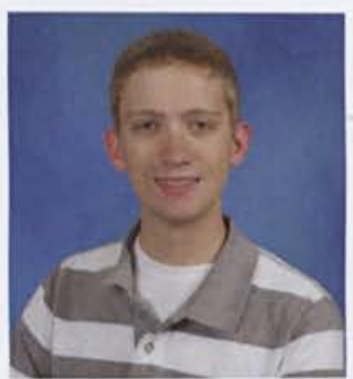

Shawn Rifner

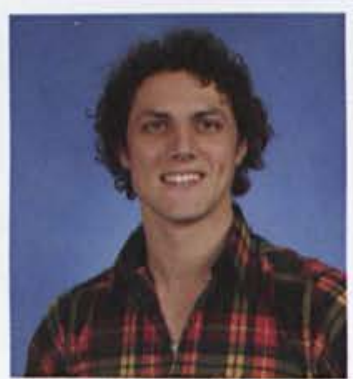

Joshua Roose

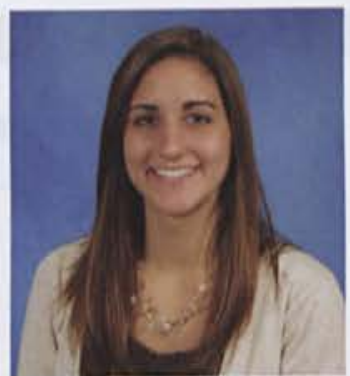

Elizabeth Petek

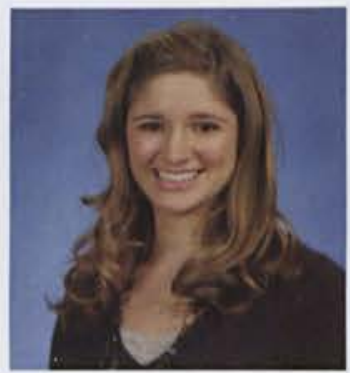

Samantha Phillis

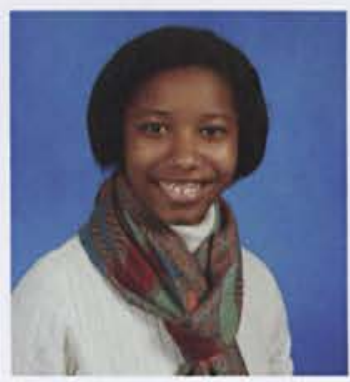

Danielle Price

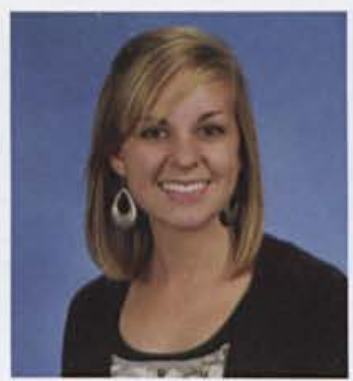

Lauren Radcliffe

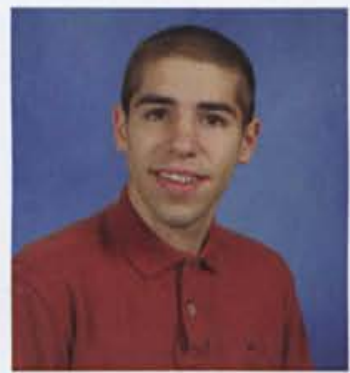

David Riggleman

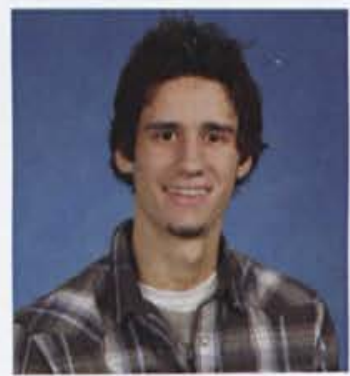

Niles Rosner 


\section{JUNIORS}

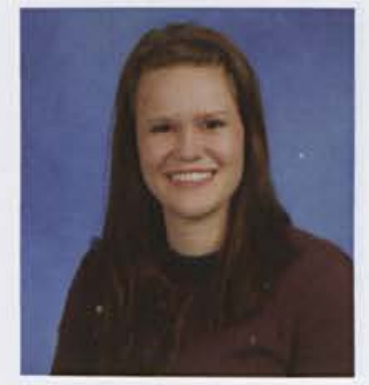

Sarah Ryker

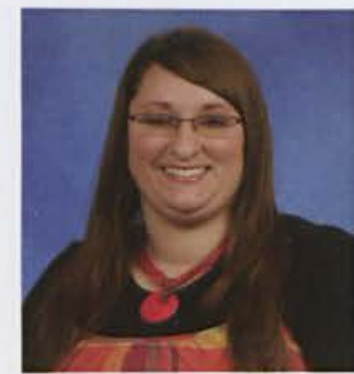

Sarah Schmidt

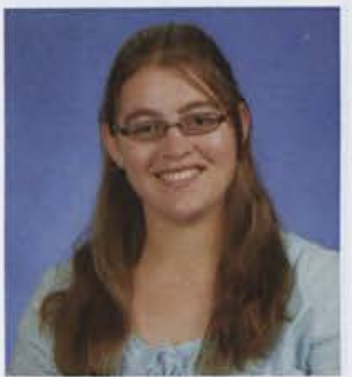

Susanne Seybold

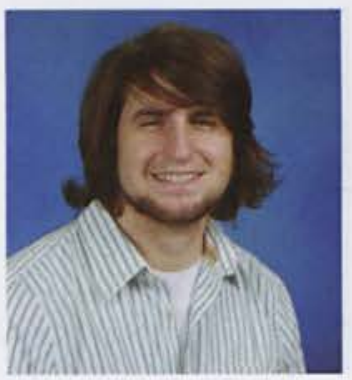

Ryan Sjoquist

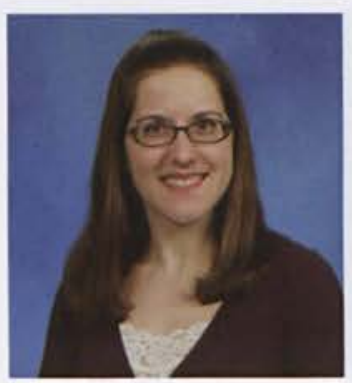

Megan Smith

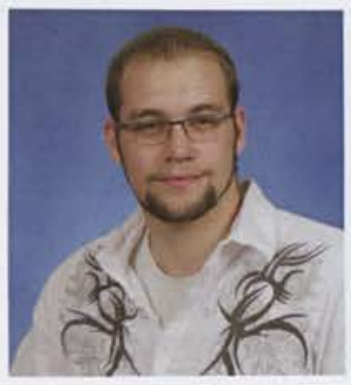

Larry Sanders, Jr.

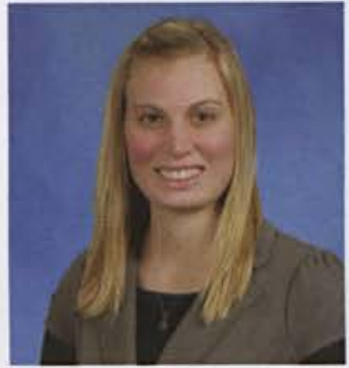

Erin Schultz

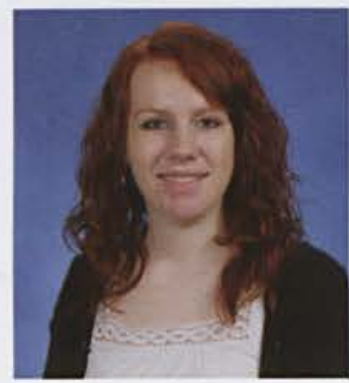

Jessica Sharp

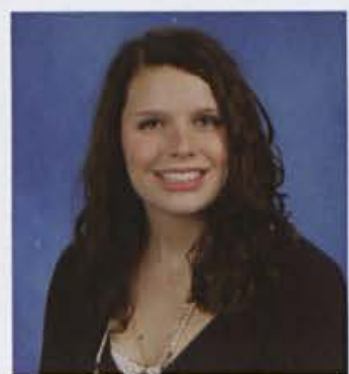

Amanda G. Smith

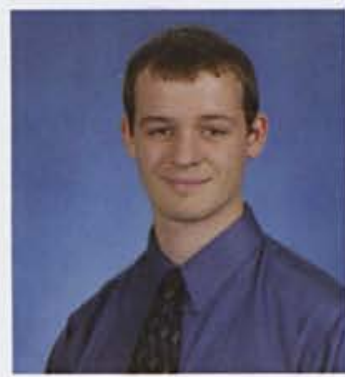

Zachary Smith

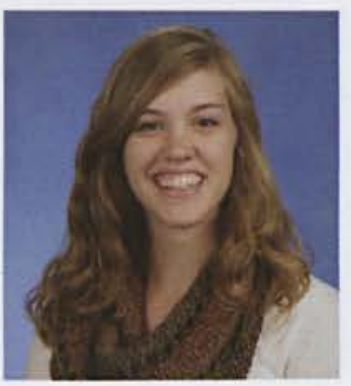

Sarah Rothhaar

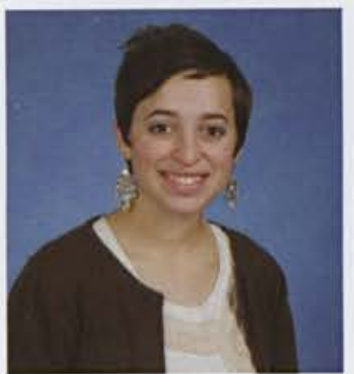

Gabrielle Sanfilippo

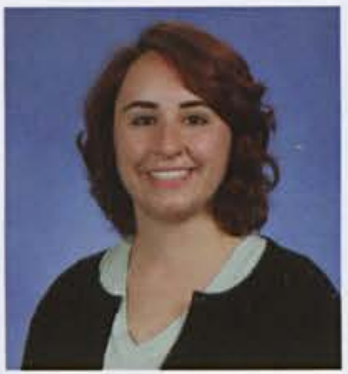

Megan Scott

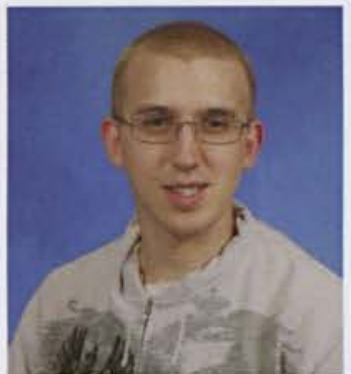

David Simic

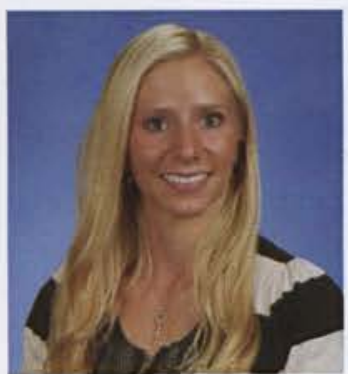

Jessica Smith

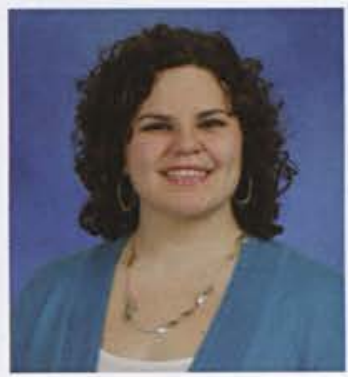

Apryl Sniffen

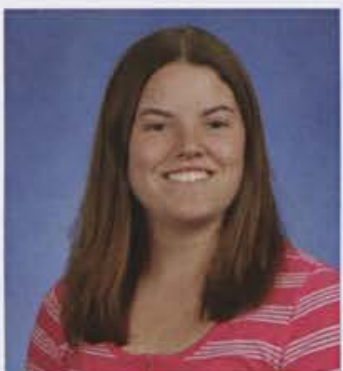

Bridget Russell

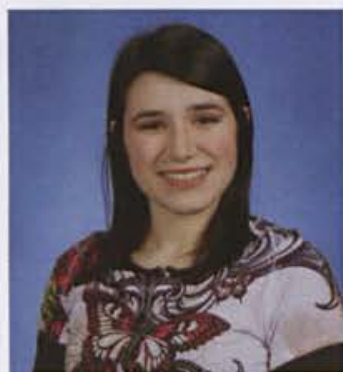

Danielle Scarpone

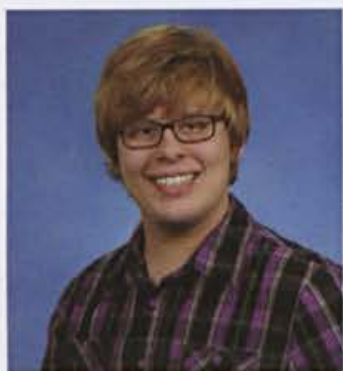

Tyler Scott

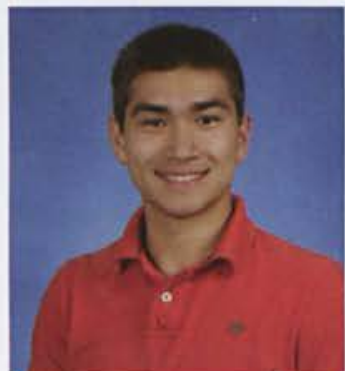

Ethan Simpson

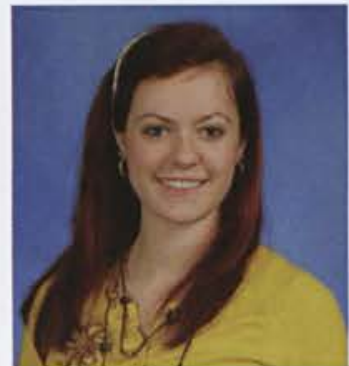

Jordan Smith

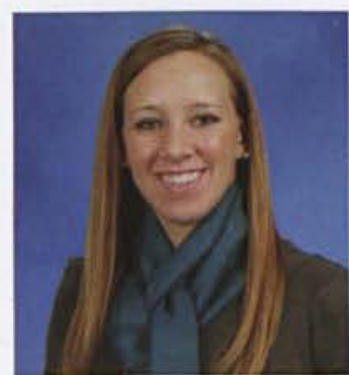

Brianne Spencer

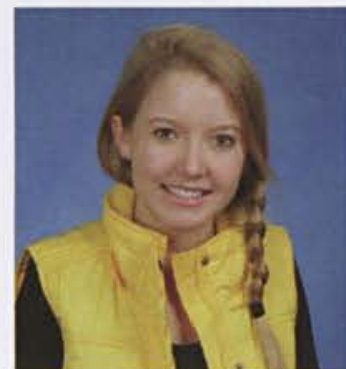

Stephanie Russell

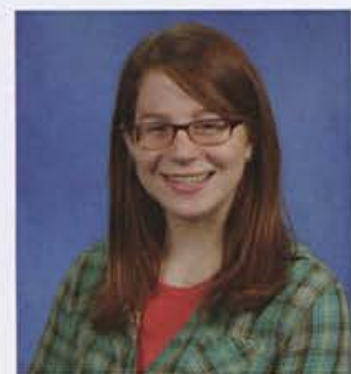

Katie Schmidt

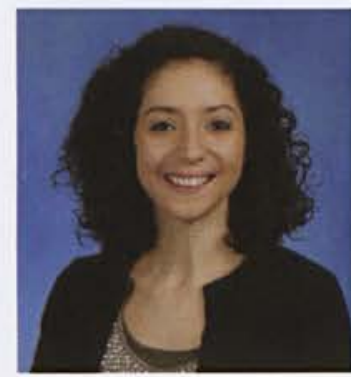

Emily Severance

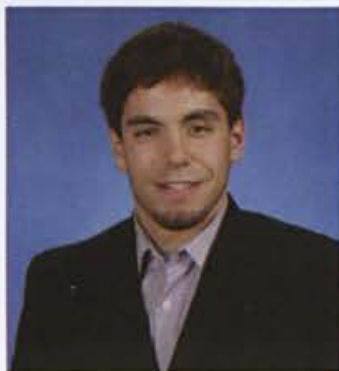

William Simpson

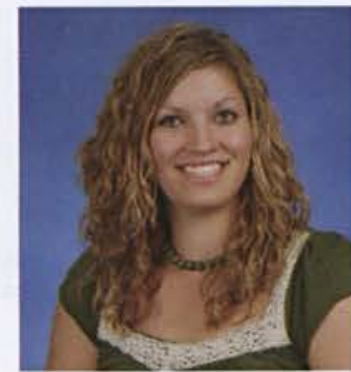

Kendra Smith

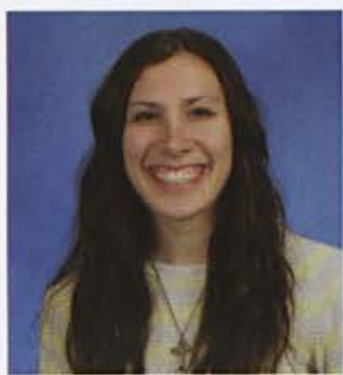

Cammy Sray 


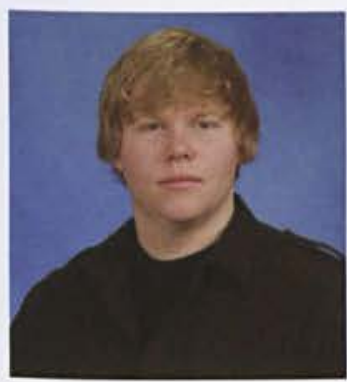

Joshua Staley

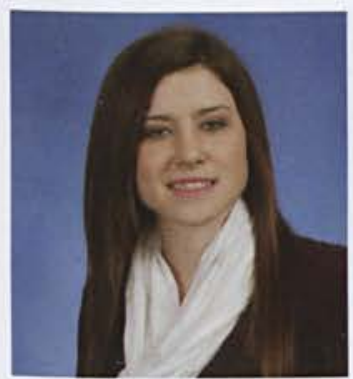

Sarah Stevens

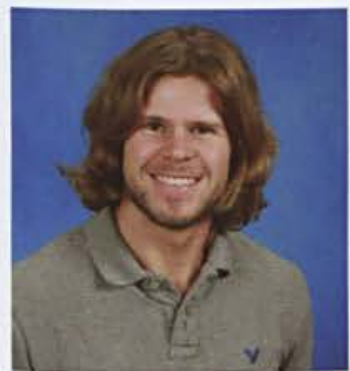

Eric Thompson

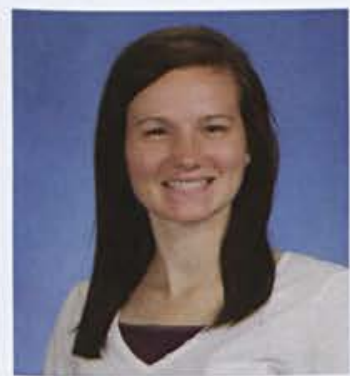

Natalie Tribbett

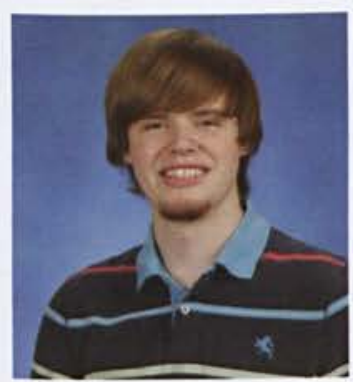

Benjamin Tuley

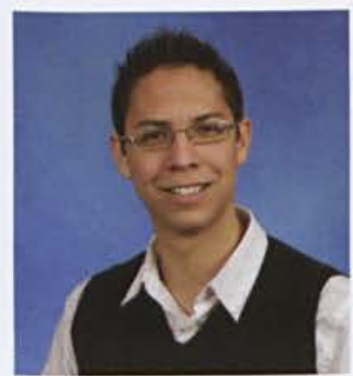

Abraham Vivas

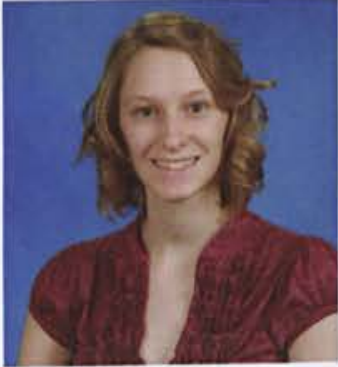

Danielle Starko

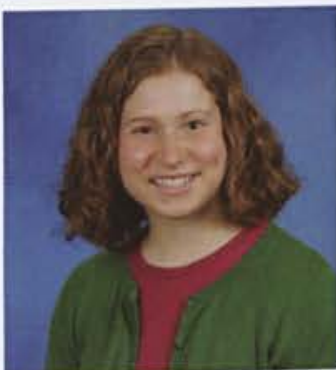

Cheryl Still

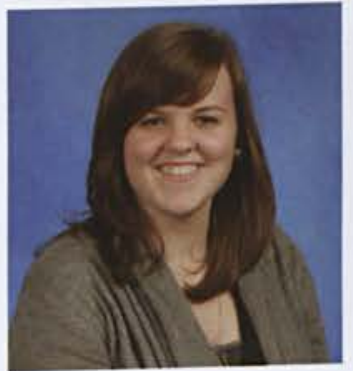

Sarah Thompson

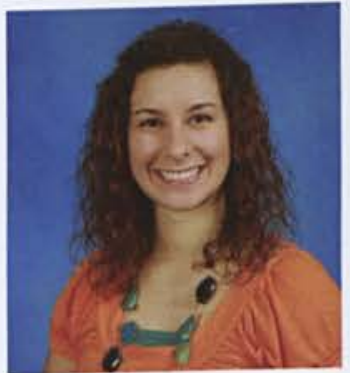

Vienna Trindal

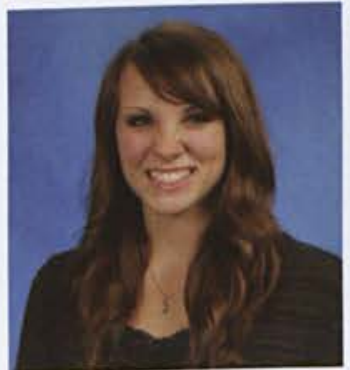

Kailey Tyson

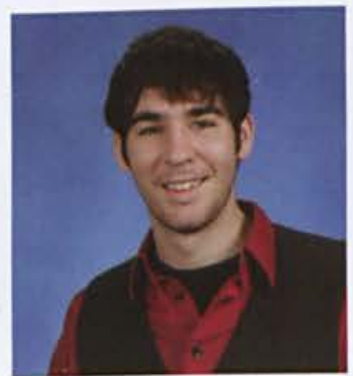

Chris Voltz

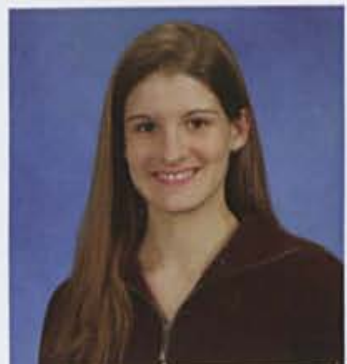

Grace Stearns

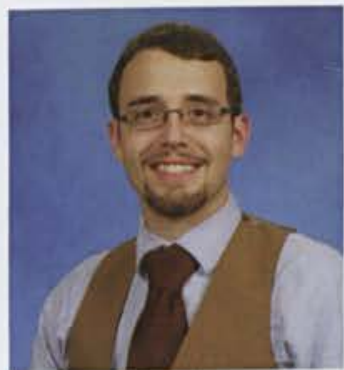

Shamus Strapp

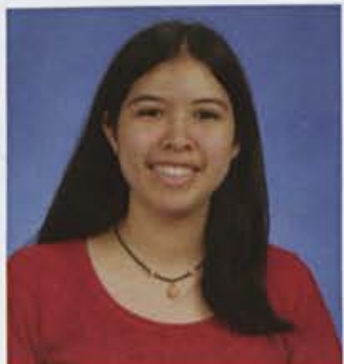

Charissa Thong

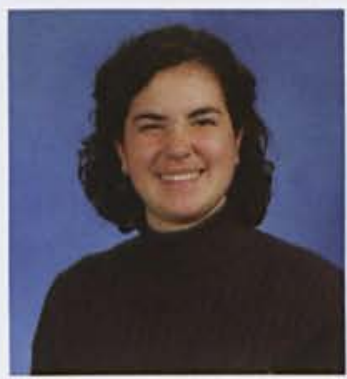

Kristin Troyer

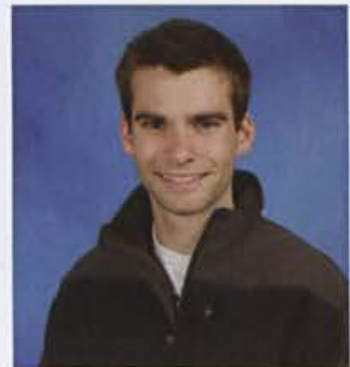

Sebastian Van Dintel

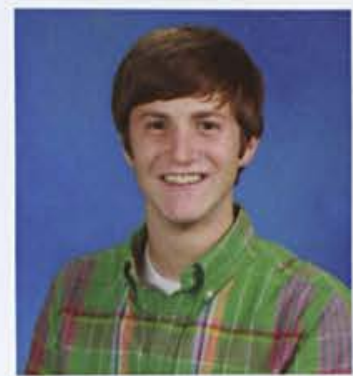

David Wagner

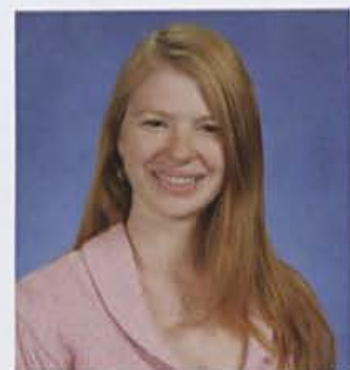

Rachel Stephens

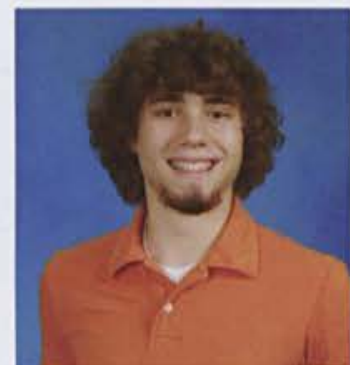

Tim Studebaker

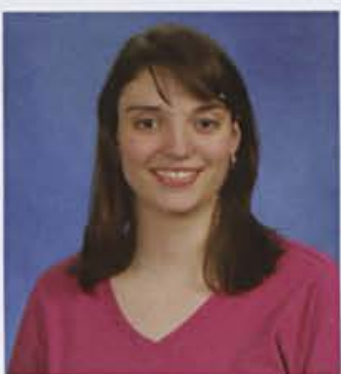

Emily Tomlinson

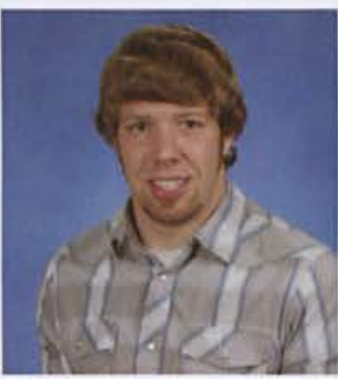

Jon Tucker

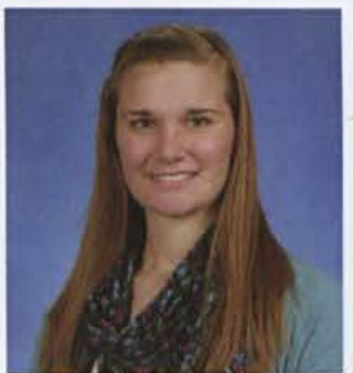

Alexandra Van Wyck

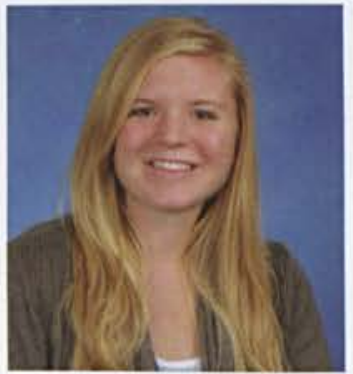

Elizabeth Walton

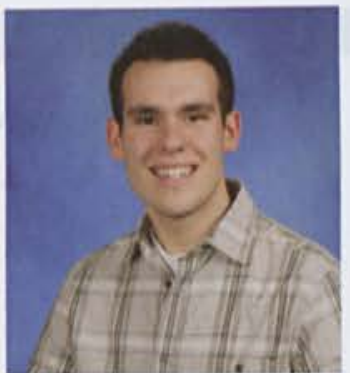

Scott Stephens

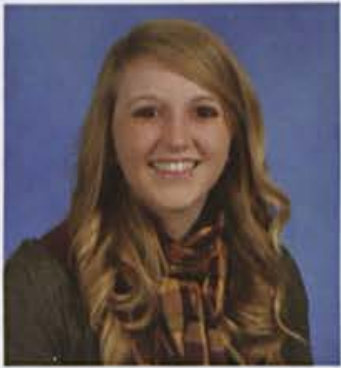

Rebecca Tervo

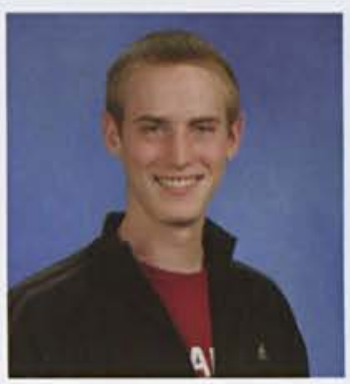

Jeffrey Travis

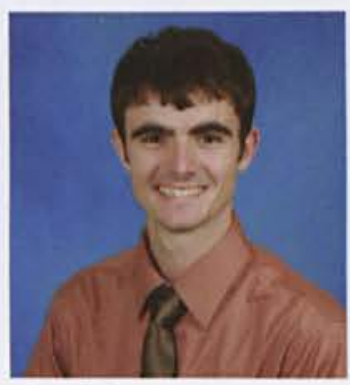

Thaddaeus Tuggle

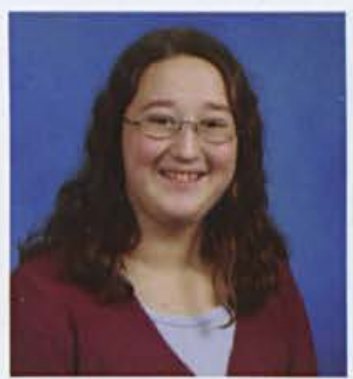

Hadassah Veldt

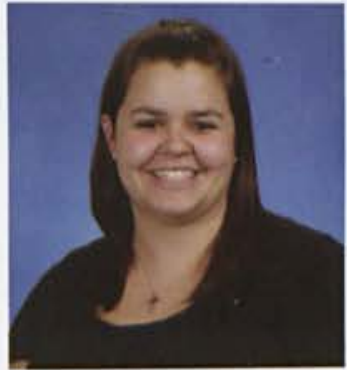

Amanda Wands 


\section{JUNIORS}

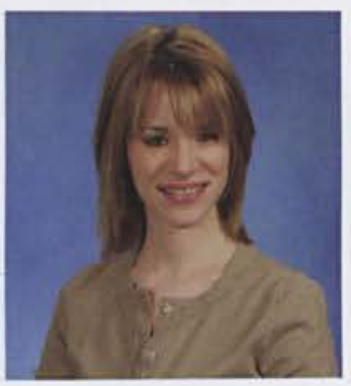

Laura Ward

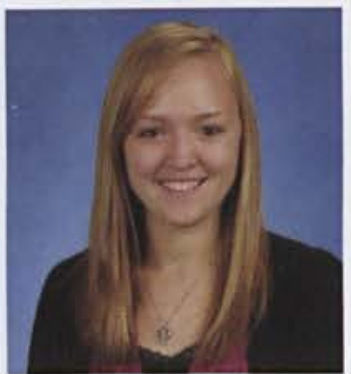

Jessica Wengerd

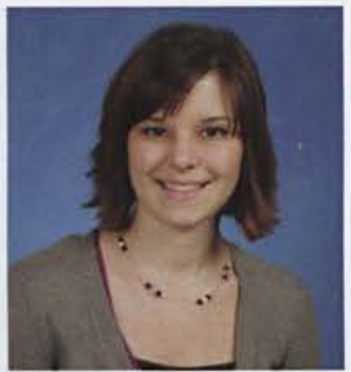

Krista Wiles

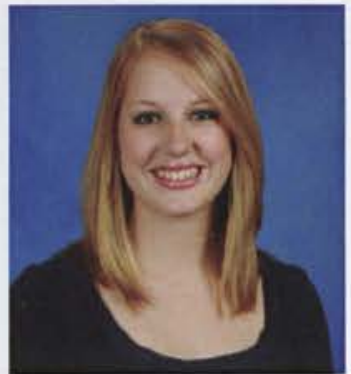

Caitlin Yoder

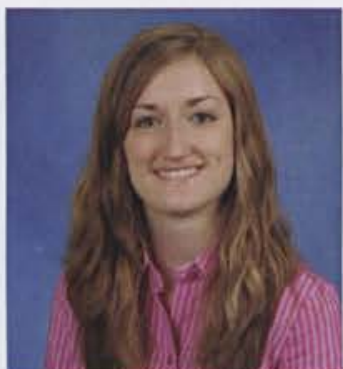

Annie Watson

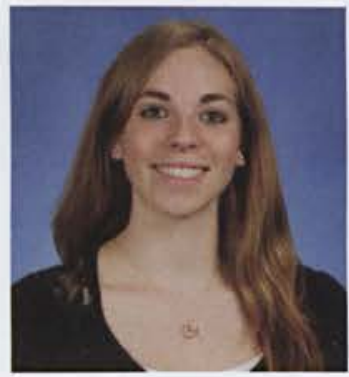

Alexandra White

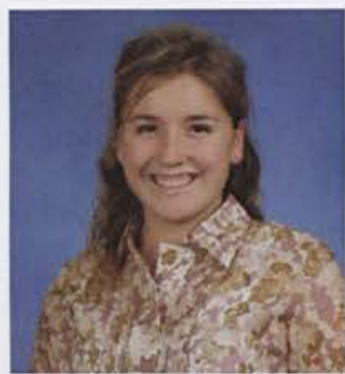

Lauren Williams

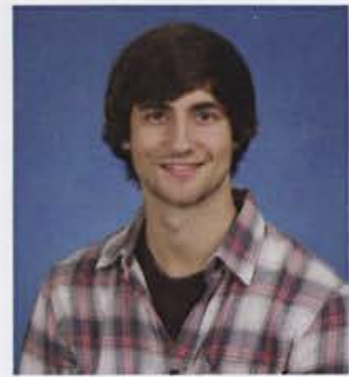

Cameron York

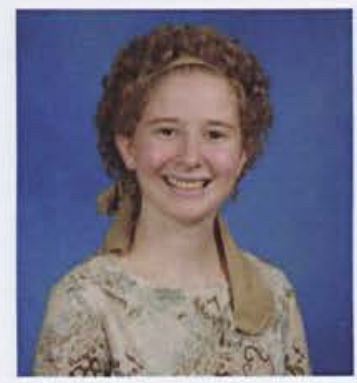

Diana Weaver

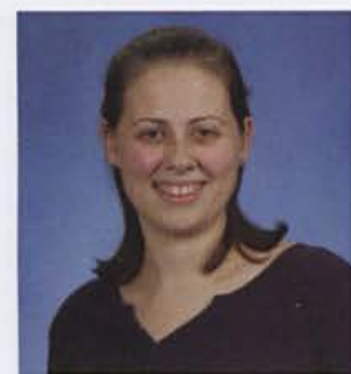

Devin Wicker

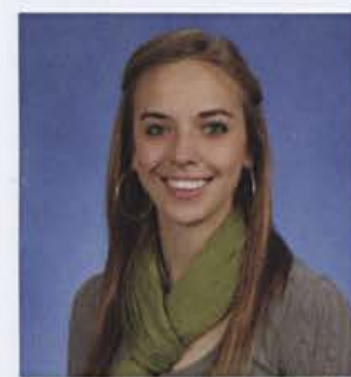

Alexa Winik

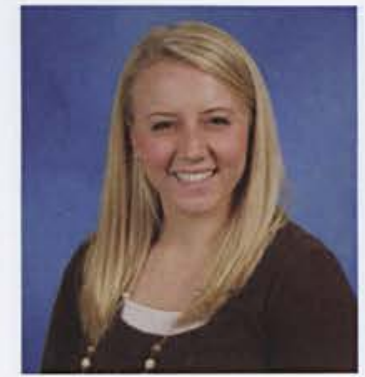

Lauren Young

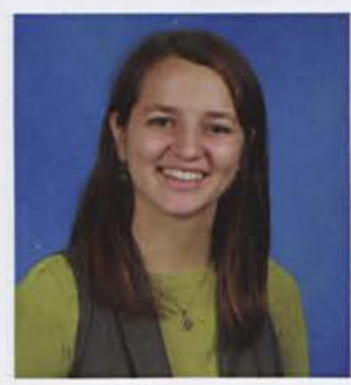

Tia Zirkle 


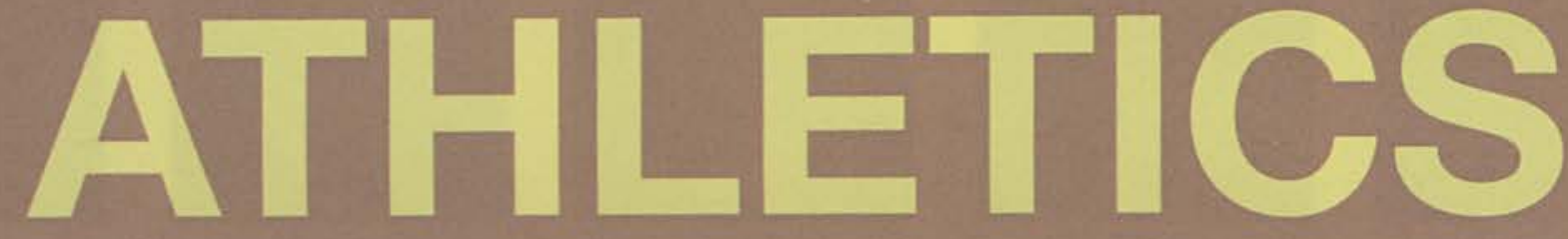

noun, plural \ath-'le-tiks\Sporting events used to unite campus; an opportunity for students to learn both how to manage their time and just how far their bodies can go. 


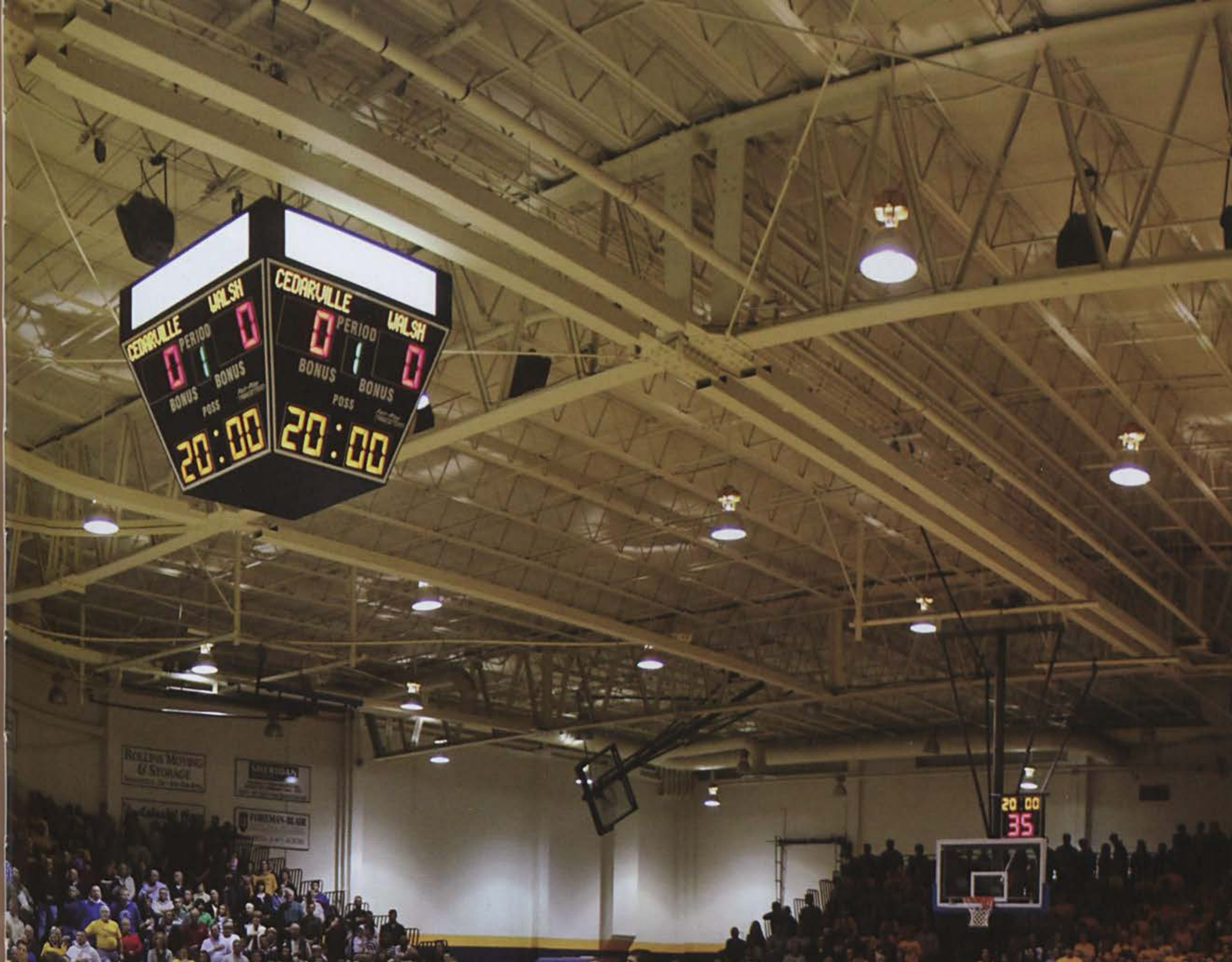
20. In $24: 24$

(*)

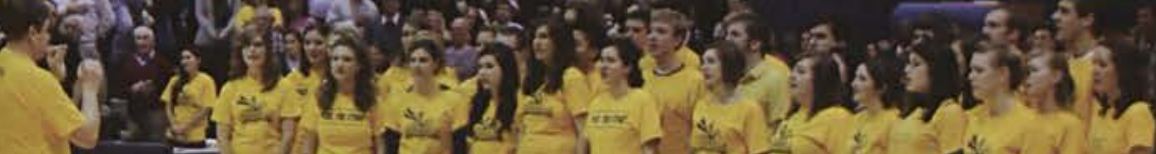

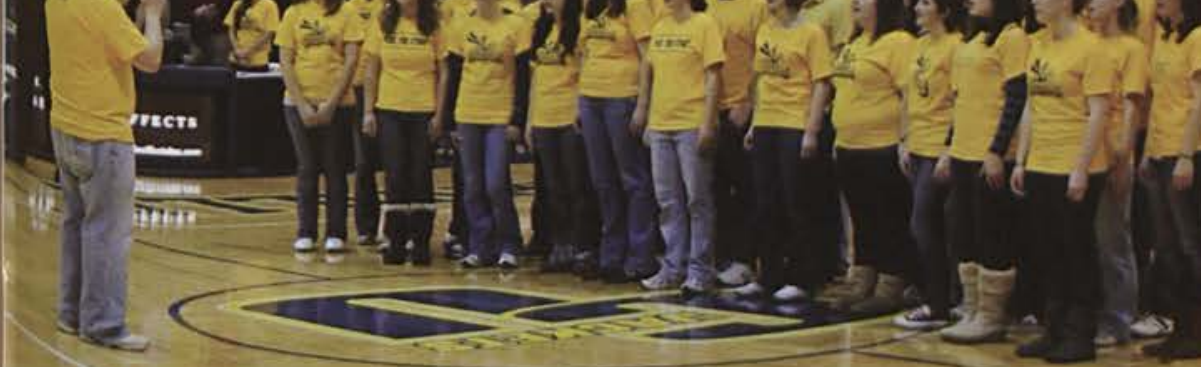

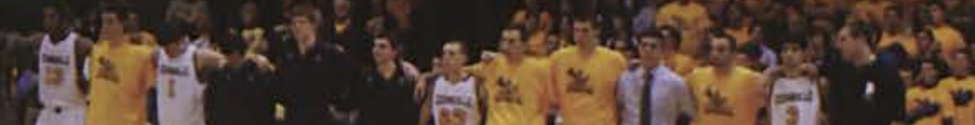

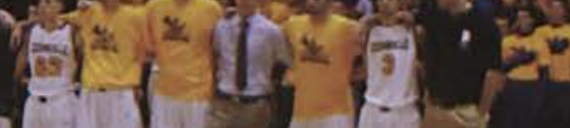

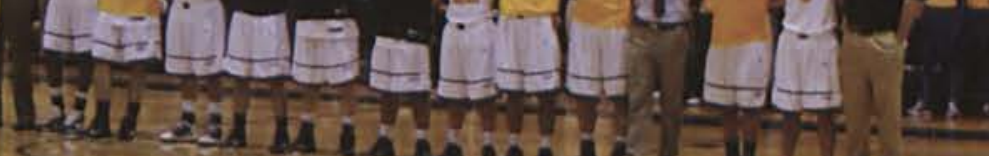

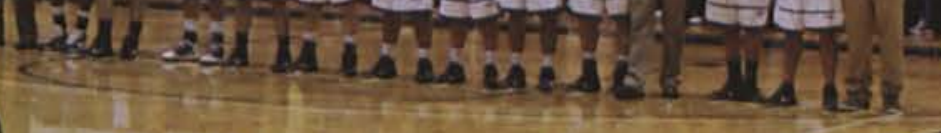

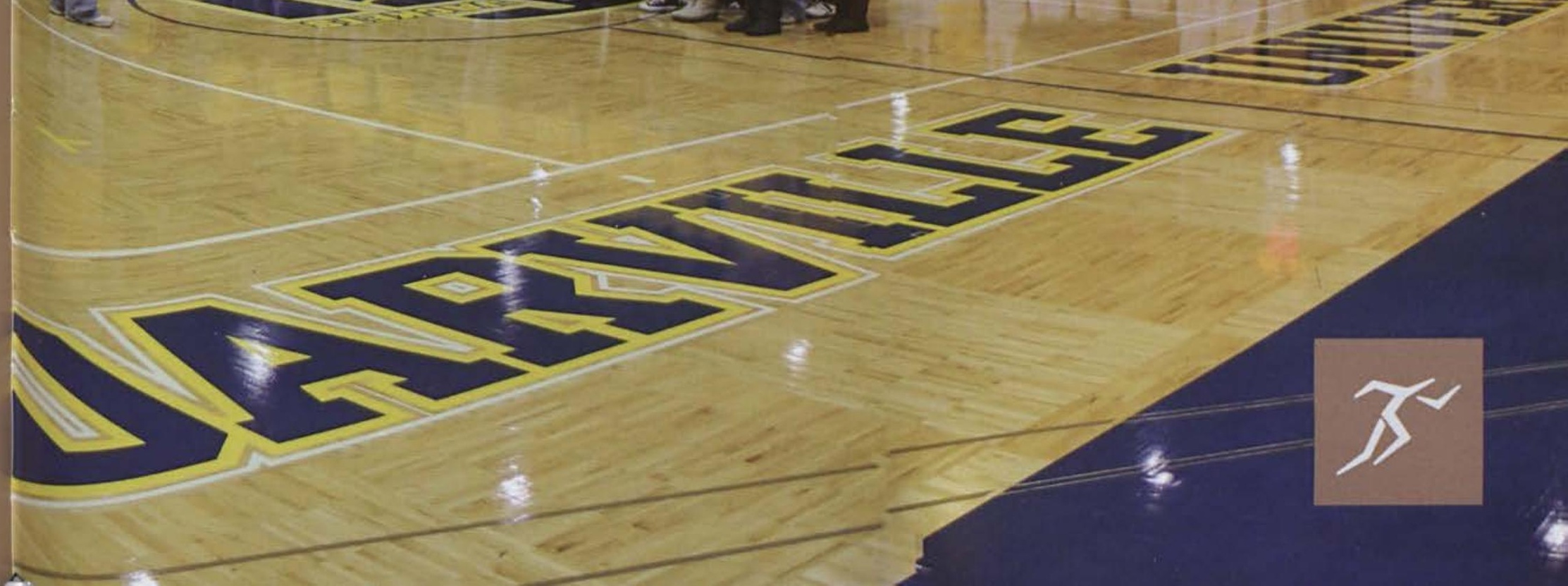




\section{MEN'S SOCCER}

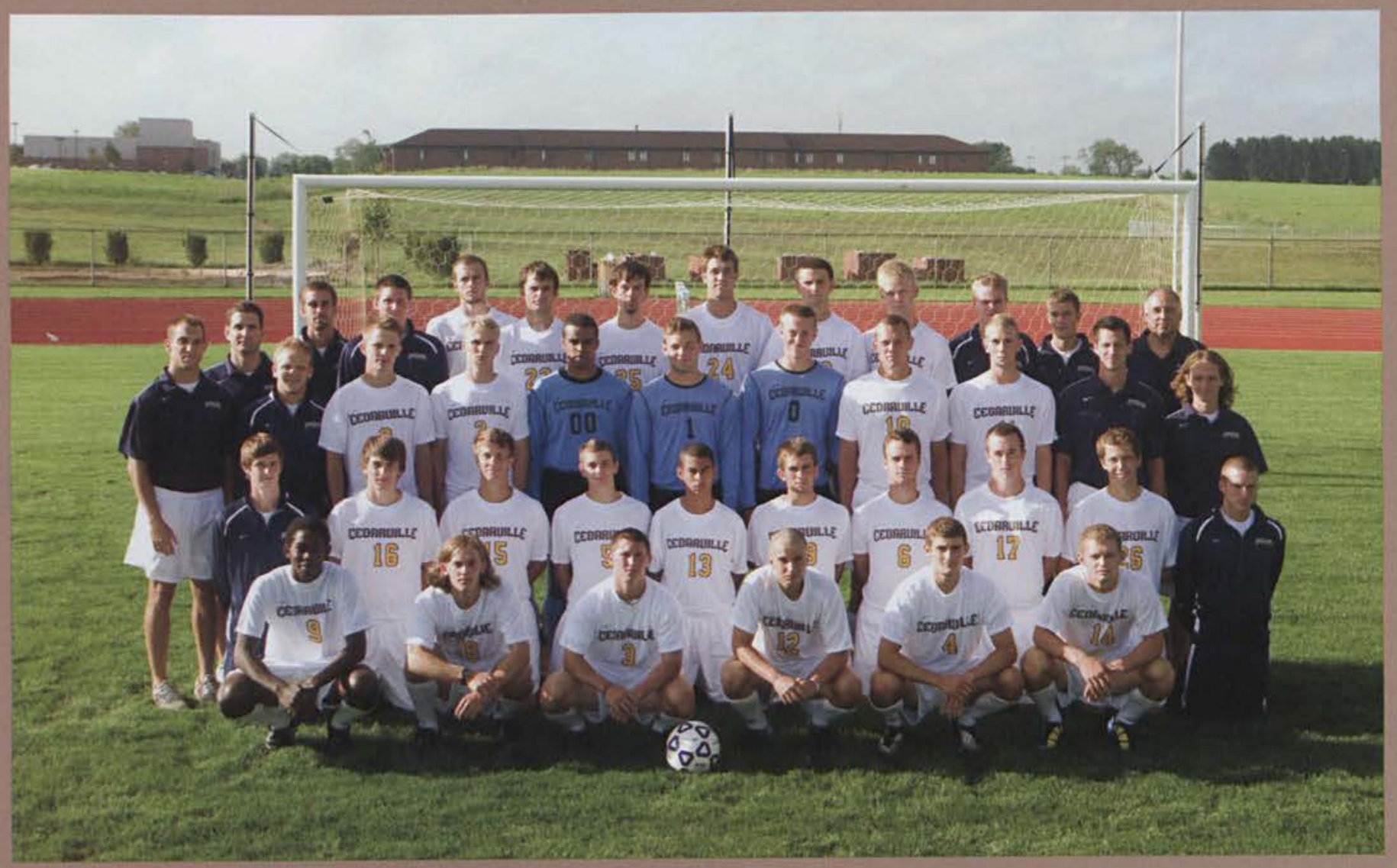

RECORD:

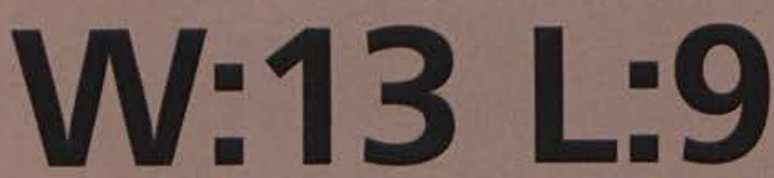

"I truly believe that most of my growth over the past two years at Cedarville is due to my teammates on the soccer team. They keep me accountable in all aspects of my life, not just soccer."

(Stephen Ellis)

Members Front row left-to-right Stephen Morris, Timmy Waller, Ryan Thurman, Tony Franco, Todd McKinley, Myles Greely. Second row Eric Brueckner, Jon Earl, Ryan Connelly, Zack Gatlin, Eric Hoober, Stephen Magee, Tim Green, Steve Ellis, Andrew Hartman, Samuel Rowe. Third row Assistant Coach Luke Marietta, Jonathan Blauert, Jason Bender, James Twinem, Stephen Campbell, Kevin Bender, Alex Scott, Matt Niemiec, Joseph Mueller, Head Coach Todd Beall, Assistant Coach Matt George. Back row Assistant Coach Jon Waldo, Matt Finkbeiner, Michael Williams, Scott Roseberg, Jordan Clark, Zakariah Ziegler, Eric Newman, Stephen Schindler, Dillon King, Ryan Young, Mitch Goodling, Assistant Coach Dr. Kevin Roper. 

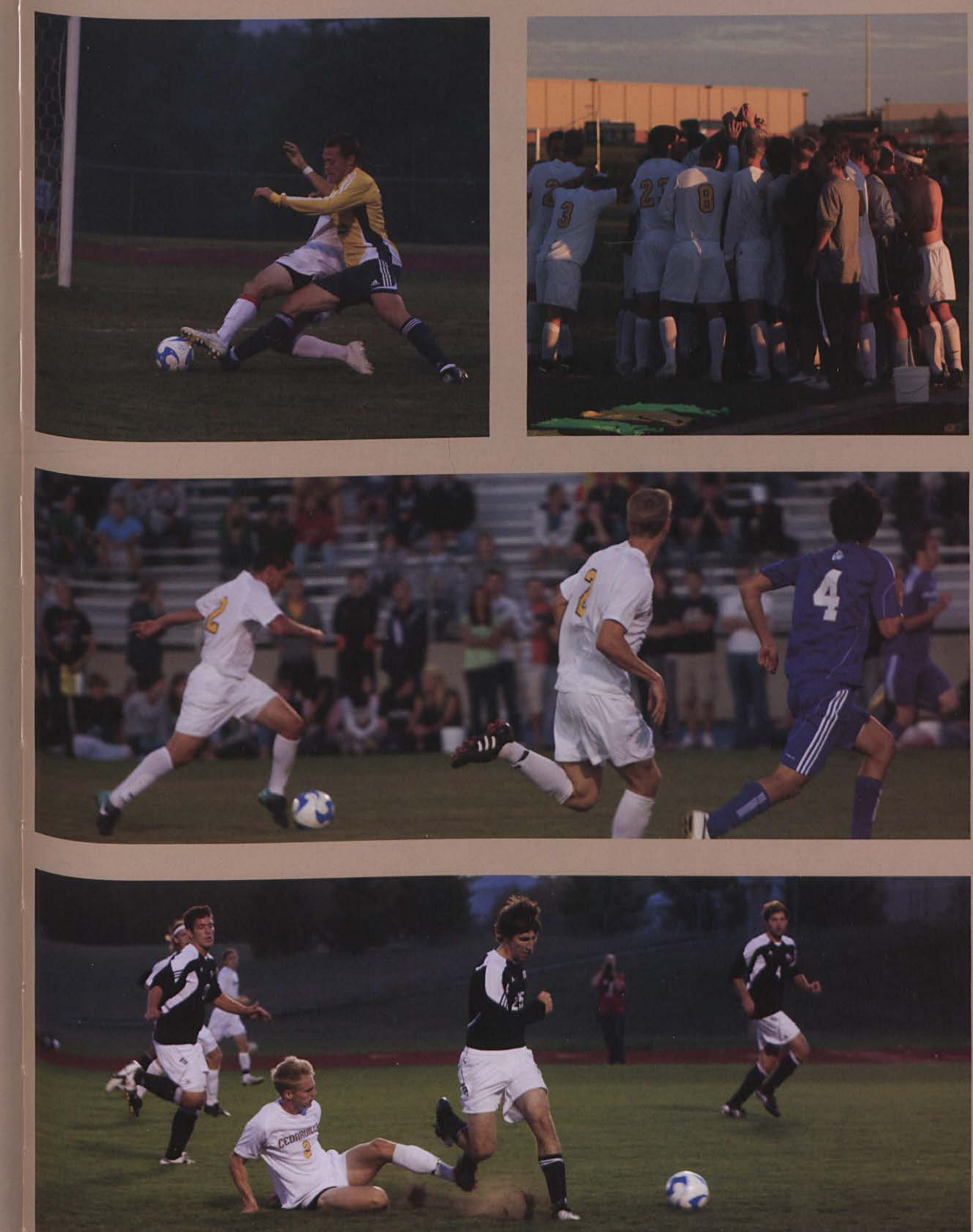


\section{WOMEN'S SOCCER}

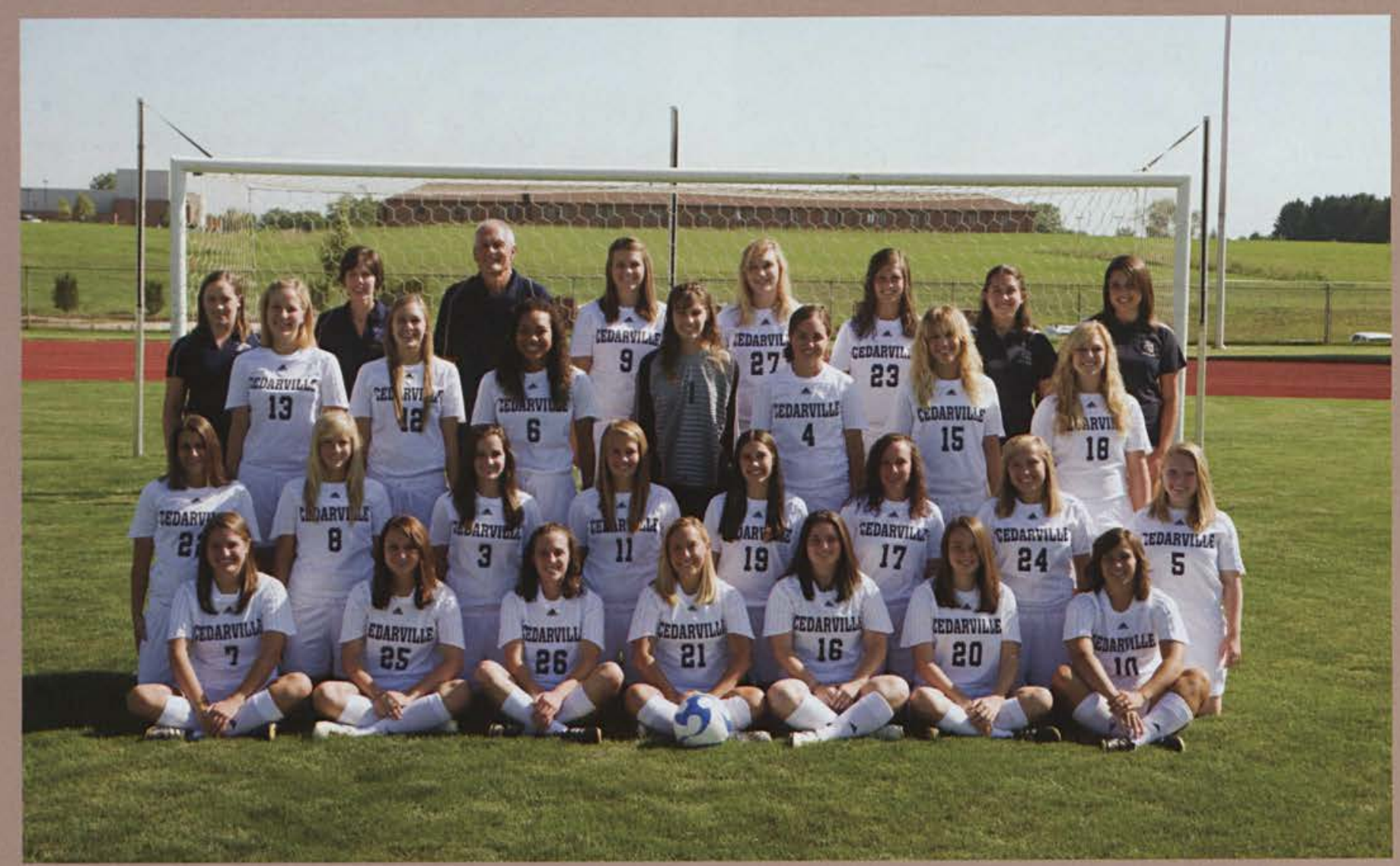

"My favorite game this year was against

\section{RECORD:}

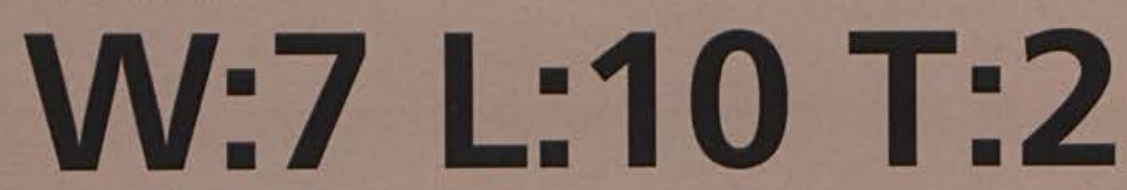

Mount Vernon. It was a tough battle. Two minutes into overtime, Rachel Brownfield recieved the ball, made her move, and succeeded! Our entire bench erupted in celebration."

(Lacie Condon)

Members Front row left-to-right Kelly Wise, Bethany Wailies, Rachel Brownfield, Jaimie Watkins, Megan Spring, Karen McCoskey, Lacie Condon. Second row Jill Carroll, Ashlee Wilson, Dresden Matson, Morgan Ziegler, Deanne Bradshaw, Sarah Brownfield, Becky Burton, Sarah Irwin. Third row Kelsey Watkins, Emily Niedermayer, Amanda Bunton, Alysia Bennett, Anna Schmid, Jill Davis, Alexis Mickle. Fourth row Assistant Coach Katelyn Reuther, Assistant Coach Krista Mattern, Head Coach John McGillivray, Erica Danner, Nicole Strehle, Arianna Pepper, Assistant Athletic Trainer Leyna Hebert, Student Athletic Trainer Erin Abbate. 


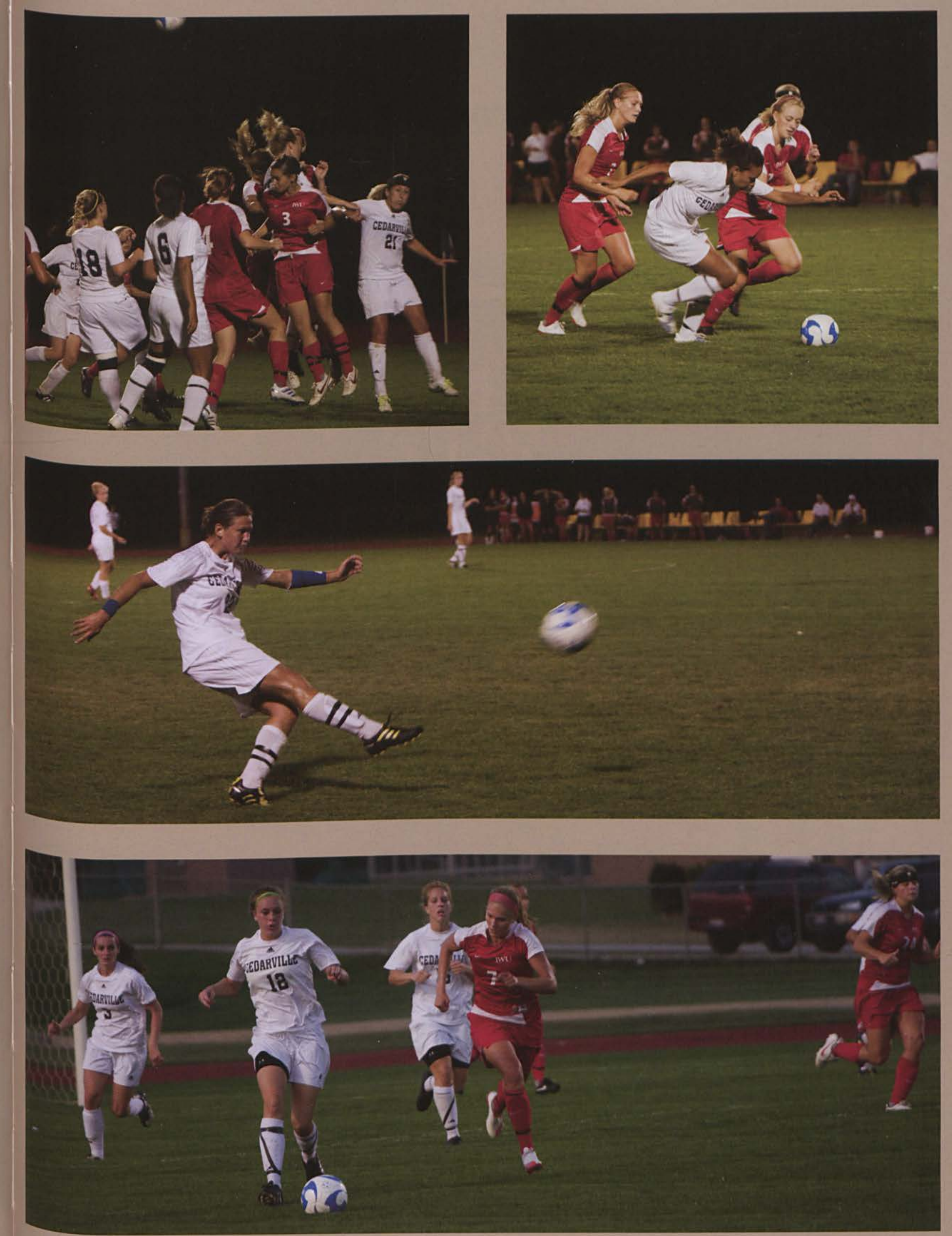

1.6.

(6)

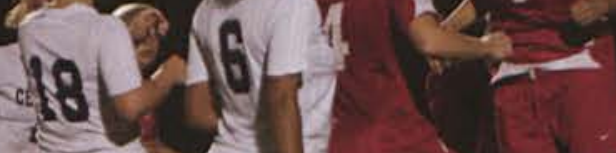
द - D

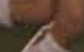

$5 \int_{1}$ a

fortions 


\section{WOMEN'S VOLLEYBALL}

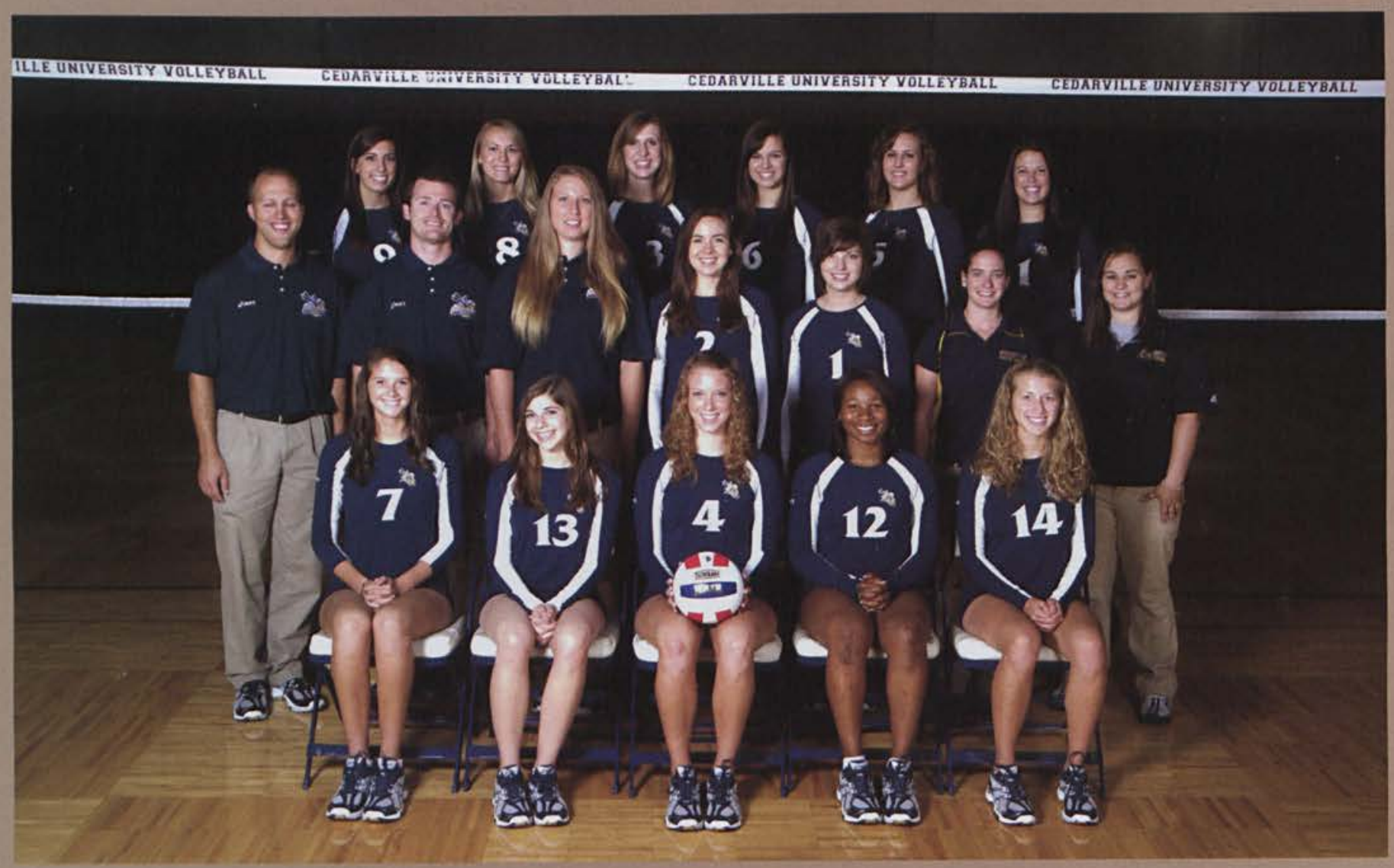

\section{RECORD:}

"I'm excited to come back and see my

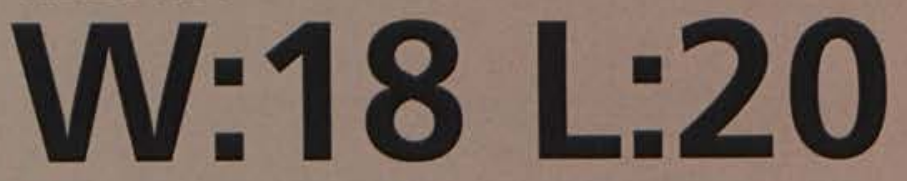
teammates play next year, because the growth they made this year was spectacular. My prayer is our passion to play, and our focus on Christ is stronger than ever."

(Kylee Husak)

Members Front row left-to-right: Nikki Siefert, Sarah Bradshaw, Emilie Lynch, Lauren Williams, Kara Yutzy. Middle row Head Coach Doug Walters, Assistant Coach Garrett Maddox, Assistant Coach Sarah Zeltman, Heather Kirkpatrick, Erica Bartholomew, Assistant Athletic Trainer Hannah Haynes, Student Athletic Trainer Jasmine Lee. Back row Stephanie Rogers, Lauren Gill, Kylee Husak, Kelsey Christiansen, Sarah Hartman, Kassi Ernsberger. 


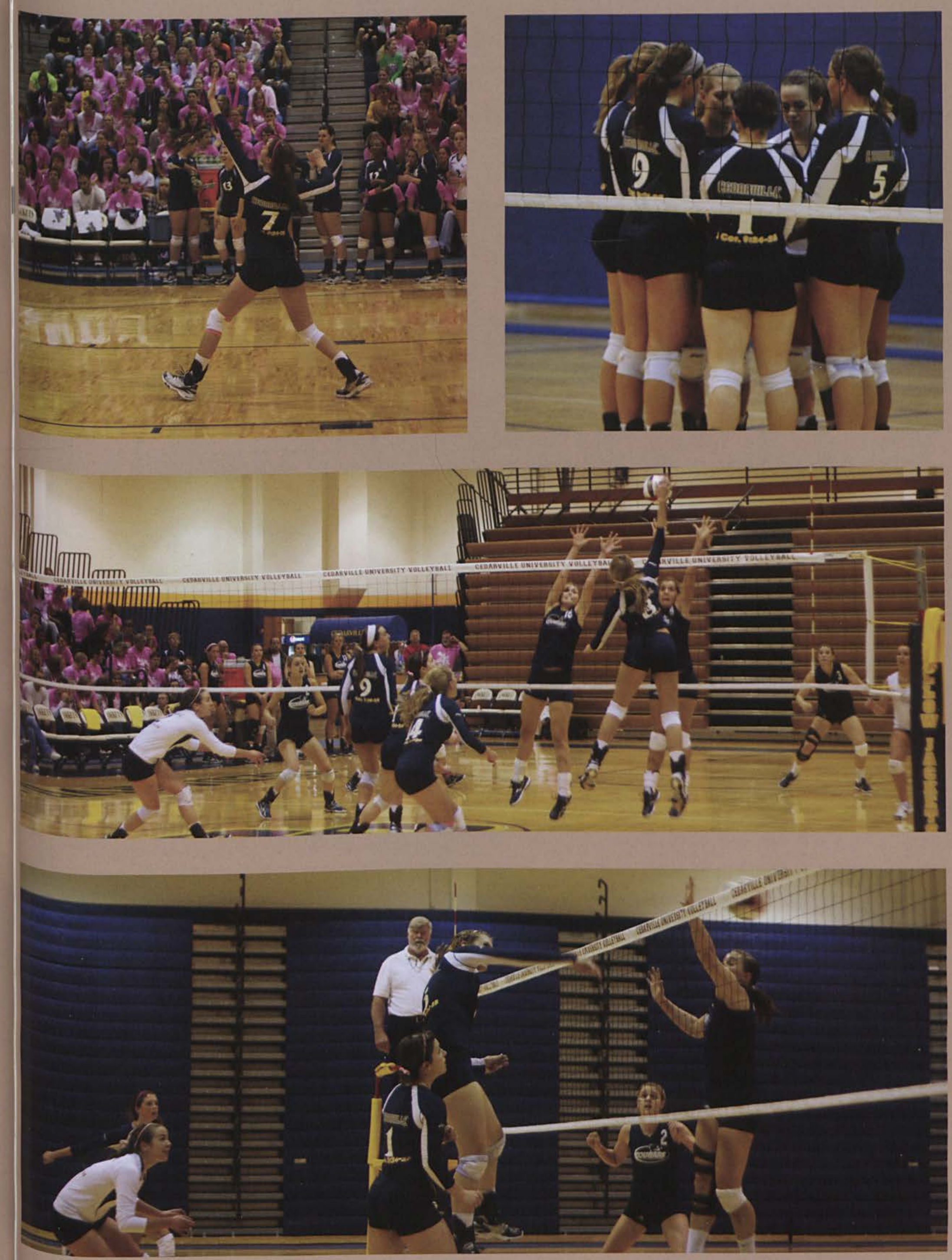




\section{MEN'S CROSS COUNTRY}

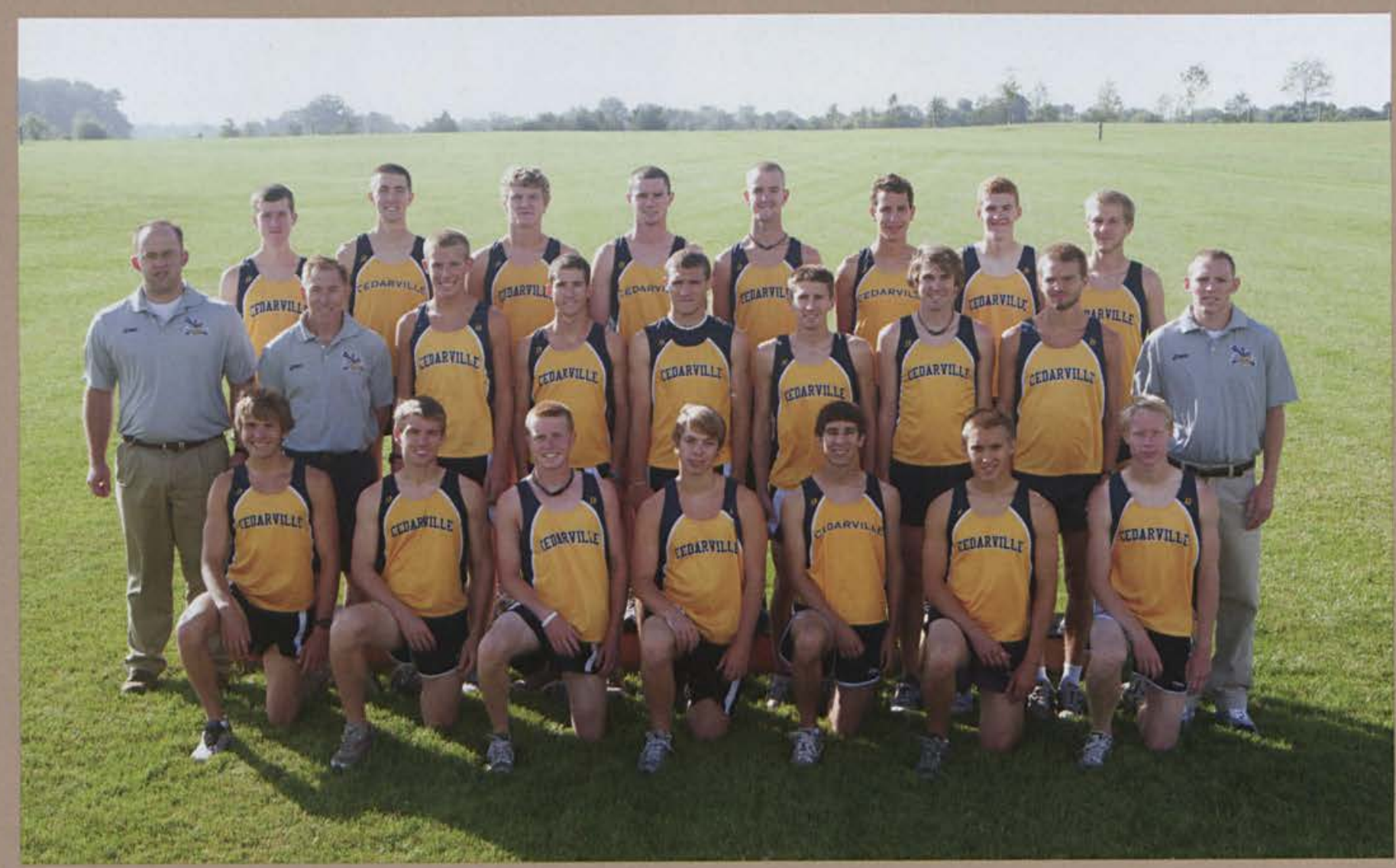

RECORD:

NCCAA National Champions (1st of 28) NAIA Nationals (15th of 32) American Mideast Conference (2nd of 9)
In the NAIA Men's Cross Country

Championship, Evan Thayer was the top runner for Cedarville. He finished 72nd out of 326 participants.

Members Kneeling Leftoto-Right Greg Johnson, Chris Vaughn, Scott Gardner, Trevor Bryant, Joseph Cathey, Ryan Gustafson, Eli Pyles. Middle row Assistant Coach Steve Powers, Head Coach Paul Orchard, Joe Niemiec, Josh Wiseman, Neil Klinger, Jordan Davies, T.J. Badertscher, Matt Brooker, Assistant Coach Jud Brooker. Back row Jacob Walter, Jacob Dubie, Hollis Troxel, Ethan Blagg, Alex Moore, Evan Thayer, Nathaniel Burrell, Josiah Bragg. 

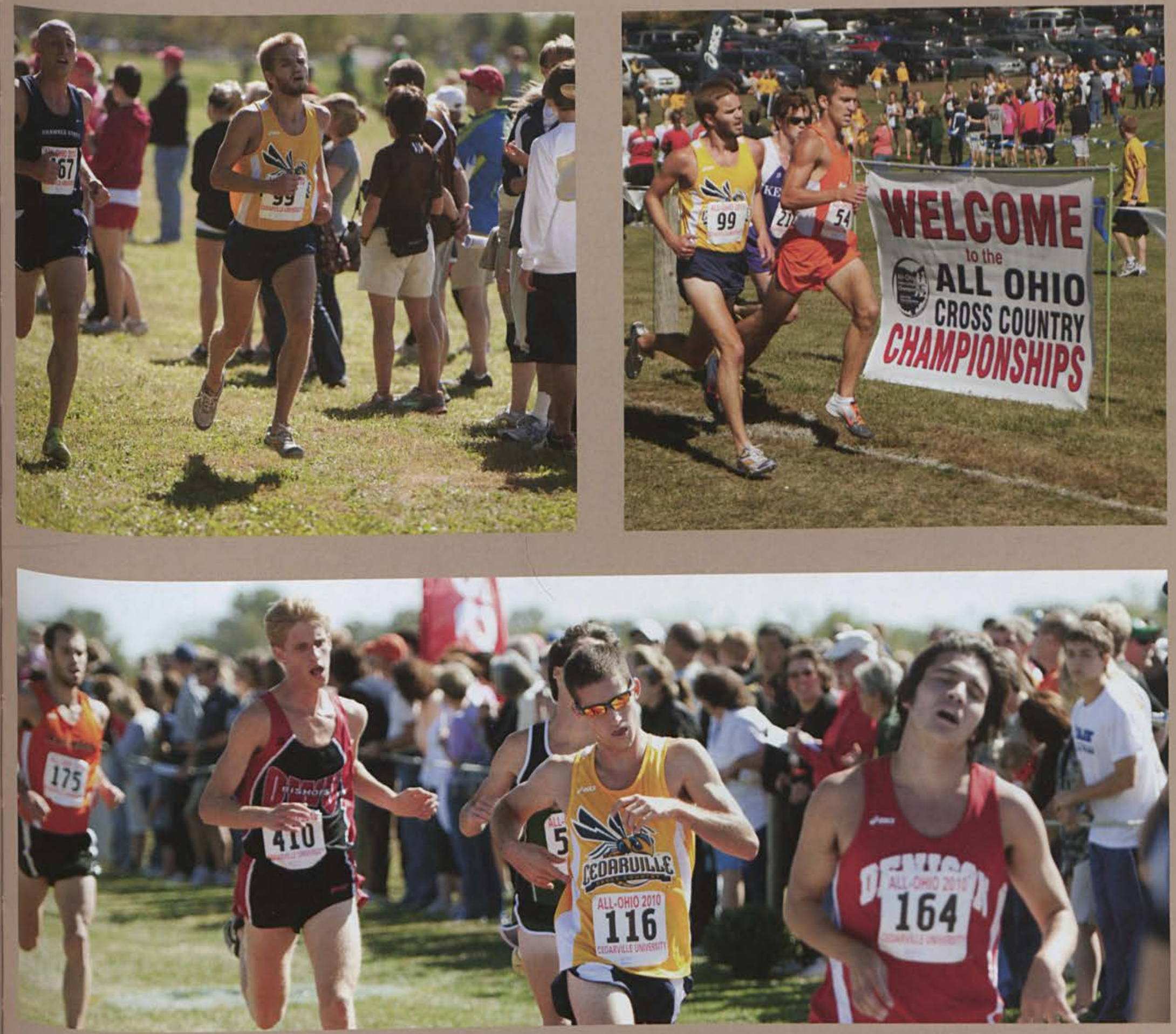

ma

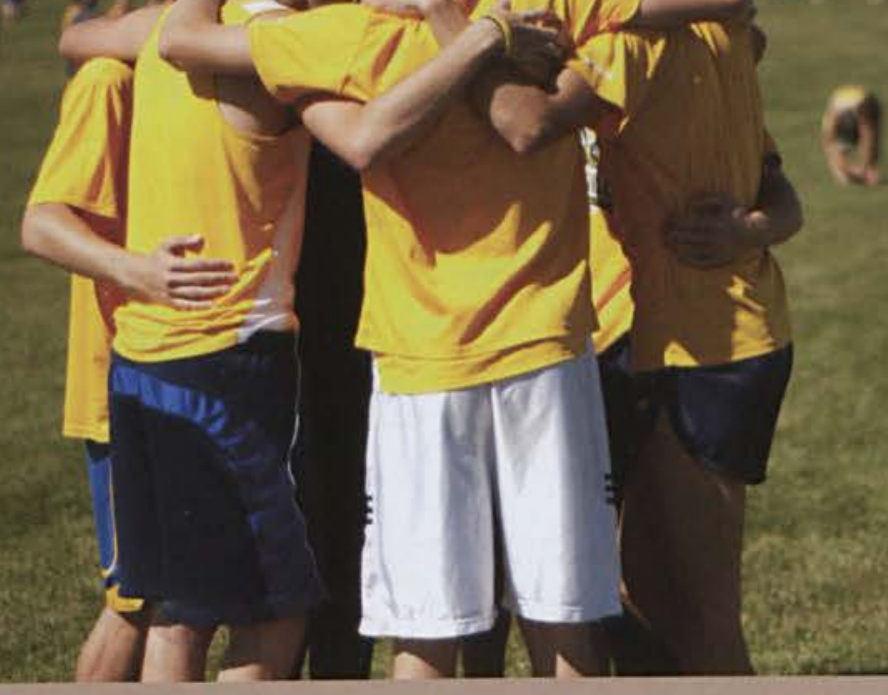




\section{WOMEN'S CROSS COUNTRY}

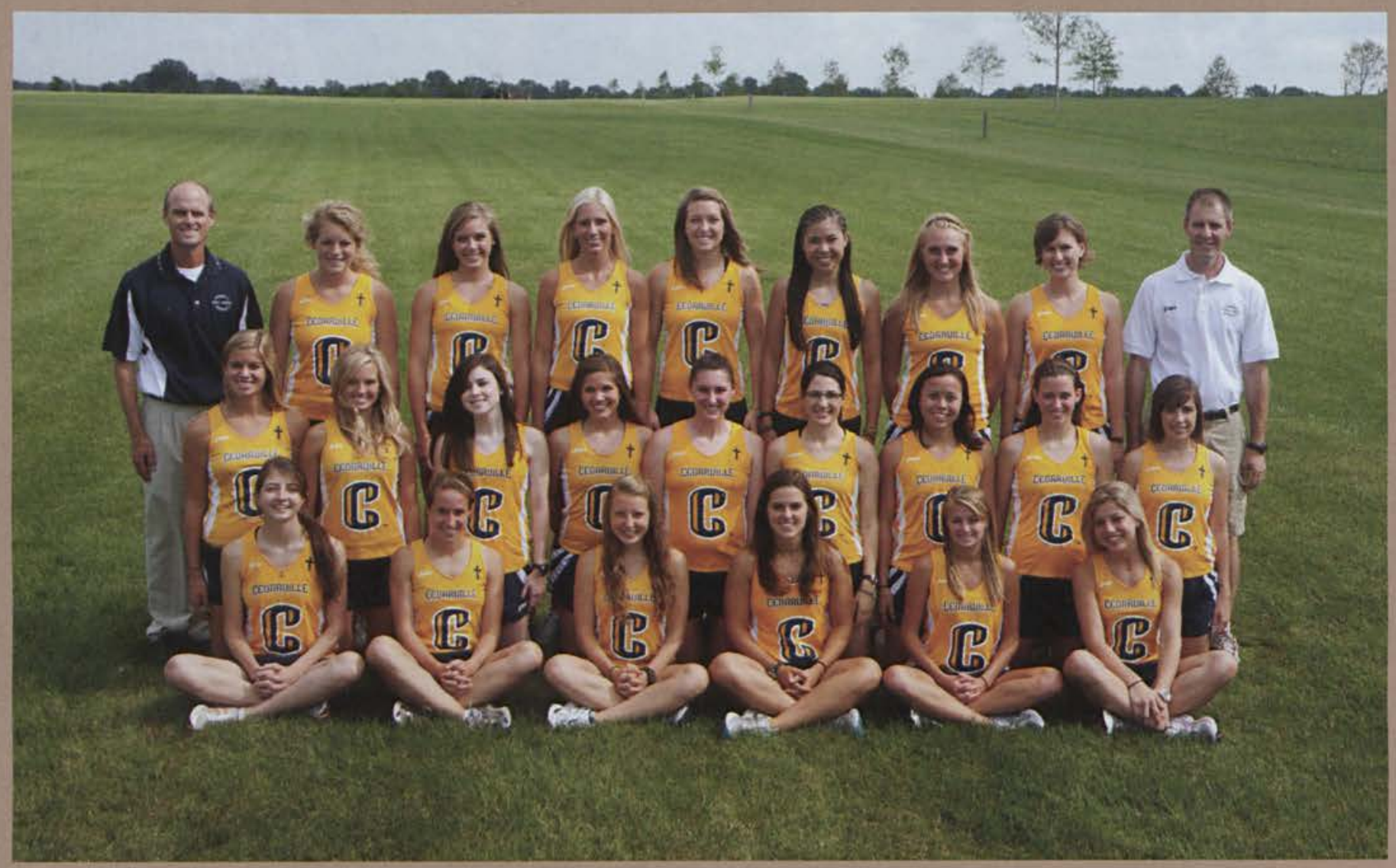

\section{RECORD:}

\section{NAIA Nationals (10th of 32)} NCCAA Nationals (10th of 21) American Mideast Conference (2nd of 10)
Competing against Division I and II teams, the Lady jackets finished 10th at the NAIA Nationals.

Members Front row left-to-right Hannah Rodriguez, Neola Putnam, Carolyn Case, Joanna Wheatley, Tabby Moore, Erica Huff. Second row Meghan Terrell, Jessica McCoy, Sarah Stevens, Jennifer Hollander, Grace Campbell, Hannah Lamos, Abby Wong, Elisa Cherry, Rachel Thompson. Third row Head Coach Jeff Bolender, Sara Moody, Katie Lanphier, Jessica Smith, Carolyn Cann, Rachel Wong, Jasmin Banachowski, Laura Backer, Assistant Coach Kris Williams 


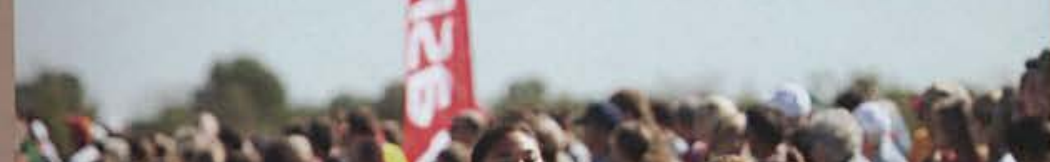
3rom.5 5 .
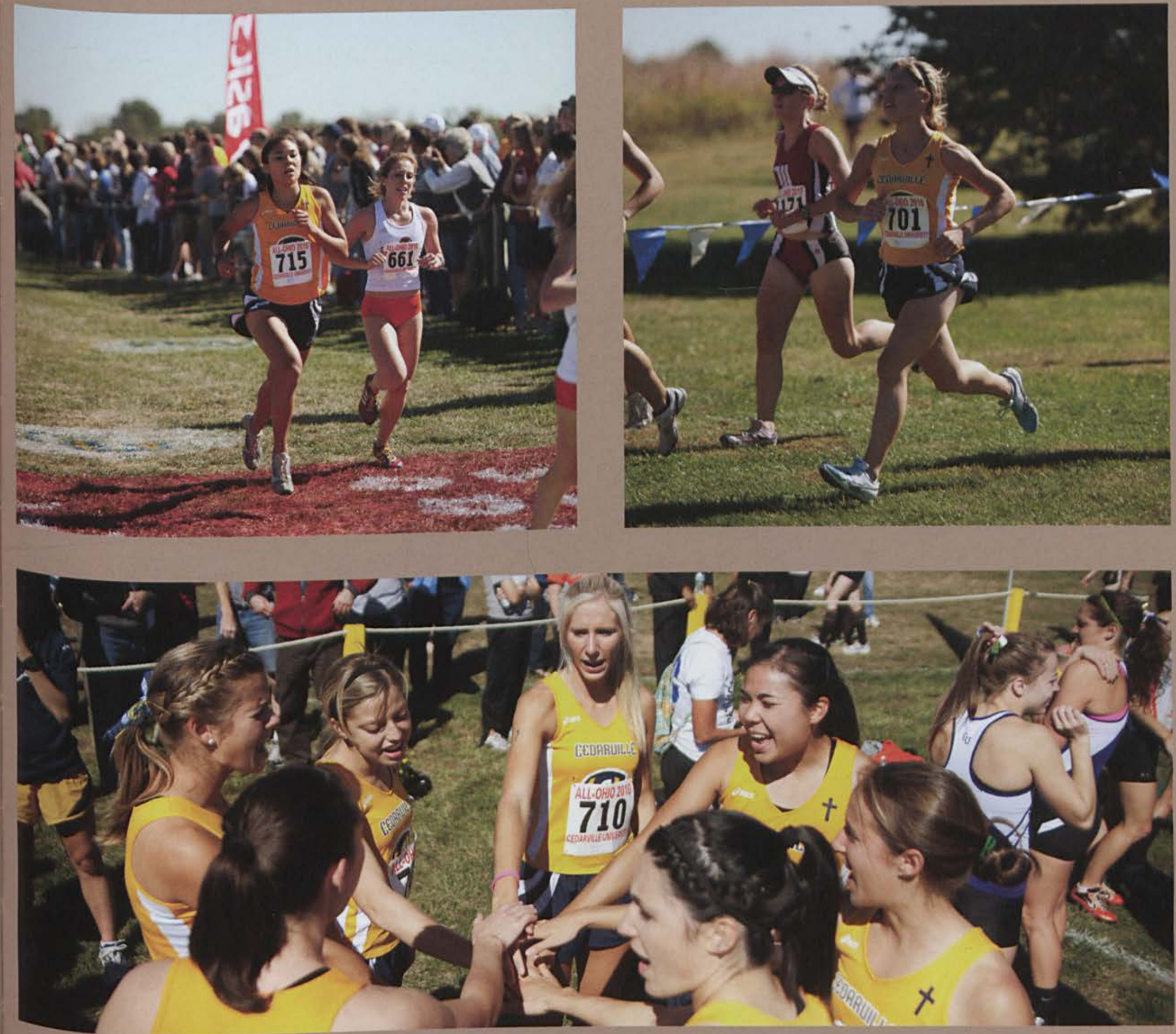

at.

(Fin

ant

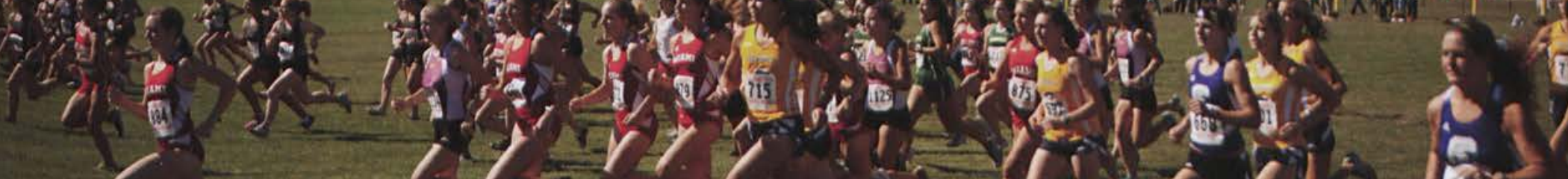

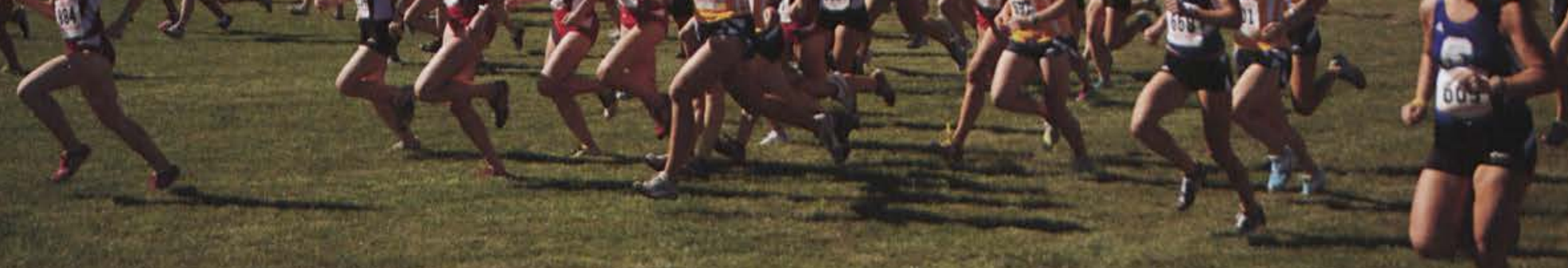




\section{FANS \& PEP BAND}

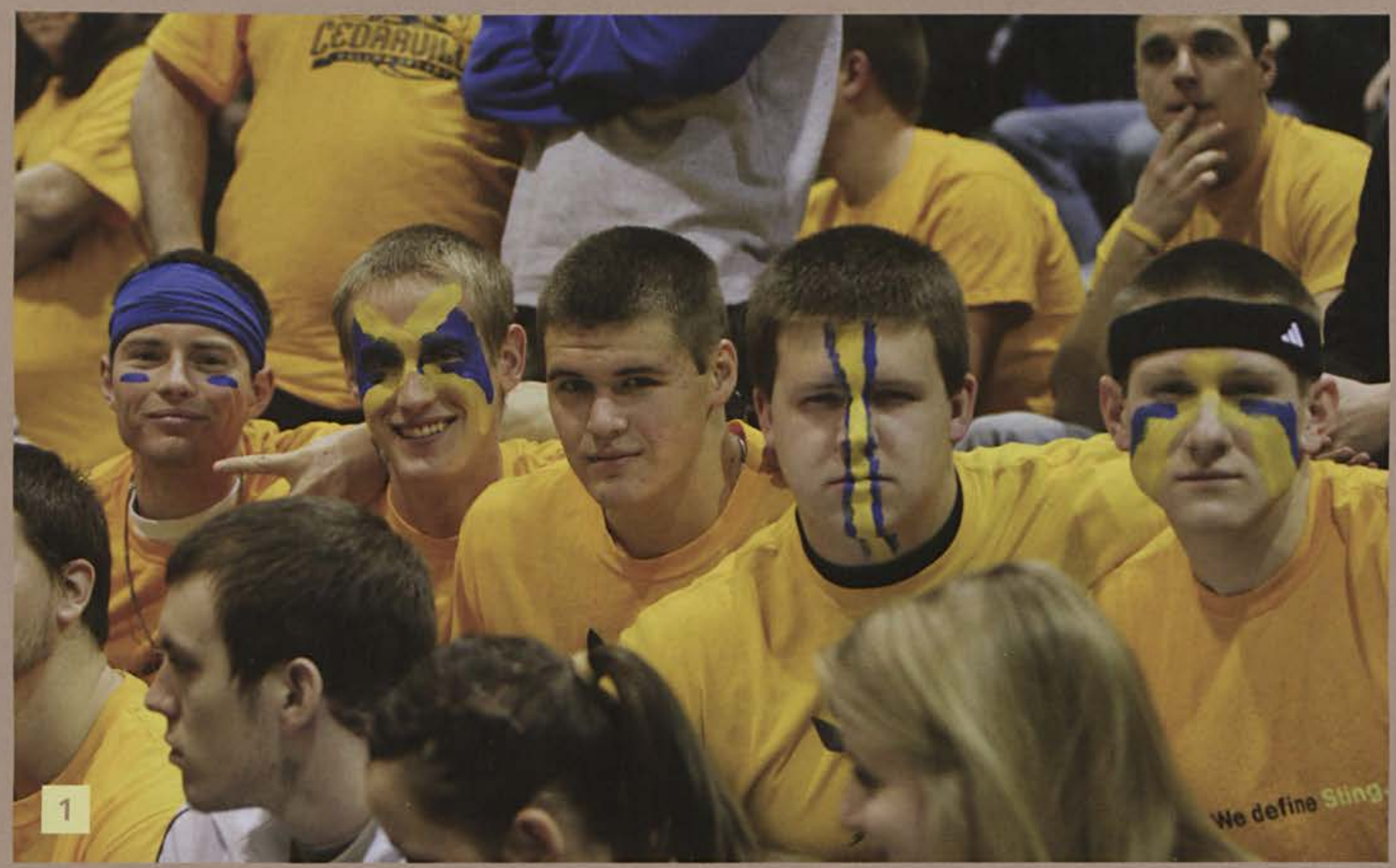

1 Student fans, Zach Murphy, Jeff Travis, David Wynalda, Zachary Franklin, and Paul Winfield, don their war paint in show of support of their favorite basketball team. 2 This line of fans could almost be mistaken as members of the Jabberwocky Dance Crew. 3 Everyone loves The Yellow Jacket, but kids from the community especially like to express their affections. 4 The Pep Band provides ambience and a much-needed pick-me-up for the crowd and players alike. 5 In a display of solidarity, fans raise their "spirit hands." 


\section{:}

ans 0 : क्षेत्र

(1) तो $($ मी 91

40 (b)

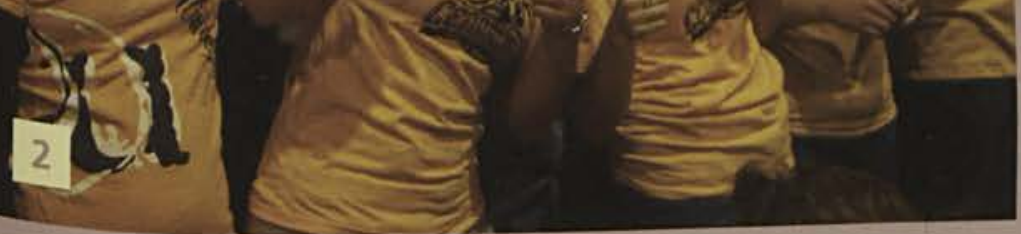
$y=1=-10$
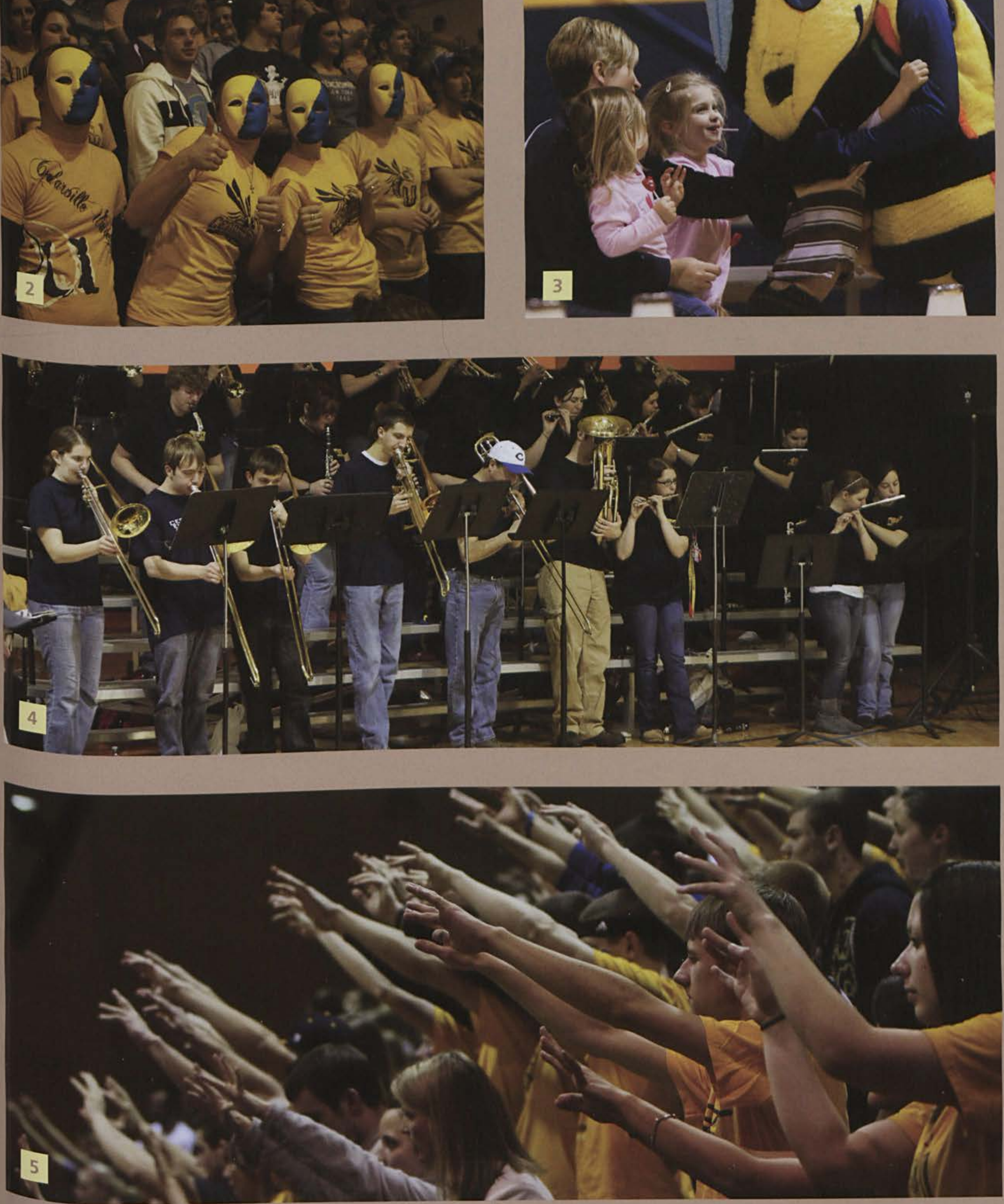


\section{FANS \& CHEERLEADERS}

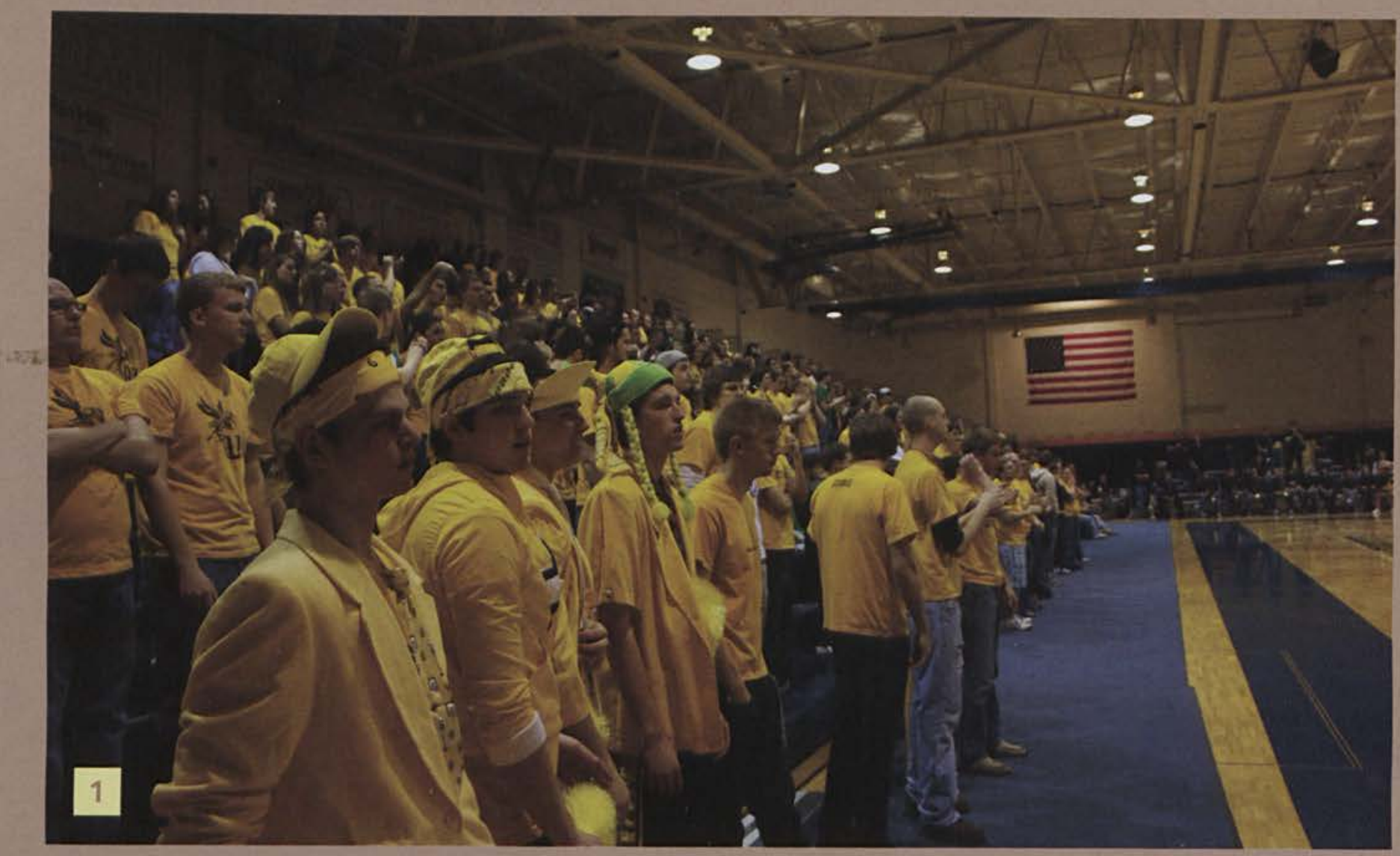

1 Student fans show their support by wearing school colors and creating a mass of yellow. 2 The male cheerleaders keep their female counterparts in the air during the game. 3 Billy Simpson shows his strength and spirit! 4 The cheerleaders keep their arms and fans' spirits high! 5 The women's volleyball team hosts Dig Pink night to raise donations for breast cancer research, and the fans happily participate by wearing pink shirts. 


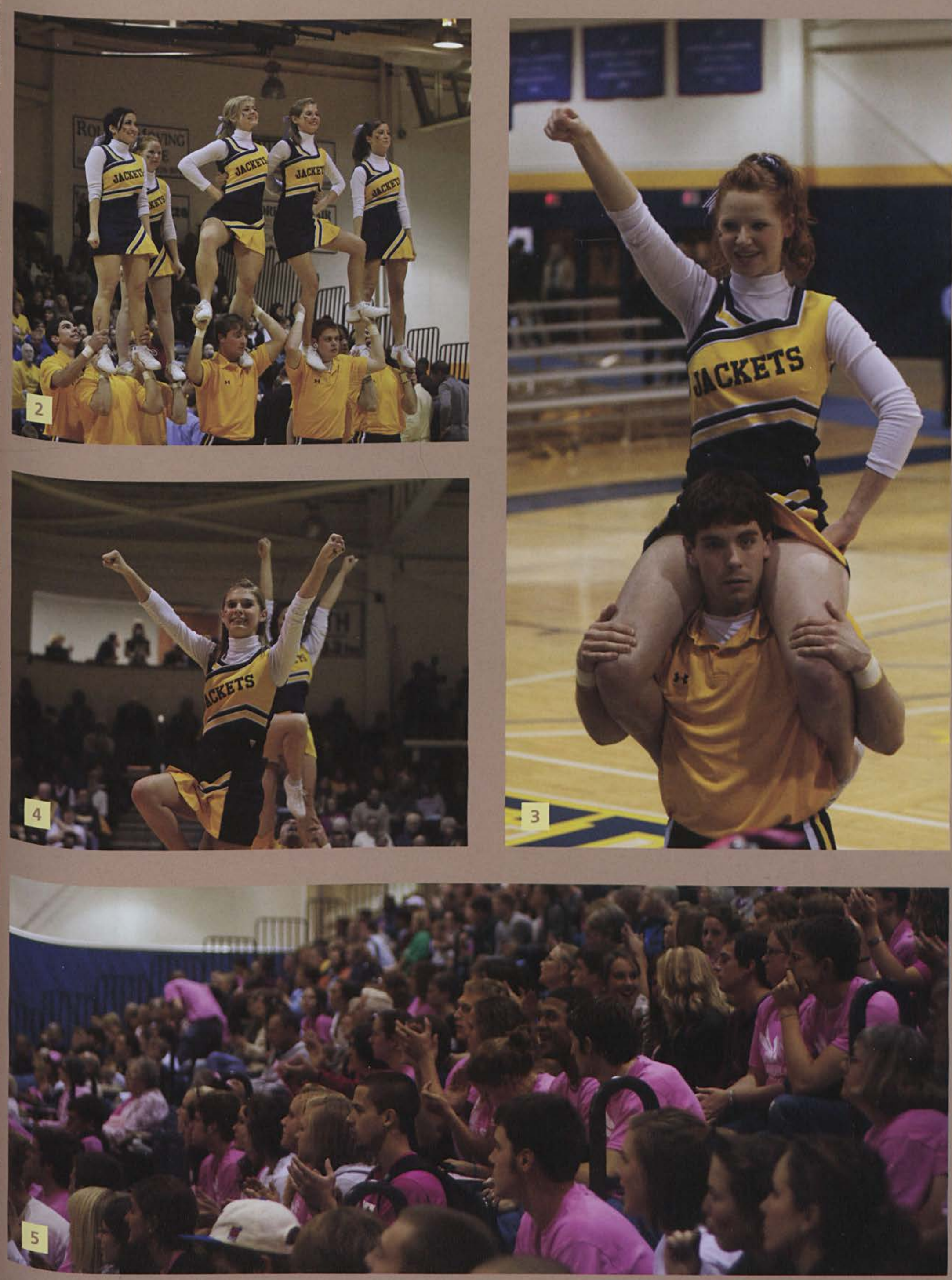




\section{MEN'S BASKETBALL}

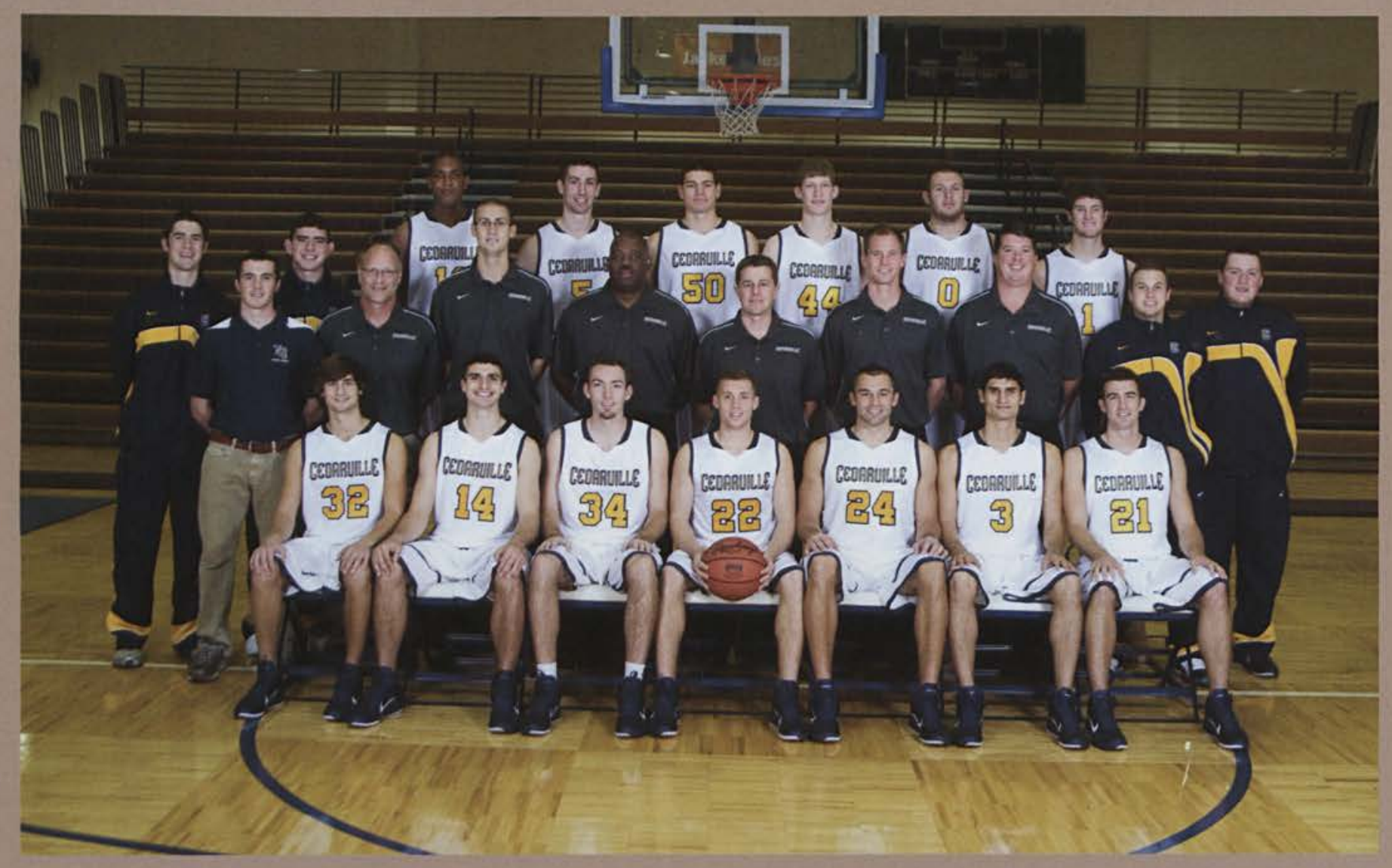

RECORD:

"I definitely had to take a new outlook on what I

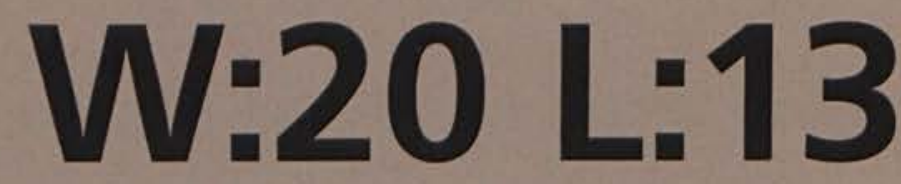

think of basketball in my life because of this year...

I wouldn't trade this season for anything."

(Mike Mapple)

Members Front row Left to Right: Cameron York, Daniel Hickman, Matt Harner, Derrick Hannon, Adam Riehle, Daniel Kohavi, Austin Foote. Middle Row Student Assistant Darren Miller, Student Athletic Trainer Nathan Deakin, Student Assistant Joe Osborne, Team Chaplain Scott Dixon, Assistant Coach Brandon Sok, Assistant Coach Terry Futrell, Head Coach Pat Estepp, Assistant Coach Jason Beschta, Head Athletic Trainer Chris Cross, Student Assistant Matt Morrison, Student Assistant Brian Aviles. Back Row Brian Grant, Zach Westrum, Kenny Reep, Caleb Maxwell, Mike Mapple, Brian Hecker. 

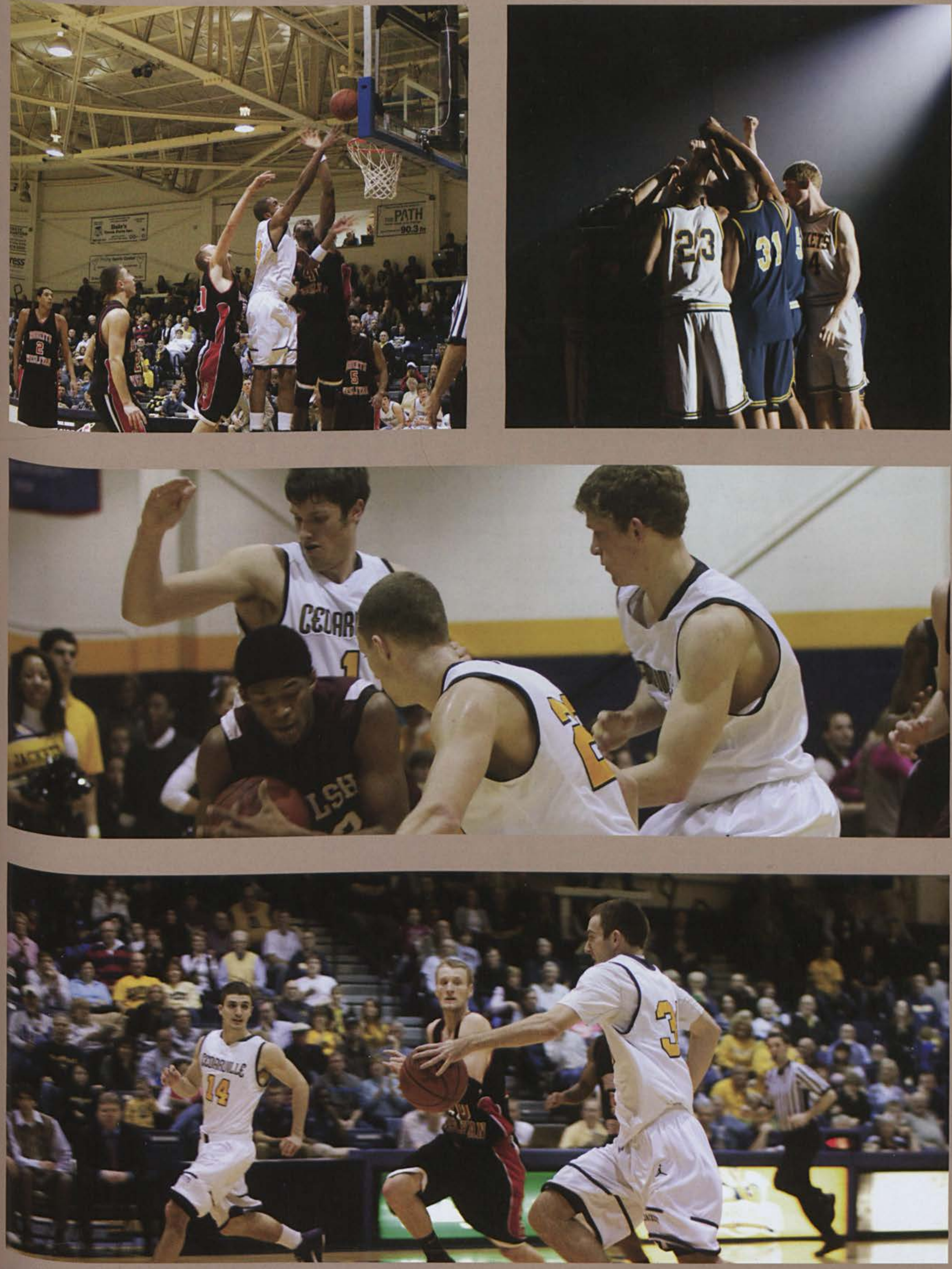


\section{WOMEN'S BASKETBALL}

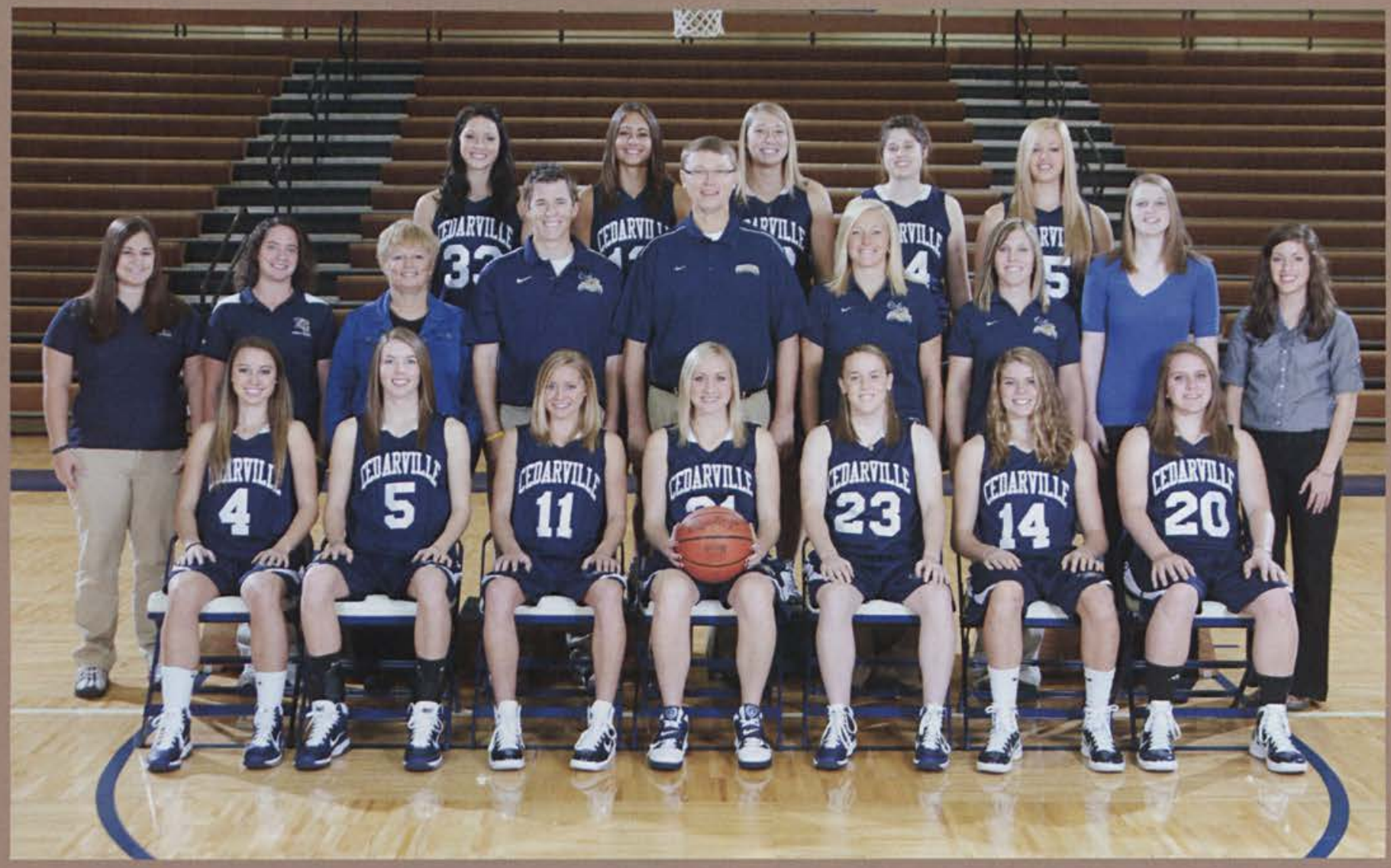

RECORD:

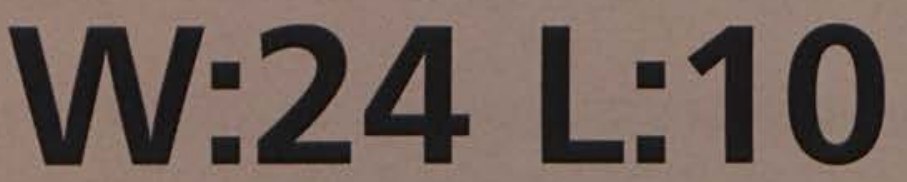

"I play for an Audience of One now at Cedarville where I used to play just for myself. The focus of the game is on Christ and being a positive light to the other teams."

(Aubrey Siemon)

Members Seated Left-to-Right Kayla Jenerette, Becky Orchard, Rachel Hurley, Lydia Miller, Kara Cayton, Heidi Ansiel, Jenna Williams. Middle Row Student Athletic Trainer Jasmine Lee, Assistant Athletic Trainer Hannah Haynes, Team Chaplain Teresa Clark, Student Assistant Kyler Ludlow, Head Coach Kirk Martin, Assistant Coach Kari Flunker, Director of Basketball Operations Stacie Travis, Student Assistant Amber Hayslip, Student Assistant Becca Roberts. Back Row Deborah Chandler, Aubrey Siemon, Jenna Smith, Danielle Spiliotis, Caitlyn Brooks. 


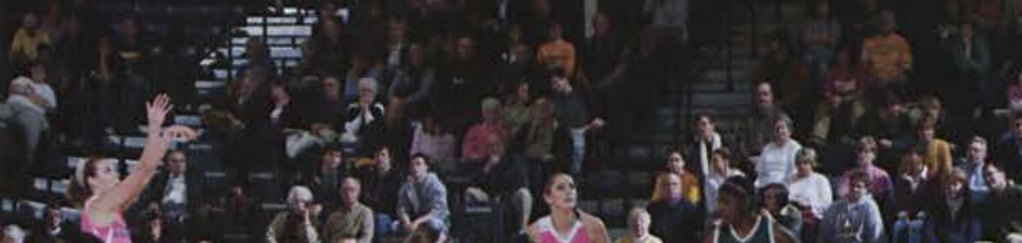
*5

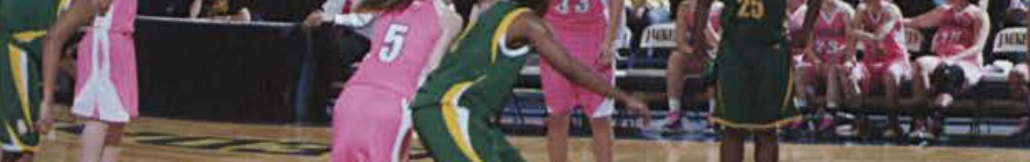
- 1.7

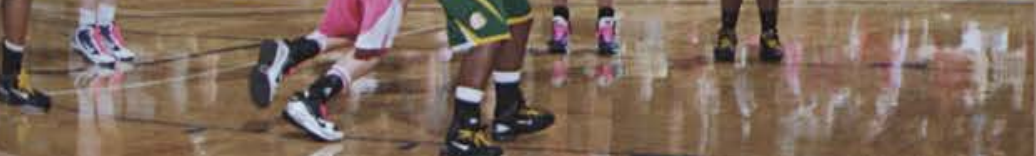

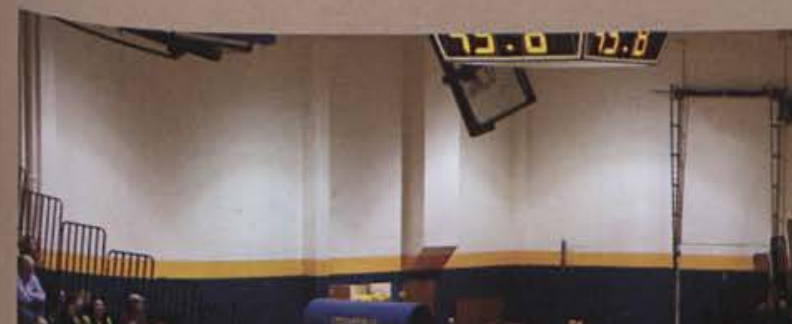

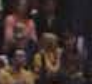

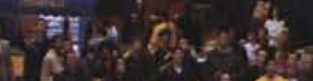
A.

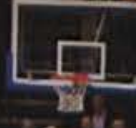

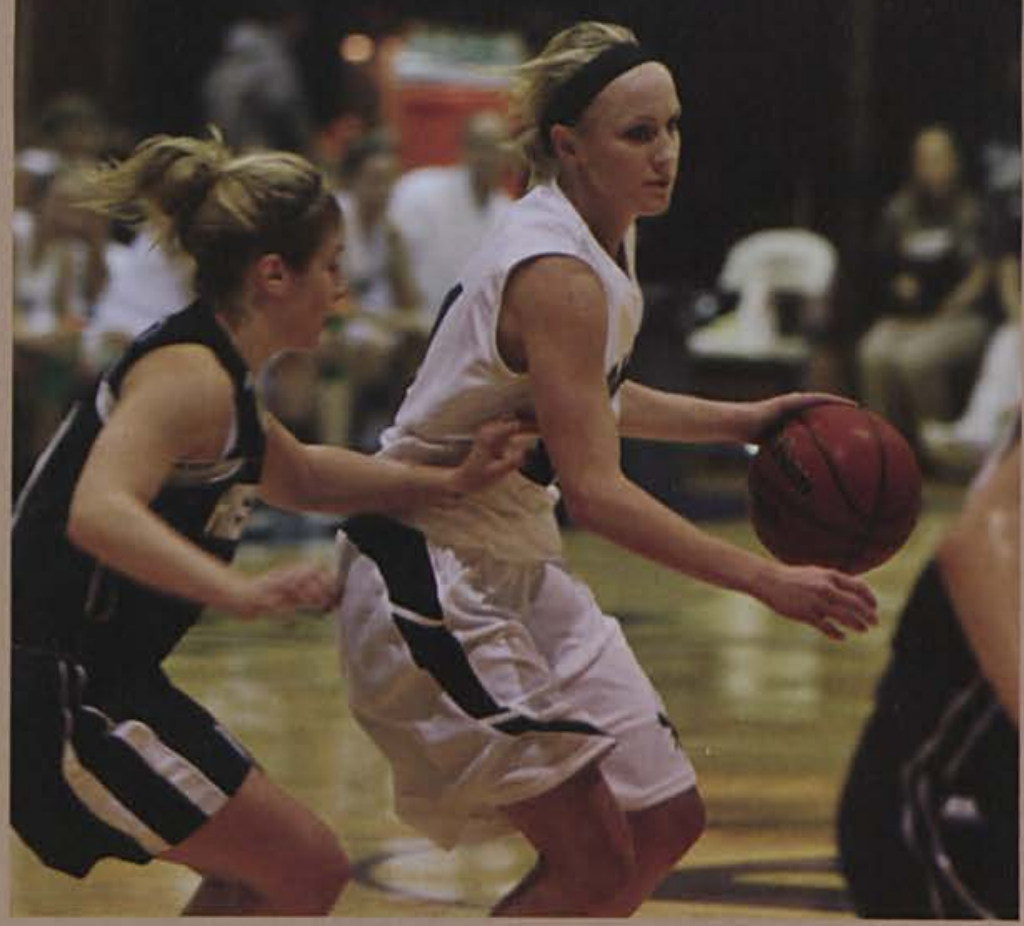

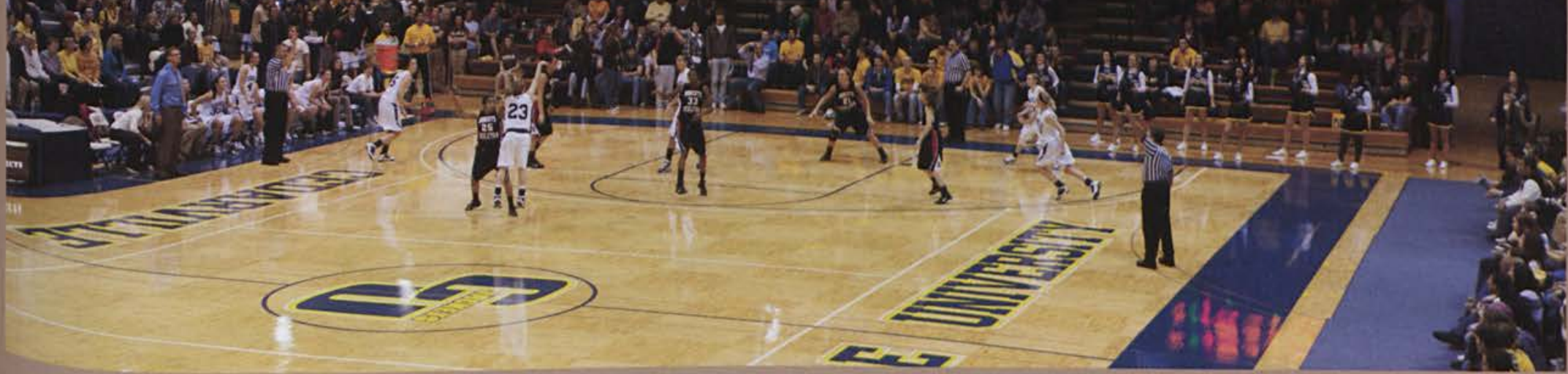

$=2$

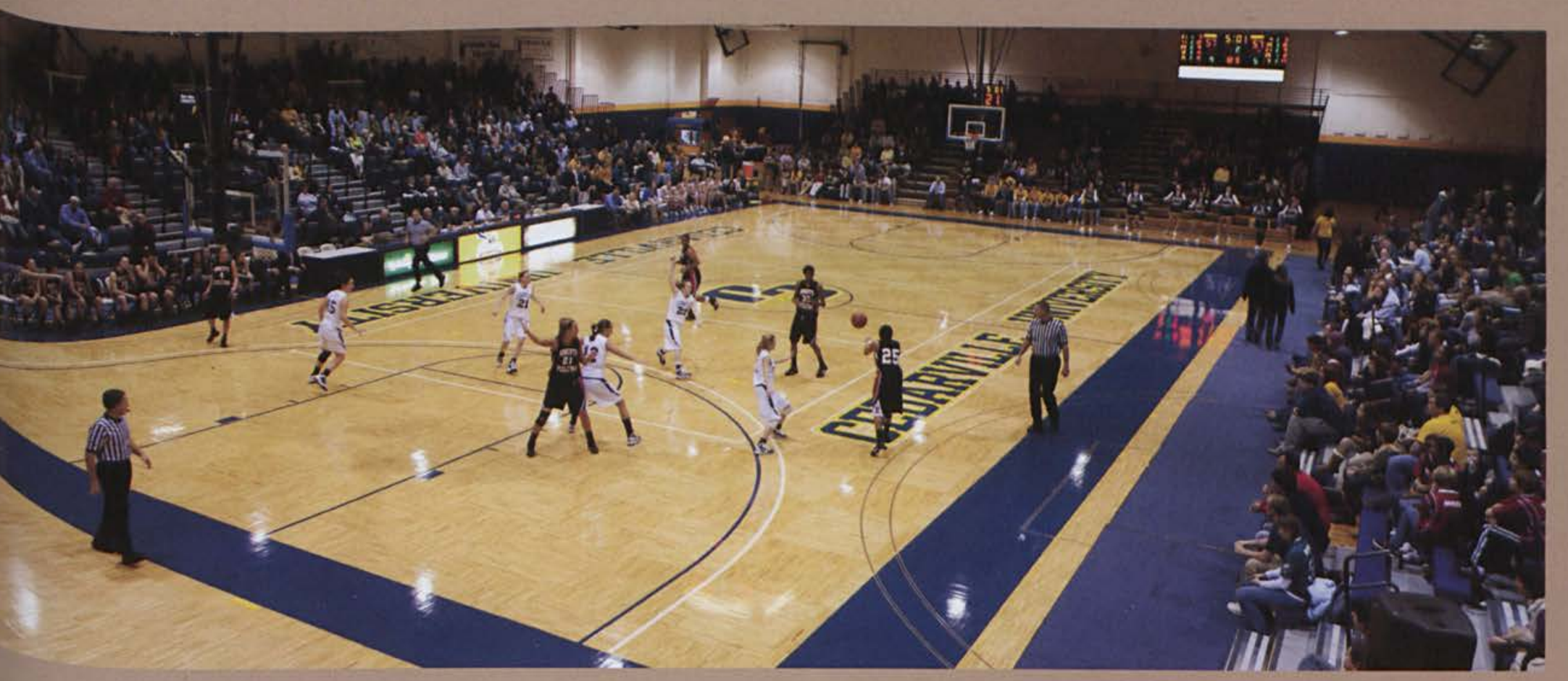




\section{MEN'S GOLF}

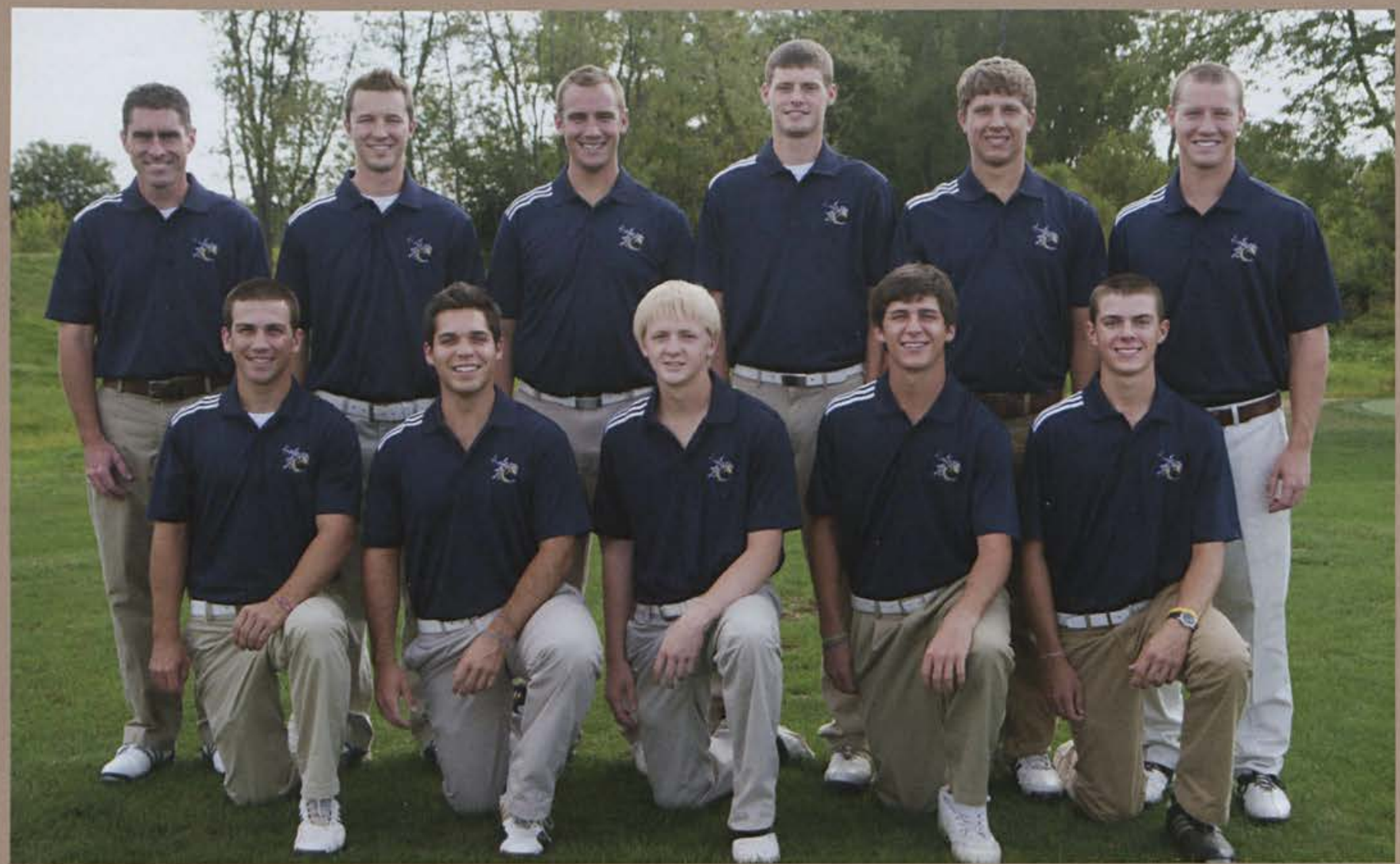

RECORD:

NCCAA Nationals(tied 10th of 18) American Mideast Conference (4th of 8 ) ended their season with a fourth-place finish at the American Mideast Conference Championship.

Members Kneeling Left-to-Right Ben Mounts, Nick Bigler, Trayton Ojala, T.J. Pancake, Jacob Nafziger. Standing Left-to-Right Head Coach Ryan Bowen, Trent Roach, Matt Yeiter, Chris Bennington, John Stonkus, Brigham Michaud. 

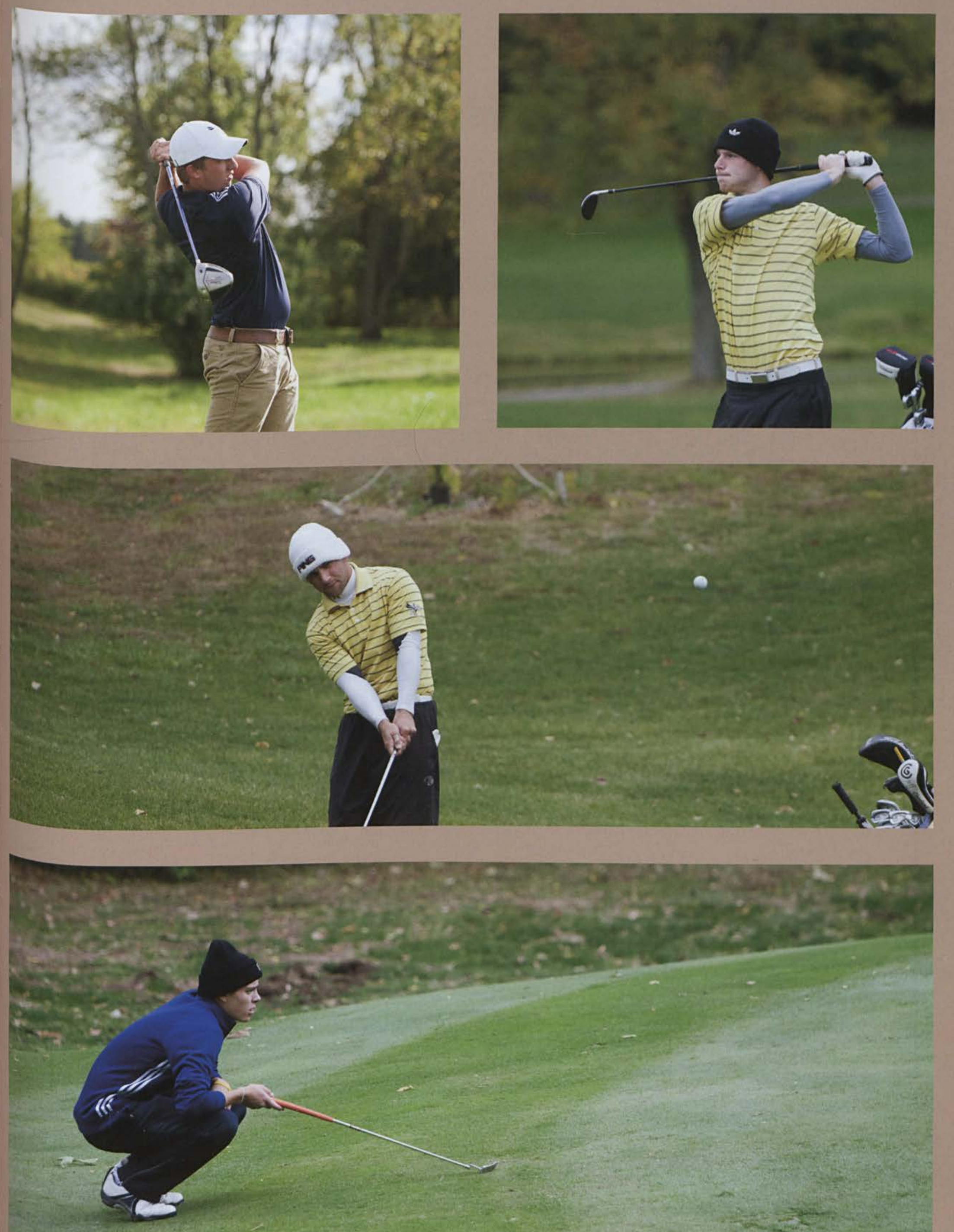


\section{MEN'S TRACK AND FIELD}

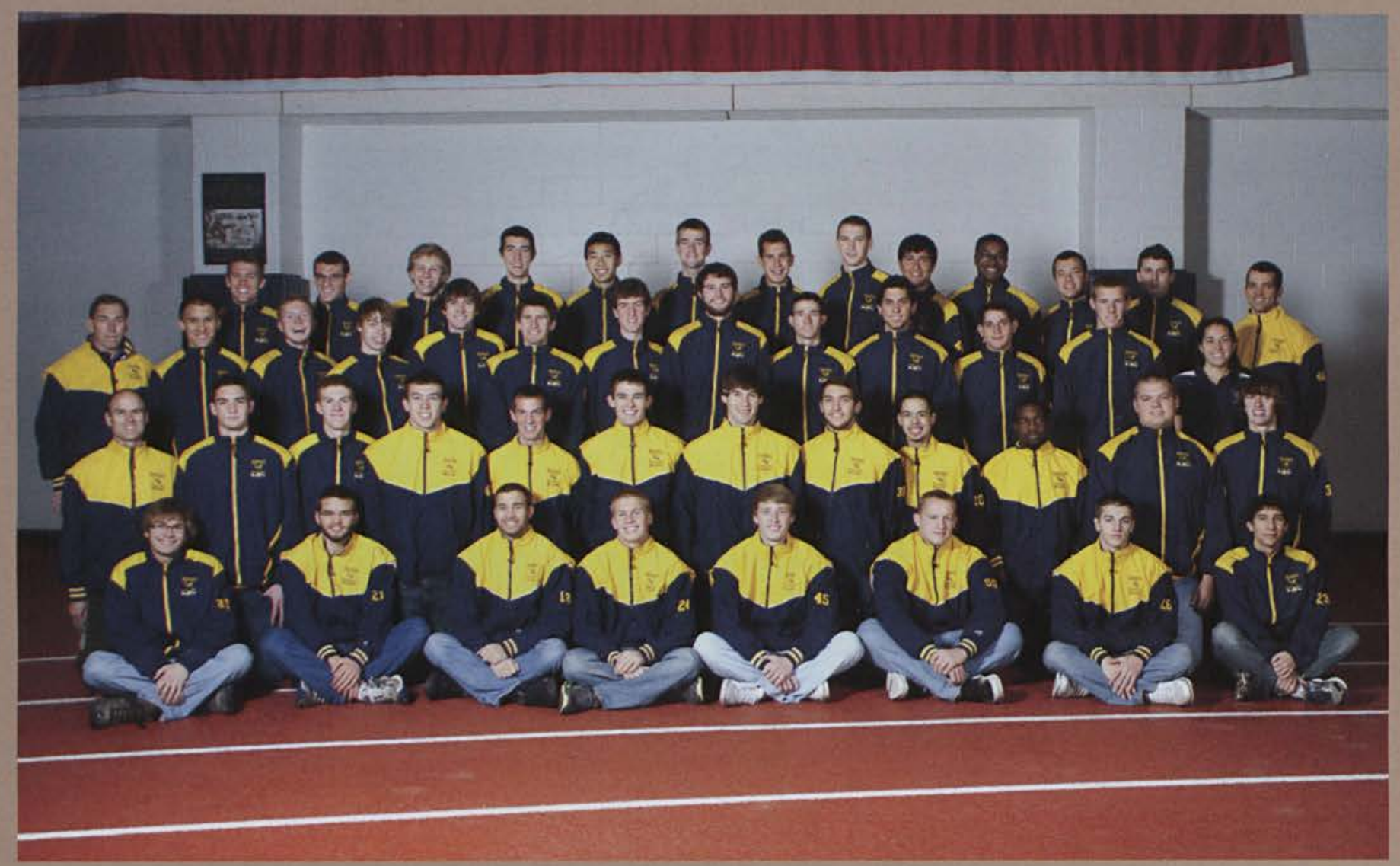

\section{RECORD:}

NCCAA Indoor Championship (3rd of 17)

NAIA Indoor Championship (tie 24th of 94)

NCCAA Outdoor Championship (1st of 15)

NAIA Outdoor Championship (tie 67th of 124)

American Mideast Conference Championship (1st of 7)
"Our men's team this year has been awesome. We have some really talented guys, and winning conference and being competitive against NCAA Div. 1 schools has been great to be a part of. " (Joel Pfahler)

Members Front Row Left-to-Right Greg Johnson, Matt Brooker, Curtis Meyer, Michael Gardner, Parker Adams, Greg Hannay, Mark Farris, Joseph Cathey. Second Row Head Coach Jeff Bolender, Landon Bundenthal, Nathaniel Burrell, Corey Caldwell, Joel Pfahler, Luke Clore, Joshua Lusk, Spencer Rioux, Rich Lozada, Johnathan Smith, Sam LeMaster, Josh Proemmel. Third Row Assistant Coach Paul Orchard, Ryan Gustafson, Scott Gardner, Trevor Bryant, T.J. Badertscher, Jordan Davies, Jacob Walter, Ethan Blagg, Joshua Wiseman, Stephen Port, Nathan Wright, Joe Niemiec, Assistant Athletic Trainer Leyna Hebert, Assistant Coach Mike Marsh. Back Row Chris Vaughn, Neil Klinger, Josiah Bragg, Jacob Dubie, Paul Ikeda, Alex Moore, Evan Thayer, Beau Michaud, Mike Herrera, Aaron Lane, Jordan Molstre, Justin Hoffman. 

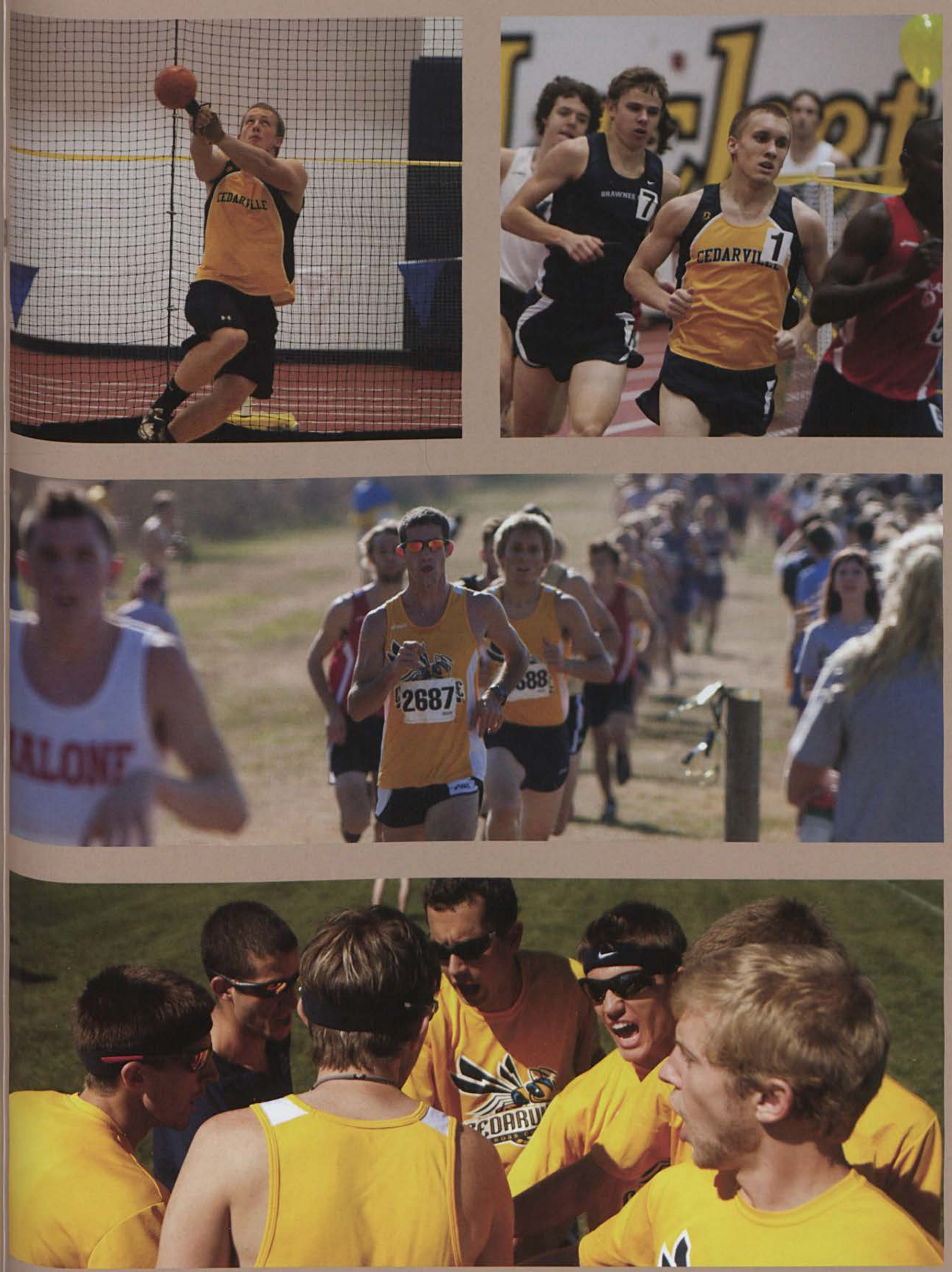


\section{WOMEN'S TRACK AND FIELD}

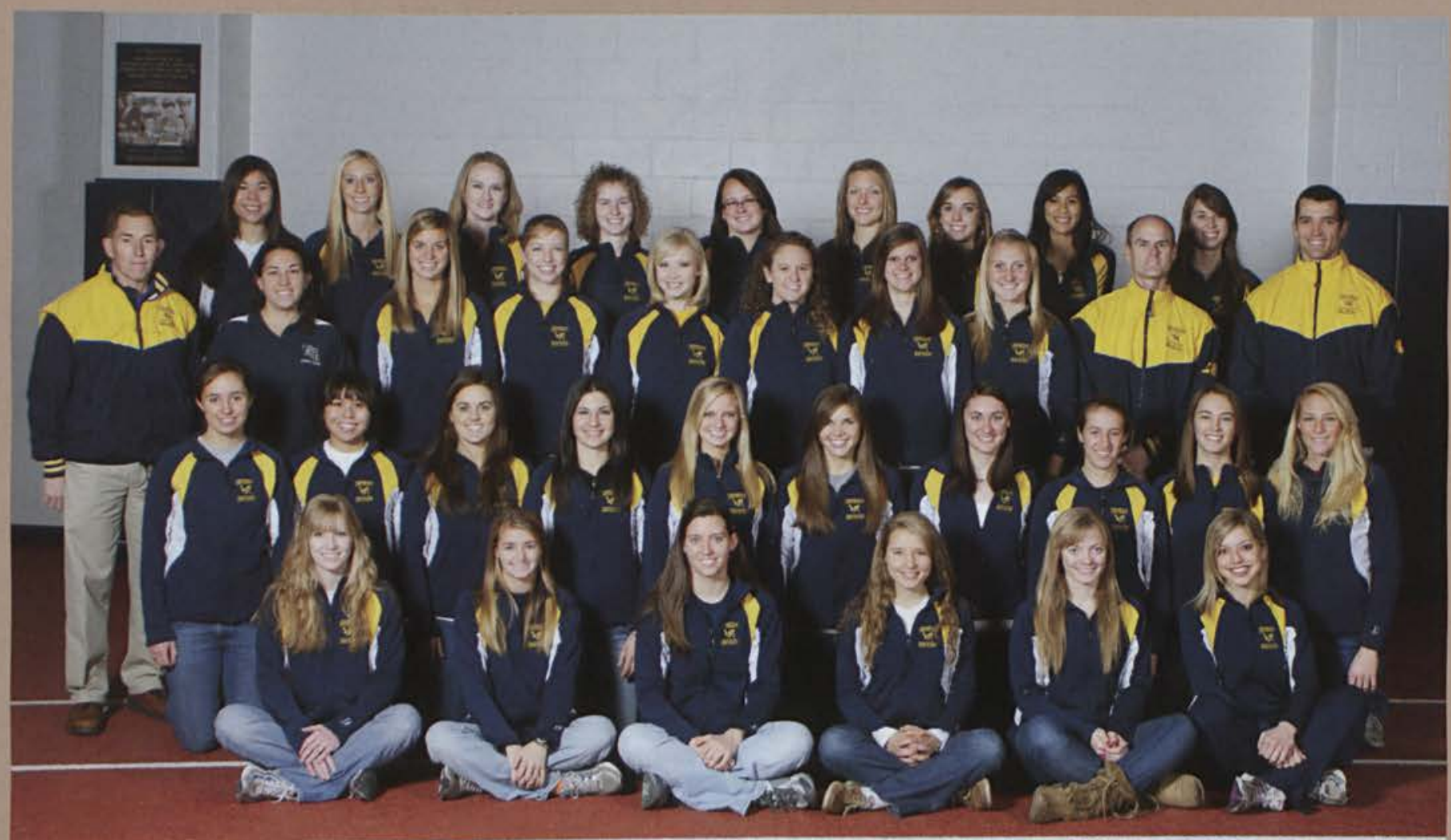

\section{RECORD:}

NCCAA Indoor Championship (5th of 18) NAIA Indoor Championship (tie 44th of 96) NCCAA Outdoor Championship (3rd of 15) NAIA Outdoor Championship (tie 47th of 120) American Mideast Conference Championship (2nd of 8)
"AMC Championships were the best meet. There was such an atmosphere of team spirit, even though track isn't as much of a team sport as some others sports."

(Michelle Mead)

Members Front Row Left-to-Right Rachel Herrera, Tabby Moore, Elisa Cherry, Carolyn Case, Krista Johnson, Erica Hoff. Second Row Anna Schmid, Abigail Wong, Joanna Wheatley, Hannah Lamos, Jessica McCoy, Jennifer Hollander, Grace Campbell, Neola Putnam, Jamie Atkins, Chelsea Gruet. Third Row Assistant Coach Paul Orchard, Assistant Athletic Trainer Leyna Hebert, Meghan Terrell, Melissa Jacob, Susie Powell, Laura Kirby, Beth Jones, Jasmin Banachowski, Head Coach Jeff Bolender, Assistant Coach Mike Marsh. Back Row Rachel Wong, Jessica Smith, Jessica Dahnke, Meagan Carns, Sarah Hannay, Carolyn Cann, Alexa Winik, Joy Santos, Michelle Mead. 

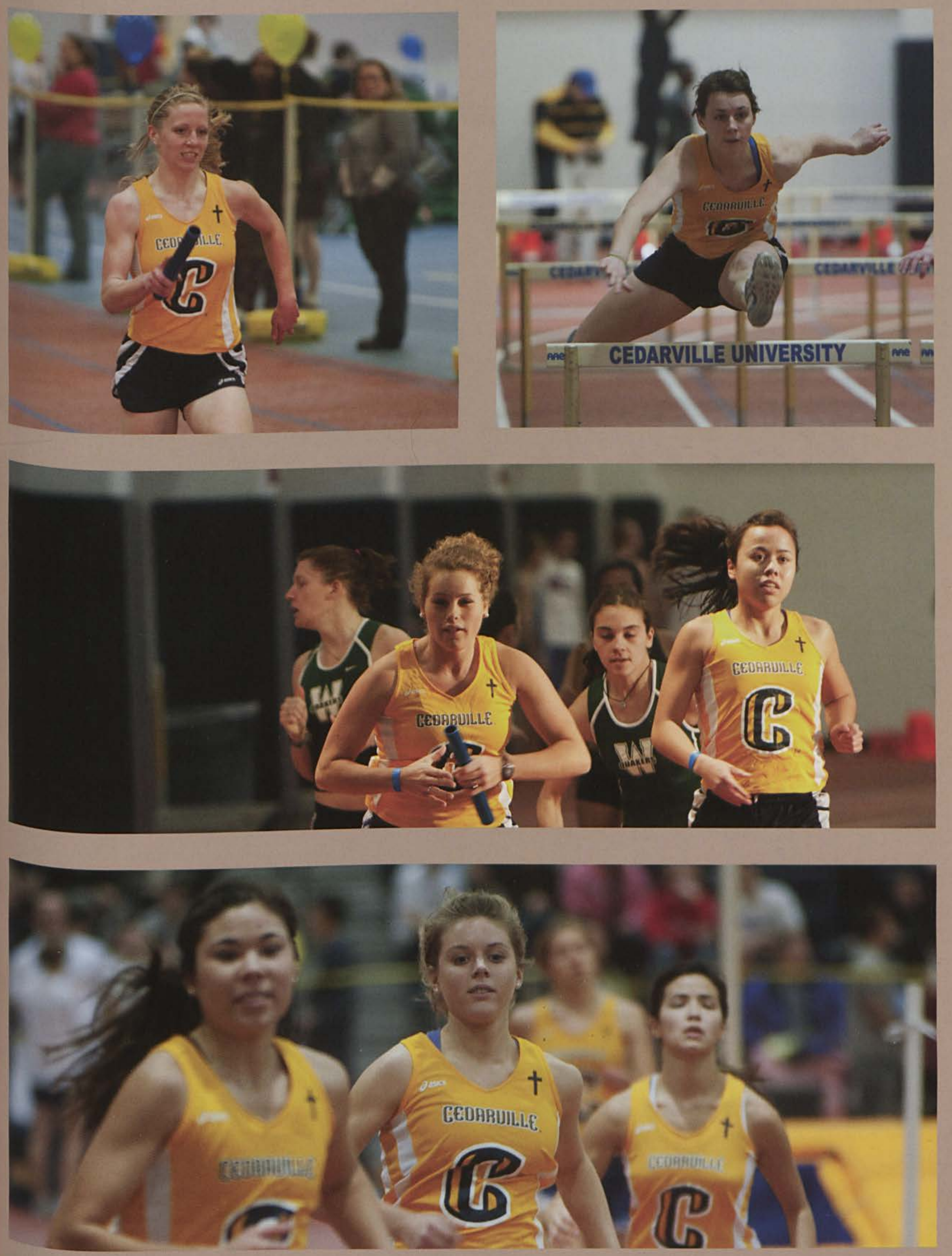


\section{MEN'S TENNIS}

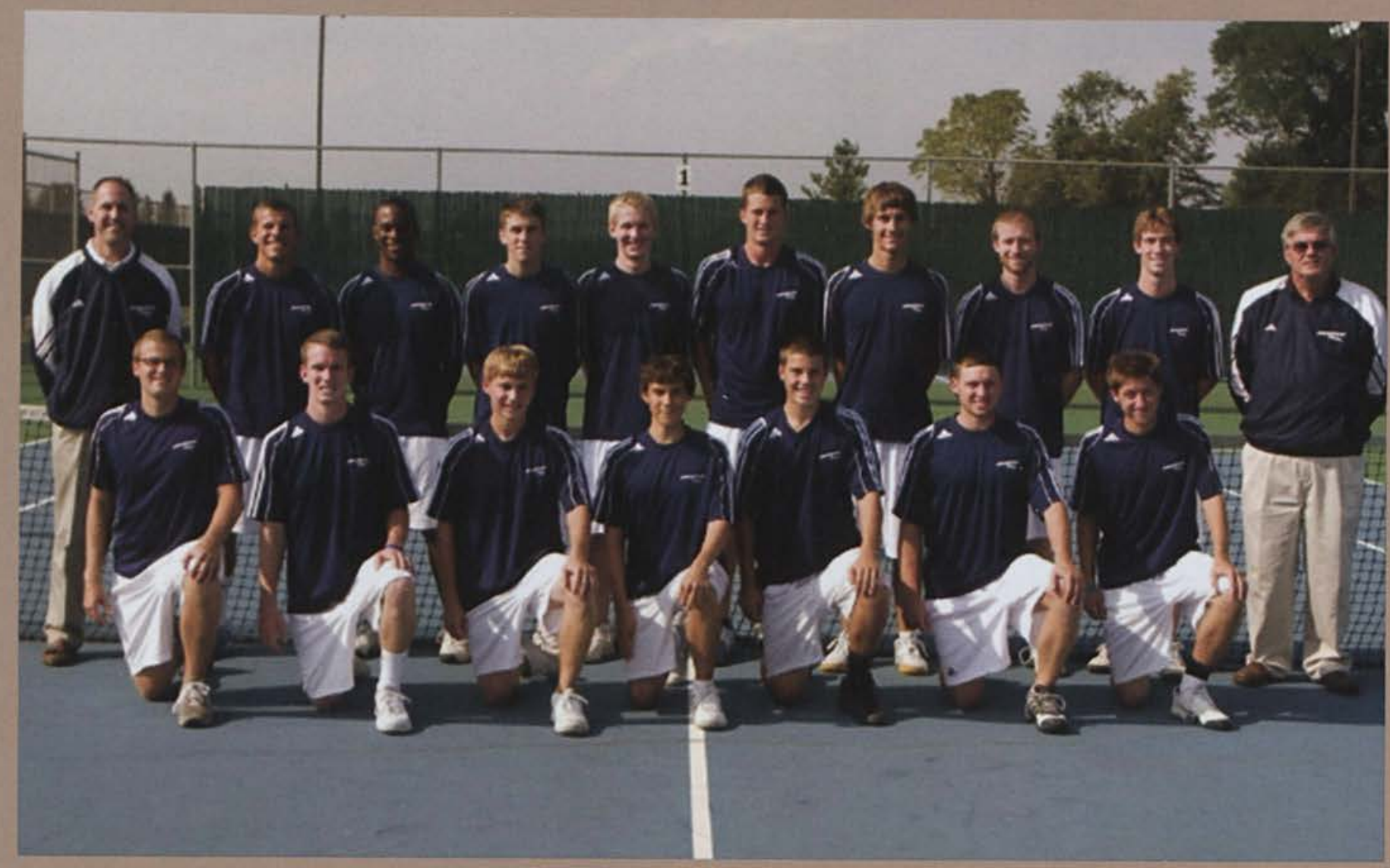

\section{RECORD: \\ W:7 L:11}

Cedarville won for the second time in three outings with a 9-0 non-conference decision at Capital. The last three victories for the Yellow Jackets and four of the last five were by $9-0$ finals.

Members Kneeling Left-to-Right Kyle Kirby, Bobby Eberhard, Corey Whitlock, Josh Van Zandt, Anthony Ganzsarto, Michael Brittan, Drew Steinhart. Standing Left-to-Right Chaplain Jeff Lewis, Aaron Niemiec, Quinton Paul, Brandon Williams, Jake Miller, David Barton, Jared Gerber, Kyle DeBoer, Mike Clark, Head Coach Alan Edlund. 


\section{WOMEN'S TENNIS}

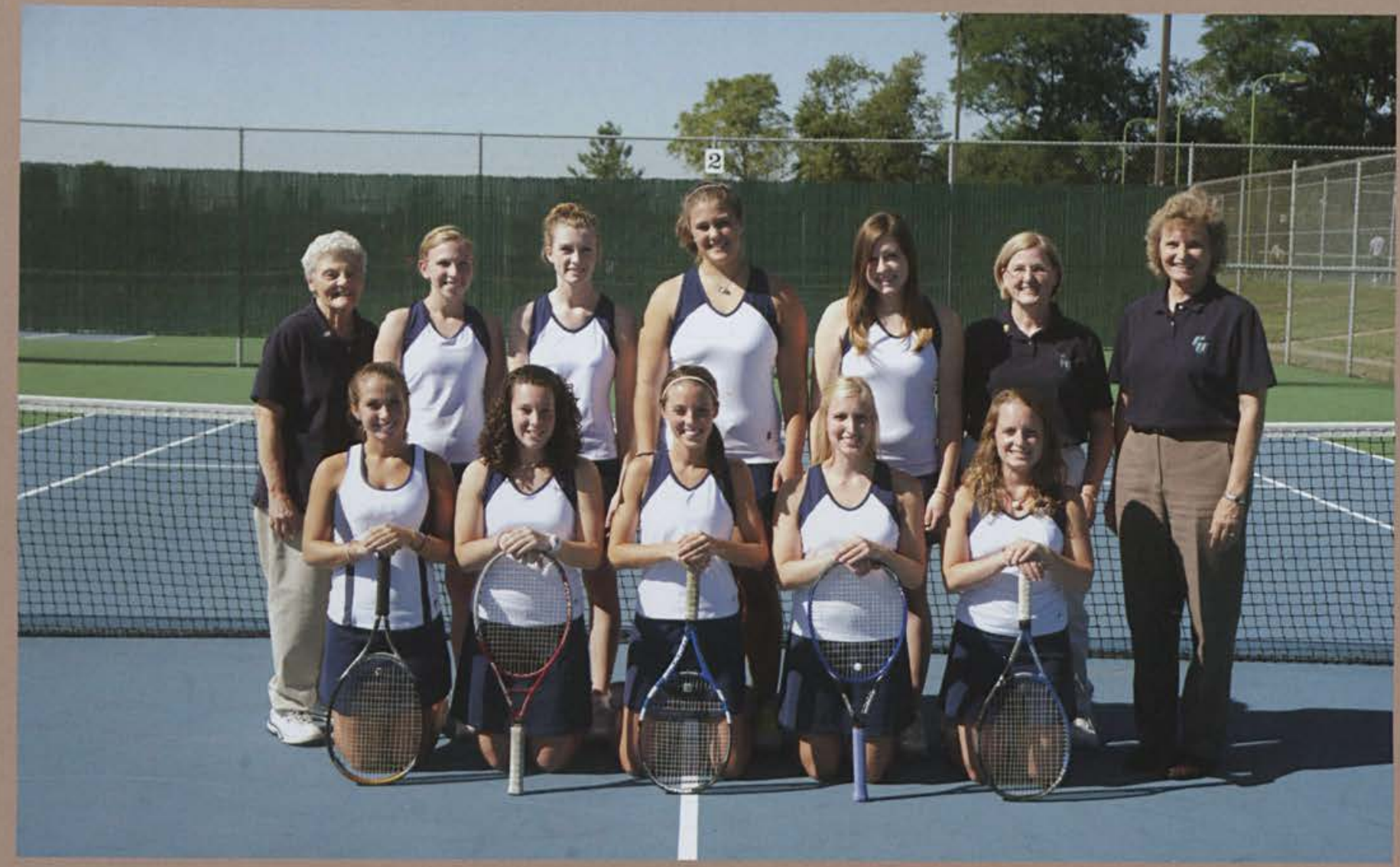

RECORD:

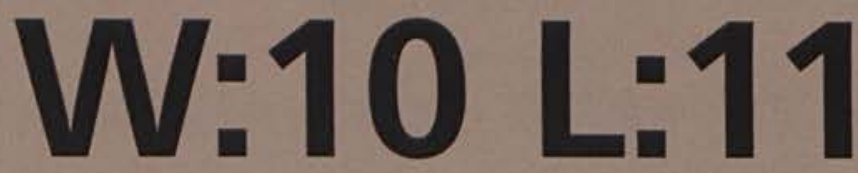

"The girls on the tennis team rally together. Particularly, the Bible study sessions are meaningful because we discuss important issues in a friendly, low-key way. " (Joy Kellog)

Members Kneeling Left-to-Right Alison Scharold, Melissa Stoltzfus, Joy Kellogg, Brooke Johnson, Cindy Hoke. Standing Left-to-Right Head Coach Dr. Dee Morris, Emma Rahn, Lyndsay Stine, Joy Dice, Hannah Fleming, Team Chaplain Becky Kuhn, Associate Head Coach Dr. Pam Johnson. 


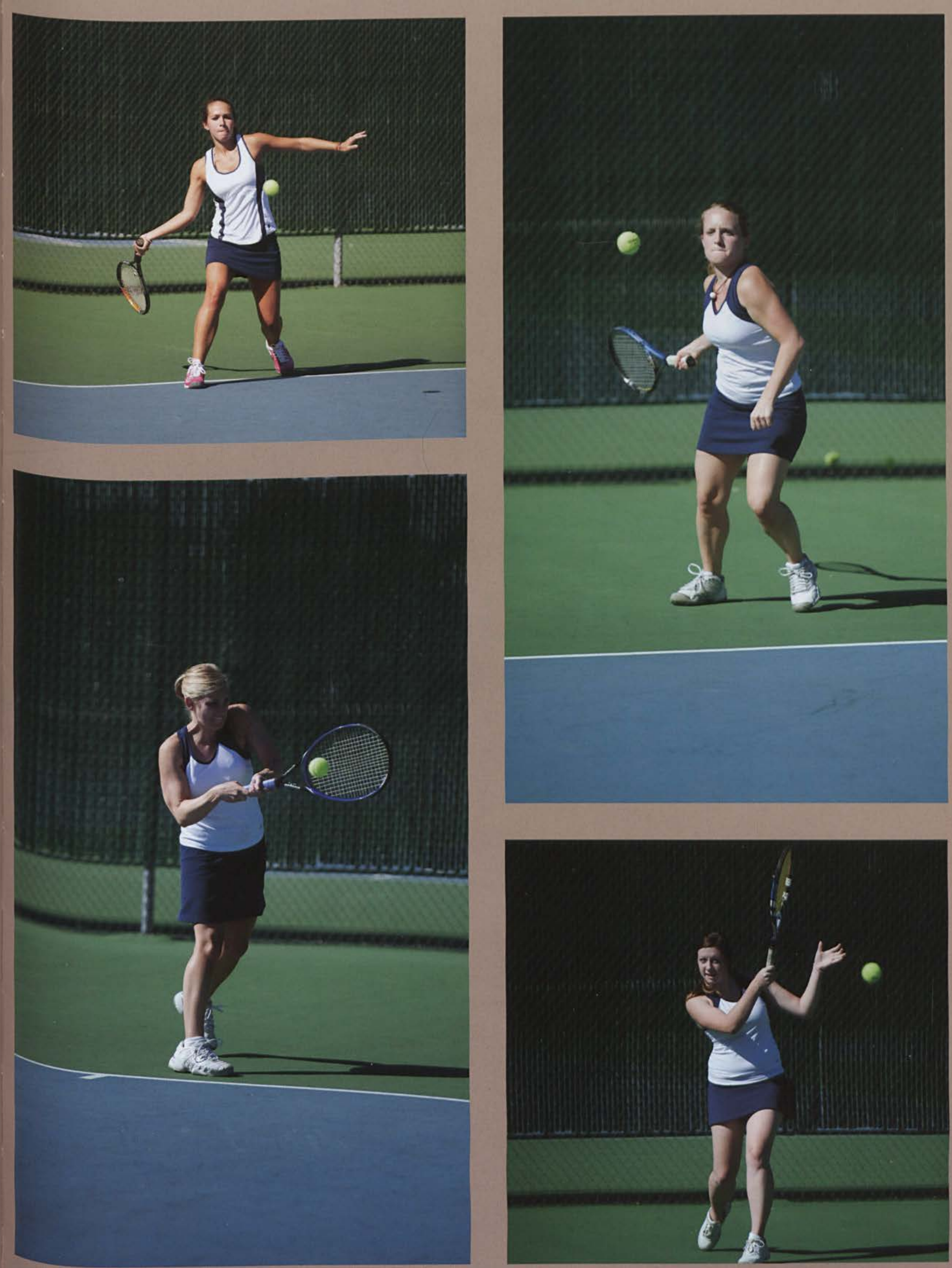




\section{BASEBALL}

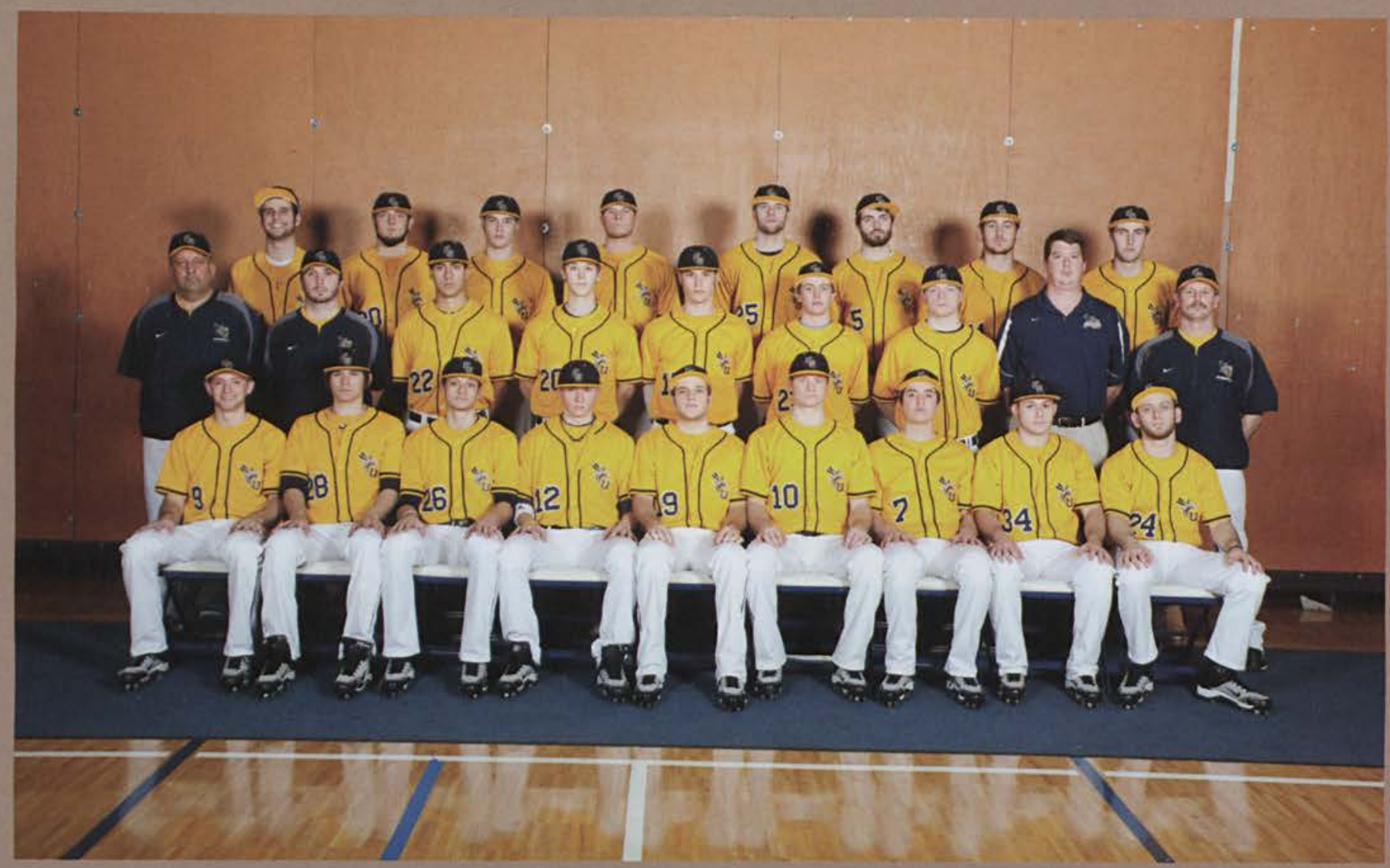

RECORD:

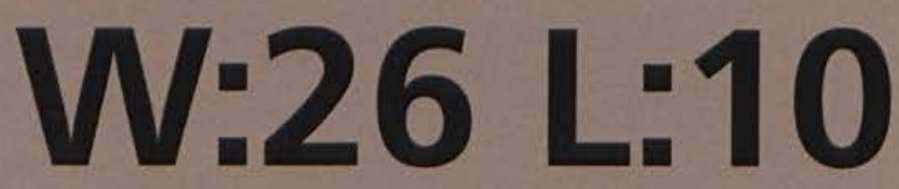

The Yellow Jackets baseball team won their fourth NCAA Midwest Regional Baseball Championship in the 2011 season. The team made their fifth appearance at the NCAA Nationals tournament.

Members Seated Left-to-Right. Alex Beelen, Dan Petke, Rob Wasem, Tyler Rost, T.J. Taylor, Andrew York, Paul Hembekides, Juan Martinez, Chris Ward. Middle Row. Head Coach Mike Manes, Assistant Coach Kiel Boynton, Student Assistant Jordan Chapman, Cameron McWilliams, Ryan Ledbetter, J.P. Perry, Aaron Smith, Head Athletic Trainer Chris Cross, Assistant Coach Rill Thompson. Back Row. Rob Nesteroff, Cullen Montgomery, David Ledbetter, Michael Roe, Nate Davenport, Derek Ogle, Logan Kasabian, Ryan Hayes. 
16.

Ri

ans
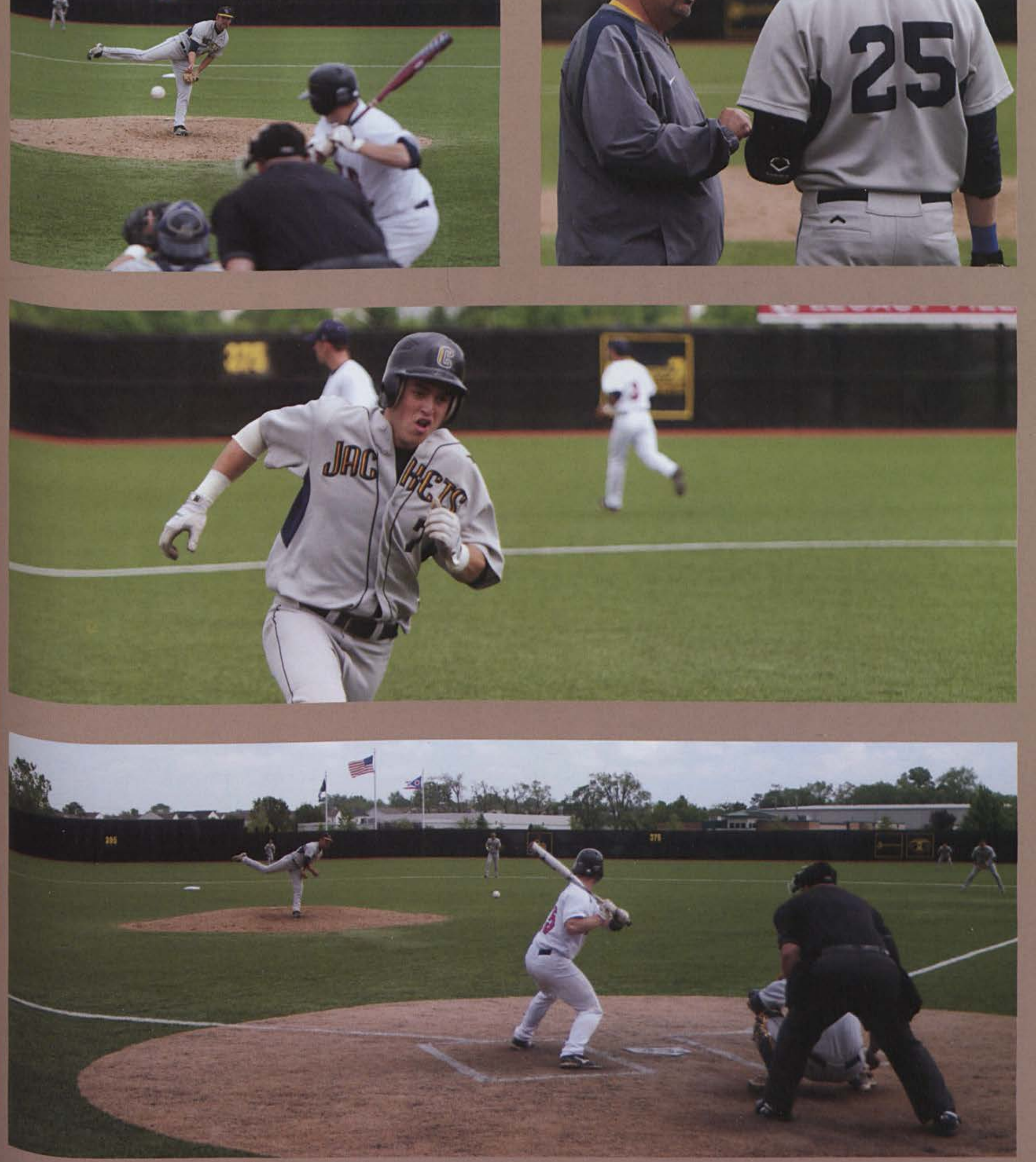


\section{SOFTBALL}

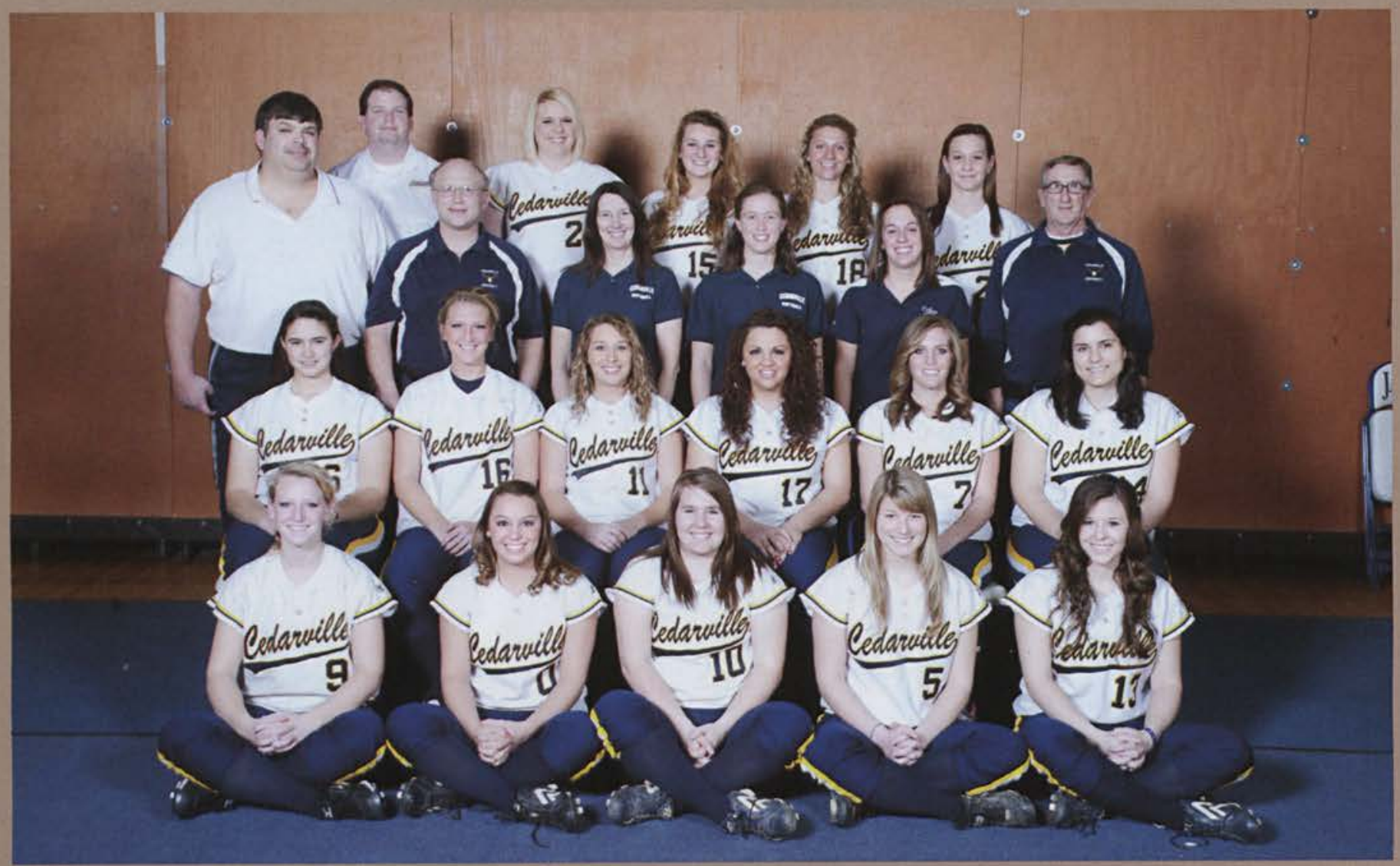

RECORD:

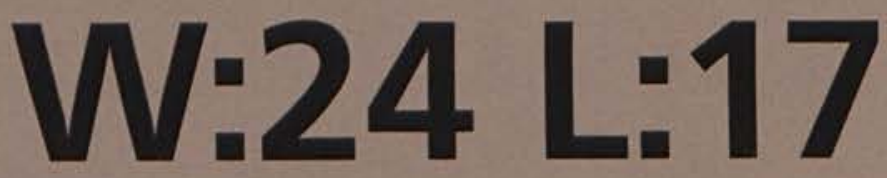

The Cedarville University softball team won their second NCCAA Midwest Region championship with a shutout game of 1-0 against Spring Arbor. The softball team advanced to NCCAA Nationals, making their seventh appearance.

Members Front Row Left-to-Right: Shelby Miller, Kendra Kassonie, Christina Zorn, Karly Heitzmann, Kenleigh Ludlow. Second Row: Jenn Spann, Sydney Miller, Brooke Skinner, Kelsey Wilson, Meghan Creech, Ariella Ortiz. Third Row: Assistant Coach Pat Spurlock, Head Coach Wes Rowe, Assistant Coach Ann Rowe, Graduate Assistant Kim Levinsky, Student Athletic Trainer Ally Stafford, Assistant Coach Dave Freese. Back Row: Associate Athletic Trainer Mike Weller, Kayla Thornsberry, Missy Murphy, Ali Stein, Kelsey Warrington. Not Pictured: Allison Schaeffer and Megan Moffitt. 

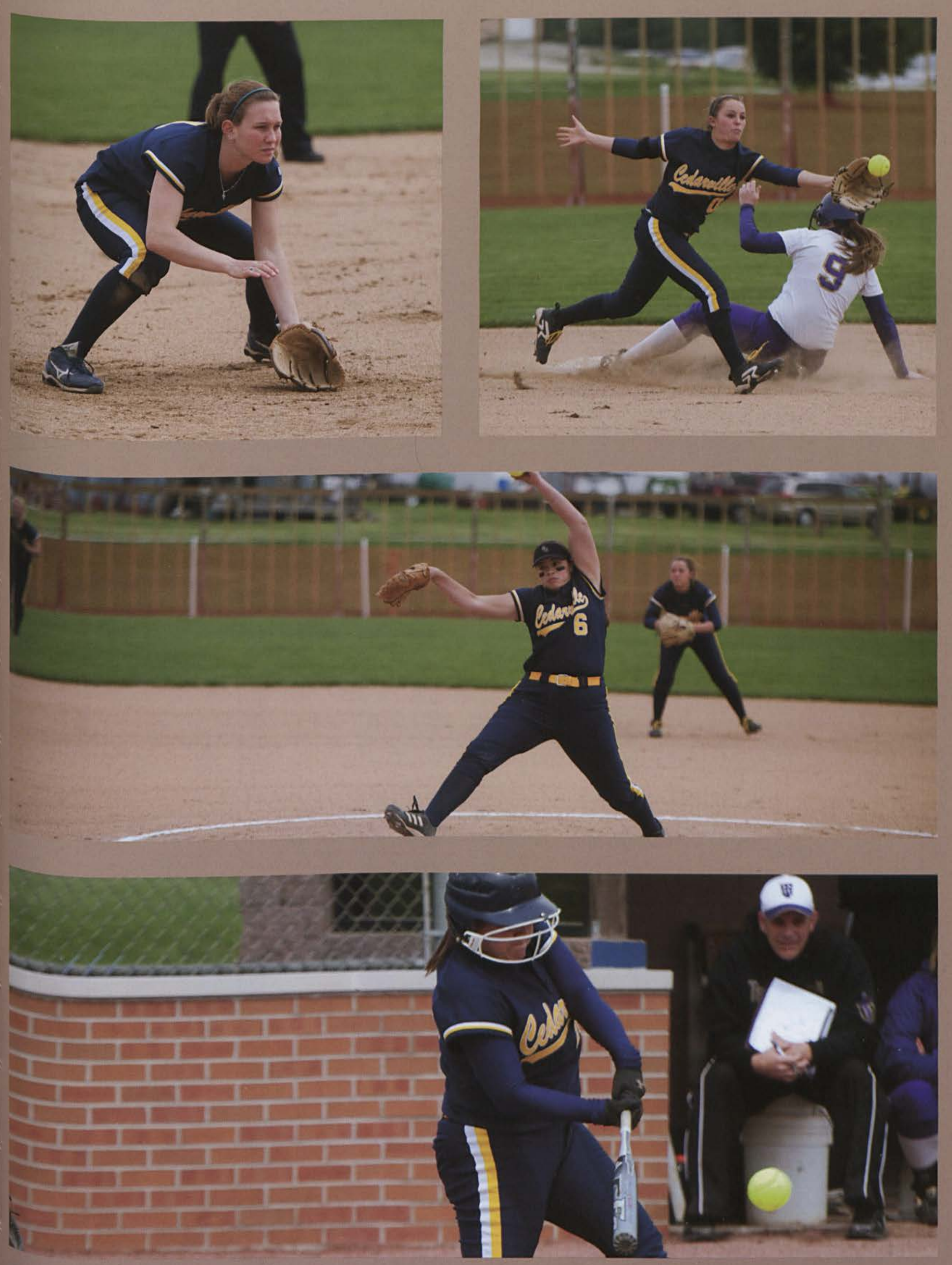


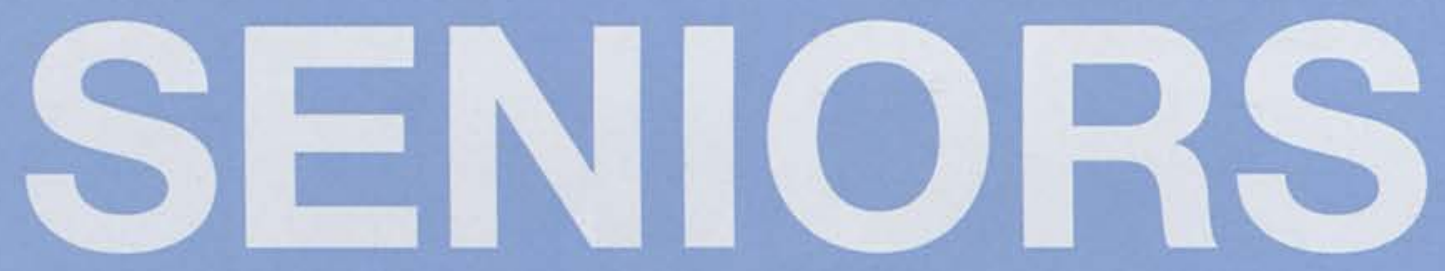

noun, plural \'seen-yers \Students in their last year of Cedarville who often feel little motivation to do any work (referred to as "senioritis"); can be heard half-jokingly talking about needing a job to pay off college loans. 


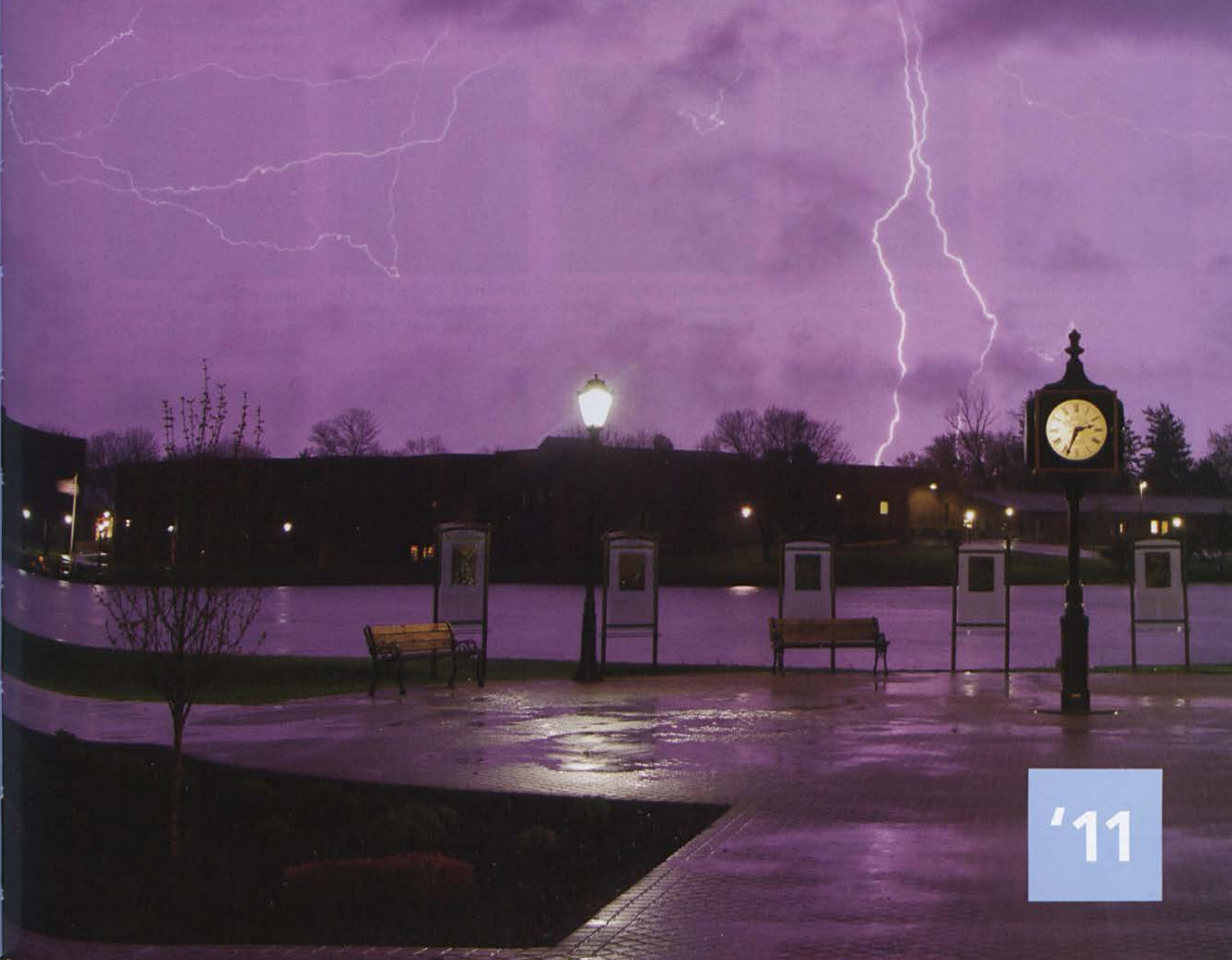




\section{SENIORS}

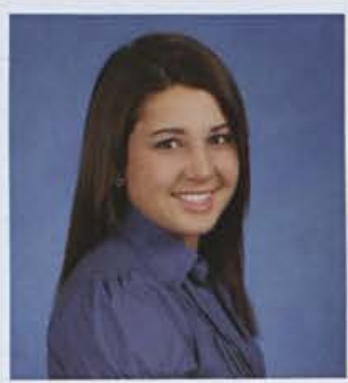

Erin Abbate

Athletic Training

Ashville, NY

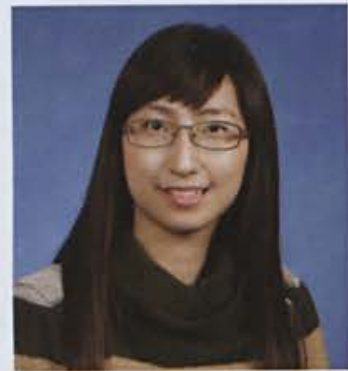

\section{Esther Ahn}

Molecular \& Cellular

Biology

South Korea

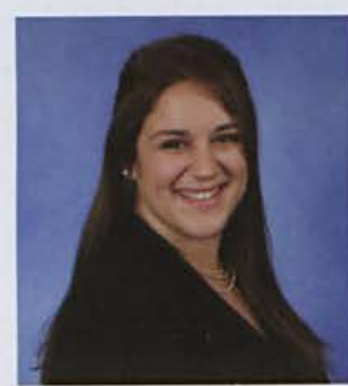

Alexandra Ajamian Marketing

Frederdick, MD

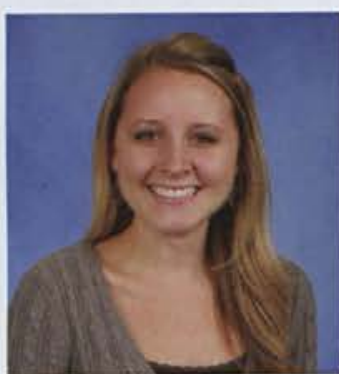

Carline Amburgy Graphic Design

Waynesville, $\mathrm{OH}$

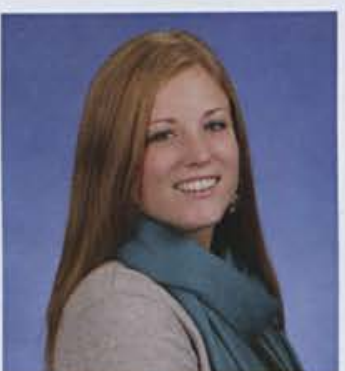

Kelly Achenbach Nursing

Quakertown, PA

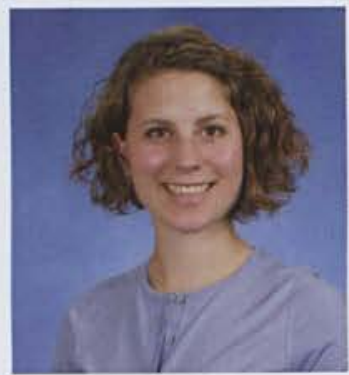

Emily Ahrens

History \& Political Science

Fort Plain, NY

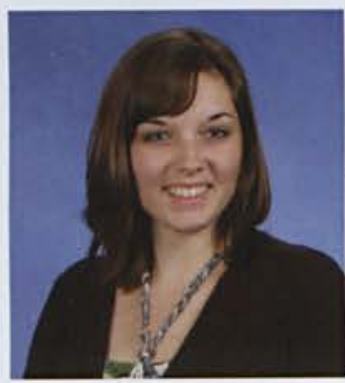

Amanda Allen

Graphic Design

Wellington, $\mathrm{OH}$

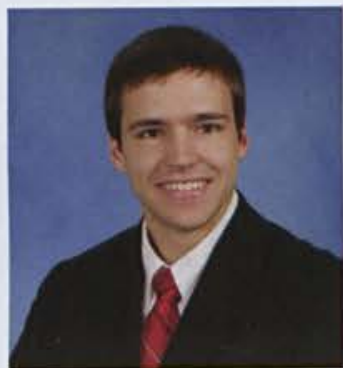

Bradley Anderson Biology

St. Joseph, MI

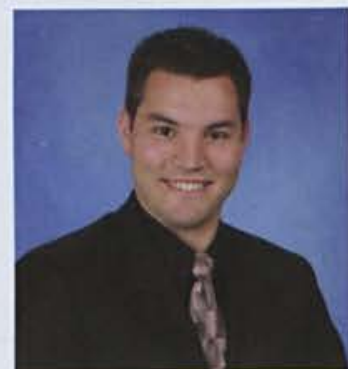

Christopher Acheson Worship

Cedarville, $\mathrm{OH}$

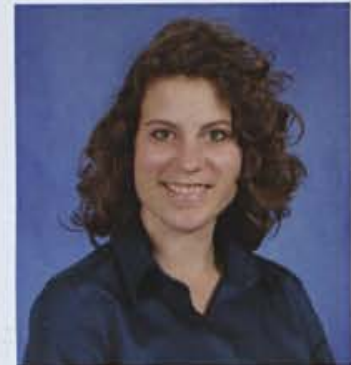

Hanna Ahrens

Early Childhood

Education

Fort Plain, NY

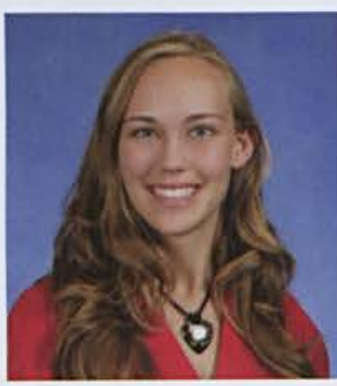

Molly Allen

Middle Childhood

Education

Medina, OH

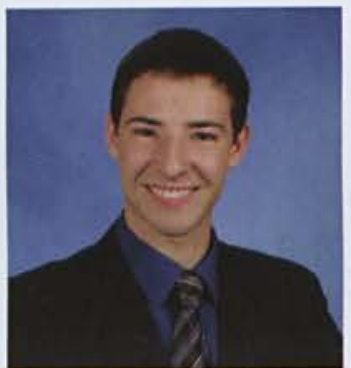

Frederick Anderson Preseminary Bible Cincinnati, $\mathrm{OH}$ 


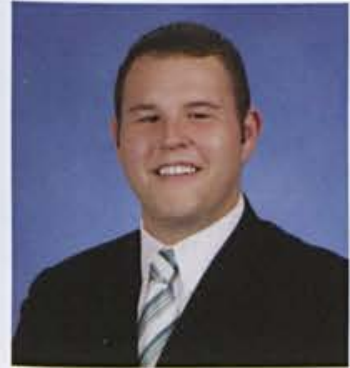

William Andres IV Allied Health

Largo, FL

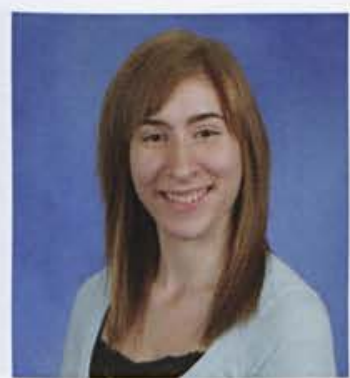

Emily Augenstein Psychology

New Albany, $\mathrm{OH}$

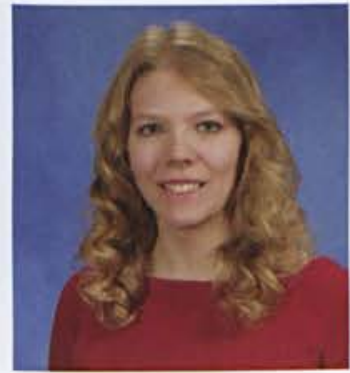

Stephanie Baker History

Columbus, $\mathrm{OH}$

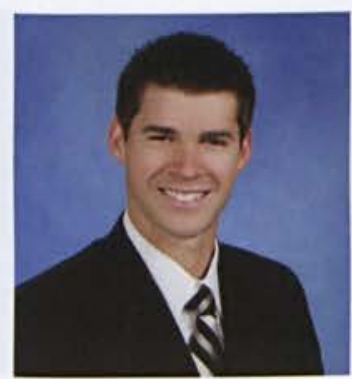

Michael Batts

Finance

Orlando, FL

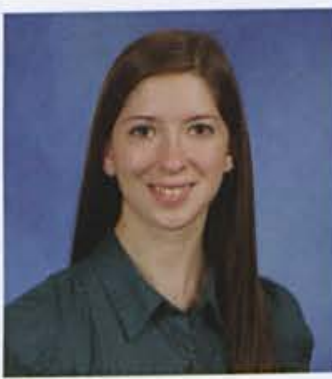

Kaitlyn Arnott

Music Education

Richwood, $\mathrm{OH}$

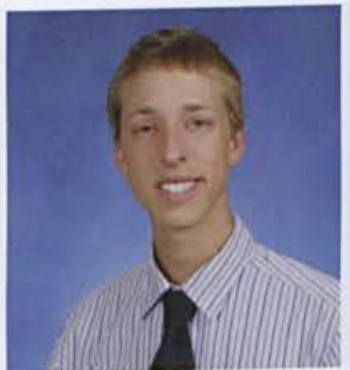

Bradley Augustine

Finance \& Marketing

Kalamazoo, MI

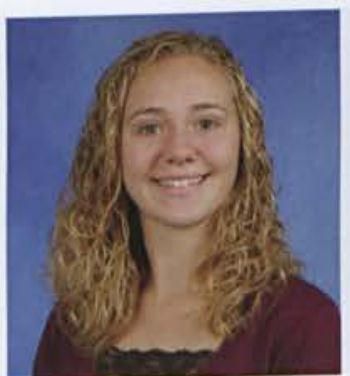

Jennifer Balint

Nursing

Pittsfield, MA

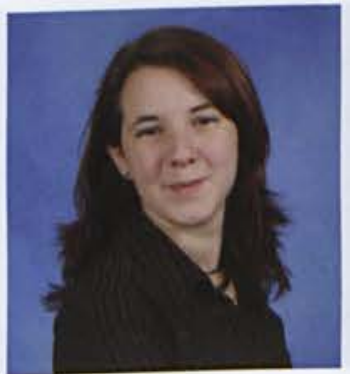

Faith Beauchemin

History \& Comprehensive Communications

Westland, MI

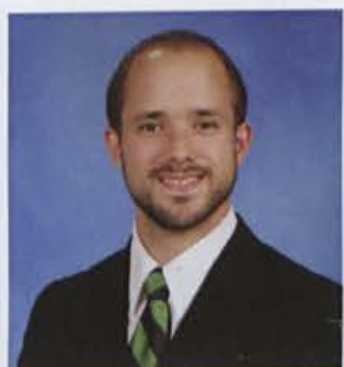

\section{Peter Arthur}

Technical \& Professional

Communication

Sao Paulo, Brazil

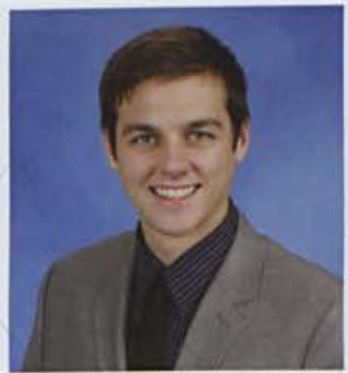

Grant Bacon

History \& Political

Science

Skowhegan, ME

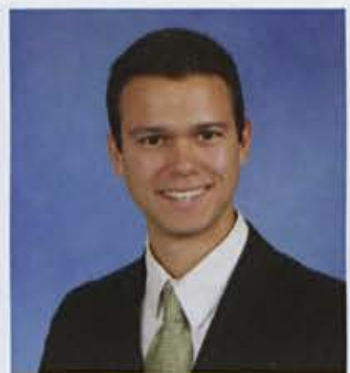

Andrew Barfell Biology

North Royalton, $\mathrm{OH}$

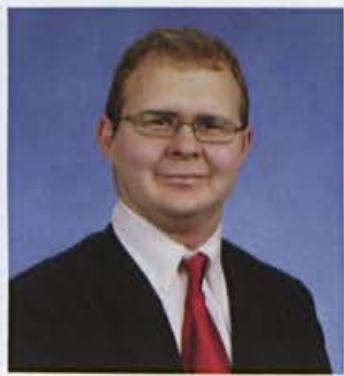

Geoffrey Beck

History \& Political

Science

Winston Salem, NC

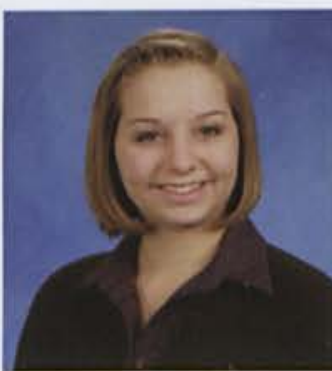

\section{Jessica Askew}

Middle Childhood

Education

Centerville, $\mathrm{OH}$

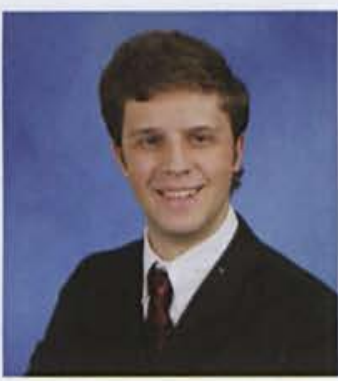

John Baden

Comprehensive

Communication

Troy, $\mathrm{OH}$

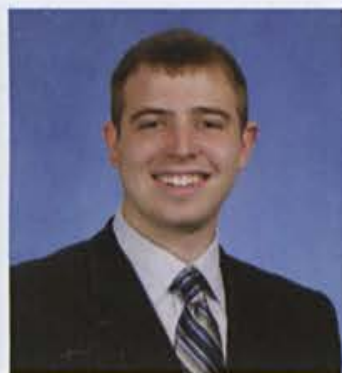

Geoffrey Barnes

Electronic Media

Oakland, NJ

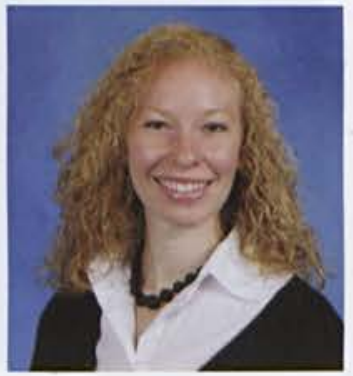

Rebecca Belote Biology \& AYA Life Science Education La Plata, MD

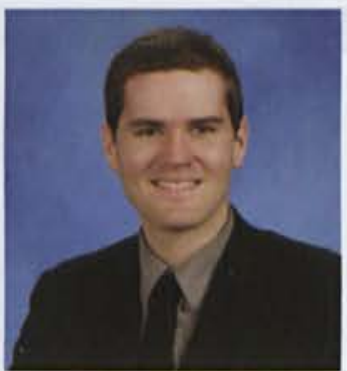

Luke Askew

Integrated Social Studies Education

Chesapeake, VA

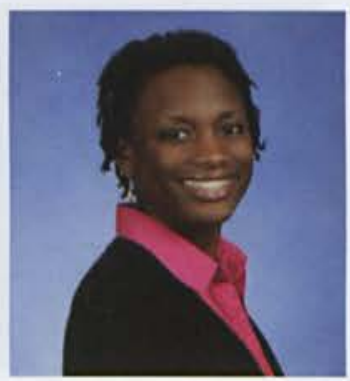

Julita Bailey

Organizational

Communication

Temple Hills, MD

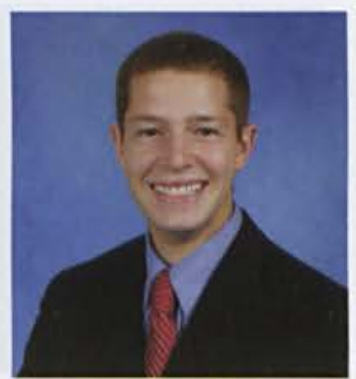

Jason Bartling

Finance

Waterville, IA

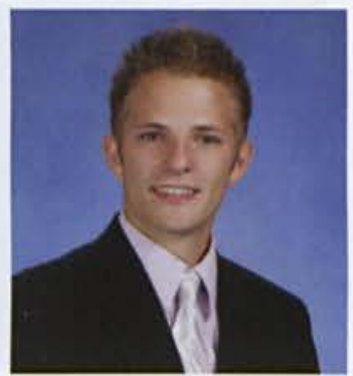

Jason Bender

Mechanical

Engineering

Lebanon, PA 


\section{SENIORS}

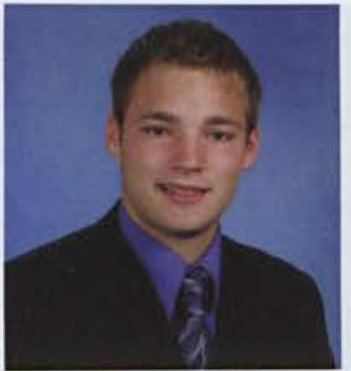

Kevin Bender

Computer Engineering Lebanon, PA

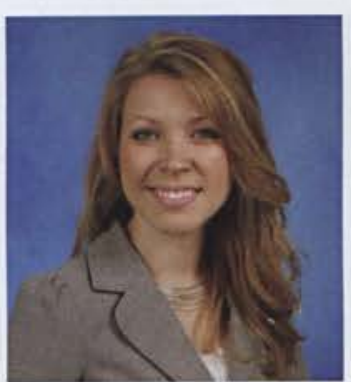

Heidi Benson

Political Science

Saginaw, MI

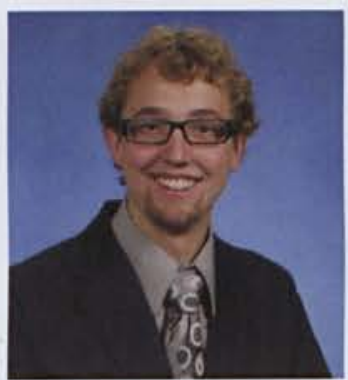

Thomas Bertagnoli Biology

De Pere, WI

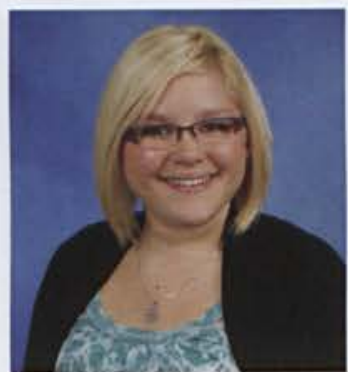

Haeli Betzold

Nursing

Veblen, SD

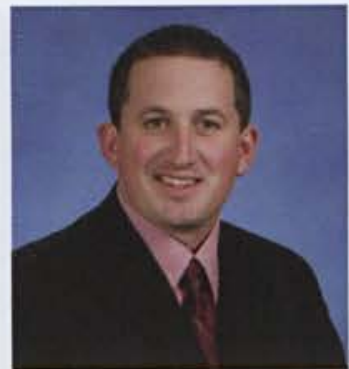

Charles Bender III

Electrical Engineering Cedarville, $\mathrm{OH}$

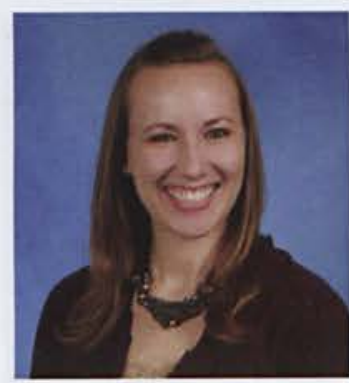

Stacie Beres

Organizationa

Communications

Green, $\mathrm{OH}$

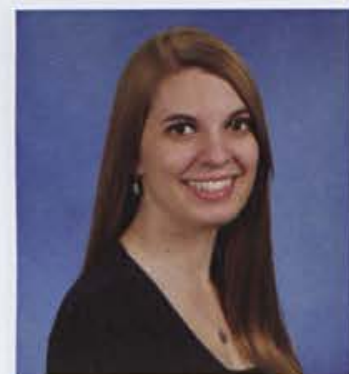

Sarah Berwager Accounting

Mechanicsburg, PA

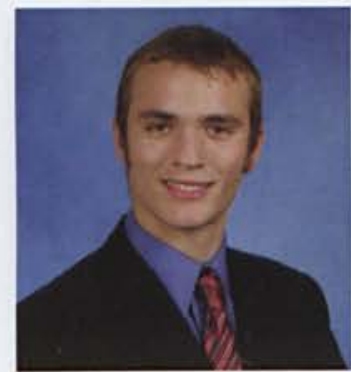

Jesse Bierer

Mechanical

Engineering

Girard, PA

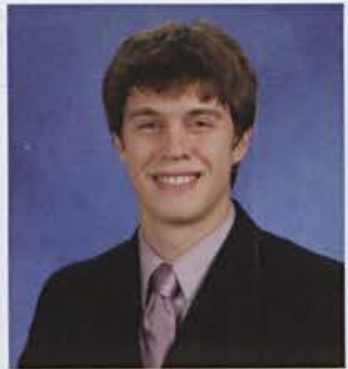

Marcus Benjamin History \& Political Science

Bowling Green, $\mathrm{OH}$

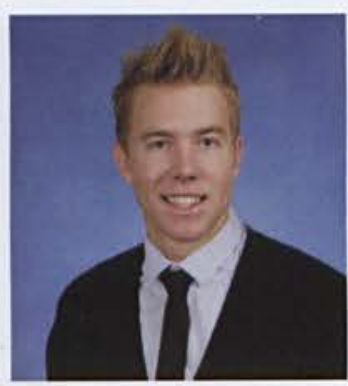

Benjamin Bernhard Management

Menomonee Falls, WI

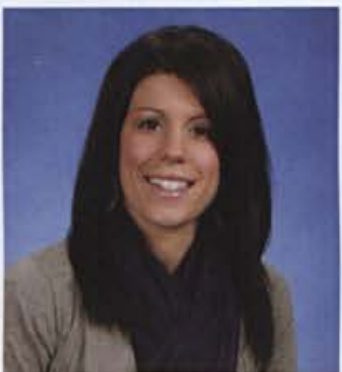

Rebecca Beschta

Nursing

North Salem, IN

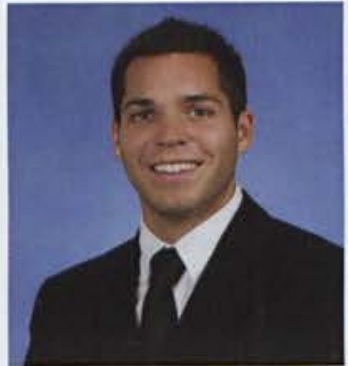

Nicholas Bigler

Accounting \& Finance Elkhart, IN 


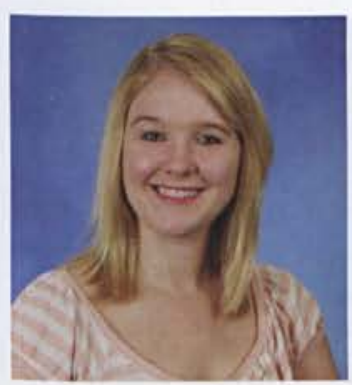

Bethany Bird

Criminal Justice

Xenia, $\mathrm{OH}$

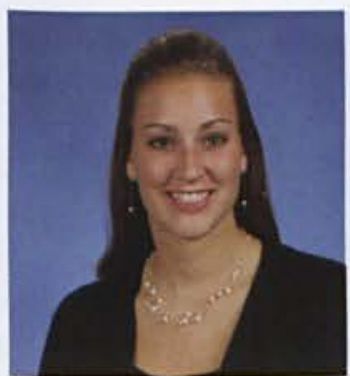

Stephanie Boice

\section{Nursing}

Mechanicsville, VA

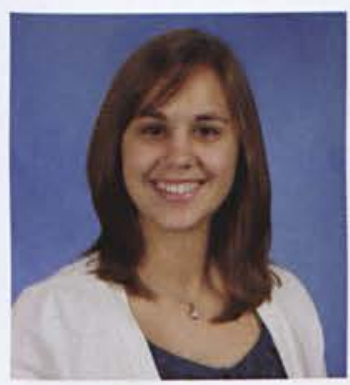

Tacie Brammer

Communication Arts

Sioux Center, IA

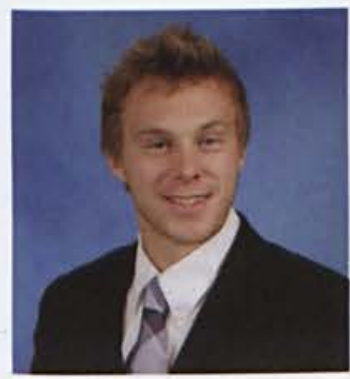

Nevin Brooks

Exercise Science

Lock Haven, PA

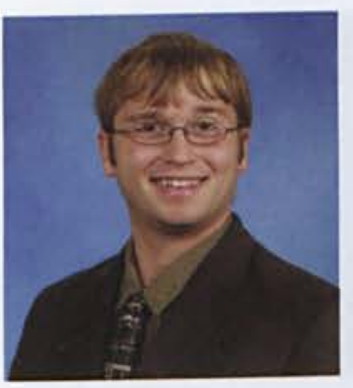

Dylan Black

Psychology

Waynesboro, PA

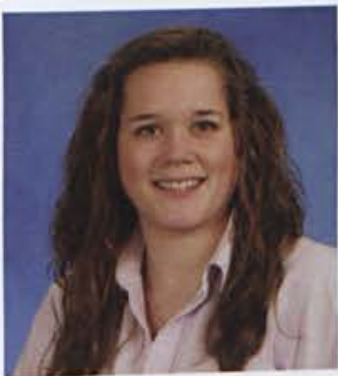

Jessie Bollback

Athletic Training

Pottersville, NY

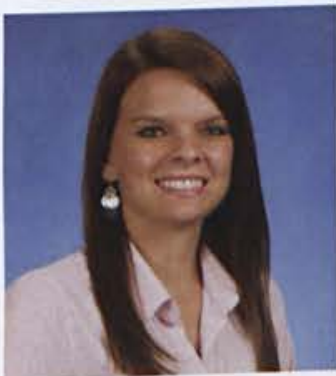

Katie Brandt

Nursing

Wheelersburg, $\mathrm{OH}$

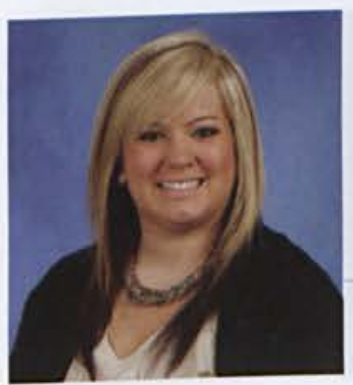

Alisha Brown

Nursing

Lapeer, MI

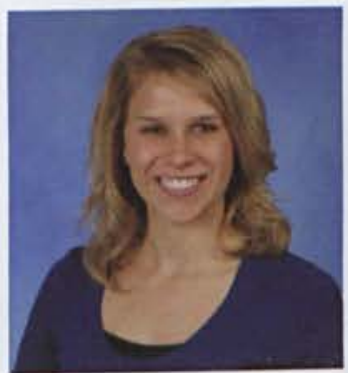

Erin Blackburn

Marketing

West Chester, $\mathrm{OH}$

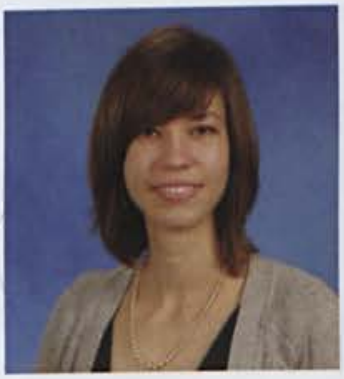

Hanna Bowes

Mechanical

Engineering

Berlin, Germany

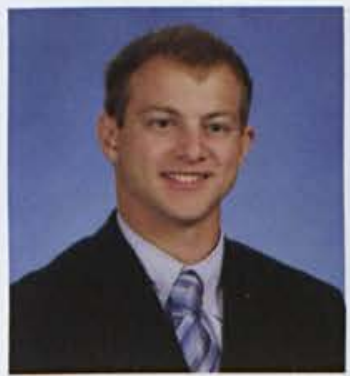

Kyle Brenneman

Management

Lima, $\mathrm{OH}$

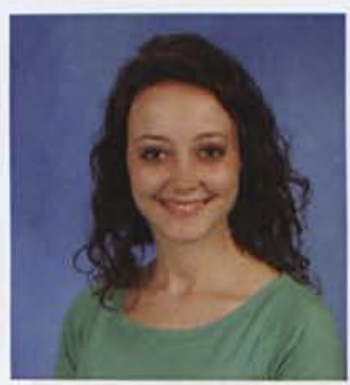

Amanda Brown

Graphic Design

Madrid, Spain

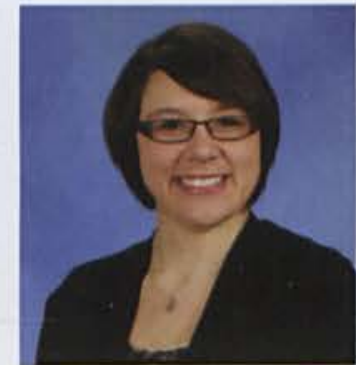

Amber Blair

Psychology

Springfield, $\mathrm{OH}$

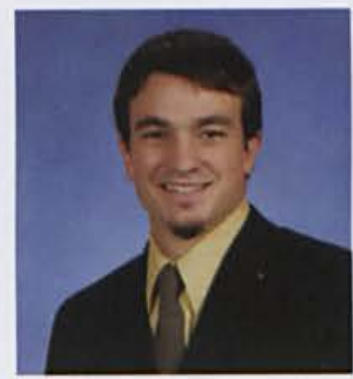

Jordan Bracy

Preseminary Bible

White River Junction, VT

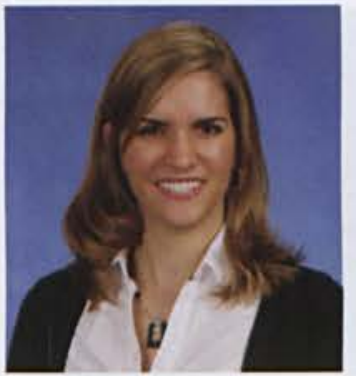

Lydia Briggs

Early Childhood

Education

Bloomington, IN

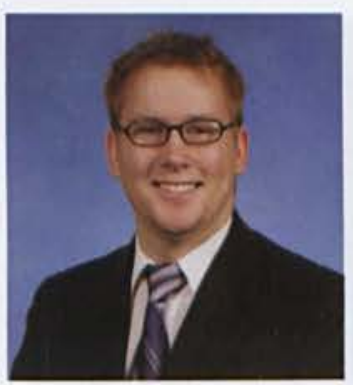

Andrew Brown

Computer Engineering

Polk City, IA

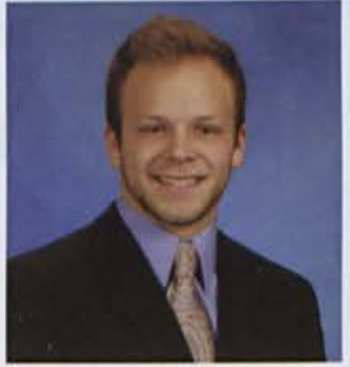

Jonathan Blauert

Comprehensive

Communications

Schwenksville, PA

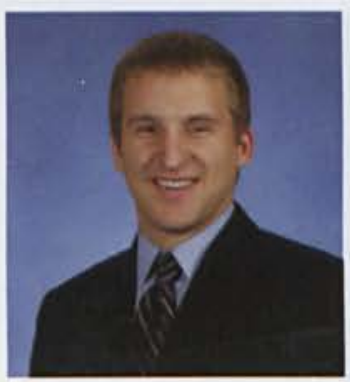

\section{Patrick Brady}

Electrical Engineering Macomb, MI

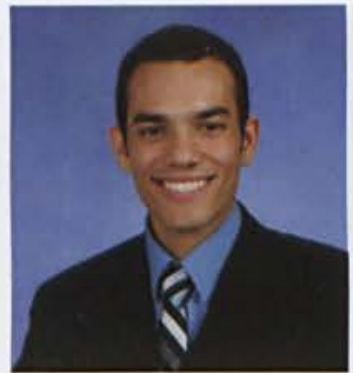

Corwin Briscoe

Technical \& Professional Communication

Flushing, MI

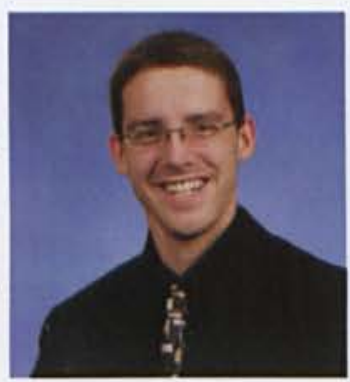

Benjamin Brown Sport and Exercise

Studies

Mentor, $\mathrm{OH}$ 


\section{SENIORS}

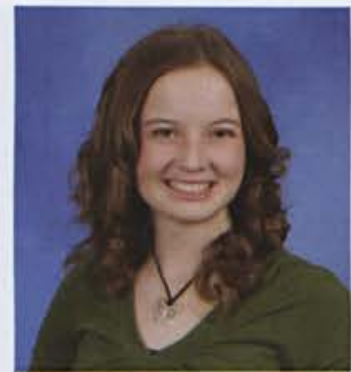

Danielle Brown

Integrated Social Studies Education

Jamestown, RI

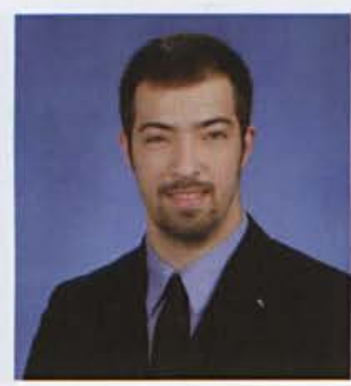

Michael Brown

Electronic Media

The Woodlands, TX

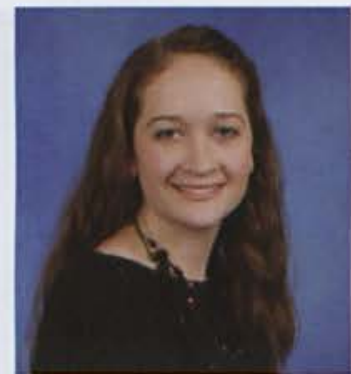

Laura Bryan

Christian Education

Baumholder, Germany

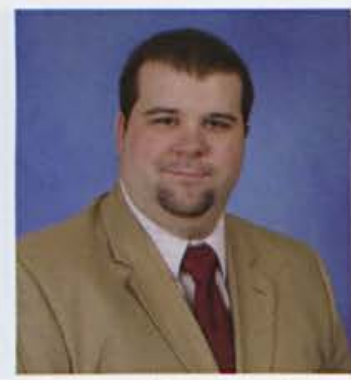

Christopher Bush

Computer Science

Eldersburg, MD

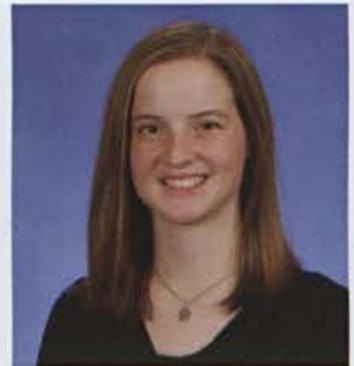

Erin Brown

Nursing

Jamestown, RI

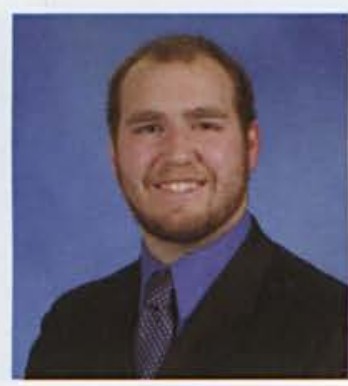

Nathaniel Brown Mechanical Engineering Pittsford, NY

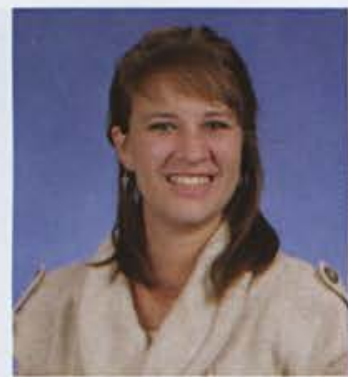

Micaela Buesgens History \& Political

Science

Bloomington, $\mathrm{MN}$

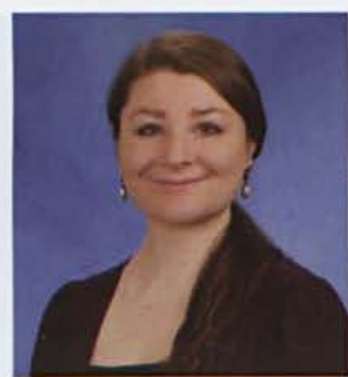

Emily Bush

Theatre

Cleveland, $\mathrm{OH}$

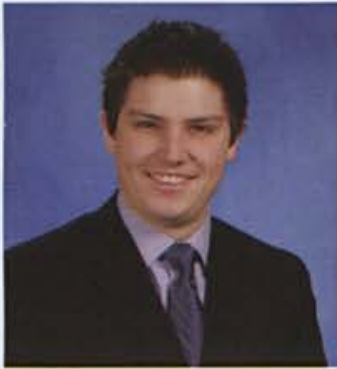

Joshua Brown

Mechanical Engineering Ashville, $\mathrm{OH}$

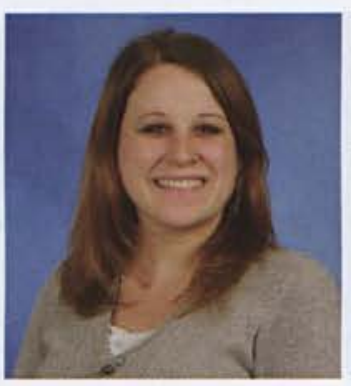

Jessica Brunelle Nursing

Hartland, CT

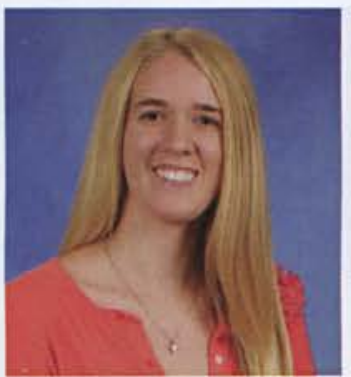

Kristin Buhr

Early Childhood

Education

Lockport, NY

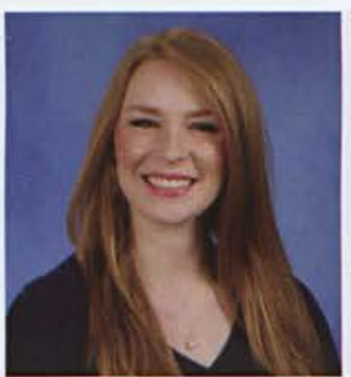

Karen Butterfield

Accounting

Mason, $\mathrm{OH}$ 


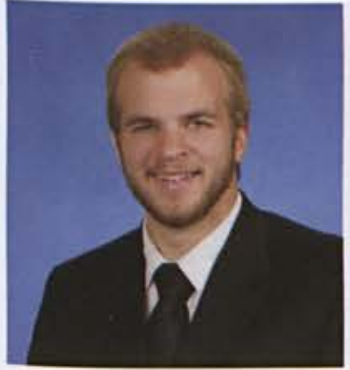

Jack Campbell

Youth Ministry

Normal, IL

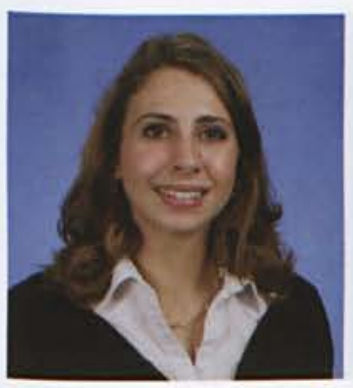

Katherine Cella

International Studies

Medford, NJ

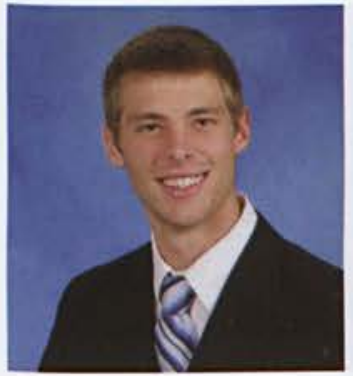

Todd Clark

Mechanical

Engineering

West Charleston, VT

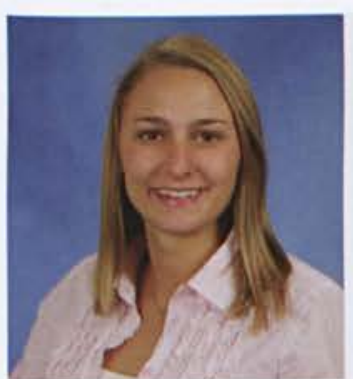

Amy Conner

Nursing

Charleston, WV

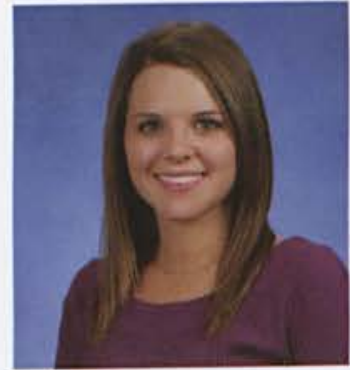

Stephanie Carr

Early Childhood

Education

Bellevue, $\mathrm{OH}$

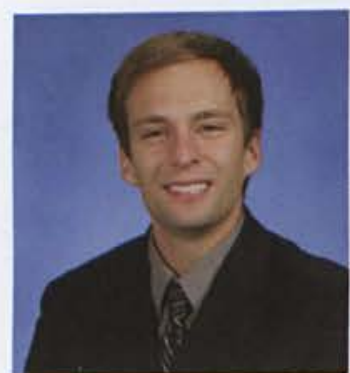

Joshua Chasteen Multi-Age Physical

Education

Lebanon, $\mathrm{OH}$

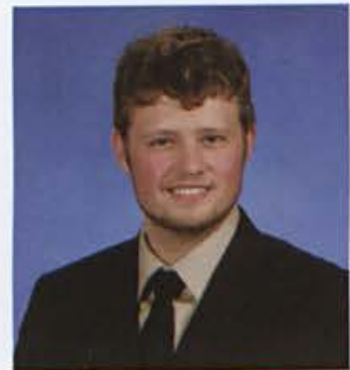

Nicholas Clason

Preseminary Bible \&

Pastoral Studies

East Peoria, IL

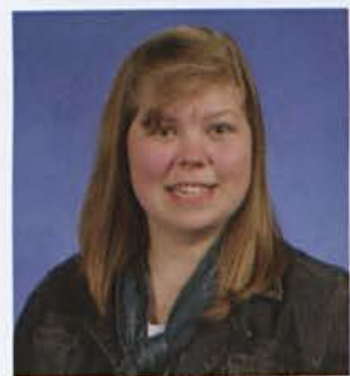

Jillanne Conway

Mechanical

Engineering

Lebanon, $\mathrm{OH}$

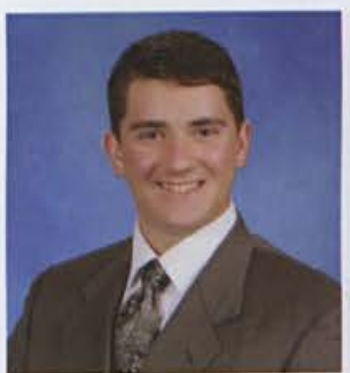

Nathaniel Casement History

Belleville, MI

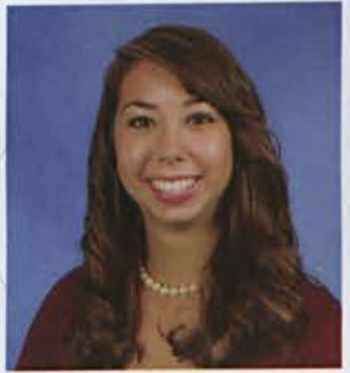

Emily Chiu

Early Childhood

Education

Vestal, NY

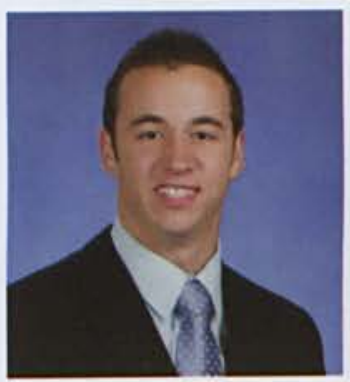

Michael Clouse

Broadcast Journalism

Marshfield, WI

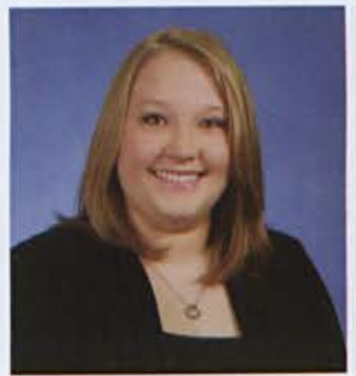

Felicia Cook

Sociology

Felton, DE

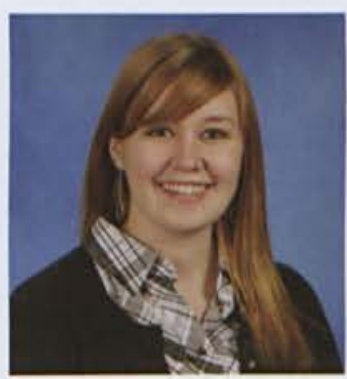

Leah Casper

AYA Math Education

Sussex, WI

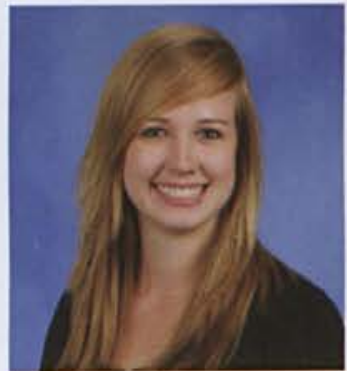

Jacqueline Clark

Early Childhood

Education

Rochester, NY

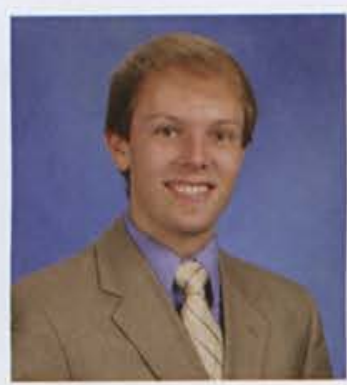

Matthew Compton Multi-Age Music

Education

Stephens City, VA

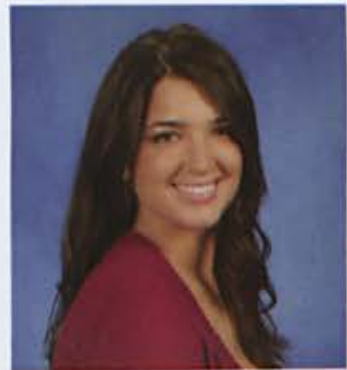

Lauren Cottings

Sociology

Glen Rock, N

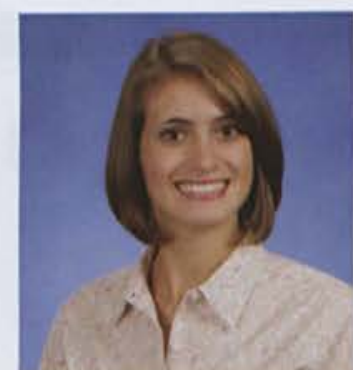

Lindsey Castle Early Childhood

Education

Endicott, NY

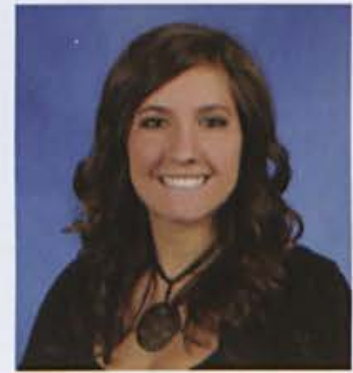

Mandy Clark

Nursing

Pittsburgh, PA

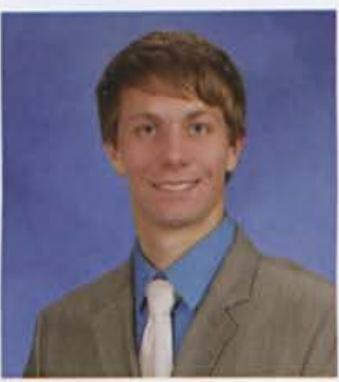

Ryan Connelly AYA Social Studies Education

Sioux City, IA

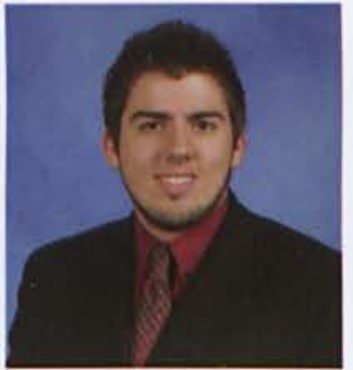

Chad Cox

Mechanical

Engineering

Houston, TX 


\section{SENIORS}

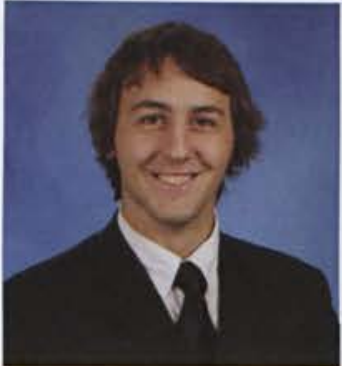

David Cox

Psychology

Beavercreek, $\mathrm{OH}$

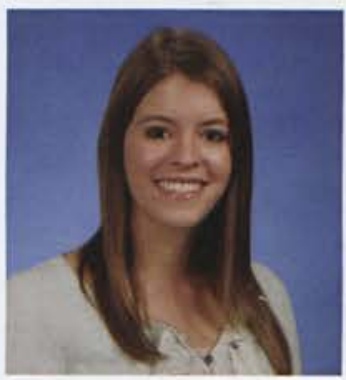

Erin Crawford Graphic Design

Beavercreek, $\mathrm{OH}$

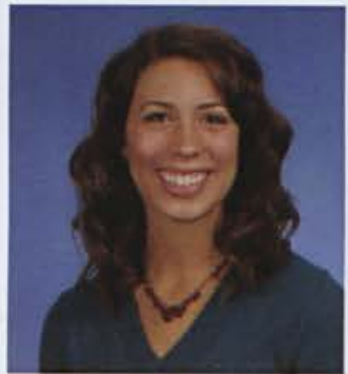

Sara Cummings AYA Social Studies Education

Oakland, MI

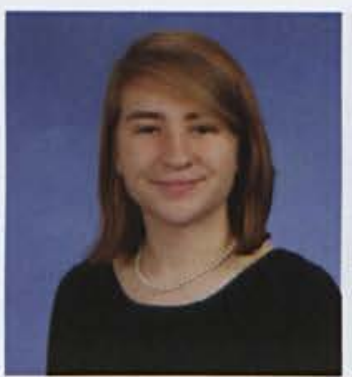

Marie Darling

Electronic Media

Johnstown, NY

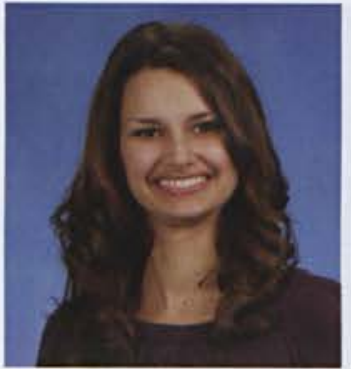

Heather Cox

Psychology

Clayton, IN

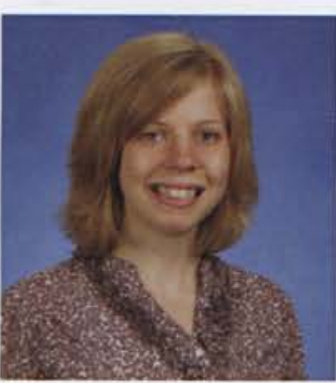

Jennifer Croft

Psychology

Endicolt, NY

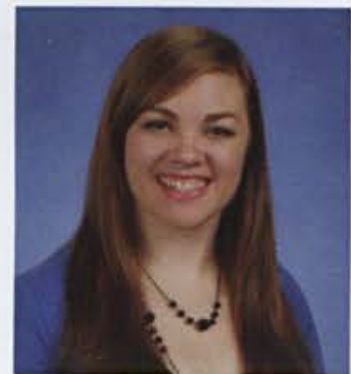

Erin Curby

Social Work

Budapest, Hungary

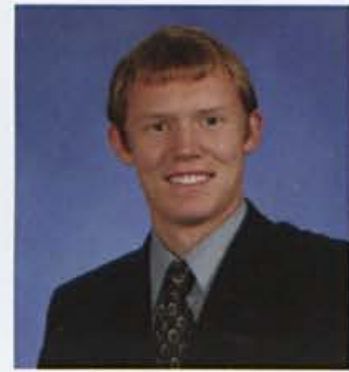

Timothy Dearden

Mechanical

Engineering

Trout Lake, WA

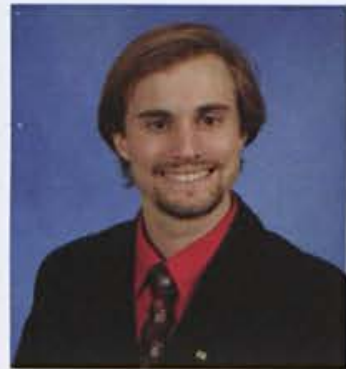

Michael Cox

Physics

Atibaia, Brazil

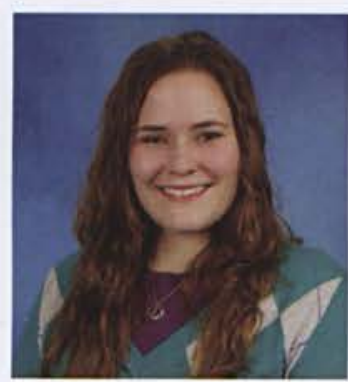

Jennifer Cronin

Early Childhood

Education

Lapeer, MI

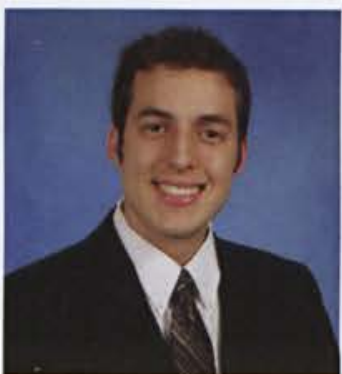

Matthew D'Anna

Electrial Engineering

Hannibal, NY

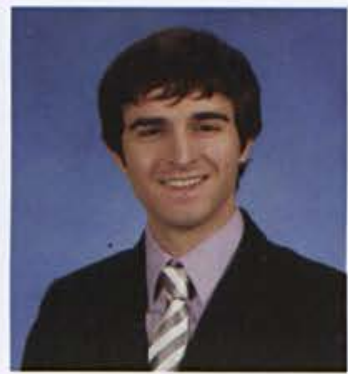

Stephen Dearth

Chemistry

Groton, MA 


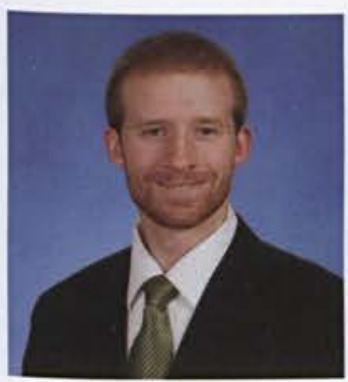

Kyle DeBoer

Preseminary Bible

Grand Rapids, MI

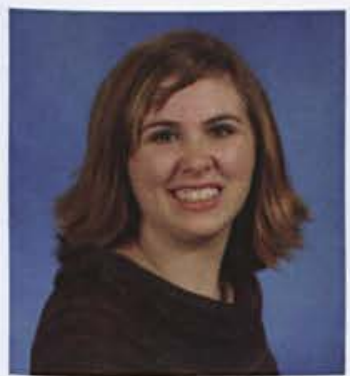

Alyssa Denen

Theatre

Xenia, $\mathrm{OH}$

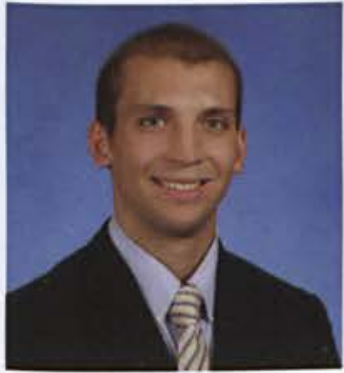

Jonathon Dias

Mechanical

Engineering

Indianapolis, IN

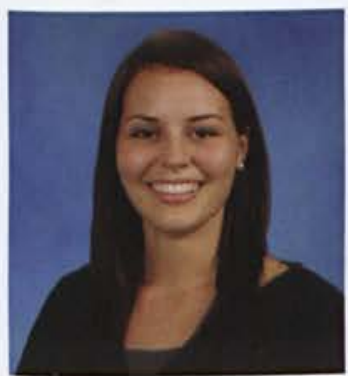

Laura Dreyer

Graphic Design

Sterling, VA

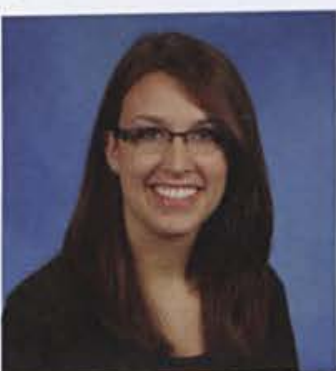

Rebekah DeBoer Psychology

Cedarville, $\mathrm{OH}$

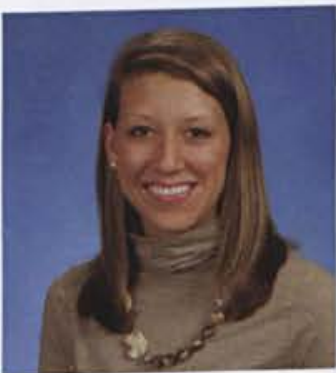

Emily Derusha

Early Childhood

Education

Milford, M

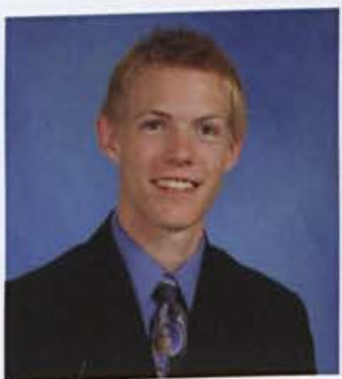

Nathan Dix

Accounting \& Finance

Lisbon, Portugal

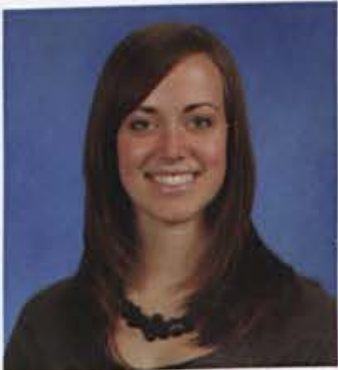

Meredith Dreyer

Multi-Age Special

Education

Potomac Falls, VA

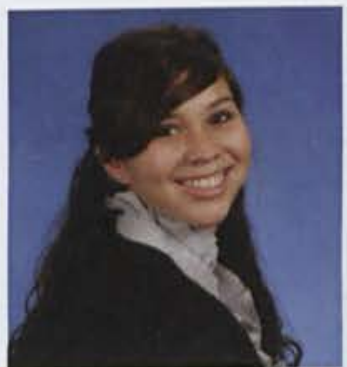

Hayley DeGraff

Social Work

Waco, TX

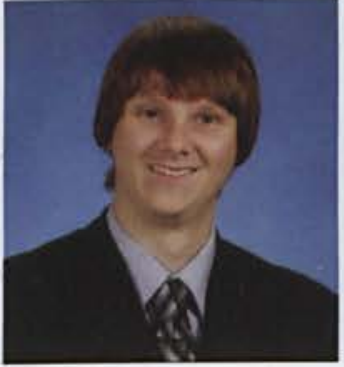

Stephen Devereaux Mathematics

Jackson, MI

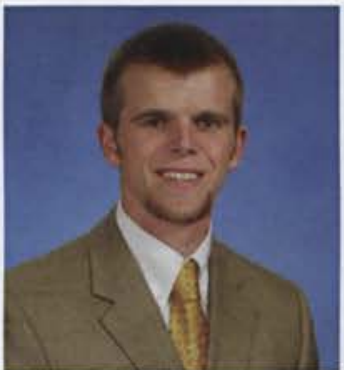

Kevin Dolan

Mechanical

Engineering

Mt. Laurel, NJ

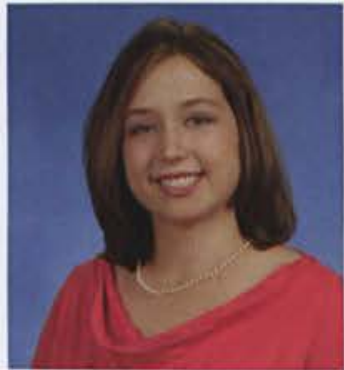

Allison Dunlap

Technical \& Professional

Communication

Pottstown, PA

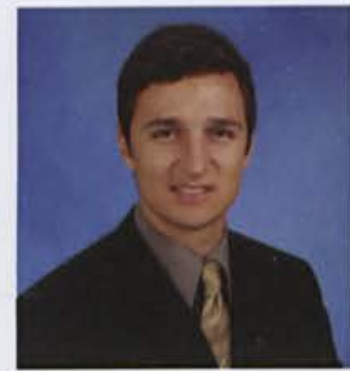

Jonathan Demers

History \& Political

Science

Auburn, MA

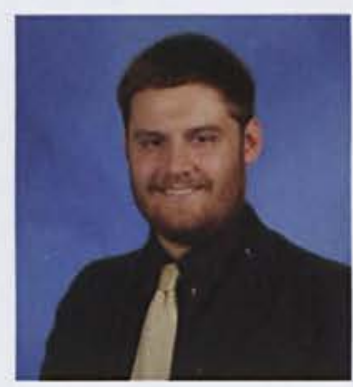

Thomas Devinney

Sport Management

Coxsackie, NY

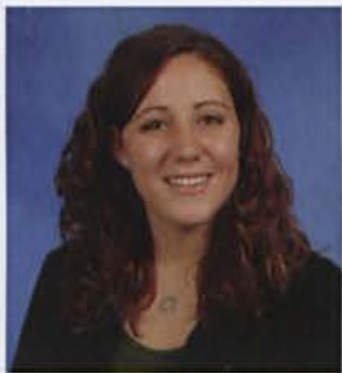

Kristina Dorbritz

Middle Childhood

Education

Van Voorhis, PA

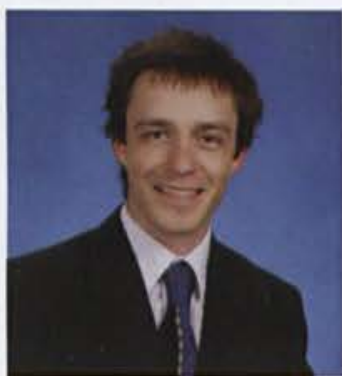

John Dunn

Chemistry

Chihuahua, Mexico

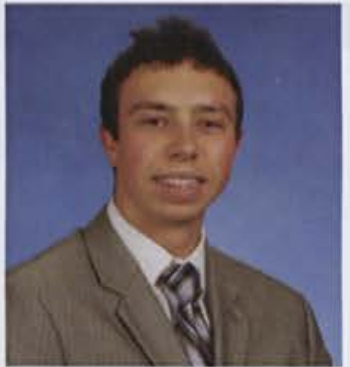

David Demeusy

Molecular \& Cellular Biology

Nashua, NH

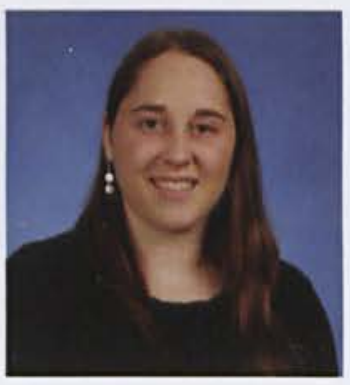

Kendra Dewese Chemistry

Carroll, $\mathrm{OH}$

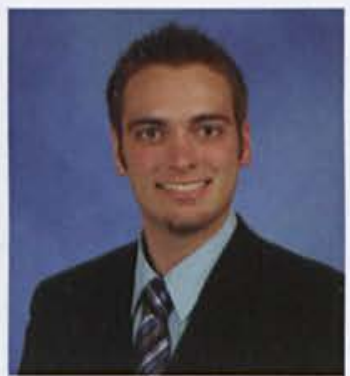

Adam Downs

Electrical Engineering Brookville, $\mathrm{OH}$

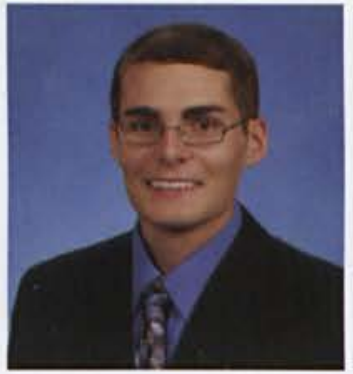

Thomas Eachus

Accounting

Elmer, NJ 


\section{SENIORS}

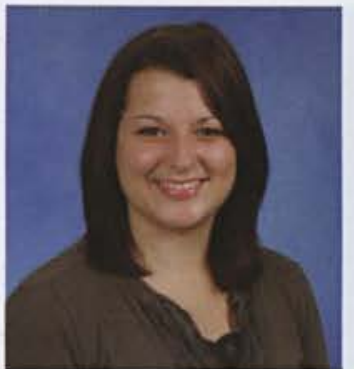

Kathryn Edens

Nursing

Ashburn, VA

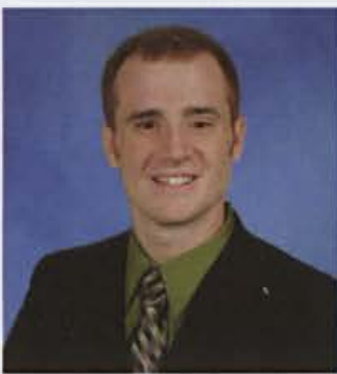

David Eiker

Early Childhood

Education

Little Egg Harbor, NJ

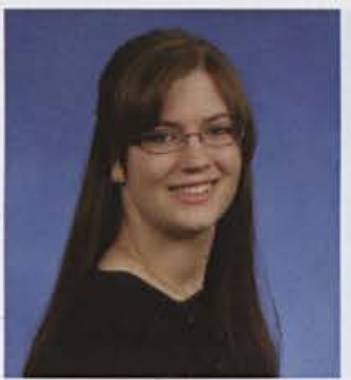

Marissa Eissler

Youth Ministry \&

Christian Education

Fredericksburg, VA

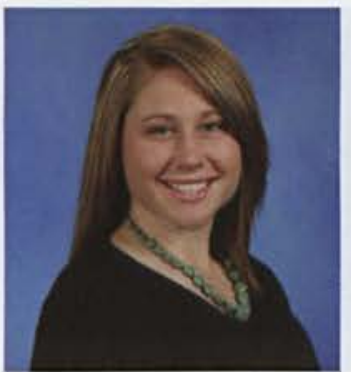

Kara Enterline

Nursing

Harrisburg, PA

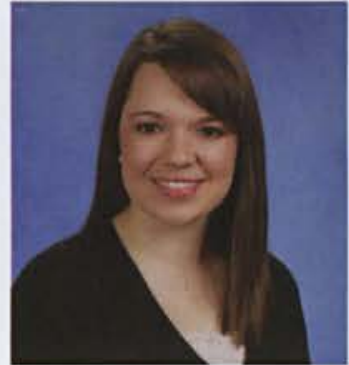

Tiffany Edmonds

Nursing

Highlands Ranch, CO

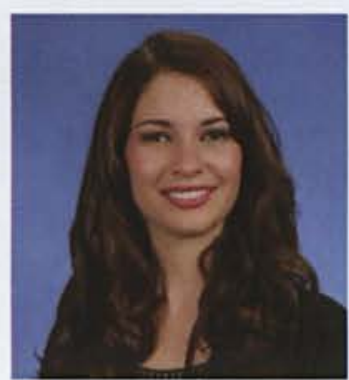

Amy Eiler

Theatre

Clearwater, FL

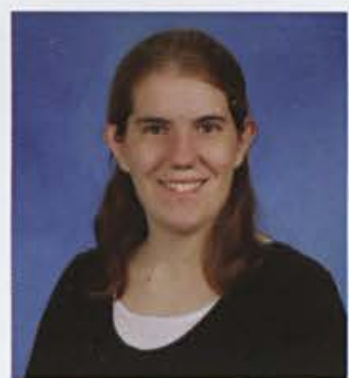

Terri Elgersma

Graphic Design

Westminster, MD

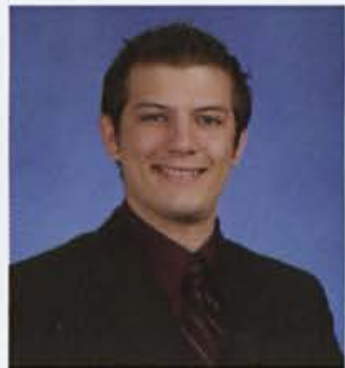

Matthew Evans

Christian Education \&

Youth Ministry

Finleyville, PA

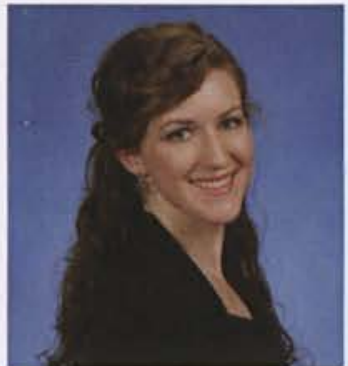

Mary Edwards

Graphic Design

Xenia, OH

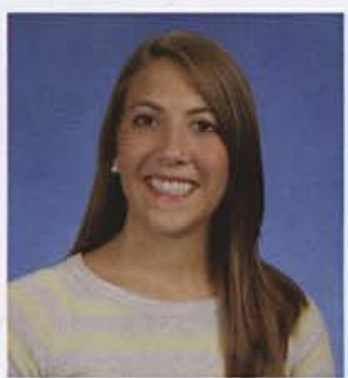

Abby Eisenlohr

Biology

Shelby, MI

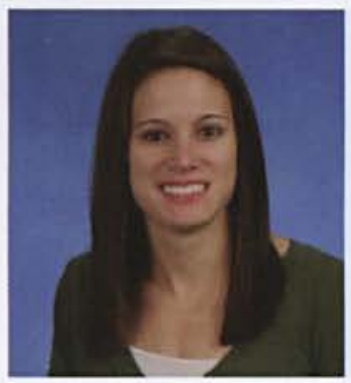

Johanna Ensslen

Nursing

Glenmoore, PA

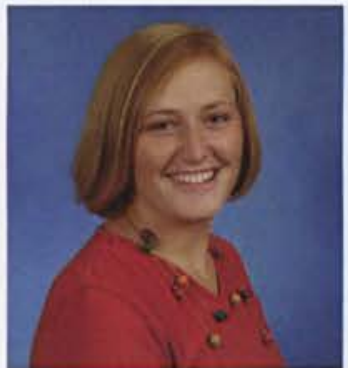

Julianne Everswick

Biology

Havare, Zimbabwe 


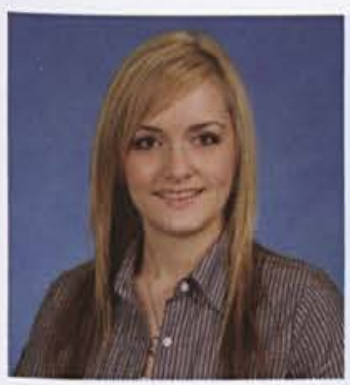

Amanda Fawcett Communications Arts Cedarville, $\mathrm{OH}$

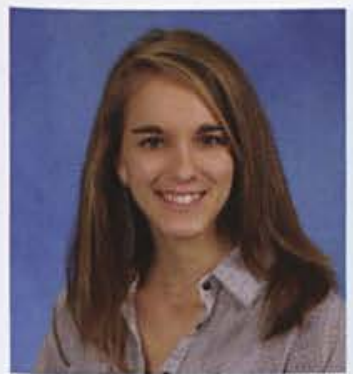

Rachel Finkbeiner

Graphic Design

Hatfield, PA

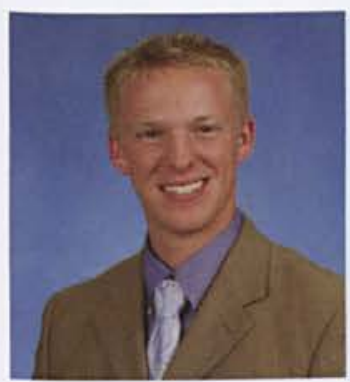

Jordan Flexman

Psychology

Xenia, $\mathrm{OH}$

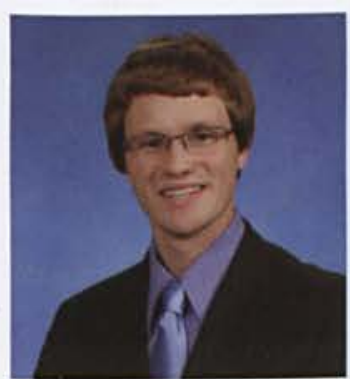

Dalen Fultz

Molecular \& Cellular Biology

Louisville, KY

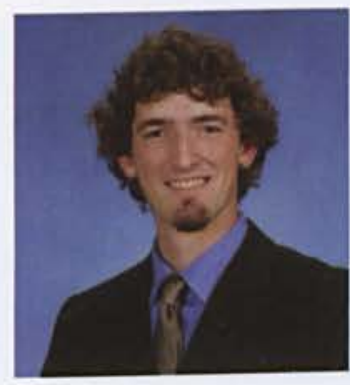

Matthew Fawcett Electronic Media Cedarville, $\mathrm{OH}$

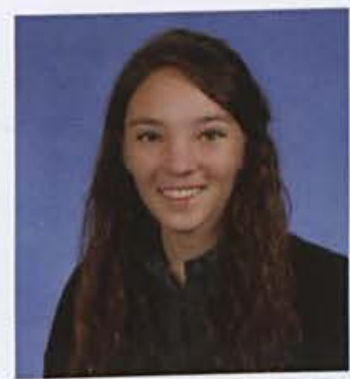

\section{Ruth Firmin}

Psychology

Cedarville, $\mathrm{OH}$

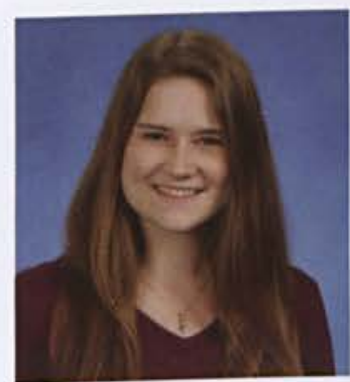

Kimberly Flynn Intercultural

Communications Winthrop, ME

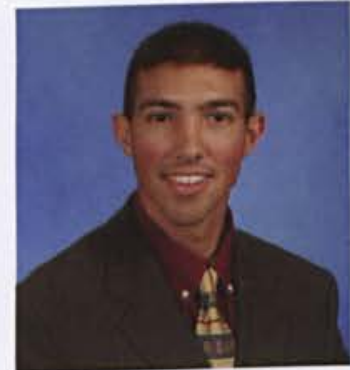

Vincent Fye

Public Administration

Jamestown, NY

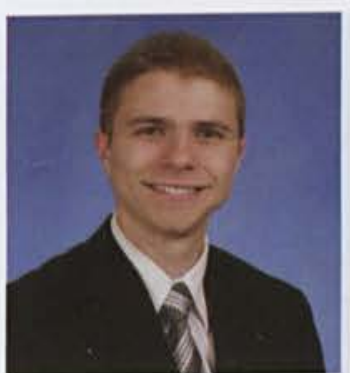

David Ferkaluk History \& Political Science

Hickory Hills, IL

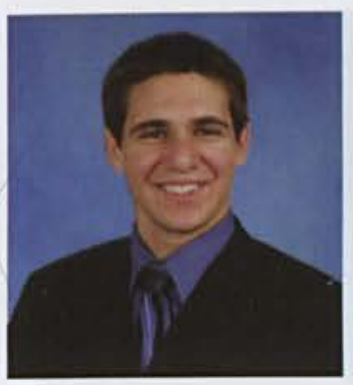

Seth Flamm

Accounting

Toledo, $\mathrm{OH}$

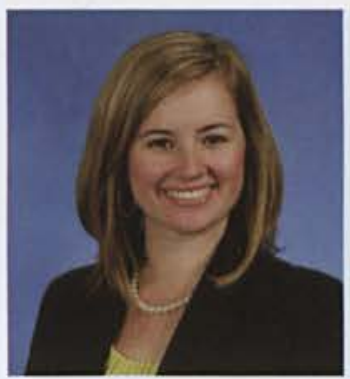

Katie Foster

Political Science

Memphis, TN

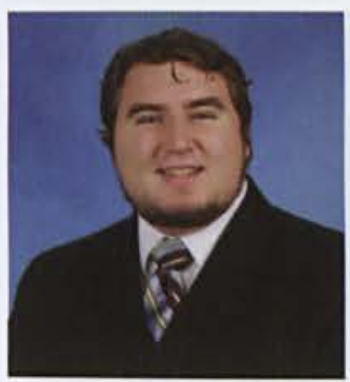

Gregory Gallagher Vocal Performance Greenville, $\mathrm{OH}$

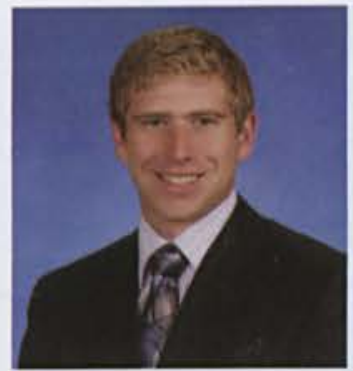

Andrew Ferrell

Marketing

Kansas City, MO

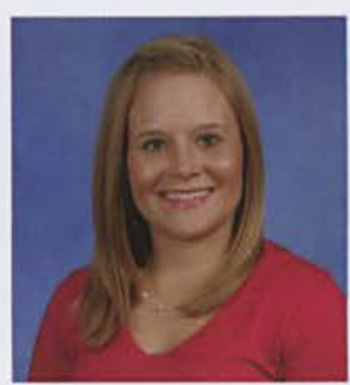

Amy Fleming

Marketing

Sylvania, $\mathrm{OH}$

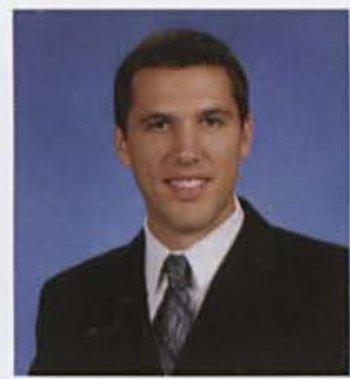

Jeremiah Fraser Athletic Training Tully, NY

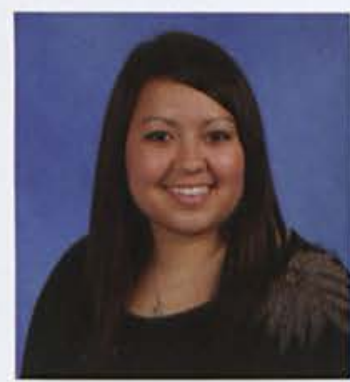

Olivia Gardner

Marketing

Linden, MI

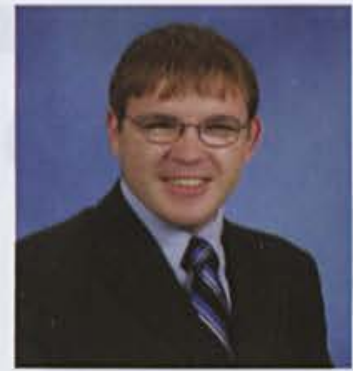

Jonathan Fields Youth Ministry \& Christian Education Louisvile, KY

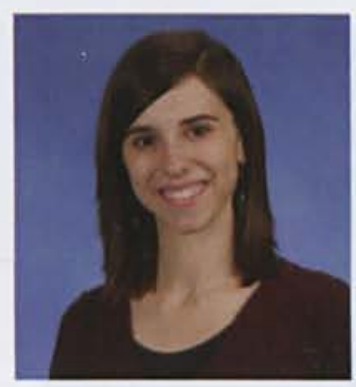

Rachel Fleming Early Childhood \& Special Education Dillsburg, PA

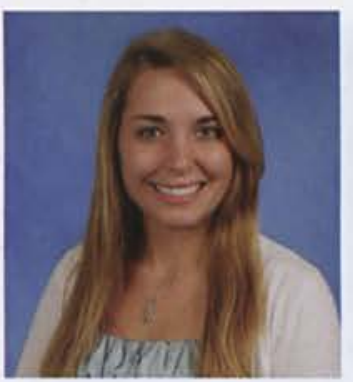

Betty Frederick Nursing Pekin, IL

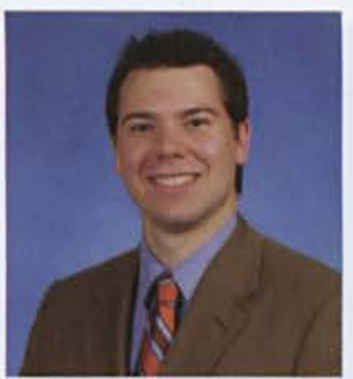

Christopher Garlick Mechanical Engineering Erie, PA 


\section{SENIORS}

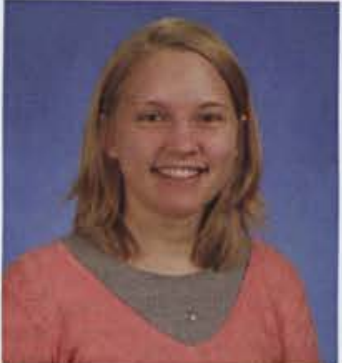

Lynn Gass

Spanish

Brown Deer, W

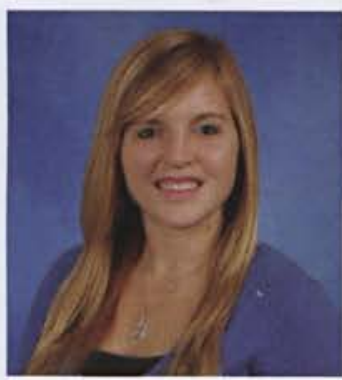

Amy Gensler

International Studies

Hampton, VA

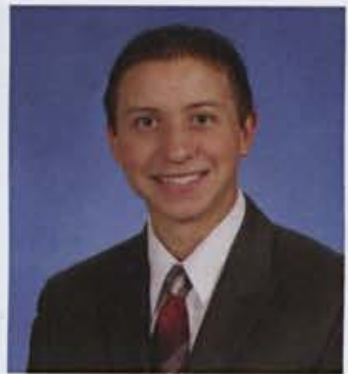

Steven Gilbert

Accounting \& Finance

Pleasant Lake, IN

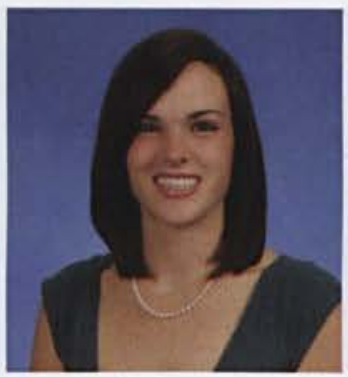

Erin Gollihue

Electronic Media

Erial, NJ

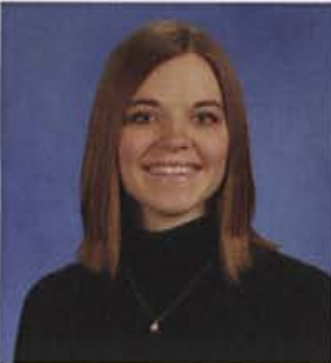

Tiffani Gaston

Middle Childhood

Education

Lynchburg, VA

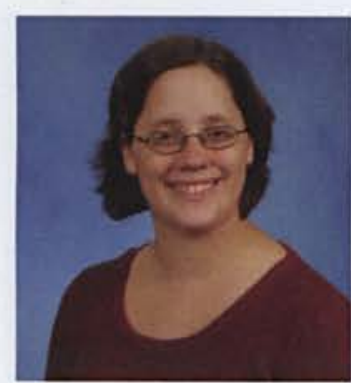

Rebekah Gifford

Studio Art

Xenia, $\mathrm{OH}$

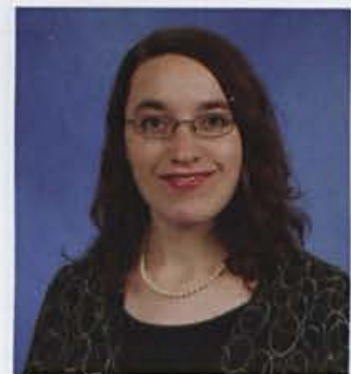

Katrina Gingerich

Piano Performance

Plain City, OH

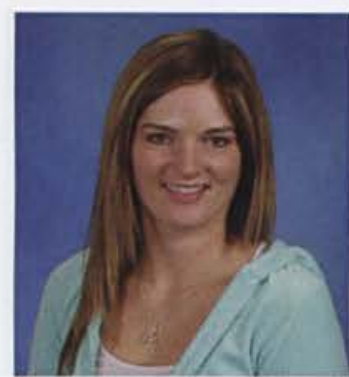

Breanna Good

Criminal Justice

Indianapolis, IN

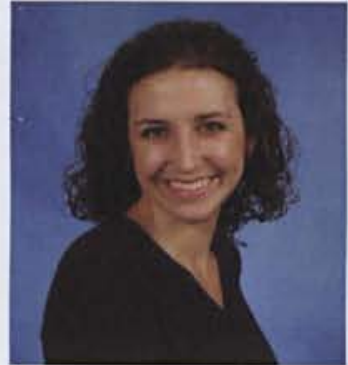

Patricia Gelwicks

Nursing

Fishers, IN

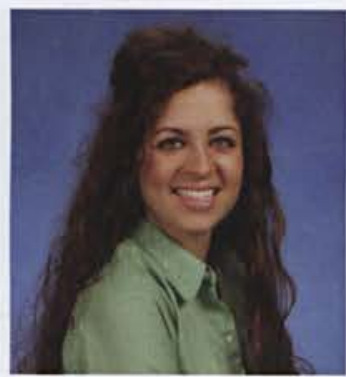

Jillian Gigliotti

Graphic Design

Waterford, CT

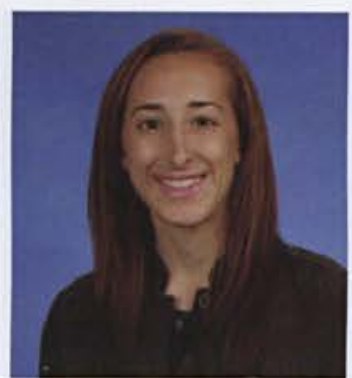

Danielle Gingrich

Nursing

Omaha, NE

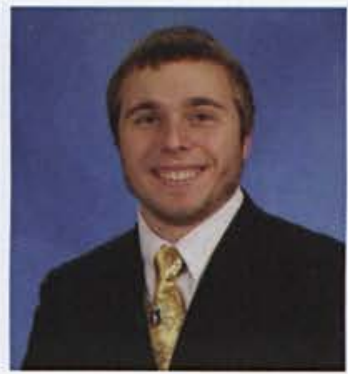

Andrew Gordon

Preseminary Bible

Knoxville, IA 


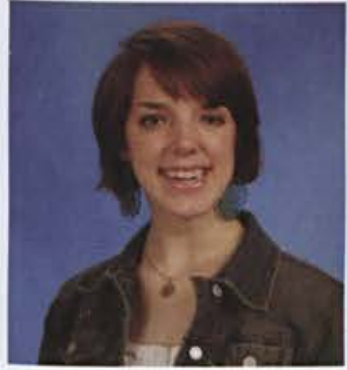

Elizabeth Graff

International Studies

Clarksville, $\mathrm{OH}$

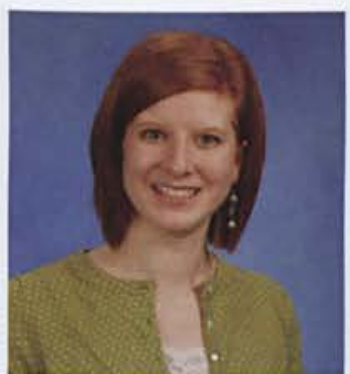

Megan Grigsby

Psychology

Nashport, $\mathrm{OH}$

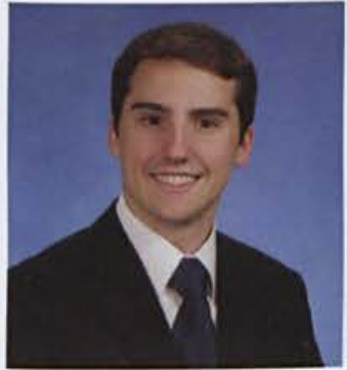

Jason Halvorsen

Mechanical

Engineering

North Haledon, NJ

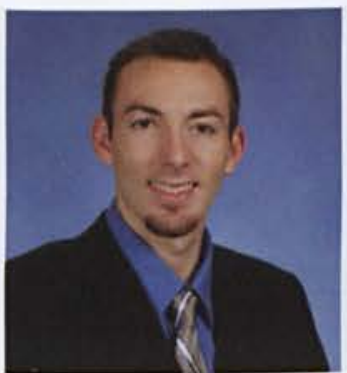

Matthew Harner Physical Education Cedarville, $\mathrm{OH}$

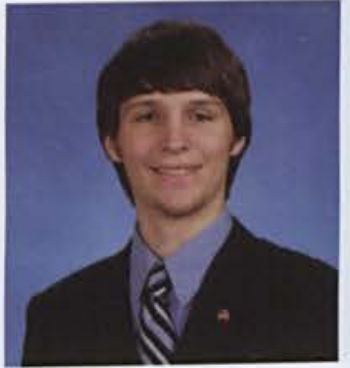

Benjamin Graham Public Administration Pryden, MI

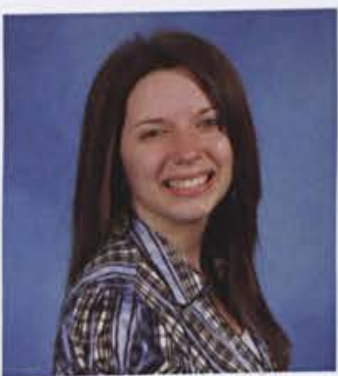

Crystal Groves

Early Childhood

Education

Redford, MI

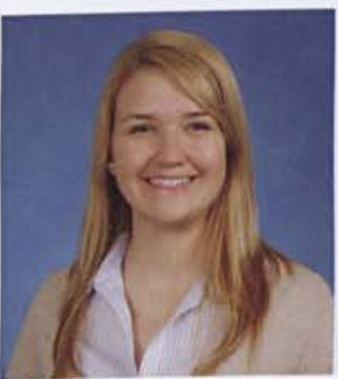

Christiana Halvorson Graphic Design

Manns Choice, PA

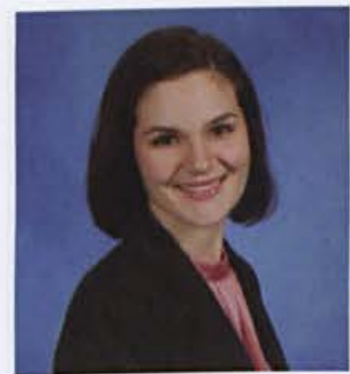

Bethany Harpole

Biology \& Chemistry Newhall, IA

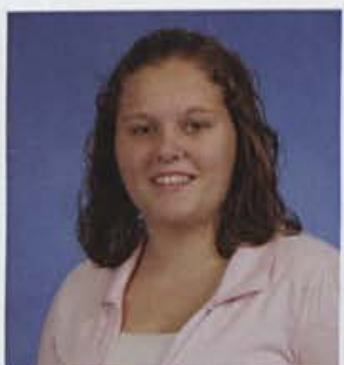

Emily Graham Management

Lopper, MI

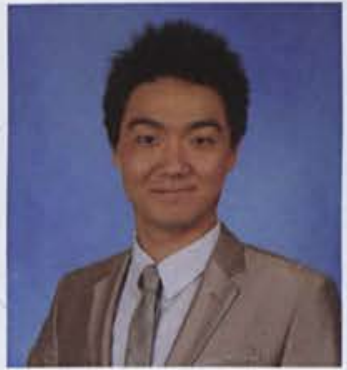

Young-Un $\mathrm{Ha}$

Finance

Cedarville, $\mathrm{OH}$

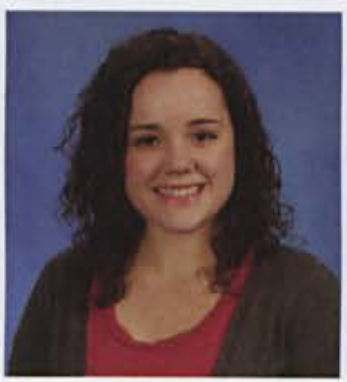

Faith Handley

Social Work

Phoenixville, PA

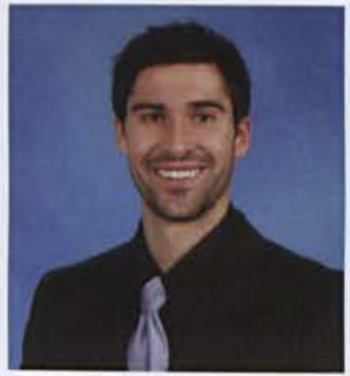

Jacob Harstel

Biology

Cedarville, $\mathrm{OH}$

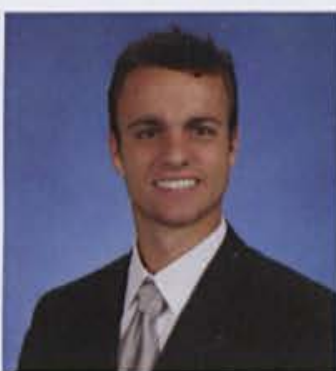

Timothy Green

Accounting

Lakeland, FL

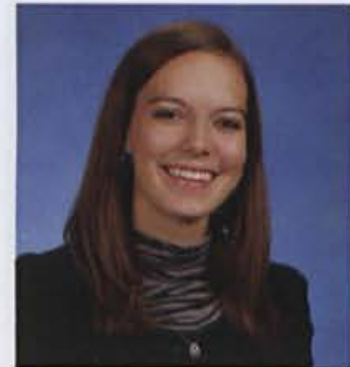

Kaylyn Haas

Middle Childhood

Education

Ironton, $\mathrm{OH}$

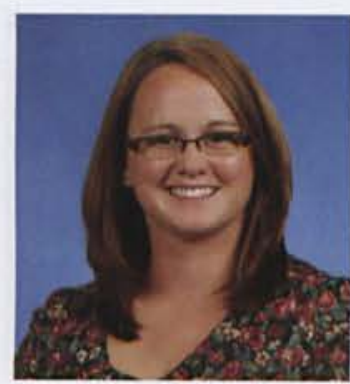

Sarah Hannay

Nursing

Westeno, NY

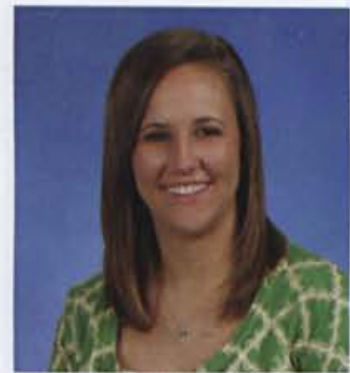

Sarah Hartman

Nursing

Delaware, $\mathrm{OH}$

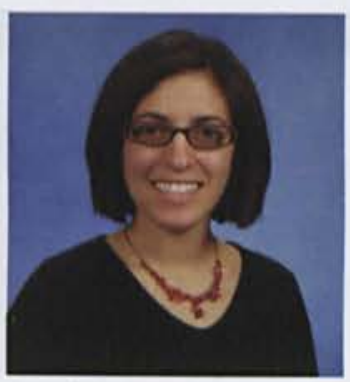

Leah Greenberg Nursing

Mays Landing, NJ

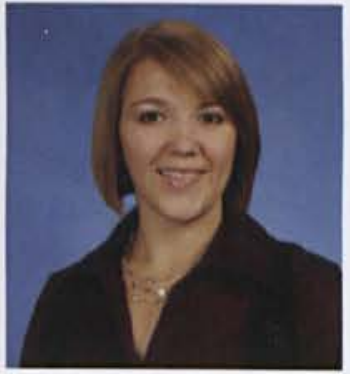

Stephanie Haines Keyboard Pedagogy Danville, IN

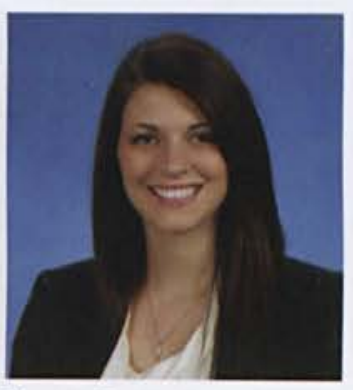

\section{Shea Hansen}

Technical \& Professional

Communication

Elkhart, IN

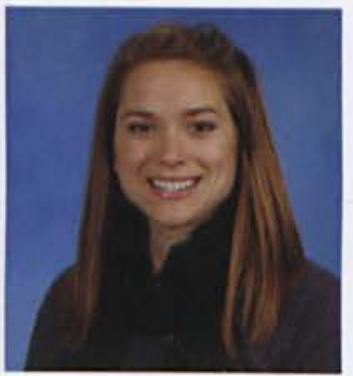

Katy Hawkins

Philosophy

Columbia, MO 


\section{SENIORS}

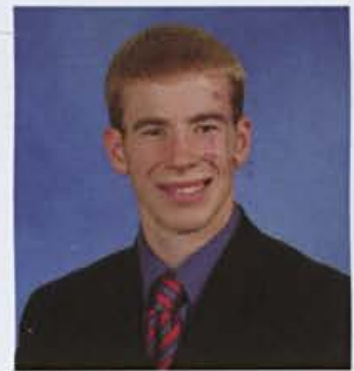

Dwight Hayes

Multi-Age Physical

Education

Burke, VA

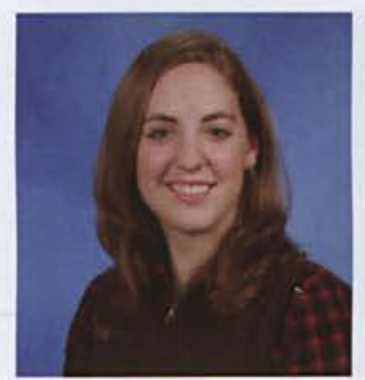

Julianne Heady

Nursing

Arlington, IN

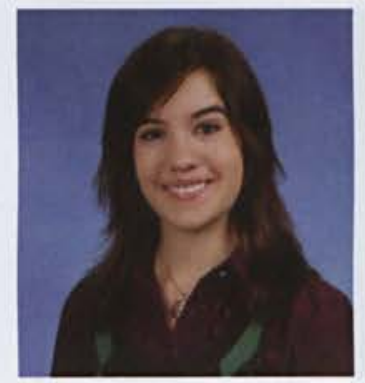

Audrey Hebson

Cello Performance

Witts Springs, AR

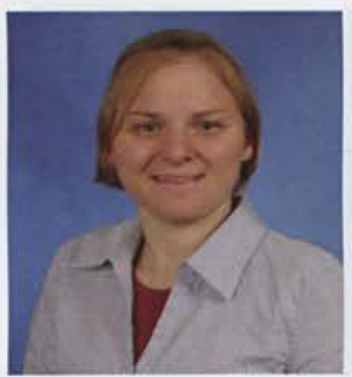

Julianne Hegna

Middle Childhood

Education

Beavercreek, $\mathrm{OH}$

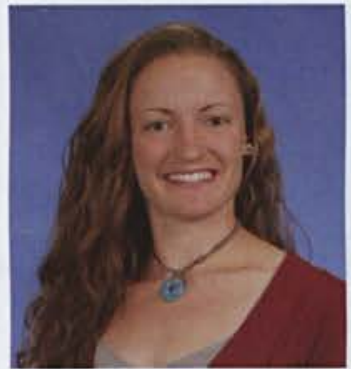

Sarah Haynes

Studio Art

Claremont, $\mathrm{NH}$

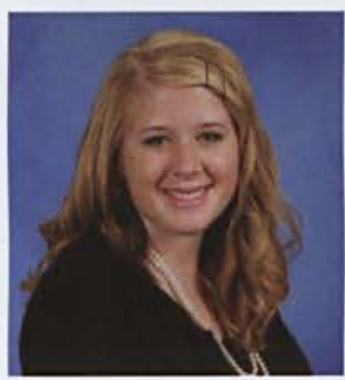

Abigail Hearle

Graphic Design

Medford, NJ

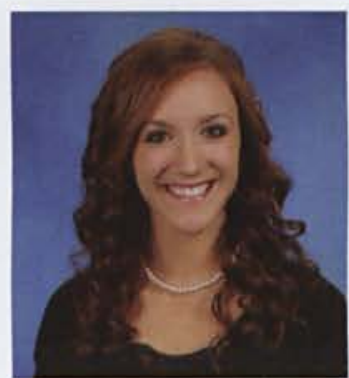

Chloe Heckman

Marketing

Rochester, NY

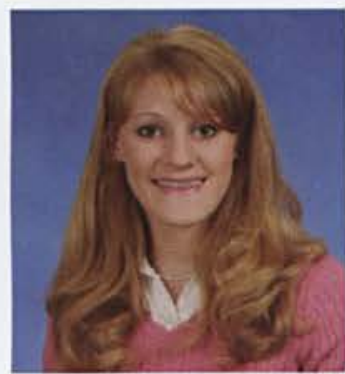

Ashley Hellwig

Early Childhood \&

Special Education

Denver, CO

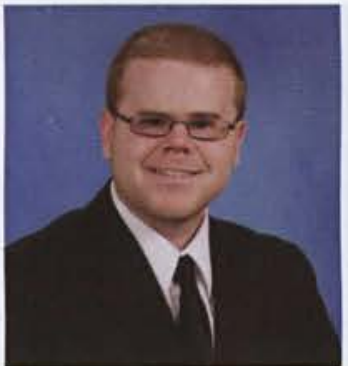

Zachary Hayter

Criminal Justice

Hollywood, MD

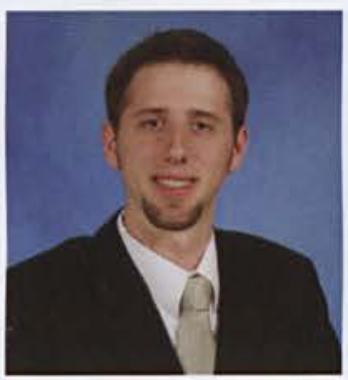

John Hearle

Computer Science

Medford, NJ

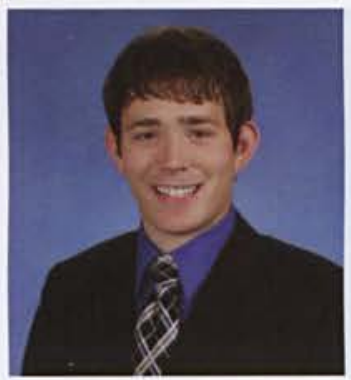

\section{Craig Hefner}

Preseminary Bible

Rochester, MI

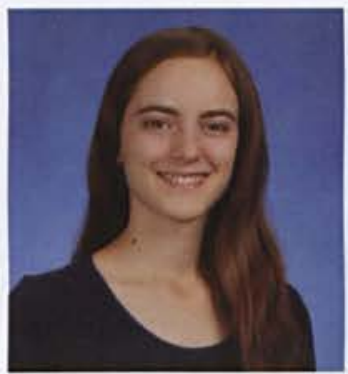

Christina Henry

Mathematics

Springfield, IL 


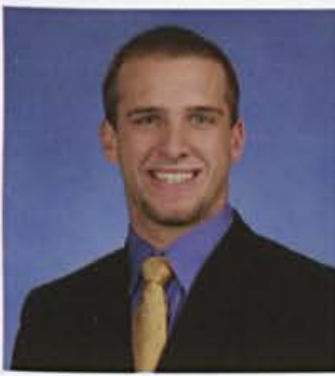

Aaron Hensler

Mechanical

Engineering

Waterford, MI

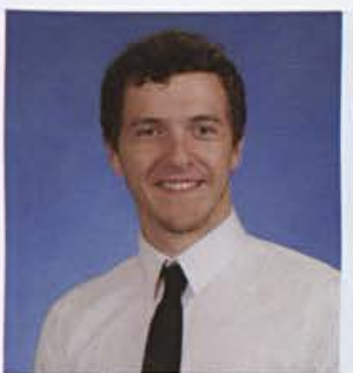

Jordan Hickling

Theatre

Warrenton, VA

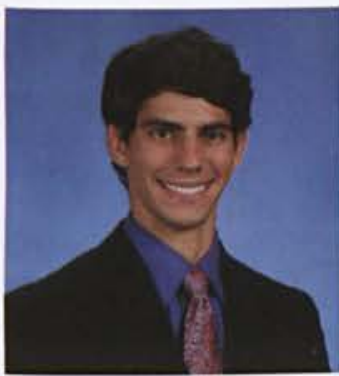

Nicholas Hobbs International Business Indialantic, FL

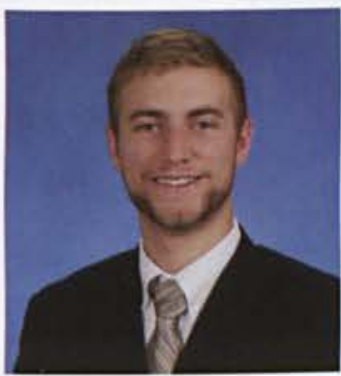

Andrew Hood

Mechanical

Engineering

Winona Lake, IN

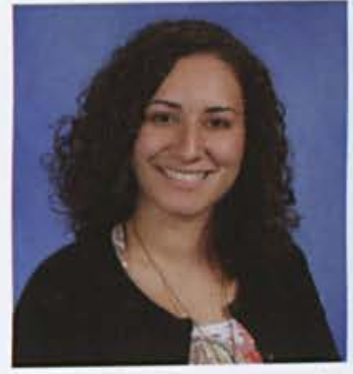

Catherine Hernandez

Social Work

Greenville, SC

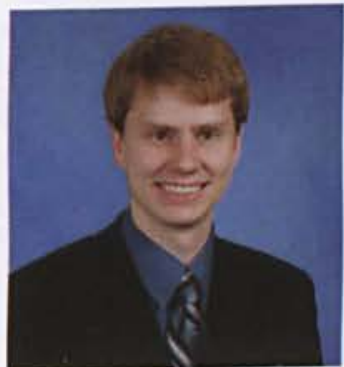

\section{Gregory Hicks}

History

Shelton, WA

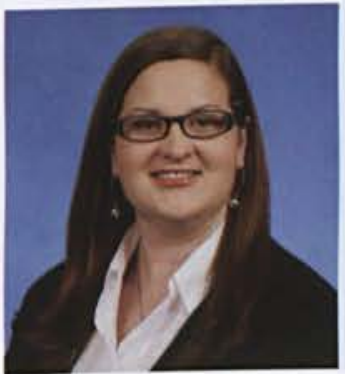

Megan Hodges

Mathematics

Richmond, VA

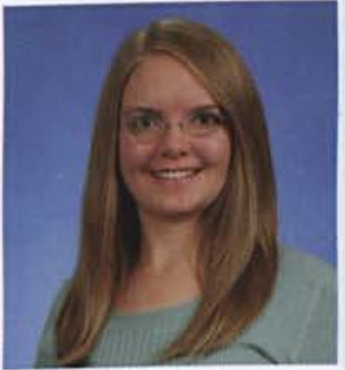

Evonne Hoogland

Nursing

Longmont, CO

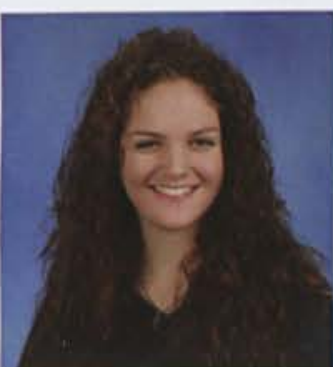

Laura Heuzey

Sociology

Lake Grove, NY

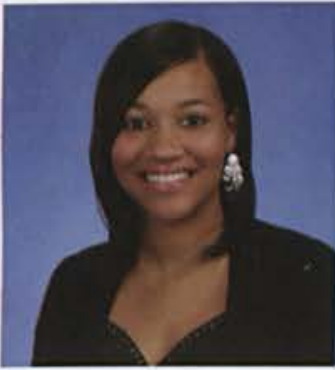

Candace Hill

Special Education

Canton, $\mathrm{OH}$

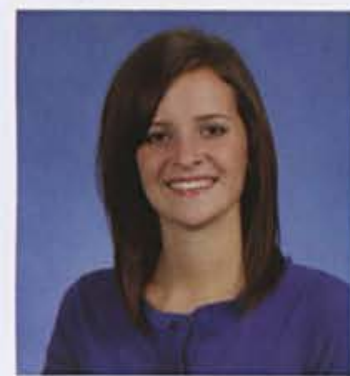

\section{Erin Hoeflinger}

Nursing

Chelsea, M

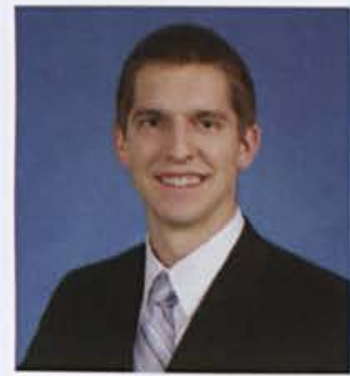

Joseph Horst

Nursing

Lancaster, PA

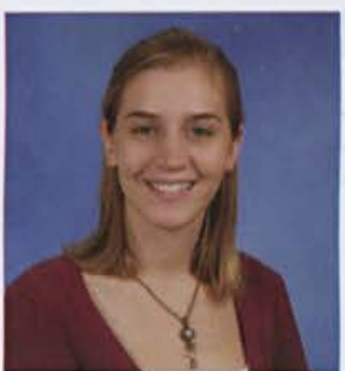

\section{Christa Hewett}

Nursing

Dayton, $\mathrm{OH}$

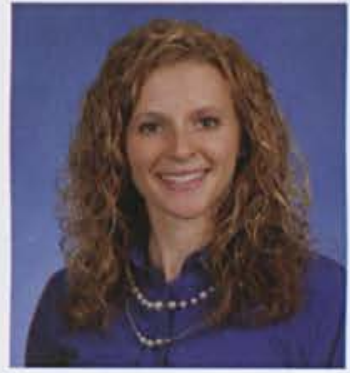

Casey Hinzman

Mechanical

Engineering

Massillon, $\mathrm{OH}$

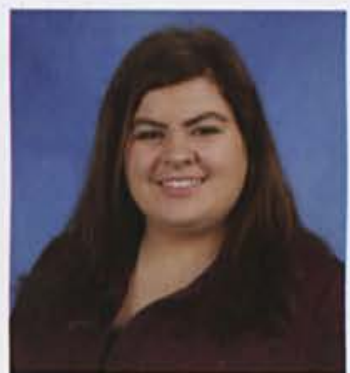

\section{Rachel Hoffman}

Theatre

Woodbridge, VA

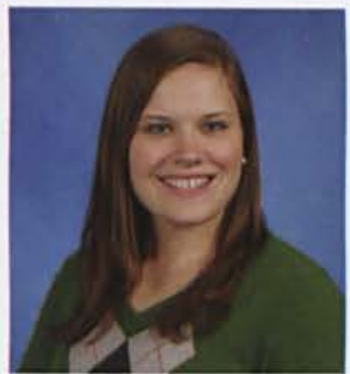

Jenny Howell

Nursing

Maineville, $\mathrm{OH}$

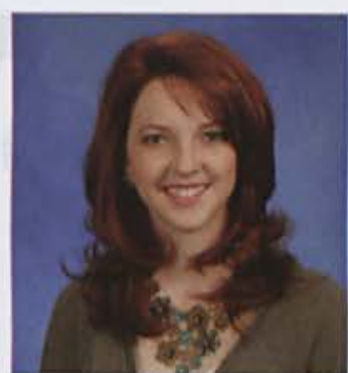

Jessica Hickling Theatre Design \&

Performance

Warrenton, VA

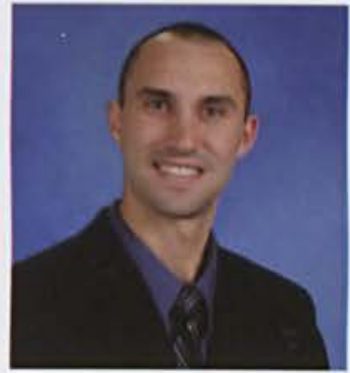

Mark Hiteshew

Electrical Engineering Middletown, $\mathrm{OH}$

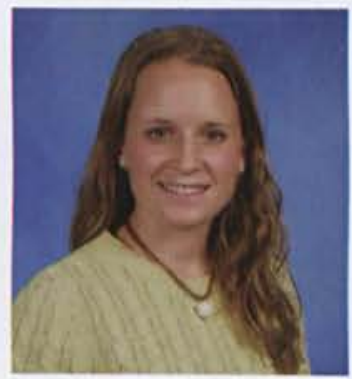

Cynthia Hoke Nursing

Elverson, PA

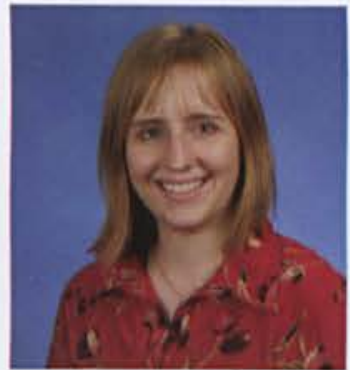

Eliane Hoyt

Nursing

Bere, Chad 


\section{SENIORS}

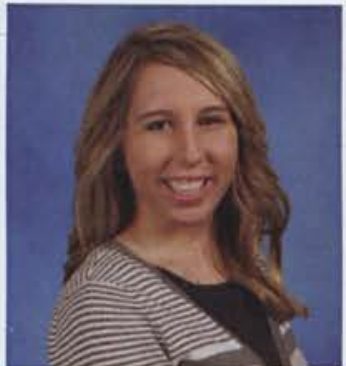

Kristina Hrabal

Early Childhood

Education

Streator, IL

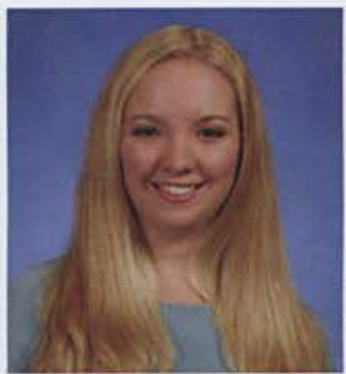

Heather Huffaker

Biology

Thomasville, NC

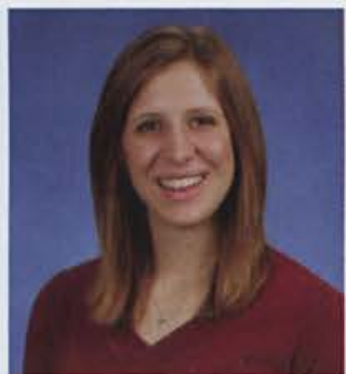

Kylee Husak

Pychology \&

Comprehensive Bible

Mount Vernon, IA

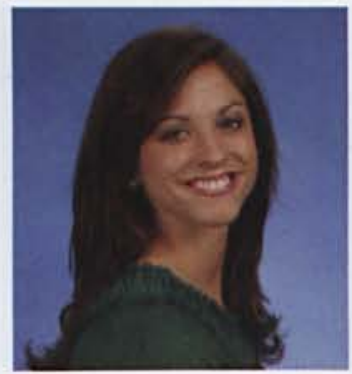

Holly Israel

Nursing

Mount Vernon, $\mathrm{OH}$

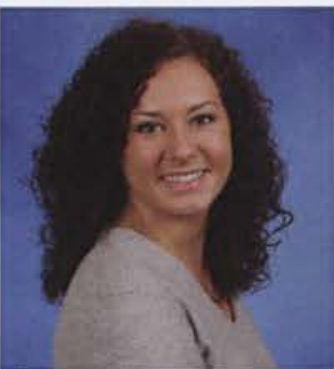

Audrey Huebert

Global Economics \&

International Business

Aurora, NE

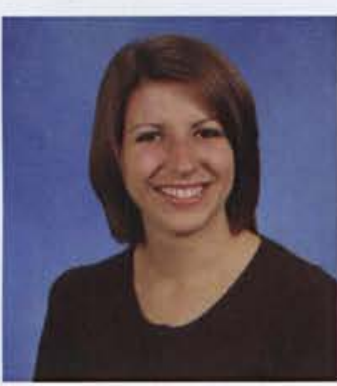

Jennifer Hull

Nursing

Pompton Plains, NJ

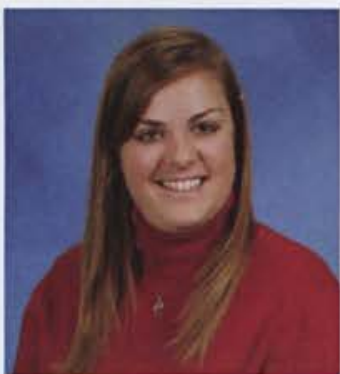

Kimberly Hutson

Intercultural

Communications

Wadsworth, $\mathrm{OH}$

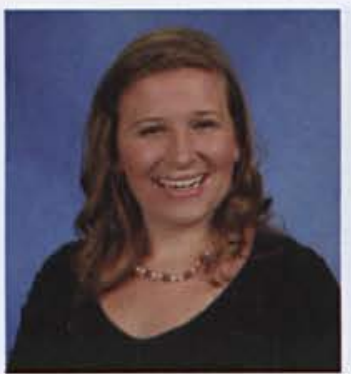

Lillian Jackson

Nursing

Sparta, MI

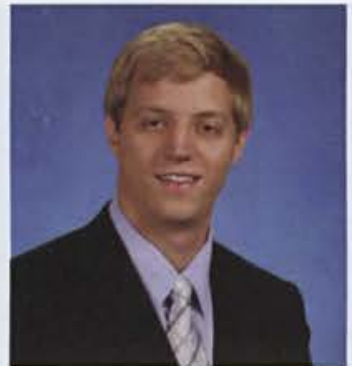

Samuel Huebner

Finance

North Platte, NE

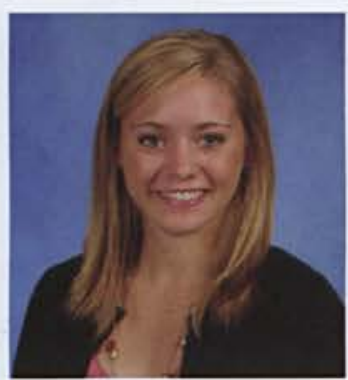

Rachel Hurley

Biology

Indiana, PA

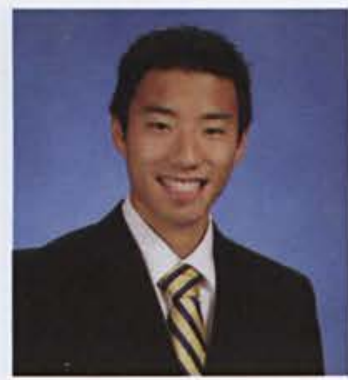

Paul Ikeda

Electrical Engineering

Shoreline, WA

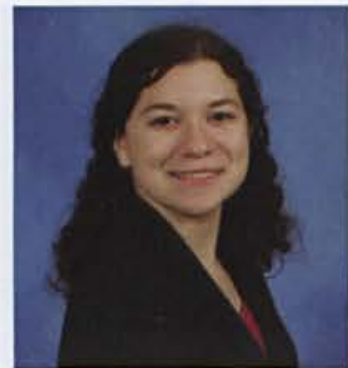

Emily Jarvis

History \& Political

Science, Spanish

Sterling, VA 


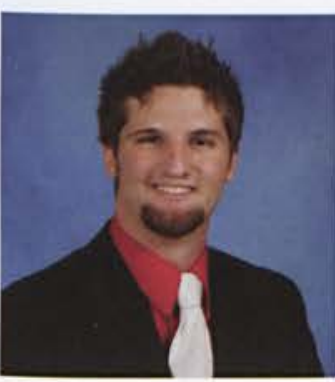

Daniel Jewett

Computer Science

Jasper, MI

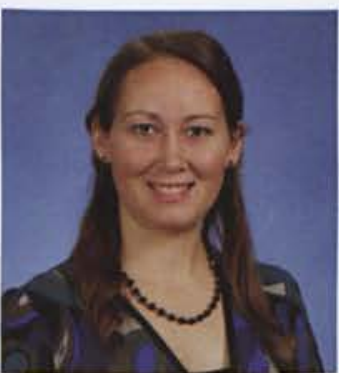

Rebekah Jones

Environmental Science

Solon, $\mathrm{OH}$

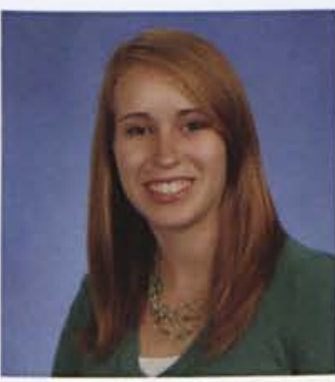

Jessica Kessler

Social Work

Brookhaven, PA

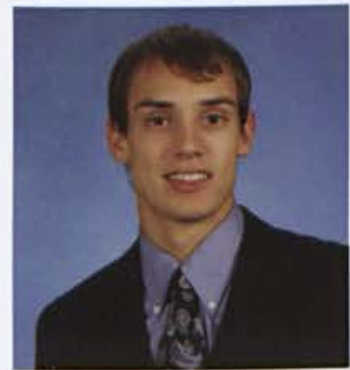

Andrew Knesnik

Mechanical Engineering Milford, PA

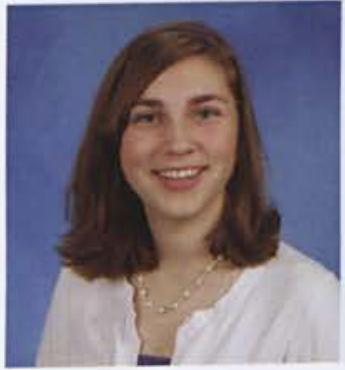

Alissa Johnson

Computer Science

Lapeer, MI

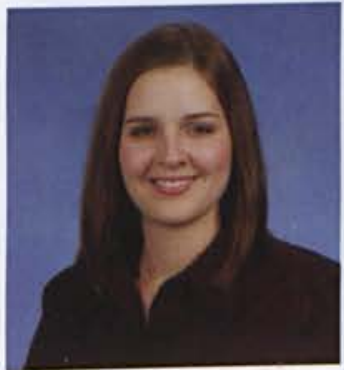

Hannah Juhant

Early Childhood \&

Special Education

Joliet, IL.

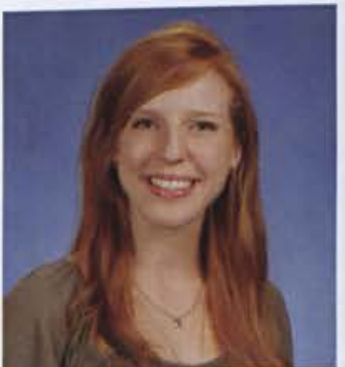

Abby Keyser

Techincal \& Professional

Communication

Haverhill, MA

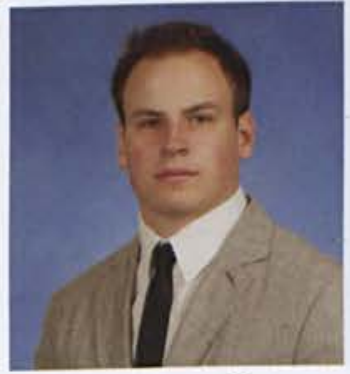

Jordan Knoedler

Organizational

Communication

Cherry Hill, N

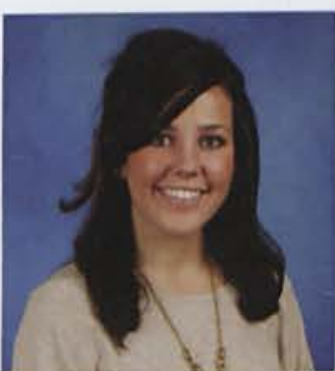

\section{Christine Johnson}

Social Work

Carmel, IN

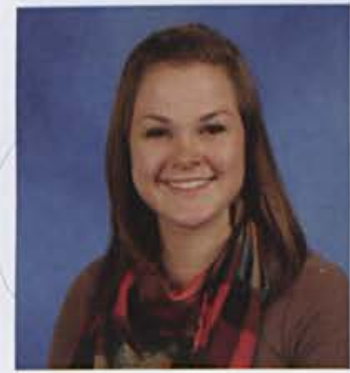

Elyse Kauffman

Communication Studies

Addison, VT

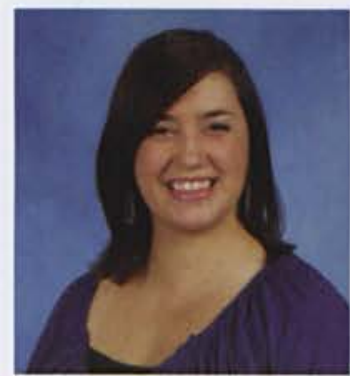

Abigail Kilian

Nursing

Greentown, PA

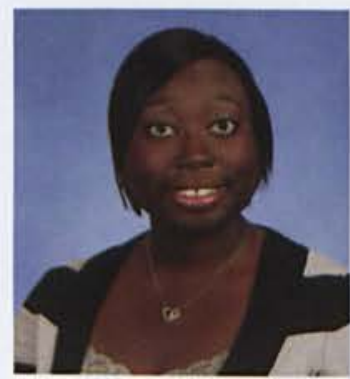

Sharon Kobinah Biology

North Haledon, NJ

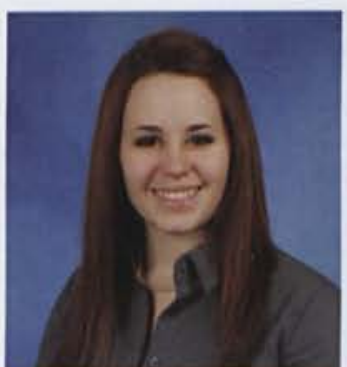

Jessica Johnson

Psychology

Xenia, $\mathrm{OH}$

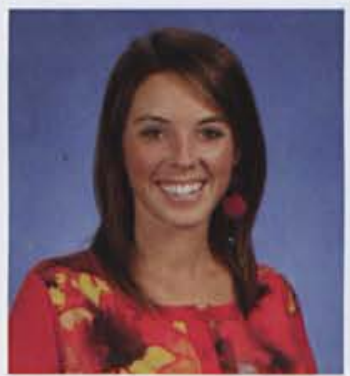

Joy Kellogg

Marketing

Arlington, $\mathrm{OH}$

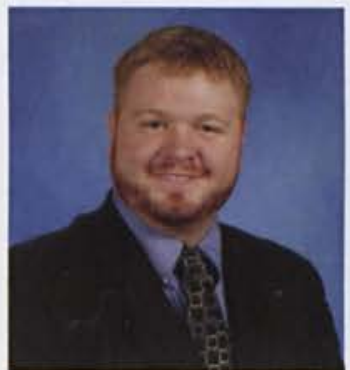

Benjamin Kilian

Molecular \& Cellular Biology

Greentown, PA

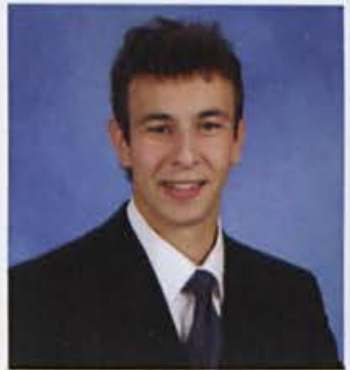

Carl Kobza

Mechanical Engineering Bath, NY

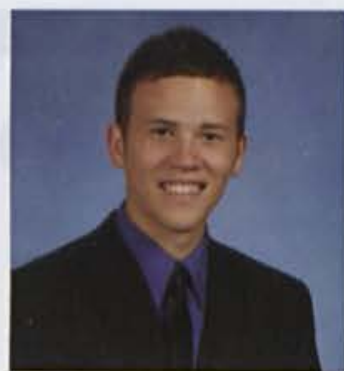

Matthew Johnson Global Economics \& International Business Lewisville, NC

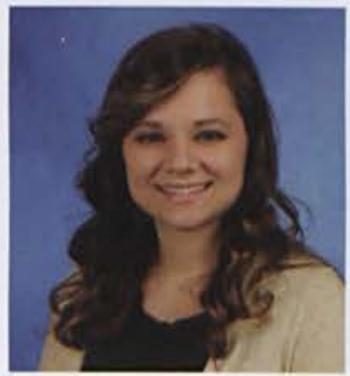

Lindsey Kepiro

Nursing

Lancaster, PA

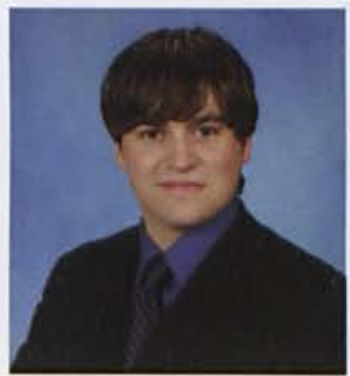

Kameron Kilmer Finance

Cranberry, PA

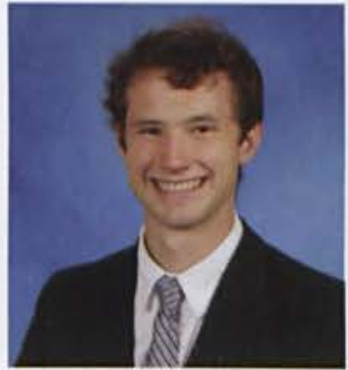

Caleb Kohl

Preseminary Bible Cedarville, $\mathrm{OH}$ 


\section{SENIORS}

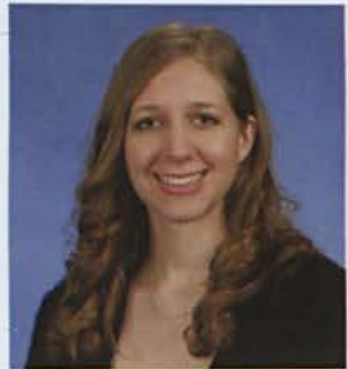

Jessica Kolody

Music Education

Bellmawr, NJ

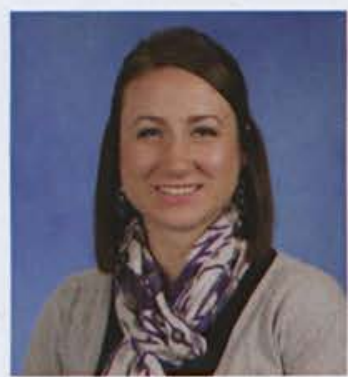

Katherine Kremer

Finance

Cincinnati, $\mathrm{OH}$

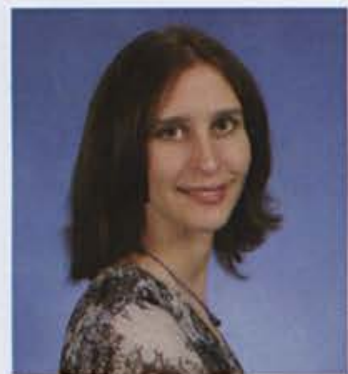

Michelle Kushnir

Chemistry \&

Mathematics

Sunbury, $\mathrm{OH}$

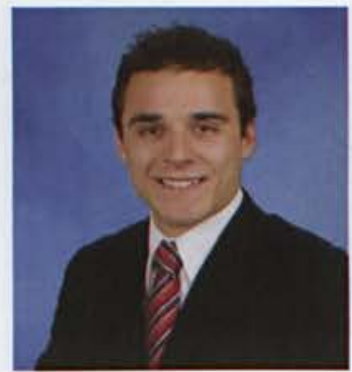

Luke LaBelle

Chemistry

Kenosha, WI

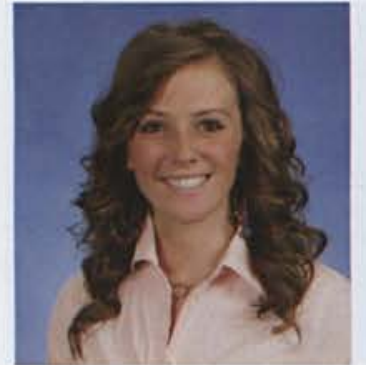

\section{Elizabeth Komar}

Middle Childhood

Education

Chesterland, $\mathrm{OH}$

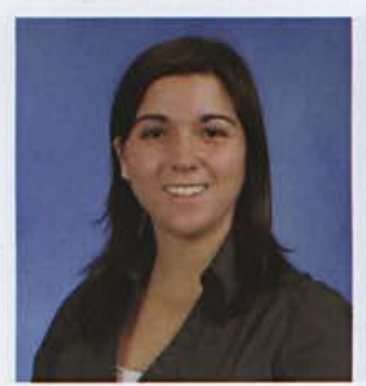

Caitlin Krop

AYA Mathematics

Education

Mourovia, MD

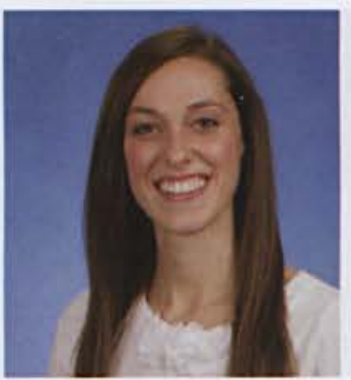

Sarah Kusky

Nursing

Austintown, $\mathrm{OH}$

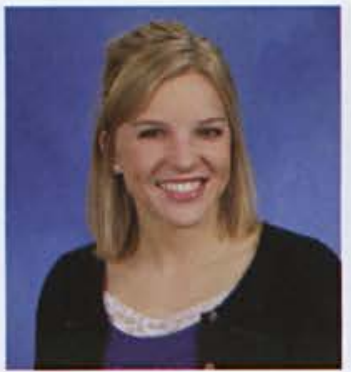

Katie Laustsen

Electonic Media

Winter Park, FL

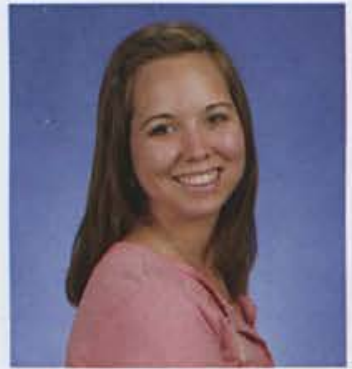

Laura Kramer

Nursing

Muskegon, MI

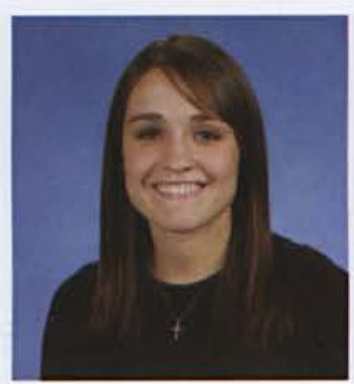

Leah Krumlauf

Social Work

Dayton, $\mathrm{OH}$

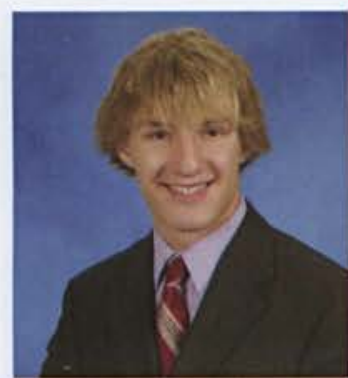

Daniel La Croix

Mechanical Engineering

South Berwick, ME

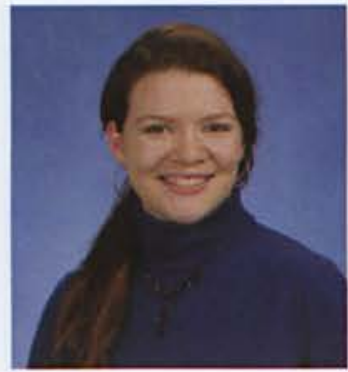

Emilie Lavallee

International Studies Abu Dhabi, UAE 


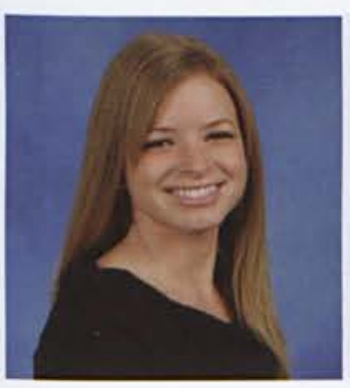

Larissa Lear

Organizational

Communications

Gallipolis, $\mathrm{OH}$

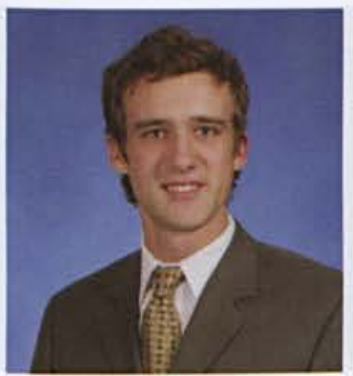

Joel Lightner

Mechancial Engineering Mentor, $\mathrm{OH}$

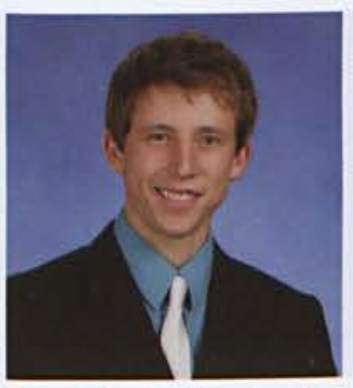

Timothy Lukasiewicz Worship

Longmont, $\mathrm{CO}$

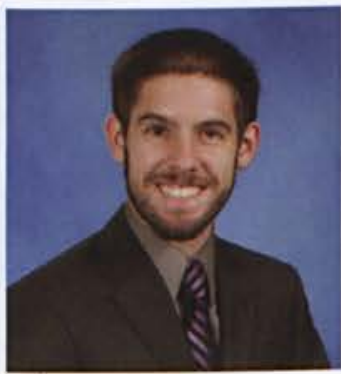

Peter Mage

Physics \& Math

Horseheads, NY

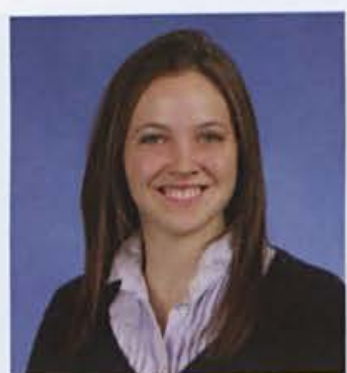

Erin Leffel

Biology

Pewaukee, WI

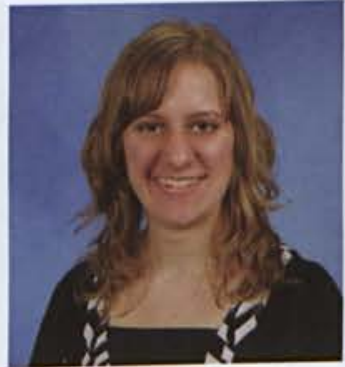

Bethanne Linden

Nursing

Wellington, $\mathrm{OH}$

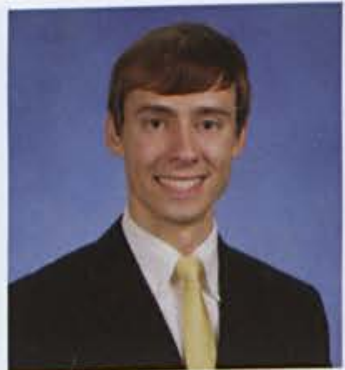

Daniel Lyman

Integrated Mathematics

Education

Akron, $\mathrm{OH}$

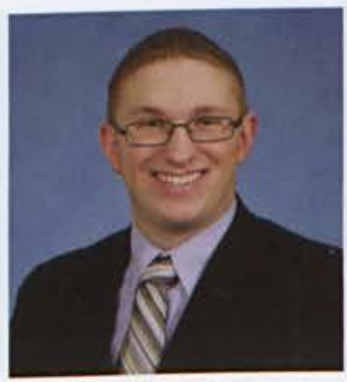

Travis Manning History

Harrisburg, PA

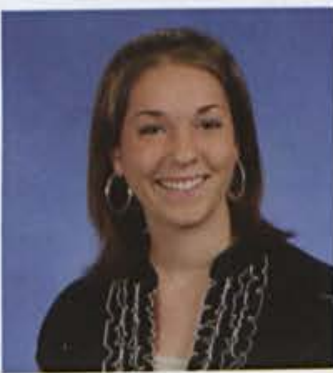

Gail Lehmann

Nursing

Lynchburg, VA

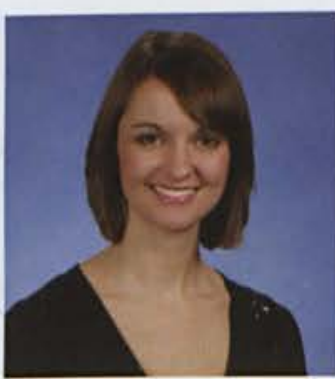

Heidi Lockridge Nursing

Pella, IA

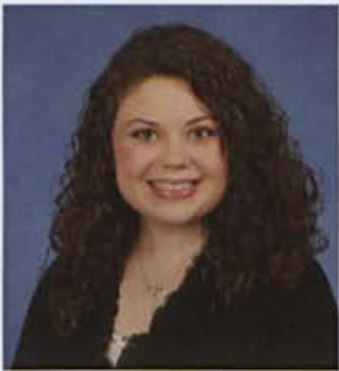

Rebekah Lynch

Comprehensive Bible

Stonewood, WV

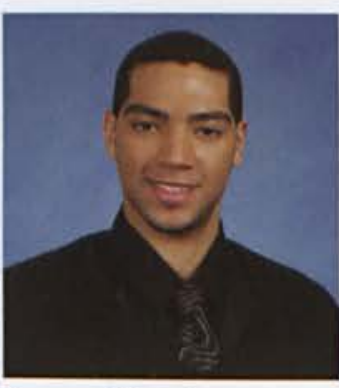

Jason Marchena Exercise Science New York, NY

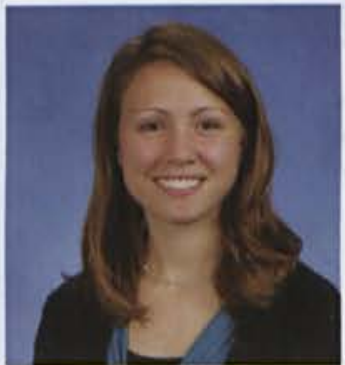

Lindsay Leppke

Early Childhood

Education

Midland, VA

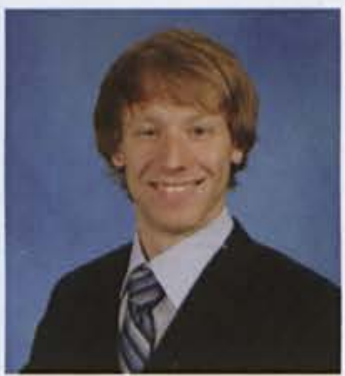

Kenneth Long

Mechancial Engineering

Florence, $\mathrm{KY}$

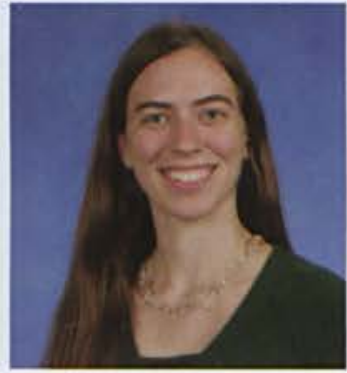

\section{Laura Mace}

International Studies

North Newton, KS

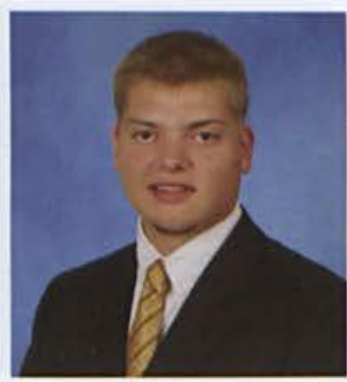

Joseph Marshall Sport Management Jenera, $\mathrm{OH}$

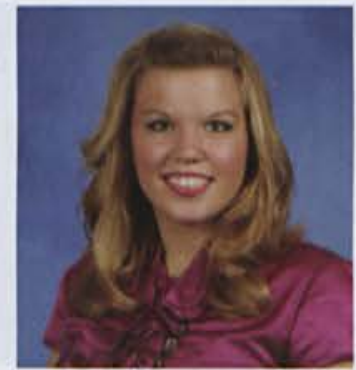

Mary Lewis

Nursing

Corpus Christi, TX

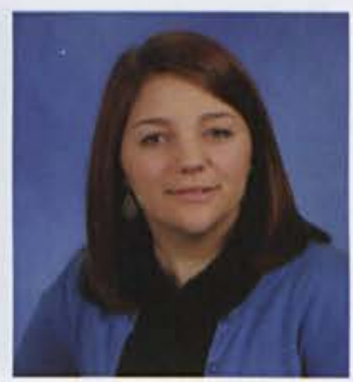

Sarah Lowry Sociology

Gobles, MI

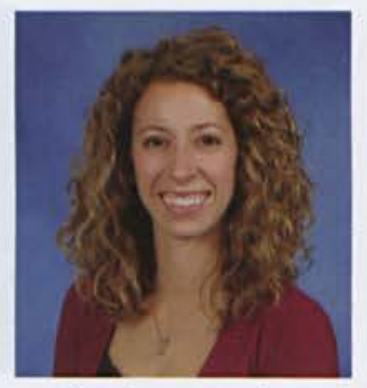

Katherine Mackenzie Nursing

Bloomington, IN

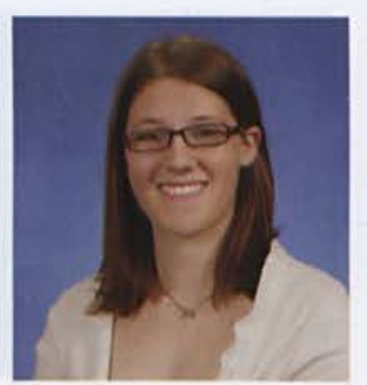

Catherine Martin Techincal \& Professional Communication Mechanicsburg, PA 


\section{SENIORS}

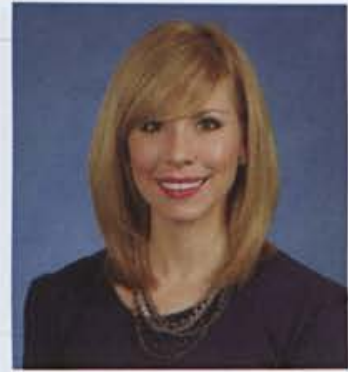

Rachel Martin

Nursing

Chillicothe, $\mathrm{OH}$

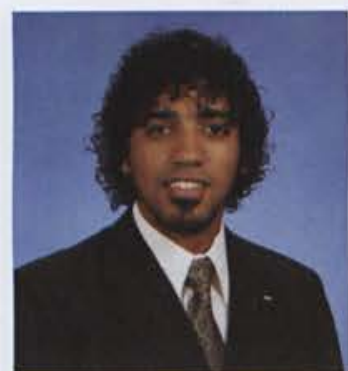

Bryan Martinez Graphic Design Bethlehem, PA

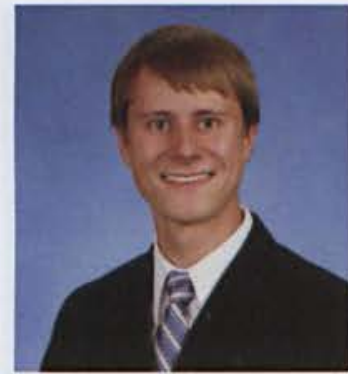

Ryan Matthews Accounting \& Finance Shelton, CT

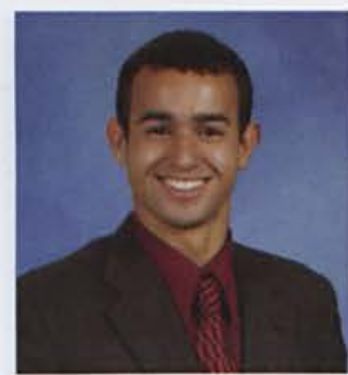

Jonathon McCoy Criminal Justice Lincolnwood, IL

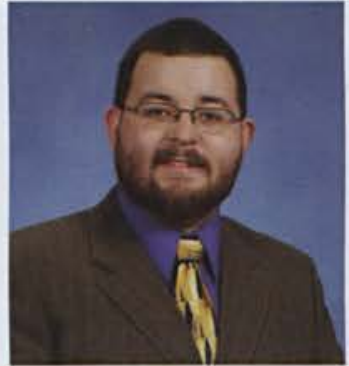

Seth Martin

Pastoral Studies

Cincinnati, $\mathrm{OH}$

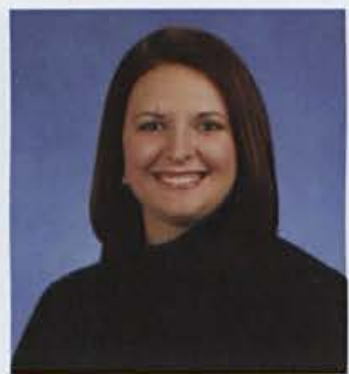

Alexa Mather

Christian Education \&

Youth Ministry

Speculator, NY

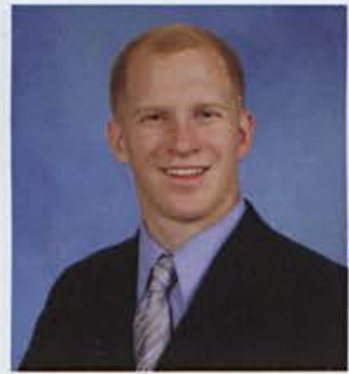

Caleb Mays

Computer Science

Highlands Ranch, $\mathrm{CO}$

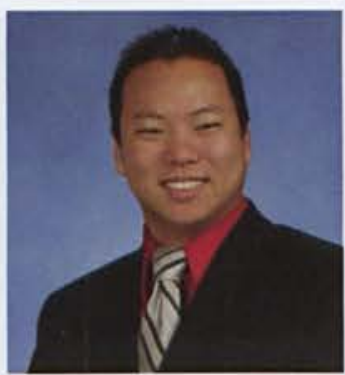

Bryan McFarland Youth Ministry \&

Christian Education

Pasadena, MD

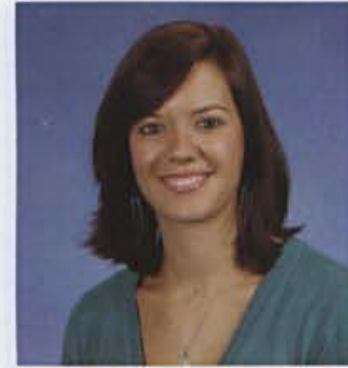

Susanna Martin

Nursing

Noble, IL

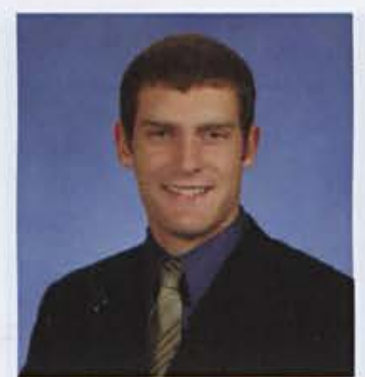

Daniel Mathews Sport Management Xenia, $\mathrm{OH}$

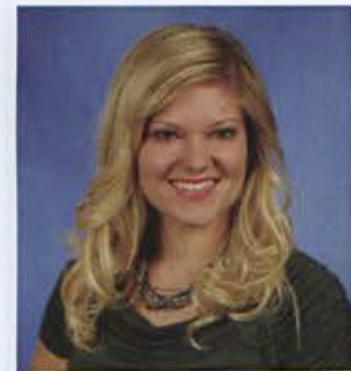

JoyAnna McBride

Electronic Media

Cumberland, MD

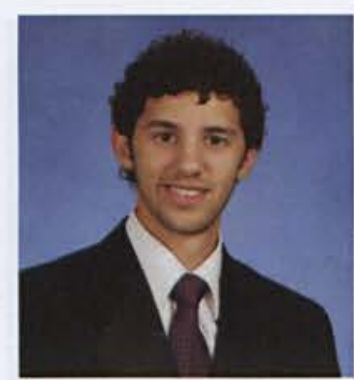

Daniel McFarlane Biology

Enfield, CT 


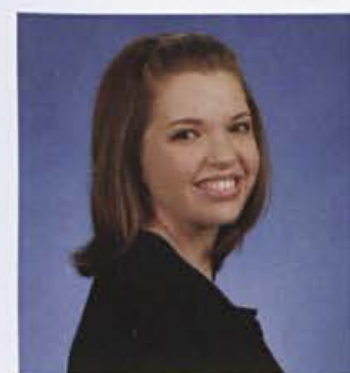

Erin McGuire

Psychology

Batavia, $\mathrm{OH}$

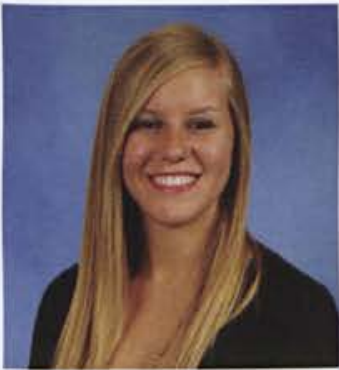

Michelle McQueen

Physical Education

St. Louis, MO

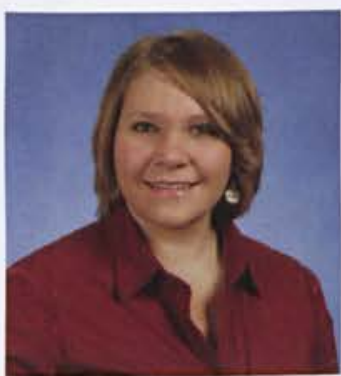

Christine Miller

International Studies,

History \& Political Science Port Orchard, WA

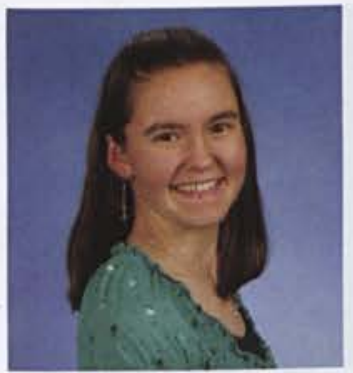

Sharon Miller

Molecular \& Cellular

Biology

Oswego, IL

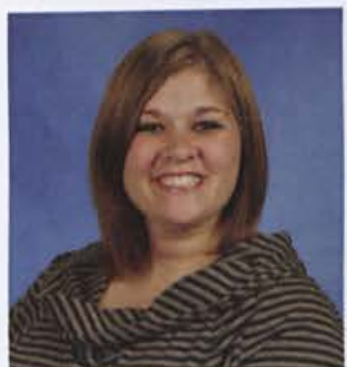

Brittany McKenna

Early Childhood

Education

Cedarville, $\mathrm{OH}$

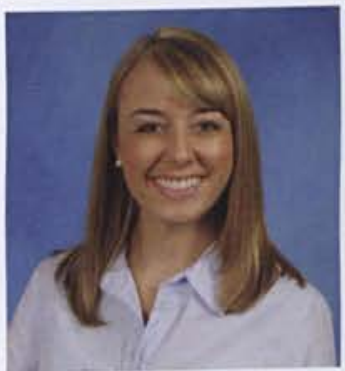

Jennifer Meade

Nursing

Ponte Vedra Beach, FL

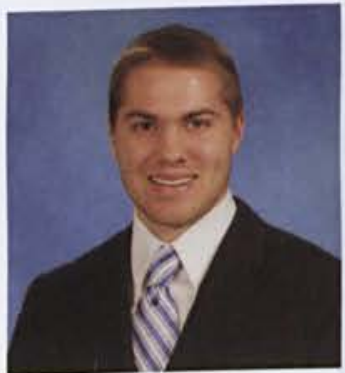

Clinton Miller

Finance

Berlin, $\mathrm{OH}$

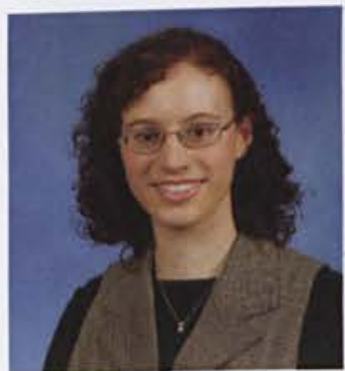

Stephanie Mills AYA Physical Science

Education

Miamisburg, $\mathrm{OH}$

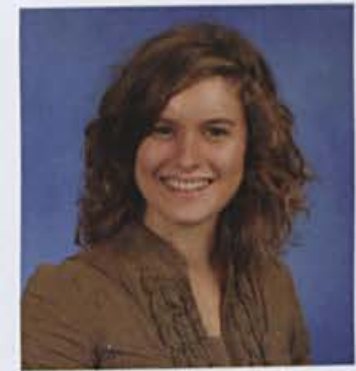

Jessie McLean

Graphic Design

Shrereport, LA

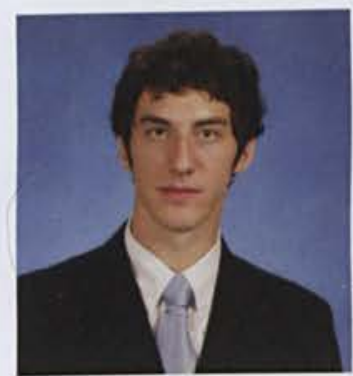

Ronald Meadors

Sport Management

Findlay, $\mathrm{OH}$

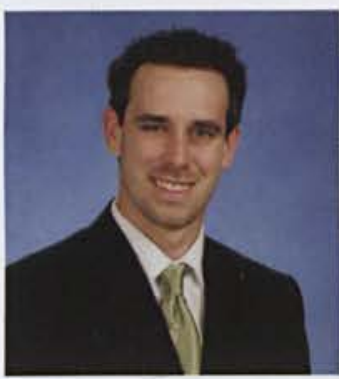

Corey Miller

Youth Ministry

Marietta, GA

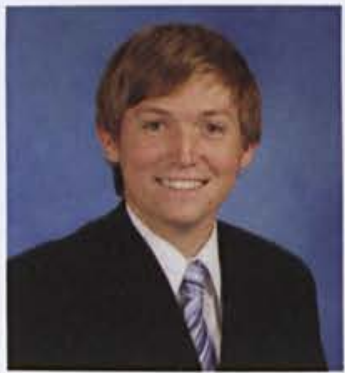

Trevor Moffitt

Psychology

Dallas, TX

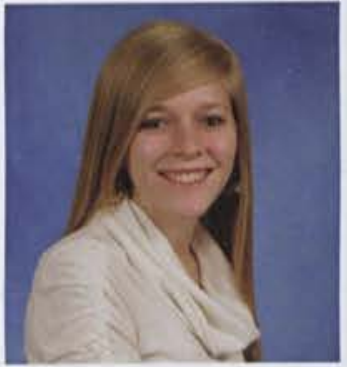

Alicia McMaster Nursing

Fortaleza, Brazil

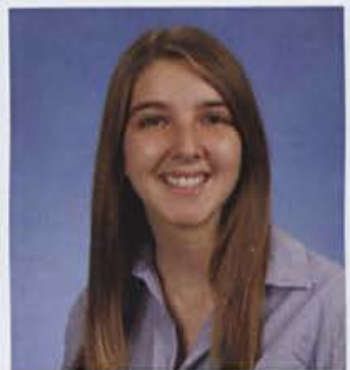

Stephanie Merritt Psychology

Wapakaneta, $\mathrm{OH}$

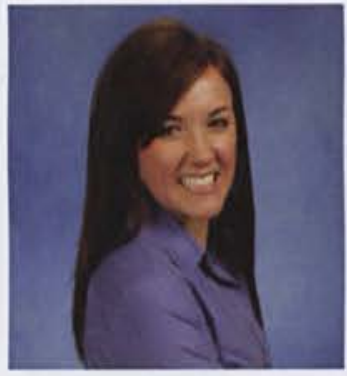

Marisa Miller

Organizational

Communications

Traverse City, MI

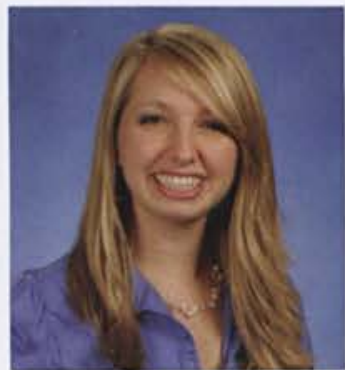

Lena Molby

Middle Childhood

Education

Westmont, IL

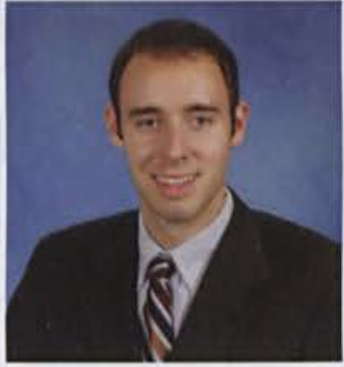

David McQuarry Accounting \& Finance Tipp City, $\mathrm{OH}$

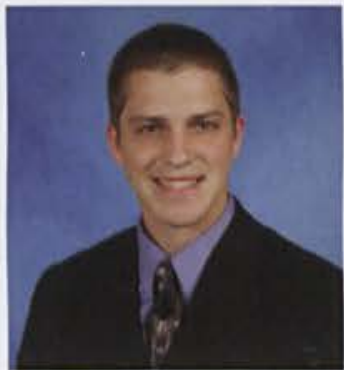

William Miedema

Mechanical

Engineering

Middletown, NY

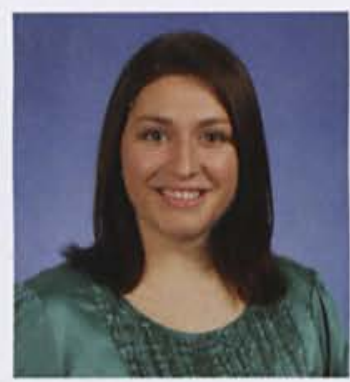

Melody Miller

Nursing

Kalona, IA

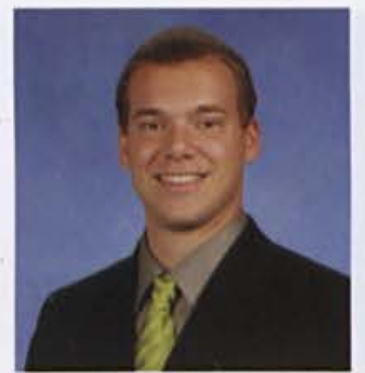

Jordan Molstre

Allied Health

Pittsburgh, PA 


\section{SENIORS}

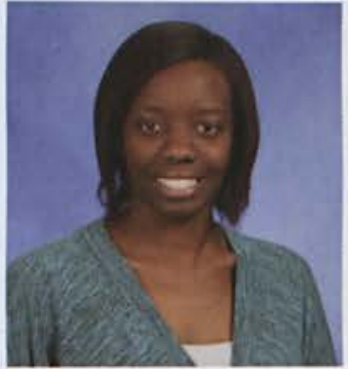

Mercie Moluche

Biology

Bedford, TX

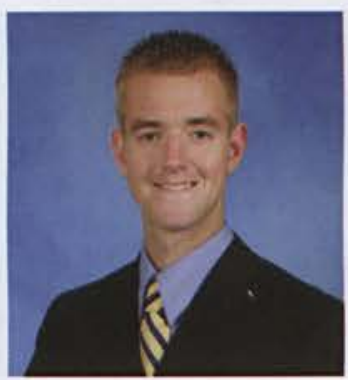

Alexander Moore Early Childhood

Development

Groveport, $\mathrm{OH}$

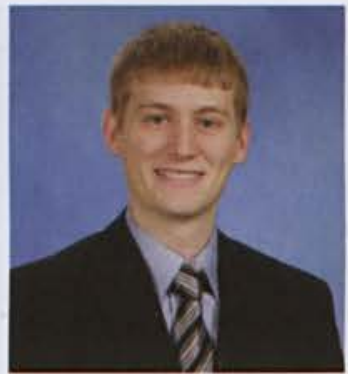

Phillip Morrison

Electrical Engineering

McConnelsville, $\mathrm{OH}$

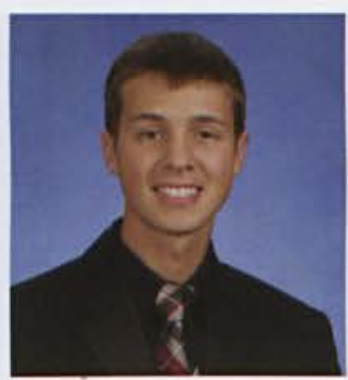

Andrew Moses

Worship

Portland, OR

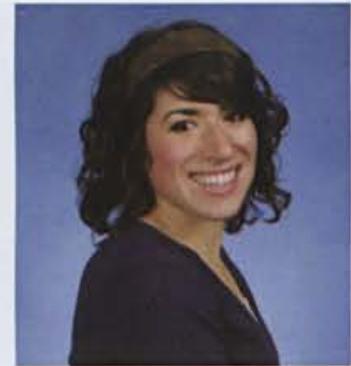

Jennifer Monroe AYALA Education \& TESOL

Mexico, NY

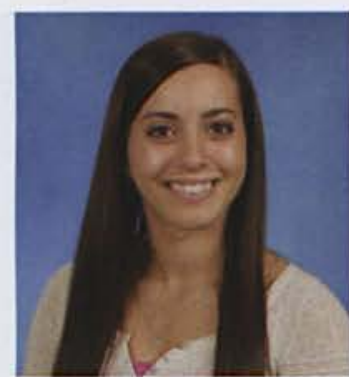

Stephanie Moore Nursing

Goshen, IN

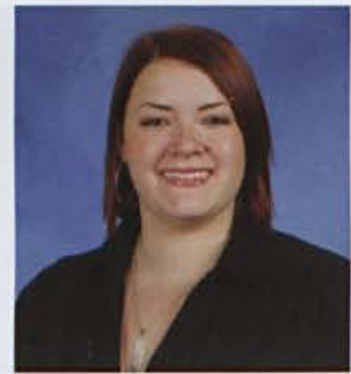

Briana Morse

Electronic Media

Danbury, CT

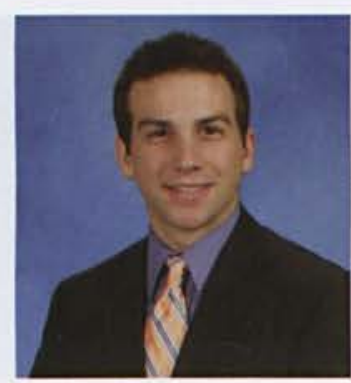

Benjamin Mounts AYA Social Studies Education

Springfield, $\mathrm{OH}$

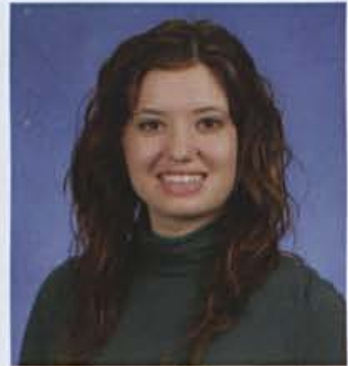

Kara Moody

Biology

Massillon, $\mathrm{OH}$

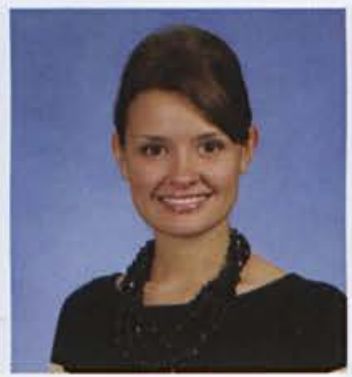

Sarah Morgan Nursing

Bremen, $\mathrm{OH}$

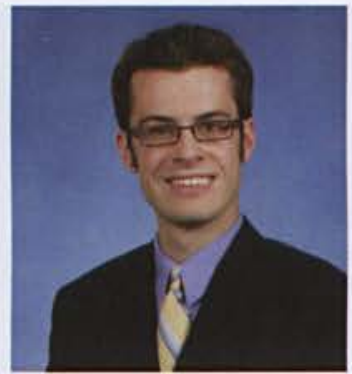

David Moser

Preseminary Bible

Columbia, MO

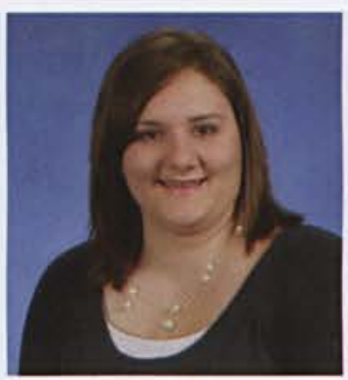

Courtney Mumme Early Childhood Education

San Antonio, TX 


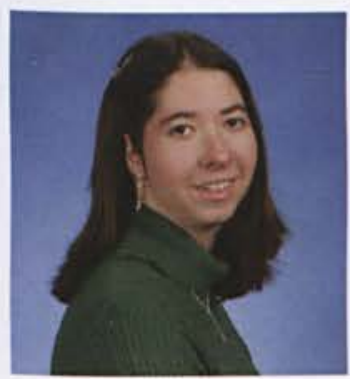

Erin Murray

Christian Education \&

Youth Ministry

Hagerstown, MD

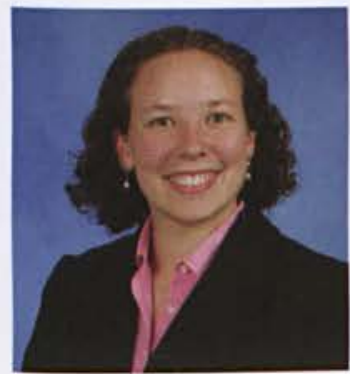

Rebecca Nesbitt

Physics \& Math

Education

Brook Park, $\mathrm{OH}$

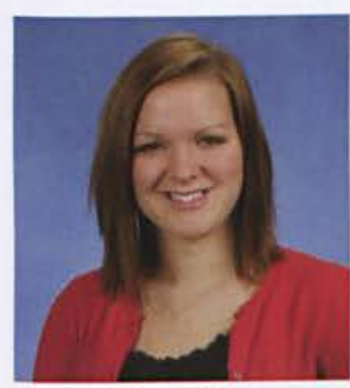

Erica O'Neal

Social Work

Noblesville, IN

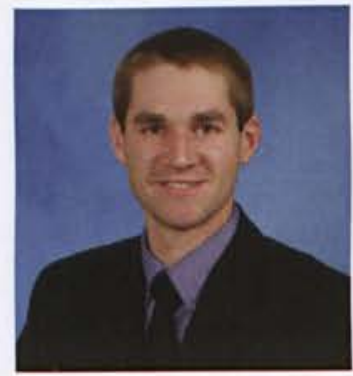

James Ouellette

Finance

Sidney, ME

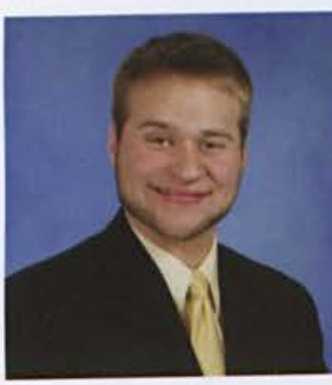

Jonathan Musser Preseminary Bible Lake Grove, NY

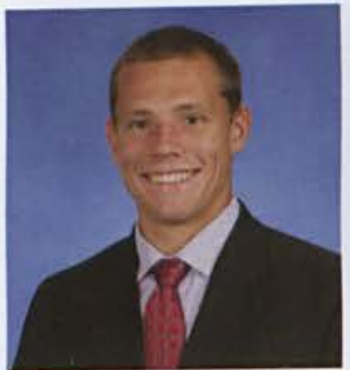

Matthew Niemiec Electrical Engineering Zeeland, MI

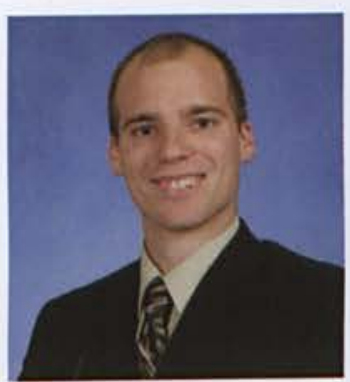

Jeffrey Oakley

Computer

Engineering

Thompson, PA

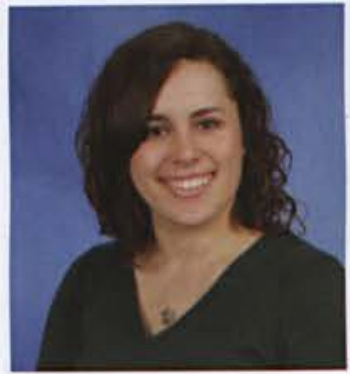

Megan Paney

Nursing

Lombard, IL

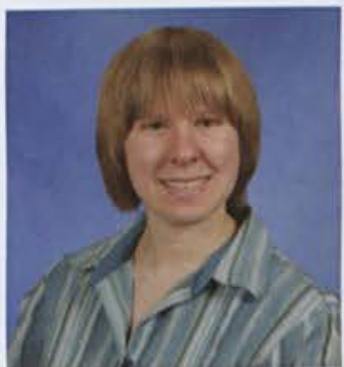

Elizabeth Nelson

Psychology

Tacoma, WA

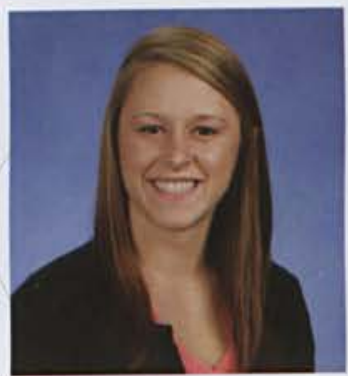

Julia Nyhuis

Nursing

Milton, WV

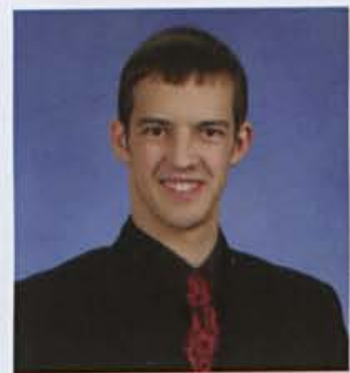

\section{Daniel Ormsby}

Mechanical Engineering

Painted Post, NY

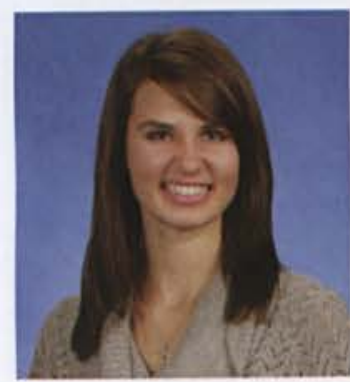

Charity Patrick

Organizational

\& Intercultural

Communications

Dillsburg, PA

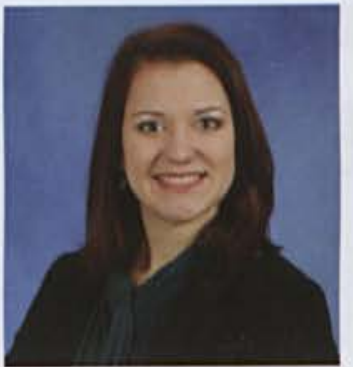

Katherine Nelson

Theatre Performance

Salisbury, MD

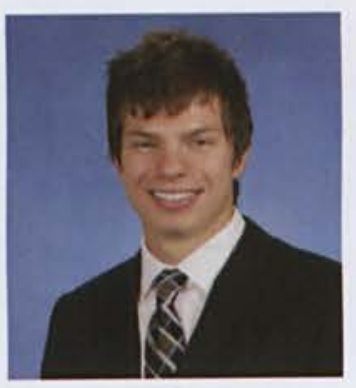

Thomas O'Connor Mechanical Engineering Angier, NC

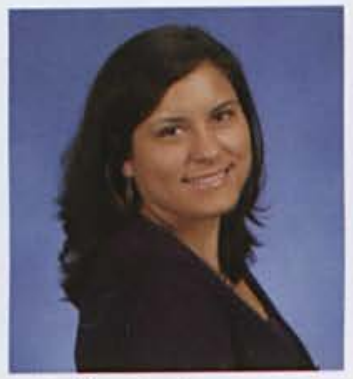

Ariella Ortiz

Biology

North Hills, CA

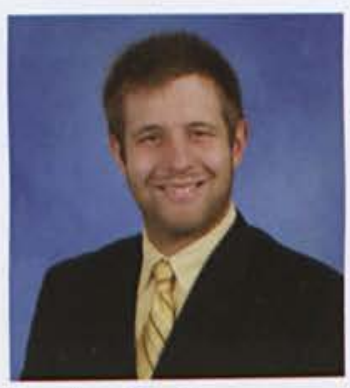

Jordan Peck

Mathematics

Menomonee Falls, WI

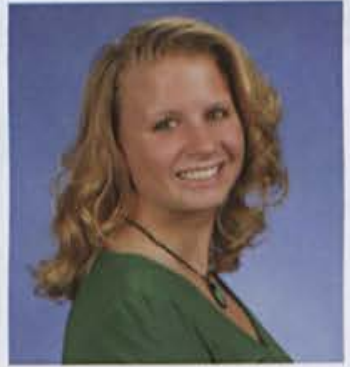

Elyse Nemec

Organizational

Communications

Winchester, VA

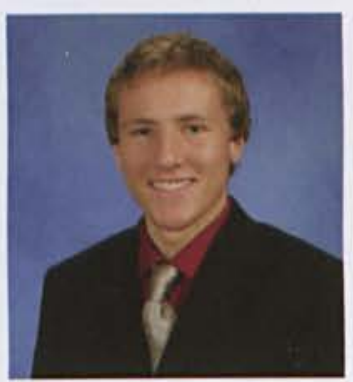

Jared O'Keefe Psychology

Oberlin, $\mathrm{OH}$

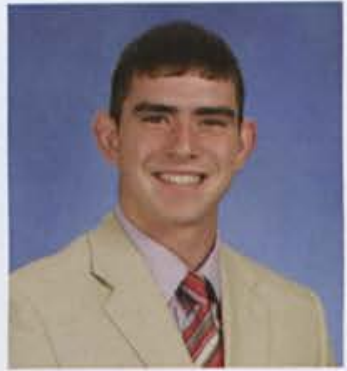

Joseph Osborn

Exercise Science

Salem, $\mathrm{OH}$

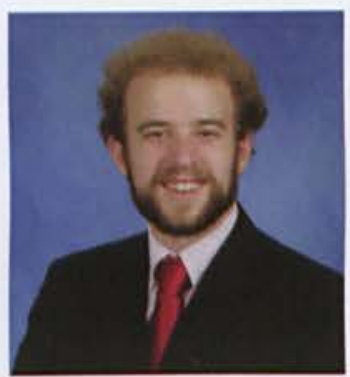

Frank Peer

Electronic Media

Columbus, $\mathrm{OH}$ 


\section{SENIORS}

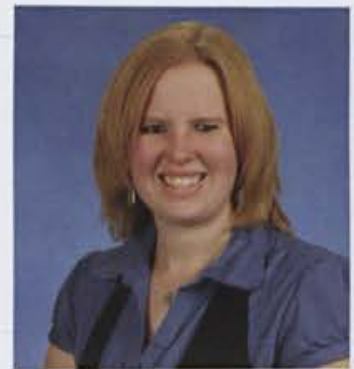

Amanda Pender

Criminal Justice

Templeton, MA

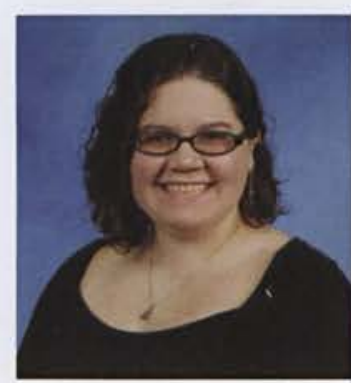

Kayla Peterson

Theatre Design

Boonsboro, MD

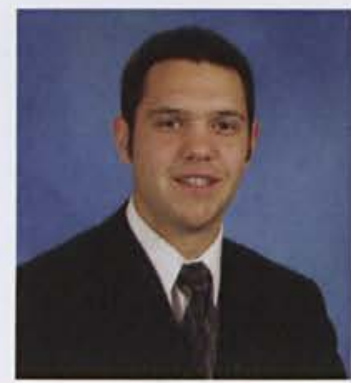

Andrew Piasecki

Biology

Swedesboro, NJ

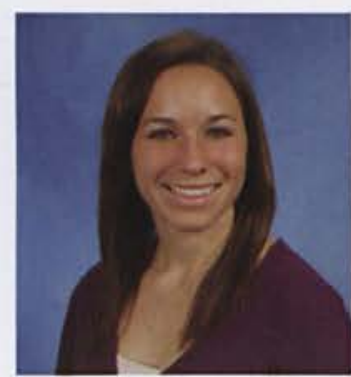

Amy Pierschbacher Nursing

Des Moines, IA

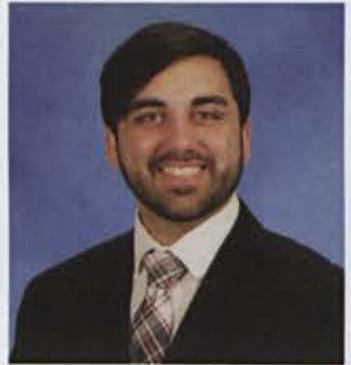

Brent Persun

Technical \& Professional Communication

Erie, PA

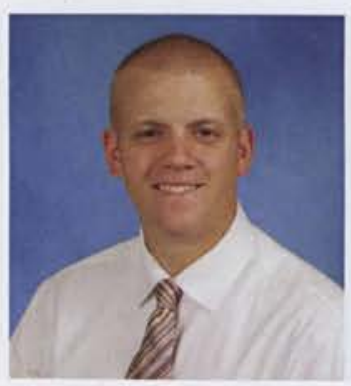

\section{Matthew Petrie}

Technical \& Professional

Communication

Peterborough, NH

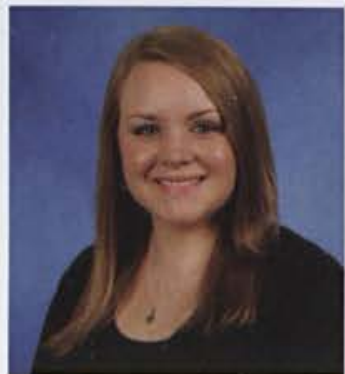

Melissa Picard

History

Bethpage, NY

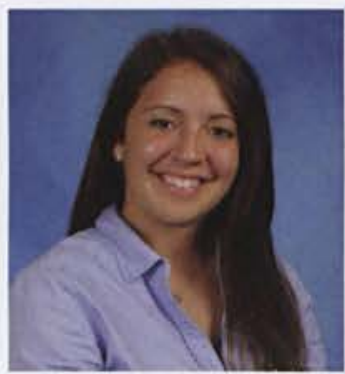

Anna Plasterer

Biology

Chambersburg, PA

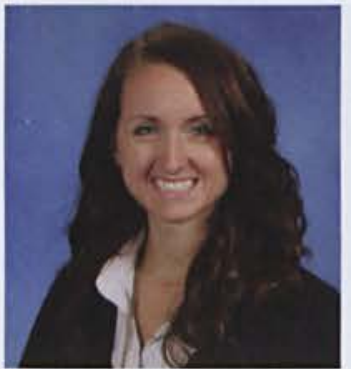

Abigail Petersen Middle Childhood Education

Brownsburg, IN

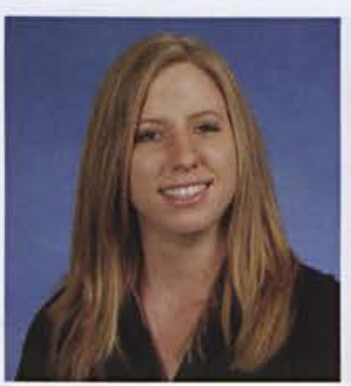

Erin Philyaw Nursing

Peoria, IL

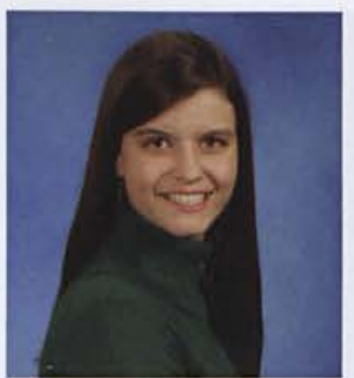

Julie Pickens

English

Nashville, TN

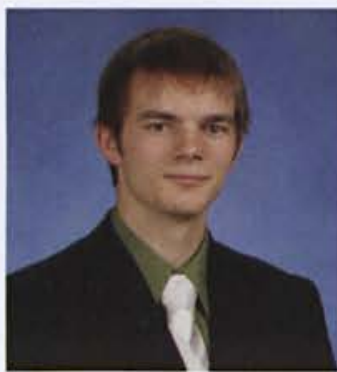

Daniel Poling

History \& Pre-Law

Grand Rapids, MI 


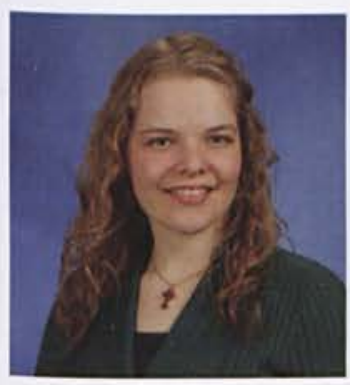

Lisa Pollock

Music

Bellingham, WA

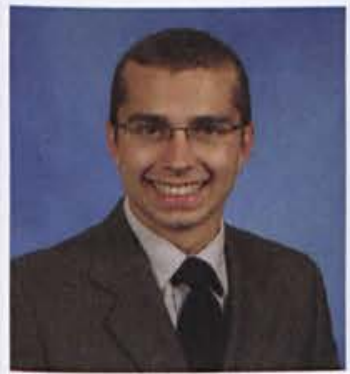

Stephen Pupillo

Biology

Clarkston, M

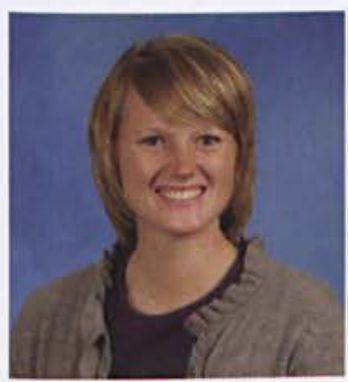

Lindsay Raybuck Accounting

Forest, VA

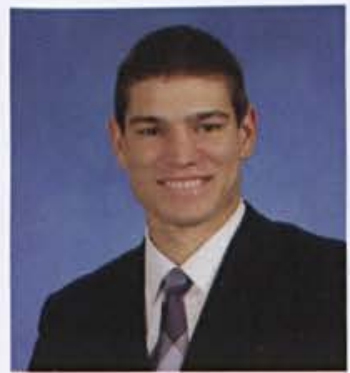

Kenneth Reep

Exercise Science

Peachtree City, GA

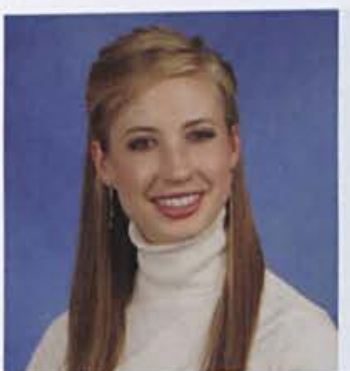

Emily Powell

Music Performance

Hopwood, PA

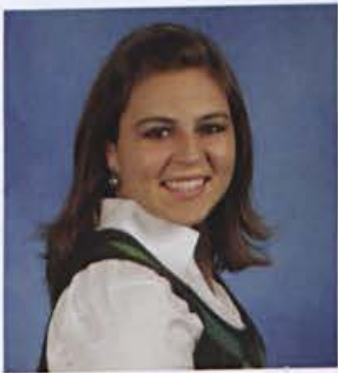

Taylor Ralph

Nursing

Lewis Center, $\mathrm{OH}$

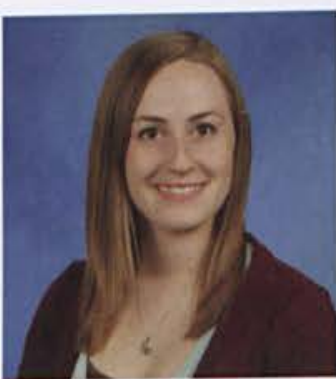

Kelley Rayder

Nursing

Hampden, MA

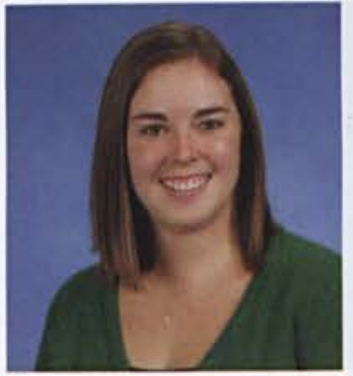

Morgan Reese

Finance \&

International Business

Louisville, KY

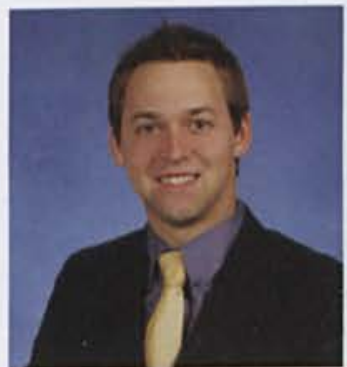

Christopher Powers

Organizational

Communications

Waynesville, Oh

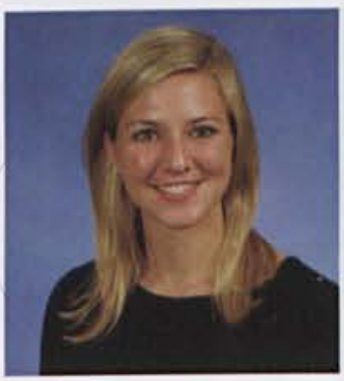

Jessica Rarick

Middle Childhood

Education

Centerville, $\mathrm{OH}$

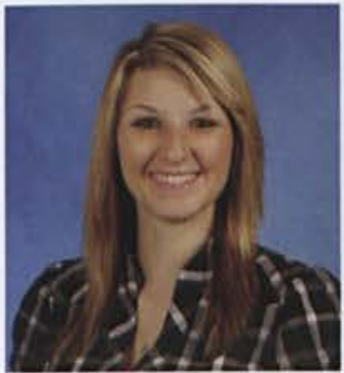

Jessii Raymond

Theatre

Jackson, MI

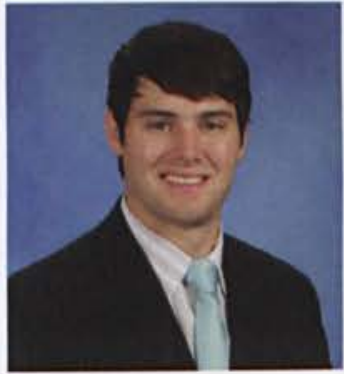

Alex Richardson

Management

Brownsburg, IN

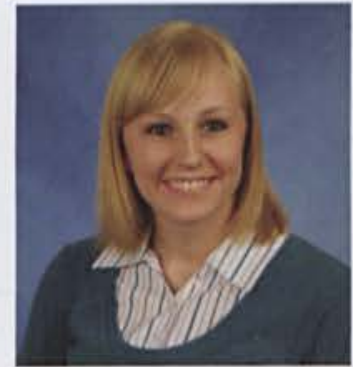

\section{Krista Price}

Early Childhood

Education

Effingham, IL

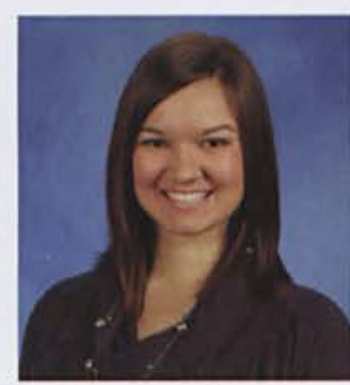

Jessica Rathburn Christian Education \& Youth Ministry Ashville, $\mathrm{OH}$

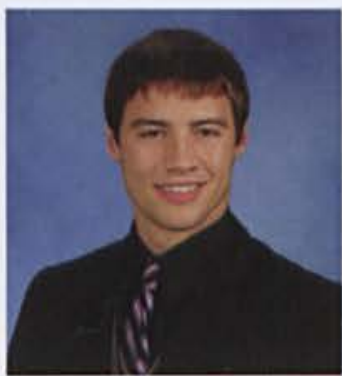

Ethan Rector

Preseminary Blble

Gardner, KS

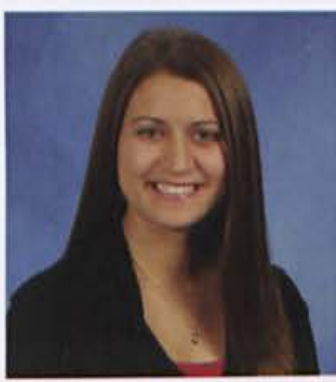

Lindsey Richardson Mathematics \& Music Ankeny, IA

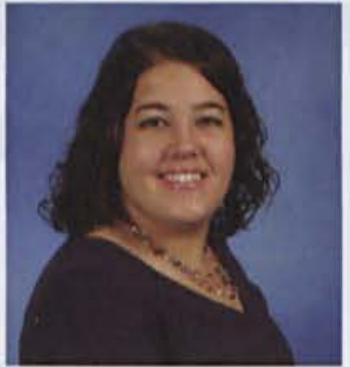

Leah Price

Nursing

South Charleston, $\mathrm{OH}$

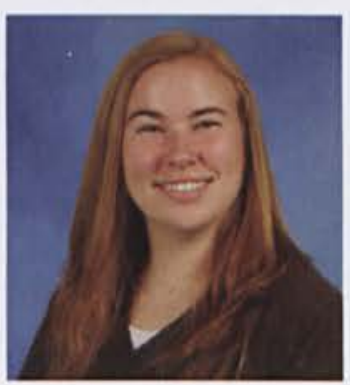

Meagan Ray

Electronic Media

Cedarville, $\mathrm{OH}$

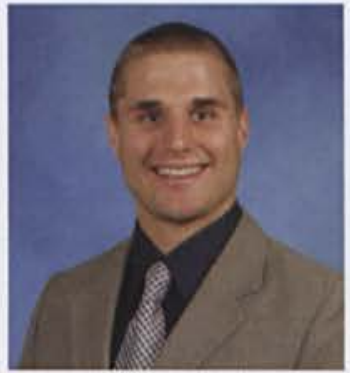

Blake Reeder

Exercise Science

Chesapeake, VA

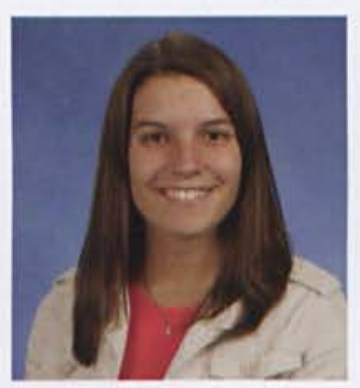

Erica Richey

Biology

Xenia, $\mathrm{OH}$ 


\section{SENIORS}

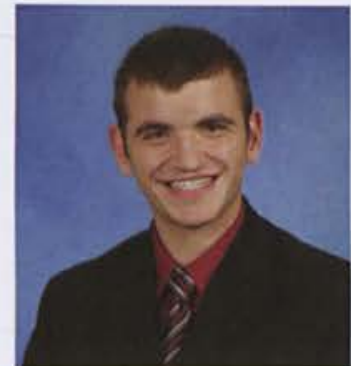

Veselin Rieches

AYA Social Studies

Education

Watseka, IL

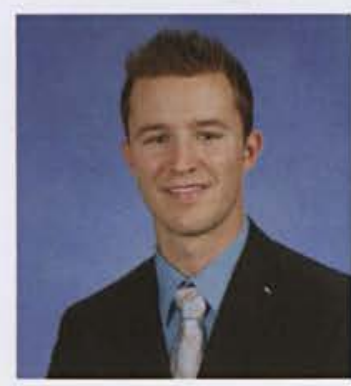

Trent Roach

Accounting \& Finance

Elkhart, IN

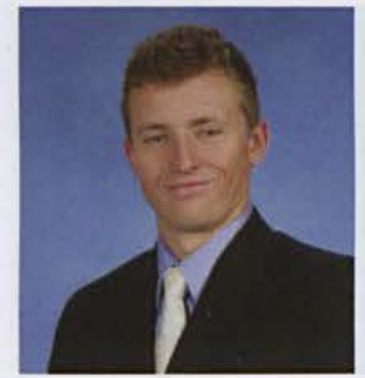

Tyler Rost

Sport Management Ravenna, $\mathrm{OH}$

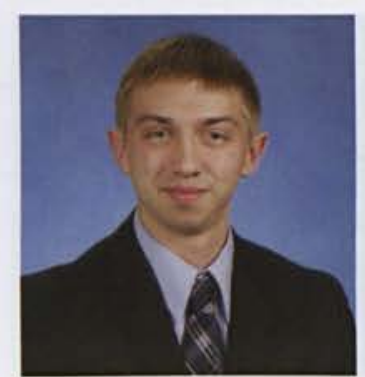

Bruce Rothhaar Information Systems Venetia, PA

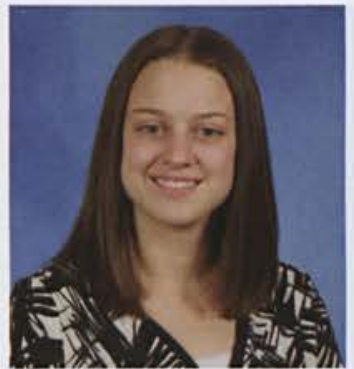

Elizabeth Rigg

Social Work

Cincinnati, $\mathrm{OH}$

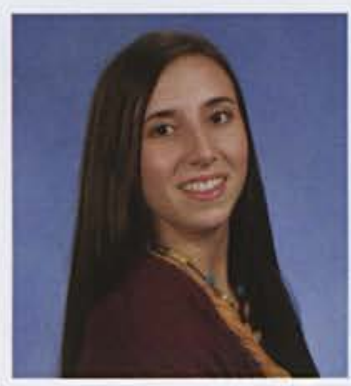

Jessica Robb

Psychology

Cuyahoga Falls, $\mathrm{OH}$

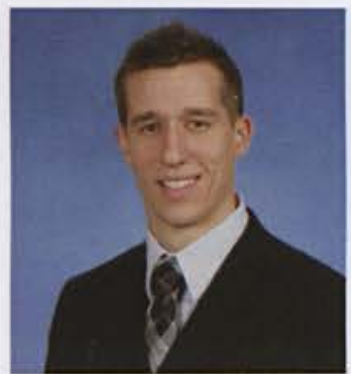

James Roten III

Preseminary Bible

Parkersburg, WV

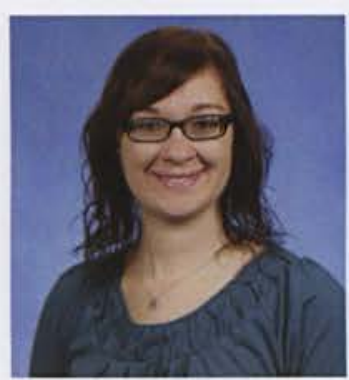

Jenna Rothhaar

Electronic Media

Ligonier, IN

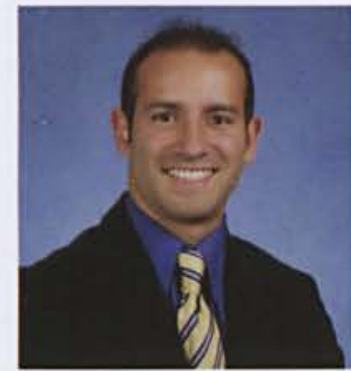

Matthew Rizzo

Finance

New Britain, CT

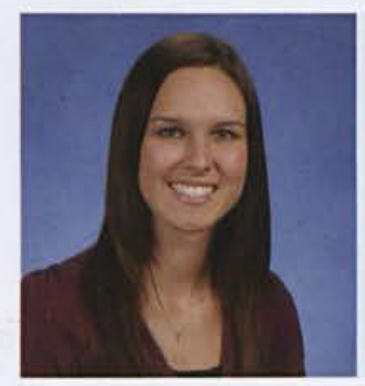

Joy Robertson

Psychology

Chesapeake, VA

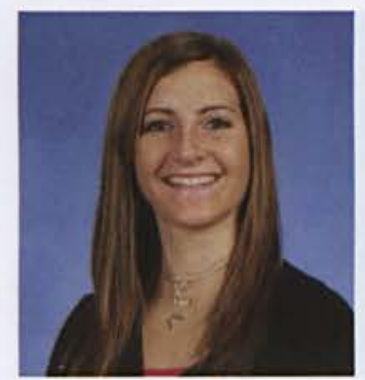

Lea Roth

Exercise Science

Butler, PA

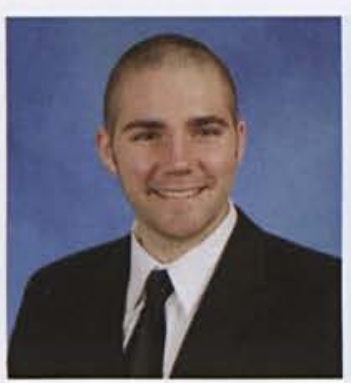

Garrett Rucinski

Communication

Wooster, $\mathrm{OH}$ 


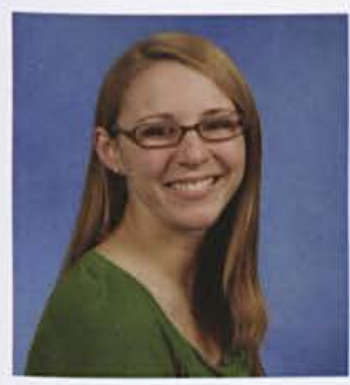

Carolyn Ruck

Theatre

Greenville, $\mathrm{OH}$

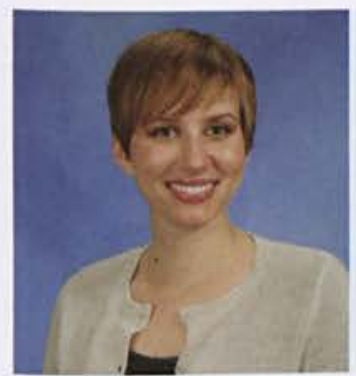

Amanda Satta

Technical \& Professional Communication

Rochester, NY

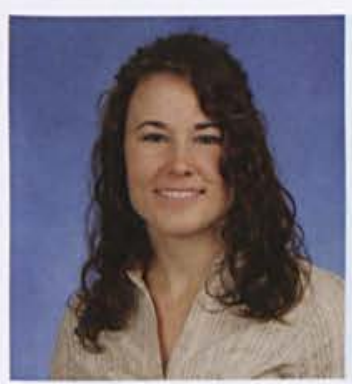

Melissa Scholes

Athletic Training

Beavercreek, $\mathrm{OH}$

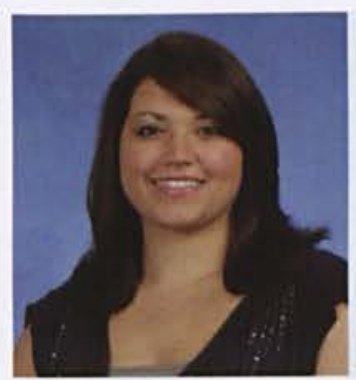

Christina Self

Nursing

Fairland, IN

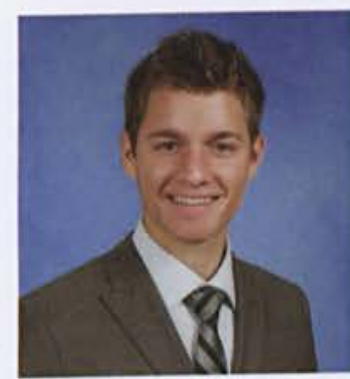

Kevin Ruhlman

Finance

Seattle, WA

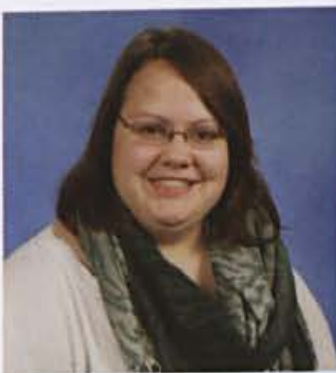

Michele Savory

Social Work

Sodus, NY

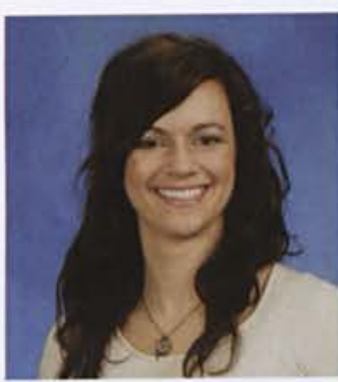

Allison Schulert

Nursing

Muncie, IN

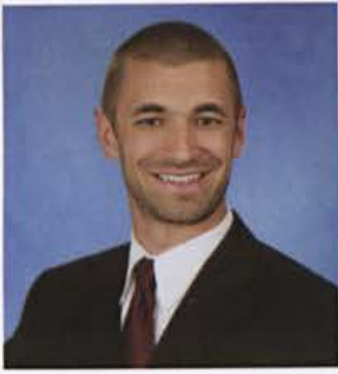

Justin Seligman

Athletic Training

Marshall, VA

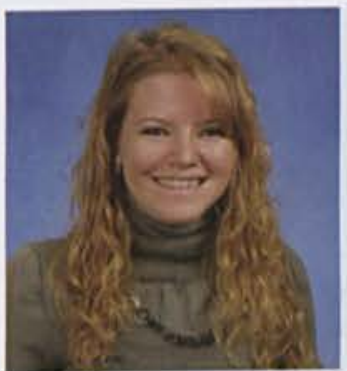

Stacey Russell

Music Education

Butler, PA

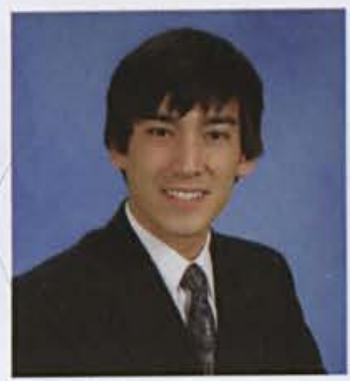

Joshua Schindehette Computer Engineering Hampstead, MD

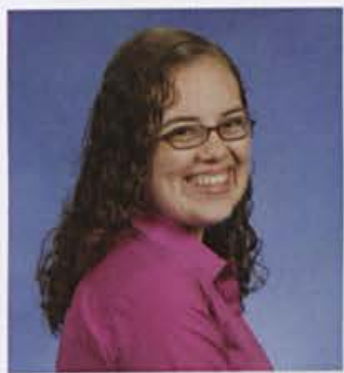

Kathryn Scott

Accounting

Haslett, MI

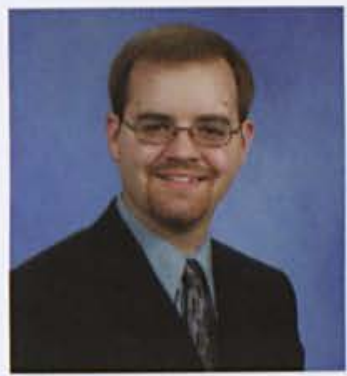

Daniel Shaffer

Computer

Engineering

Gambier, $\mathrm{OH}$

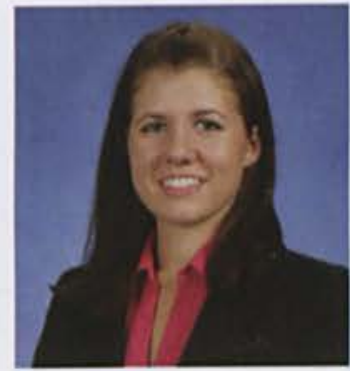

Shauna Rydman

Worship

Brier, WA

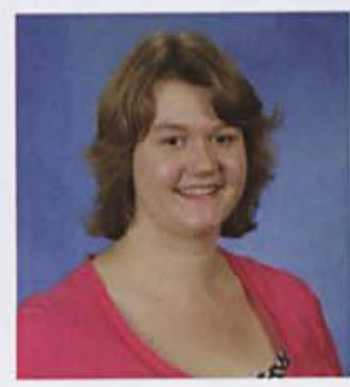

Stacie Schmidt History

Santa Barbara, CA

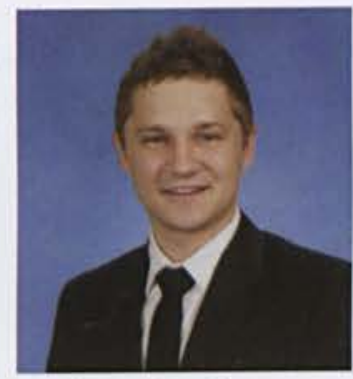

Zachary Seelye

Comprehensive

Communications

Bath, MI

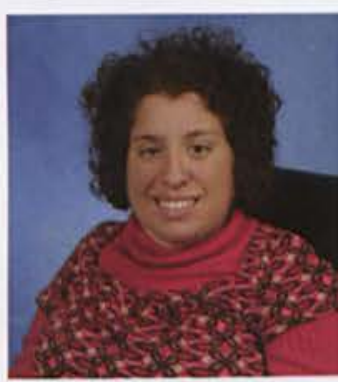

Emily Shanahan

Communication

West Carrollton, $\mathrm{OH}$

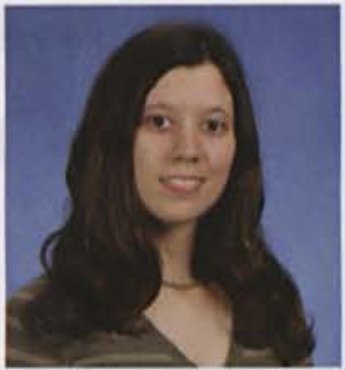

Shannon Saraco

Graphic Design

Franklin Square, NY

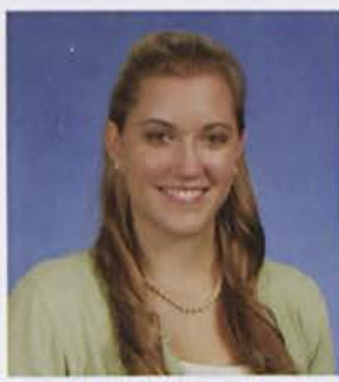

Tanja Schneider English

Dublin, $\mathrm{OH}$

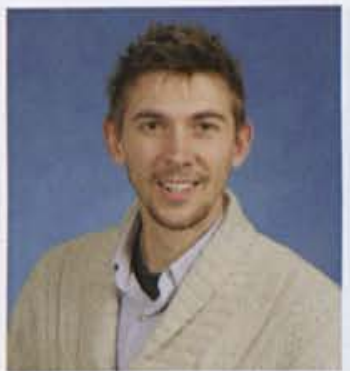

Kyle Segebart

Sport Management Dayton, $\mathrm{OH}$

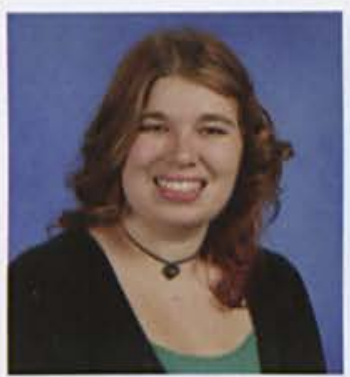

Kelly Shaw

Graphic Design

North Ridgeville, $\mathrm{OH}$ 


\section{SENIORS}

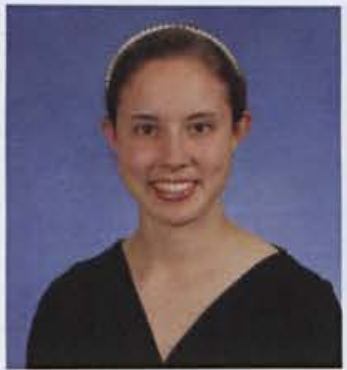

Ami Shetler

Nursing

Plain City, $\mathrm{OH}$

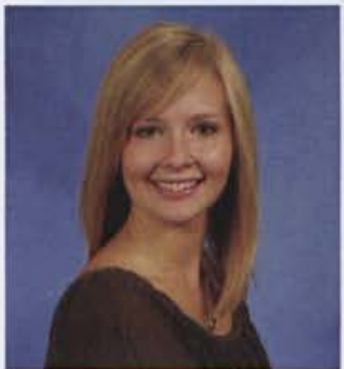

Danielle Sigmon Integrated Language Arts Education Mt. Airy, MD

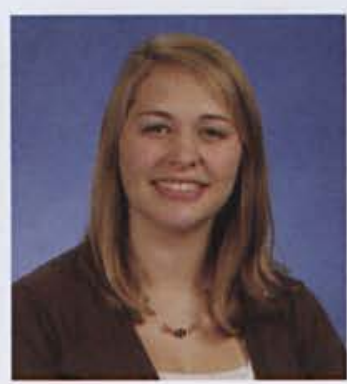

Anna Sloan Nursing

Providence, NC

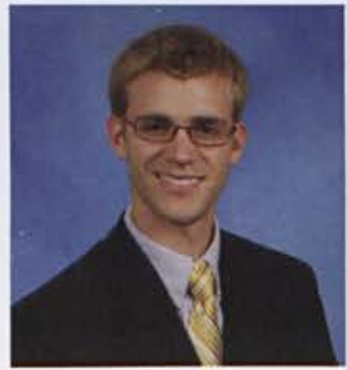

Andrew Smith

Journalism

Springfield, $\mathrm{OH}$

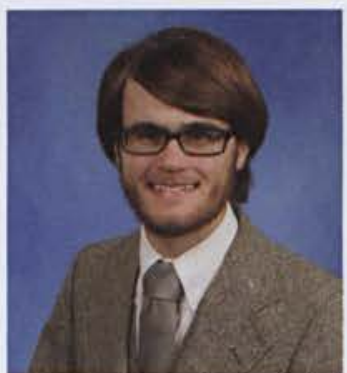

Daniel Sizemore

Psychology

Freehold, NJ

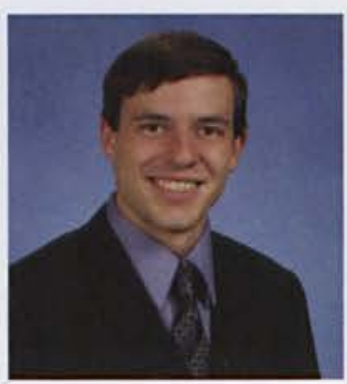

Steven Small

Mechanical

Engineering

Seoul, South Korea

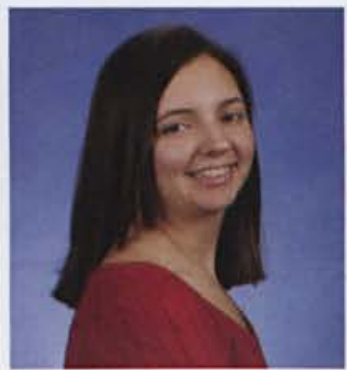

Erika Smith

Nursing

Waterloo, NY

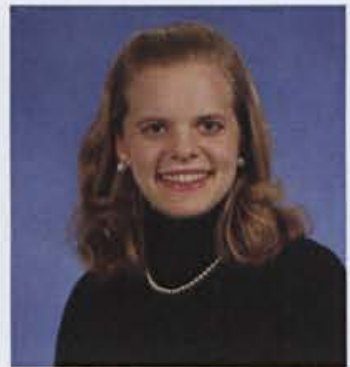

Rebekah Shinabarger Nursing

Evansville, TN

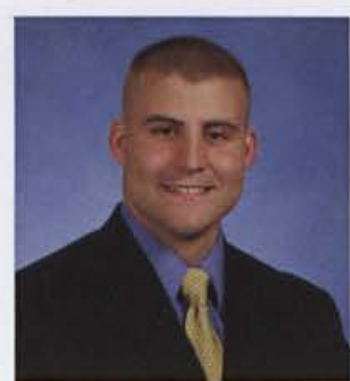

Nathan Sjoquist

Political Science

Xenia, $\mathrm{OH}$

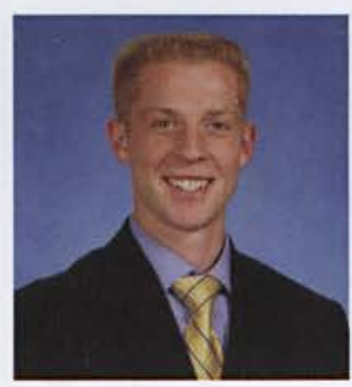

Tyler Smidt

Mechanical

Engineering

Springville, AL

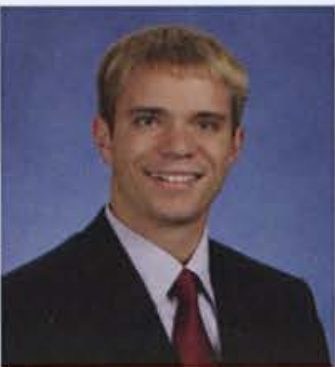

Ethan Smith

Psychology

Princeton, IL

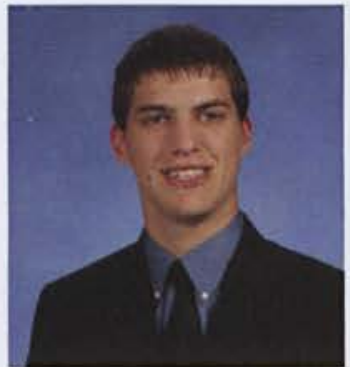

Stephen Shirey

Physics

Fort Wayne, IN

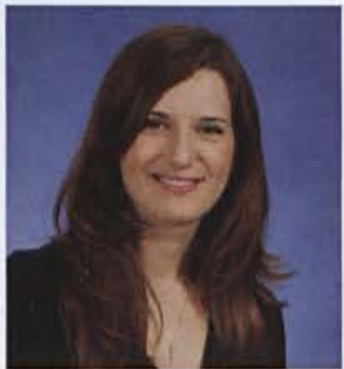

Mary Slifka

Biology

Centerville, $\mathrm{OH}$

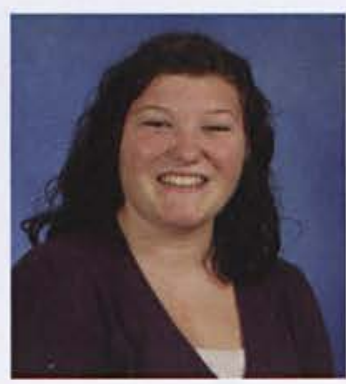

Amanda Smith Youth Ministry \&

Christian Education

Columbus, $\mathrm{OH}$

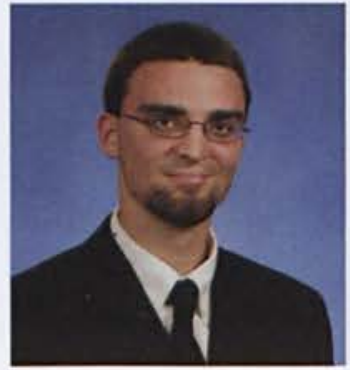

Jonathan Smith

History

Lebanon, PA 


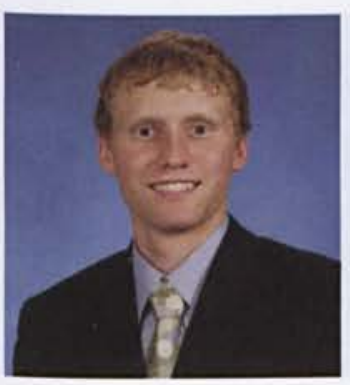

Matthew Smith

Finance

Wawaka, IN

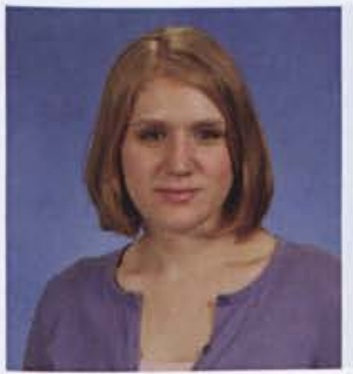

Katherine Soules

English \& Music

Randolph, VT

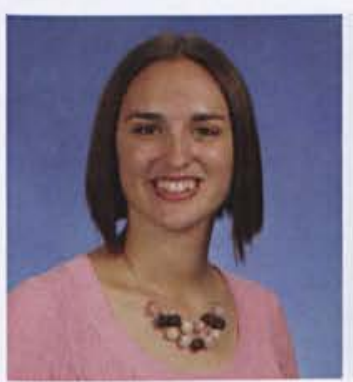

Kaitlin Start

Graphic Design

St. Charles, MO

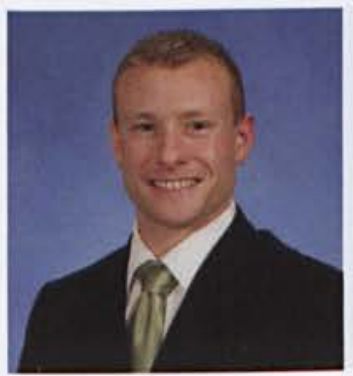

Daniel Stone

Allied Health

Syracuse, NY

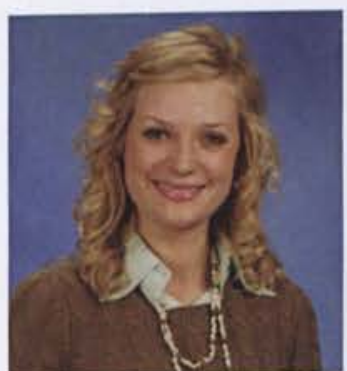

Morgan Smith

Nursing

Columbus, $\mathrm{OH}$

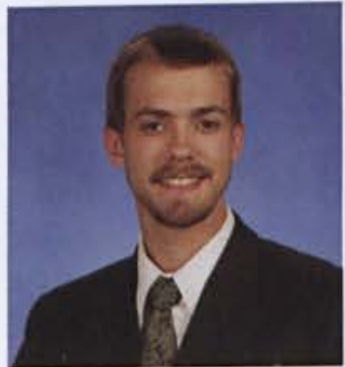

Douglas Sponsler

Biology

Philadelphia, PA

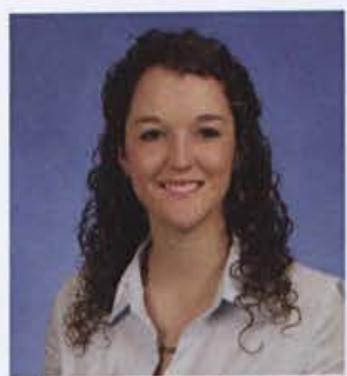

Kelsey Stauffer

Social Work

Montrose, M

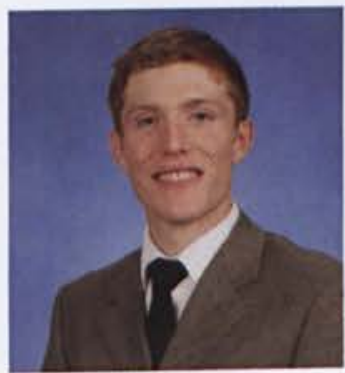

Jonathan Storch Multi-Age Music

Education

Joliet, IL

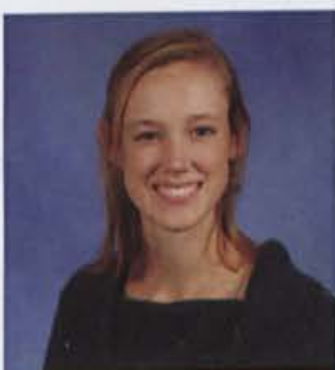

Rebecca Smith

Accounting

Hudson, NH

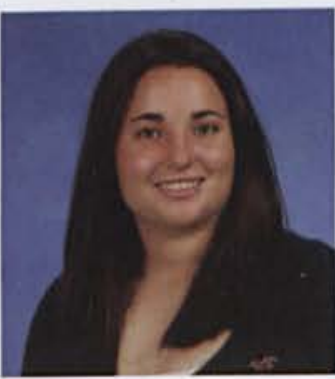

Megan Spring

Technical \& Professional

Communication

Miami, FL

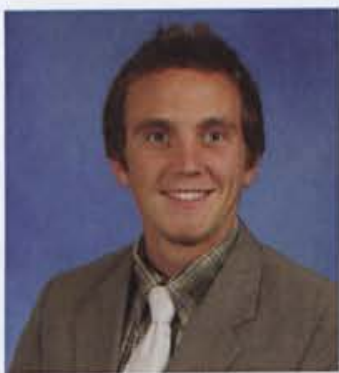

Joshua Steckel

Exercise Science

Columbus, $\mathrm{OH}$

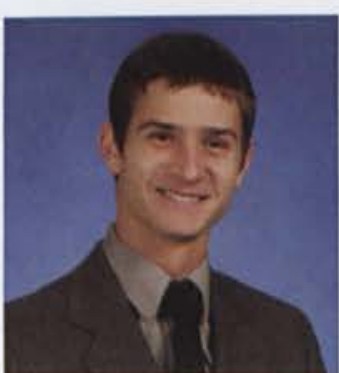

Daniel Suarez

Biology

Sayre, PA

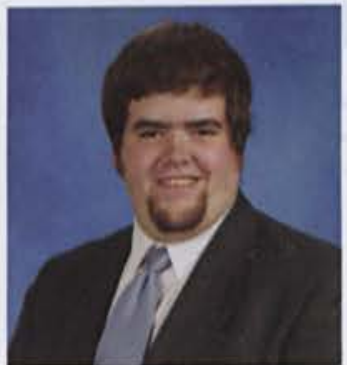

Christopher Smith, Jr Information Systems \& Marketing

Creston, $\mathrm{OH}$

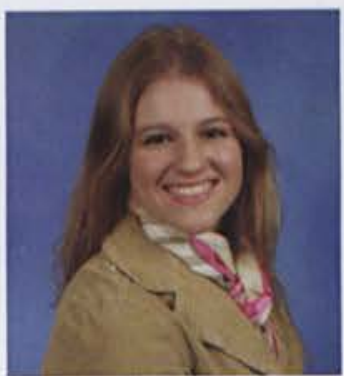

Catherine Stampfli Music Performance

Greenville, IL

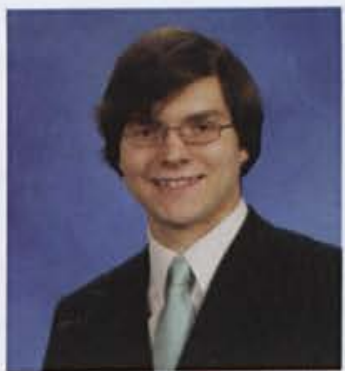

Andrew Sterling

Computer Science

Elyria, $\mathrm{OH}$

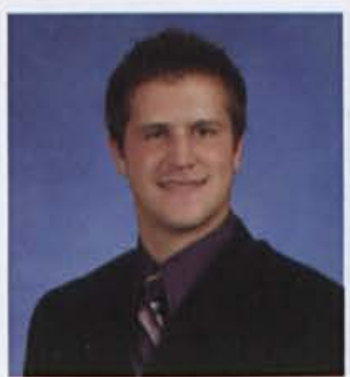

Adrian Summers

Finance

Lewisburg, $\mathrm{OH}$

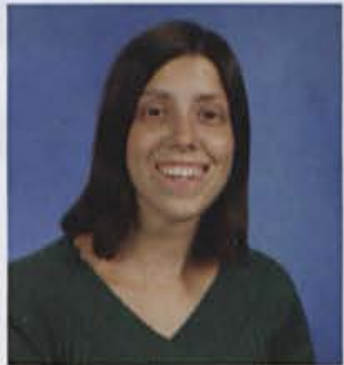

Amanda Snyder History

Camp Hill, PA

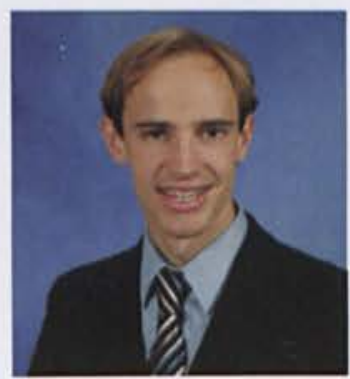

Joshua Stands

Integrated Mathematics

Education

Columbus, $\mathrm{OH}$

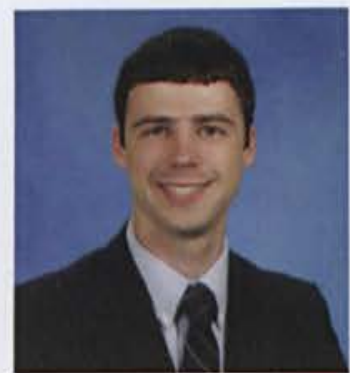

Daniel Stevens

Electronic Media Raleigh, NC

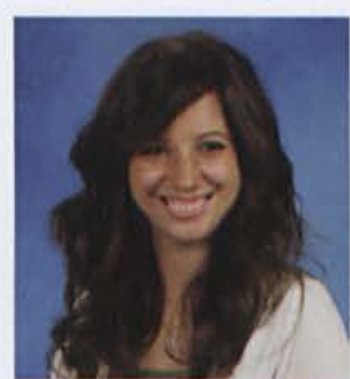

Meredith Sumner

Organizational

\& Intercultural

Communications

Williamsport, MD 


\section{SENIORS}

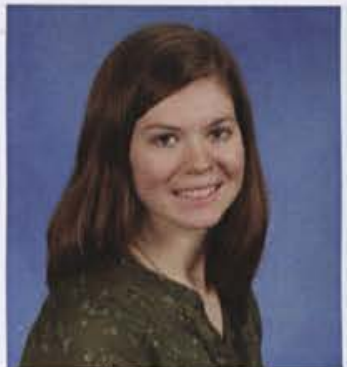

Alanna Swett

Nursing

Morrice, MI

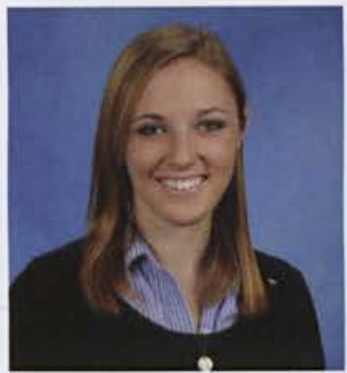

Julie Terrall

Psychology

Allen, TX

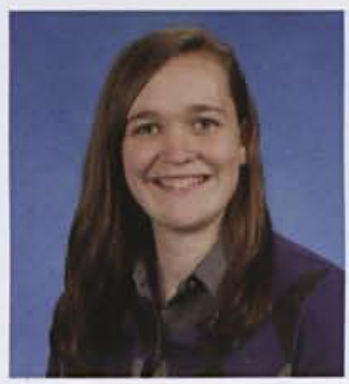

Seth Thomas

Management

Lancaster, $\mathrm{OH}$

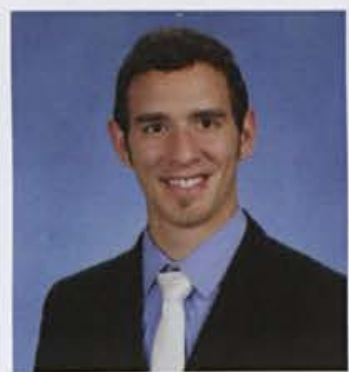

David Tofilon

Worship

Columbia, SC

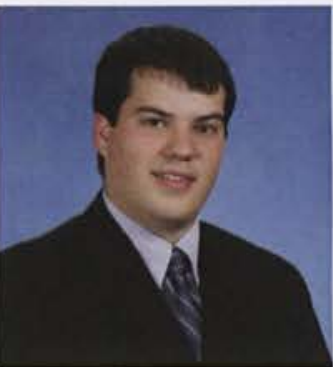

Jonathan Swoveland Electrical Engineering Sterling Heights, MI

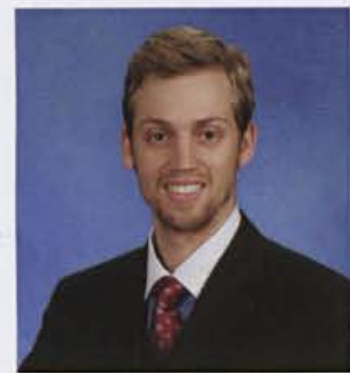

Johann Terreblanche Mechanical Engineering Cincinnati, $\mathrm{OH}$

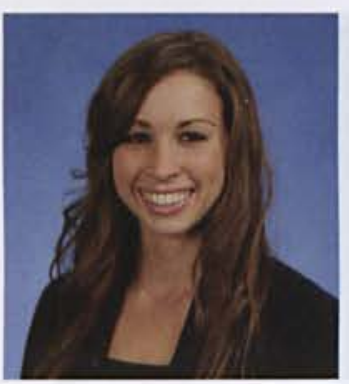

Katelyn Tilli Early Childhood Education

Pequannock, NJ

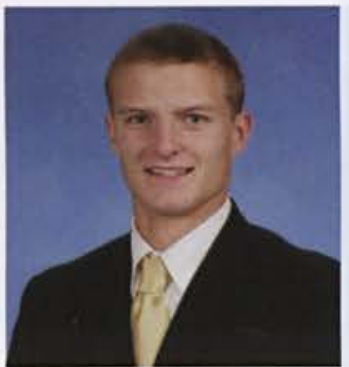

Hollis Troxel

Management

Anchorage, AK

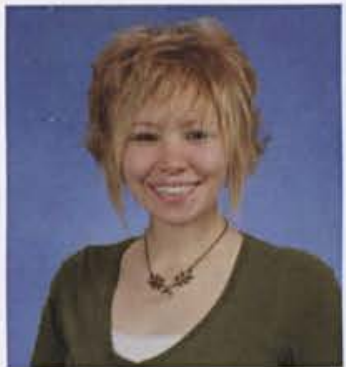

Joanna Taylor Nursing

Nashua, $\mathrm{NH}$

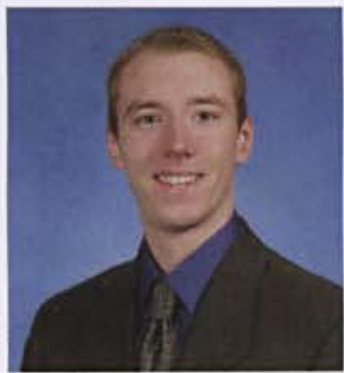

Bradley Thomas

Criminal Justice

Shippensburg, PA

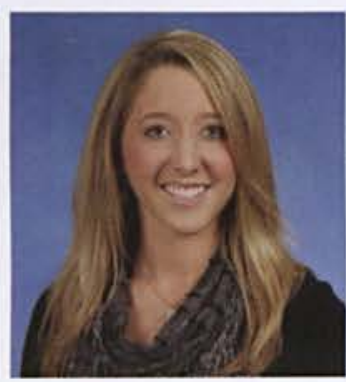

Megan Tinsley

Nursing

Denver, CO

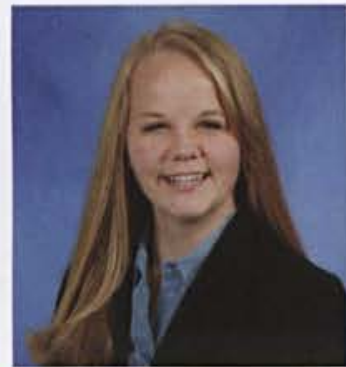

Jannae Turley

International Studies Loveland, $\mathrm{OH}$ 


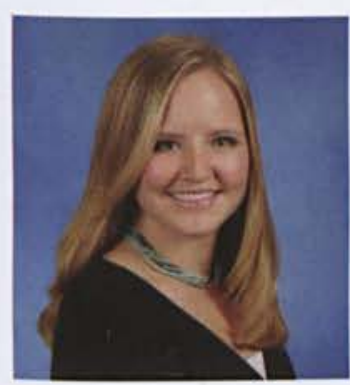

Kimberly Turner Marketing

Atlanta, IL
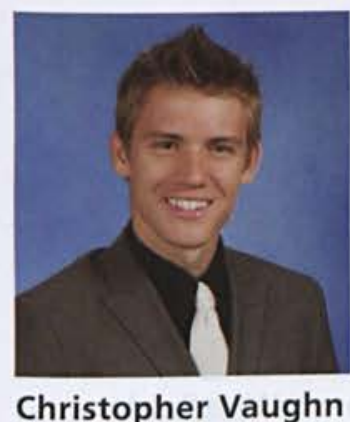

Biology

Millington, TN

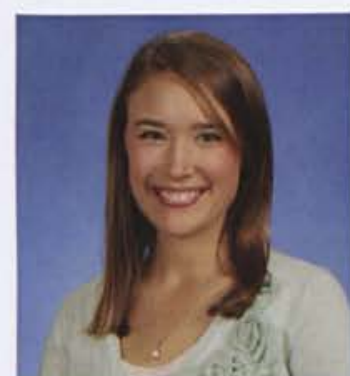

Cameron Walters-Carlson Psychology

Lakeland, FL

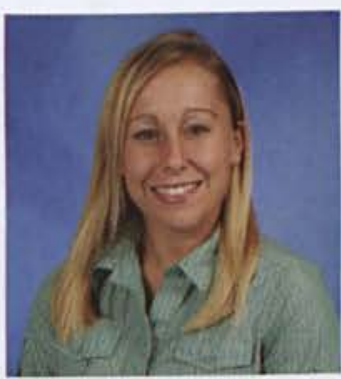

Jaimie Watkins Exercise Science Aiea, $\mathrm{HI}$

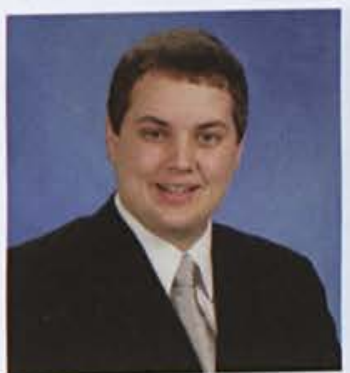

Joshua Uhorchuk Comprehensive Bible Pitman, NJ

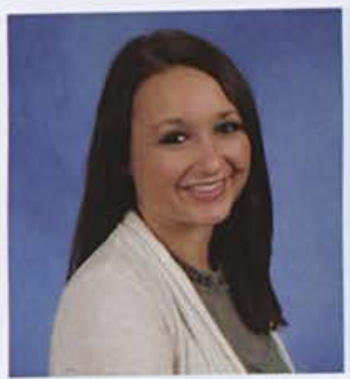

Bethany Wailes Nursing

Cedarville, $\mathrm{OH}$

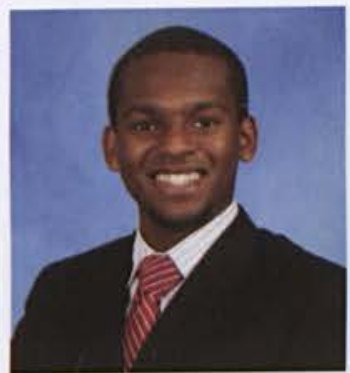

Joseph Wanderi Accounting \& Finance Elyria, $\mathrm{OH}$

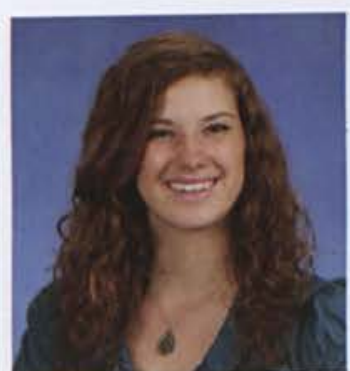

Katherine Watson

Organizational

Communication Homer, NY

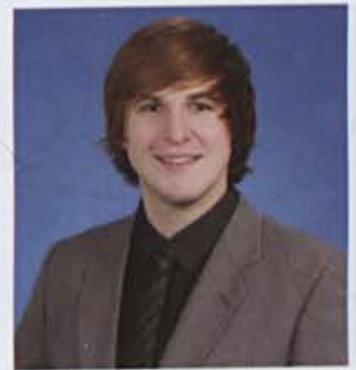

Taylor Valarik

Electronic Media

Mt Desert Island, ME

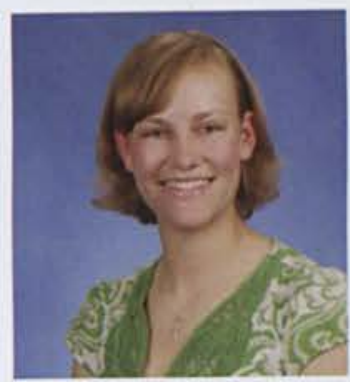

Rebekah Wallin

Criminal Justice

Torrence, CA

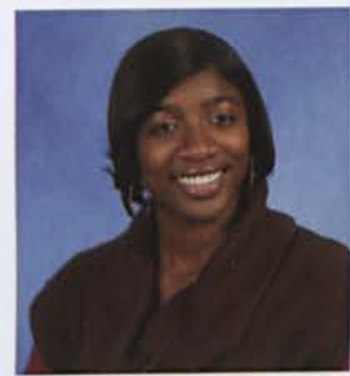

Jernelle Ward

Early Childhood

Education

Woodstock, MD

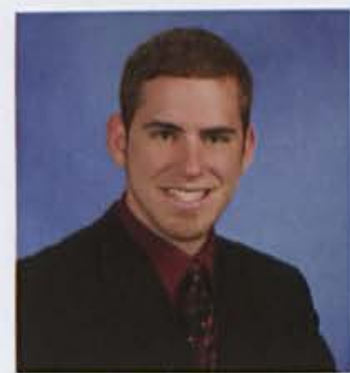

Cameron Weaver

Criminal Justice

Mt. Holly Springs, PA

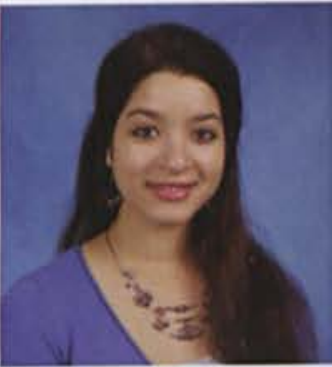

Emily Valji

Biology

Cary Pit, ME

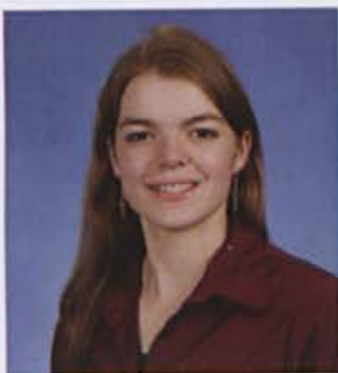

Rachelle Walter

Organizational

Communication

St. Johns, MI

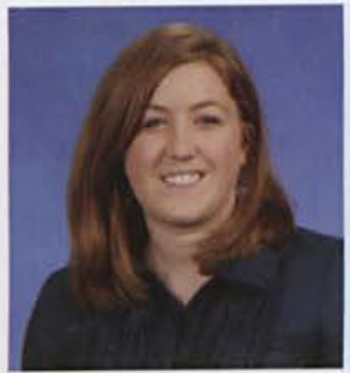

Amanda Waring

Multi-Age Special

Education

Westminster, MD

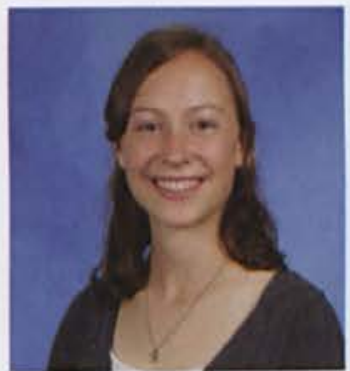

Amanda Weber

Sociology

Rosedale, $\mathrm{OH}$

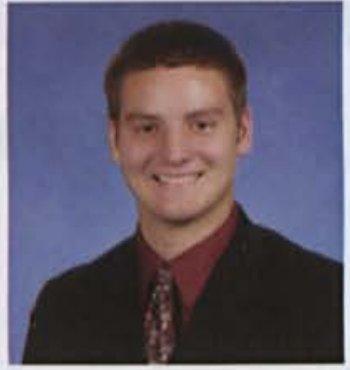

John Van Schepen Jr. Biology

Demotte, IN

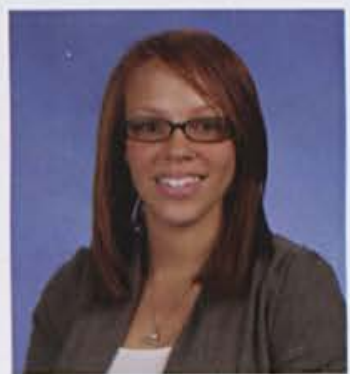

Alyssa Walters Nursing Lorton, VA

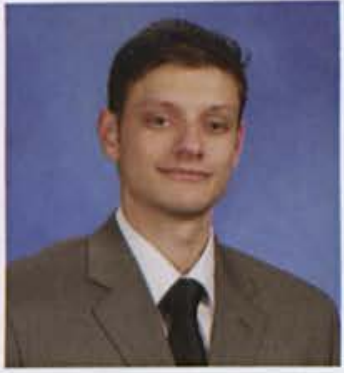

Robert Wasem Mechanical Engineering Dover, $\mathrm{OH}$

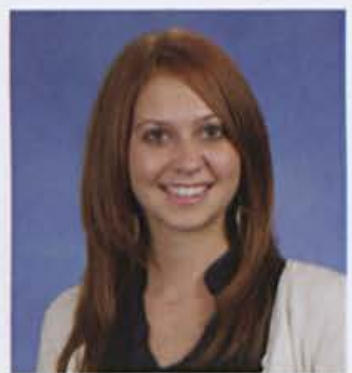

Jennifer Webster

Nursing

Mt. Airy, MD 


\section{SENIORS}

Education

Mt. Holly, NC

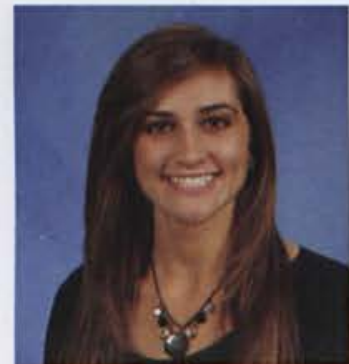

Jaclyn Willert

Management

Clarence, NY

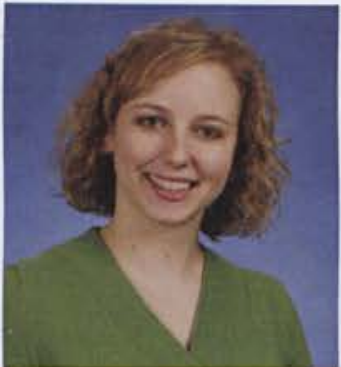

Karli Weed

Nursing

Wichita, KS

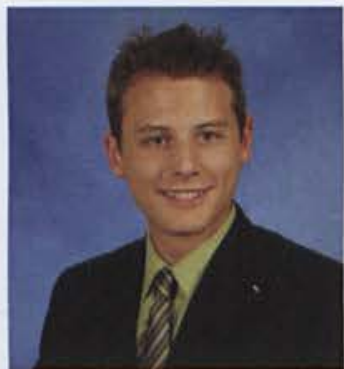

Jeffery Whitcomb II Biology

Anderson, IN

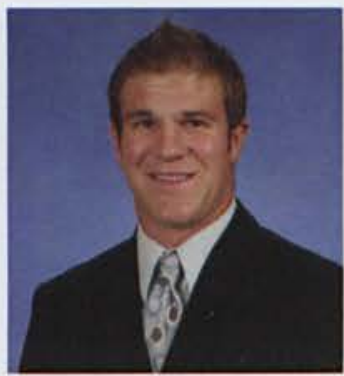

Samuel Wichael Athletic Training

Conifer, CO

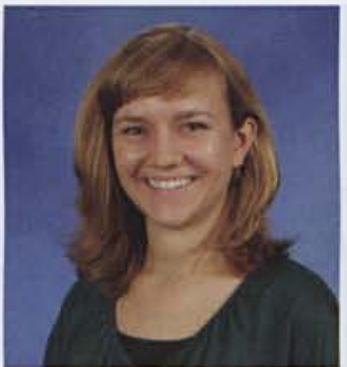

Megan Welborn

Biology

Sacramento, CA

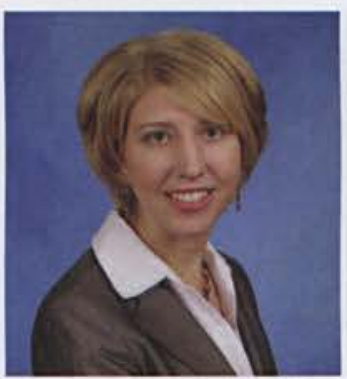

Katrina Whitecavage International Studies Eagle River, AK

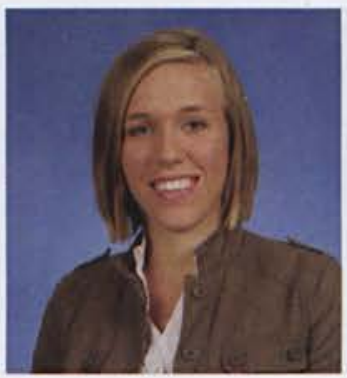

Jamie Widman Nursing

Winona Lake, IN

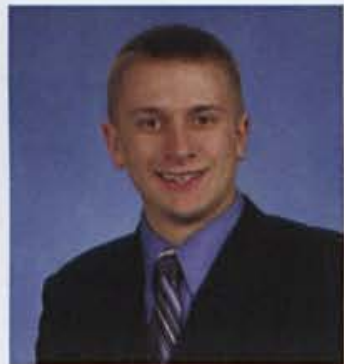

Richard Williams

Marketing

Xenia, $\mathrm{OH}$

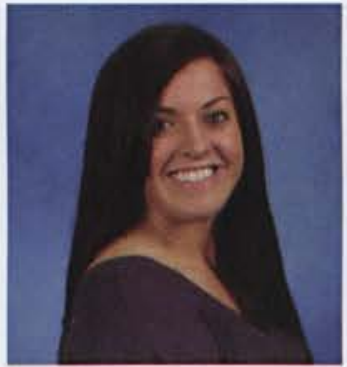

Psychology

Ironton, $\mathrm{OH}$
Hannah Willis

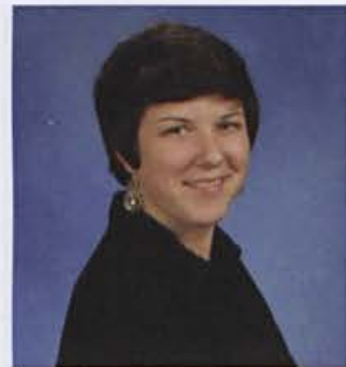

Krista West

Political Communications Norwalk, $\mathrm{OH}$

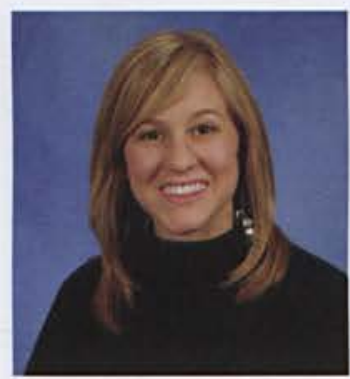

Sarah Whitfield Music

Madisonville, KY

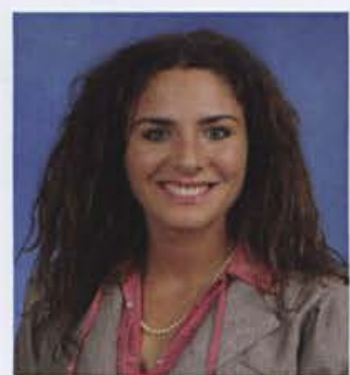

Veronica Wilkins Psychology

Bow, NH

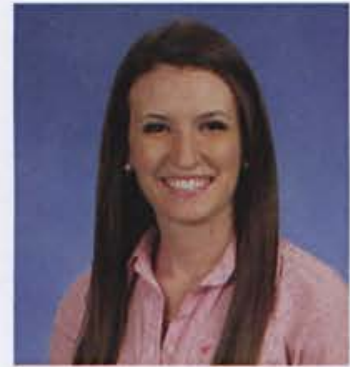

Ashley Wilson

Nursing

Concord, NH 


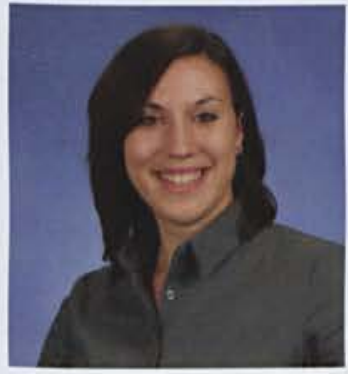

Lindsay Wilson

Finance

Newport News, VA

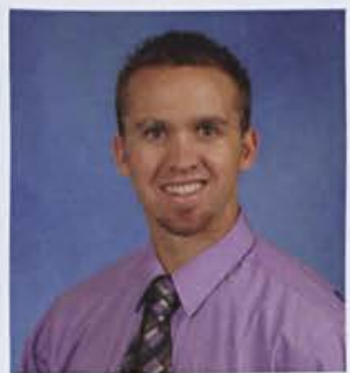

Tyler Worosher

Sport Management

Wauseon, $\mathrm{OH}$

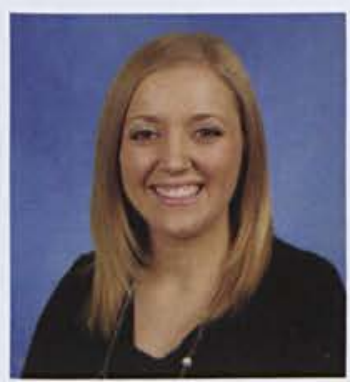

Janelle Yoder

Accounting \& Finance

Berne, IN

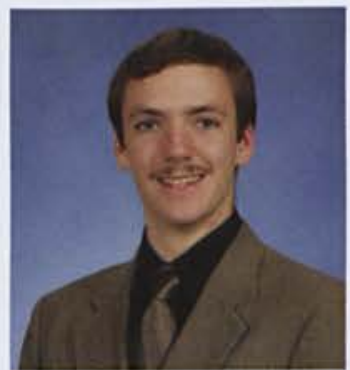

Lucas Zellers

Comprehensive

Communications

Ashton, IL

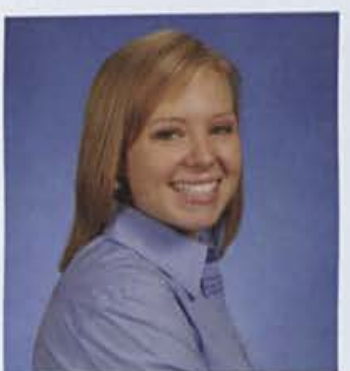

Melissa Winkle

\section{Accounting}

Carmel, IN

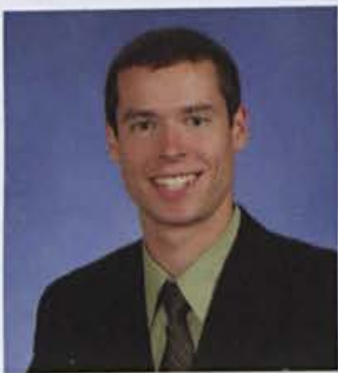

Joshua Woyak

Electrical Engineering

Troy, MI

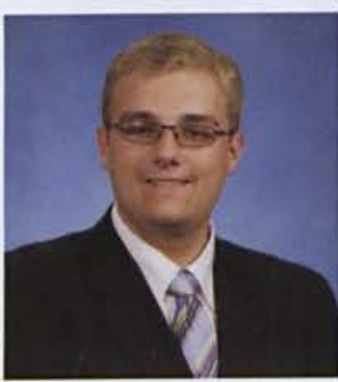

\section{Lance Yoder}

Information Systems

West Liberty, $\mathrm{OH}$

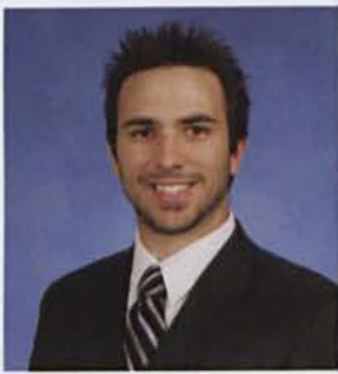

Mark Zellner

Youth Ministry \&

Christian Education

Lehighton, PA

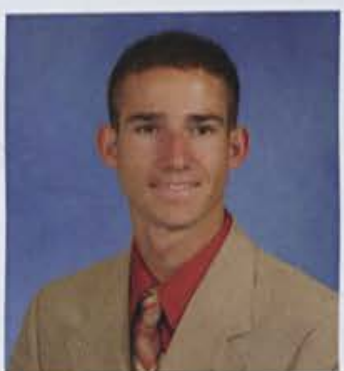

Joshua Wiseman Mechanical Engineering Springfield, $\mathrm{OH}$

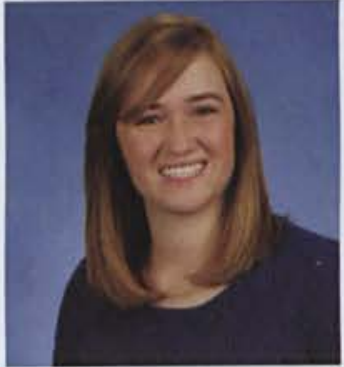

Jessica Wynalda

Accounting

Comstock Park, MI

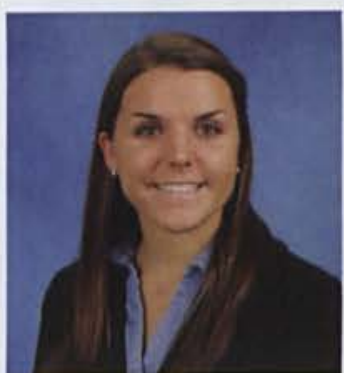

Jennifer Yorgey

Accounting

Rochester, NH

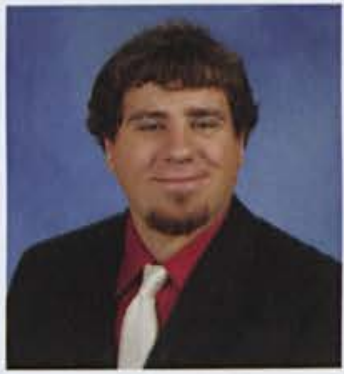

Jordan Zimmerman

Sport Management Rochester, NH

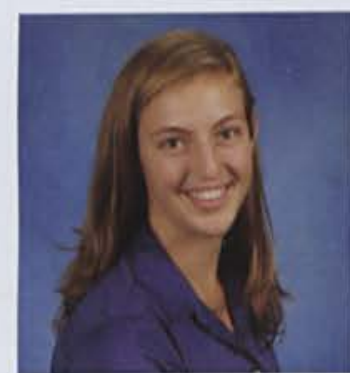

Rene Wolf

Spanish

Ramsey, MN

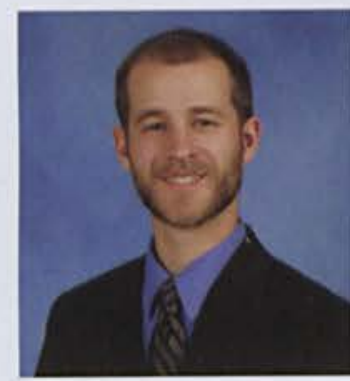

Micah Yarbrough Biology

Salem, OR

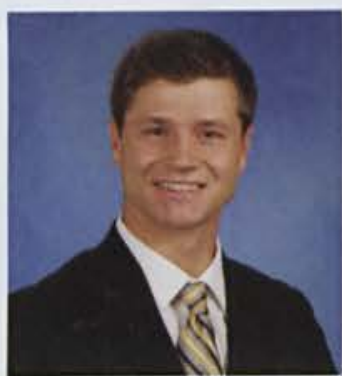

Andrew York

Finance

Mars Hill, ME

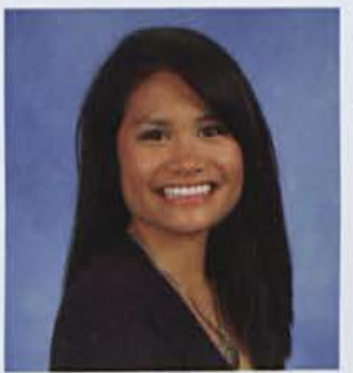

Kristiana Zimmerman Early Childhood

Education

Winthrop, ME

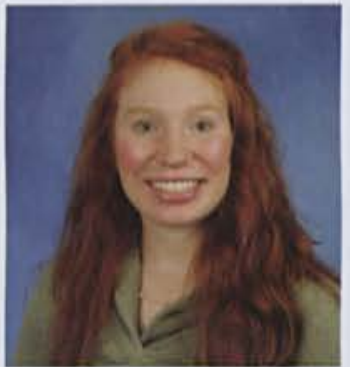

Caribeth Wolfe Middle Childhood Education

Fort Plain, NY

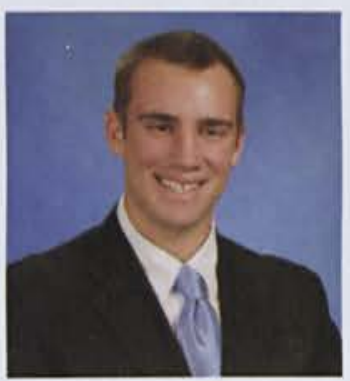

Matthew Yeiter Marketing \& Finance Traverse City, MI

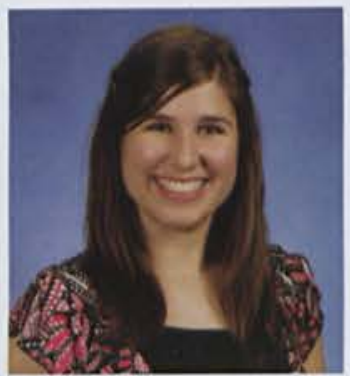

Jessica Zboran

Mechanical

Engineering

Lilburn, GA

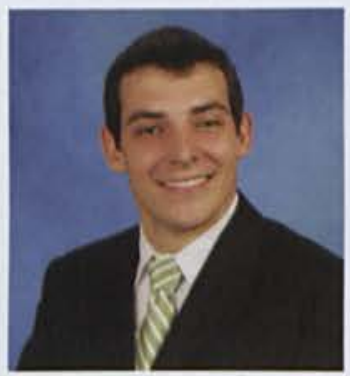

Nathan Zion

Pre-Law

Independence, $\mathrm{OH}$ 


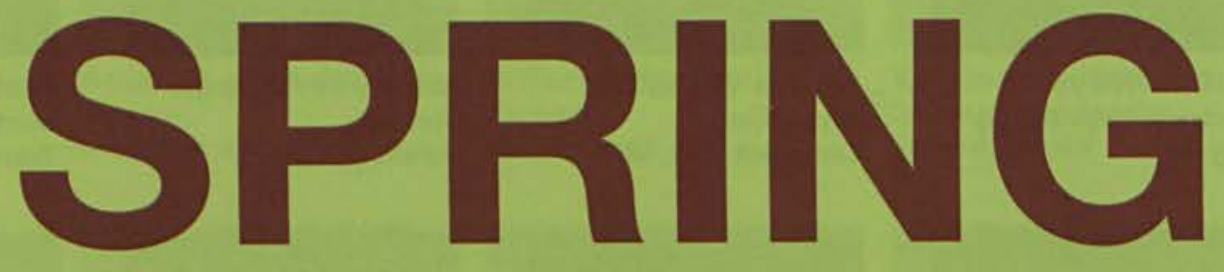

noun \'sprin \The time of the year when it snows during April, and the semester goes faster than anticipated. 


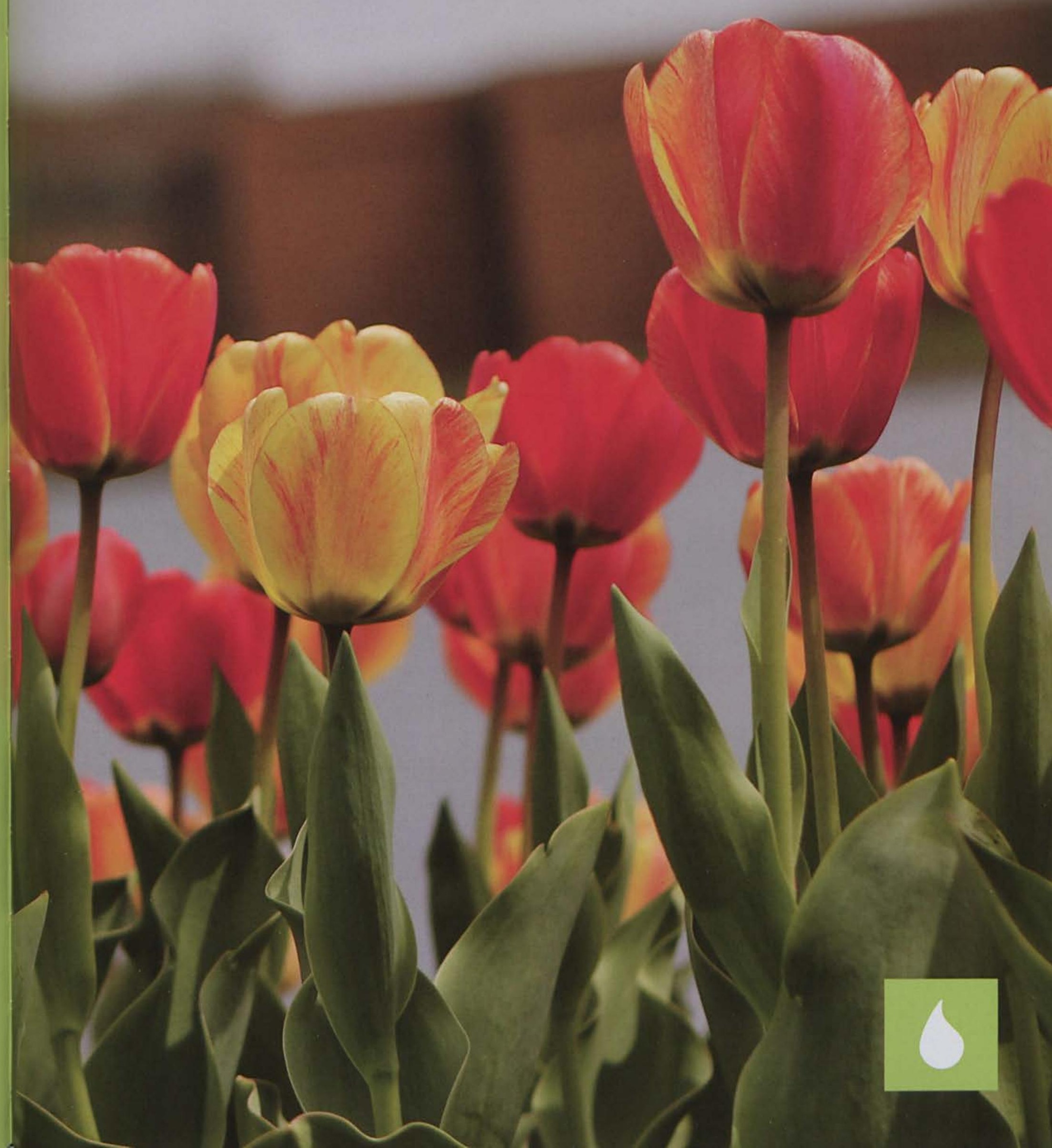




\section{MISSIONS CONFERENCE}

Through the flags waving in the DMC to the display tables set up throughout Alumni Hall, missionaries from all over the world welcomed students back from winter break. The annual missions conference brought in missionaries, mission speakers, and Bible scholars to challenge the student body to think outside the realm of the "Cedarville Bubble." The whole goal of the missions conference was to expose the student body to the many cultures and people groups that still need a clear representation of the gospel, which was reflected in this year's theme, "Redeem Lives, Restore Hope."

The missions conference provided students who were considering going into the field with connections and wisdom from those who were already living their callings, as well as helping many students realize their calling toward missions for the first time. The conference also allowed students to see how their specific area of academic training and personal interests could be used to benefit the mission field. The keynote speaker, Dr. John Barnett, emphasized this by reminding Cedarville that we are all missionaries, in whatever field or whatever city we end up; we are called to do our part to reach "Jerusalem, Samaria, and the uttermost parts of the world."
"Therefore go and make disciples of all nations, baptizing them in the name of the Father and of the Son and of the Holy Spirit, and teaching them to obey everything I have commanded you. And surely I am with you always, to the very end of the age." (Matthew 28:19-20)

During the Missions Conference, all of the attending missionaries give a brief introduction of themselves. All the introductions are given on the first night, so they have to be quick about it! 2 The Missions Conference is one of the few times during the year that Cedarville students are asked to give an offering. 3 Some couples are rather familiar with the introduction process as they have been coming to the Missions Conference for many years. 


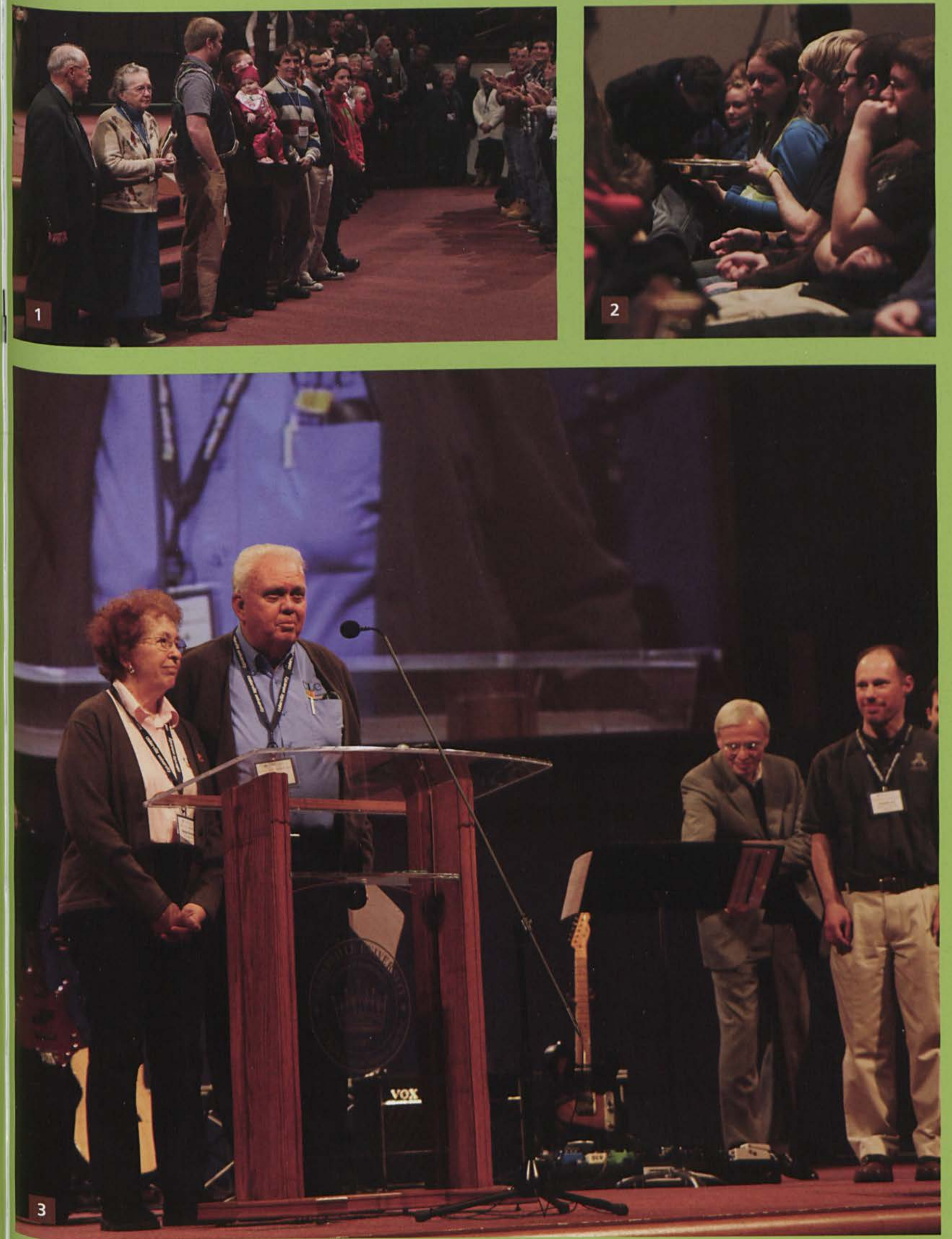




\section{WINTER PLAY}

Hello, Cedarville! This winter, the theatre department put on the classic musical Hello, Dolly! Based on The Matchmaker by Thornton Wilder, Hello, Dolly! debuted on Broadway in 1964 with music by Jerry Herman. This dynamic show tells the story of Dolly Levi, self-proclaimed matchmaker in the small town of Yonkers, as she rediscovers what it means to live life to the fullest. Throughout the story she is joined by a whole cast of interesting, spirited characters who add a lively dimension to the show and help remind the audience to embrace life's adventures. The show's energetic songs, dance numbers, and bright costumes made it a spectacular experience for audience members to enjoy.

Putting on a major stage production such as Hello, Dolly! is no small task. Cast members spent hours in long rehearsals learning songs, dance numbers, and lines before finally putting it all together with costumes, hairstyles, make up, and props. Performance weekends were definitely a crazy time for those involved in the show, with multiple performances on some days. All cast members had to get to the theatre early - sometimes as much as four hours early - to put on costumes and make up, and for the girls to get their hair done. But according to Grace Pilet, who played the part of Ermengarde, the performance weekends were the most fun part of the entire process. "We all felt a little silly running into Chuck's with our crazy hair and make up, but we needed food!" she says. Pilet admits that the process was a lot of hard work, but that it was definitely a great experience to be a part of this show.

Cedarville's production of Hello, Dolly! was an enormous success, and a lot of fun for performers and audience members alike.

"We all felt a little silly running into Chuck's with our crazy hair and make up, but we needed food!"

(Grace Pilet)

\section{Grace Pilet charms the crowd and a group of male admirers in the winter play Hello, Dolly!} 2 The cast of Hello, Dolly! stepped into the 1940s, the turn of the century in America, and brought the audience along for the ride. 3 Grace Pilet, who plays Dolly, prepares herself-and the audience - for herself for adventure and life in Yonkers with a song. 


\section{SPRING HAPPENINGS}

Spring - a time when the ground thaws, but not in Cedarville. This year particularly held us captive to a harsh winter, but eventually the ground did thaw, and the buds did blossom, and in the meantime Cedarville played in the snow. When the weather got too warm for the snow, late spring thunderstorms held the town of Cedarville under flood and tornado watches for weeks.

Spring semester is a time when freshmen finally have a firm grasp on the culture of college life and can honestly claim to know what they are doing, and seniors start thinking about their good-byes. Second semester plays host to a number of traditions on campus: the Missions Conference, Lil Sibs weekend, Junior Senior, Elliv, and finally graduation.

Among the yearly traditions were a few new events that earned their place in Cedarville's legacy, among them, the International Justice Mission's second annual Impossible Possibilities, a 10k walk/run/relay. This year, the $10 \mathrm{~K}$ raised "Did I hear, 'Brock to the Rock'!?" (Zachary Heady) over twenty thousand dollars to be donated to a local sex trafficking safe home. "I really loved it. Personally, I really like to run, and this was a great way to do something I enjoy in a competitive manner. And it was for a great cause, which made it all the more delightful," said Chris Pedro, a freshman.

Always tinged bittersweet, students said good-bye at the end of spring, some forever and others just until next fall as students drove their broken and beat up cars home into the summer sun.

As always, Spring semester brought with it the emergence of new couples, Brock to the Rock, campus golf, and other shenanigans that prove students are really just kids trying to have fun.

\footnotetext{
1 When the (relatively) warm weather hits, engineers break out all the projects they've been working hard on over the winter months. 2 Dodgeball: an Cedarville spring-time favorite. 3 What better way to welcome spring than with some sweet, sugary cotton candy!
} 

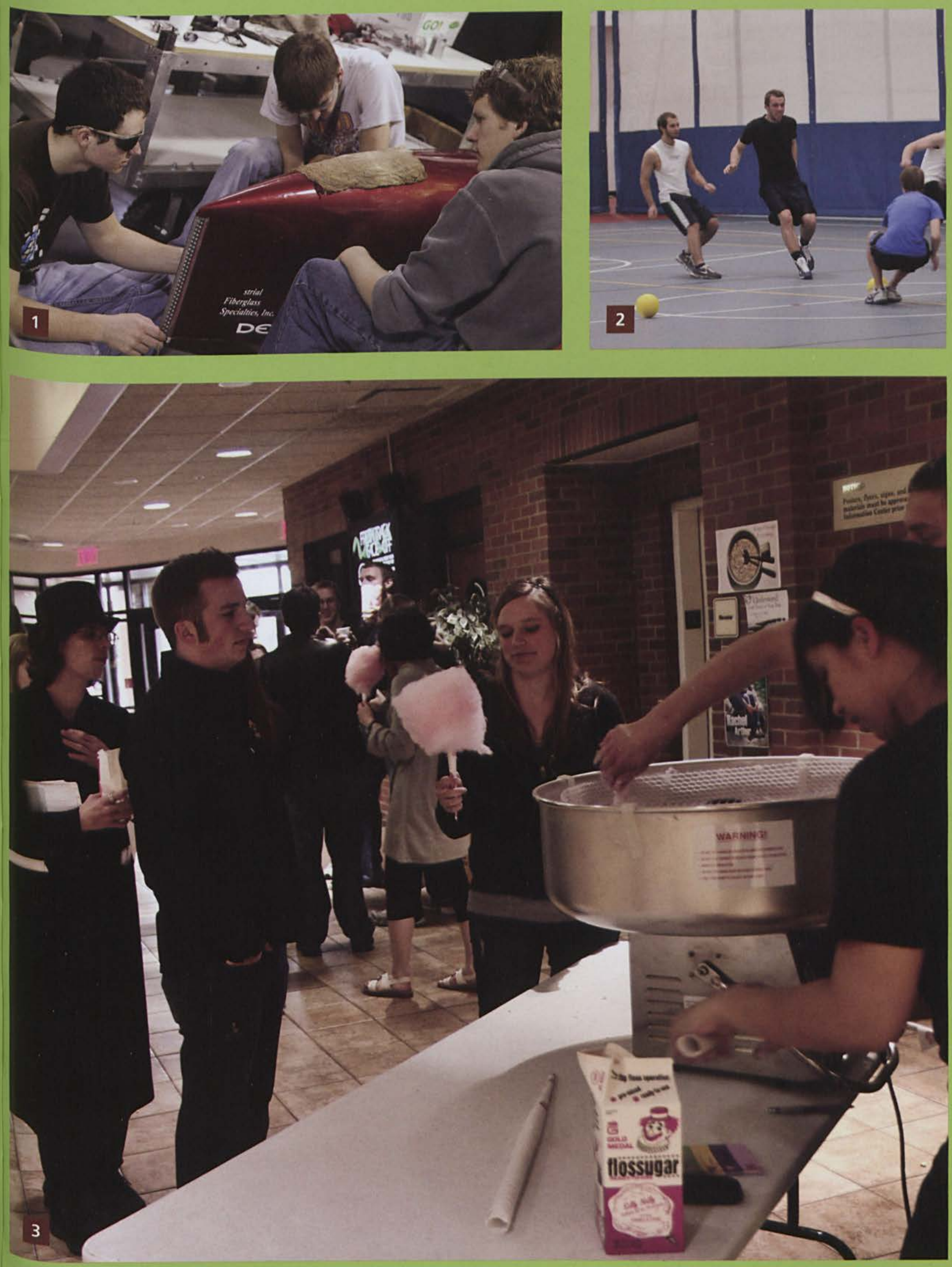


\section{SPRING STUFF}

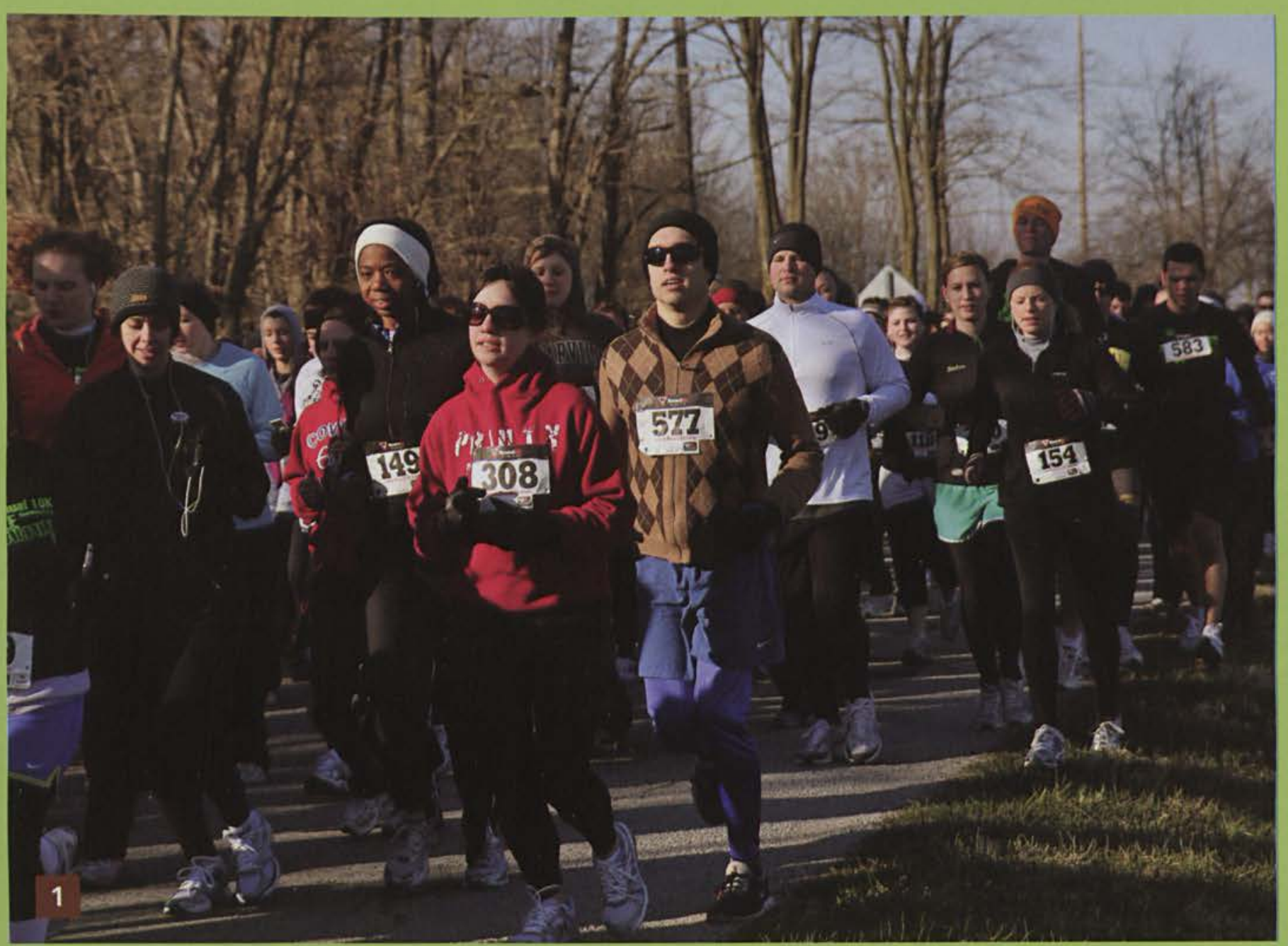

1 The Impossible Possibilities $10 \mathrm{~K}$ gives students the chance to stretch their legs after cramped winters and helps out a great cause at the same time! 2 Tution Freedom Day lets students say a big "thank you" to all the donors who have made their education possible. 3 Allison Dunlap and the rest of the Irish band serenade students during the Honors Coffee House. 4 Mary Lewis, Jessica Wynalda, and Andrew Barfell excitedly show just how many days they have left until graduation at the 100 Days Party. 

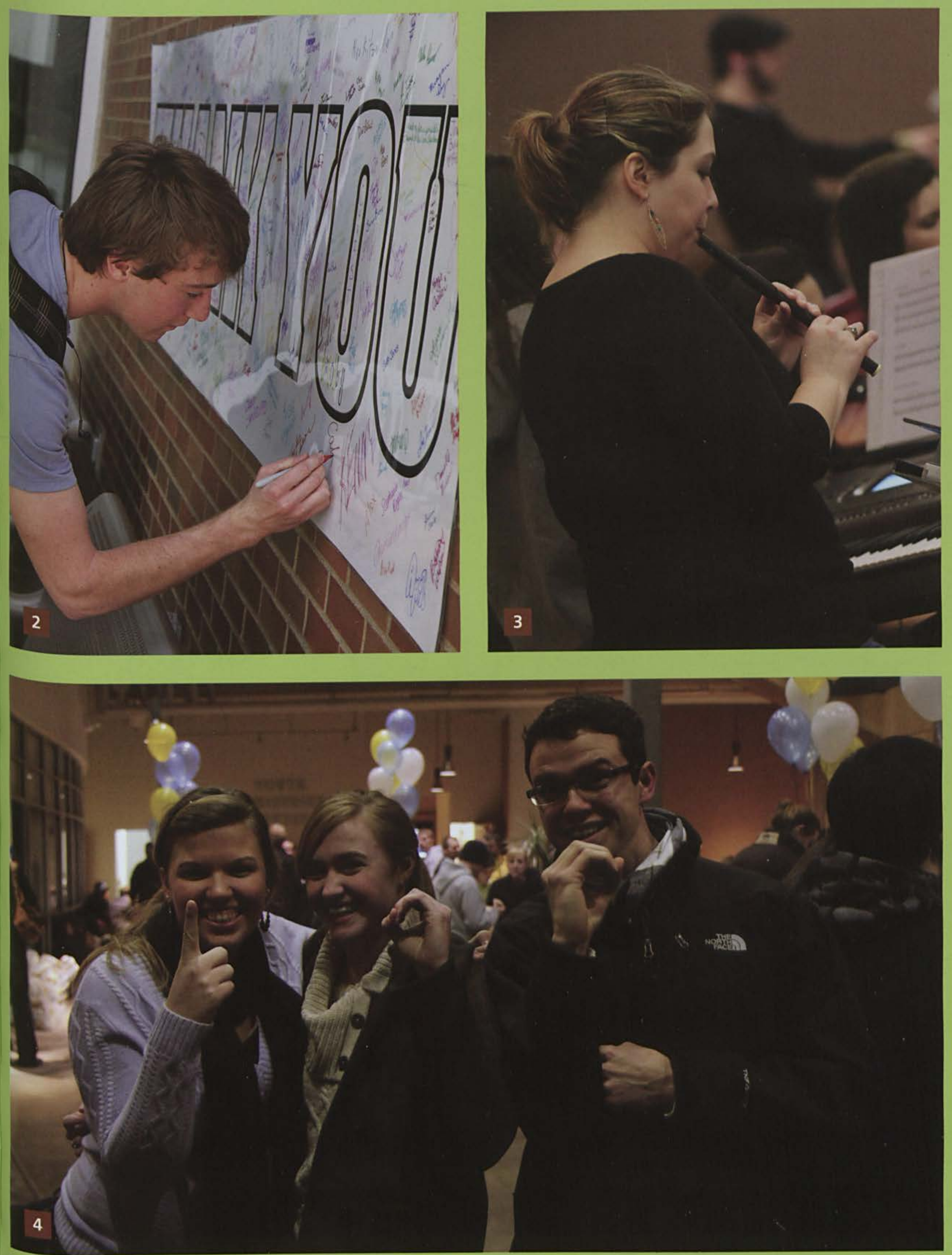


\section{LI'L SIBS WEEKEND}

Li'l Sibs weekend was a time to catch up with the family and show those younger siblings the fun that occurs on Cedarville's campus. Cedarville students invited their younger siblings for a great weekend with activities that gave siblings the full Cedarville experience. Little brothers and sisters lived the dorm life and could really see what Cedarville has to offer. The fun was endless, and the hardest part, as always, was letting the li'l sibs go home after such fun times together.

The Cedarville Yellow Jackets played an intense basketball game on Saturday night, giving the opposing team a real fight. Brothers and sisters all over the stadium watched in awe as the Jackets went into overtime and fought their way to a well-deserved victory. Beaver-Vu Lanes in Beavercreak opened their doors

"It was nice to stay in the dorm and to go to the game and just have fun time together." (Hannah Burns) to anxious late-night bowlers, promoted through Student Life. A special ALT night offered a movie that both younger and older siblings enjoyed: "Up."

Sibs were identifiable not only by their smaller size, but also by the tee shirts that displayed Cedarville's logo and the title of the weekend. Along with the activities that were offered, siblings really enjoyed the fellowship involved in the weekend. They had the option of sleeping in their older siblings' dorms and really experience what college is like. Many also joined their siblings as they went to class, and li'l sibs had the opportunity to see what the average college day was like. Hannah Burns said her favorite part about Li'l Sibs weekend was "just being able to hang out with my sister. It was nice to stay in the dorm and to go to the game and just have a fun time together." Li'l Sibs weekend gave Cedarville students a taste of home while still here at school.

1 Older siblings sometimes have to help out the li'I sibs during beachball volleyball, but it's still a load of fun! 2 Li'l Sibs get pretty excited about the rock wall! It's not something they get to experience every day. 3 Aw, how cute! 


\section{SPRING PLAY}

Drama at Cedarville this year focused on the comedic fallout of mistaken identities. In April, much like the Fall performance of The Importance of Being Earnest, the Cedarville University Theatre Department presented another comedy of errors, See How They Run, the classic English farce by Phillip King.

In this production, the sporadic comings and goings of an actor (Clive), actress (Penelope), cockney maid (Ida), four men in clergy suits (Lionel, Bishop, Reverend Humphrey, and The Intruder) and a church-going scold (Miss Skillon) who unknowingly gets into the cooking sherry, all contributed to a presentation of mistaken identities and constant laughter from the Cedarville student body, faculty, staff, and community.

According to the Dramaturg, Katherine Nelson, "See How They Run honestly portrays the culture of life during World War II and did not remove audience members of the time from their struggles. Rather, the play showed them the potential for humor in the conflicts."

Many of the cast members, including Dylan Cimo, who played the part of Clive, and Josiah Hutchings, who played the part of Lionel, have taken the stage in DeVries Theatre multiple times, but even first-timers Sara Daransky (Penelope) and Emily Dykeman (Ida) wowed the crowd with their performances.

As always, those involved in making this play a reality did not disappoint the audience. Erin Schultz described the play as "by far the best [she] had ever seen before at Cedarville. It was entertaining and funny from beginning to end."

1 Josiah Hutchins coerces Keely Heyl into a drink from the sherry bottle. The few sips the characters take set the events in action for the entire play. 2 Emily Dykeman and Ben Lenox play the parts of Ida, a maid, and Sergeant Towers. 3 Dylan Cimo leaps over Keely Heyl, who seems to be having a bit of trouble staying on her feet. 


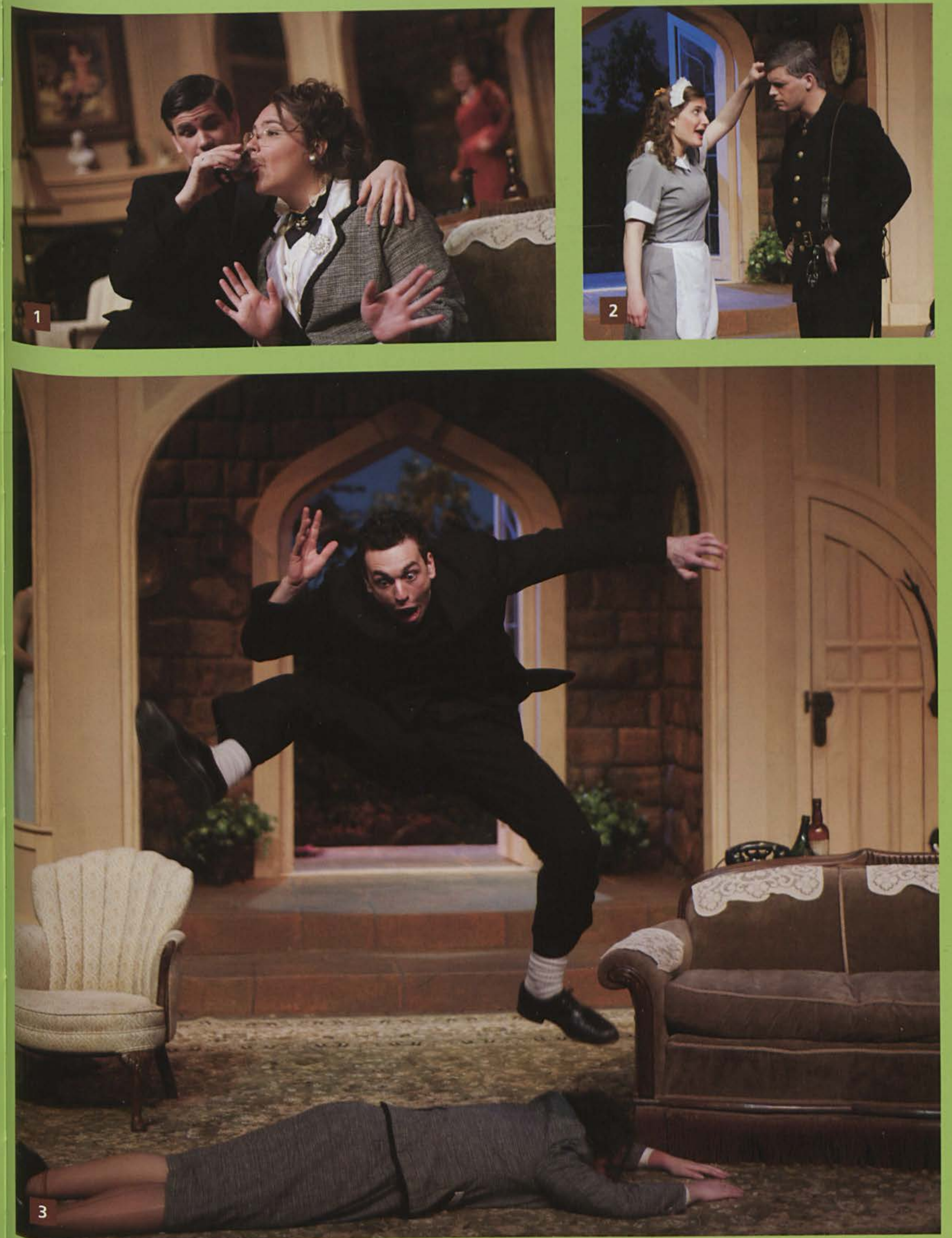




\section{ELLIV}

Step right up! Come one, come all, to see the greatest show on campus! And many Cedarville students did just that. On that Saturday night, students flooded the DMC. Groups of students came dressed as characters from movies, video games, and books. Particularly notable themes of the night included a group of guys dressed as army men, complete with their weapons, poses, and platforms to stand on; characters from Mario; and a team on Minios and Gru from Despicable Me. Mostly, those who didn't go as a theme dressed in formal attire.

Designed around a lively circus theme, Elliv opened with a pre-show act that featured an illusionist and a performer who juggled and swallowed fire. To begin the annual show, cannons mounted on either side of the stage fired, and Willow Smith's "Whip My Hair" filled the chapel.

Many diverse performances comprised this year's Elliv. Musical performances of popular songs such as "Don't Stop Believing" and "Living on a Prayer" were a hit, as was "Hey Jude," performed in a tribute to The Beatles. Acts this year also featured dancing in its various forms. There was hip-hop, ballet, and swing dancing. Dr. Brown's summary of the year's chapel messages in the form of the "Ask Jack" rap was definitely a quality performance all its own. The tradition of the Elliv Rock was also continued for its second year in a row, as deserving students were recognized for their accomplishments in performing arts, athletics, campus impact, and unique talents. An award was also given for the best campus-wide event of the school year.

More than just providing an evening of fun with friends, Elliv showcased the work of many talented Cedarville students. Elliv proved itself a huge success and was without a doubt the greatest show on campus.

1 Candy Hill and her back-up dancers start the show off with a bang! Or with a whip, rather. 2 Jordan Doyle and Allistar Littrell challenge Chris Voltz for the position of SGA chaplain. The contenders had some...interesting ideas about how to run chapel. 3 With their performance art presentation, the Army Men won the contest for best costume. They looked so real! Or well, so plastic. Realistically plastic? 


\section{ELLIV}

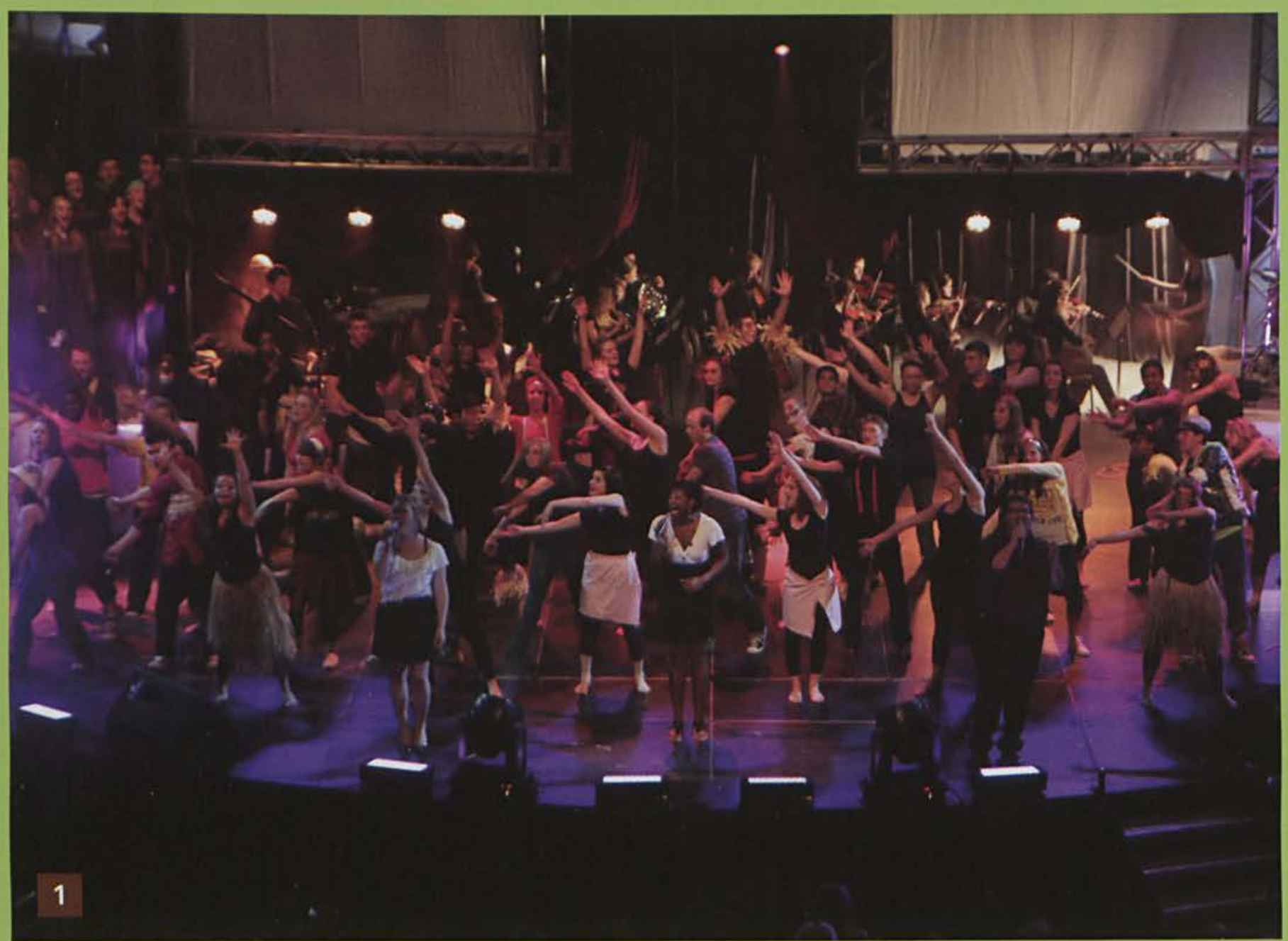

1 For the final number, all the performers return to the stage to sing "Hold Your Dream" from the movie Fame. 2 Brad Augustine and Dr. Brown break it down with the "Jack Attack" rap. 3 Richard Lozada tries to woo Hannah Denton during "Just the Way You Are," but she doesn't look like she's buying it. 4 The pre-show starts in true circus fashion with a live fire-handler. 5 Zach Seelye, with back-up from Dexter Carpenter on the bass, sing the Mumford \& Sons hit "The Cave" to the excitement of many students. 

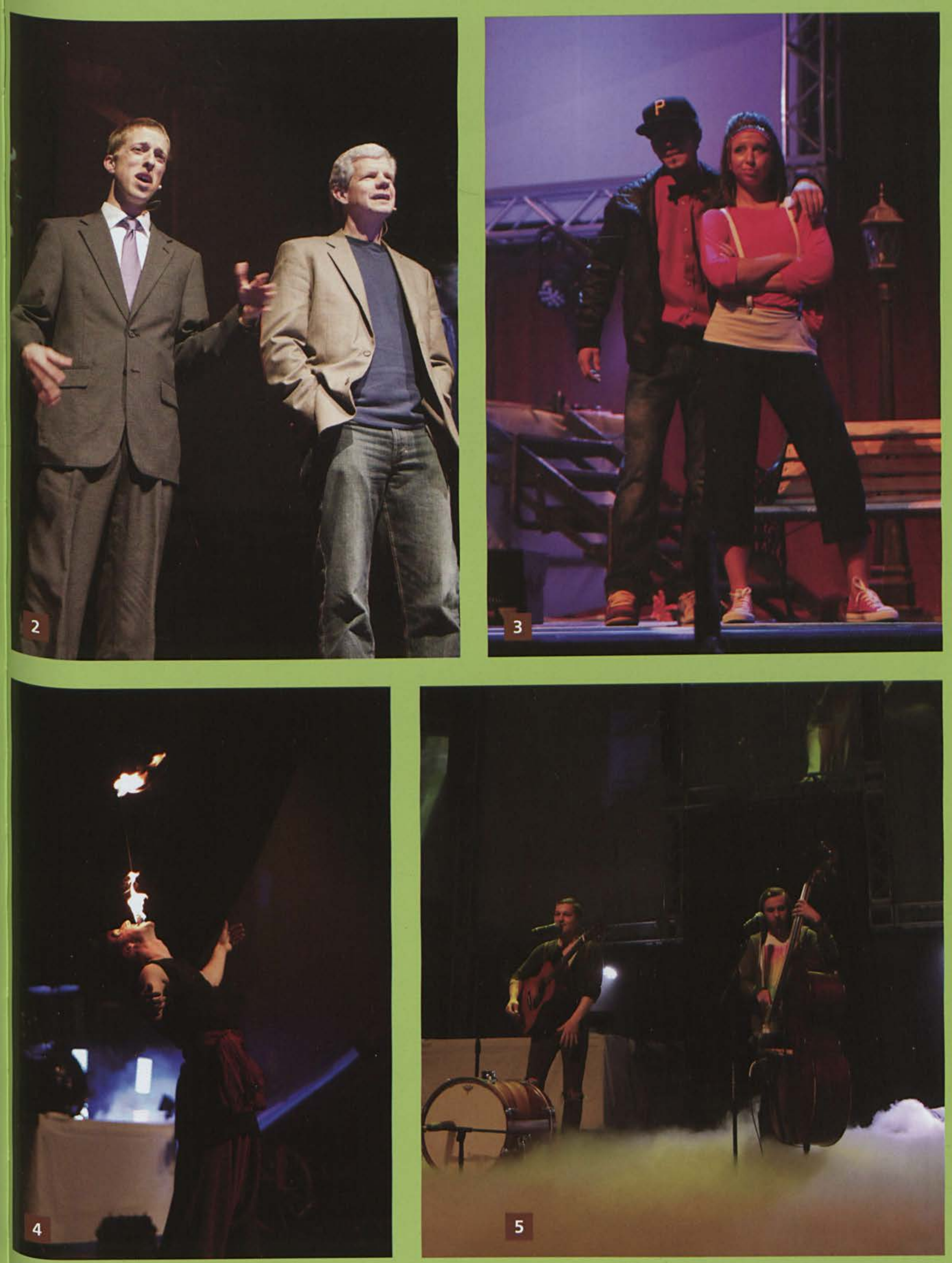


\section{FACULTY/STAFF of the YEAR}

Greg Couser, Professor of New Testament and Greek, viewed his job as more than just a paycheck. He looked at his encounters with others, including students at Cedarville, as an opportunity to advance the kingdom of God.

And this outlook did not go unnoticed. Couser received the Faculty of the Year award March 29 at Faculty Recognition Chapel. He said his family and Bible Department Chair, Chris Miller, did a good job of surprising him and that he did not expect to receive the award. "It was a humbling and sweet surprise," he said.

Couser certainly liked teaching college students. "I enjoy being able to teach the word of God to a group of people who are just at a crucial point in their lives," he said. "They are finding out what they really believe and how that affects their life."

When Couser was not teaching, he could often be found investing in students' lives. "I have lots of students that come to my office to talk about all kinds of stuff," he said. Couser and his wife even counseled couples that were getting married.

Kylee Husak, President of Student Academic Advisory Board, said, "Dr. Couser has a really good reputation at Cedarville."

Kim Ahlgrim, Staff Member of the Year, earned her Bachelor's degree at National Louis University in education. She earned her Masters at Wright State University in Marriage and Family Therapy, and at Cedarville, she specialized in Presentations, Group Dynamics, and Student Success. She enjoyed caring for her family, reading, seeing the ocean, researching genealogies, studying history, and collecting antiques. She made an impact on several students' lives, dedicating her time and energy to helping students become the best they could be.

Kim Ahlgrim impacted so many lives, and this award provided the Cedarville community the opportunity to thank her for her service.

\section{Kim Ahlgrim graciously accepts her award. \\ 2 Greg Couser gives the students some appreciative words. \\ 3 The honorees pose with their awards.}

\author{
"Everyday is a day to \\ either give ground or \\ take ground for the \\ kingdom." \\ (Greg Couser)
}



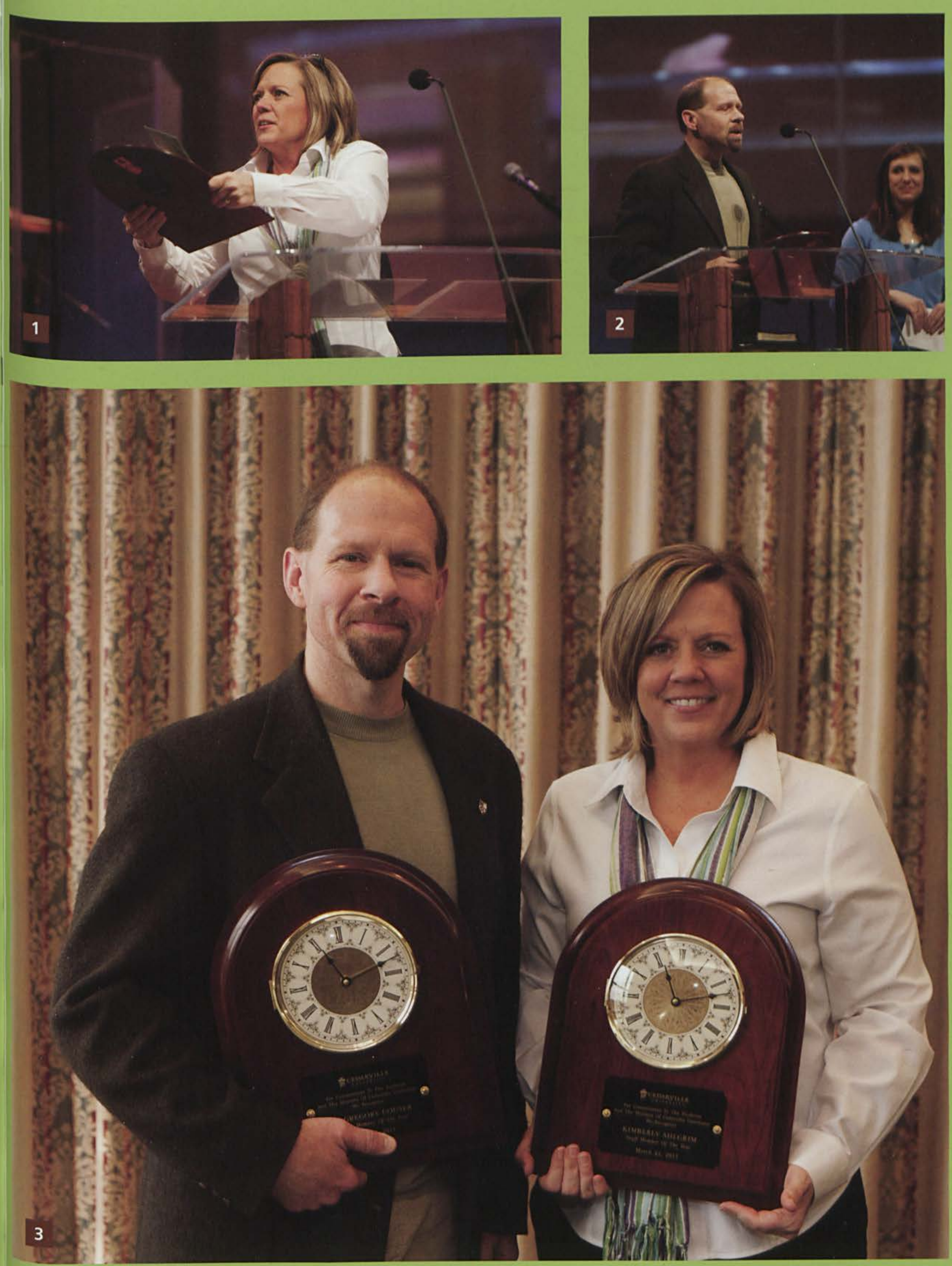


\section{HONORS CHAPEL}

Close to a hundred academic awards and scholarships were given out at Academic Honors Day Chapel. "It was cool to see Cedarville recognize the efforts of the quality individuals who walked across the stage to receive welldeserved awards," Justin Nichols said. Nichols received the Roloff Incentive Award. This was awarded to a biological sciences student who was involved in community service or leadership roles.

Rachel Greenwood, a psychology major, also wanted to use her career to help those who need help. "I would love to work with those living in the inner city that cannot afford counseling, but are in need of love and restoration," she said after accepting the Kimberly S. Ahlgrim Counseling Scholarship.

Other awards include the Sandra Harner Technical and Professional Communcation Scholarship, presented to William Brannon, and the Mary Jane DeBlanc Missions Award, given to Julie Christiansen.

The Academic Honors Day Chapel is an encouragement to all students, both who recieve awards and who do not. For students who do: their hard work and time have recieved attention, and those late library nights are not pointless; for students who don't: more of a push for the next year.

"Therefore, since we are surrounded by such a great cloud of witnesses, let us throw off everything that hinders and the sin that so easily entangles, and let us run with perseverance the race marked out for us."

(Hebrews 12:1)

Julie Christiansen accepts the Mary Jane DeBlanc Missions Award from Dr. Miller. This scholarship is awarded each year to a female student preparing for full-time ministry. 2 Rebekah Lynch smiles after receiving the Ruby Jeremiah Scholarship from Mrs. Brown. 3 Gabriel Pyle, an Industrial Design major, accepts his award from the Chair of Art and Design, Professor Terry Chamberlain. 


\section{JUNIOR/SENIOR BANQUET}

Cedarville's Junior/Senior banquet, affectionately known as JS, is a formal event organized by the junior class in honor of the graduating seniors. This year's theme, Urban Interference, incorporated the idea that the heartbeat of a city is found in its art, music, and industry. Holding true to the theme, this year's surprise location was held at the East Club Lounge in Paul Brown Stadium, nestled within the heart of Cincinnati. The venue encouraged a less formal atmosphere as it boasted of fresh, vibrant, and creative table settings, decorations, and dress attire.

As far as JS interfering, it did that as well. Saturday night the monotony of daily life was broken as half of the student population headed to overlook the cityscape of Cinci and of course the Bengals field to enjoy a night of dinner, music, and dates. Stars Go Dim, a band that had previously opened for Switchfoot and Daughtry, provided the entertainment for the night. Their melodious indie/modern pop-rock sound and authentic lyrics provided the soundtrack to a night full of swagger and fun. It was a night made for memories as the senior class spent one of their last evenings amongst the friends who had become more like family.
"JS was a great last hurrah before graduation. I had a blast catching up with everyone, and I didn't mind having an excuse to dress up and get the group together for one last night out. It was definitely a great way to end senior year."

(Corwin Briscoe)

Emily Chiu and Kathryn Heckendorn, past roommates and forever friends, take the required backwards camera picture. 2 Robbie Carter, Katherine Watson, Kara Obuchowski, and Joshua Paul Roose spend some time taking silly photos. 3 The Bengals stadium provides a lovely room for the night of the banquet. 


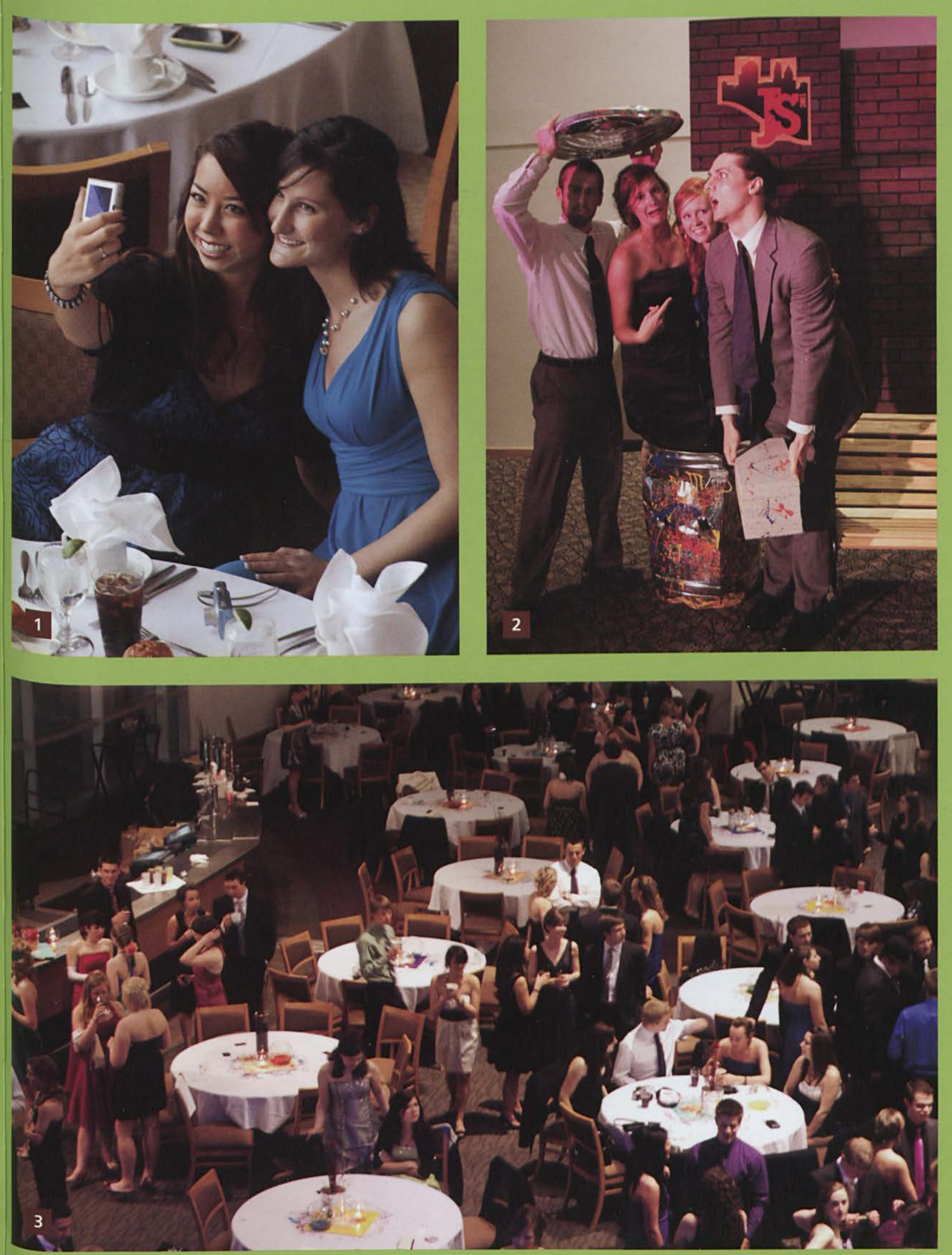




\section{JUNIOR/SENIOR BANQUET}

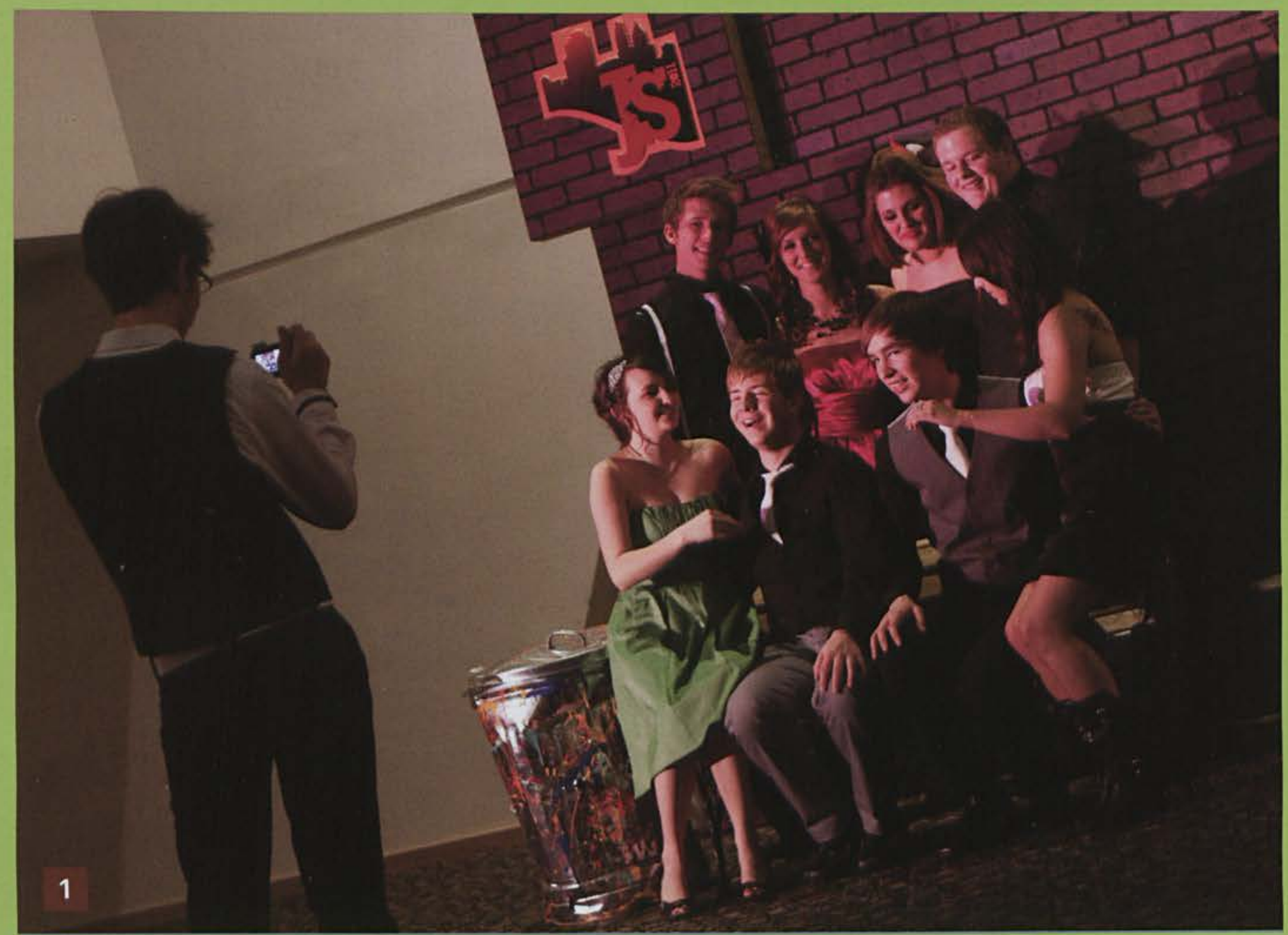

1 JS gives students a chance to get dressed up and take plenty of pictures. What better way to remember their junior and senior years? 2 The JS committee spent hours and hours getting the Bengels stadium ready for the night of music and fun. 3 Brian Johnson presides over his friends during his JS photobooth. 4 Dr. and Mrs. Brown take the time out of their busy schedules to attend JS. 


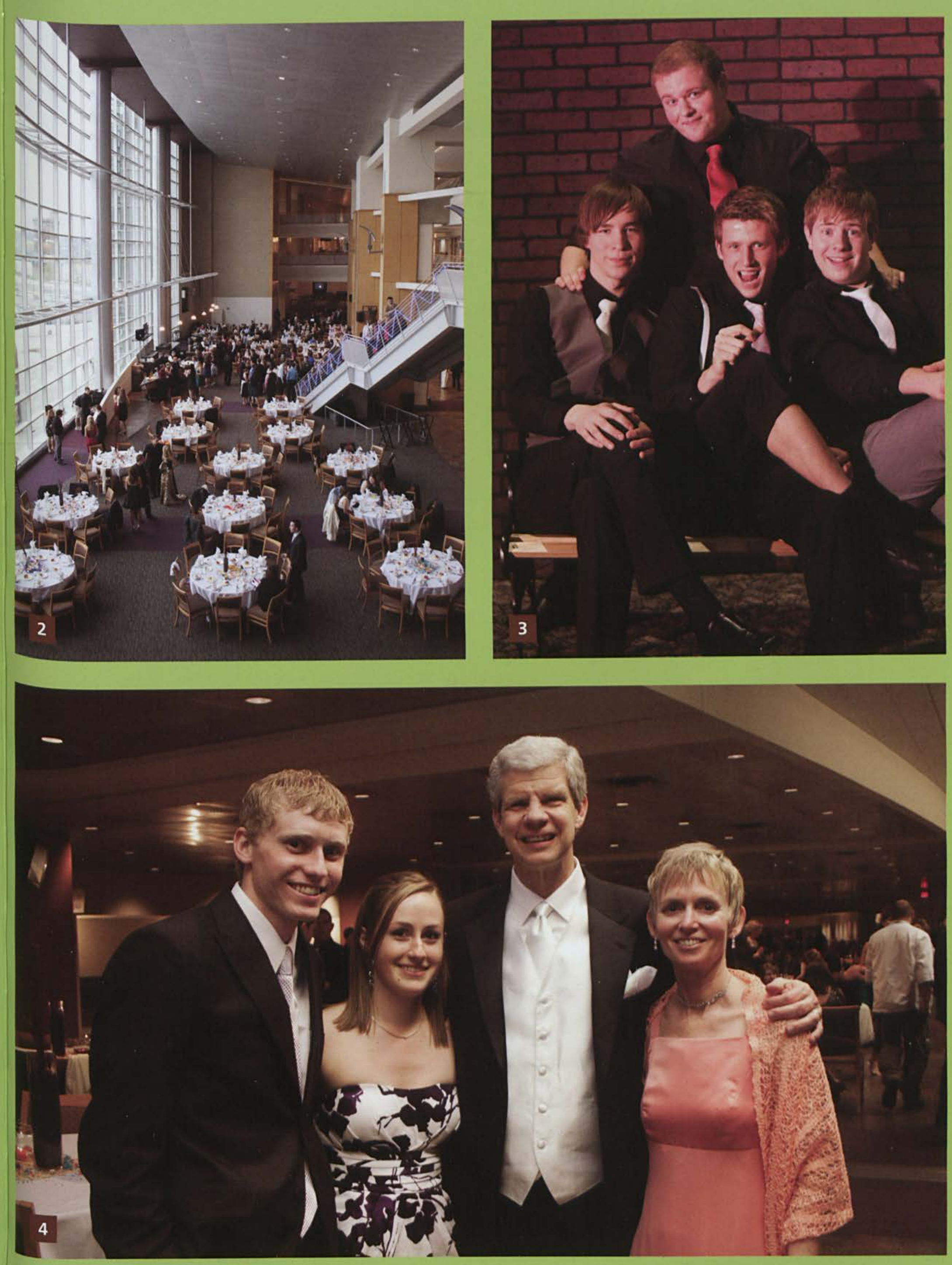




\section{SENIOR RECEPTION}

Upon stepping foot on the campus, students are introduced to the man, the myth, the legend that is Dr. Brown. He is Cedarville's biggest celebrity. To get a nod of approval, or a friendly "how are you" from Dr. Brown is a highlight for any day. Underclassmen may be wondering where he lays his head at night, secretly wishing to get an inside look into his life. Then after four years, it happens - the senior reception at Dr. Brown's.

Every year the Brown family is gracious enough to open their home to the graduating class. Students wore their Sunday best while they munched on hors d'oeuvres of cheesecake balls, fruit tarts, and sparkling punch. But the real highlight was the grand tour of the Browns' home given by Dr. Brown himself. He guided students through his home, graciously allowing them to poke through his personal life. As a side note, upon the tour, some students happened to notice, Harry Potter and the Deathly Hallows on his library shelf. They thought Dr. Brown couldn't get any cooler, but he did.

The afternoon culminated in personal conversations with our President and a photograph to remember the moment. The senior reception at Dr Brown's is always a highlight as students get to make last memories with their friends and spend time with our beloved president, Dr. Brown.

"It's really great to have a president who goes out of his way to get to know the students personally." (Caitlin Krop)

1 The Browns put out quite the spread of hors d'oeuvres for the visiting seniors. As college students, they definitely appreciate free food! 2 Dr. and Mrs. Brown take the time to reminisce with the senior students. 3 Shauna Acheson engages Dr. Brown in stimulating conversation during the reception. Students enjoy taking the time to have a talk with the University president. 

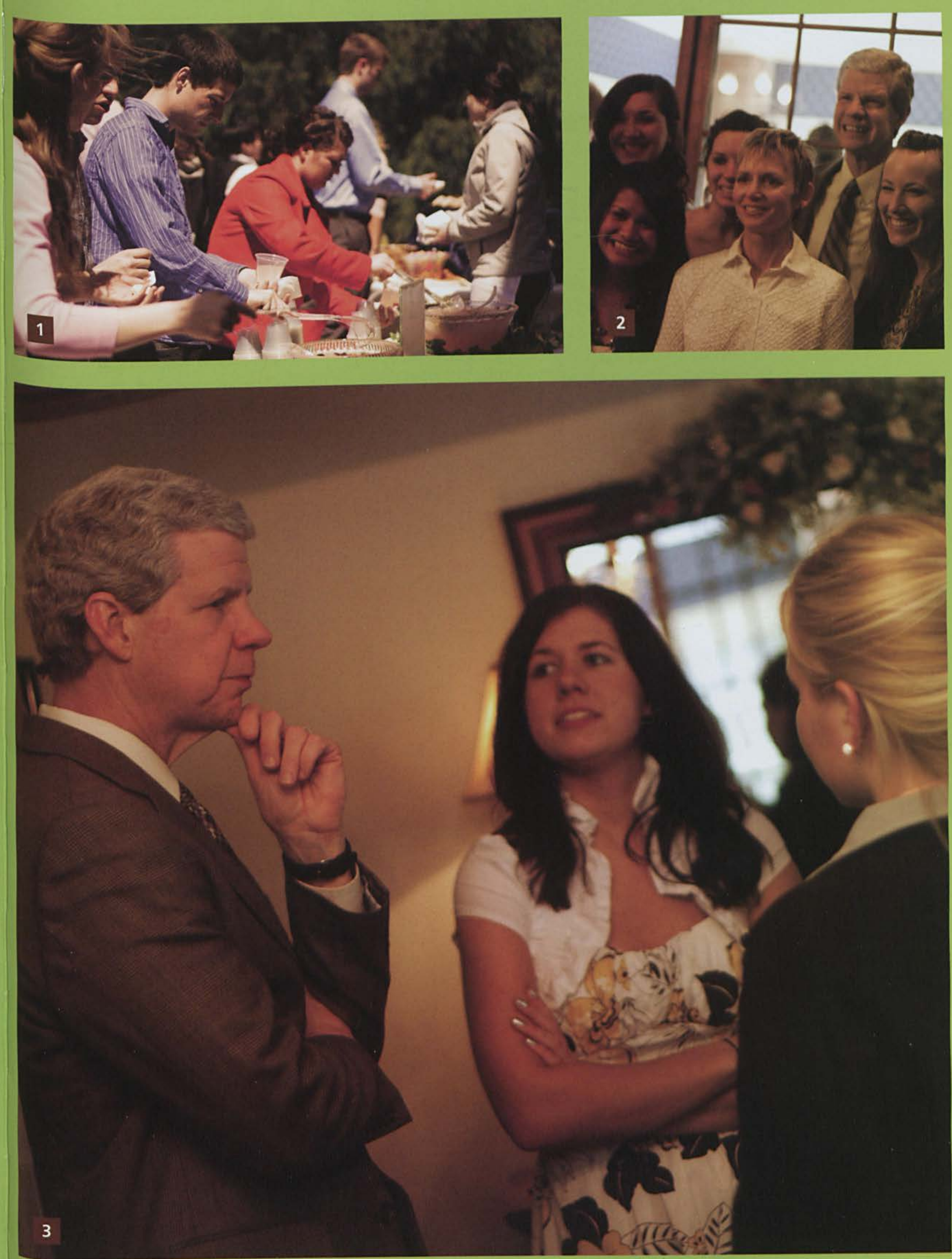


\section{COMMENCEMENT}

Rear Admiral Dr. Barry C. Black, 62nd Chaplain of the U.S. Senate, challenged the 608 graduates at Cedarville University's 115 th commencement ceremony to be open about their faith through the hope found in a risen savior.

"There will come days when your dreams may dry up," shared Black. "I challenge you to stay strong and continue to believe."

Cedarville President Dr. Bill Brown conveyed to the class a message on rising above the norm.

"When everyone around you is looking for an easy path," shared Brown, "your commitment to excellence and quality should stand above the rest."

Also, during commencement, three graduates were honored with the University's most prestigious student award. The President's Trophy, the highest honor for a graduating senior, recognizes leadership, ministry, community and campus involvement, athletic performance, and academic achievement. The recipients were Emily Shanahan, a communication studies major from West Carrollton, Ohio; Emily Chiu, early childhood education major, from Vestal, N.Y.; and Andrew Barfell, biology major, from North Royalton, Ohio.

After the ceremony, excited graduates spent the day taking pictures with their families and saying good-bye to their friends through tears. But commencement is a beginning: the beginning of each student's life after college.
"Graduation was the perfect way to end my time at Cedarville; I loved being able to graduate with my friends and share that time with my family." (Abby Keyser)

1 Jernelle Ward joins in the class song along with the her fellow graduates. 2 Tim Lukasiewicz, Garrett Rucinski, and Zach Seelye sing the class song, "Beautiful." 3 Dr. Brown address the graduates, calling them to make "slam dunk" choices. 


\section{COMMENCEMENT}

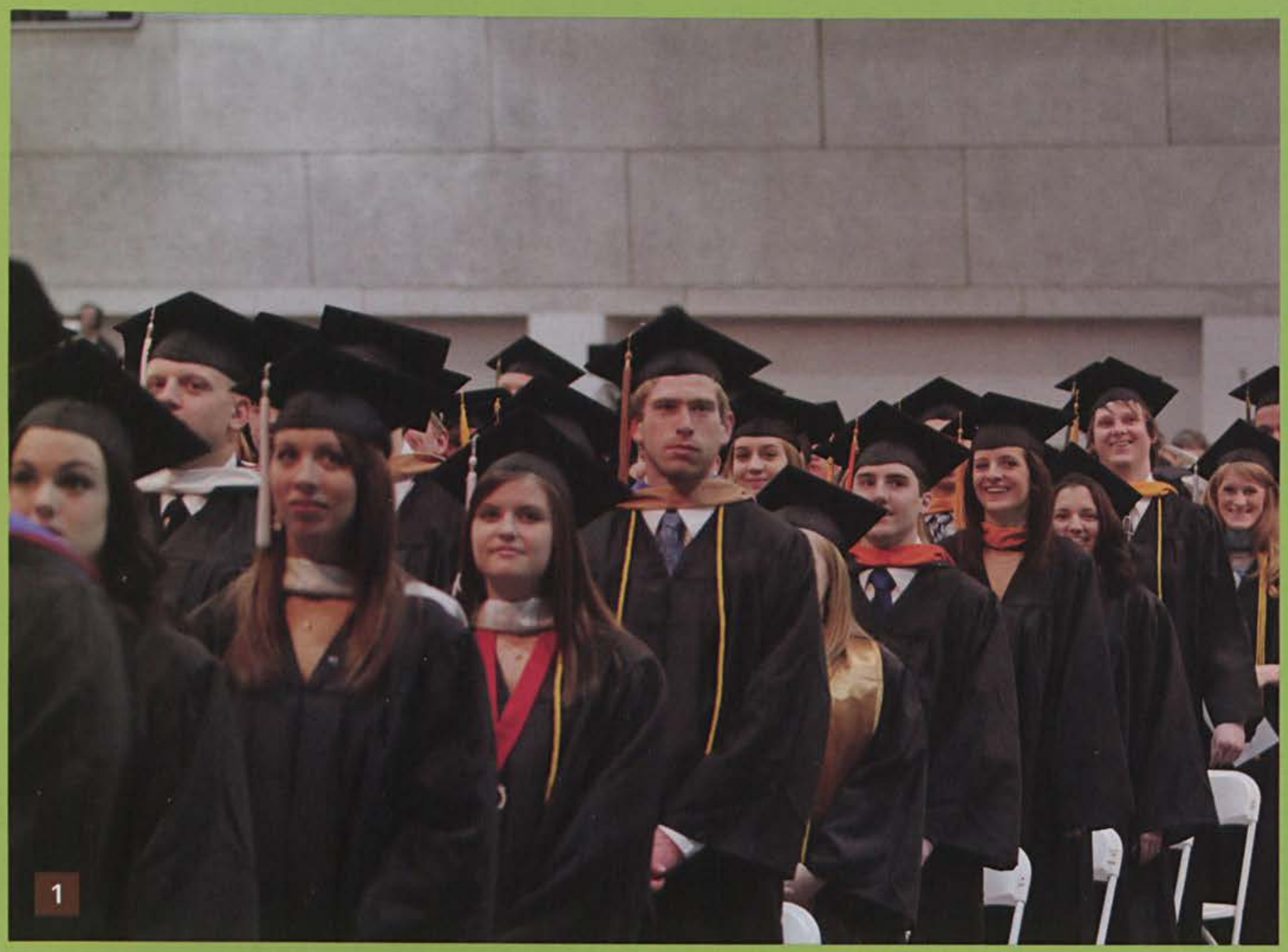

1 The graduates eagerly await the moment when they can walk across the stage and shake Dr. Brown's hand and receive their diploma. 2 Dr. Barry C. Black gives a rousing address to the graduates. He even started with a joke about putting bologna in your own life. 3 Andrew Barfell accepts his President's Trophy from Dr. Brown. 4 Few dry eyes are left at the ceremony as Emily Shanahan accepts her a ward from Dr. Brown. 5 Emily Chiu graciously receives her President's Trophy from Dr. Brown. 


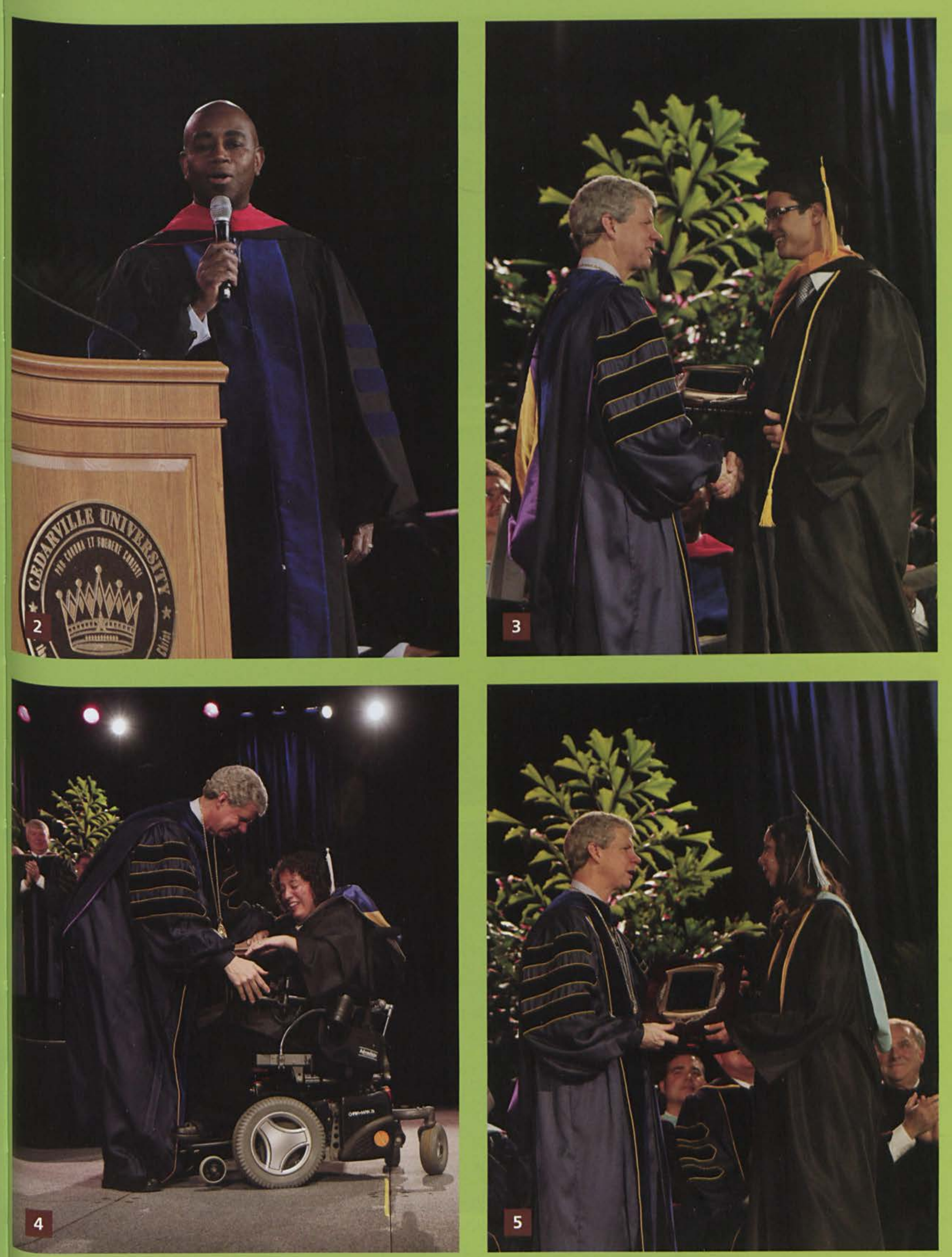




\section{YEARBOOK STAFF}

Layout staff,

I'd like to take some time to thank the three dedicated people on Layout Staff this year: Terri Elgersma, Peter Arthur, and Kelly Shaw. Your help with the book this year made my job much easier. I appreciate the three of you putting up with me especially since I'm two years behind the rest of you and wasn't sure what I was doing half of the time. Thanks for always turning in your assignments on time even at the end of the year when things got crazy. I will definitely miss filling your inboxes with mile-long emails of instructions. I wish the best to you all as you graduate and thanks so much for your help with this year's book. I could not have done it without you.

Kathryn Kramer

Dearest photo staffers,

Thank you for putting up with copious amounts of email and requests for coverage and hasty uploads. It's been a great year, and a privilege to work with such a talented group of photographers. You've brought your own creativity and personality through while still providing such awesome pictures to help remember the year. I want to especially thank Stuart, Caleb, and Cameron, because you guys literally seemed to be everywhere at once, always shooting and submitting the most fantastic photos. To my whole staff: you rock. Fo' realz.

Tyler Scott

To my writers:

Thank you for putting up with me this year. You guys were really great about getting deadlines in... even when I didn't exactly give you much time to get them in. Zack, though you came on late in the year, thanks for coming through when I needed a new copy writer. Christina, you were excellent! You were always willing to tackle those pieces and get them in for me, and you were AMAZING about getting it in on time. Dani, way to stick with me even when you had to email me to remind me about something. Megan, thank you for coming through in a clutch; I desperately needed more copy staff and there you were! You all were outstanding this year. Thank you, I couldn't have done it without you all!

Apryl Sniffen

1 Layout Staff Kelly Shaw, Peter Arthur, Terri Elgersma, Kathryn Kramer 2 Photography Staff

Rachel Hoffman, Stuart Li, Jordan Doyle, Caleb Wagner, Korinna Wagner, Lyssa Pasma Not

pictured Andrew Bash, Cameron Hill, Jessii Raymond, Ben Salzman, Christi Peterson 3 Copy

Staff Dani Holloway, Megan Spring, Apryl Sniffen Not pictured Zach Anderson, Jonathan Bundy,

Christina Burns, Lauren Trumble 


\section{YEARBOOK EDITORS}

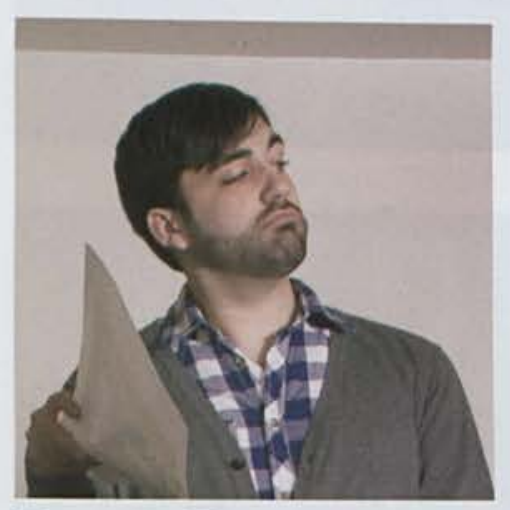

Brent Persun

Editor-in-chief

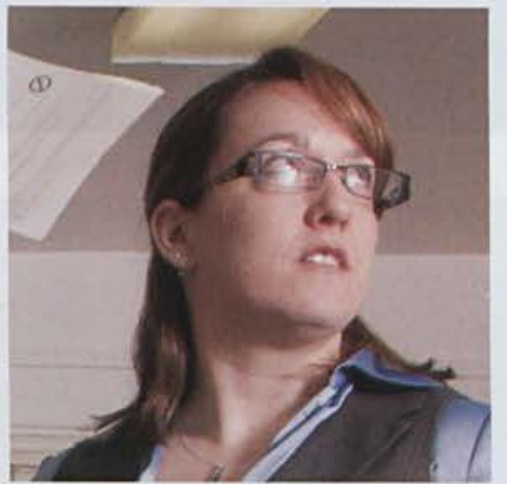

Cyndi Messer Advisor

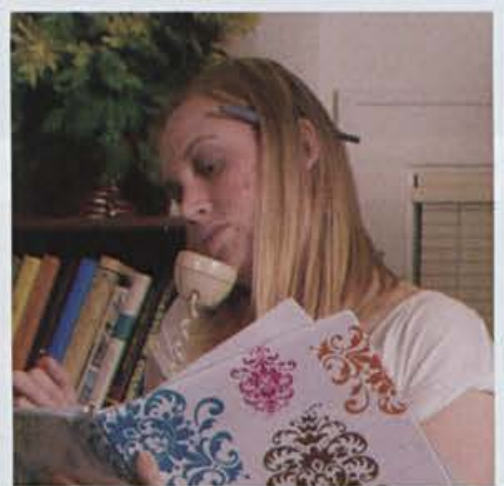

Erin Schultz Admin. Asst.

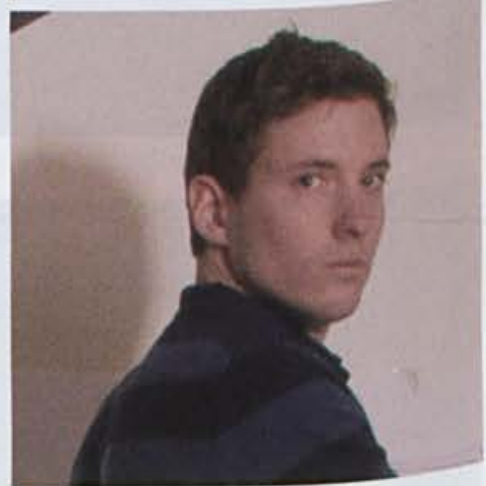

Nathan Anderson Design Editor

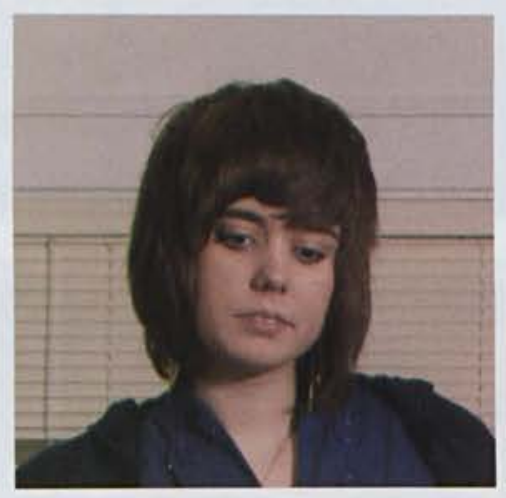

Kathryn Kramer Layout Editor

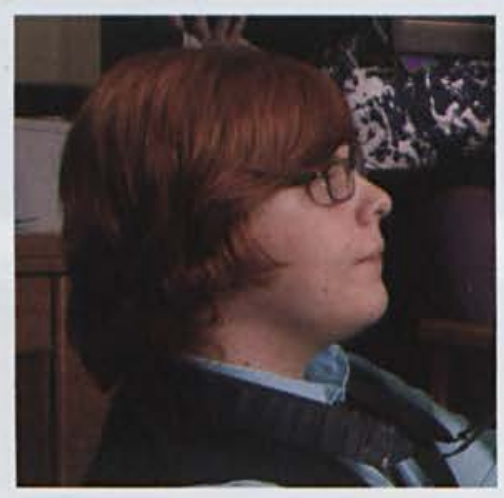

Tyler Scott Photography Editor

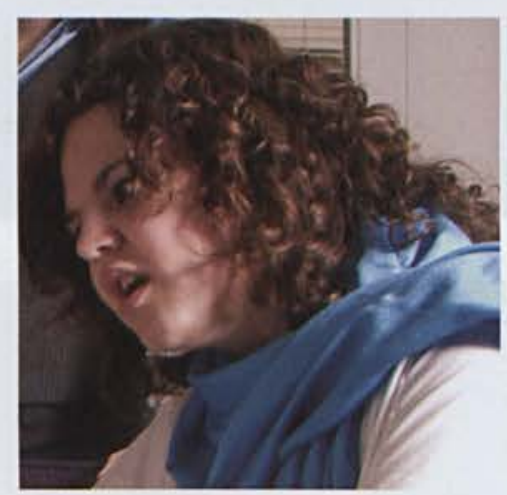

Apryl Sniffen

Copy Editor 

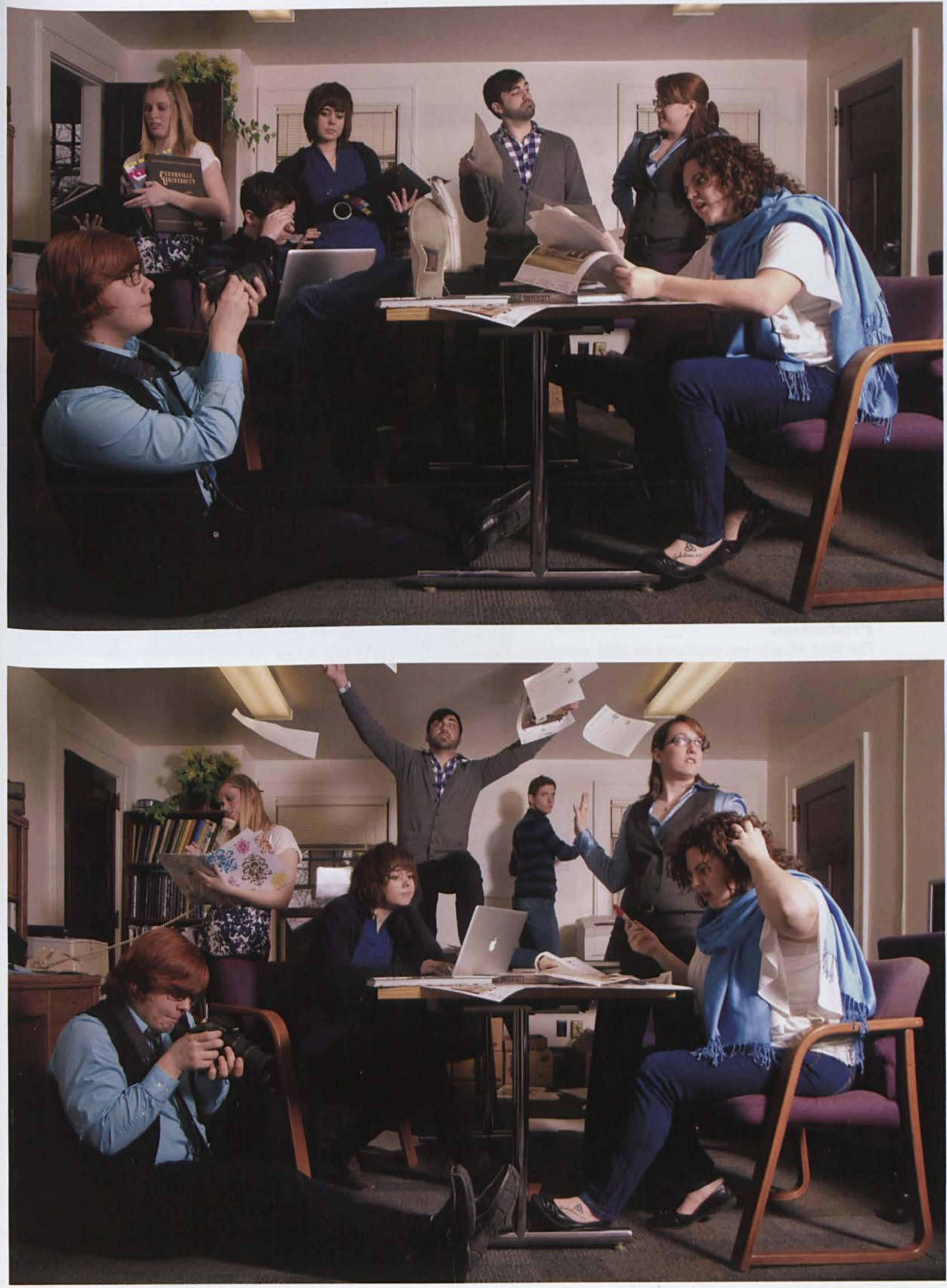


\section{COLOPHON}

\section{Publisher}

The 2011 Miracle was published by Jostens, Inc. It was printed at their plant located in State College, PA. The Jostens representative was Eric Howard, and the plant coordinator was Crystal Gault.

\section{Cover}

The cover is custom screened and is custom art designed by Nathan Anderson.

\section{Paper Stock}

The paper for this book is $80 \#$ gloss finish. 256 all color pages were used.

\section{Color}

The 2011 Miracle was printed with four color process ink.

\section{Design}

The 2011 Miracle yearbook design theme was created by Nathan Anderson, and other design work is credited to Kathryn Kramer and Brent Persun.

\section{Theme}

The 2011 Miracle theme was a combined brainstorm of the editorial staff with input and commentary from the Miracle staffers.

\section{Production}

The 2011 Miracle was produced on IBM computers. Layouts were created using Adobe InDesign CS4 and CS5.

Photos were cropped, resized, edited using Adobe Photoshop CS4 and CS5. Copy was typed in Microsoft Word and then imported into InDesign.

\section{Typography}

The main fonts used in the book are Latin Modern Roman and CartoGothic. Stories are 10 point Latin Modern Roman. Captions are 11 point CartoGothic. Titles and divider text are various sizes of Bernard Helvetica Neue. Page numbers are 15 point CartoGothic.

\section{Photography}

The majority of pictures were taken by Tyler Scott and his photography staff. Student submissions were also accepted. Several photos were also taken by Scott Huck, photographer for Cedarville University. Jim Rainey acted as the DaVor representative for portraits.

\section{Inquiries}

The Miracle Yearbook office may be contacted for additional information about this book's production at:

Miracle, Cedarville University

251 N. Main St.

Cedarville, Ohio 45314

(937) $766-4995$

miracle@cedarville.edu 


\section{EDITOR'S PAGE}

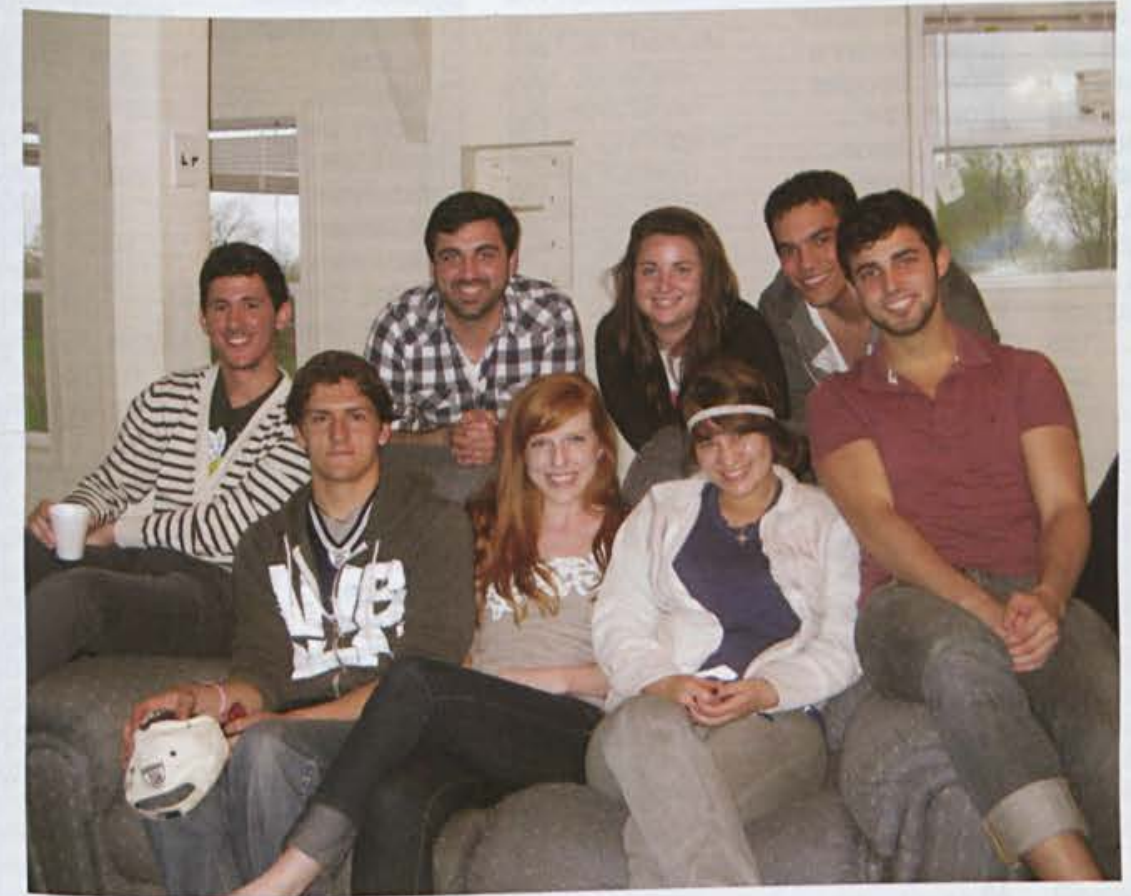

Well first I want to say thank you to my editorial staff. I didn't always know how to tell you what I wanted, but you managed to do a pretty good job anyway. Special shout out to Kathryn who definitely did an amazing job. And to Cyndi who has been so supportive throughout this whole publication process. I also want to say how incredibly thankful I am to my amazing professors, especially Mrs. Harner and Dr. Heath, both of whom have taught me so much about writing and life.

Finally I want to say how much I love all my friends who have been with me through this rather insane final semester of my undergrad career. All of you are so fantastic, and I will cherish all our memories together.

And now I'm moving to Boston!

-Brent
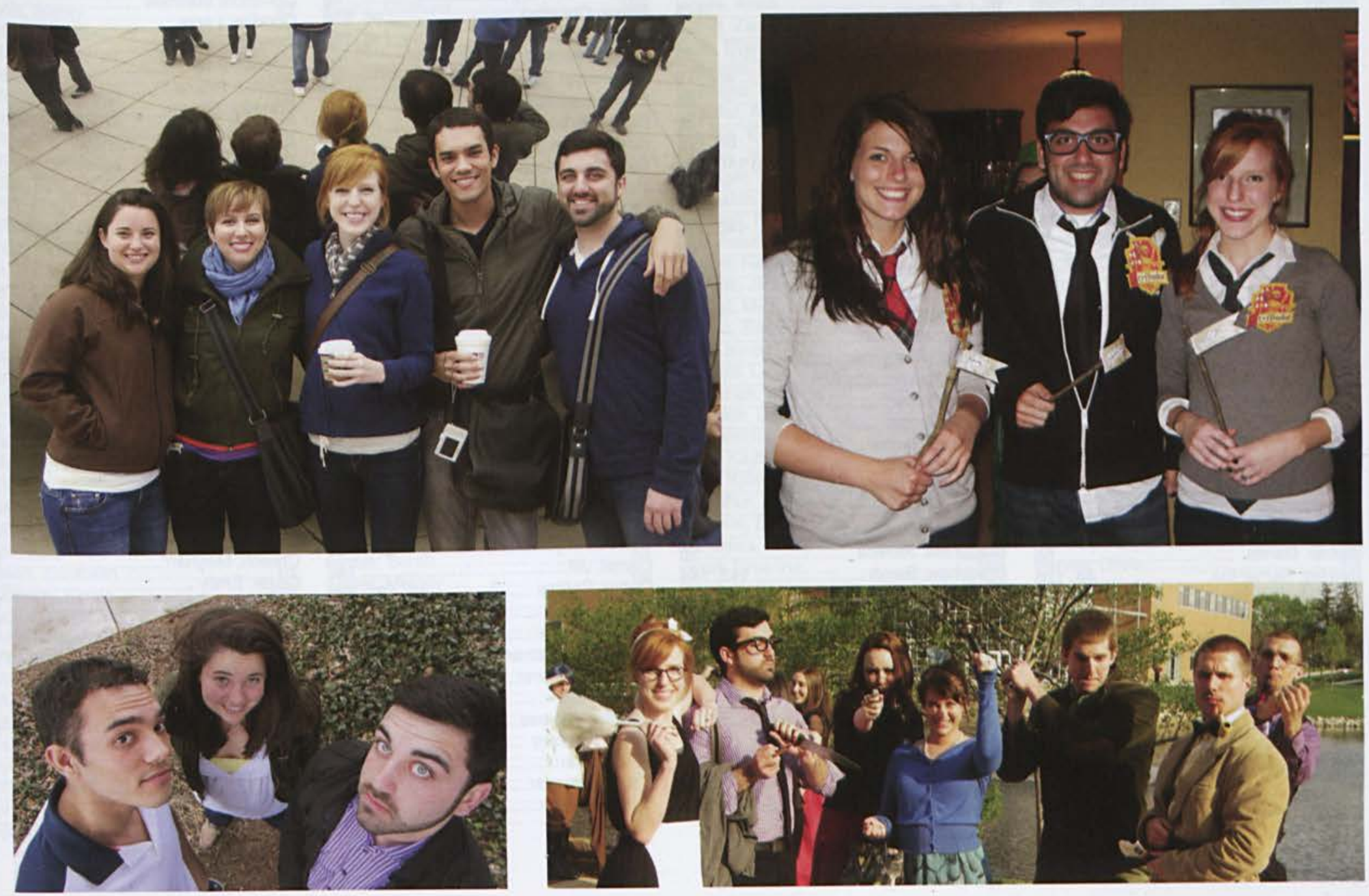
INDEX

A

Abbate, Erin

Achenbach, Kelly

Acheson, Christopher............................. 176

Adams, John...................................... 58

Adams, Mitchell ................................... 58

Adams, Parker ..................................... 160

Adler, Jonathan ................................... 126

Adrian, Bryan......................................... 96

Adriansen, Daniel

Ahlgrim, Brianna.................................... 96

Aho, Eric

Ahrens, Emily ........................................ 176

Ahrens, Hanna...................................... 176

Ajamian, Alexandra.............................. 176

Allen, Amanda ..................................... 176

Allen, Angela ........................................ 126

Allen, Molly ........................................... 176

Alley, Caleb............................................... 96

Amburgy, Carline ................................. 176

Ames, Robert ............................................ 58

Amick, Lauren........................................96

Amtower, Jessica...................................... 58

Anderson, Bradley ............................... 176

Anderson, Calvin ....................................58

Anderson, Frederick ........................... 176

Anderson, Michael.

Anderson, Nathan......................240, 242

Anderson, Stephanie ................... 18, 126

Anderson, Zachary ............................. 238

Andres, William .................................. 177

Andrews, Rebekah …............................ 58

Ansiel, Heidi......................................... 156

Armstrong, Mary.

Armstrong, Samuel...

Arni, Sarah

76

Arthur, Peter .............................. 177, 238

Arthur, Rachel.................................... 126

Ashley, Jonathan ................................. 126

Askew, Jessica ..................................... 177

Askew, Luke.......................................... 177

Atkins, Jamie .............................96, 162

Augenstein, Emily................................ 177

Augustine, Bradley..................... 177, 222

Ault, Kayla......................................... 58

Aviles, Brian

154

\section{$B$}

Bach, Moriah ......................................... 96

Backer, Laura..................................... 148

Bacon, Daniel ....................................... 126

Bacon, Grant ...................................... 177

Bacon, Victoria ...................................... 58

Baden, John ...................................... 177

Bailey, Julita.......................................... 177

Baker, Jonnah........................................ 58

Baker, Stephanie .................................. 177

Baldwin, Dane .................................... 126

Balint, Jennifer...................................... 177

Balkus, Alexandra...............................96

Banachowski, Jasmin ......... 58, 148, 162

Banz, David .......................................... 58

Barber, Daniel....................................... 58

Barclay, Samantha...................... 48, 126

Bardakjy, Timothy ................................. 96

Barfell, Andrew .......... 177, 214, 234, 236

Barfell, Kaitlyn......................................... 96

Barkas, Julianna ...................................... 58

Barker, Jacob..................................... 126

Barnes, Geoffrey ................................ 177

Baron, Daniel.......................................... 58

Barron, Hannah .................................... 126

Bartholomew, Erica .............................. 144

Bartling, Jason ...................................... 177

Barton, David....................................... 164
126,238

Bashore, Andrea.

58

96

Bates, Sarah.......

attis, Christine

126
177

Batts, Michael ..................................... 177

Baumer, Jeanetta ................................... 96

Beach, Michael ..................................... 58

Beach, Ryan

Beachy, Rachel.

... 58

Beauchemin, Faith ............................... 177

Beck, Geoffrey .................................... 177

Beckler, Joshua ...................................... 96

Beelen, Alexander ............................. 168

Bellanti, Brandon .................................. 58

Belote, Rebecca …............................. 177

Belth, Rachel ........................................ 58

Bender, Charles.................................... 178

Bender, Jason............................ 140, 177

Bender, Kevin ........................... 140, 178

Benjamin, Marcus............................... 178

Bennett, Alysia.................................... 142

Bennett, Elizabeth .................................... 96

Bennett, Rebecca ................................... 58

Bennington, Christopher....................... 158

Benson, Heidi ...................................... 178

Bercaw, Andrew.................................5 58

Bernecker, Mary ................................. 126

Bernhard, Benjamin .............................. 178

Berrigan, Jennifer .............................. 126

Berwager, Sarah .........................50, 178

Beschta, Rebecca ............................. 178

Betori, Stefanie ..................................... 126

Betz, Stephen ......................................... 58

Betzold, Haeli ................................................ 178

Beverly, Nicole ...................................... 59

Bewley, Molly ........................................ 126

Bierer, Jesse ........................................ 178

Bierer, Leah ......................................... 59

Bigler, Nicholas...........................158, 178

Bird, Bethany ...................................... 179

Bisbee, Lauren ...................................... 59

Bitzer, Deborah ........................................59

Black, Dylan................................. 46, 179

Blackburn, Valentina ........................... 126

Blackburn, Vawny ................................... 126

Blackstone, Michelle .................... 80, 126

Blagg, Ethan .......................126, 146, 160

Blair, Amber ...................................... 179

Blair, Ryanna ........................................ 59

Blauert, Jonathan ..........................140, 149

Blunt, Joel.............................................. 59

Boice, Stephanie …................................... 179

Bollback, Jessie ................................... 179

Bond, Nathaniel ............................ 59, 80

Bonifas, Jonathan .................................. 59

Boucher, Alexander ............................. 110

Bouws, Todd ............................................ 96

Boward, Alicia .......................................... 96

Bowes, Hanna ......................................... 179

Bowman, Rachel ................................. 126

Boyd, Heather.................................... 126

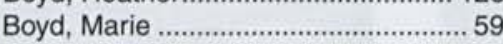

Bracy, Jordan....................................... 179

Bradshaw, Deanne ............................... 142

Bradshaw, Jessica......

Bradshaw, Sarah

Brady, Patrick

Brandt, Katie .........................146, 160

Brannon, William................................... 226

Braun, Nathanael.................................. 126

Brenneman, Kyle .................................. 179

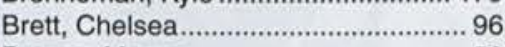

Brewer, Megan ....................................... 59

Brewer, Rebekah .................................... 96

Breyfogle, Emily.

Briggs, Lydia...

179

riggs, Nathan.

Brindley, Amanda

Briscoe, Corwin

Brittan, Michael

Brittan, Sarah

Broad, Emily.

Brock, Bethany ......

Brooker, Matthew

Brooks, Caitlyn

Brooks, Nevin

Brown, Alisha.

Brown, Amanda.

Brown, Amy.

Brown, Andrea

Brown, Andrew

Brown, Benjamin

Brown, Breanna.

Brown, Douglas

Brown, Erin....

Brown, Jacob.

Brown, Joshua

Brown, Michael...

Brown, Nathaniel

Brownfield, Rachel

Brownfield, Sarah

Browning, Hayden

Brueckner, Eric

Bruer, Elizabeth....

Brunelle, Jessica

Brush, David

Bryan, Hannah

Bryan, Laura

Bryant, Trevor..

Buehler, Tiffany

Buesgens, Micael

Buhr, Kristin .

Bundenthal, Landon.

Bundy, Joel ...

Bundy, Jonathan

Bunting, Luke..

Bunton, Amanda

Burkholder, Brittany

Burkholder, Mary

Burns, Christina.

Burrell, Nathaniel

Burton, Rachel..

Busemeyer, Sarah

Bush, Austin

Bush, Christopher.

Bush, Emily

Butterfield, Karen

Byerly, Alivia

\section{C}

Caldwell, Corey

Campbell, Benjamin

Campbell, Grace.

Campbell, Hannah

Campbell, Jack

Campbell, Stephen

Cann, Carolyn...

Cannon, Victoria

Carmichael, Amy

Carns, Meagan

Carr, Stephanie

Carril, Gregory.

Carroll, Amy

Carroll, Jill.

Carter, Robbie

Carver, Eric..

Case, Carolyn

Casement, Nathaniel

Casillo, Margaret

Casper, Leah

Castillo, Chelsea

Castle, Lindsey

Cates, Brian.

Cathey, Joseph

Cato, Grayson.

son.....................

. 146,160

160

97

\section{2}

81

.... 181

$.127,140$
148,162

.... 97

.. 59

62

181
59

59

228
59

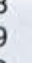

.

. \\ .}

.


Cummings, Sara

Cundall, Casey.......

Curby, Casey ......................................6 60

Curby, Erin ……...................................... 182

Curran, Rebecca ………………............. 97

Currie, Rachael..................................... 127

Curwick, Elizabeth ..................................97

Cushing, Marissa..................................... 127

Custer, Gavin .......................................... 97

Cvetich, Rebekah ................................. 128

\section{D}

D'Anna, Mark ........................................ 128

D'Anna, Matthew ................................... 182

Dahl, Amy .............................................. 97

Dahnke, Jessica ...................................... 162

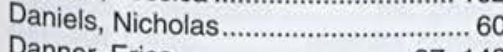

Danner, Erica................................. 97, 142

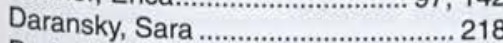

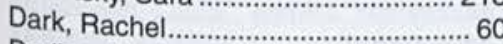

Darling, Marie ....................................... 182

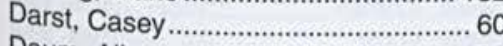

Daum, Alisa …………........................... 128

Davenport, Nathan ............................... 168

Davies, Jordan ........................... 146, 160

Davis, Andrea ....................................... 128

Davis, Jill ............................................... 142

Day, Kristen ................................................ 60

Day, Megan ............................................... 60

Deakin, Nathan..................................... 154

Dearden, Timothy ................................... 182

Dearth, Stephen ………........................ 182

DeBoer, Kyle................................ 164, 183

DeBoer, Rebekah ................................ 183

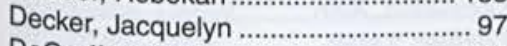

DeGraff, Hayley ....................................... 183

Deitner, Sarah..........................................97

Demers, Jonathan ................................. 183

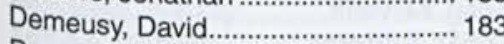

Denen, Alyssa ...................................... 183

Denen, Sarah …………………................ 60

Dennis, Becky.......................................... 97

Denton, Hannah

DeRossett, Garrett........................... 60, 90

DeRusha, Emily..................................... 183

DeValve, Suzanne ................................... 90

Devereaux, Brooke ................................. 98

Devereaux, Stephen ............................. 183

DeVinney, Thomas.............................. 183

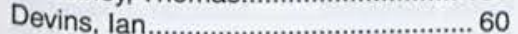

DeVos, Gregory ....................................... 60

Dewese, Kendra ................................... 183

DeWitt, Brittany........................................ 61

Dias, Jonathon ...................................... 183

Dice, Joy ............................................... 166

Dietz, BrookeLyn .................................. 98

Dinse, Molly.........

Dion, David.....

Dirks, Andrew

Dix, Matthew.

Dix, Nathan.

Dixson, Benjamin

Dixson, Jennifer..

Docter, Stephanie

Dodson, Rebekah.

Doellstedt, Andrina

Dolan, Kevin ...................................... 183

Dougherty, Eimile .................................. 128

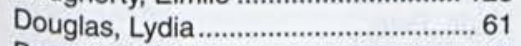

Downs, Adam ….............................. 183

Doyle, Jordan ........................128, 220, 238

Doyle, Michelle...

Drake, Katherine

48,128

Dreisbach, Hannah $\ldots$

Dresbach, Kyler .................................... 128

Dreyer, Laura ......................................... 183

Drimalla, Jean................................... 128

Duarte, Aaron..

DuBeau, Anna

98

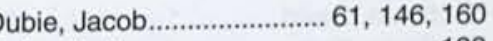

Dulin, Joel............................................. 128

Dunlap, Allison............................ 183, 214

Dunn, John ......................................... 183

Durant, Kelsey .......................................61

Durbin, Christopher ............................ 128

Dykeman, Emily................................... 218

Dykes, Lisa ................................... 76, 98

Dyksterhouse, David ............................ 98

Dykstra, Leanne ….......................... 8, 98

Dykstra, Nicole

... 61

Dyson, Jessica

\section{$E$}

Eachus, Thomas................................. 183

Earl, Jonathan ..................................... 140

Earwood, Bryan ....................................99 98

Eaton, Christopher............................... 128

Edens, Kathryn ................................... 184

Edmonds, Tiffany .................................. 184

Edwards, Heidi .................................... 128

Edwards, Mary.................................... 184

Eiker, David ......................................... 184

Eiler, Amy ................................... 18, 184

Eisenlohr, Abby.................................. 184

Elgersma, Sabrina ................................. 128

Elgersma, Terri............................. 184, 238

Elliot, Anna .............................................. 61

Ellis, Stephen...................................... 140

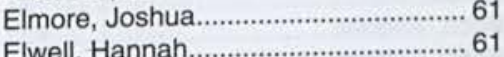

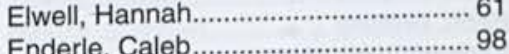

Englund, Andrew .................................. 128

Ensslen, Johanna ................................ 184

Enterline, Kara .............................. 50, 184

Erickson, Garrett....................................98

Ernsberger, Kassi ............................... 144

Esbenshade, Alexander........................61 61

Esbenshade, Allison .............................. 98

Evans, Jeffrey …................................ 128

Evans, Jennifer ...................................... 61

Evans, Matthew …................................ 98

Everard, Stephanie .................................98

Everswick, Julianne .............................. 184

\section{$\boldsymbol{F}$}

Fain, Kaitlin

61

Farrell, Ryan ............................................. 61

Farris, Mark .......................................... 160

Fawcett, Amanda .............................. 185

Fawcett, Andrew ....................................61 61

Fawcett, Jillian ..................................... 98

Fawcett, Matthew.............................. 185

Featherman, Melissa ............................ 98

Ferkaluk, David.................................... 185

Ferrell, Andrew ..................................... 185

Fields, Jonathan ................................. 185

Figueredo, Christian

Filbey, Hannah..

Finkbeiner, Matthew

Finkbeiner, Rachel

Firebaugh, Stacia

Firmin, Ruth.

Firmin, Sarah

Fisher, Melody

Fitzpatrick, Anna.

Flack, Nathaniel.

Fladda, Kelsey

Flaming, Aron

Flamm, Seth ....

Fleming, Hannah

Fletcher, Kaitlyn

Flexman, Jordan.

Flores, Aaron

Flow, Walter

Flynn, Christopher

98,140
Flynn, Kimberly
Foley, Eric....

Fonseca, Rachel.

Foote, Austin.

Foster, Nikal.......................... 54, 185

Fote, Kaitlyn ......................................... 128

Fouch, Elena ………………………...... 61

Foulk, Casey.......................................... 128

Fox, Kyle .......................................... 128

Frame, Bryan ........................................ 129

Frangos, John

Franklin, Brianna.

Franklin, Josiah.......

Franklin, Zachary.

.... 61

Fraser, Jeremiah.................................. 185

Frazer, Michelle ........................................ 61

Frazier, Shaun ....................................... 129

Frederick, Betty..................................... 185

Frederick, Grace .................................... 99

Fredette, Luke....................................... 129

Free, Aaron .....................................61, 86

Frey, Stephanie

... 129

Fultz, Dalen .

Fye, Vincent

... 185

\section{G}

Gabbert, Kolby

Gahman, Brandon

Gallagher, Gregory

Gallagher, Joe

Gamberdella, Lauren

Gardner, Amber.

Gardner, Michael

Gardner, Olivia.

Gardner, Scott ....

Garlick, Christopher

Garlick, Kimberly

Garrett, Anna

Gass, Lynn.

Gaston, Tiffani

Gates, Anna.

Gatlin, Zachary

Geib, Ellen .

Gelwicks, Patricia

Gelwicks, Roger

Gensler, Amy...

George, Elizabeth

Gerber, Jared

Geringer, Keely.

Gesualdo, Emilie.

Getchell, Paige

Giambalvo, Jennifer.

Gifford, Rebekah

Gigliotti, Jillian.

Gilbert, Michelle.

Gilbert, Steven

Gill, Lauren

Gillispie, Leah.

Gingerich, Katrina

Gingrich, Danielle .

Giovacchini, Nicholas

Girtz, Kayla

Girtz, Kyle

Glenchur, Amelia

Gollihue, Erin .

Gonzalez, Alexander

Good, Breanna ...

Good, Kortney

Goodliffe, Diane

Goodling, Mitchel

Goodman, Steven

Goodrow, Samuel

Gordon, Andrew

Gordon, Dane

Gordon, Joshua

Gordon, Paul

Gordon, Seth

Gorrell, Rebecca

Gowdy, Sean 112

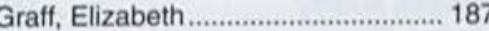

Grafton, Sharon ................................. 99

Graham, Benjamin ............................. 187

Graham, Emily ................................... 187

Grahn, Daniel .........................................99 99

Granger, Amy ..................................... 129

Grant, Brian ......................................... 154

Graves, Courtney ................................... 62

Gray, Cassandra ................................... 99

Gray, Cora ............................................ 99

Grayton, Katie ........................................ 62

Greely, Myles ..................................... 140

Green, Bethany ……….......................... 62

Green, Timothy .......................... 140, 187

Greenberg, Leah-Ruth........................ 187

Greenwell, John................................... 129

Greenwood, Jonathan ............................ 62

Greenwood, Rachel................... 129, 226

Gregory, James ..................................... 99

Gregowske, Emily............................... 129

Grier, Jason ....................................... 129

Griffin, Christopher ............................... 99

Griffith, Elizabeth ..................................... 99

Griffith, Stephanie................................. 129

Grigsby, Megan...................................... 187

Groman, Joel .......................................... 62

Grosso, Heather ................................... 129

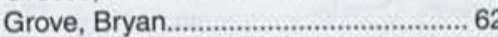

Groves, Crystal........................110, 187

Gruet, Chelsea .................................... 162

Gullion, Morgan ……........................... 99

Gunderson, Joshua ........................ 16, 62

Gunter, Angela..

Gustafson, Ryan

129

H

$\mathrm{Ha}$, Young-Un

Haas, Shelby

Haines, Stephanie

.... 62

Hall, Alice.

Hallisy, Shannon.

208 
Hearle, John ...................................... 188

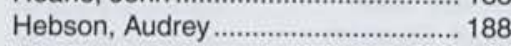

Hecker, Brian ....................................... 154

Heckman, Chloe ......................... 118, 188

Hedges, Tessa ........................................ 99

Hefner, Craig .............................. 78, 188

Hegle, Janalyn ...................................... 129

Hegna, Julianne .................................... 188

Hein, Josephine ..................................... 63

Heineman, Kara...................................... 63

Heitzmann, Karly ......................... 63, 170

Heller, Candace ...................................... 63

Hellwig, Ashley ..................................... 188

Hellwig, Brandon ................................ 130

Hellwig, Caitlynn ..................................... 99

Hembekides, Paul................................ 168

Hendricks, Tiffany .............................. 130

Henley, Susan......................................... 63

Henry, Allison........................................... 99

Henry, Christina ................................... 188

Hensler, Aaron ..................................... 189

Herbert, Ashley ..................................... 130

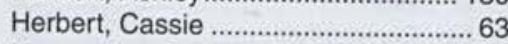

Hernandez, Catherine ........................ 189

Herrera, Miguel...................................... 160

Herrera, Rachel ................................... 162

Herting, Andrew...................................... 99

Heuzey, Laura........................................ 189

Hewett, Christa .................................... 189

Heyl, Keely............................................ 218

Hickling, Jessica ................................. 189

Hickling, Jordan ............................ 18, 189

Hickman, Daniel .................................... 154

Hicks, Elizabeth ........................................ 63

Hicks, Gregory .................................... 189

High, Brandon....................................... 63

Hilditch, Jenna ..................................... 130

Hill, Amanda ............................................. 63

Hill, Cameron........................................ 238

Hill, Candace ..................... 118, 189, 220

Hill, Hanna.

Hill, Stephanie ....................................... 130

Hinks, Robert........................................ 99

Hiteshew, Mark ..................................... 189

Hobba, Tayler........................................99

Hobbs, Nicholas ................................. 189

Hodecker, Julia ................................... 99

Hodges, Megan .................................. 189

Hoeflinger, Patrick............................... 130

Hof, Marina ......................................... 100

Hoff, Erica............................................. 162

Hoff, Jessica ............................................. 63

Hoffer, Brandi...................................... 100

Hoffman, Justin ..................................... 160

Hoffman, Rachel....................... 189, 238

Hogan, Melissa ................................... 63

Hoke, Cynthia ................................... 189

Holck, Micah ........................................... 63

Holck, Timothy ......................................... 63

Holland, Shanna ................................... 63

Hollander, Jennifer..................... 148, 162

Holloway, Danielle........................63, 238

Holmes, Hannah ................................ 100

Hoober, Eric........................................ 140

Hood, Andrew...................................... 189

Hoogland, Evonne ................................ 189

Hook, Hillary .......................................... 63

Horst, Joseph ........................................ 189

Hotchkiss, Bethany ................................ 63

Houser, Autumn ..................................... 63

Houston, Rebekah................................. 63

Howell, Jenny .................................... 189

Howland, Britney ..................................... 63

Howsden, Lauren .................................. 63

Hoyt, Eliane ......................................... 189

Hrabal, Kristina ..................................... 190

Hrdina, Robin ...................................... 100

Hubbard, Chelsea................................... 63

Huddle, Kelsey........................................ 63

Huebert, Audrey .................................. 190

Huebner, Samuel................................. 190 uffaker, Heather................................ 190

Hulbert, Roxanne................................. 100

Hull, Andrew ......................................... 100

Hull, Bethanie ..........................................63

Hull, Jennifer.......................................... 190

Hulsey, Kristen...................................... 130

Hulsey, Lauren............................................. 63

Hultz, Kyle.

100

Hundley, Allie ..............................100, 120

Hundley, Patrick ...................................... 63

Hunt, Katelyn ...................................... 130

Hunter, Craig .................................... 130

Hurley, Rachel ..........................156, 190

Huschilt, Joanna .................................. 64

Huseman, Eric ........................................ 64

Huston, Nathaniel ................................. 100

Hutchings, Josiah ............................... 218

Hutson, Kimberly ..........................50, 190

Hutton, Mary ….................................... 100

Huwer, Jessica .................................... 130

\section{I}

Ikeda, Paul.......

Ingram, Caleb

160,190

Ingram, Joel

130

Irwin, Sarah

100,142

Isaac, Rebekah....

100

Israel, Holly.

\section{J}

Jacob, Melissa .................................... 162

Jacobsen, Leif ...................................... 130

Jahnke, Megan ..................................... 100

Jakucki, Katherine .............................. 130

Janczewski, Ashley............................. 130

Jarrett, Brittnie ......................................... 64

Jarvis, Emily .......................................... 190

Jeanneret, Elizabeth................................ 64

Jenerette, Kayla ..................................... 156

Jewett, Daniel.

191

John, Tyler

$80,142,208$

Johnson, Alissa .................................... 191

Johnson, Brian ..................................... 230

Johnson, Brooke..........................100, 166

Johnson, Chloe.................................... 100

Johnson, Christine ..................... 146, 191

Johnson, Clayton .................................... 64

Johnson, Frederick ................................ 100

Johnson, Hayley ...................................... 130

Johnson, Jessica .................................. 191

Johnson, Kaela .......................................... 64

Johnson, Kendra................................. 130

Johnson, Kirsten .................................. 100

Johnson, Krista..................................... 162

Johnson, Matthew ..................... 160, 191

Johnson, Olivia ...................................... 64

Johnson, Rachael.................................. 100

Johnson, Sarah ……….......................... 64

Johnson, Stephen................................ 100

Johnson, Tonya..................................... 130

Jones, Elizabeth ..................................... 64

Jones, Lindsay...................................... 130

Jones, Rebekah................................... 191

Juhant, Hannah .................................. 191

Jungbauer, Sarah ................................64

Junge, Jared .................................50, 130

Jupe, Linda.

.. 130

\section{$K$}

Kacho, Erica

64

Kane, Erik ............................................ 130

Kanning, Matthew................................. 100

Karhan, Joshua .................................. 100

Kasabian, Logan .................................... 168

Kassonie, Kendra

.170
Hman, David ..................................110

Kauffman, Elyse ................................... 191

Kazulak, Ruth ..................................... 100

Kee, Kevin...

64

Kellogg, Joy

166,191

elly, Ashlynn ........................................6 64

Kemmenoe, David .................................. 130

Kepiro, Lindsey .................................... 191

Kessler, Jessica..................................... 191

Keur, Jonathan

.... 64

Keyser, Abby ................................. 46, 191

Kilian, Abigail.

.. 191

Kilian, Benjamin ..................................... 191

Kilmer, Kameron.

191

.......... 64

Kim, SangYo …………………............. 100

Kinch, Christina .................................. 130

King, Dillon ........................................... 140

Kirby, Kyle......

.. 164

Kirby, Laura............................... 130, 162

Kirkpatrick, Heather ................... 100, 144

Kitzmiller, Alexander ............................... 64

Kleinberg, Kristen ............................... 100

Klinger, Neil ................................ 146, 160

Klink, Zachary .................................... 130

Klob, Austin.......................................... 100

Knesnik, Andrew................................. 191

Knoedler, Jordan ................................... 191

Knott, Rebeccah ............................... 130

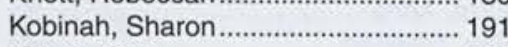

Kobza, Carl.......................................... 191

Koch, Andrew ...................................... 131

Koch, Brittany

Kochanowski, Sara

100

Kochsmeier, Philip ................................ 100

Kohavi, Daniel..................................... 154

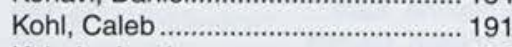

Kolody, Jessica ...................................... 192

Komar, Elizabeth ................................. 192

Koranek, Matthew.

Kostreva, Katelyn.

131

Kostusyk, Steven

.... 64

Kramer, Kathryn ....... 131, 238, 240, 242

Kramer, Laura ..............................90, 192

Krapohl, Christine ................................ 101

Kremer, Katherine ............................... 192

Kroening, Matthew.............................. 131

Kroninger, Krista.

Krop, Caitlin ...

Krumlauf, Leah

Kuhn, Megan ...

Kuiken, Rachel.

Kushnir, Michelle

$L$

La Croix, Christopher

La Croix, Daniel.

101

La Croix, Stephanie

46, 192

LaBelle, Luke.

.64

Lacombe, Tania .

Lagucki, Jessica

Lamb, Eric .........

Lamos, Hannah

Lamy, Joseph..

Lane, Aaron.

Lane, Lauren

Lange, Layna

Langenderfer, Jonah

Langton, Katherine

Lanphier, Katherine

Larrabee, Brittany.

Larson, Caleb.

Laskowske, Tieg

Lassetter, Gabrielle

Laub, Jason.

Laustsen, Katie...

Lavallee, Emilie

Lavoie, Evan.

101

131

64

101

131

... 64

.. 64

101

, 148

64

65

101

131

101

192

192

131

Lawhorn, Brittany...

Lawler, Amanda

Lawrence, Meredith

Lawton, Sarah

Layer, Jacob

Lear, Lani.....

Lear, Larissa...

Learst, Elizabeth

Leavens, Scott

Lee, Jasmine

Leese, Hilary.

Leffel, Erin

Lehman, Michayla 


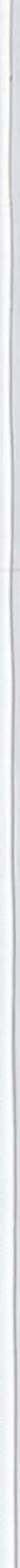

Marple, Ashley....................................... 65

Marquardt, Christa................................ 102

Marriott, Richard ....................................... 50

Marshall, Joseph ................................... 193

Martin, Catherine ..................................... 193

Martin, Laura ................................................ 102

Martin, Rachel ..................................... 194

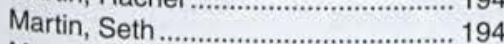

Martin, Susanna ...................................... 194

Martinez, Bryan …………....................... 194

Martinez, Juan ..................................... 168

Marvin, Katherine .................................... 131

Mather, Alexandrea ............................ 194

Mathews, Daniel ..................................... 194

Matson, Dresden .................................... 142

Mattheis, Jeffrey ..................................... 131

Matthews, Ryan …….......................... 194

Mattison, Christopher ........................... 102

Maxwell, Caleb .................................. 154

Mays, Caleb......................................... 194

McBride, JoyAnna ..........................20, 194

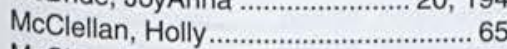

McClenahan, Ivy..................................... 102

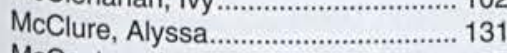

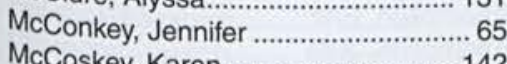

McCoskey, Karen.................................. 142

McCown, Stephen .................................65

McCoy, Jessica........................... 148, 162

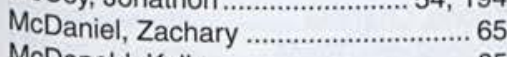

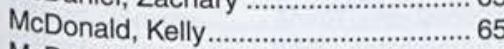

McDonald, Matthew.................................. 78

McEllhenney, Sarah............................. 131

McFarland, Bryan …................................. 194

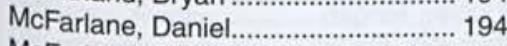

McFarlane, Mark ................................. 131

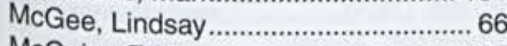

McGuire, Erin......................................... 195

McKenna, Brittany ............................... 195

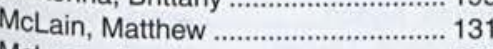

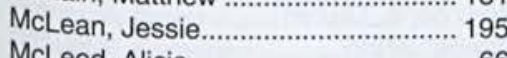

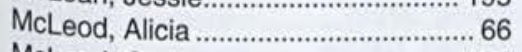

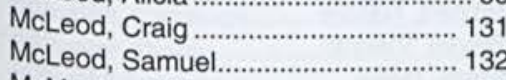

McMaster, Alicia ................................... 195

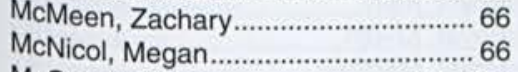

McQuarry, Alison .......................... 88, 102

McQuarry, David............................... 52, 195

McQueen, Michelle ................................ 195

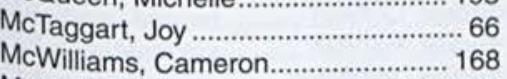

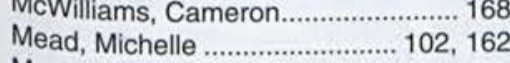

Meade, Jennifer..................................... 195

Meadors, Ronald ……........................... 195

Medearis, David..................................... 132

Medina, KaLee .................................... 132

Melucci, Sara ............................................. 66

Menendez, April..................................... 102

Miceli, Rachel .................................. 132

Michaud, Beau...................................... 160
Michaud, Brigham............................ 158

Mickle, Alexis ........................................... 142

Miedema, William ………………......... 195

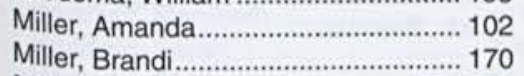

Miller, Christine ............................ 195, 224

Miller, Clinton .......................................... 195

Miller, Corey.................................... 195

Miller, Darren .................... 132, 154, 164

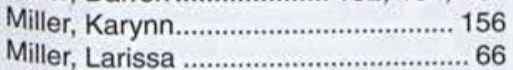

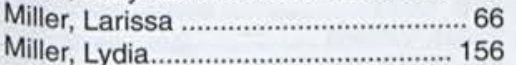

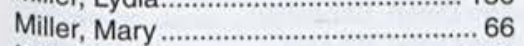

Miller, Melody......................................... 195

Miller, Nathan........................................... 66

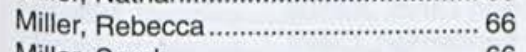

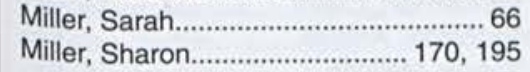

Miller, Sydney ....................................... 170

Mills, Stephanie ............................... 195

Mitchell, Collin .................................... 8, 134

Mitchener, Michelle _............................. 132

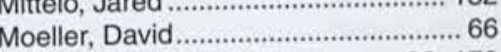

Moffitt, Megan................................66, 170

Moffitt, Trevor ....................................... 195

Molby, Lena ....................................... 195

Moline, Meredith .................................. 102

Molstre, Jordan .......................... 160, 195

Molstre, Rachel..................................... 66

Moluche, Mercie ….............................. 196

Monroe, Jennifer.................................... 196

Monroe, Michael ................................. 102

Montgomery, Cullen........................... 168

Moody, Kara...................................... 148 148

Moore, Alexander ..............146, 160, 196

Moore, Alyssa ........................................ 66

Moore, Ashley.......................................... 66

Moore, Ellen ............................................ 66

Moore, Joel.......................................... 132

Moore, Tabitha .................... 102, 148, 162

Moran, Jennifer..................................... 132

Morell, Simeon......................................... 66

Morgan, Sarah...................................... 196

Morin, Bradley ....................................... 132

Morris, Abigail.................................... 132

Morris, Anne ....................................... 66

Morris, Brittney …............................... 16, 132

Morris, Stephen ..................................... 140

Morrison, Matthew ................................. 154

Morrison, Phillip..................................... 196

Morrow, Heather ................................... 102

Morse, Briana ...................................... 196

Morse, Sarah ......................................... 102

Moses, Andrew.................................... 196

Moughon, Micah .................................. 102

Moulden, Mami ....................................... 66

Mounts, Abigail ................................. 102
Mounts, Benjamin ................... 158, 196

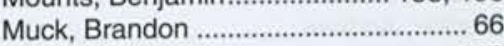

Muckley, Karen ............................................ 132

Mueller, Joseph ................................... 140

Mueller, Victoria ...................................... 66

Muhlenkamp, Mitchell ......................... 132

Muller, Joshua ……........................... 132

Mumme, Courtney .............................. 196

Mumme, John Michael ....................... 80

Muncy, Peter ......................................... 80

Murphy, Zachary...................... 102, 150

Murray, Erin ....................................... 197

Musselman, Larissa................................ 66

Musser, Chelsea....................................... 66
Musser, Jonathan ............................ 197

Myers, James ....................................... 132

Myers, Nyomi ........................................ 66

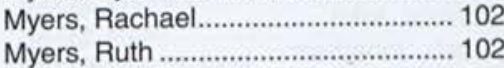

\section{N}

Nafziger, Jacob

Nagelkirk, Laura

Neal, Emily

Nelson, David

Nelson, Dustin

Nelson, Elizabeth.

Nelson, Garrett

Nelson, Katherine

Nemec, Elyse

Nesbitt, Rebecca

Nesteroff, Robert.

Neville, Emily....

Newcomer, Elise.

Newman, Eric

Newman, Joseph

Newman, Kelsey.

Nichelson, Craig

197,218

132
Nichelson, Sarah ............................... 102

Nichols, Justin .................................. 226

Nicolaisen, Kirsten ............................... 132

Niedermayer, Emily ............................. 142

Niemi, Rachel..

.67

Niemiec, Aaron .................................... 164

Niemiec, Joseph ............... 140, 146, 160

Niemiec, Matthew ...................... 140, 197

Nikkel, Kayla ........................................ 67

Nine, Jerilynn ........................................ 132

Nine, Juliana ....................................... 132

Nissley, Caleb...

Norris, Emma.

Norris, Krista.

... 67

Norris, Sarah

Nygren, Allison

Nygren, Ashley

Nyhuis, Julia

........

102

0

O'Connor, Thomas.

197

O'Keefe, Jared

197

O'Neel, Natalie

... 102

Oakley, Adam

48,132

Oakley, Jeffrey

... 197

Obielodan, Mary ….............................. 132

Obuchowski, Kara................................ 228

Ogle, Derek .......................................... 168

Ojala, Trayton....................................... 158

Oliger, Brandon........................................ 88

Olsen, Phillip.......................................... 102

Olson, Karl..

132

Oosterhouse, Jennifer ........................ 132

Ormsby, Daniel

Ortiz, Ariella.

Osborn, Joseph.

197

Ouellette, James

$P$

Paddock, Nathan .

Palumbo, Ashley

Pancake, Troy

Paney, Megan.

Parker, Joseph

Parker, Kendra

Parrish, Brianna

Pasma, Alyssa

Patrick, Charity

.. 170, 197

Patterson, Elizabeth

197

Patton, Sandra

Patton, William

Patznick, Ryan

Paul, Quinton...

Pauling, Rachel

Paulsen, Daniel

Payne, Jillian

Peck, Jordan...

Pedro, Christopher

Peer, Frank .

Pelletier, Sarah

Pelyhes, Michael

Pender, Amanda

Pent, Victoria

Pepper, Arianna

Pernicano, Kara.

Pernicano, Leah

Persun, Brent.

Petek, Danielle

Petek, Elizabeth

Peters, Breanne

Petersen, Abigail

Petersen, Jordan

Peterson, Ashley

Peterson, Christi

Peterson, Daniel

Peterson, Ethan

Peterson, Kayla ................................ 198

Petke, Daniel .............................. 133, 168

Petroff, Matthew.................................. 103

Petry, Lauren ......................................... 103

Pfahler, Joel............................... 103, 160

Phillips, Alyssa .................................... 133

Phillips, Gwendolyn ............................... 67

Phillis, Samantha ................................. 133

Philyaw, Erin ..................................... 198

Piasecki, Andrew ................................. 198

Piasecki, Rebekah ................................. 67

Piazza, Joseph .................................... 103

Picard, Melissa ..................................... 198

Pickens, Julie ...................................... 198

Pickett, Benjamin ..................................... 67

Pierschbacher, Amy.............................. 198

Pilet, Grace................................. 18, 210

Pilkenton, Kimberly .............................. 103

Pilling, Nathan ........................................ 67

Pinkerton, Marcia ..........................6.67, 86

Plasterer, Anna .................................... 198

Plumley, Janette ................................... 103

Poling, Daniel....................................... 198

Pollock, Lisa........................................... 199

Poore, Thomas …................................. 133

Port, Stephen.............................. 103, 160

Porter, Andrew. ...................................... 67

Porter, Matthew ..................................... 133

Powell, Chelsea ...................................... 67

Powell, Susan ..................................... 162

Powers, Christopher ............................ 199

Powers, Sean ...................................... 110

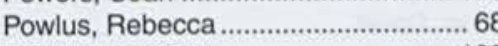

Presley, Jessica ..................................... 133

Price, Andrew ...................................... 133

Price, Danielle ..................................... 133

Price, Krista ............................................ 199

Price, Leah …........................................ 199

Price, Stephanie ................................... 103

Proctor, Jonathan .................................... 68

Proemmel, Joshua.................... 103, 160

Prozzo, Nina ......................................... 133

Pryor, John ......................................... 133

Pryor, Rebecca .........................................6 68

Puckett, Keri …..................................... 68

Pupillo, Stephen .................................. 199

Purtell, Steven …............................. 133

Putnam, Neola........................... 148, 162

Pyle, Gabriel _......................... 226

Pyles, Elijah.

68,146

$Q$ 
Reisenweaver, Anna.

Reiter, Crystabel...

Rethmeier, Eadie

Rich, Rebecca .

Richardson, Alex .......

Richardson, Lindsey.

Richey, Erica...

Richied, Philip

Rieches, Veselin ........................116, 200

Riehle, Adam ....................................... 154

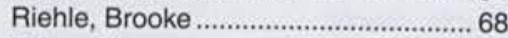

Rifner, Shawn ..................................... 133

Rigg, Elizabeth ................................... 200

Riggleman, David ................................ 133

Rioux, Spencer................................... 160

Ripley, Adam.........................................6 68

Ripperger, Kyle .................................. 103

Rizzo, Matthew ……………................ 200

Roach, Trent ............................ 158, 200

Robb, Jessica ...................................... 200

Roberts, Nicole ..................................... 103

Roberts, Rebecca................................ 133

Robertson, Joy .................................... 200

Robertson, Leah................................... 133

Roe, Michael.....

Rogers, Stephanie.

Ronco, Timothy.

68,144

............ 46, 48, 133

Rose, Heather ……............................. 103

Roseberg, Scott................................... 140

Rosner, Niles ....................................... 133

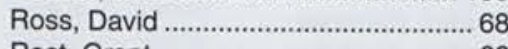

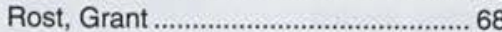

Rost, Tyler................................... 168, 200

Rostan, Hannah.................................... 68

Roten, James ....................................... 200

Roth, Lea .............................................. 200

Rothhaar, Bruce ................................... 200

Rothhaar, Jenna .................................. 200

Rothhaar, Sarah ............................... 134

Rotroff, Mark …..................................... 103

Rowe, Samuel .................................... 140

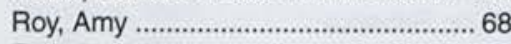

Rozelle, Amanda .................................. 68

Rucinski, Garrett.......................200, 234

Ruck, Carolyn .......................................201

Ruhlman, Kevin .................................. 201

Ruman, Deanna ................................... 103

Russell, Bridget ................................... 134

Russell, Stacey .................................... 201

Russell, Stephanie............................... 134

Rydman, Shauna ................................ 201

Ryker, Sarah...

134

\section{$s$}

Salzmann, Benjamin............................ 103

Sanders, Larry ...................................... 134

Sanfilippo, Gabrielle .......................... 134

Santee, Brittany ........................................ 68

Santiso, Daniel .................................... 103

Santos, Joy ........................................... 162

Saraco, Shannon ................................. 201

Sargent, Justina .................................. 103

Satta, Amanda...................................... 201

Sauer, Danielle .................................... 103

Saunders, Ashley ................................68 68

Savard, Sara............................................ 68

Savory, Michele ................................... 201

Scarpone, Danielle ............................... 134

Scarpone, Rebecca................................. 68

Schaefer, Allison ....................................... 68

Scharold, Alison.................................... 166

Schick, Kyle...

Schindehette, Joshua

Schindler, Stephen

.......................... 104

Schmid, Anna ........................... 142, 162

Schmidt, Katherine .............................. 134

Schmidt, Lauren ...

68
Schmidt, Sarah

Schmidt, Stacie.

134

Schneider, Tanja ...................................... 201

Schoenwald, Matthew ...........................69 69

Scholes, Melissa................................... 201

Schroeder, Niklaus

Schulert, Allison............................. 50, 201

Schultz, Kurtis...................................... 104

Schumacher, Carly ................................. 69

Schweitzer, Kristi ....................................... 69

Scott, Austin

2,201

Scott, Kathryn.

Scott, Megan

... 134

Scott, Tyler ............... 134, 238, 240, 242

Seabold, Paul

.. 69

Sears, Emily

.69

Seegers, Caitlyn

Seelig, Kaitlin ........................................ 104

Seelye, Zachary................................. 201, 222, 234

Seeman, Melissa..................................... 69

Segebart, Kyle ..................................... 201

Self, Christina ....................................... 201

Seligman, Justin ................................. 201

Settle, Jessica ........................................ 69

Setzkorn, Kirsten ............................... 104

Severance, Emily..................................... 134

Seybold, Rahel ..................................... 69

Seybold, Susanne ................................. 134

Shaffer, Daniel ..................................... 201

Shanahan, Emily ............... 201, 234, 236

Sharp, Jessica ...................................... 134

Shaw, Kelly .................................. 201, 238

Shaw, Lauren...................................... 104

Shenk, McKenzie..................................... 69

Shepherd, Rachel................................. 104

Shetler, Ami ........................................ 202

Shiff, Alexandra ................................... 104

Shimeall, Caroline .................................. 104

Shinabarger, Rebekah........................ 202

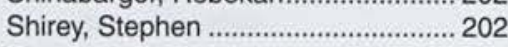

Shoemaker, Michael ...............................69

Shomo, Eric ........................................... 69

Shonk, Kaleigh ....................................... 69

Short, Amanda ……………………......... 69

Short, Ashley ........................................... 69

Shoulders, Caleb ..................................... 69

Shuck, Shayla.

Siefert, Nicole ............................. 104, 144

Siemon, Aubrey ........................................ 156

Sigmon, Danielle ................................... 202

Silbak, Rose .......................................... 104

Silk, Jesse .............................................. 69

Silvey, Rachel ........................................ 69

Simpson, Ethan .................................. 134

Simpson, Marissa.................................. 104

Simpson, William ................................. 134

Sincock, Jesse ........................................69

Sizemore, Daniel ..................................... 202

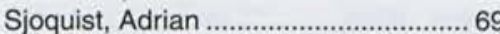

Sjoquist, Nathan ................................... 202

Sjoquist, Ryan …………………….... 134

Skinner, Brooke ................................... 170

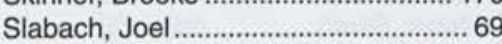

Slifka, Mary............................................ 202

Sloan, Anna .......................................... 202

Small, Kimberly........................................ 69

Small, Steven.......................................... 202

Smidt, Tyler ............................................ 202

Smith, Aaron ......................................... 168

Smith, Amanda ..................................... 202

Smith, Andrew ……............................ 202

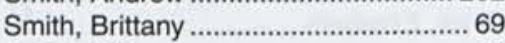

Smith, Brittany .........................................69 69

Smith, Caleb ............................................. 69

Smith, Christopher................................ 203

Smith, Courtney …….................................. 69

Smith, Daniel .................................... 22, 76

Smith, Erika ........................................... 202

Smith, Ethan …….................................... 202

Smith, Jenna.

156
Smith, Jessica ............ 54, 134, 148, 162 Smith, Johnathan................................. 160

Smith, Jonathan .................................... 202

Smith, Jordan ...................................... 134

Smith, Josiah .......................................... 18

Smith, Kendra .......................................... 134

Smith, Laura ...

.. 104

Smith, Lindsay ...............................69, 110

Smith, Matthew............................. 12, 203

Smith, Meagan ………........................ 134

Smith, Morgan ….................................. 203

Smith, Rebecca ................................... 203

Smith, Samantha ................................... 160

Smith, Zachary ................................... 134

Sneed, Darris.

Sniffen, Apryl

$134,238,240$

Snowden, Riley.................................... 104

Snyder, Amanda ................................... 203

Snyder, Audrey ........................................ 70

Soules, Katherine

203

Southworth, Aaron

70,170

Spann, Jennifer ...

Spencer, Brianne

Speros, Olivia ...

Spiliotis, Danielle

Sponsler, Douglas

.. 134

Spring, Megan

Spudie, Erika

Sray, Camila

Stack, Peter

Stafford, Ally.

Staley, Joshua

Stampfli, Catherine

Stands, Joshua.

Stanley, Jessica

Starko, Danielle

Start, Gerrit

Start, Kaitlin....

Stauffer, Kelsey

Stearns, Audrey

Stearns, Grace

Steckel, Joshua

Stecker, Andrew

Stein, Alicyn..

Stephens, Rachel

Stephens, Scott

Sterling, Andrew.

Stern, Suzanna

Stevanus, Jessica

Stevens, Daniel.

Stevens, Lillian

Stevens, Sarah

Still, Cheryl

Stine, Lyndsay

Stitzinger, Abigail

Stockwell, Derek

Stoltzfus, Melissa

Stone, Daniel

Stonkus, John.

Storch, Jonathan

Stover, Katelyn

Straitiff, Oliver .

Strapp, Shamus.

Strayer, Hope...

Strehle, Nicole

Strejc, Caleb

Strickland, Amber

Strickland, Michelle

Studebaker, Timothy

Sturgeon, Cameron

Sturm, Kaitlyn...

Suarez, Daniel.

Summerlin, Chase

Summers, Adrian

Sumner, Meredith

Sunden, Kerith.

Swanson, Emily

Swayze, Taylor

Sweet, Emily

Sweetapple, Jaclyn

Swett, Alanna

Swett, Cameron.

Swoveland, Jonathan

.70

\section{$T$}

Taylor, Joanna

Taylor, Joshua.

Taylor, Rockwell

Taylor, Thomas

Teat, John

Terrall, Julie

Terrazas, Melissa.

TerreBlanche, Bernardus.................. 104

TerreBlanche Jhann 204

Terrell, Meghan..

Terry, Krista.

148,162

Tervo, Rebecca

Thacher, Anne

Thayer, Evan..

Thomas, Seth

Thompson, Allison

Thompson, Ashley

Thompson, Debra

Thompson, Eric

Thompson, Julia

Thompson, Kyle

Thompson, Rachel

Thompson, Sarah

Thong, Charissa

Thornsberry, Kayla

Throgmorton, John

Thurman, Ryan.

Tilli, Katelyn

Tinsley, Megan. 
Williams, Jenna .................................... 156

Veith, Jonathan ..................................... 105

Veldt, Hadassah ................................... 135

Vendl, Anna ......................................... 105

Venturini, Tara ........................................... 71

Voland, Peter ........................................ 105

Voltz, Christopher ...................... 135, 220

\section{w}

Waggoner, Korinna

71

Wagner, Caleb

105,238

Wagner, David ...................................... 135

Wailes, Bethany .................................... 205

Walker, Chelsea...................................... 71

Walker, Ethan ...................................... 105

Wallace, Zachary....................................71

Waller, Timothy ....................................... 140

Wallin, Rebekah............................... 205

Walter, Jacob ............................... 146, 160

Walter, Rachelle ……....................... 205

Walter, Samuel ........................................71

Walters, Alyssa

Walters-Carlson, Cameron ..................205

Walton, Elizabeth................................. 135

Wanderi, Joseph................................... 205

Wands, Amanda ................................. 135

Ward, Chelsae ........................ 71

Ward, Christopher ........................ 105, 168

Ward, Jerielle

Ward, Jernelle ...............20, 22, 205, 234

Ward, Laura .......................................... 136

Ware, Elisabeth …………................... 105

Waring, Amanda …………………..... 205

Warner, Ashley .........................................71

Warrington, Kelsey ................................ 170

Wasem, Robert.......................... 168, 205

Watkins, Jaimie ............................ 142, 205

Watkins, Kelsey ..................................... 142

Watson, Annie ..................................... 136

Watson, Bayer ...................................... 110

Watson, Katherine ............... 12, 205, 228

Weaver, Cameron.................................. 205

Weaver, Diana ....................................... 136

Weber, Amanda ..................................... 205

Webster, Jennifer. 205

Weed, Karli ............................................206

Wegman, Hannah................................ 105

Weigand, Josee ....................................... 71

Weiser, Elizabeth ...................................... 136

Welborn, Megan .................................... 206

Welkie, Matthew …..................................71

Wemple, Lucas .......... 136

Wengerd, Jessica ................................. 136

West, Kara ............................................... 71

West, Krista ............................................. 206

West, Matthew....................................... 179

Weston, Zachary .................................. 105

Westrum, Zachary ................................. 154

Weyandt, Krissa......................................... 71

Wheatley, Joanna ...................71, 148, 162

Wheeler, Amanda ................................ 206

Whitcomb, Jeffery................................. 206

White, Alexandra .................................. 136

Whitecavage, Katrina............................ 206

Whitfield, Marybeth .................................. 71

Whitfield, Sarah .................................... 206

Whitlock, Corey.................................... 164

Whitmore, Sarah _................................ 206

Wichael, Samuel.................................... 206

Wicker, Allyson ....................................... 14

Widder, Rebecca ................................. 136

Widman, Jamie ...................................... 206

Widman, Joel............................................. 71

Wildman, Jane ........................................ 136

Wiles, Krista ........................................ 136

Wilkie, Patrick .......................................... 71

Wilkins, Veronica ................................. 206

Willeford, Megan ....................................... 71

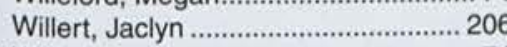

Willey, Jessica ........................................... 71

Williams, Alexander ............................. 122

Williams, Brandon ....................... 71, 164

Williams, Kaitlyn ......................... 71, 144 Williams, Lauren ................. 105, 136, 144

Williams, Michael.................................. 140

Williams, Richard...................................206

Willis, Hannah 206

Wilson, Ashlee..................................... 142

Wilson, Ashley ..................................... 206

Wilson, Bethany...................................... 71

Wilson, Kelsey ….................................. 170

Wilson, Lindsay ................................... 207

Wilson, Michelle..................................... 105

Winfield, Paul..............................105, 150

Winik, Alexa ............................... 136, 162

Winslow, Natalie .................................. 105

Winston, Benjamin .................................... 72

Winters, Kelsey ……………………......... 72

Wise, Kelly ............................................ 142

Wiseman, Ellen...................................... 105

Wiseman, Joshua .............. 146, 160, 207

Wisniewski, Kadie.................................. 72

Witt, Amy ………………....................... 72

Wojnarowski, Tiffany............................ 105

Wolf, Rene .......................................... 207

Wolfe, Caribeth ..................................... 207

Wong, Abigail .............................. 148, 162

Wong, Rachel ............................. 148, 162

Woodard, Taylor .................................... 72

Woodbury, Jarrod .................................. 105

Woolley, Kera......................................... 105

Woolston, Susanna ............................... 72

Workman, Warner................................. 105

Worosher, Tyler ...................................... 207

Woyak, Joshua ………….................... 207

Wright, Kristin ...................................... 106

Wright, Lauren ...................................... 72

Wright, Nathan...........................106, 160

Wunderlich, Rebecca ........................... 72

Wuobio, Amy ........................................ 106

Wynalda, David.................................... 150

Wynalda, Jessica........................ 207, 214

Wyse, Evie............................................ 136

\section{$Y$}

Yarbrough, Micah.................................207

Yeh, Benjamin ....... 136

Yeiter, Matthew …........................ 158, 207

Yelinek, Hannah..................................... 72

Yoder, Caitlin........................................ 136

Yoder, David............................................ 72

Yoder, Jacie .......................................... 106

Yoder, Janelle ......................................... 207

Yoder, Lance................................. 46, 207

Yorgey, Jennifer .................................... 207

Yorgey, Marissa ...................................... 72

York, Andrew …........................ 168, 207

York, Cameron ............................ 136, 154

Young, Lauren ...................................... 136

Young, Ryan ........................................ 140

Youngquist, Natalie ............................. 106

Yutzy, Kara.......................................... 144

\section{$Z$}

Zavodney, Anna .................................. 106

Zboran, Jessica ................................... 207

Zehel, Tiffany ......................................... 72

Zellers, Lucas........................................207

Zellner, Mark........................................ 207

Zerka, Joseph...................................... 106

Ziegler, Grace ........................................ 72

Ziegler, Morgan.......................... 136, 142

Ziegler, Zakariah................................. 140

Zimmerman, Jordan ........................... 207

Zimmerman, Kristiana ........................ 207

Zimmerman, Mary ............................... 106

Zion, Nathan $\ldots 207$

Zirkle, Tia.............................................. 136

Zonca, Ethan ........................................ 106

Zorn, Christina .................................... 170

Zuercher, Emily...................................... 106

Zwiebel, Heidi ....................................... 106 


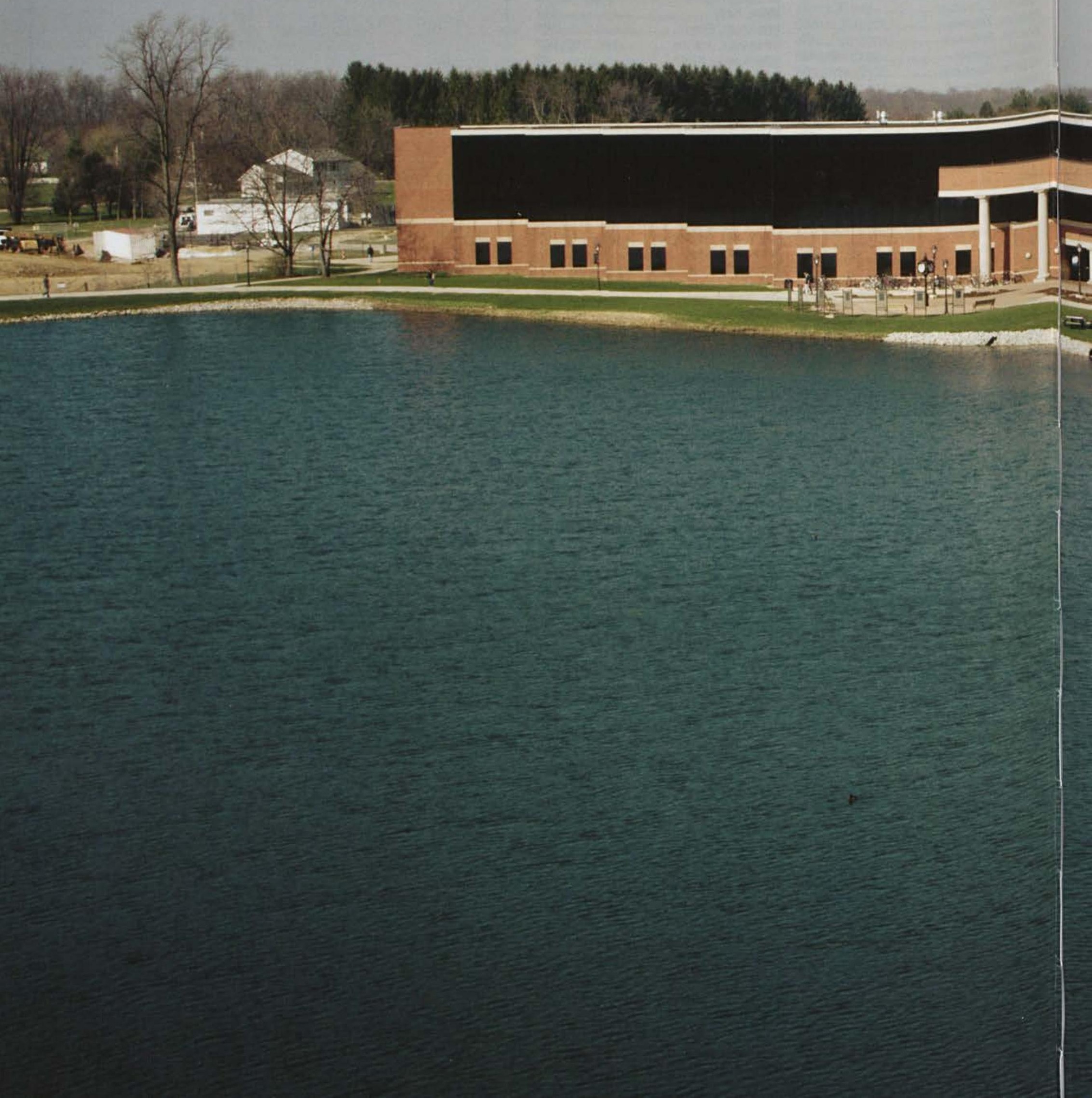




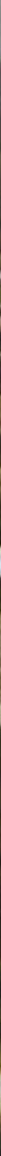


20

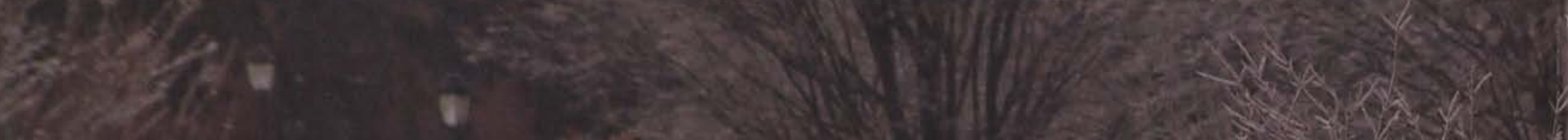

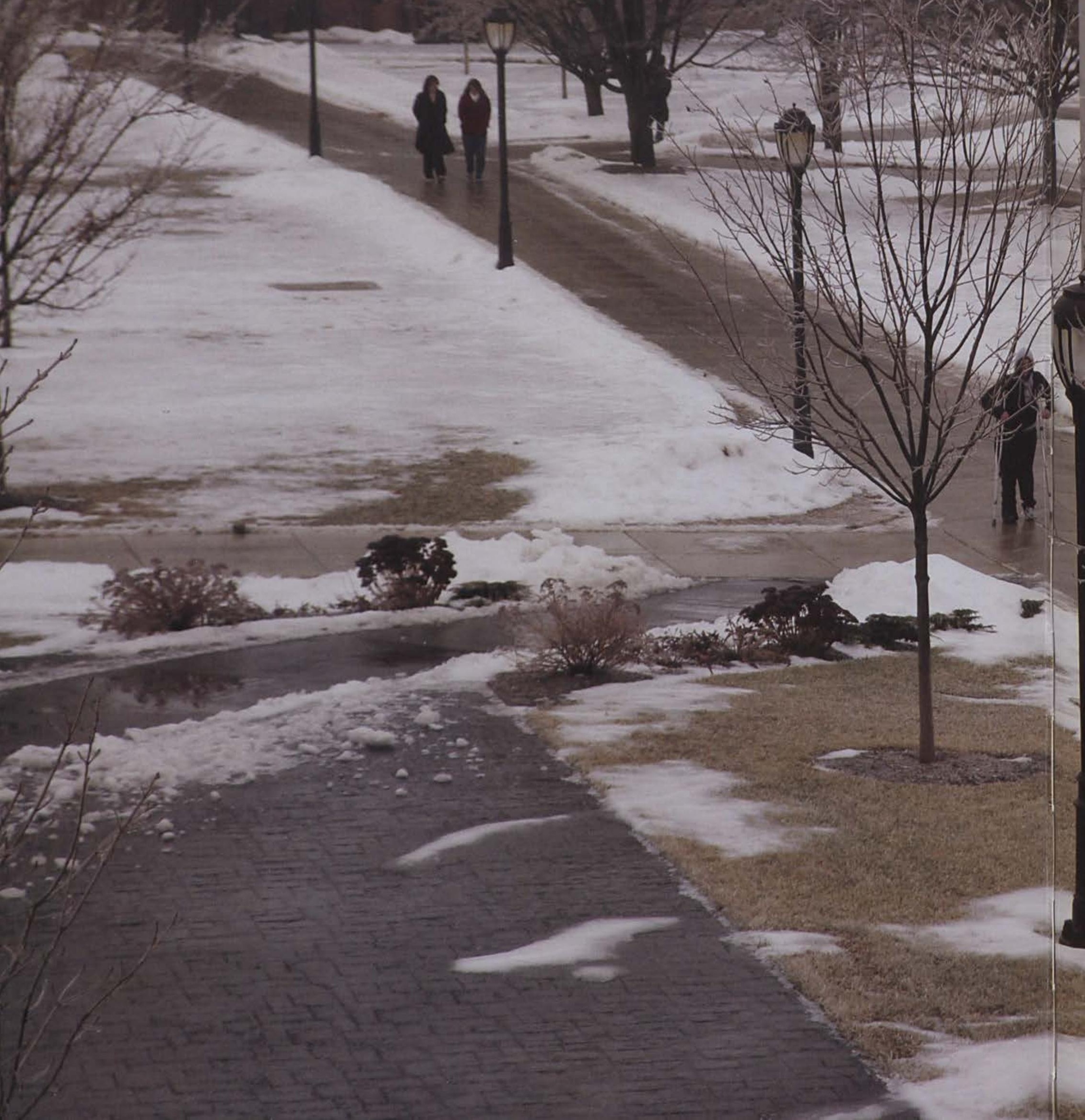




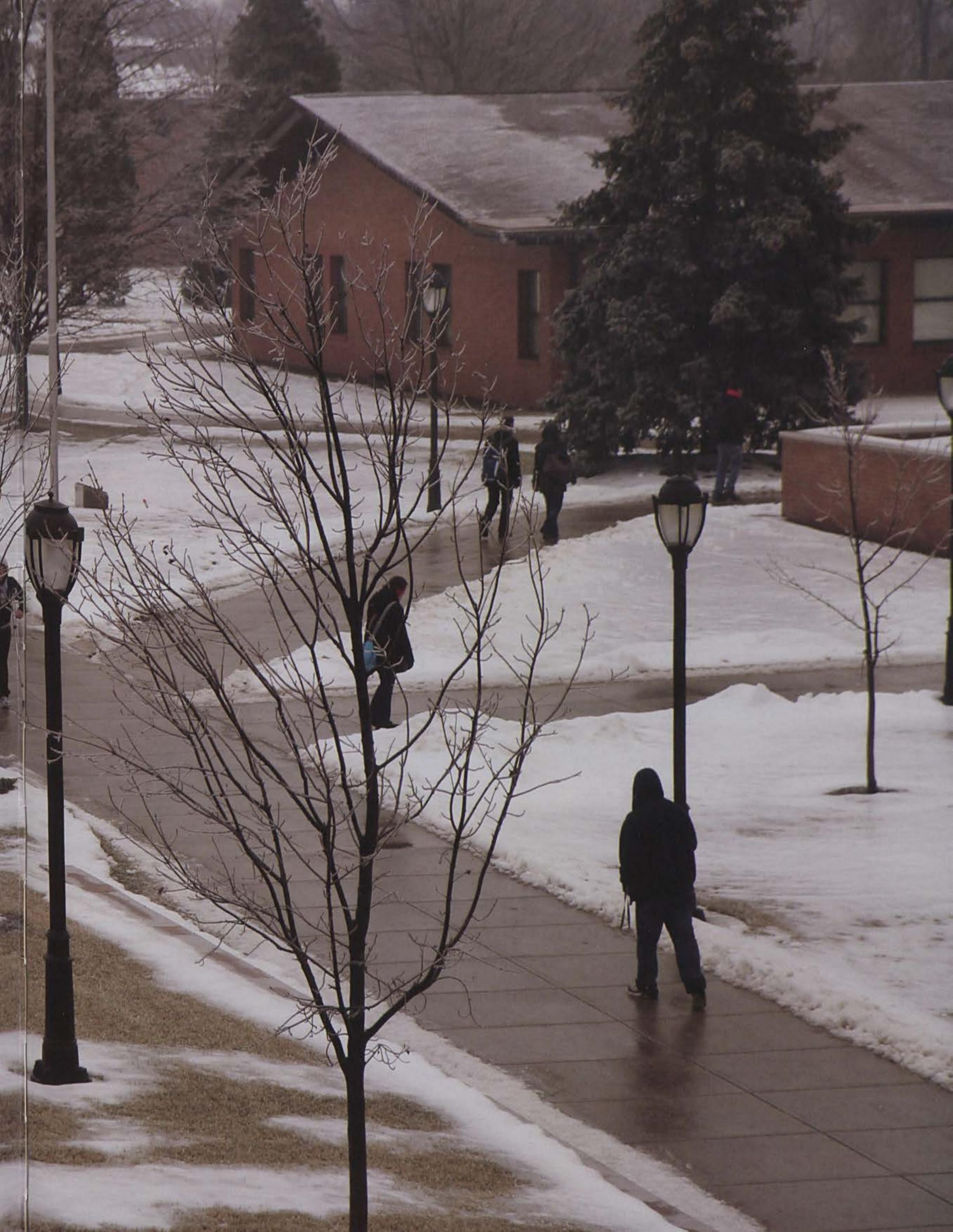




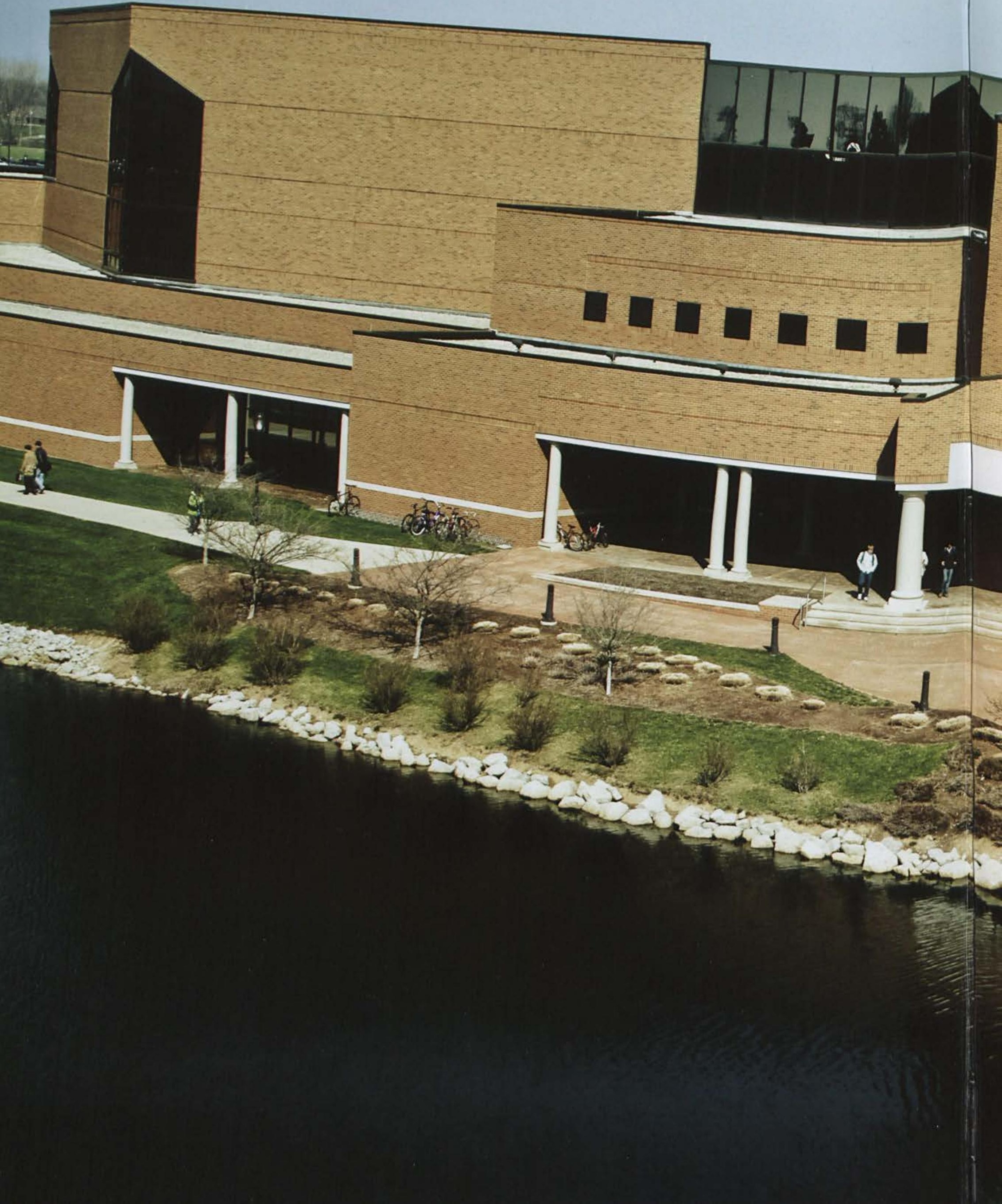




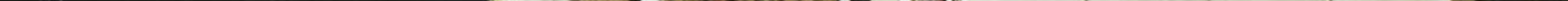



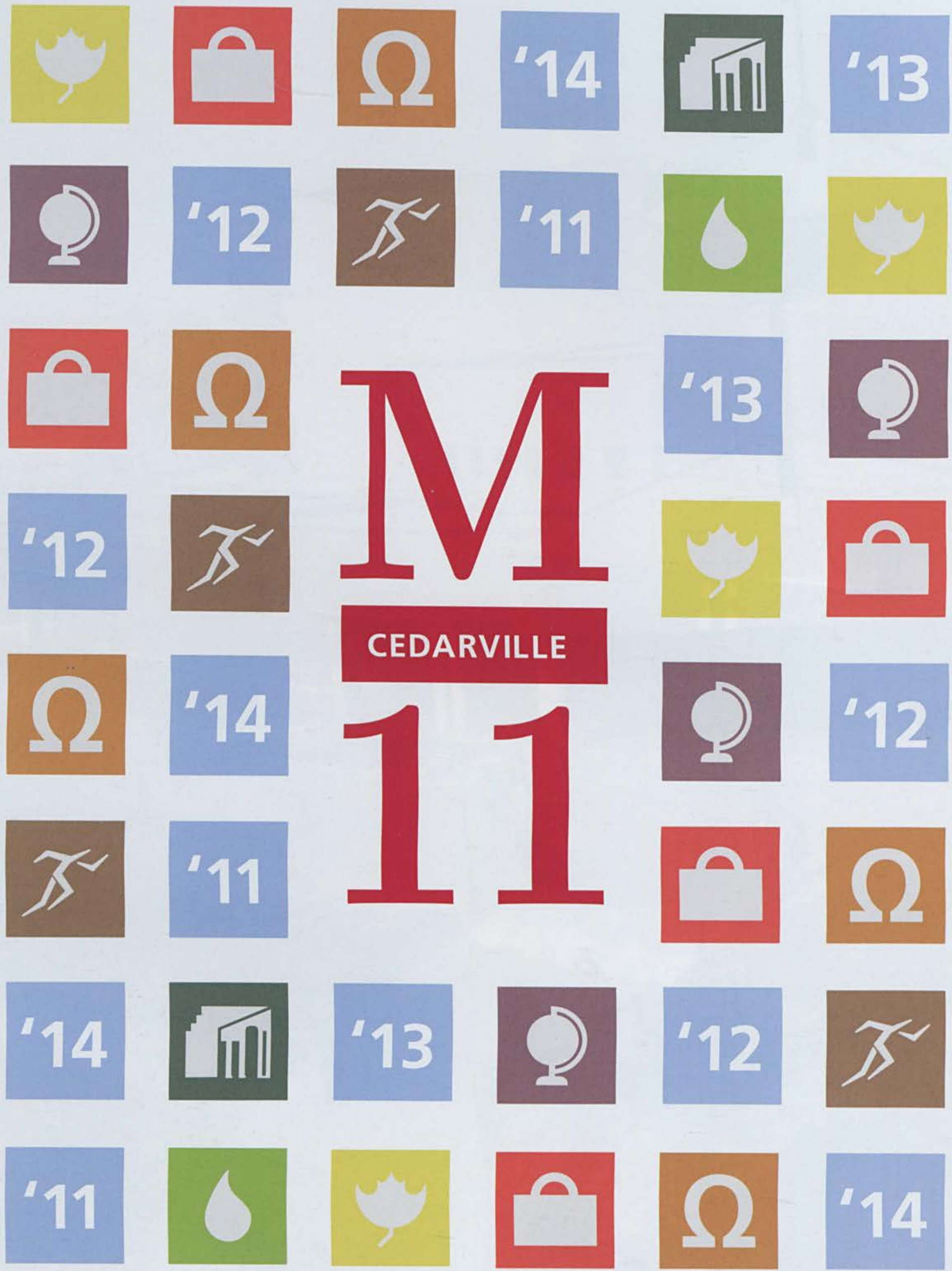

